\title{
ASSESSMENT OF THE POTENTIAL OF PROPOSED STATIONS OF THE CALIFORNIA HIGH-SPEED RAIL AS MAJOR HUBS FOR PHYSICAL AND ECONOMIC DEVELOPMENT
}

\author{
A Thesis \\ presented to \\ the Faculty of California Polytechnic State University, \\ San Luis Obispo
}

In Partial Fulfillment of the Requirements for the Degrees

Master of City and Regional Planning and Master of Science in Engineering with a Specialization in Transportation Planning

by

Seitu Akira Coleman

June 2018 
(C) 2018

Seitu Akira Coleman

ALL RIGHTS RESERVED 


\section{COMMITTEE MEMBERSHIP}

TITLE: Assessment of the Potential of Proposed Stations of the California High-Speed Rail as Major Hubs for Physical and Economic Development

AUTHOR: Seitu Akira Coleman

DATE SUBMITTED: June 2018

COMMITTEE CHAIR: Cornelius Nuworsoo, Ph.D.

Professor of City and Regional Planning

COMMITTEE MEMBER: Anurag Pande, Ph.D.

Associate Professor of Civil Engineering

COMMITTEE MEMBER: Kimberley Mastako, Ph.D.

Lecturer of Civil Engineering 


\begin{abstract}
Assessment of the Potential of Proposed Stations of the California High-Speed Rail as Major Hubs for Physical and Economic Development

Seitu Akira Coleman
\end{abstract}

This study investigated the potential for development of station catchment areas around the proposed California High-Speed Rail System. The study was prompted by a review of practices of Japanese railway company groups that engage not only in train operations, but also in business diversification and property development within the station areas of their lines. These actions allow the company groups to diversify their revenues streams, increase ridership on their lines, and operate as a whole with net profits. This is in contrast to transit agencies in the United States, which only focus on transporting passengers along their lines and do not engage in other commercial activities. This situation limits the potential for transit in the United States to play a larger role in urban transportation.

With the implementation of the California High-Speed Rail System, an opportunity exists to introduce the commercial transit model seen in Japan to the United States. Since the California High-Speed Rail System is a brand-new system with few entrenched interests to impede change, it has the potential to lead as an example of transit operating with net profits and providing additional benefits to the station areas it serves.

However, since planning for station areas to turn into commercially successful activity centers is still a new concept and practice in the United States, a methodology has to be developed to assess the potential for development of station areas. This study set out to answer the two questions: 1) To what extent are the locations of the California High- 
Speed Rail System's planned stations currently attractive to development within their respective contexts? 2) Given the information gathered from the study, what policies should be taken to enhance the future development potential of the California High-Speed Rail System's planned stations as activity centers within their respective station areas?

The potential for development was quantified by calculating accessibility indices for each station catchment area using the inputs of number of jobs, population size, and number of housing units within a gravity model.

The results of the analysis indicate that the station areas at the ends of the alignment in the San Francisco Bay Area and the Los Angeles Metropolitan Area will benefit the most. The next biggest beneficiaries are the major population centers in the San Joaquin Valley, which are Fresno and Bakersfield. Other stations that are not likely enjoy the benefits of a high-speed rail connection as much as other stations are those that have very little development around them currently, such as Kings Tulare and Madera.

However, the potential exists for all stations to enjoy substantial development opportunities if the proper plans, policies, and business strategies are implemented early on and at the corridor level to make the station areas attractive for development. The study makes the following recommendations:

- Promote the commercialization of train operations and station areas to capitalize on their long-term economic value;

- Integrate the planning, construction, ownership, and management of train operations and station area development and services to reduce transaction costs; 
- Develop plans or business strategies for each station area to create roadmaps and timelines for their development;

- And plan for land use activities at station areas on a corridor level to capitalize on specific synergies between station origin-destination pairs (e.g., land use activities that accommodate long-distance travelers between the San Francisco Bay Area and the Los Angeles Metropolitan Area, or those that accommodate commuter needs between up-and-coming station areas in the San Joaquin Valley with major job centers).

Keywords: California High-Speed Rail, station area, development, Japan, transit, gravity model, accessibility, attractiveness 


\section{ACKNOWLEDGMENTS}

There are many people I owe an endless number of thanks to for helping me to complete this study. First, and foremost, my family and friends, for all their love and support as I navigated the labyrinth of challenges that was graduate school. Mom and dad, thank you for all that you have done for me. My little brother, Randy ("Randay"), thanks for making me laugh all the time. I hope you find your purpose in life soon, and good luck in the Army. My little sister, Minami ("Minampow"), thank you for keeping me up with the happenings within the family. Remember to watch your forehead when

I'm around. My pet dog, Cocoa (“Doggy-Dog”), you have been a lot of fun to play catch with all these years. Uncle Anthony, Aunt Vernell, Toshihiro (“Toshi-kun”) Tamano.

I would also like to express a great amount of gratitude to my Committee members Dr. Kimberley Mastako and Dr. Anurag Pande, and especially my academic advisor, Committee Chair, and mentor for the last five years since I was a sophomore undergraduate student at Cal Poly, San Luis Obispo, Cornelius Nuworsoo. Your methodical teaching style, entertaining lectures, sense of understanding when things get delayed, provision of opportunities to work on environmental planning documents and to lead the general plan studio, and big laugh have made undergraduate school and graduate school a much more positive experience than it otherwise would have been.

A very special thank you goes to my co-team captain for the Lemoore General Plan Studio and Weed Environmental Impact Report, Jesse Ann Carpentier. You were my best "friemb" during my final year at Cal Poly, and your selfless efforts to encourage me and to pay attention to me throughout the year, despite my weirdness and 
obsessiveness, were greatly appreciated and will be remembered. I'm sure you'll do great in your career and as a social activist. You're an awesome Pop Tart!

Finally, to my grandparents, Akira Tamano and Shigeko Tamano, both of whom I have looked up to since my childhood. To my grandfather in particular, Akira Tamano ( 玉野明), you've been an incredible model of duty, responsibility, commitment, and honor to the family. I am happy to have made you proud in me by pursuing higher education and upholding the family name. 


\section{TABLE OF CONTENTS}

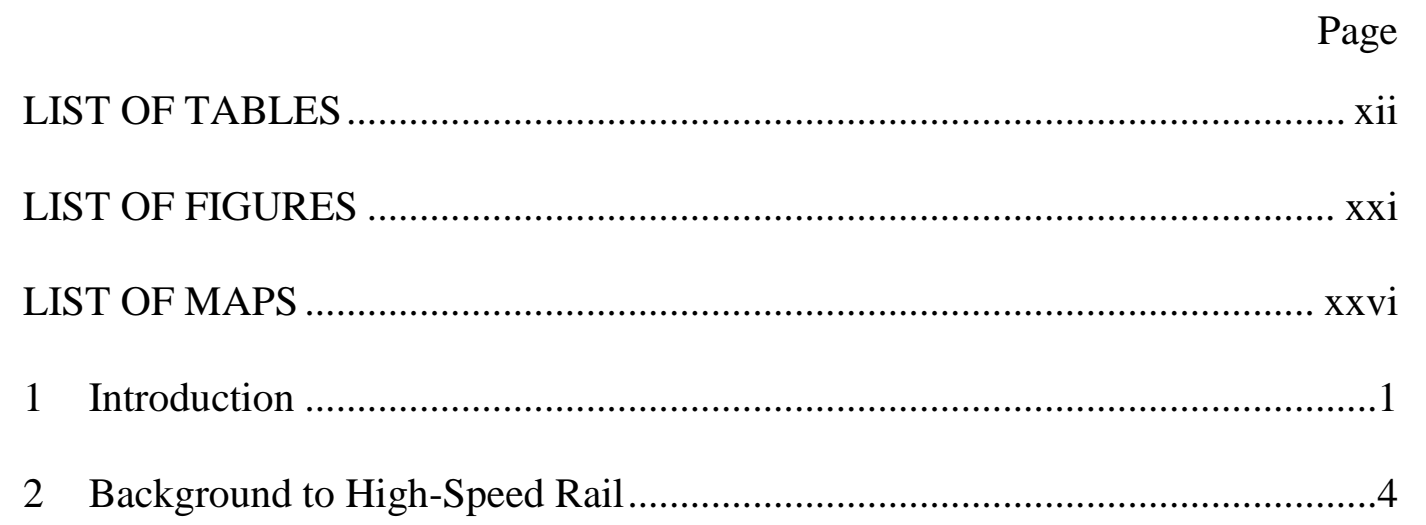

2.1 History and General Characteristics of the Shinkansen .......................... 4

2.2 Factors that Affect the Success of the Japanese Shinkansen ................. 10

2.2.1 Physical Characteristics .......................................................... 10

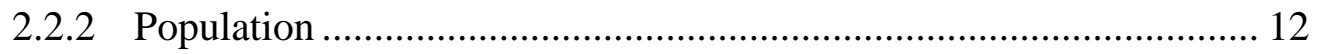

2.2.3 Government and Industry .................................................... 17

2.3 History and General Characteristics of California High-Speed Rail ...... 35

2.4 Factors that May Affect the Success of the California High-Speed Rail 49

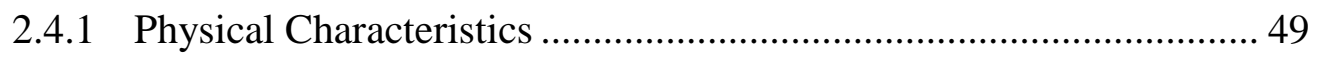

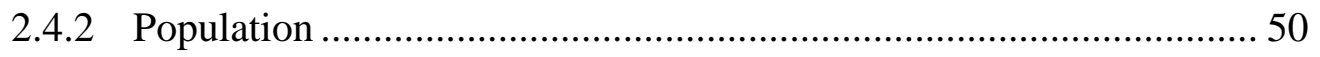

2.4.3 Government and Industry ..................................................... 54

2.5 Comparison between Japan and the United States ............................. 73

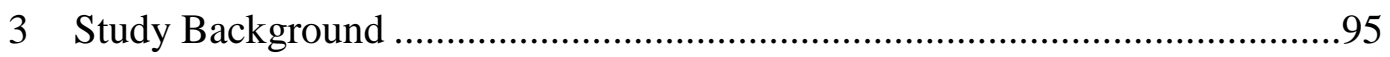

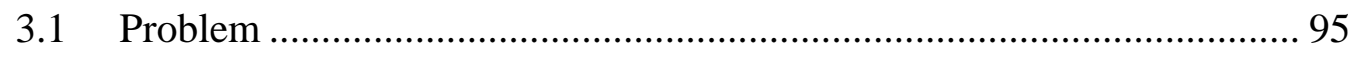

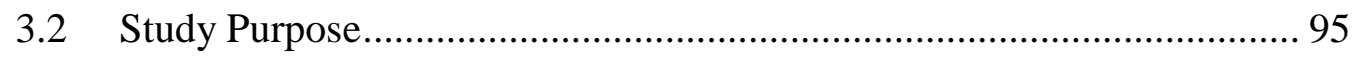

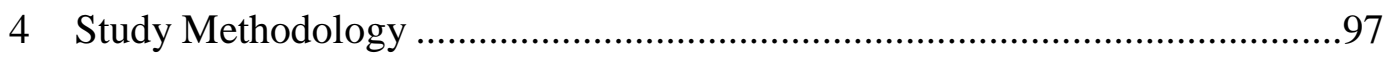


4.1 Defining the Accessibility of Station Catchment Areas........................ 97

4.2 Determining the Size of Station Catchment Areas............................... 99

4.3 Defining the Station Locations with Google My Maps ....................... 102

4.4 Retrieving Jobs Data with OnTheMap ............................................. 106

4.5 Retrieving Population and Housing Data with TIGER and GIS.......... 111

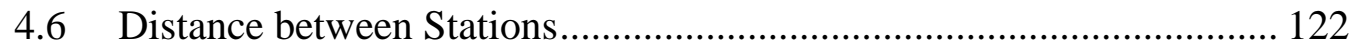

4.7 Application of the Gravity Model ................................................... 125

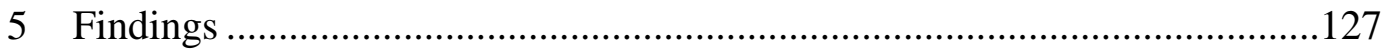

5.1 Half-Mile Radius Results ......................................................... 127

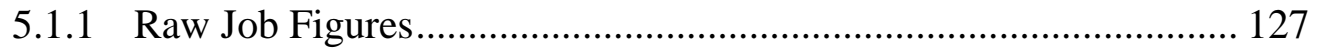

5.1.2 Normalized Job Figures ......................................................... 130

5.1.3 Raw Population Figures .......................................................... 132

5.1.4 Normalized Population Figures .................................................. 134

5.1.5 Raw Housing Unit Figures....................................................... 136

5.1.6 Normalized Housing Unit Figures .............................................. 138

5.2 Three-Mile Radius Results........................................................... 140

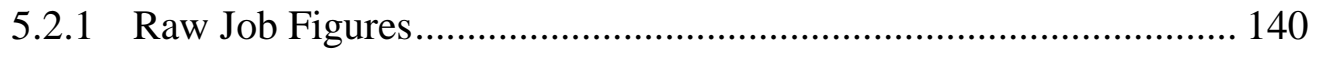

5.2.2 Normalized Job Figures ......................................................... 142

5.2.3 Raw Population Figures ........................................................ 144

5.2.4 Normalized Population Figures ................................................ 146

5.2.5 Raw Housing Unit Figures....................................................... 148

5.2.6 Normalized Housing Unit Figures ......................................... 150 
5.3 Five Mile Radius Results

5.3.1 Raw Job Figures.................................................................. 152

5.3.2 Normalized Job Figures ........................................................... 154

5.3.3 Raw Population Figures ......................................................... 156

5.3.4 Normalized Population Figures ............................................ 158

5.3.5 Raw Housing Unit Figures...................................................... 160

5.3.6 Normalized Housing Unit Figures ........................................... 162

5.4 Corridor Level Results .............................................................. 164

5.5 Categorization of Station Area Synergy by Distance.......................... 168

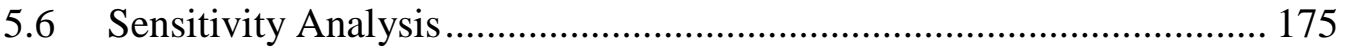

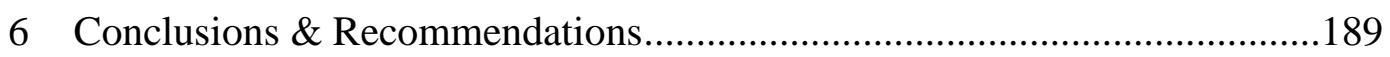

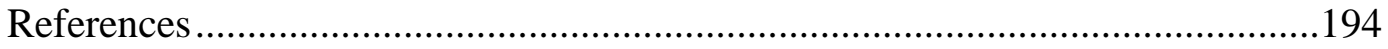

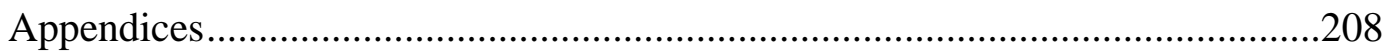

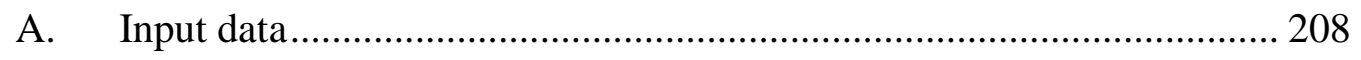

B. Accessibility Calculations ........................................................... 230

C. Results Matrices ....................................................................... 260 


\section{LIST OF TABLES}

Table

Page

Table 2.1 Opening dates and characteristics of various Shinkansen lines.

(a) "Mini"-shinkansen running on conventional track with added third rail to convert to standard gauge. (b) Connecting with Hokaido through the Seikan Tunnel, with additional third rail, speed limited by interactions with conventional freight trains in tunnel (Smith, 2014, p. 10) 8

Table 2.2 Business expansion during the early days of the railway group founded by Ichizo Kobayashi. Modified from (Industrial Bank of Japan, 2001, p. 11) 20

Table 2.3 Types of businesses operated by Japanese railway consortia and their affiliated companies. (Cervero, 1998, p. 191). 21

Table 2.4 Major private railway company statistics and operating revenues from 1994. The original 1994 figures in Yen have been converted to 2016 dollars. (Saito, 1997, p. 6; Federal Reserve Bank of St.

Louis, 2017; Federal Reserve Bank of Minneapolis, 2017). 26

Table 2.5 Major private railway company statistics and operating revenues from 1994 (contd.). The original 1994 figures in Yen have been converted to 2016 dollars. (Saito, 1997, p. 6; Federal Reserve Bank

of St. Louis, 2017; Federal Reserve Bank of Minneapolis, 2017) 27

Table 2.6 Operating profits and loss of major private railway companies in 1994. The original 1994 figures in Yen have been converted to 
2016 dollars. (Saito, 1997, p. 6; Federal Reserve Bank of St. Louis, 2017; Federal Reserve Bank of Minneapolis, 2017). 28

Table 2.7 Passenger rail figures in Japan in 2014. (Statistics Bureau of Japan, 2017). 33

Table 2.8 Financial performance of main island (Honshu) JRs in 2015.

(Japan Times, 2016; Federal Reserve, 2017) 35

Table 2.9 Cost estimates for the California High-Speed Rail Project by business plan. Note: YOE = year of estimate. (Authority, 2011, p. ES-9; 2012, p. ES-15; 2014a, p. 35; 2016, p. 68; 2018b, p. 48) 41

Table 2.10 Top 50 Transit Agencies in Terms of Farebox Recovery Rate in the National Transit Database . Note: Yellow cells indicate transit agencies that operate in California. (National Transit

Database [NTD], 2015a; NTD, 2015b; NTD, 2016). 71

Table 2.11 Top 50 Transit Agencies in Terms of Farebox Recovery Rate in the National Transit Database (cont.). Note: Yellow cells indicate transit agencies that operate in California. (National Transit Database [NTD], 2015a; NTD, 2015b; NTD, 2016) 72

Table 2.12 The partnership responsibilities in a station area development project. Modified from (Cervero \& Murakami, 2008, p. 72). 76

Table 2.13 The partnership responsibilities in a station area development project (cont.). Modified from (Cervero \& Murakami, 2008, p. 72) 77

Table 4.1 Raw job numbers by station catchment area radius, 2014 .

Courtesy of the United States Census Bureau (2017c). 109 
Table 4.2 Descriptive statistics of jobs by station catchment area radius, 2014. Courtesy of the United States Census Bureau (2017c). 110

Table 4.3 Normalized job numbers by station catchment area radius, 2014.

Courtesy of the United States Census Bureau (2017c).

Table 4.4 Raw population numbers by station catchment area radius, 2014.

Courtesy of the United States Census Bureau (2017d). 116

Table 4.5 Descriptive statistics of population by station catchment area radius, 2014. Courtesy of the United States Census Bureau (2017d). 117

Table 4.6 Normalized population numbers by station catchment area radius, 2014. Courtesy of the United States Census Bureau (2017d). 117

Table 4.7 Raw housing unit numbers by station catchment area radius, 2014. Courtesy of the United States Census Bureau (2017d). 118

Table 4.8 Descriptive statistics of housing units by station catchment area radius, 2014. Courtesy of the United States Census Bureau (2017d).

Table 4.9 Normalized housing unit numbers by station catchment area radius, 2014. Courtesy of the United States Census Bureau (2017d). 120

Table 4.10 Distances of links between stations along the high-speed rail alignment. 125 
Table 4.11 The distance between each station along the California HighSpeed Rail line. 125

Table 5.1 Accessibility indices for origin-destination pairs from raw job figures for half-mile buffer. Green, yellow, and red cells denote relatively high, medium, and low values, respectively. Blue cells denote row or column totals

Table 5.2 Accessibility indices for origin-destination pairs from normalized job figures for half-mile buffer. Green, yellow, and red cells denote relatively high, medium, and low values, respectively. Blue cells denote row or column totals.

Table 5.3 Accessibility indices for origin-destination pairs from raw population figures for half-mile buffer. Green, yellow, and red cells denote relatively high, medium, and low values, respectively. Blue cells denote row or column totals. 133

Table 5.4 Accessibility indices for origin-destination pairs from normalized population figures for half mile buffer. Green, yellow, and red cells denote relatively high, medium, and low values, respectively. Blue cells denote row or column totals. 135

Table 5.5 Accessibility indices for origin-destination pairs from raw housing unit figures for half-mile buffer. Green, yellow, and red cells denote relatively high, medium, and low values, respectively. Blue cells denote row or column totals. 
Table 5.6 Accessibility indices for origin-destination pairs from normalized housing unit figures for half-mile buffer. Green, yellow, and red cells denote relatively high, medium, and low values, respectively. Blue cells denote row or column totals. 139

Table 5.7 Accessibility indices for origin-destination pairs from raw job figures for three-mile buffer. Green, yellow, and red cells denote relatively high, medium, and low values, respectively. Blue cells denote row or column totals

Table 5.8 Accessibility indices for origin-destination pairs from normalized job figures for three-mile buffer. Green, yellow, and red cells denote relatively high, medium, and low values, respectively. Blue cells denote row or column totals.

Table 5.9 Accessibility indices for origin-destination pairs from raw population figures for three-mile buffer. Green, yellow, and red cells denote relatively high, medium, and low values, respectively. Blue cells denote row or column totals 145

Table 5.10 Accessibility indices for origin-destination pairs from normalized population figures for three-mile buffer. Green, yellow, and red cells denote relatively high, medium, and low values, respectively. Blue cells denote row or column totals. 147

Table 5.11 Accessibility indices for origin-destination pairs from raw housing unit figures for three-mile buffer. Green, yellow, and red 
cells denote relatively high, medium, and low values, respectively.

Blue cells denote row or column totals.

Table 5.12 Accessibility indices for origin-destination pairs from normalized housing unit figures for three-mile buffer. Green, yellow, and red cells denote relatively high, medium, and low values, respectively. Blue cells denote row or column totals.

Table 5.13 Accessibility indices for origin-destination pairs from raw job figures for five-mile buffer. Green, yellow, and red cells denote relatively high, medium, and low values, respectively. Blue cells denote row or column totals.

Table 5.14 Accessibility indices for origin-destination pairs from normalized job figures for five-mile buffer. Green, yellow, and red cells denote relatively high, medium, and low values, respectively. Blue cells denote row or column totals. 155

Table 5.15 Accessibility indices for origin-destination pairs from raw population figures for five-mile buffer. Green, yellow, and red cells denote relatively high, medium, and low values, respectively. Blue cells denote row or column totals. 157

Table 5.16 Accessibility indices for origin-destination pairs from normalized population figures for five-mile buffer. Green, yellow, and red cells denote relatively high, medium, and low values, respectively. Blue cells denote row or column totals. 
Table 5.17 Accessibility indices for origin-destination pairs from raw housing unit figures for five-mile buffer. Green, yellow, and red cells denote relatively high, medium, and low values, respectively.

Blue cells denote row or column totals. 161

Table 5.18 Accessibility indices for origin-destination pairs from normalized housing unit figures for five-mile buffer. Green, yellow, and red cells denote relatively high, medium, and low values, respectively. Blue cells denote row or column totals. 163

Table 5.19 Accessibility indices for San Francisco and other stations from raw job figures for all catchment area radii. Green, yellow, and red cells denote relatively high, medium, and low values, respectively 164

Table 5.20 Accessibility indices for all stations along the corridor comparing raw figures for jobs, population, and housing units for all catchment area radii. Green, yellow, and red cells denote relatively high, medium, and low values, respectively. 166

Table 5.21 Accessibility indices for origin-destination pairs from raw job figures for three-mile buffer, less pairs where the origin and destination are the same. Green, yellow, and red cells denote relatively high, medium, and low values, respectively. Blue cells denote row or column totals. 169

Table 5.22 Rank of origin-destination pairs based on accessibility indices from raw job figures for three-mile buffer, less pairs where the 
origin and destination are the same. The eleven station-area origin destination pairs with the highest ranks are highlighted in yellow.

Table 5.23 Characteristics of top eleven station area origin-destination pairs at the three-mile radius

Table 5.24 Methodology of incrementally increasing Fresno's and Bakersfield's number of jobs to match that of San Francisco's. 178

Table 5.25 Number and percent of jobs at each three-mile radius station area under different scenarios.

Table 5.26 Sum of accessibility indices from raw job figures for half-mile buffer of each station area as a destination by scenario. Green, yellow, and red cells denote relatively high, medium, and low values, respectively. Blue cells denote row or column totals. 181

Table 5.27 Comparison of 1) accessibility indices for all station areas along the corridor, 2) percent change of accessibility indices with respect to corresponding origin-destination under Scenario A with conditional formatting by scenario, and 3) percent change of accessibility indices with respect to corresponding origindestination under Scenario A with conditional formatting of all origin-destination pairs. Green, yellow, and red cells denote relatively high, medium, and low values, respectively. 182

Table 5.28 Number and percent of jobs at each three-mile radius station area from Gilroy to Palmdale under different scenarios. 185 
Table 5.29 Sum of accessibility indices from raw job figures for half-mile buffer of each station area from Gilroy to Palmdale as a destination by scenario. Green, yellow, and red cells denote relatively high, medium, and low values, respectively. Blue cells denote row or column totals 186

Table 5.30 Comparison of 1) accessibility indices for all station areas from Gilroy to Palmdale along the corridor, 2) percent change of accessibility indices with respect to corresponding origindestination under Scenario A with conditional formatting by scenario, and 3) percent change of accessibility indices with respect to corresponding origin-destination under Scenario A with conditional formatting of all origin-destination pairs. Green, yellow, and red cells denote relatively high, medium, and low values, respectively. 187 


\section{LIST OF FIGURES}

Figure

Page

Figure 2.1 The number of passengers on all Shinkansen lines from 1964 to 2007 is shown. (Publictransit.us, 2010)................................................... 9

Figure 2.2 Stopping patterns of different services on Tokaido Shinkansen.

(Central Japan Railway Company, 2008, p. 5)........................................ 9

Figure 2.3 Number of daily scheduled train service by year and by type on the Tokaido Shinkansen. (Suyama, 2014, p. 19). 10

Figure 2.4 "Be on the way" transit planning concept. (Walker, 2012, p. $185)$. 14

Figure 2.5 "Urban Density versus Transit Use in the Los Angeles Region, 1990.” (Newman \& Kenworthy, 2006, p. 41) 16

Figure 2.6 Population density of cities along Tokaido Shinkansen. ("List of cities of Japan,” 2017; Central Japan Railway Company, n.d.). 17

Figure 2.7 Transportation-Land use dynamic. (Giuliano, 2004, p. 227) 22

Figure 2.8 Original group management model for railway companies.

(Industrial Bank of Japan, 2001, p. 8).

Figure 2.9 Business expansion of railway groups and the flow of funds.

(Industrial Bank of Japan, 2001, p. 12).

Figure 2.10 An example of maximizing the commercial value of station

buildings. (Sayama, n.d., pdf-p. 12)

Figure 2.11 Phase 1 system cost estimate by project section and range.

(Authority, 2018a, p. 43) 48 
Figure 2.12 Range of cost estimates by phase. (Authority, 2018b, p. 36). 48

Figure 2.13 Percent of urban and rural population in the United States by year. (United States Census Bureau, 1993; United States Census Bureau, 2000; United States Census Bureau, 2010). 55

Figure 2.14 Change in transportation mode usage in the United States, 1890-2014. Note that transit trips include roadway modes and all fixed-guideway modes reported. State motor vehicle registrations include automobiles, buses, and trucks. (American Public Transportation Association, 2015, pp. 20-27; Federal Highway Administration [FHWA], 1997; FHWA; 2015). 58

Figure 2.15 Passenger-Miles by mode in the United States by year. The figures for transit and intercity rail are too small to be shown graphically. (DOT, 2016a) 61

Figure 2.16 Percent of passenger-miles in the United States by mode and by year. The figures for transit and intercity rail are too small to be shown graphically. (DOT, 2016a). 62

Figure 2.17 Federal transportation expenditures by mode and year. "Other" includes figures for "Water," "Pipeline," and "General" transportation modes. (DOT, 2016b; Federal Reserve Bank of Minneapolis, 2016). 63

Figure 2.18 Percent of federal transportation expenditures by mode and year. "Other" includes figures for "Water," "Pipeline," and 
"General" transportation modes. (DOT, 2016b; Federal Reserve Bank of Minneapolis, 2016). 64

Figure 2.19 State and local transportation expenditures by mode and year. "Other" includes figures for "Water," "Pipeline," and "General" transportation modes. (DOT, 2016b; Federal Reserve Bank of Minneapolis, 2016). 65

Figure 2.20 Percent of state and local transportation expenditures by mode and by year. "Other" includes figures for "Water," "Pipeline," and "General" transportation modes. (DOT, 2016b; Federal Reserve Bank of Minneapolis, 2016). 66

Figure 2.21 United States real gross domestic product per capita per year in 2005 dollars. (Johnston \& Williamson, 2017).

Figure 2.22 Spatial pattern of urban growth around the automobile and highways. (Muller, 1995, p. 43) 70

Figure 2.23 Two institutional models for rail and property developments.

(Tang et al., 2005, p. 8). 75

Figure 2.24 The components of a station area development with MTRC.

(Cervero \& Murakami, 2008, p. 72). 76

Figure 2.25 The components of a station area development with MTRC

(cont.). (Cervero \& Murakami, 2008, p. 72) 77

Figure 2.26 Berlin's main railway station. (Tillier, 2009). 81 
Figure 2.27 "Transit-Adjacent Development" around Valley Transit Authority light rail in San Jose, California. (Cervero \& Murakami, 2008, p. 27). 82

Figure 2.28 Example of a North American joint development project.

(Government Accountability Office [GAO], 2010, p. 6) 82

Figure 2.29 Status of property ownership around Shibuya Station. (Tokyu Group, 2013) 84

Figure 2.30 Tokyu Group's “PEAs” Strategy. (Cervero \& Murakami, 2008, p. 151) 84

Figure 2.31 Corridor planning by the East Japan Railway Company.

(Sayama, n.d., pdf-p. 25) 85

Figure 2.32 Delivery model of California High-Speed Rail. (Authority, 2018a, p. 26). 92

Figure 4.1 Newton's Law of Universal Gravitation. (Sir Isaac Newton The Universal Law of Gravitation, n.d.). 97

Figure 4.2 Gravity model used in the transportation field. 98

Figure 4.3 Accessibility of station areas in relation to the size of its attractions and its distance to relevant points. 99

Figure 4.4 Column chart of raw job numbers by station catchment area radius, 2014. Courtesy of the United States Census Bureau (2017c). 109 
Figure 4.5 Column chart of normalized job numbers by station catchment area radius, 2014. Courtesy of the United States Census Bureau (2017c).

Figure 4.6 Column chart of raw population numbers by station catchment area radius, 2014. Courtesy of the United States Census Bureau (2017d). 116

Figure 4.7 Column chart of normalized population numbers by station catchment area radius, 2014. Courtesy of the United States Census Bureau (2017d). 118

Figure 4.8 Column chart of raw housing unit numbers by station catchment area radius, 2014. Courtesy of the United States Census Bureau (2017d).

Figure 4.9 Column chart of normalized housing unit numbers by station catchment area radius, 2014. Courtesy of the United States Census Bureau (2017d). 121

Figure 4.10 Formula for accessibility index of station origin-destination pairs. 126

Figure 5.1 High job attractiveness by station separation. 173 


\section{LIST OF MAPS}

Map

Page

Map 2.1 The Tokaido Main Line (in red) running along the Tokai Region in Japan. The path of the Shinkansen is shown in black (East Japan

Railway Culture Foundation, n.d., p. 2) ............................................. 5

Map 2.2 The Shinkansen Network. (Ministry of Land, Infrastructure,

Transport and Tourism, 2016)...................................................... 7

Map 2.3 A Map of Japan. (Warta, 2008)................................................... 11

Map 2.4 Population density of Japan in 2010. (Statistics Bureau of Japan,

2013). 13

Map 2.5 Territory of six passenger Japan Railway companies. (Japan-

Cycling.com, 2017)

Map 2.6 Proposed statewide alignment of the California High-Speed Rail

System. (Authority, 2017c).

Map 2.7 Segments of the California High-Speed Rail System in the 2012

Revised Business Plan. IOS = Initial Operating Segment.

(Authority, 2011, p. 2-2).

Map 2.8 Segments of the California High-Speed Rail System in the 2014

Business Plan. (Authority, 2014a, p. 14).

Map 2.9 Segments of the California High-Speed Rail System in the 2016

Business Plan. (Authority, 2016, p. 48).

Map 2.10 Segments of the California High-Speed Rail System in the 2018

Business Plan. (Authority, 2018b, p. 19). 45 
Map 2.11 Proposed statewide alignment of the California High-Speed Rail

System. (Authority, 2017c).

Map 2.12 Population density and distribution of State of California.

(Bostock, 2017) 52

Map 2.13 Proposed statewide alignment and population per square mile.

(Authority, 2017b). 53

Map 4.1 Station locations of the California High-Speed Rail System.

Created using Google My Maps (2017). 103

Map 4.2 Status of the stations of California High-Speed Rail. Existing:

Future high-speed rail service will utilize existing facilities.

Finalized: Future station locations have been determined under the environmental review process. Proposed: Future station locations have been identified, but not yet finalized under the environmental review process. Under Construction: Future high-speed rail service will utilize facilities that are under construction at the time of this writing. 105

Map 4.3 California High-Speed Rail station locations and alignment. Created using ArcMap GIS (2017). (United States Census Bureau, 2017b; Duncan, 2017). 123 


\section{Introduction}

On January 6, 2015, California doubled down on its effort to transform its transportation network. California Governor Jerry Brown, and an entourage of policymakers, supporters, and news reporters, held a ceremony in Fresno, California, to mark the start of construction for a statewide high-speed rail system (Sheehan, 2015). The event represented a point of tremendous progress for the California High-Speed Rail Project, as the state agency that was responsible for its implementation, the California High-Speed Rail Authority, has had to navigate a political obstacle course since its inception in 1996 to move the project forward (Subramani, 2008). More importantly, the event demonstrated a shift in strategy for the Authority, as it was moving from primarily planning for the system to managing the full-scale construction of the system (Sheehan, 2015). As the Authority Board Chairman, Dan Richard, noted at the event, "We are entering a period of sustained construction on the nation's first high-speed rail system for the next five years in the Central Valley, and in the decade beyond that we will be building across California” (Sheehan, 2015).

While one can celebrate the progress behind the California High-Speed Rail Project, one wonders how useful the system will really be once it is up and running. A notable criticism of the Project has been the fact that it is being built in a country that has essentially left mass transit and railroads behind for the past several decades. Adding more fuel to the fire, its initial construction segment (in the San Joaquin Valley) is being built in a part of the State that has relatively little transit service compared to the State's urban areas. To illustrate, the Authority's (2012, p. ES-2) 2012 Revised Business Plan stated that "[ $\mathrm{t}]$ he benefits of the initial investment in the Central Valley were not clear 
enough and were seen by some as imposing a risk of stranded investment if the program did not continue". During the California Legislature's debate in 2012 to vote to approve or not to approve bond funding for the Project, State Senator Mark DeSaulnier introduced an alternative plan that would redirect bond funding away from the initial construction segment in the San Joaquin Valley and towards urban areas like the San Francisco Bay Area or the Los Angeles Metropolitan Area (Burk for Akley, 2012). In a follow-up interview in 2014, State Senator Mark DeSaulnier stated that while he was not against the Project in general, he was worried that the State was "in danger of having to pay money back for an isolated facility that will never give real function ..." (Richman, 2014). It should be noted that the State Senator was referring to $\$ 3.3$ billion in federal grants (much of it from the American Recovery and Reinvestment Act of 2008 [ARRA]) that California competitively applied for and secured against other states (Authority, 2017a). As a condition of being awarded the money, California had to spend the federal funds by the sunset date of September 30, 2017, to fulfill the legislative intent of stimulating the economy in the aftermath of the crash of the housing bubble in 2007 and the concomitant Great Recession (Authority, 2012, p. 2-12). In another example, during a radio show hosted by KQED, a commentator questioned why money was being spent to build highspeed rail instead of "expanding the well-used BART system or the LA Metro" (Krasny, 2016). Finally, in response to a revision outlined in the Authority's (2016, p. 116) 2016 Business Plan that the planned initial operating segment would be between San Jose Diridon Station and an interim terminal 20 miles north of Bakersfield until additional funding can be secured, the Investor's Business Daily, and many other news outlets, responded by calling the Project a "Train to Nowhere" (Merline, 2016). 
These discussions intrigued the author to investigate the potential functionality of the California High-Speed Rail System's future stations. The author wanted to examine, with a focus on station area planning, what made the world's arguably most successful high-speed rail system, the Japanese Shinkansen, so patronized. After learning from the Shinkansen and the contextual government policies and industrial structure that support it, what lessons could be applied to help make California's future bullet train system successful? Is the State of California taking steps to incorporate these important lessons into the planning, construction, and eventual operations of its very own high-speed rail system? Relevant background material is reviewed below to answer these inquiries. 


\section{Background to High-Speed Rail}

This section describes the background of the Japanese Shinkansen, and the supportive policies and underlying institutions that enabled it to be implemented. A similar process is conducted for the California High-Speed Rail Project.

\subsection{History and General Characteristics of the Shinkansen}

The Shinkansen, or "new trunk line," draws its origins from a project dubbed the dangan ressha, or "Bullet Train," which was conceived in 1939 by the Japanese Government to modernize the country's transportation network (Nippon.com, 2014). During this period, more and more traffic was carried along the narrow-gauge (i.e., 1,067 millimeters or 3 feet 6 inches) Tokaido Main Line (shown in Map 2.1), and the Government recognized that it would be advantageous "to link Tokyo with the western part of Japan, which, in turn, linked up with Japanese-held territory in China and Korea" (Smith, 2003, p. 225). A new development introduced by the dangan ressha was the introduction of 1,435-millimeter (4 feet 8.5 inches) standard gauge track, as opposed to the narrow-gauge system that is common throughout Japan (Smith, 2003, p. 224). The motivation was to provide for greater stability, allowing for higher speeds, and wider vehicles, meaning greater capacity (Smith, 2003, p. 225; Nippon.com, 2014). Despite land being procured for tracks and tunnels, the dangan ressha had to be put on hold indefinitely in 1943 as the Pacific War, part of World War II, began to turn against Japan's favor (Nippon.com, 2014). 


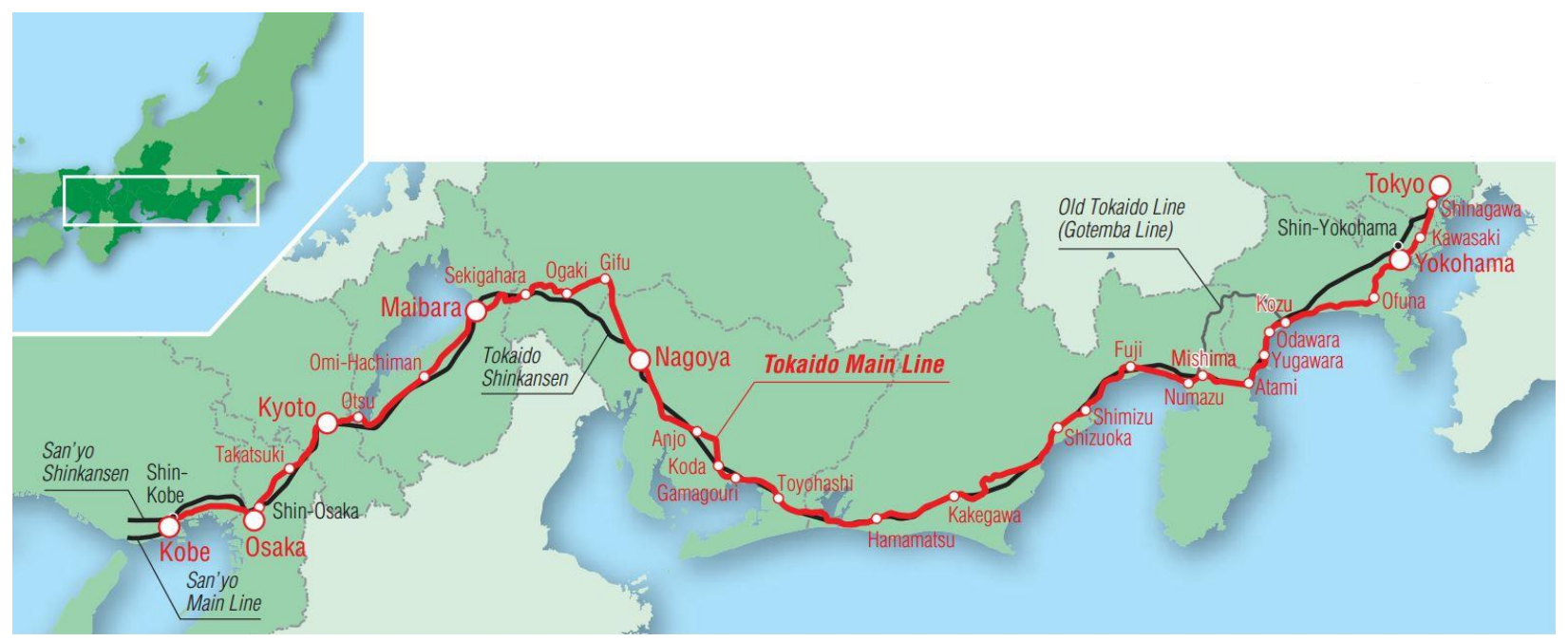

Map 2.1 The Tokaido Main Line (in red) running along the Tokai Region in Japan. The path of the Shinkansen is shown in black (East Japan Railway Culture Foundation, n.d., p. 2).

In the 1950s, the concept of a high-speed train line along the Tokaido Corridor was revived (Smith, 2003, p. 226). While comprising only three percent of the length of the national railway network, the 589.5-kilometer-long (366.3-mile-long) Tokaido Main Line handled 24 percent of the passenger traffic and 23 percent of the freight traffic of the national railway operator, Japan National Railways (JNR) (Takashima \& Miki, 2003, p. 52; Smith, 2003, pp. 225-226). By 1956, a segment of the line between the two most populated metropolitan areas in the country, Tokyo and Osaka, had been fully electrified, allowing new "Kodama” express trains to run the distance in a shorter six-and-a-half hours than previous travel times (Smith, 2003, p. 226). Nevertheless, "[p]rojections of the increase in passenger traffic, linked with economic growth, indicated that traffic was likely to double by 1975 and that this growth could be accommodated only by a new line" (Smith, 2003, p. 226).

An alternative to building a new line that was considered was to simply add additional tracks to the existing line (Smith, 2003, p. 226). The alternative was found to be impracticable, however, due to "the congestion of new buildings along the route, the 
large number of level crossings and the radii of the existing curves preventing high-speed running" (Smith, 2003, p. 226). The benefits of constructing a new line included the fact that it "would allow a standard-gauge track to be laid, free from crossings, with shallow curves and, crucially, free from the constraints of older facilities and 'released from JNR old habits"' (Smith, 2003, p. 226). The main motive was to boost capacity, rather than speed (Smith, 2003, p. 227).

One point that should be mentioned is that a notion called the "railway downfall theory" existed in Japan and other countries during the 1950s (Smith, 2003, p. 226). The notion alluded to a feeling that railways would eventually be superseded by automobiles and airplanes during the latter half of the $20^{\text {th }}$ Century in the same way that railways and steamships superseded horse-drawn carriages, canals, and sailing ships in the $19^{\text {th }}$ century (Smith, 2003, p. 226). "In Japan at the time, automobile production was gradually increasing, the construction of highways was about to start, and civil aviation had been resumed" (Smith, 2003, p. 226). Thus, many personnel in JNR believed that investing in the new main line was a mistake (Smith, 2003, p. 226). This resistance, however, was overcome by the determined efforts and vision of a "small number of managers, central amongst whom were Hideo Shima, chief engineer of JNR, and Shinji Sogo, the newly appointed president" (Smith, 2003, p. 226). A detailed biography of Shinji Sogo and his push to build the Shinkansen is available from Hosokawa (1997).

In the end, the Japanese Government accepted plans in December 1958 to construct a New Tokaido Main Line within five years (Smith, 2003, p. 227). The plans called for the development and implementation of new technology and standards for track, safety, trolley wire, and train control that would make covering the 550 kilometers 
between Tokyo and Osaka possible in three hours by electric train and at a maximum speed of 250 kilometers per hour (kph) (155 miles per hour [mph]) (Smith, 2003, p. 226). Construction began on April 20, 1959, and the line opened to traffic on October 1, 1964, just nine days prior to the start of the Tokyo Olympics (Smith, 2003, p. 222; Osamu, 2014, p. 6).

"Ridership on the Tokaido Shinkansen built up rapidly after its opening[,]" and by the time construction on the westward extension to Kobe and Okayama began in March 1966, the Tokaido Shinkansen recorded its one-hundred millionth passenger (Smith, 2003, p. 228). Because of the success of the first line, the Japanese Government approved the National Shinkansen Railway Development Act in 1970, enabling the expansion of the Shinkansen network across the entire country, as shown in Map 2.2.

\section{Total Length}

$2,388 \mathrm{~km} \fallingdotseq 1,487$ miles

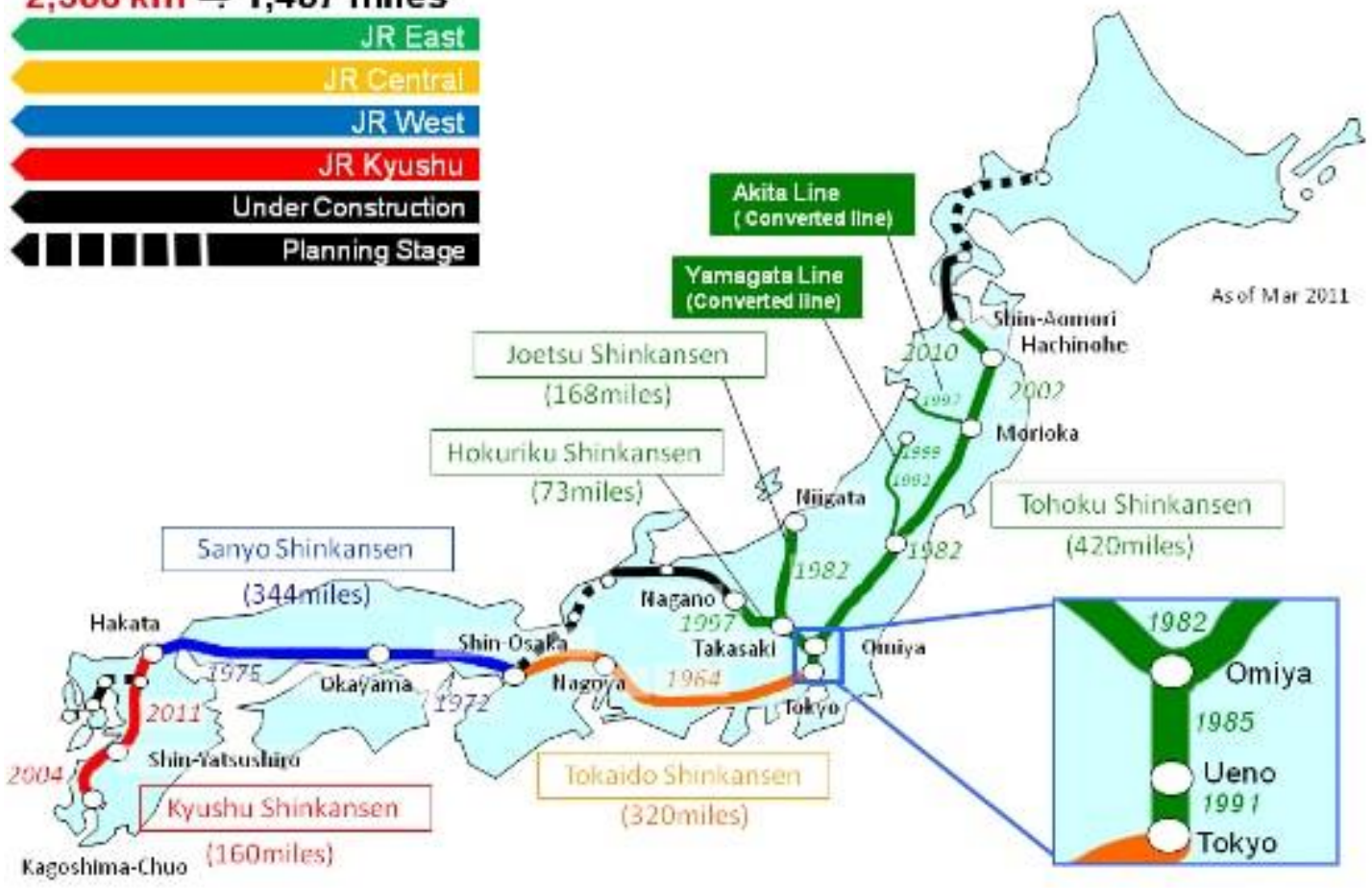

Map 2.2 The Shinkansen Network. (Ministry of Land, Infrastructure, Transport and Tourism, 2016). 
Since then, subsequent lines have opened for service, and ridership has steadily

increased across the entire network, as shown in Table 2.1 and Figure 2.1.

Table 2.1 Opening dates and characteristics of various Shinkansen lines. (a) "Mini"'-shinkansen running on conventional track with added third rail to convert to standard gauge. (b) Connecting with Hokaido through the Seikan Tunnel, with additional third rail, speed limited by interactions with conventional freight trains in tunnel (Smith, 2014, p. 10)

\begin{tabular}{|c|c|c|c|c|}
\hline Line & From/To & Length $(\mathrm{km})$ [mph] & Opening Year(s) & $\begin{array}{c}\text { Maximum Speed } \\
(\mathrm{kph})[\mathrm{mph}]\end{array}$ \\
\hline Tokaido & Tokyo-Shin Osaka & $515[320]$ & 1964 & $270[168]$ \\
\hline San'yo & Shin Osaka-Hakata & $554[344]$ & $1972-1975$ & $300[186]$ \\
\hline \multirow{2}{*}{ Tohoku } & \multirow{2}{*}{ Tokyo-Morioka } & \multirow{3}{*}{675 [419] } & 1982-1985 & \multirow{5}{*}{$320[199]$} \\
\hline & & & $1991-2002$ & \\
\hline \multirow{3}{*}{ Hokkaido } & Morioka-Shin Aomori & & 2011 & \\
\hline & $\begin{array}{l}\text { Shin Aomori-Shin } \\
\text { Hakodate }\end{array}$ & $149[93]$ & 2016 & \\
\hline & Shin Hakodate-Sapporo & $211[131]$ & 2035 & \\
\hline Joetsu & Tokyo-Niigata & $270[168]$ & 1982 & $275[171]$ \\
\hline Nagano & Takasaki-Nagano & $117[73]$ & 1997 & $260[162]$ \\
\hline \multirow{2}{*}{ Hokuriku } & Nagano-Kanazawa & 228 [142] & 2015 & \multirow{2}{*}{$260[162]$} \\
\hline & Kanazawa-Tsuruga & 349 [217] & 2026 & \\
\hline Yamagata (a) & Fukushima-Shinjo & 149 [93] & 1992-1999 & $130[81]$ \\
\hline Akita (a) & Morioka-Akita & $127[79]$ & 1997 & $130[81]$ \\
\hline \multirow{2}{*}{ Kyushu } & $\begin{array}{l}\text { Kagoshima-Shin } \\
\text { Yatsushiro }\end{array}$ & $127[79]$ & 2004 & \multirow{4}{*}{$260[162]$} \\
\hline & Shin Yatsushiro-Hakata & $130[81]$ & 2011 & \\
\hline \multirow[t]{2}{*}{ Hokkaido (b) } & $\begin{array}{l}\text { Shin Aomori-Shin } \\
\text { Hakodate }\end{array}$ & \multirow[t]{2}{*}{360 [224] } & \multirow[t]{2}{*}{2016} & \\
\hline & Shin Hakodate-Sapporo & & & \\
\hline
\end{tabular}




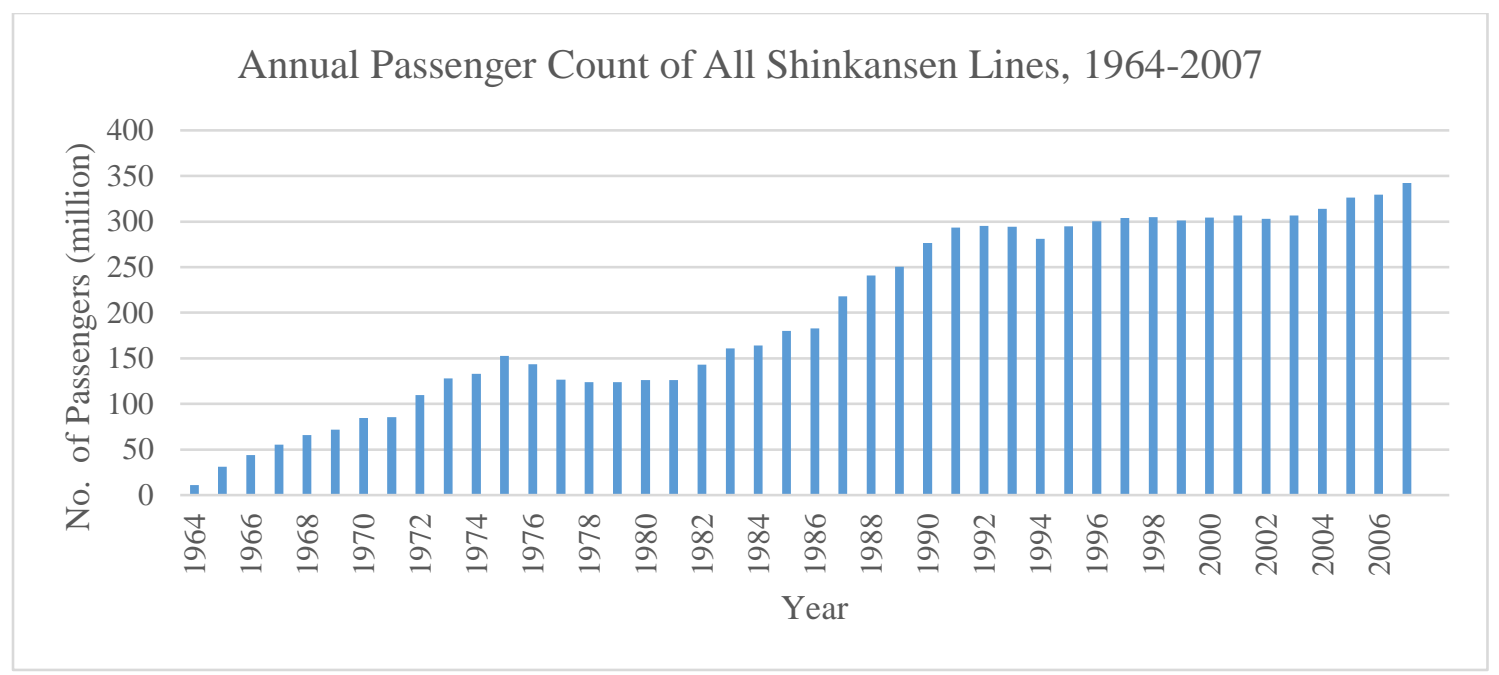

Figure 2.1 The number of passengers on all Shinkansen lines from 1964 to 2007 is shown. (Publictransit.us, 2010).

The type and number of train services have also increased since the start of operations. To illustrate, Figure 2.2 displays the stopping patterns of different services on the Tokaido Shinkansen. In general, Kodama, Hikari, and Nozomi trains correspond to all-stop, limited-stop, and express services, respectively. Figure 2.3 shows the number of daily scheduled train services by type and year on the Tokaido Shinkansen.

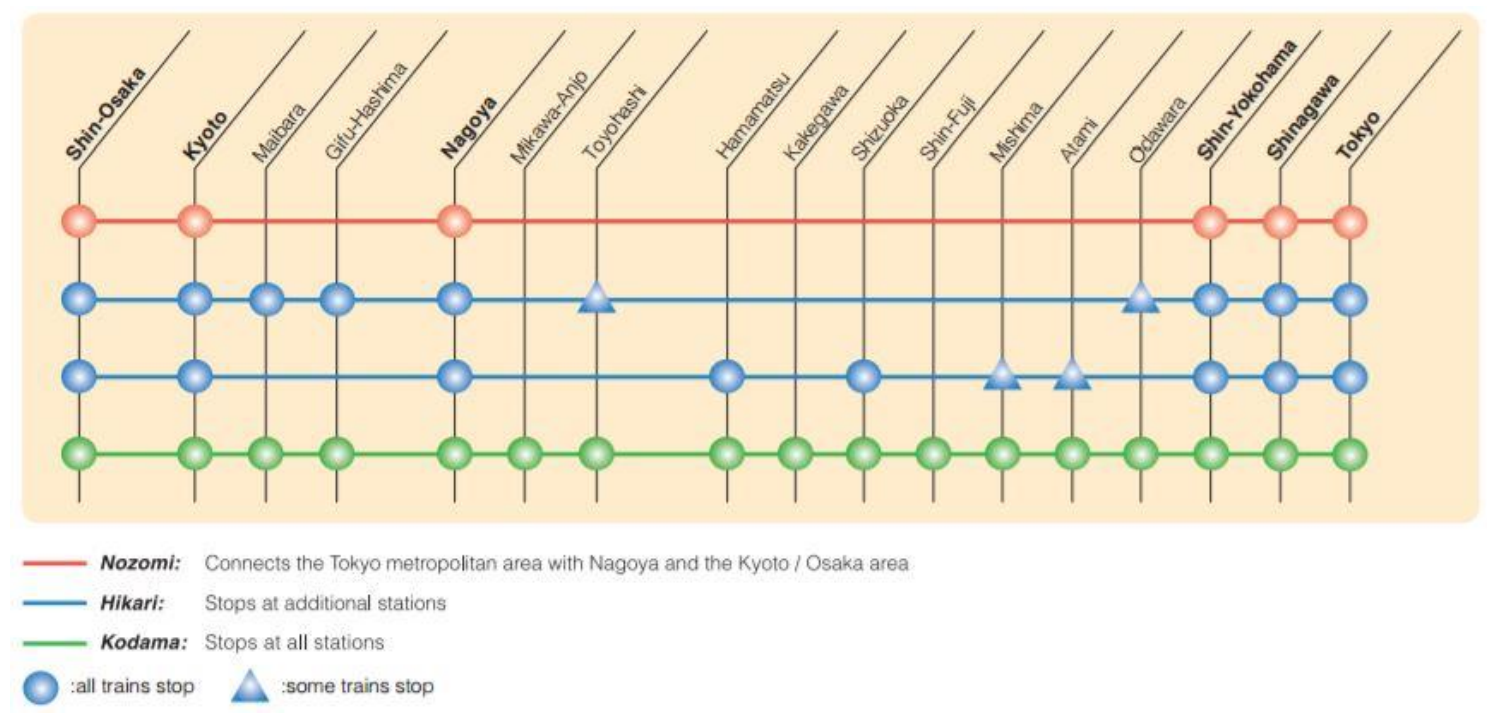

Figure 2.2 Stopping patterns of different services on Tokaido Shinkansen. (Central Japan Railway Company, 2008, p. 5). 


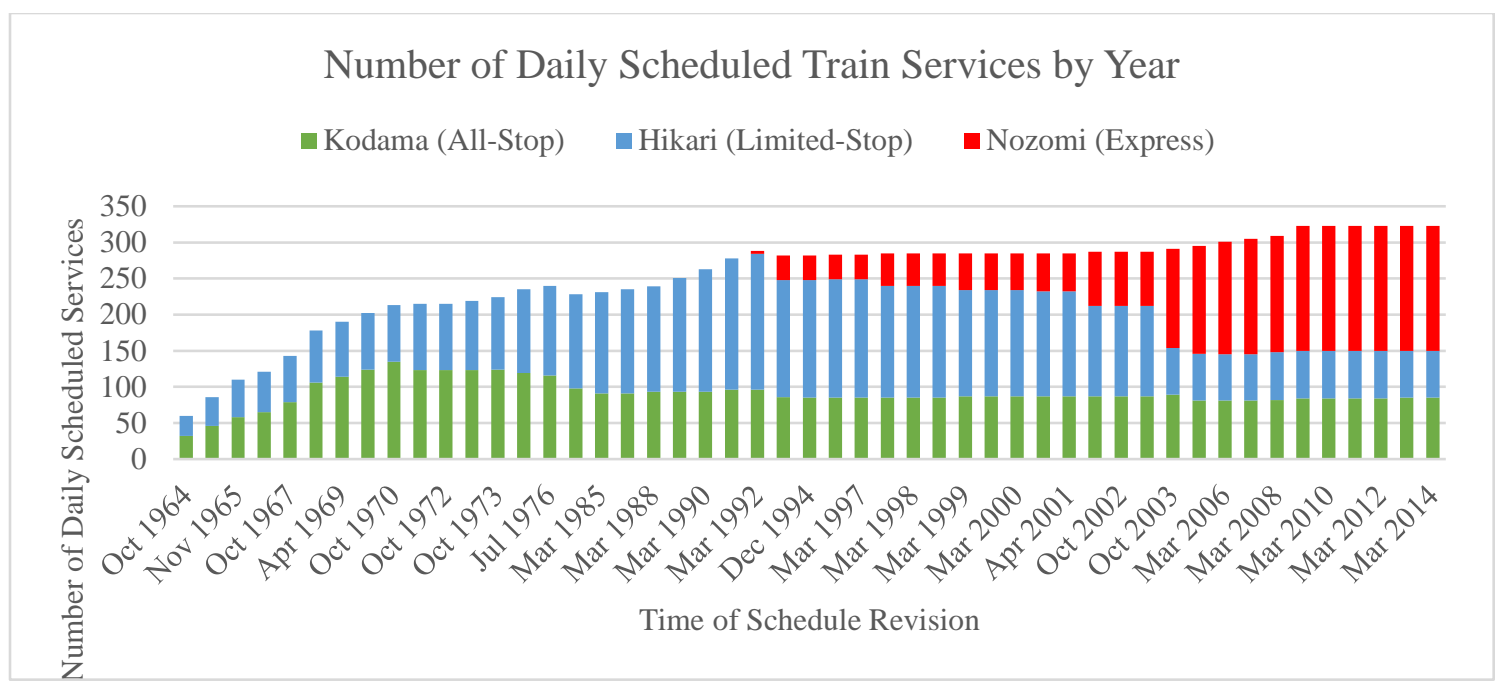

Figure 2.3 Number of daily scheduled train service by year and by type on the Tokaido Shinkansen. (Suyama, 2014, p. 19).

As of 2012, the Tokaido Shinkansen has carried approximately 5.3 billion passengers since it began operations in 1964 (Central Japan Railway Company, 2012, p. 16).

\subsection{Factors that Affect the Success of the Japanese Shinkansen}

The previous section discussed the successful implementation and performance of the Shinkansen. This success, however, did not occur in a vacuum. Because of their massive scope, costs, and impacts, transportation projects are inherently affected by existing institutional trends, and the Shinkansen is no exception. This section investigates such trends to identify the variables of success of the Shinkansen.

\subsubsection{Physical Characteristics}

Japan is an archipelago nation located off the east coast of Asia. It stretches from south of Russia's Sakhalin Island to south of the Korean Peninsula, as shown in Map 2.3. As such, its climate ranges from cool temperate in the north to tropical in the south. 
The country has a land area of 586,583 square kilometers (226,481 square miles), comprising of four main islands (Hokkaido, Honshu, Shikoku, and Kyushu) in addition to thousands of smaller islands and islets (Central Intelligence Agency [CIA], 2017). Most of its terrain is rugged and mountainous, rendering only 12.5 percent of its land to be arable (CIA, 2017). The country has virtually no natural mineral resources, and thus, "is the world's largest importer of coal and liquefied natural gas, as well as the second largest importer of oil" (CIA, 2017).

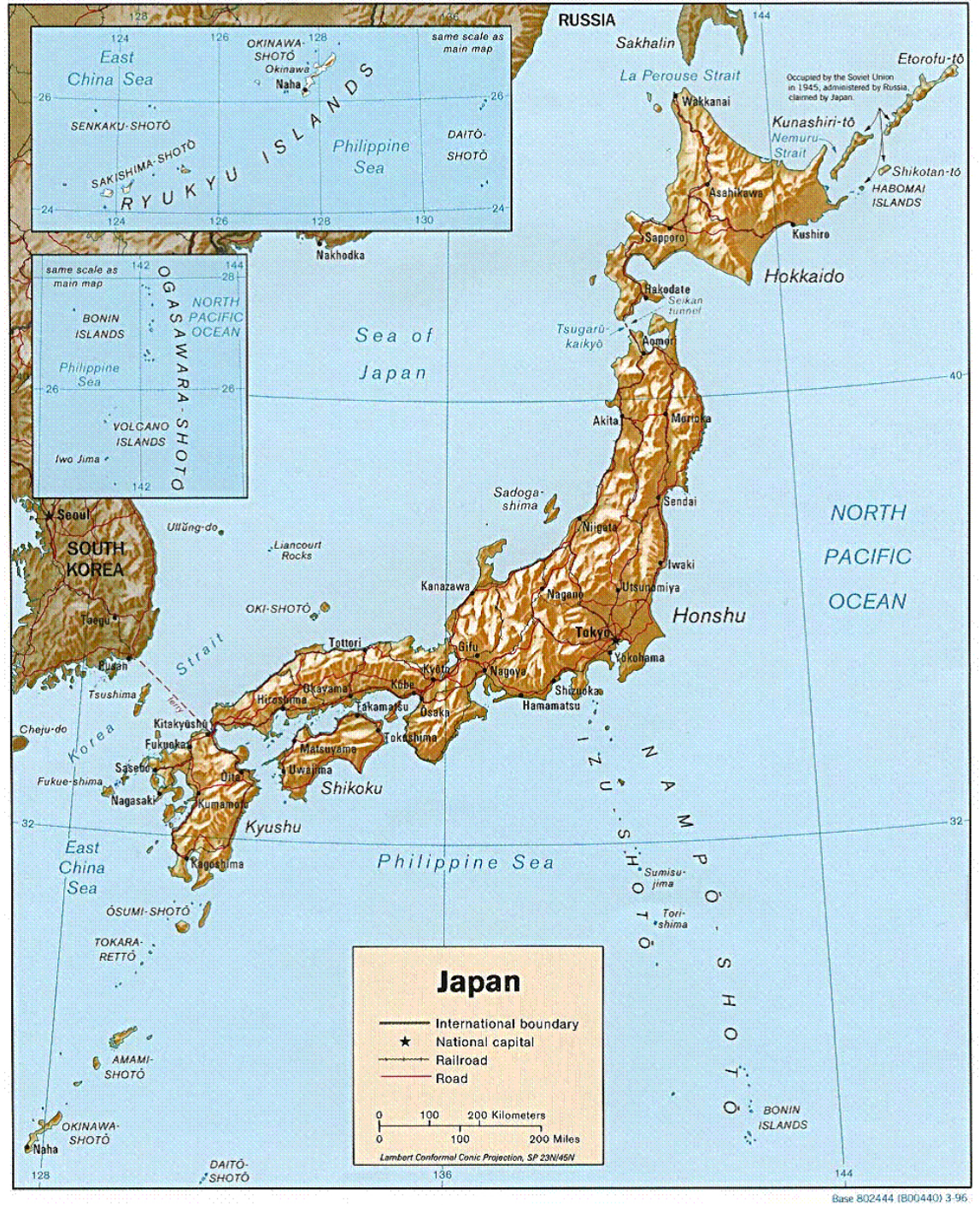

Map 2.3 A Map of Japan. (Warta, 2008). 


\subsubsection{Population}

Japan's population is estimated to be 126,702,133 as of July 2016 (CIA, 2017). Since much of the country is centrally bisected by the Japanese Alps, as shown in Map 2.3, the population has tended to concentrate along the coastline where the presence of flat plains allows for easier land development. Map 2.4 provides a visualization of the population concentration in Japan. As Map 2.4 shows, most of the population has concentrated along the southern coastline of the main island, Honshu. This area is referred to as the Tokaido Corridor (i.e., "East Sea Road" Corridor) and is named after the old imperial road that led from Edo (now Tokyo) to Kyoto (the old imperial capital) (Rodrigue, 2017). The area is also known as the Taiheiyo Belt (i.e., "Pacific Ocean” Belt) (Rodrigue, 2017). The Tokaido Corridor is home to 83 million people, or 70 percent of the national population, and includes major metropolitan areas, such as Tokyo (35 million people), Nagoya (8 million people), and Osaka (17 million people), as well as several other large cities with populations of over 1 million people, including Kobe, Kyoto, and Yokohama (Rodrigue, 2017). As a result, the Tokaido Corridor has a relatively large accumulation of Japan's infrastructure and industrial capacity (Rodrigue, 2017). 


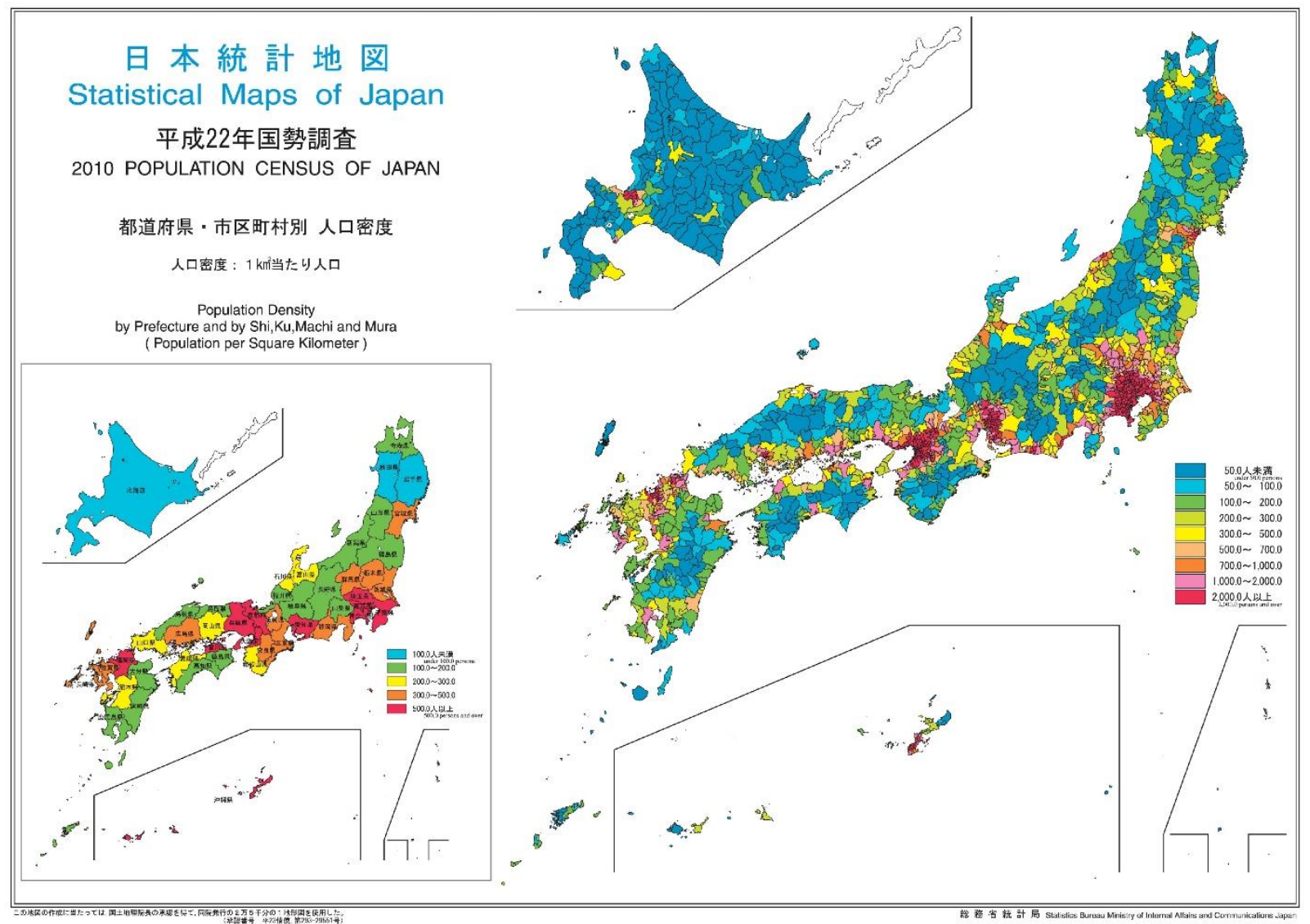

Map 2.4 Population density of Japan in 2010. (Statistics Bureau of Japan, 2013).

Two important effects of Japan's geography on its population distribution is that, firstly, many of the major cities are in a line, and secondly, high population densities are made practicable within the cities. Figure 2.4 and the discussion by Walker (2012, p. 185) expand on the importance of the first point regarding the routing of transit lines with respect to the destinations of their passengers:

An efficient transit line — and, hence, one that will support good serviceconnects multiple points but is also reasonably straight so that it's perceived as a direct route between any two points on the line ... . Even if it's a U, O, or L shape, an efficient line is at least locally straight and thus able to be the most 
direct route between two points on a long portion of the line. (Again, this is not always a geometrically straight line; it may be a path defined by existing roads or rail corridors that everyone perceives as reasonably direct given the terrain and natural chokepoints.)

For that reason, good transit geography is any geography in which highdemand transit destinations are on a direct and operable path between other highdemand transit destinations. A bad geography for transit, then, is one that indulges in cul-de-sacs on a large scale. It sets destinations a little back from the line, so that transit must either bypass them or deviate to them, where deviating means delaying all the other passengers riding through this point ...

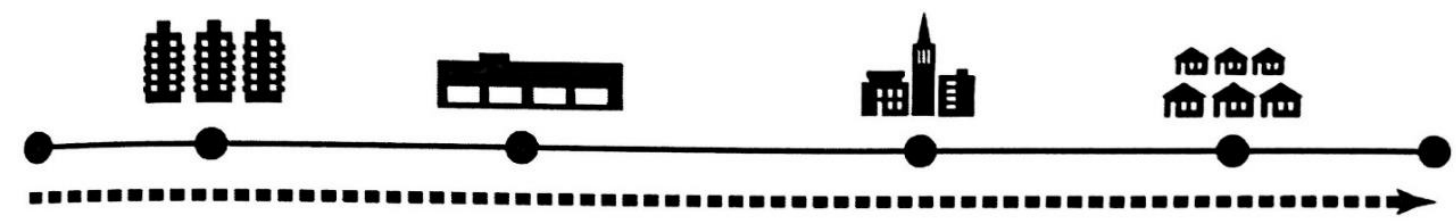

Ideal geometry for transit. Credit: Alfred Twu

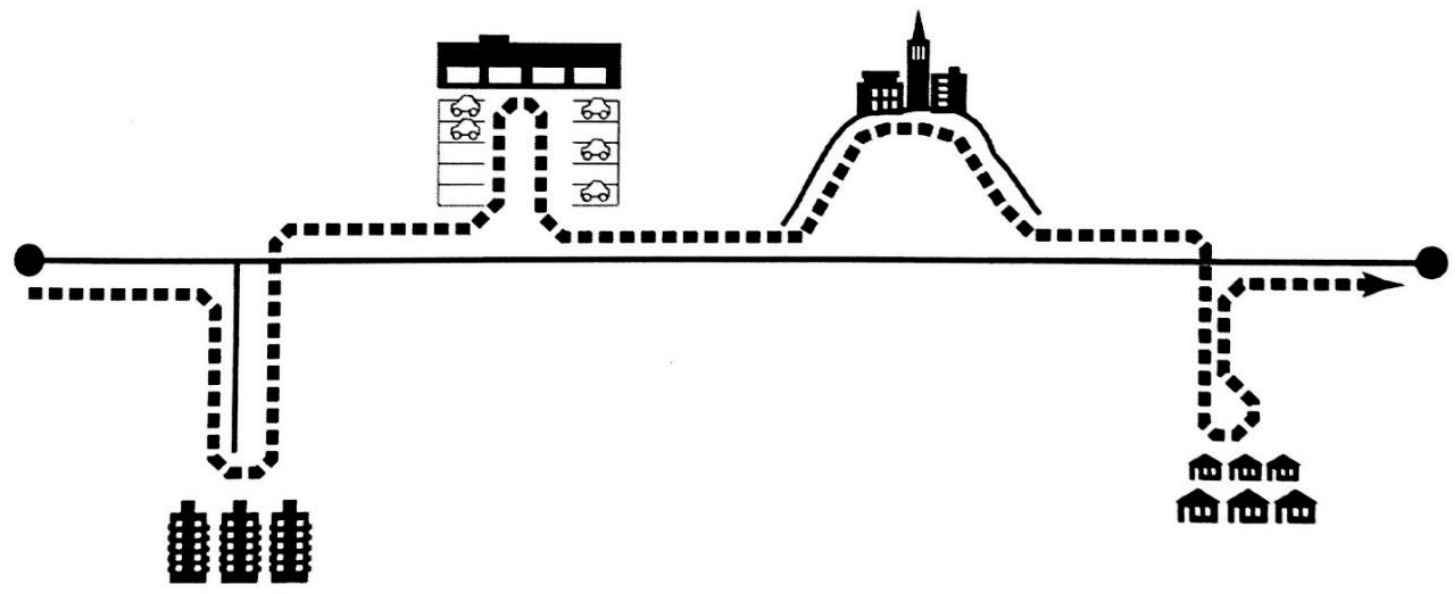

Terrible geometry for transit. Credit: Alfred Twu

Figure 2.4 "Be on the way" transit planning concept. (Walker, 2012, p. 185). 
On the second point about the importance of density to transit service, Jeffrey Zupan, quoted by Owen (2004), who in turn is quoted by Newman and Kenworthy (2006, pp. 39-41) elaborates on the concept:

The basic point is that you need density to support public transit. In all cities, not just in New York, once you get above a certain density two things happen. First, you get less travel by mechanical means, which is another way of saying you get more people walking and biking; and second, you get a decrease in trips by auto and an increase in trips by transit. That threshold tends to be around seven dwellings per acre. Once you cross that line, a bus company can put buses out there, because they know they're going to have enough passengers to support a reasonable frequency of service.

Figure 2.5 visualizes Zupan's statement by presenting an exponential relationship between urban density and the number of annual transit boardings per capita. The relationship appears to be very strong, with urban density accounting for 96.32 percent of the variability in the number of annual transit boardings per capita (Newman \& Kenworthy, 2006, p. 41). 


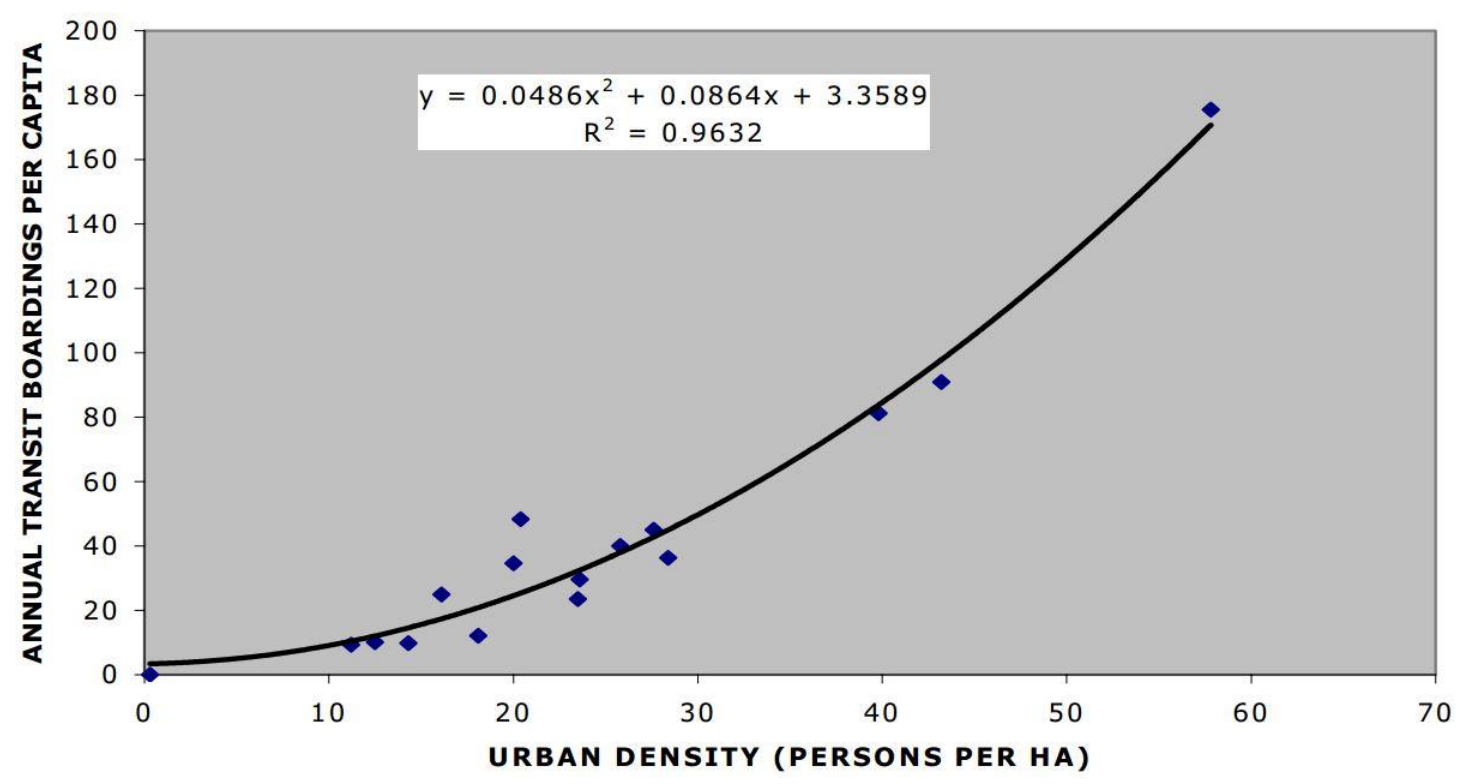

Figure 2.5 “Urban Density versus Transit Use in the Los Angeles Region, 1990.” (Newman \& Kenworthy, 2006, p. 41).

Newman and Kenworthy (2006, p. 41) note that the transit ridership threshold of "[s]even dwellings per acre at a reasonable dwelling occupancy is equivalent to around 35 to 40 persons per hectare." This range equates to about 4,828 to 6,437 persons per square kilometer, or 7,770 to 10,360 persons per square mile. As Figure 2.6 shows, several of the cities that are served by the Tokaido Shinkansen easily surpass this threshold, while others do not. 


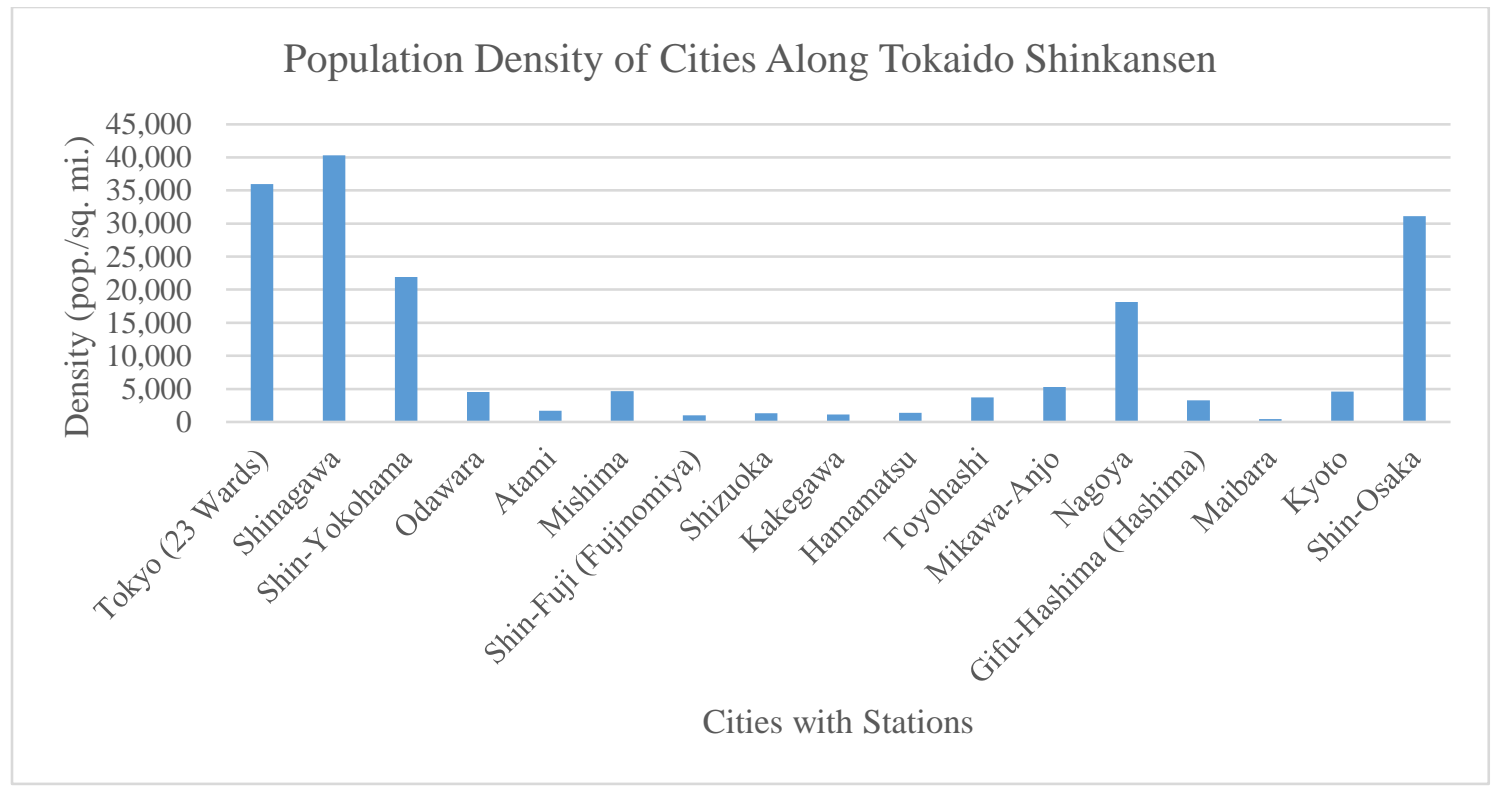

Figure 2.6 Population density of cities along Tokaido Shinkansen. ("List of cities of Japan," 2017; Central Japan Railway Company, n.d.).

Thus, Japan's geography has created conditions that are very beneficial for transit by putting important origins and destinations in a line and supporting urban densities that generate an adequate amount of ridership.

\subsubsection{Government and Industry}

It is doubtful that the success of the Shinkansen would have been as pronounced as it is without the supporting pre-conditions and high level of development of Japan's railway policies and industry. Since the opening of the first line in 1872, Japan's railways have undergone many changes that involved transfers of ownership between the public sector and the private sector (Terada, 2001, p. 48). The national railway network expanded in several booms during Japan's era of industrialization, including the years of 1885 to 1892 (first railway boom), 1896-1898 (second railway boom), 1906-1907 (nationalization), 1907-1911 (light railway boom), and in Osaka around 1910 and Tokyo in the 1920s (Saito, 1997, p. 3). In the early years, the mileage of the private railway lines 
was more than double that of the government railways (i.e., 5,231 versus 2,562

kilometers, or 3,250 versus 1,592 miles) (Saito, 1997, p. 3). In 1906-1907, the Japanese Government nationalized 17 private railway companies, with a total of 4,527 kilometers (2,813 miles), to promote national and military interests (Saito, 1997, p. 3). "After this nationalization, [the] establishment of new private railways was permitted only when they were to be engaged in local transport not interfering with" national railway operations (Saito, 1997, p. 3).

Consequently, many local private railway companies were compelled to extend their lines into rural areas and engage in a diversity of business activities to increase the population near their lines and to increase their revenues (Saito, 1997, p. 3). Hanshin Electric Railways, which connected Osaka and Kobe with a large-scale tram in 1905, was the pioneer of this model (Saito, 1997, p. 4). The "company developed residential areas and recreational facilities (spas, mountain-climbing sites, and playgrounds) along the line," and additionally built houses and department stores within its railway terminals (Saito, 1997, p. 4). A later emulator of Hanshin was Hankyu, which laid an electric railway line between Osaka, Takarazuka and Minoo (Saito, 1997, p. 4; Industrial Bank of Japan, 2001, p. 8). Foreseeing the long lag time that the railway company would take to recover its investment in the new line, the founder and company president, Ichizo Kobayashi, took initiative by purchasing and developing land along the planned line, even before railway operations commenced (Saito, 1997, p. 4; Industrial Bank of Japan, 2001, p. 8). By the time the line began operations, the company had already purchased 820,000 square meters (76,180 square feet) of land (Industrial Bank of Japan, 2001, p. 8). Prior to selling the residences along the line, Hankyu distributed marketing pamphlets to 
citizens in Osaka to describe the pleasures of living along the new line; the pamphlets read "What kind of land you should purchase, and what kind of housing you should live in" (Saito, 1997, p. 4; Industrial Bank of Japan, 2001, p. 8). "The Company equipped the housing with electric lights, innovative for the time, and introduced an installment plan for purchasers. Due to these devices, the housing sold extremely well" (Industrial Bank of Japan, 2001, p. 8). "The management practice adopted by Hanshin and Hankyu strongly influenced the management of private railway companies in Tokyo in the 1920s when a real private railway boom occurred" (Saito, 1997, p. 4).

Soon after engaging in land development, Ichizo Kobayashi’s Hankyu Corporation expanded into additional business ventures, as shown in Table 2.2. 
Table 2.2 Business expansion during the early days of the railway group founded by Ichizo Kobayashi. Modified from (Industrial Bank of Japan, 2001, p. 11).

\begin{tabular}{|c|c|c|c|}
\hline Business & Kickoff of Operation & Details and Location & Present Situation \\
\hline Housing for Sale & $\begin{array}{l}\text { Began sale in June } \\
1910\end{array}$ & Sale of housing in Ikeda & $\begin{array}{l}\text { Operation under way } \\
\text { primarily by Hankyu } \\
\text { Corporation }\end{array}$ \\
\hline Power Supply & $\begin{array}{l}\text { Began power supply } \\
\text { in July } 1910\end{array}$ & Supplied power to housing & $\begin{array}{l}\text { Business transferred to } \\
\text { Kansai Electric Power } \\
\text { Co., Inc. in } 1941 \text { in } \\
\text { compliance with the } \\
\text { related law }\end{array}$ \\
\hline Zoo & $\begin{array}{l}\text { Opened in November } \\
1910\end{array}$ & Minoo Zoo & Closed in 1916 \\
\hline Leisure Facilities & $\begin{array}{l}\text { Opened in May } 1911 \\
\text { First performance of } \\
\text { the Theater in April } \\
1914\end{array}$ & $\begin{array}{l}\text { Takarazuka New Spa } \\
\text { (multifaceted leisure facility) } \\
\text { Public bath, indoor } \\
\text { swimming pool, etc. } \\
\text { Takarazuka Choral Group } \\
\text { (forerunner of Takarazuka } \\
\text { Music School) }\end{array}$ & $\begin{array}{l}\text { Takarazuka Grand } \\
\text { Theater } \\
\text { Takarazuka Family Land }\end{array}$ \\
\hline Department Store & Opened in April 1925 & $\begin{array}{l}\text { Hankyu Market (shop area: } \\
1,056 \text { sq. meters or } 11,367 \\
\text { sq. ft) opened in Umeda } \\
\text { Hankyu Department Store } \\
\text { opened in Umeda in April } \\
1929 \text { (shop area: } 10,000 \text { sq. } \\
\text { meters or } 107,639 \text { sq. feet; } \\
\text { Hankyu market was closed) }\end{array}$ & $\begin{array}{l}\text { Spun off into Hankyu } \\
\text { Department Store in } 1947\end{array}$ \\
\hline Hotel & Opened in May 1926 & Takarazuka Hotel & $\begin{array}{l}\text { Merged with other hotels } \\
\text { within the Group, and } \\
\text { adopted } \\
\text { ownership/operation } \\
\text { method in October } 2000\end{array}$ \\
\hline Baseball Team & $\begin{array}{l}\text { Established in January } \\
1936\end{array}$ & $\begin{array}{l}\text { Osaka Hankyu Kyokai } \\
\text { (Hankyu Professional } \\
\text { Baseball Team; forerunner of } \\
\text { the Hankyu Braves) }\end{array}$ & Sold to Orix in 1988 \\
\hline
\end{tabular}

Other major railway companies followed suit and began to engage in a variety of business ventures; their engagement into a variety of business functions makes it more appropriate to refer to them as company groups or conglomerates. The full range of activities that they operate in are shown in Table 2.3. 
Table 2.3 Types of businesses operated by Japanese railway consortia and their affiliated companies. (Cervero, 1998, p. 191).

\begin{tabular}{|l|l|}
\hline \multicolumn{2}{|c|}{ Types of Businesses Operated by Railway Companies and Affiliated Companies } \\
\hline \multicolumn{1}{|c|}{ Business } & $\begin{array}{l}\text { Range of Activities } \\
\text { Transportation } \\
\text { shipping; freight forwarding; package delivery; manufacturing of rolling stock }\end{array}$ \\
\hline Real Estate & $\begin{array}{l}\text { Construction, sale, and leasing of housing, office space, hotels; architectural } \\
\text { and engineering services; landscaping }\end{array}$ \\
\hline Retailing & $\begin{array}{l}\text { Construction and operation of department stores, supermarket chains, station } \\
\text { kiosks, catering services, and specialty stores }\end{array}$ \\
\hline Leisure and Recreation & $\begin{array}{l}\text { Construction and operation of resorts and spas, amusement parks, baseball } \\
\text { stadia, multiplex movie theaters, fitness clubs, golf courses; operation of travel } \\
\text { agencies }\end{array}$ \\
\hline
\end{tabular}

Theoretically speaking, the business diversification that the railway companies in Japan have engaged in represents an advanced exploitation of the transportation-land use dynamic. As Giuliano (2004, p. 227) explains:

The characteristics of the transportation system determine accessibility, or the ease of moving from one place to another. Accessibility in turn affects the location of activities, or the land use pattern. The location of activities in space affects daily activity patterns, which in turn result in travel patterns (daily trips within the region). These travel patterns, expressed as flows on the transportation network, affect the transportation system.

The dynamic is illustrated by Figure 2.7. 


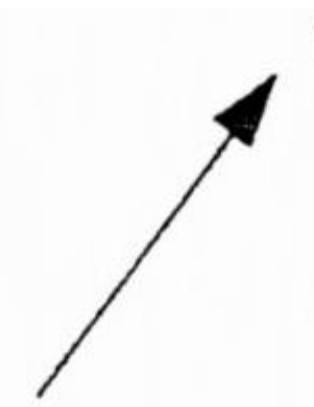

ACTIVITY PATTERNS

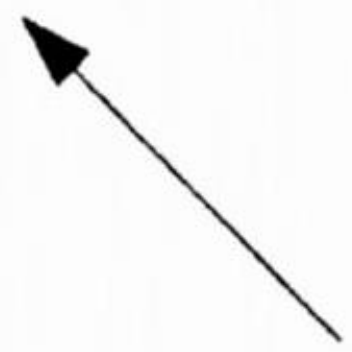

\section{TRANSPORTATION}

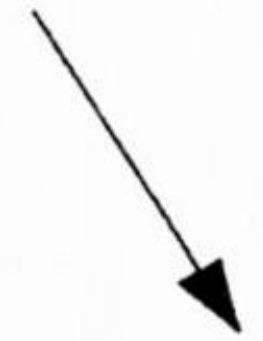

ACCESSIBILITY

\section{LAND USE}

Figure 2.7 Transportation-Land use dynamic. (Giuliano, 2004, p. 227).

In the context of the railway companies in Japan, the exploitation of the transportation-land use dynamic is explained as follows:

The [c]ompany concurrently constructed railway tracks and purchased land (railway construction, land purchase and development). In the second stage, by subdividing the land it had developed and then selling the lots, the [c]ompany earned profits (recovery of investments through marketing of housing). In the third stage, since the residents of those lots used the railway, the [c]ompany also secured stable freight receipts (hence, recovery of investment through the railway service) (Industrial Bank of Japan, 2001, pp. 8-9).

The dynamic is illustrated in the context of railway companies in Japan with Figure 2.8 and Figure 2.9. 


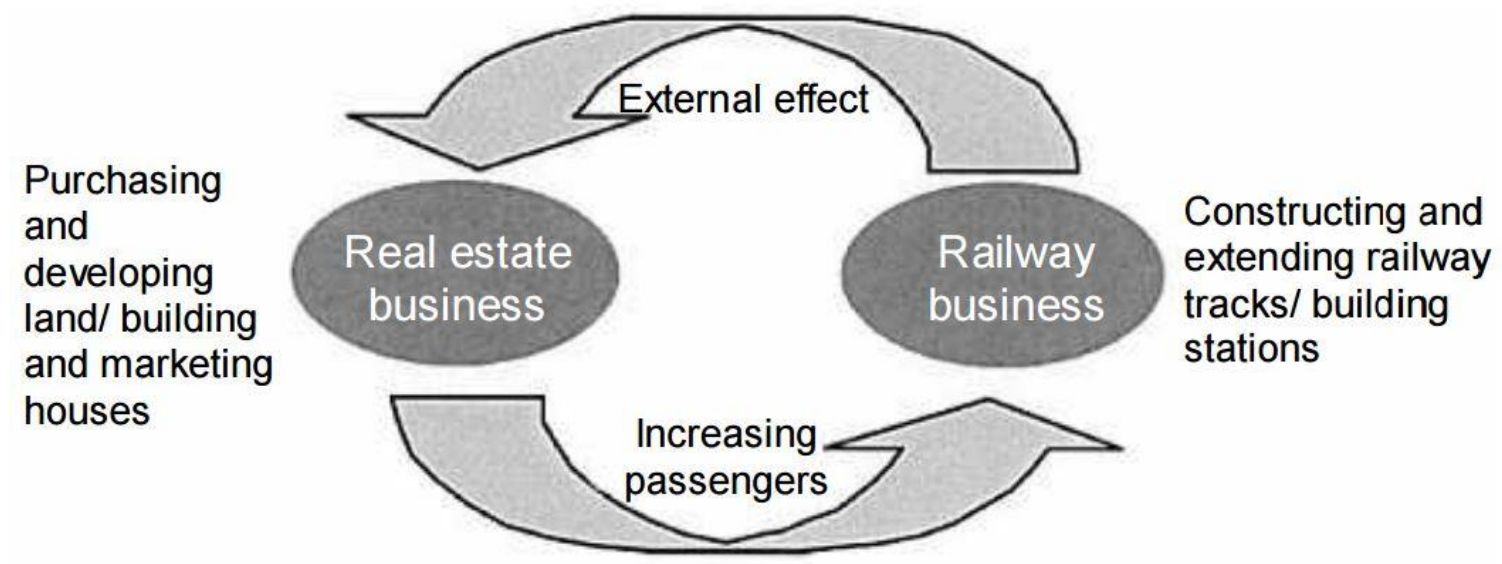

Figure 2.8 Original group management model for railway companies. (Industrial Bank of Japan, 2001, p. 8).

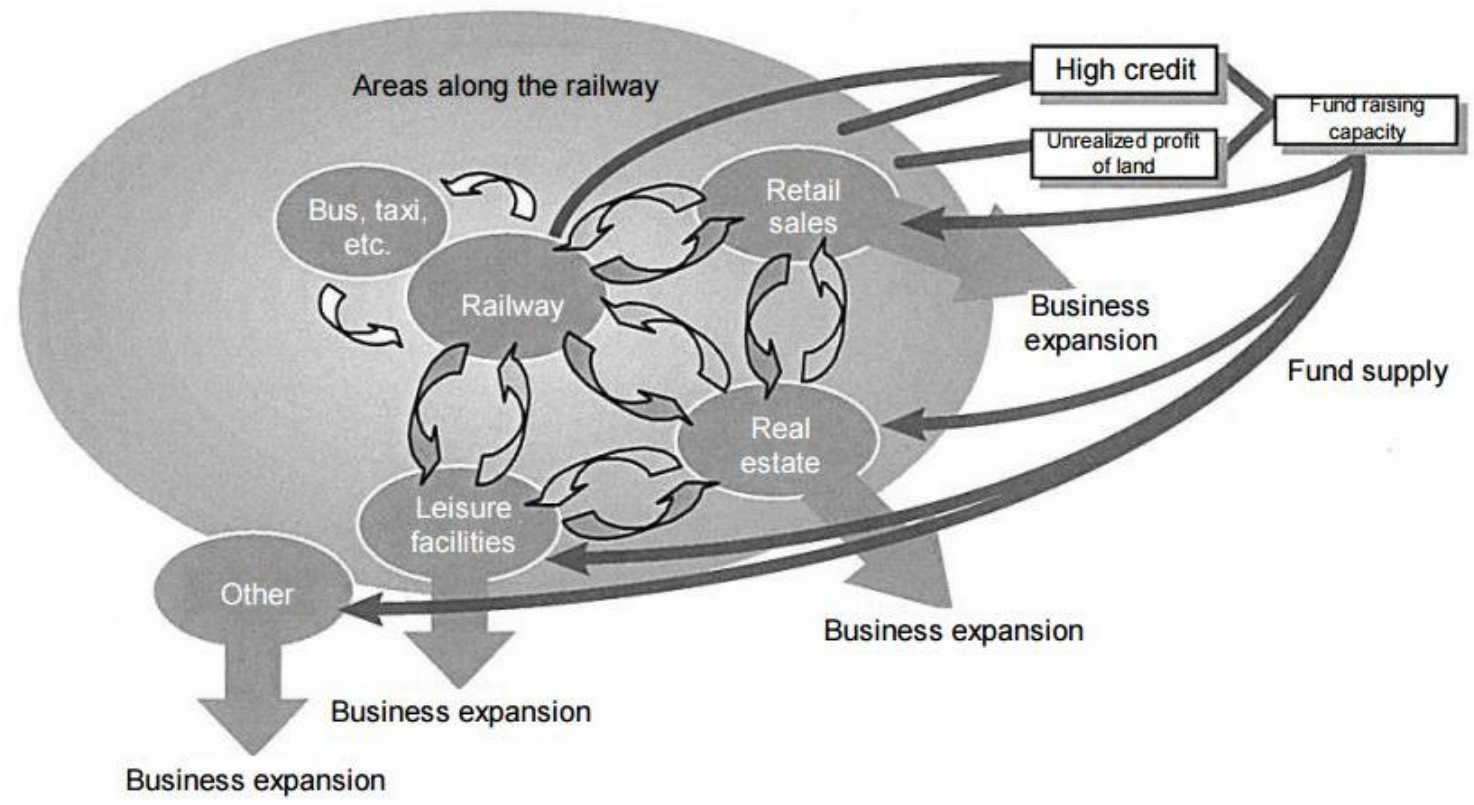

Figure 2.9 Business expansion of railway groups and the flow of funds. (Industrial Bank of Japan, 2001, p. 12).

Whereas Japanese private railway company groups have engaged in a multitude of businesses, Calimente (2009, p. 41) notes that the property development business is the most profitable of all. The property development business has been the most profitable chiefly due to the opportunities that land "value capture" offers. Historically, the process of value capture has involved a railway company group purchasing cheap land (usually agricultural or on the outskirts of cities) adjacent to where future stations of a newly 
constructed line will be (Cervero, 1998, p. 194). As the land around the stations appreciates, or increases, in value due to its increase in accessibility from proximity to the stations, the potential development opportunities for the land increases (Cervero, 1998, p. 194). At this point, the railway company either has a member company of its group, or a separate business entity, develop the land around its stations on terms favorable to the railway company (Cervero, 1998, p. 196). In addition to the ticket fares from the extra passenger traffic that the developments generate and the income from the land developments themselves, railway groups can capitalize from the latent land values of the highly-valued properties that they own to finance additional business opportunities. The property development business has "increased the liquidity and creditworthiness of rail companies to the point that loans they need to finance rail expansion are usually available at very favorable terms (and often from the consortia themselves, if necessary)" (Cervero, 1998, quoted by Calimente, 2009, p. 41).

Shoji (2001, p. 16, quoted by Calimente, 2009, p. 41) sums up the benefits of business diversification below:

- Rail ridership increases as passengers are attracted to other in-house or group businesses

- Short- and long-term changes in ridership contributes to levelling off passenger volumes between peak and off-peak periods (and direction)

- Group companies can utilize rail passenger base

- Internalization of externalities brought about by creation of rail infrastructure lead[s] to profitability which makes it easier for the company (and group companies) to improve services 
- The company can more easily develop a market-oriented outlook based on experience from operating [in a] non-rail deregulated business environment

- Railway operation costs are reduced by sharing operating costs [of] group members between rail and diversified divisions

- Group managerial resources are used effectively, reducing operating costs

Table 2.4, Table 2.5, and Table 2.6 show that the benefits of business diversification allow the major railway company groups to diversify their revenue streams and enjoy profitable operations. 
Table 2.4 Major private railway company statistics and operating revenues from 1994. The original 1994 figures in Yen have been converted to 2016 dollars. (Saito, 1997, p. 6; Federal Reserve Bank of St. Louis, 2017; Federal Reserve Bank of Minneapolis, 2017).

\begin{tabular}{|c|c|c|}
\hline \multicolumn{3}{|c|}{ Major Private Railway Company Statistics and Operating Revenues, 1994} \\
\hline Company & Line Length (kilometers) [miles] & $\begin{array}{l}\text { Million Passenger-Kilometers } \\
\text { [Million Passenger-Miles] }\end{array}$ \\
\hline \multicolumn{3}{|l|}{ [Tokyo Area] } \\
\hline Tobu & $464.1[288.4]$ & $14,366.6[8,927]$ \\
\hline Seibu & 179.8 [111.7] & $9,488.7[5,896]$ \\
\hline Keisei & $91.6[56.9]$ & $3,859.2[2,398]$ \\
\hline Keio & 84.8 [52.7] & $6,936.3[4,310]$ \\
\hline Odakyu & $121.7[75.6]$ & $10,983.7[6,825]$ \\
\hline Tokyu & $100.7[62.6]$ & $8,759.6[5,443]$ \\
\hline Keikyu & $83.8[52.1]$ & $6,274.8[3,899]$ \\
\hline Sotetsu & 34.9 [21.7] & $2,822.8[1,754]$ \\
\hline \multicolumn{3}{|l|}{ [Osaka Area] } \\
\hline Kintetsu & $594.2[369.2]$ & $15,251.7[9,477]$ \\
\hline Nankai & 172.4 [107.1] & $5,035.6[3,129]$ \\
\hline Keihan & 91.9 [57.1] & $5,318.9[3,305]$ \\
\hline Hankyu & $146.1[90.8]$ & $10,338.4[6,424]$ \\
\hline Hanshin & $45.1[28.0]$ & $2,187.1[1,359]$ \\
\hline \multicolumn{3}{|c|}{ [Nagoya/Fukuoka Areas] } \\
\hline Meitetsu & $539.3[335.1]$ & $7,312.8[4,544]$ \\
\hline Nishitetsu & $121.0[75.2]$ & $2,088.9[1,298]$ \\
\hline \multicolumn{3}{|l|}{ [Reference] } \\
\hline JR East & $7,501.9[4,661.5]$ & $128,143.7[79,625]$ \\
\hline JR Central & $1,983.5[1,232.5]$ & $49,508.1[30,763]$ \\
\hline JR West & $5,070.1[3,150.4]$ & $55,483.6[34,476]$ \\
\hline TRTA & $162.2[100.8]$ & $15,881.0[9,868]$ \\
\hline
\end{tabular}


Table 2.5 Major private railway company statistics and operating revenues from 1994 (contd.). The original 1994 figures in Yen have been converted to 2016 dollars. (Saito, 1997, p. 6; Federal Reserve Bank of St. Louis, 2017; Federal Reserve Bank of Minneapolis, 2017).

\begin{tabular}{|c|c|c|c|c|c|c|c|}
\hline \multicolumn{8}{|c|}{ Major Private Railway Company Statistics and Operating Revenues, 1994 (contd.) } \\
\hline \multirow{3}{*}{ Company } & \multicolumn{7}{|c|}{ Revenue in millions of 2016 US Dollars } \\
\hline & \multicolumn{2}{|c|}{ Railway } & \multicolumn{2}{|c|}{ Bus } & \multicolumn{2}{|c|}{ Other } & \multirow[b]{2}{*}{ Total } \\
\hline & $\begin{array}{c}\text { Raw } \\
\text { Number }\end{array}$ & $\begin{array}{l}\text { Percent } \\
\text { of Total }\end{array}$ & $\begin{array}{c}\text { Raw } \\
\text { Number }\end{array}$ & $\begin{array}{c}\text { Percent of } \\
\text { Total }\end{array}$ & $\begin{array}{c}\text { Raw } \\
\text { Number }\end{array}$ & $\begin{array}{l}\text { Percent } \\
\text { of Total }\end{array}$ & \\
\hline \multicolumn{8}{|l|}{ [Tokyo Area] } \\
\hline Tobu & $\$ 2,244$ & $59 \%$ & $\$ 561$ & $15 \%$ & $\$ 1,003$ & $26 \%$ & $\$ 3,809$ \\
\hline Seibu & $\$ 1,384$ & $39 \%$ & - & - & $\$ 2,192$ & $61 \%$ & $\$ 3,576$ \\
\hline Keisei & $\$ 813$ & $59 \%$ & $\$ 426$ & $31 \%$ & $\$ 128$ & $9 \%$ & $\$ 1,368$ \\
\hline Keio & $\$ 1,100$ & $59 \%$ & $\$ 338$ & $18 \%$ & $\$ 422$ & $23 \%$ & $\$ 1,859$ \\
\hline Odakyu & $\$ 1,515$ & $63 \%$ & $\$ 11$ & $0.5 \%$ & $\$ 894$ & $37 \%$ & $\$ 2,420$ \\
\hline Tokyu & $\$ 1,672$ & $40 \%$ & - & - & $\$ 2,526$ & $60 \%$ & $\$ 4,198$ \\
\hline Keikyu & $\$ 975$ & $46 \%$ & $\$ 379$ & $18 \%$ & $\$ 745$ & $35 \%$ & $\$ 2,098$ \\
\hline Sotetsu & $\$ 447$ & $21 \%$ & $\$ 141$ & $7 \%$ & $\$ 1,498$ & $72 \%$ & $\$ 2,086$ \\
\hline \multicolumn{8}{|l|}{ [Osaka Area] } \\
\hline Kintetsu & $\$ 3,000$ & $74 \%$ & $\$ 162$ & $4 \%$ & $\$ 865$ & $22 \%$ & $\$ 4,027$ \\
\hline Nankai & $\$ 1,041$ & $56 \%$ & $\$ 195$ & $11 \%$ & $\$ 612$ & $33 \%$ & $\$ 1,848$ \\
\hline Keihan & $\$ 953$ & $57 \%$ & - & - & $\$ 718$ & $43 \%$ & $\$ 1,670$ \\
\hline Hankyu & $\$ 1,642$ & $58 \%$ & - & - & $\$ 1,168$ & $42 \%$ & $\$ 2,810$ \\
\hline Hanshin & $\$ 458$ & $41 \%$ & $\$ 86$ & $8 \%$ & $\$ 578$ & $52 \%$ & $\$ 1,122$ \\
\hline \multicolumn{8}{|c|}{$\begin{array}{l}\text { [Nagoya/Fukuoka } \\
\text { Areas] }\end{array}$} \\
\hline Meitetsu & $\$ 1,298$ & $55 \%$ & $\$ 353$ & $15 \%$ & $\$ 715$ & $30 \%$ & $\$ 2,366$ \\
\hline Nishitetsu & $\$ 403$ & $17 \%$ & $\$ 1,193$ & $51 \%$ & $\$ 758$ & $32 \%$ & $\$ 2,354$ \\
\hline \multicolumn{8}{|l|}{ [Reference] } \\
\hline JR East & $\$ 29,674$ & $96 \%$ & - & - & $\$ 1,301$ & $4 \%$ & $\$ 30,975$ \\
\hline JR Central & $\$ 17,735$ & $92 \%$ & - & - & $\$ 1,526$ & $8 \%$ & $\$ 19,261$ \\
\hline JR West & $\$ 13,557$ & $98 \%$ & - & - & $\$ 295$ & $2 \%$ & $\$ 13,852$ \\
\hline TRTA & $\$ 4,138$ & $98 \%$ & - & - & $\$ 67$ & $2 \%$ & $\$ 4,205$ \\
\hline
\end{tabular}


Table 2.6 Operating profits and loss of major private railway companies in 1994. The original 1994 figures in Yen have been converted to 2016 dollars. (Saito, 1997, p. 6; Federal Reserve Bank of St. Louis, 2017;

Federal Reserve Bank of Minneapolis, 2017).

\begin{tabular}{|c|c|c|c|c|c|c|c|}
\hline \multicolumn{8}{|c|}{ Operating Profits and Loss of Major Private Railway Companies, 1994} \\
\hline \multirow{3}{*}{ Company } & \multicolumn{7}{|c|}{ Revenue in millions of 2016 US Dollars } \\
\hline & \multicolumn{2}{|c|}{ Railway } & \multicolumn{2}{|c|}{ Bus } & \multicolumn{2}{|c|}{ Other } & \multirow{2}{*}{$\begin{array}{l}\text { Total Income } \\
\text { or Loss }\end{array}$} \\
\hline & $\begin{array}{l}\text { Income } \\
\text { or Loss }\end{array}$ & Margin & $\begin{array}{c}\text { Income or } \\
\text { Loss }\end{array}$ & Margin & $\begin{array}{c}\text { Income or } \\
\text { Loss }\end{array}$ & Margin & \\
\hline Tobu & $\$ 237.7$ & $44 \%$ & $-\$ 33.6$ & $-6 \%$ & $\$ 340.6$ & $63 \%$ & $\$ 544.7$ \\
\hline Seibu & $\$ 226.8$ & $52 \%$ & - & - & $\$ 206.4$ & $48 \%$ & $\$ 433.2$ \\
\hline Keisei & $\$ 133.9$ & $87 \%$ & $-\$ 5.5$ & $-4 \%$ & $\$ 25.7$ & $17 \%$ & $\$ 154.1$ \\
\hline Keio & $\$ 174.8$ & $58 \%$ & $-\$ 4.0$ & $1 \%$ & $\$ 120.1$ & $40 \%$ & $\$ 298.9$ \\
\hline Odakyu & $\$ 222.2$ & $51 \%$ & $\$ 2.5$ & $-6 \%$ & $\$ 213.0$ & $49 \%$ & $\$ 432.7$ \\
\hline Tokyu & $\$ 323.2$ & $49 \%$ & - & - & $\$ 341.1$ & $51 \%$ & $\$ 664.2$ \\
\hline Keikyu & $\$ 155.0$ & $55 \%$ & $-\$ 10.5$ & $-4 \%$ & $\$ 135.7$ & $48 \%$ & $\$ 280.2$ \\
\hline Sotetsu & $\$ 72.0$ & $28 \%$ & $-\$ 16.8$ & $-6 \%$ & $\$ 198.1$ & $78 \%$ & $\$ 253.3$ \\
\hline Kintetsu & $\$ 254.2$ & $51 \%$ & $-\$ 22.7$ & $-5 \%$ & $\$ 263.6$ & $53 \%$ & $\$ 495.1$ \\
\hline Nankai & $\$ 128.1$ & $44 \%$ & $-\$ 19.8$ & $-7 \%$ & $\$ 182.3$ & $63 \%$ & $\$ 290.5$ \\
\hline Keihan & $\$ 105.2$ & $49 \%$ & - & - & $\$ 111.3$ & $51 \%$ & $\$ 216.5$ \\
\hline Hankyu & $\$ 138.4$ & $42 \%$ & - & - & $\$ 189.7$ & $58 \%$ & $\$ 328.1$ \\
\hline Hanshin & $\$ 43.7$ & $23 \%$ & $\$ 2.1$ & $1 \%$ & $\$ 148.7$ & $76 \%$ & $\$ 194.6$ \\
\hline Meitetsu & $\$ 114.7$ & $43 \%$ & $-\$ 19.7$ & $-7 \%$ & $\$ 174.0$ & $65 \%$ & $\$ 269.1$ \\
\hline Nishitetsu & $\$ 38.5$ & $25 \%$ & $\$ 12.2$ & $8 \%$ & $\$ 100.8$ & $67 \%$ & $\$ 151.4$ \\
\hline
\end{tabular}

While the Shinkansen is not operated by any of the major private railway groups outside of the Japan Railway companies, it should be noted that they had an influence on the current structure of the companies that operate the Shinkansen. When the Shinkansen began service in 1964, it was operated by the national railway corporation, JNR. JNR, which was founded on June 1, 1949, was one of several state-owned enterprises (SOE) to form in Japan under the direction of a 1948 order from American General Douglas MacArthur to "suppress the growing left-wing labor movement, which was thriving in the middle of the inflation-driven economic confusion, and the growth of communism" (Imashiro, 1997, p. 46). Whereas General MacArthur's incentive to convert the Japanese 
Government railways into a SOE were political, there were practical benefits that accompanied the transition. As Chang (2008, p. 112) notes, SOEs are useful entities in the earlier stages of an industry's development within a country that wishes to start that industry. In the earlier stages of an industry's development, no private capital flows into the industry due to a high amount of risk and long-gestation periods that lengthen the payback period of investments (Chang, 2008, p. 112). SOEs allow the state to socialize risk and cost by injecting a steady flow of public capital into the stakeholders (e.g., companies and academic institutions) of an industry of interest (Chang, 2008, p. 113). Once the industry has grown and matured, has demonstrated that it provides value to the national economy, and can generate a return on investment, private capital moves in while public capital may or may not continue (Chang, 2008, p. 113). Given the massive amount of damage incurred by its cities and infrastructure during World War II, Japan was rendered back to the status of a developing country, and it made sense for many industries (including railways) to receive public assistance for rebuilding after the war. JNR played an important role during the rebuilding effort, as "[a] heavy burden was placed upon railways because motor and coastal transportation was still unrestored" (Imashiro, 1997, p. 48). At the same time, "[t]ransportation demand rose rapidly as people flocked to trains; soldiers returning from Manchuria, Korea, etc., schoolchildren evacuees returning from the countryside, GIs, foreigners, and hungry people going to farming villages in search of food" (Imashiro, 1997, p. 48).

In the decades after the war, however, JNR's competitive edge gradually eroded as Japan's automobile industry and aviation industry rebuilt (Nakamura, 1996, p. 4). From 1965 to 1985, JNR's national market share in terms of passenger-kilometers 
declined from 45 percent to 23 percent (Nakamura, 1996, p. 4). Additional factors contributed to JNR's financial decline from 1963 (the final year that JNR was profitable) to 1987 (the year of JNR's privatization), including high personnel expenses, high-cost capital investments, lack of freedom in setting fares or its own budget, and a uniform fare structure across the country (Nakamura, 1996, p. 4). The problems caused by these conditions mounted steadily until by 1985 , subsidies from the national government amounted to 600 billion Yen, or over \$5.6 billion in 2016 United States dollars (Nakamura, 1996, p. 4). The excessive subsidies made it necessary for the national government to step in and restructure JNR in 1987.

The privatization of JNR was not a simple switch in ownership from public to private (Mizutani \& Nakamura, 2004, p. 307). When restructuring took place, JNR was split into seven separate railways companies (six dedicated to passenger service and one dedicated to freight service). The companies were geographically separated into territories in which they could operate 95 percent of their railway services, as shown in Map 2.5 (Mizutani \& Nakamura, 2004, p. 309). The geographic separation was intended to allow the new companies to provide services that were specialized to the specific needs of each geographic region, and to decide which lines within each region should be closed or continued (Mizutani \& Nakamura, 2004, p. 309). Note that the freight railway company, Japan Railway Freight, owns no tracks and must negotiate trackage rights with the passenger railway companies to run services (Mizutani \& Nakamura, 2004, p. 309; Funahashi, 2009, p. 41). 


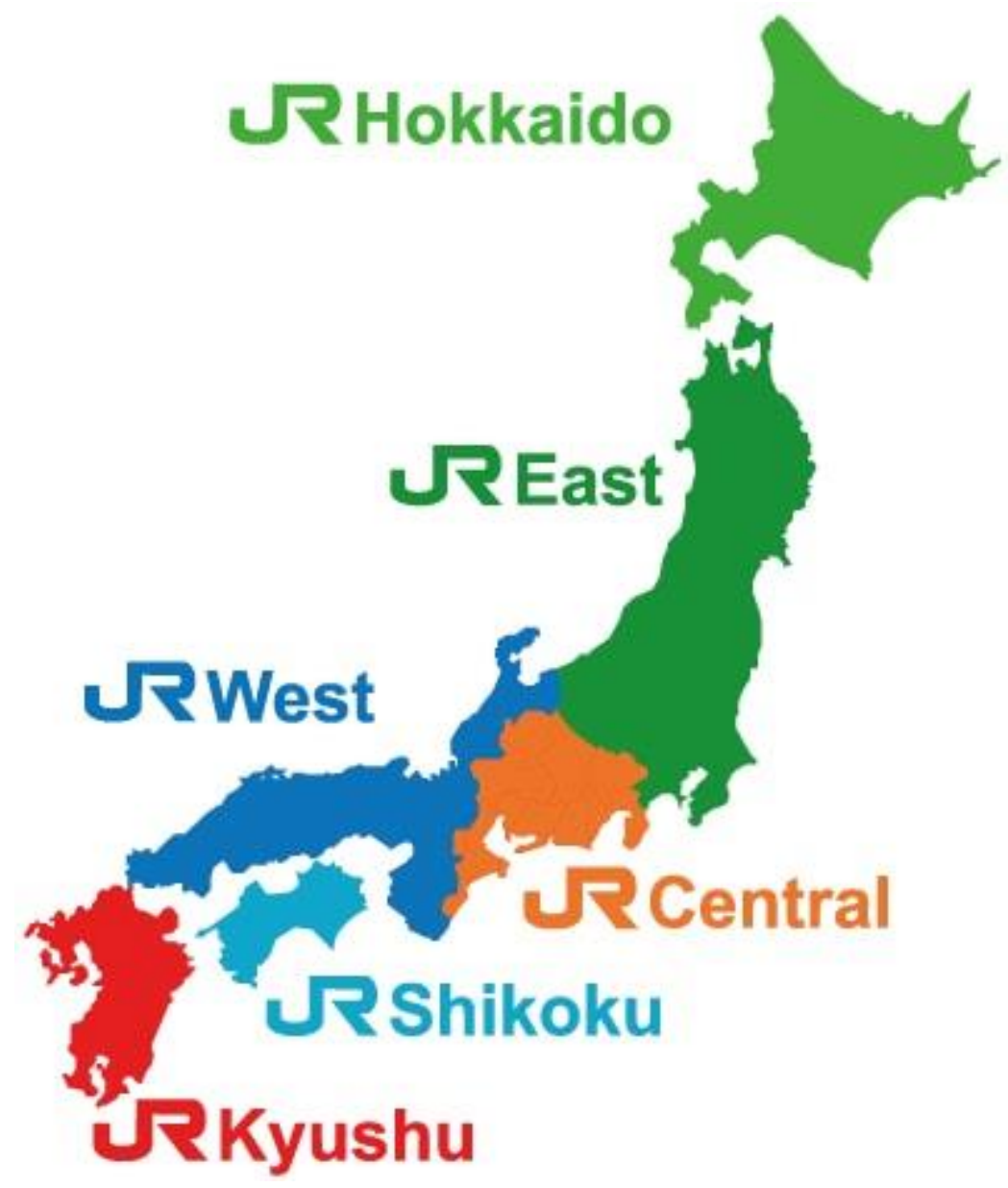

Map 2.5 Territory of six passenger Japan Railway companies. (Japan-Cycling.com, 2017).

A temporary holding company of JNR stock, the Japan National Railway

Settlement Corporation (JNRSC), was also established to manage the selling of stock (Mizutani \& Nakamura, 2004, p. 307).

Stock was not immediately offered to the public, because the government was concerned that the dismal reputation of the deficit-laden and inefficient JNR would affect stock prices negatively, and embarrassingly few investors would be interested in acquiring stock in the new railway companies. It was necessary to sell the stock at as high a price as possible, to help alleviate some of the immense 
debt bequeathed by the JNR. The newly created JNRSC would hold railway stocks until the newly privatized companies could establish a reputation worthy of a respectable stock offering, by increasing efficiency and showing profits (Mizutani \& Nakamura, 2004, p. 307).

Thus, it is more accurate to say that JNR was put on a path towards privatization, rather than simply being transferred from public ownership to private ownership (Mizutani \& Nakamura, 2004, p. 307).

Additional steps taken to restructure JNR include the preservation of vertical integration of operations and maintenance, the transfer of redundant personnel to other public corporations or to retirement, allowing the new Japan Railway (JR) companies to engage in non-rail businesses, and the introduction of a yardstick competition scheme to encourage competition between railway operators (Mizutani \& Nakamura, 2004, pp. 309310). These measures were undertaken so that the new JR companies could mimic the success of the private urban railway groups. Shoji (2001, p. 2) notes that

Japanese private railway companies, which operate with no government subsidy, offered services at lower costs than did the former JNR, especially in large cities. Because of their efficient management, they won high social recognition and their success had a significant effect on the government plan to privatize JNR, by helping [to] reduce much of the uncertainty and hesitation in deciding to privatize. The practice of JR management following the example of private railway companies has proved very successful. Since privatization, the huge annual loss in the JNR days has returned to the black. 
Table 2.7 summarizes the operating characteristics of the different sectors of the Japanese railway industry.

Table 2.7 Passenger rail figures in Japan in 2014. (Statistics Bureau of Japan, 2017).

\begin{tabular}{|l|r|r|r|r|r|r|}
\hline \multicolumn{7}{|c|}{ Passenger Rail Figures in Japan, 2014} \\
\hline \multirow{2}{*}{ Sector } & \multicolumn{1}{|c|}{ Passenger Line Length } & \multicolumn{2}{c|}{ Ridership } & \multicolumn{2}{c|}{ Traffic Volume } \\
\cline { 2 - 8 } & $\begin{array}{c}\text { Kilometers } \\
\text { [Miles] }\end{array}$ & Percent & $\begin{array}{c}\text { Million } \\
\text { Passengers }\end{array}$ & Percent & $\begin{array}{c}\text { Million Passenger- } \\
\text { Kilometers [Miles] }\end{array}$ & Percent \\
\hline JRs & $20,022[12,441]$ & $72.1 \%$ & 14,512 & $50.0 \%$ & $260,097[161,617]$ & $62.8 \%$ \\
\hline Private & $7,117[4,422]$ & $25.6 \%$ & 11,320 & $39.0 \%$ & $133,443[82,918]$ & $32.2 \%$ \\
\hline 15 Major & $2,917[1,813]$ & $10.5 \%$ & 9,810 & $33.8 \%$ & $120,752[75,032]$ & $29.2 \%$ \\
\hline $\begin{array}{l}\text { Medium and } \\
\text { Small }\end{array}$ & $4,200[2,610]$ & $15.1 \%$ & 1,510 & $5.2 \%$ & $12,691[7,886]$ & $3.1 \%$ \\
\hline Public & $615[382]$ & $2.2 \%$ & 3,192 & $11.0 \%$ & $20,430[12,695]$ & $4.9 \%$ \\
\hline Total & $27,754[17,246]$ & $100.0 \%$ & 29,024 & $100.0 \%$ & $413,970[257,230]$ & $100.0 \%$ \\
\hline
\end{tabular}

While the six passenger JRs own the largest networks in terms of line length by 72.1 percent of the total, the private railway groups, with 25.6 percent of the line length, carry a disproportionate amount of the ridership. The private railway groups carried 39 percent of all passengers in 2014 compared to 50 percent of all passengers by the JRs. The private railway groups also carried just under half of the JR traffic volume in 2014, despite operating on smaller railway networks. In other words, the private railway groups, many of which operate in urban areas, have a greater utility per unit of line length (2,560 passengers per mile of line length) compared to the JRs (1,166 passengers per mile of line length).

One other point to note is that prior to the 1987 privatization, the JRs were not allowed to engage in any other activities besides transportation (Chorus, 2012, p. 115). Additionally, there was an emphasis to sell the surplus land of the former JNR, including disused freight yards and marshalling yards, to redeem some of the huge JNR debts (Chorus, 2012, p. 115). A government agency, the Japan Railway Construction 
Transportation Technology Agency, was set up and given ownership of the excess land with the task of selling it (Chorus, 2012, p. 115). Thus, the JRs virtually own no land, and cannot rely on substantial landholdings like the major private railway groups do (Chorus, 2012, p. 115). Instead, the JRs are forced to maximize commercial operations within their station buildings, like that shown in Figure 2.10 (Chorus, 2012, p. 115).

\section{Maximizing the potential of stations}

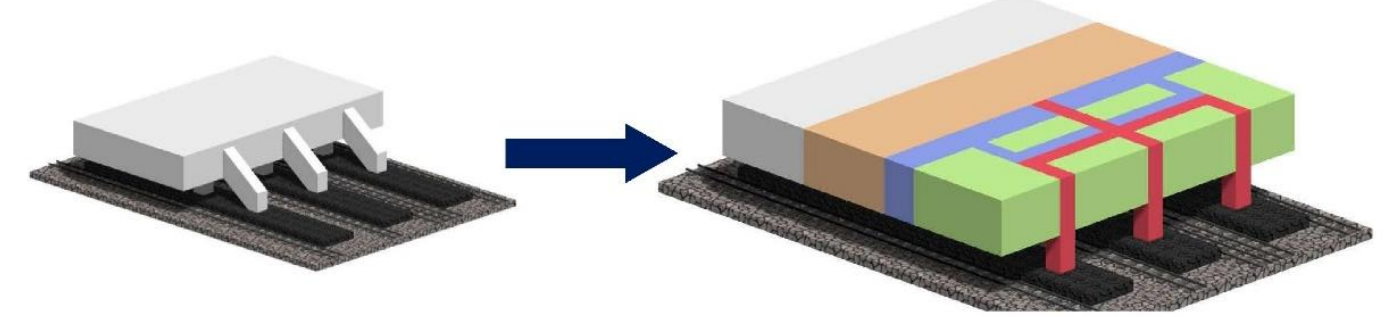

To create an extra space in the station, the concourse-level floor over the railway tracks are sometimes extended

The effects of the extension

- Concourses can be widened

- Barrier-free space can be extended

- Congestion can be mitigated

- Additional commercial space can be created

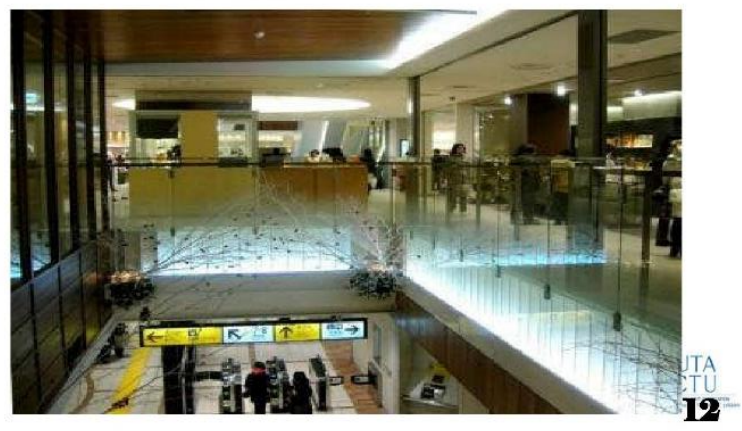

Figure 2.10 An example of maximizing the commercial value of station buildings. (Sayama, n.d., pdf-p. 12).

Despite the difference in utilization and landholdings from the private urban railway groups, the JRs are still able to enjoy profitable operations because of the restructuring from the 1987 privatization, as shown in Table 2.8. 
Table 2.8 Financial performance of main island (Honshu) JRs in 2015. (Japan Times, 2016; Federal Reserve, 2017).

\begin{tabular}{|l|r|r|r|}
\hline \multicolumn{5}{|c|}{ Financial Performance of Main Island JRs, 2015 } \\
\hline \multicolumn{1}{|c|}{ Company } & \multicolumn{1}{|c|}{ JR East } & \multicolumn{1}{c|}{ JR West } & \multicolumn{2}{c|}{ JR Central } \\
\hline Profit (billion) & $\$ 4.0$ & $\$ 1.5$ & $\$ 4.8$ \\
\hline Revenue (billion) & $\$ 23.1$ & $\$ 11.6$ & $\$ 14.0$ \\
\hline
\end{tabular}

The figures shown in Table 2.8 are record consolidated sales and operating profits for JR East, JR West, and JR Central during fiscal year 2015. The Japan Times noted that the surge in sales and profits resulted from high demand for Shinkansen services.

\subsection{History and General Characteristics of California High-Speed Rail}

High-Speed Rail in California has its origins from the 1980s when the State initially pursued the concept for implementation between Los Angeles and San Diego in partnership with Japanese interests (Authority, 2017a). While the pursuit never materialized, the concept was revisited in the 1990s when state leaders and politicians grew aware of the limitations of highways and airports to accommodate the State's growing travel demands (Subramani, 2008, p. 2; Authority, 2017a). In 1993, an Executive Order from the Governor of California and a Concurrent Resolution 6 from the California State Senate created the California Intercity High-Speed Rail Commission, which was tasked with evaluating the possibility of a high-speed rail system in California and drafting a plan for implementation (Subramani, 2008, pp. 2-3). After undertaking studies that looked at Corridor Evaluation, Ridership Analysis, Economic Impact, and Financing Options, the Commission concluded that "the development of a [high-speed rail] network in California was technically and environmentally feasible, economically viable, and strongly supported by the public" (Subramani, 2008, p. 3). The Commission also determined the cost in 1993 dollars to be $\$ 25$ billion with a projected completion year of 2013 (Subramani, 2008, p. 3). 
Given the Commission's conclusions, the California State Senate passed Senate Bill 1420 in 1996 to create the California High-Speed Rail Authority (Subramani, 2008, p. 3). The Authority was a "state entity responsible for planning, constructing[,] and operating a high-speed train system serving California's major metropolitan areas" (Subramani, 2008, p. 3). Senate Bill 1420 of 1996, also known as the California HighSpeed Rail Act, defined high-speed rail as "intercity passenger rail service that utilizes an alignment and technology that make it capable of sustained speeds of 200 miles per hour or greater" (Subramani, 2008, p. 3). The premise of Senate Bill 1420 outlined many of the findings from the Commission's report, in that the State's existing transportation infrastructure was very congested, and that expanding existing highways and airports to match the State's growing travel demands would be cost prohibitive (Subramani, 2008, p. 4). Additional reasons that were given for implementation of high-speed rail were that the mode had proven itself to be a viable alternative to automobile and air transportation in Europe and Japan for trips over 200 miles and under 500 miles in length, and that the construction of the project would generate a short-term boost for the State's job market and manufacturing interests, and would contribute to long-term economic growth (Subramani, 2008, p. 4).

From 1997 to 2008, the Authority focused on conducting environmental and economic studies, determining the general alignment of the high-speed rail system, maneuvering state politics to preserve its existence, and seeking sources of funding for construction of the system (Subramani, 2008). In 2008, California's voters passed Senate Bill 1856 as Proposition 1A, also known as the Safe, Reliable High-Speed Passenger Train Bond Act for the $21^{\text {st }}$ Century, which authorized $\$ 9.95$ billion in general obligation 
bonds to fund the planning and construction of the system (Authority, 2017a).

Additionally, California competitively won $\$ 3.3$ billion in federal grants that were authorized under the American Recovery and Reinvestment Act of 2009 as part of an $\$ 8$ billion nationwide stimulus to kick-start high-speed rail projects. Finally, in 2012, California Governor Jerry Brown, who has made high-speed rail a priority for his administration, signed into law the 2014-2015 budget for California, which allocated $\$ 250$ million in funds from the State's cap-and-trade emissions regulatory program to the high-speed rail program for the 2014-2015 fiscal year, and 25 percent of future cap-andtrade revenues each year to the high-speed rail program (Sheehan, 2014). The ongoing commitment of future cap-and-trade funds is important because it provides the Authority with a cash flow that can be used as leverage to debt finance the construction of the rest of the system with private equity funds.

The Authority has divided the construction of the envisioned network into two phases, as shown in Map 2.6. Phase 1 extends from San Francisco to Los Angeles, while Phase 2 includes extensions towards Sacramento and San Diego. The overall length of the system is anticipated to be 800 miles (Authority, 2017a). 


\section{CALIFORNIA HIGH-SPEED RAIL}

STATEWIDE SYSTEM

Proposed Statewide Alignment

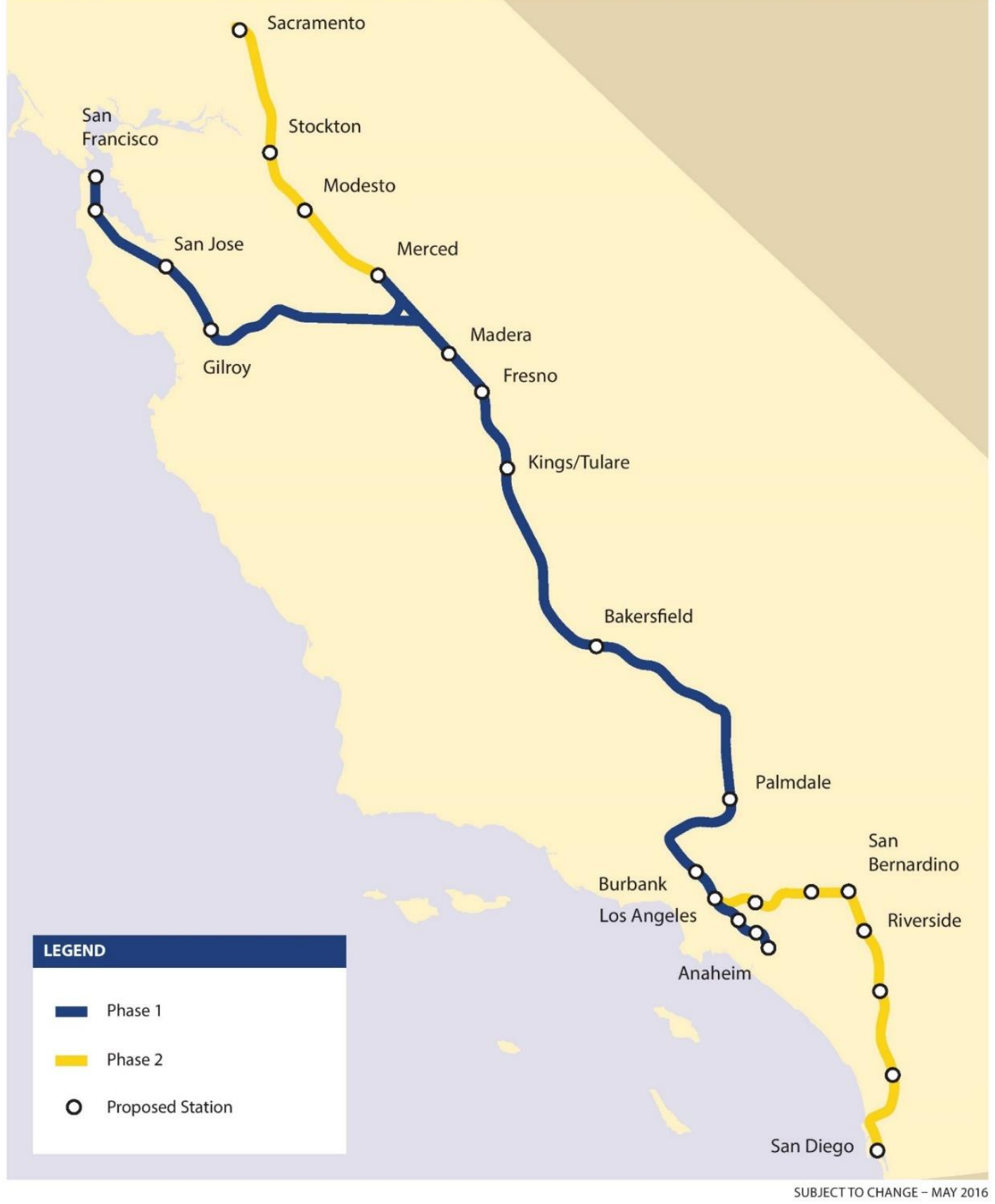

Map 2.6 Proposed statewide alignment of the California High-Speed Rail System. (Authority, 2017c). 
Within the Phase 1 segment, the direction of construction has shifted with the release of each business plan that the Authority released in 2012, 2014, 2016, and 2018. By law, the Authority is required to release a business plan every two years that describes the type of service that the Authority anticipates it will develop, a description of system benefits, project milestones, forecasts of ridership levels, operations and maintenance costs and capital costs, and estimates of anticipated funding sources (Authority, 2017b). The 2012 Revised Business Plan contained Map 2.7, which shows that the first segment to be constructed is the initial operating segment (IOS) located in the California San Joaquin Valley. While starting construction in the center, or "spine," of the network may seem counter-intuitive because it is not within any of the major metropolitan areas of the State, it makes sense for other reasons, including:

- Providing an economic stimulus in a part of the State that habitually has higher poverty rates, lower educational attainment rates, higher unemployment rates, and lower household incomes relative to the rest of the State (Authority, 2015)

- Maintaining the option to construct the system north or south, depending on the readiness of each corridor

- Allowing the testing and commissioning of trainsets up to the top operating speed of 220 miles per hour, which is not possible in the urban segments of the system where the alignment is not being designed to accommodate such speeds 
Map 2.8 also shows that the next section to be constructed is the "early priority" gap between Bakersfield and Palmdale, where currently no passenger railway service exists. Note that lines for other passenger rail providers, such as Caltrain, Altamont Commuter Express, Metrolink, and Amtrak are shown as well. The Authority (2017a) has been working with regional rail providers to provide funding to improve their services. Improvements to the services of regional rail providers, such as electrification and gradeseparation of at-grade highway-rail crossings, is anticipated to improve connection opportunities with high-speed rail service (increasing potential ridership) and lower capital costs by allowing high-speed rail service to share existing rail rights-of-way.

The effort to share existing rights-of-way in urban areas was prompted by the fact that construction costs for the entire Phase 1 segment, assuming a right-of-way built to full high-speed rail standards, had risen from the original \$25 billion in 1993 dollars to $\$ 65.4$ billion in 2010 dollars, or $\$ 98.1$ billion in year-of-expenditure dollars in the Draft 2012 Business Plan that was released in November 2011 (Authority, 2011, p. ES-9). In response to the political backlash that this price tag generated, the Authority (2012, p. ES-15) released a 2012 Revised Business Plan in April 2012 that lowered the costs of construction to $\$ 53.4$ billion in 2011 dollars, or $\$ 68.4$ billion in year-of-expenditure dollars (Authority, 2012, p. ES-15). The Authority (2014a, p. 36; 2016, p. 68; 2018b, p. 48) lowered the constructions costs for Phase 1 further with subsequent business plans, with the 2014 Business Plan showing a $\$ 54.9$ billion price tag in 2013 dollars, or $\$ 67.6$ billion in year-of-expenditure dollars, the 2016 Business Plan showing a cost of $\$ 55.295$ billion in 2015 dollars, or $\$ 64.238$ billion in year-of-estimate dollars, and the 2018 Draft 
Revised Business Plan showing a mid-range cost estimate of $\$ 67.490$ billion in 2017

dollars, or $\$ 77.295$ billion in year-of-estimate dollars.

The cost estimates are summarized in Table 2.9.

Table 2.9 Cost estimates for the California High-Speed Rail Project by business plan. Note: YOE = year of estimate. (Authority, 2011, p. ES-9; 2012, p. ES-15; 2014a, p. 35; 2016, p. 68; 2018b, p. 48).

\begin{tabular}{|c|c|c|}
\hline \multirow{5}{*}{ 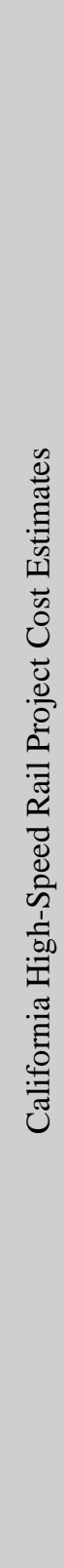 } & 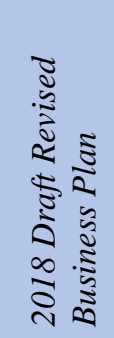 & 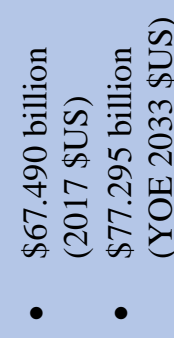 \\
\hline & 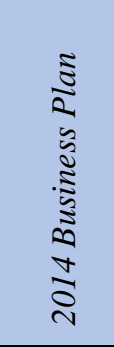 & 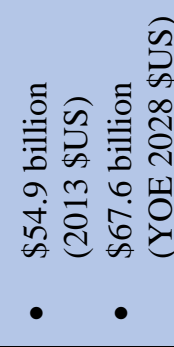 \\
\hline & 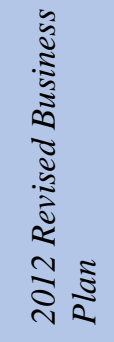 & 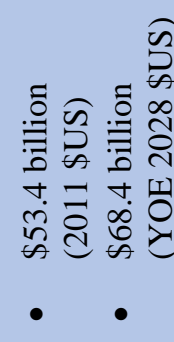 \\
\hline & 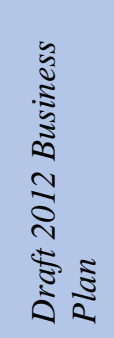 & 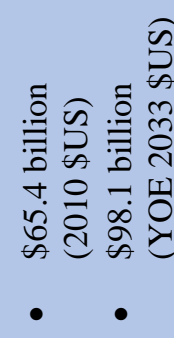 \\
\hline & 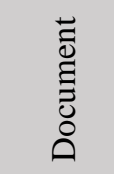 & $\overrightarrow{0}$ \\
\hline
\end{tabular}




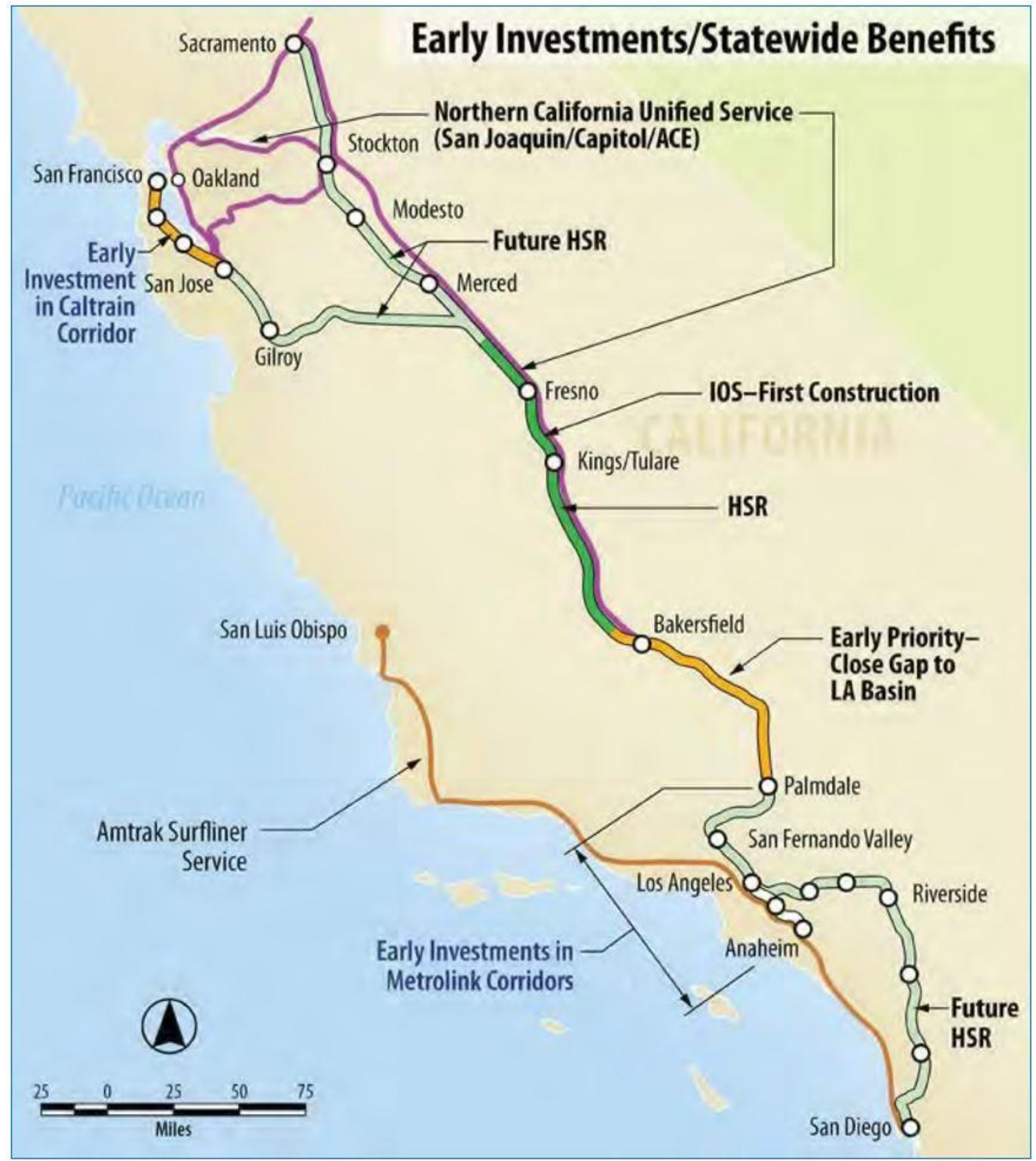

Map 2.7 Segments of the California High-Speed Rail System in the 2012 Revised Business Plan. IOS = Initial Operating Segment. (Authority, 2011, p. 2-2). 


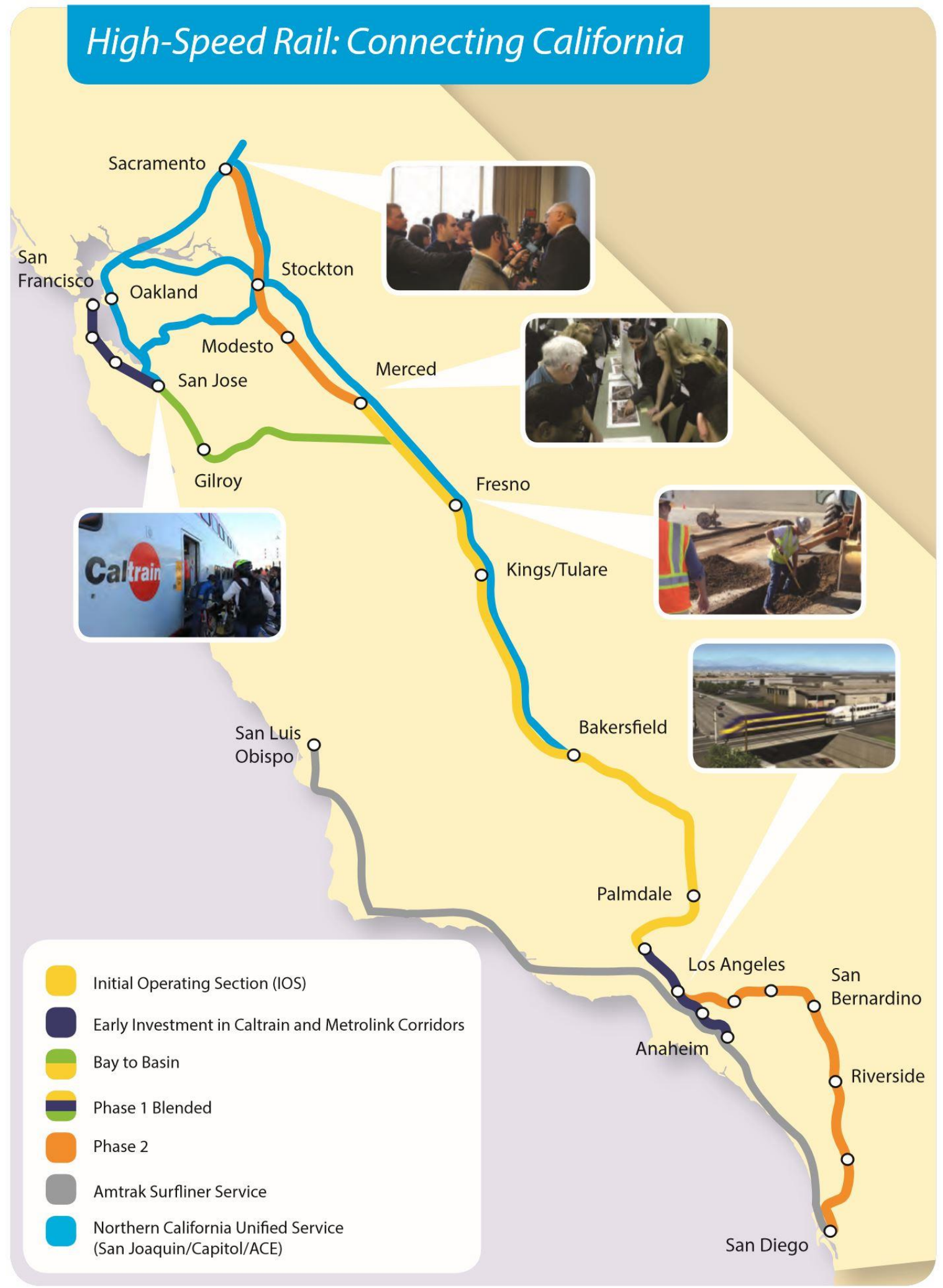

Map 2.8 Segments of the California High-Speed Rail System in the 2014 Business Plan. (Authority, 2014a, p. 14). 


\section{EXHIBIT 4.1 HIGH-SPEED RAIL SYSTEM}

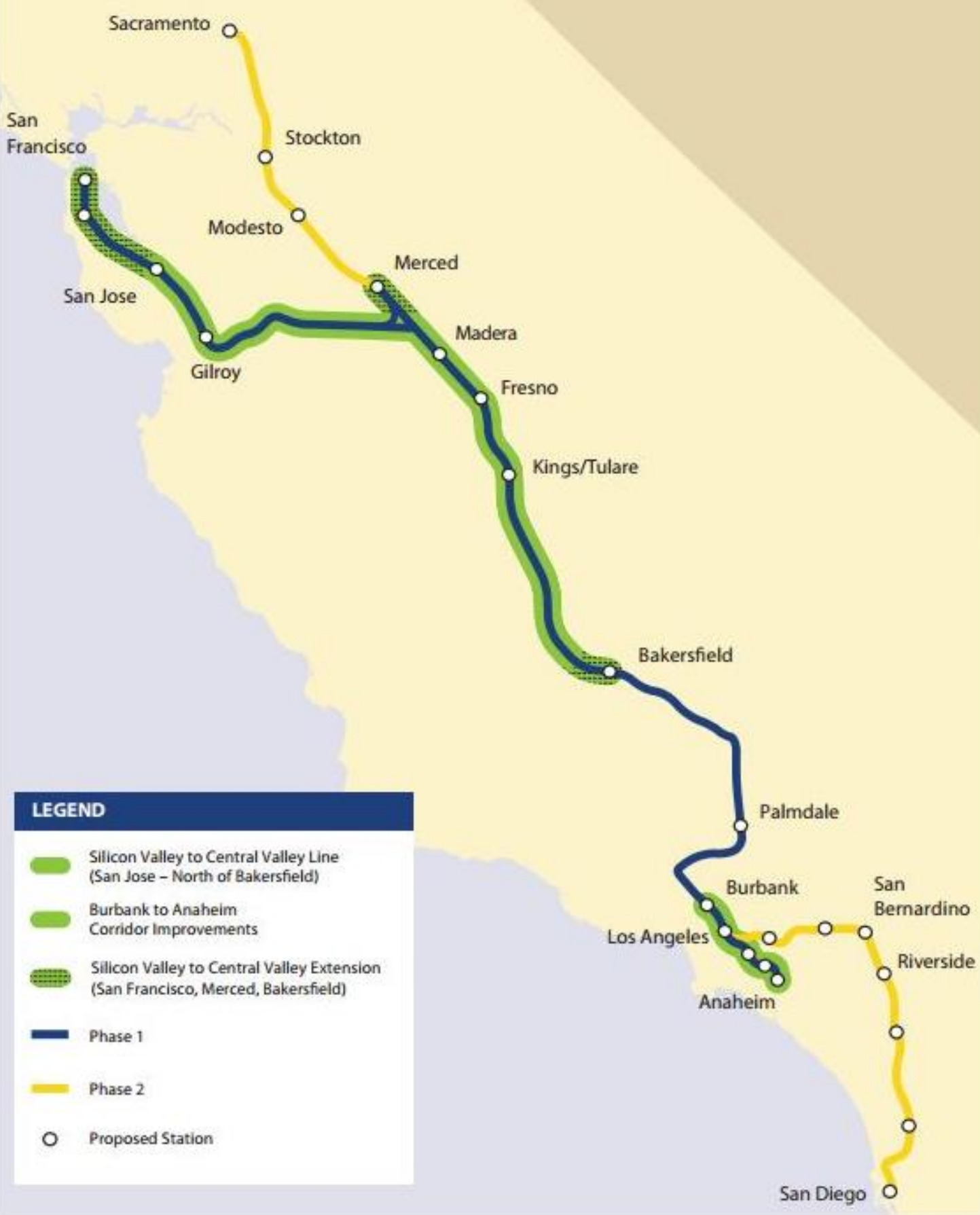

Map 2.9 Segments of the California High-Speed Rail System in the 2016 Business Plan. (Authority, 2016, p. 48). 


\section{EXHIBIT 2.1 SILICON VALLEY TO CENTRAL VALLEY}

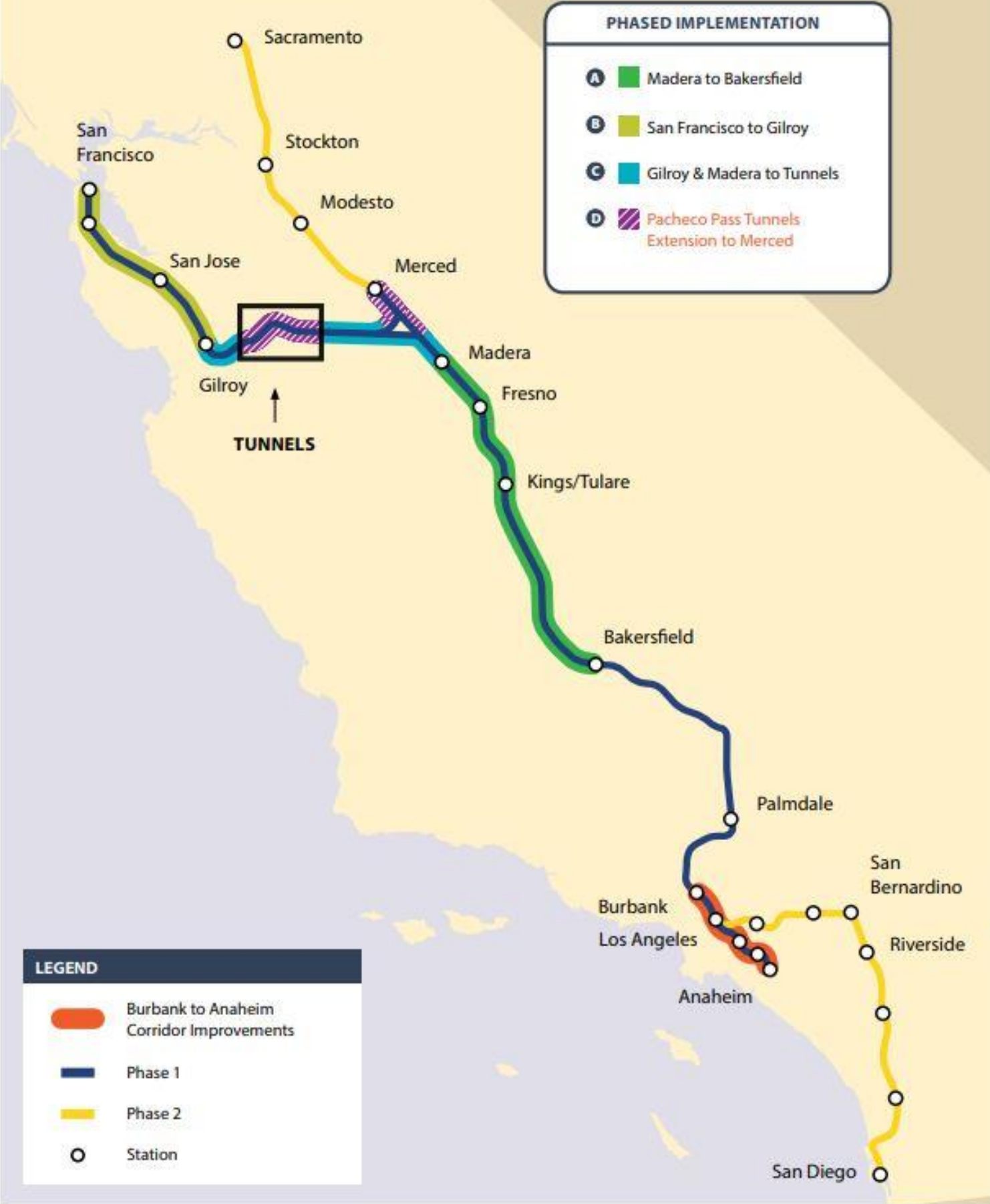

Map 2.10 Segments of the California High-Speed Rail System in the 2018 Business Plan. (Authority, 2018b, p. 19). 
Map 2.9 and Map 2.10 show the subsequent changes in direction of the California High-Speed Rail System. In the 2014 Business Plan, the Authority originally committed to building the IOS from Merced to Burbank. The System would then share right-of-way with Metrolink so that high-speed rail trains could serve Los Angeles and other destinations in the metropolitan area. In the 2016 Business Plan, the Authority changed direction by committing to build the IOS between San Jose and north of Bakersfield at Poplar Avenue. By connecting to San Jose, high-speed rail trains would be able to share right-of-way with Caltrain to connect to San Francisco. The IOS does not extend all the way to Bakersfield due to a lack of identified funds. The Authority $(2016$, p. 11) stated in its 2016 Business Plan, however, that

[t]he Silicon Valley to Central Valley line, from Diridon Station in San Jose to a station north of Bakersfield, which includes an interim facility that functions as a temporary station, meets Proposition 1A requirements including non-subsidized operations. It can be built with available funding from Proposition 1A bonds, federal funds, and the continued anticipated Cap and Trade proceeds. The reason for identifying an interim station is to avoid a potential situation where a fully Prop 1A compliant line remains idol because of insufficient funding to reach the next station. The Authority's goal is to avoid the need for an interim station. If, however, an interim station is needed due to funding constraints, consideration will be given to alternative locations, such as adjacent to the existing Amtrak station in the City of Wasco, with the goals of reducing the level of interim investment, minimizing impacts, and maximizing connectivity with the permanent station in Bakersfield. 
With the release of the 2018 Draft Revised Business Plan, the Authority (2018b, p. 17) redefined the IOS as the Silicon Valley to Central Valley Line between San Francisco and Bakersfield. The Authority (2018b, p. 17) justified this change by stating that the "line has stronger ridership potential and higher commercial value than the shorter line between San Jose and Poplar Avenue (north of Bakersfield)" that was laid out in the 2016 Business Plan. The extra revenue that could be generated by the higher ridership of the new IOS could be used to "help fund expanding the system in Southern California" (Authority, 2018b, p. 17). The Authority also noted that funding shortfalls existed for the Pacheco Pass tunnels and the extension to Merced between Gilroy and Madera (Authority, 2018b, p. 17). The Authority (2018b, p. 17) would seek to build the segments of San Francisco to Gilroy and Madera to Bakersfield first to provide initial interim service while funding for the Pacheco Pass tunnels, extension to Merced, and the rest of Phase 1 down to southern California is identified.

Figure 2.11 and Figure 2.12 show the range of capital costs by project section and phase, respectively. 


\begin{tabular}{|c|c|c|c|}
\hline SEGMENT & LOW (YOE \$\$, MILLIONS) & $\begin{array}{l}\text { BASE (YOE \$\$, } \\
\text { MILLIONS) }\end{array}$ & $\begin{array}{l}\text { HIGH (YOE \$\$, } \\
\text { MILLIONS) }\end{array}$ \\
\hline Silicon Valley to Central Valley & $\$ 25,138$ & $\$ 29,539$ & $\$ 36,840$ \\
\hline San Francisco to San José (balance/full investment)* & $\$ 1,659$ & $\$ 2,074$ & $\$ 2,696$ \\
\hline Merced to Wye & $\$ 2,028$ & $\$ 2,386$ & $\$ 2,863$ \\
\hline Bakersfield to Palmdale** & $\$ 13,076$ & $\$ 16,345$ & $\$ 19,614$ \\
\hline Palmdale to Burbank & $\$ 13,159$ & $\$ 17,546$ & $\$ 25,442$ \\
\hline Burbank to Los Angeles & $\$ 1,256$ & $\$ 1,478$ & $\$ 1,699$ \\
\hline Los Angeles to Anaheim & $\$ 3,049$ & $\$ 3,587$ & $\$ 4,125$ \\
\hline Heavy Maintenance Facility (Balance) & $\$ 173$ & $\$ 216$ & $\$ 281$ \\
\hline Rolling Stock (Balance) & $\$ 3,712$ & $\$ 4,124$ & $\$ 4,536$ \\
\hline TOTAL* & $\$ 63,250$ & $\$ 77,295$ & $\$ 98,097$ \\
\hline
\end{tabular}

Figure 2.11 Phase 1 system cost estimate by project section and range. (Authority, 2018a, p. 43).

\begin{tabular}{|c|c|c|c|}
\hline \multicolumn{4}{|c|}{$\begin{array}{l}\text { EXHIBIT } 3.2 \text { SUMMARY OF COST ESTIMATES BY PHASE AND BY RANGE } \\
\text { (IN BILLIONS) }\end{array}$} \\
\hline & $\begin{array}{l}\text { LOW } \\
\text { (YOES) }\end{array}$ & $\begin{array}{l}\text { BASE } \\
\text { (YOE\$) }\end{array}$ & $\begin{array}{l}\text { HIGH } \\
\text { (YOE\$) }\end{array}$ \\
\hline Central Valley Segment & $\$ 10.1$ & $\$ 10.6$ & $\$ 12.2$ \\
\hline $\begin{array}{l}\text { Silicon Valley to Central Valley } \\
\text { Line* }^{*}\end{array}$ & $\$ 25.1$ & $\$ 29.5$ & $\$ 36.8$ \\
\hline Phase 1 System ** & $\$ 63.2$ & $\$ 77.3$ & $\$ 98.1$ \\
\hline
\end{tabular}

Figure 2.12 Range of cost estimates by phase. (Authority, 2018b, p. 36).

The difference in costs, and the shift in direction and scope between each business plan reflects the dynamic political and financial realities of the California High-Speed Rail Program, and the Authority has had to adapt as circumstances change.

The Authority (2018b, p. 33) anticipates in its 2018 Draft Revised Business Plan for service between San Francisco and Bakersfield to begin in 2029, and for Phase 1 service between San Francisco and Anaheim to start in 2033. For the purposes of forecasting ridership and revenue, the Authority (2018b, p. 94) has assumed an average 
ticket price of $\$ 93$ in today's dollars for a trip between San Francisco and Los Angeles. The train operator, however, will ultimately decide the ticket prices based on yield management techniques like those performed by airlines (Authority, 2018b, p. 94). For example, tickets that are bought far in advance of a scheduled trip will cost less than tickets bought at the last minute, and separate service levels (first-class and reserved seats versus economy class) will have different price points (Authority, 2018b, p. 94).

\subsection{Factors that May Affect the Success of the California High-Speed Rail}

This section discusses the characteristics of California and the state of transit in the United States (which is very applicable to California). The physical characteristics and the population distribution of the State are covered. Then, the condition of transit in the United States is discussed.

\subsubsection{Physical Characteristics}

California is the third largest state in the United States, with a total area of 163,695 square miles (United States Census Bureau, 2012). It is located on the southwestern coast of the contiguous 48 states, and borders Oregon to the north, Nevada and Arizona to the east, Mexico to the south, and the Pacific Ocean to the west.

In terms of geography, California has many physical contrasts. The State's northern and coastal areas are characterized by a Mediterranean climate of warm summers and mild winters. The San Joaquin Valley, which makes up the southern half of the Central Valley, experiences semi-arid summers and mild winters. The southeastern portion of the State has a desert-like climate with hot summers and little rainfall throughout the year. 
There are many mountain ranges in California. The most notable include the Klamath Mountains in the northwest, the Coastal Ranges along the western coast, and the Sierra Nevada Mountains along the eastern border. Between these mountain ranges is the California Central Valley, which has a strong agricultural economy and serves as the breadbasket for the western United States.

Map 2.11 shows the proposed alignment of the California High-Speed Rail System over a topographic map of California. The Phase 1 alignment traverses the Coastal Ranges, the San Joaquin Valley, the Tehachapi Mountains, and the San Gabriel Mountains.

\subsubsection{Population}

According to the United States Census Bureau (2017a), California is the most populous state in the nation with an estimated population of 39,250,017. Map 2.12 shows the density and distribution of the population in California. As one can see, most of the population is located along the coast and in the Central Valley. The major metropolitan areas are concentrated in the San Francisco Bay Area, the Los Angeles Basin, and San Diego. Other major population centers include Sacramento, Stockton, Modesto, Fresno, and Bakersfield. Map 2.13 shows that the high-speed rail alignment passes through and connects to these population centers to form a transportation corridor. 


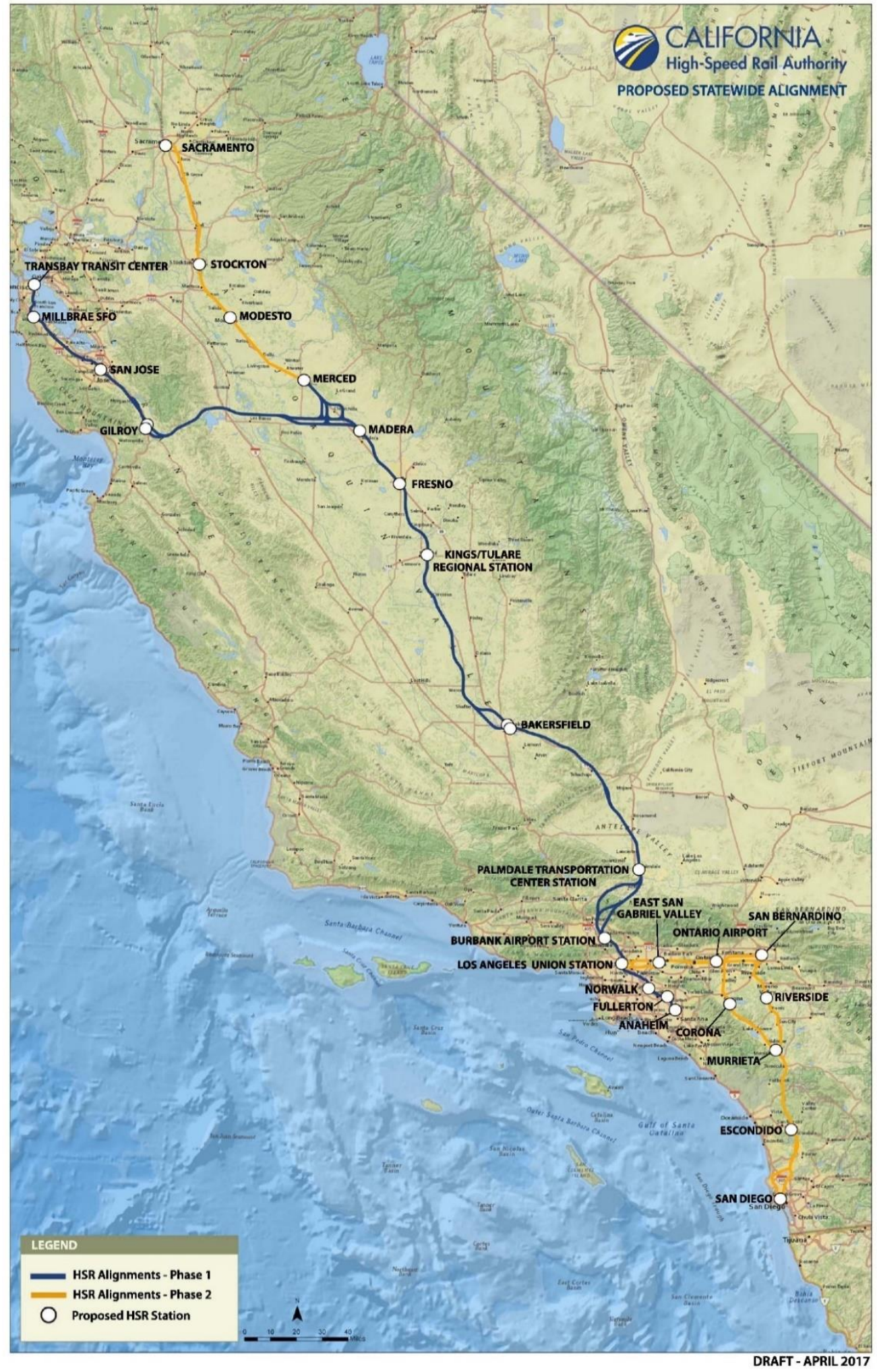

Map 2.11 Proposed statewide alignment of the California High-Speed Rail System. (Authority, 2017c). 


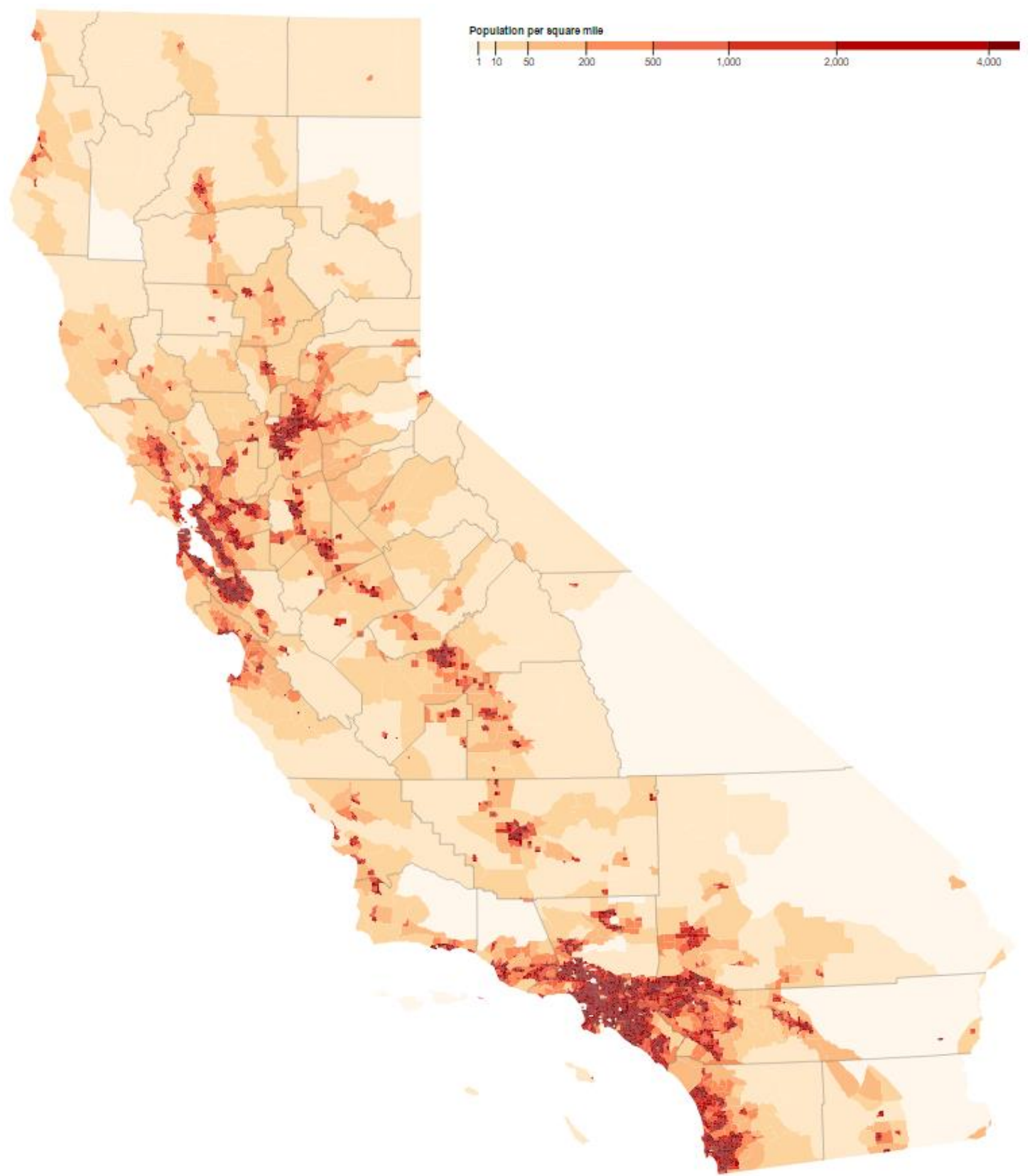

Map 2.12 Population density and distribution of State of California. (Bostock, 2017). 


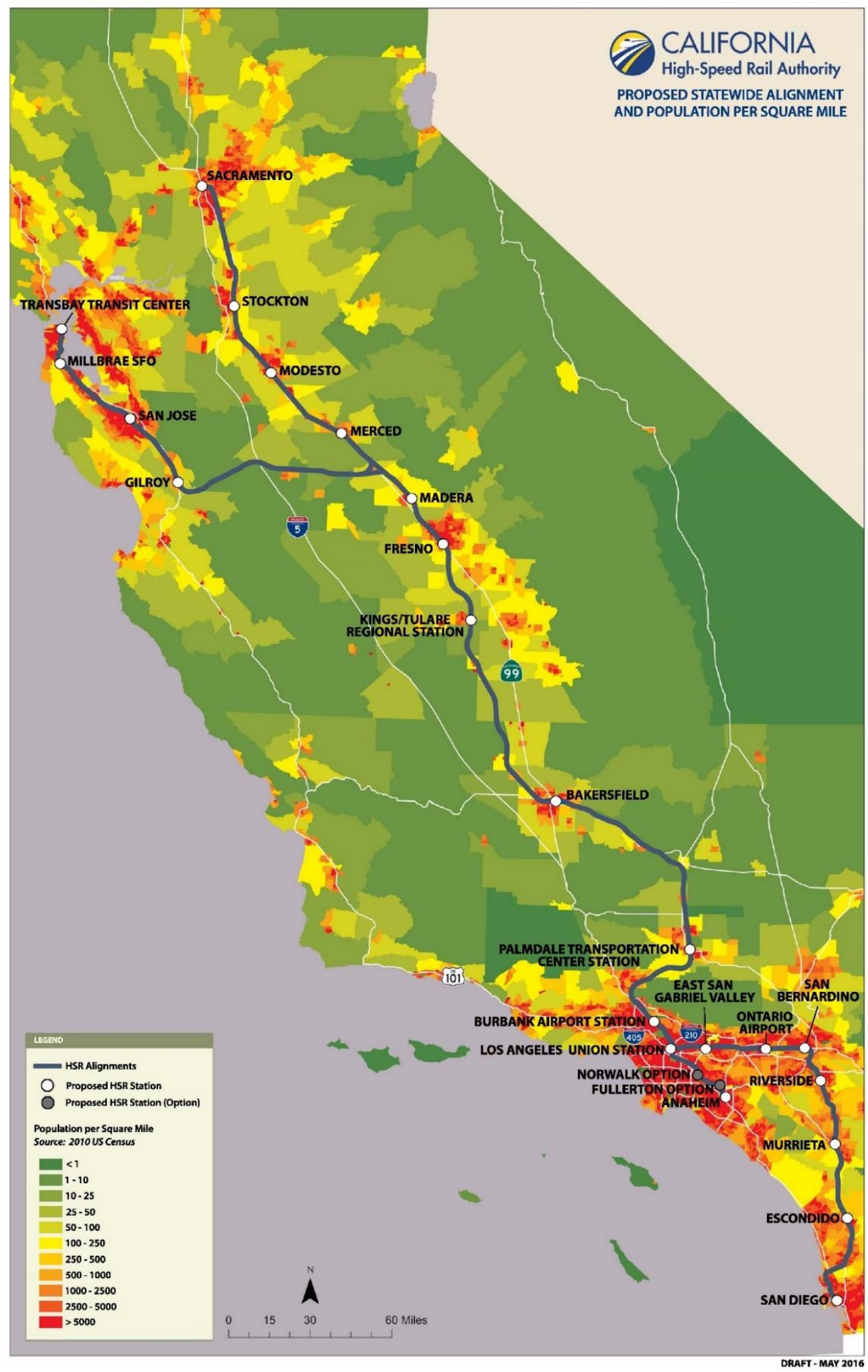

Map 2.13 Proposed statewide alignment and population per square mile. (Authority, 2017b). 


\subsubsection{Government and Industry}

The history of transit and land use in the United States is different from Japan's, to say the least. The beginning of transit services in the United States took place in Boston, Massachusetts, in the form of chartered ferry and horse cart services as early as 1630 (Thompson, 2008, p. 1). By the early 1800s, stagecoach services had spread to urban areas in New York City, Boston, Chicago, and other large cities in the United States (Thompson, 2008, p. 1). Later in the late 1800s, horse- and cable-drawn systems that ran on rails appeared in many cities (Thompson, 2008, p. 1). Finally, in the early $20^{\text {th }}$ century, motor-powered buses and subways were constructed in many American cities (Thompson, 2008, p. 1). It should be noted that "[i]n almost all cases, these urban transit systems were built and operated by private companies, sometimes under local public charter, and often in conjunction with real estate development objectives[,]" similar to that of Japan's railway companies (Thompson, 2008, p. 1). "In many cases, the suburban rail passenger services were adjuncts to private railroads that provided freight and intercity passenger services" (Thompson, 2008, p. 1).

Before World War II, automobile-based suburbanization was relatively constrained. Automobile ownership was confined to the relatively wealthy, the national highway system was underdeveloped, and intercity airline service was virtually nonexistent (Thompson, 2008, p. 1). The pre-conditions for suburbanization, however, formed during this period. Firstly, the trend of urbanization of the population that was spurred by the industrial revolution in the first half of the $19^{\text {th }}$ Century continued into the $20^{\text {th }}$ Century, as shown in Figure 2.13. Secondly, suburbanization had already begun in American cities in the late $19^{\text {th }}$ century to the early $20^{\text {th }}$ century, though at a smaller scale 
and with the accessibility provided by transit lines rather than automobiles. During this period, many American cities established streetcar and trolley lines to relieve congestion in their downtown areas (Chudacoff, Smith, \& Baldwin, 2010, p. 85). The transit lines became popular with commuters wishing to cut down their travel times, or those who wished to travel farther in the same amount of time as before (Chudacoff, Smith, \& Baldwin, 2010, p. 85). Consequently, "[1]and values along streetcar lines soared, and real estate developers scrambled to buy up property on projected routes" (Chudacoff, Smith, \& Baldwin, 2010, p. 85). Thus, "[m]ass transit transformed the shape of the city, stimulating both outward [and compact] sprawl and greater specialization of land use" (Chudacoff, Smith, \& Baldwin, 2010, p. 86).

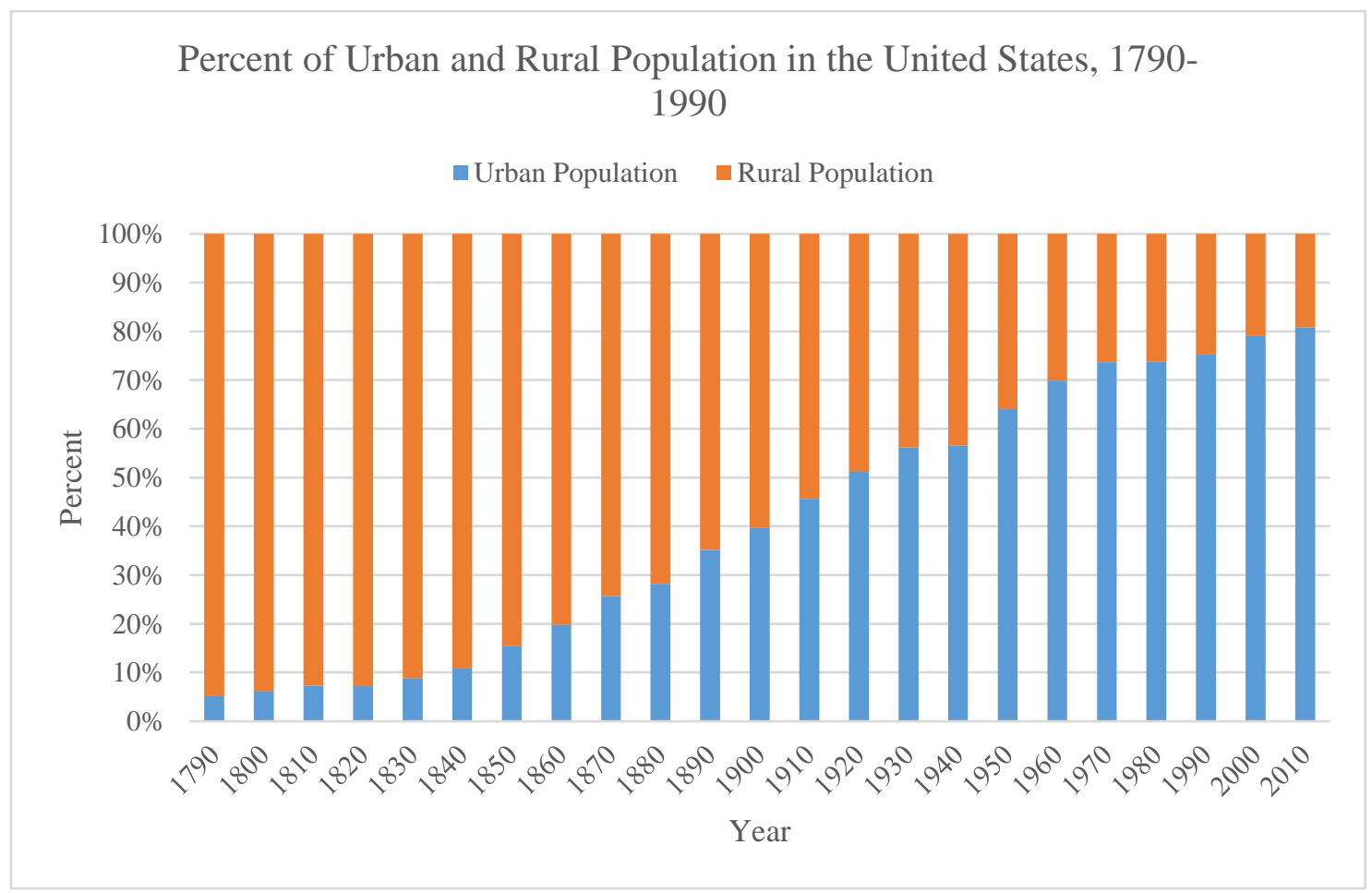

Figure 2.13 Percent of urban and rural population in the United States by year. (United States Census Bureau, 1993; United States Census Bureau, 2000; United States Census Bureau, 2010). 
A point that should be noted is that transit companies were often pressured to keep their fares, or ticket prices, low from self-imposed policies, legislation by government, and the incentive to not price out riders (Chudacoff, Smith, \& Baldwin, 2010, p. 86). Given their need to maintain profitable operations, transit companies were forced to expand lines ever farther from central business districts to allow empty land to develop and to attract more riders (Chudacoff, Smith, \& Baldwin, 2010, p. 86). Yet, accommodating more passengers with transit line extensions and more cars required huge capital investments that strained the financial health of transit companies (Chudacoff, Smith, \& Baldwin, 2010, p. 86). A cycle developed where transit companies expanded services to generate more revenues from more riders, only to find that serving more riders exacerbated their financial standing (Chudacoff, Smith, \& Baldwin, 2010, p. 86). For this reason, municipal ownership of mass transit systems came to be a rational response to maintain transit service in American cities (Chudacoff, Smith, \& Baldwin, 2010, p. 86). "As scores of companies went bankrupt during and after World War I, public ownership became the only way that many cities could sustain mass transit" (Chudacoff, Smith, \& Baldwin, 2010, p. 86).

In the period after World War II, many forces allowed suburbanization to takeoff. Firstly, the end of wartime rationing and a large increase in production and consumption resulting from the "permanent war economy" greatly increased workers" incomes and raised their standards of living (Thompson, 2008, p. 1; Noble, n.d.). The increase in personal incomes of the general populace allowed many households to afford automobiles. Secondly, the launch of the Federal-Aid highway program in 1956 and the subsequent construction of the Interstate Highway System allowed automobiles to be a 
much more attractive travel mode than they were previously for short-haul intracity and intercity travelers (Thompson, 2008, p. 1). Finally, the beginning of the National Highway Network was paired with the advent of the Federal-Aid Airport Program in 1946, which provided the public policy and funding for the development of a national system of civil aviation (Federal Aviation Administration, 2016). The rise of commercial airliners had the effect of "shifting most long haul intercity passenger transport to airlines from rail and bus" (Thompson, 2008, p. 1). Transit and railway services in the United States were essentially under a two-prong attack by automobiles and airlines, which were backed by federal policy and funding.

The ensuing years after World War II predictably resulted in a rapid decline of ridership on transit systems in the United States, as shown in Figure 2.14. At the same time, the growing popularity of the automobile is reflected by the increase in the number of state motor vehicle registrations. 


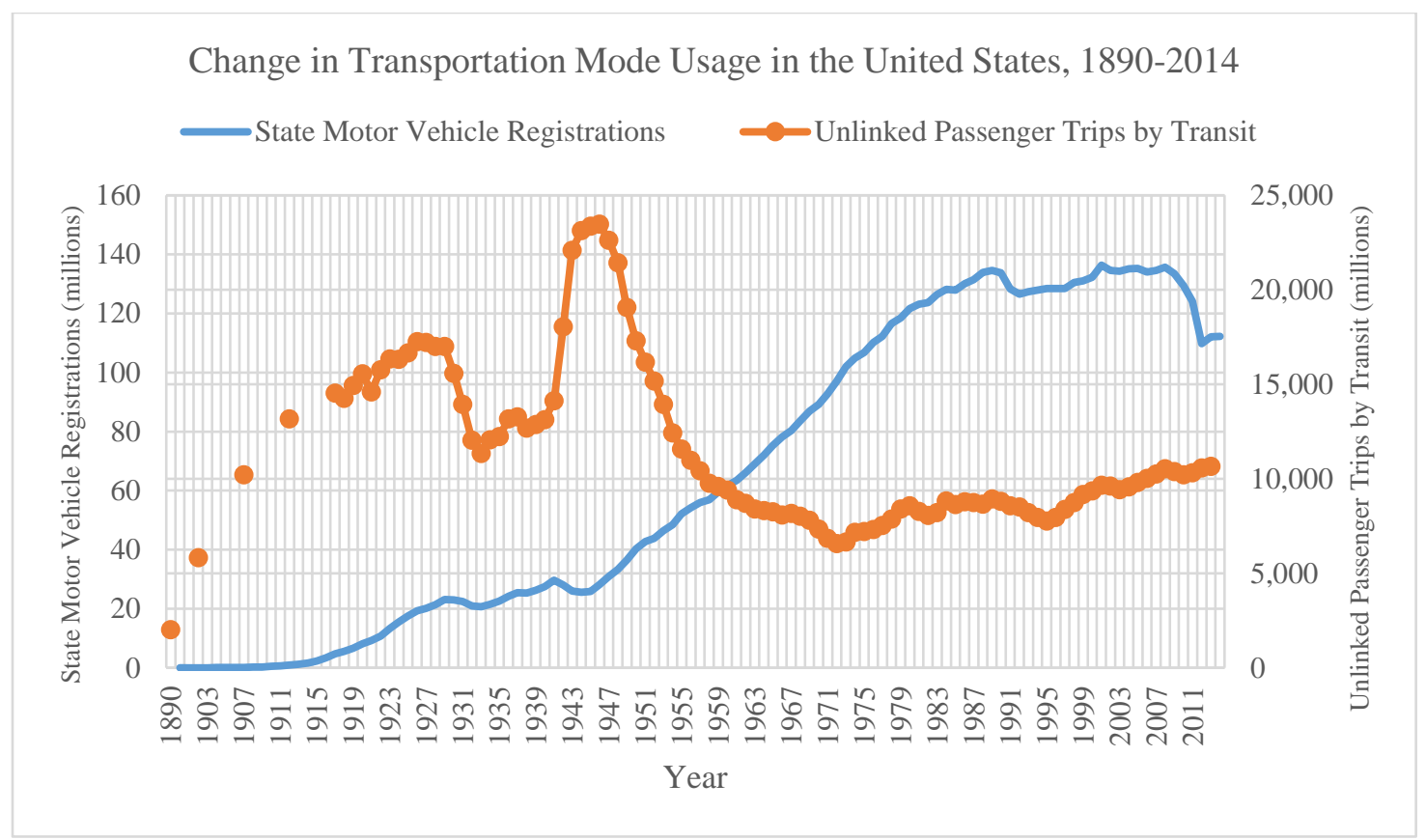

Figure 2.14 Change in transportation mode usage in the United States, 1890-2014. Note that transit trips include roadway modes and all fixed-guideway modes reported. State motor vehicle registrations include automobiles, buses, and trucks. (American Public Transportation Association, 2015, pp. 20-27; Federal Highway Administration [FHWA], 1997; FHWA; 2015).

When transit ridership fell by two-thirds to 8.4 billion riders in 1963 from a peak of 23.4 billion in 1946, policymakers realized that the post-war trend of "allowing the local authorities to deal with what was then seen as a local problem - the collapse of the formerly private operators and the need for public involvement - was not working" (Thompson, 2008, p. 3). In 1961, the United States Congress passed the Housing Act of 1961 to provide public transit with minor amounts of federal funding and loans (Thompson, 2008, p. 3). The action is notable in the sense that the aid was provided in the form of a housing program rather than as an urban development or transportation issue (Thompson, 2008 p. 3). Three years later, Congress passed the Urban Mass Transportation Act of 1964, which authorized minimal funding for a nascent program of loans, grants, and protections for affected transit employees (Thompson, 2008, p. 3). 
Thompson (2008, p. 3-4) states that the legislative findings of the Urban Mass

Transportation Act of 1964 contained the following:

"[T]he welfare and vitality of urban areas, the satisfactory movement of people and goods within such areas, and the effectiveness of housing, urban renewal, highway, and other federally aided programs were being jeopardized by the deterioration or inadequate provision of urban transportation facilities and services ..."By this finding, the Congress had explicitly (albeit belatedly) established that individual urban transport problems, though not in themselves national problems, were, when taken together, a threat to national economic and social development. To this was added the conclusion that urban transport failures could threaten the success of well-established federal programs such as highway planning and construction. On this base - that urban transport issues are, when taken together, a national issue - the Government has slowly built all that has followed.

In 1968, transit programs under the newly formed United States Department of Housing and Urban Development were transferred to the Urban Mass Transit Administration (the precursor agency to the Federal Transit Administration [FTA]) under the also recently formed United States Department of Transportation (DOT) (Thompson, 2008, p. 4). From this point on, urban transport began to be seen as more of a transportation problem rather than an urban development and housing problem, though the latter two were still factored into decisions (Thompson, 2008, p. 4). Additionally, three main developments of transit in the United States have generally occurred since the 
1960s. Firstly, funding levels at the federal level has "continuously increased as the importance of urban transit as a national priority has gradually been accepted" (Thompson, 2008, p. 5). Secondly, flexibility in using funds from the Highway Trust Fund for transit initiatives has also gradually increased, despite the backlash and resistance from highway zealots (Thompson, 2008, p. 5; Mohl, 2008). Thirdly, the federal role has expanded into practically every aspect of transit, from funding for maintenance, capital projects, and operations, to planning of future projects (Thompson, 2008, p. 5). Furthermore, federal assistance in such programs requires transit systems to be fully accessible and useable by persons with physical disabilities and by the elderly (Thompson, 2008, p. 5). As Thompson (2008, p. 2) states,

[i]n broad terms, the decades after World War II saw an undermining of the old model whereby the private sector was able to provide mass public transport without significant public support .... The net result was the collapse of the old model of private ownership and operation of urban systems to be replaced by much greater involvement of the public sector in planning, management, and financing.

Despite the increase in public sector involvement in transit, the level of use of transit in the United States falls far below that of highway and air modes. Figure 2.15 and Figure 2.16 show the decadal passenger-miles by mode in the United States from 1960 to 2010 and the percent of passenger-miles by mode in the United States from 1960 to 2010, respectively. In Figure 2.15, highways experienced a strong and steady increase in passenger-miles until 2000. The drop in highway passenger-miles from 2000 to 2010 is 
presumed to be a result of the crash of the housing bubble in 2007 and the concomitant economic recession. The number of passenger-miles by air also increased between 1960 and 2010, although at a much slower rate and at lower nominal values compared to that of highways. Passenger-miles for transit and intercity rail (Amtrak) were comparably a tiny fraction of that of highways and air and remained flat for the period between 1960 and 2010 .

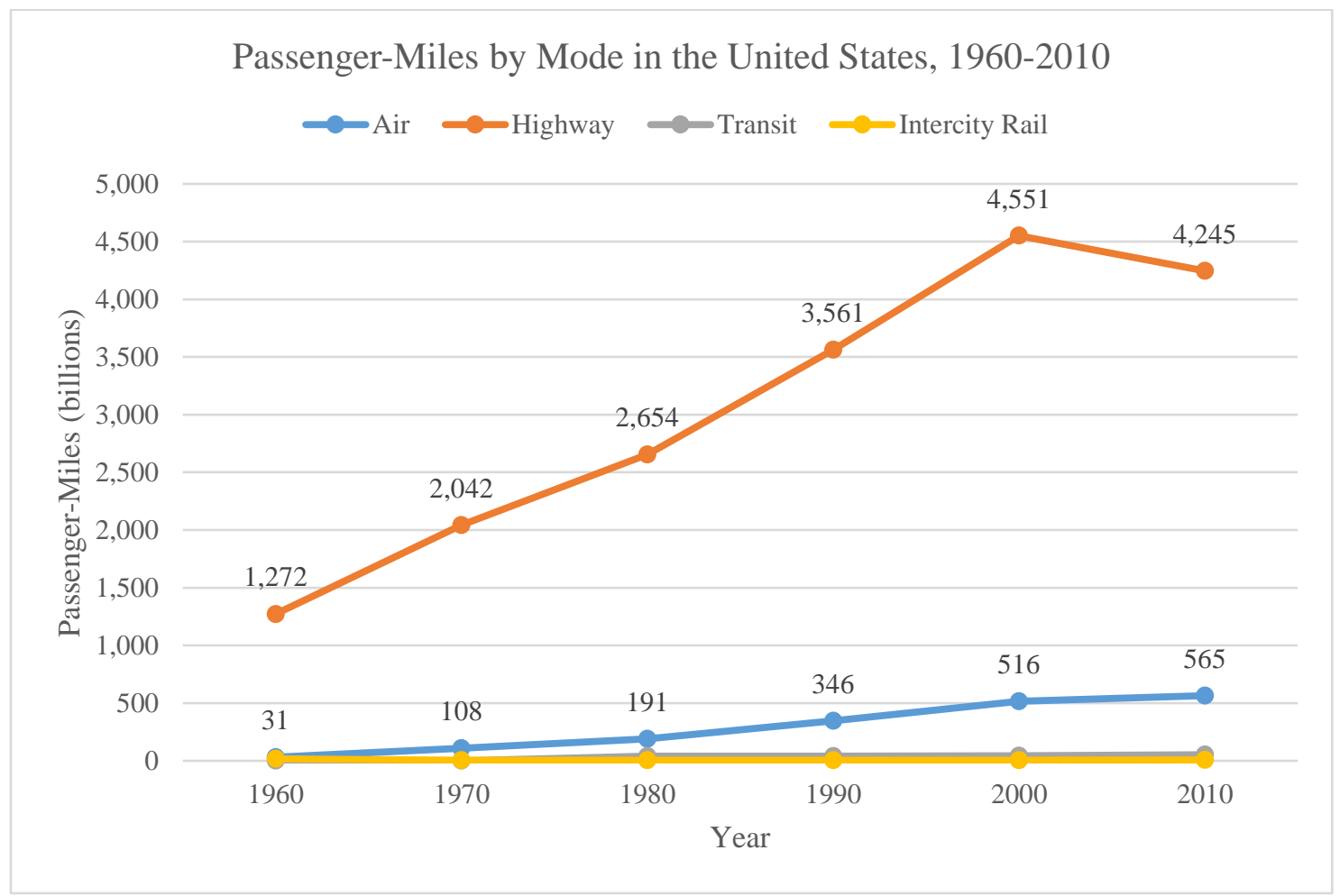

Figure 2.15 Passenger-Miles by mode in the United States by year. The figures for transit and intercity rail are too small to be shown graphically. (DOT, 2016a).

In Figure 2.16, highways gradually declined in percent of passenger-miles for all modes from 1960 to 2010, though they remained the dominant mode of transportation with 87 percent of the market share. Air gradually captured the market share from highways with a slow increase in the percent of total passenger-miles between 1960 and 2010. 12 percent of passenger-miles in the United States were by air in 2010. Once again, 
transit and intercity rail both experienced dismal percentages of passenger-miles with respect to air and highways, with virtually no change from 1960 to 2010.

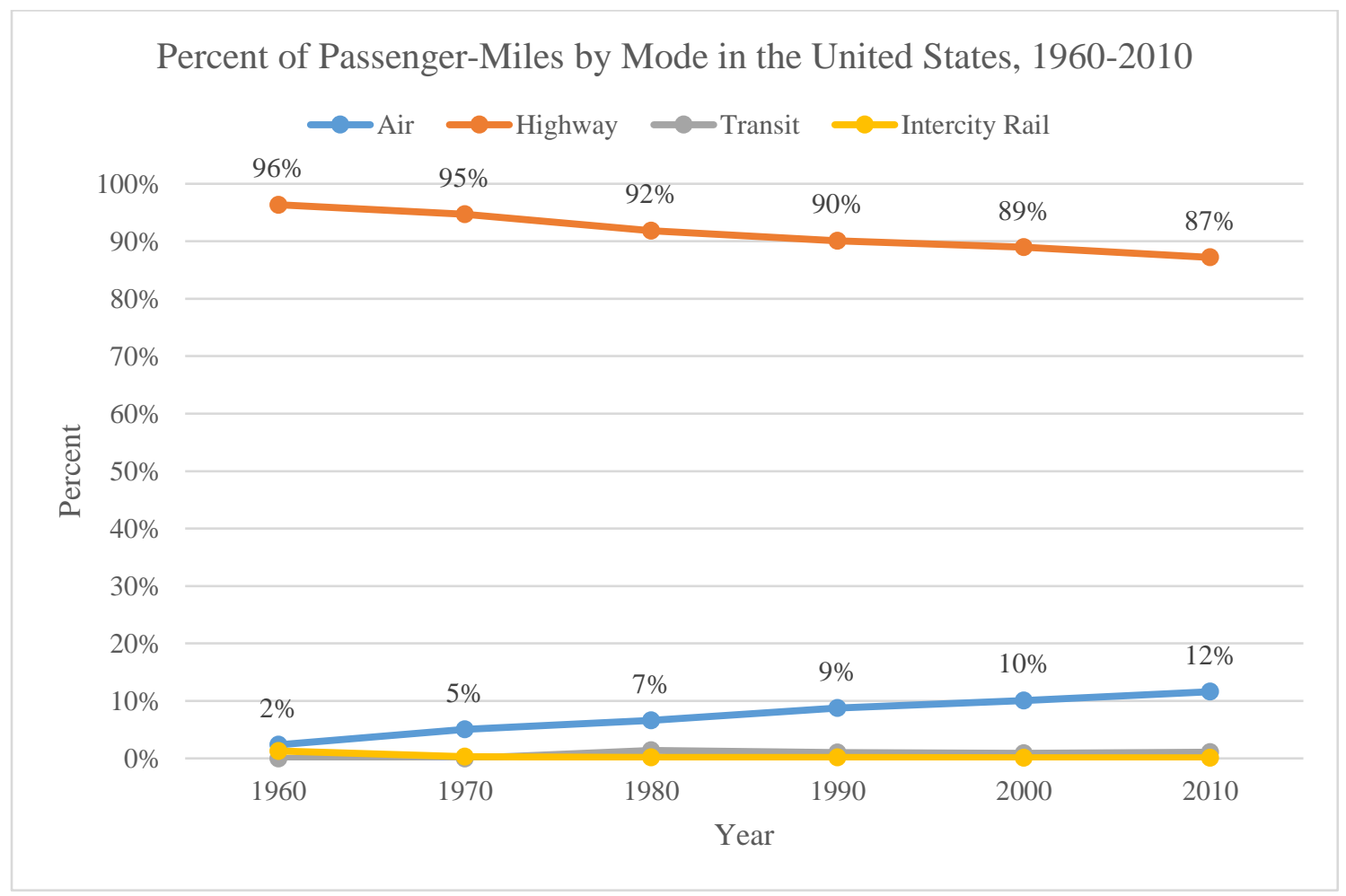

Figure 2.16 Percent of passenger-miles in the United States by mode and by year. The figures for transit and intercity rail are too small to be shown graphically. (DOT, 2016a).

By looking at transportation outlays at different levels of government for each mode, a similar narrative appears. Figure 2.17 shows the transportation expenditures of the federal government by mode from 1995 to 2012. Once again, the emphasis seems to be on highways as spending for that mode was greater than the other modes. The mode with the second highest amount of spending was air, which experienced a relatively large increase in spending during the early 2000s. Interestingly, the increase began a year prior to the September 11, 2001, attacks, which presumably would explain the increase in subsequent years for improved security. Transit expenditures were a fraction of those for highways and air modes from 1995 to 2010. Rail, which includes intercity Amtrak 
service, ranged from about $\$ 2.87$ billion to $\$ 648$ million in annual federal transportation outlays.

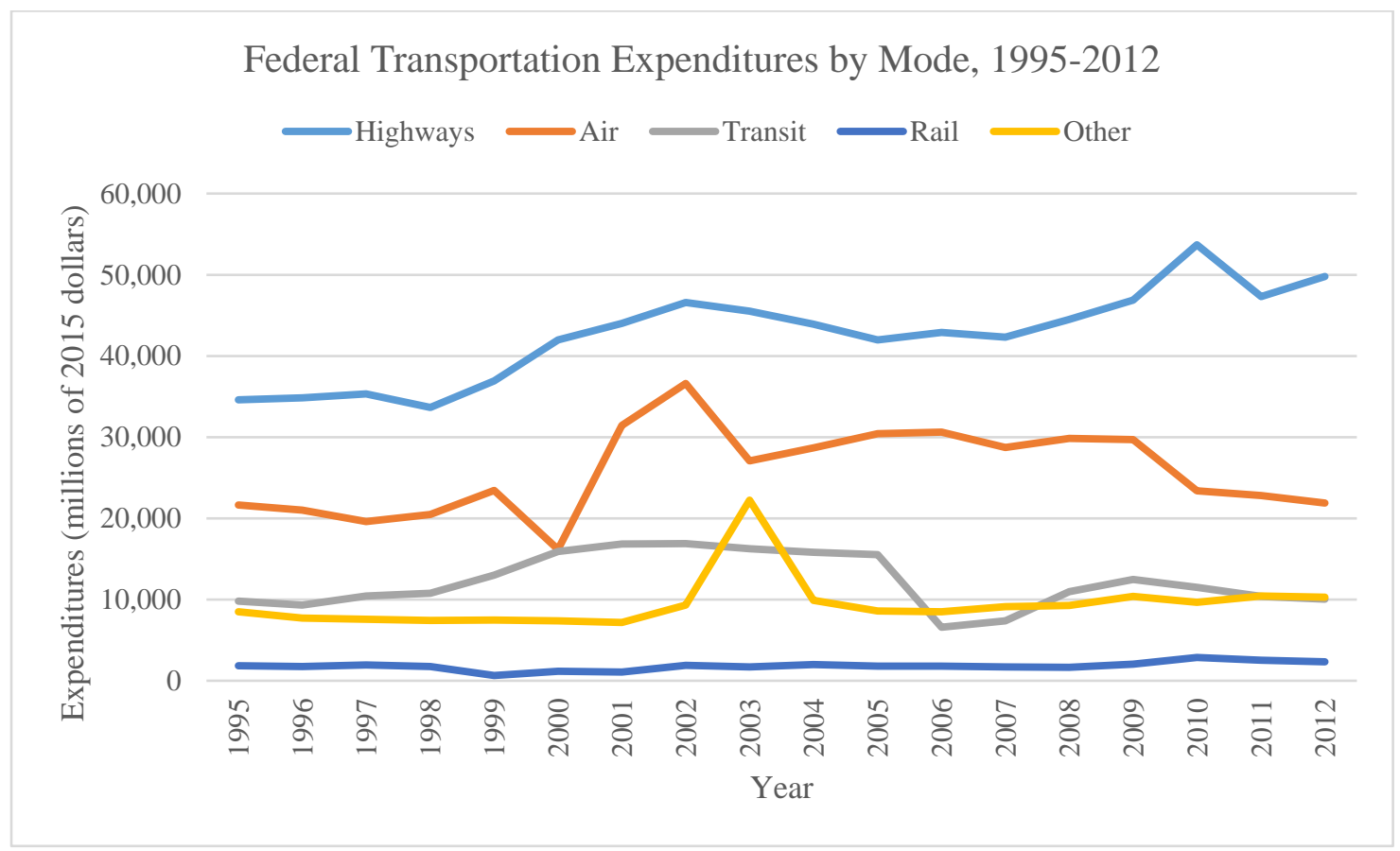

Figure 2.17 Federal transportation expenditures by mode and year. "Other" includes figures for "Water," "Pipeline," and "General" transportation modes. (DOT, 2016b; Federal Reserve Bank of Minneapolis, 2016).

In Figure 2.18, highways encompass between 40 percent and 53 percent of federal transportation expenditures during the period between 1995 and 2012. Air received between 34 percent and 20 percent of federal outlays during the same timeframe, while transit modes received between seven percent to 19 percent of the federal expenditures. Rail service was dismally low, with at most three percent of federal transportation spending. 


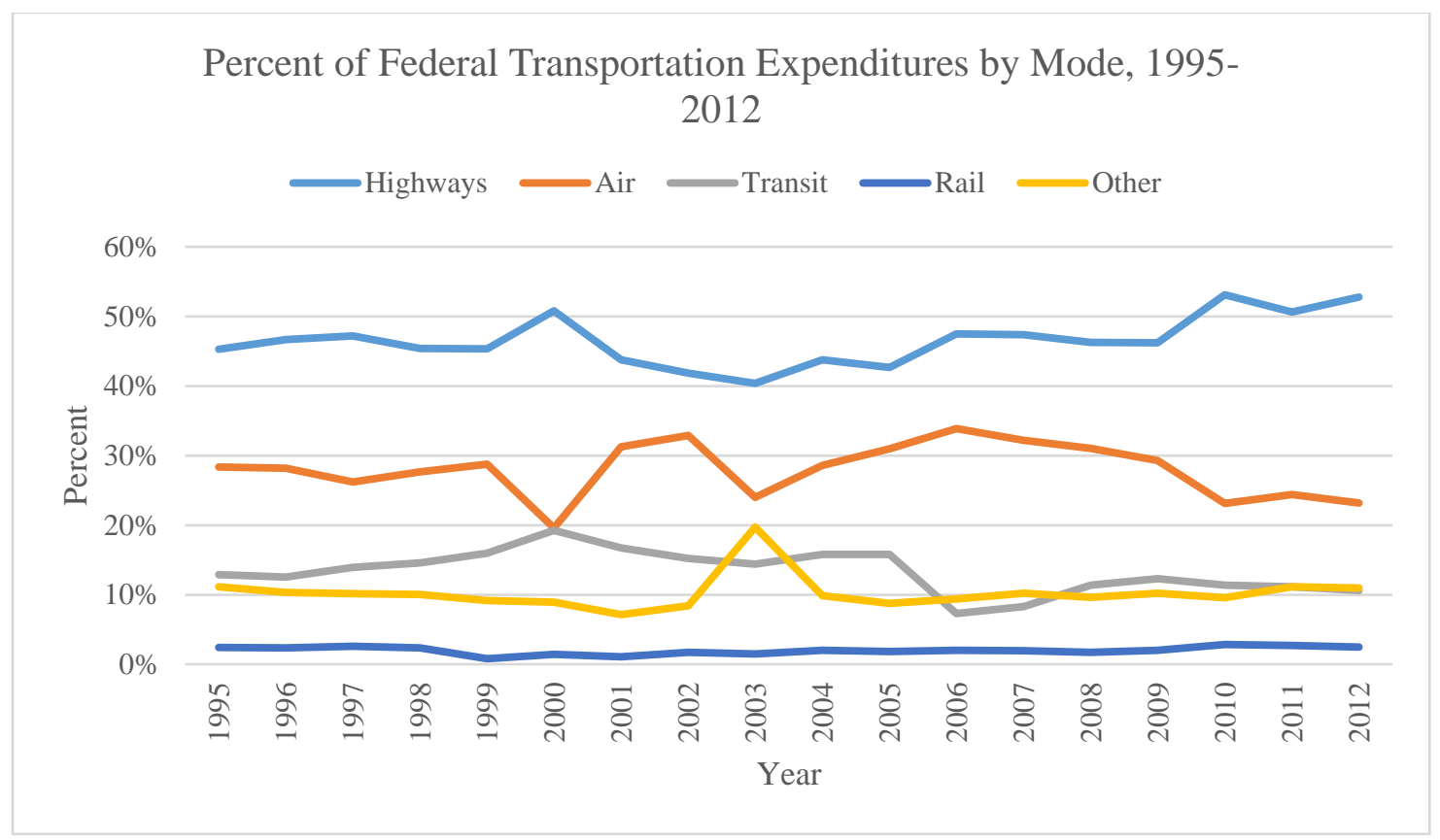

Figure 2.18 Percent of federal transportation expenditures by mode and year. "Other" includes figures for "Water," "Pipeline," and "General" transportation modes. (DOT, 2016b; Federal Reserve Bank of Minneapolis, 2016).

Figure 2.19 shows the transportation expenditures of state and local governments by mode from 1995 to 2012. Clearly, highways made up the bulk of expenditures.

Interestingly, transit received a greater amount of funding than air modes, while rail, and other transportation modes respectively received a decreasing amount of transportation outlays. What is noticeable about state and local transportation expenditures is that they were much more consistent on a year-by-year basis compared to those at the federal level. 
State and Local Transportation Expenditures by Mode, 1995-2012

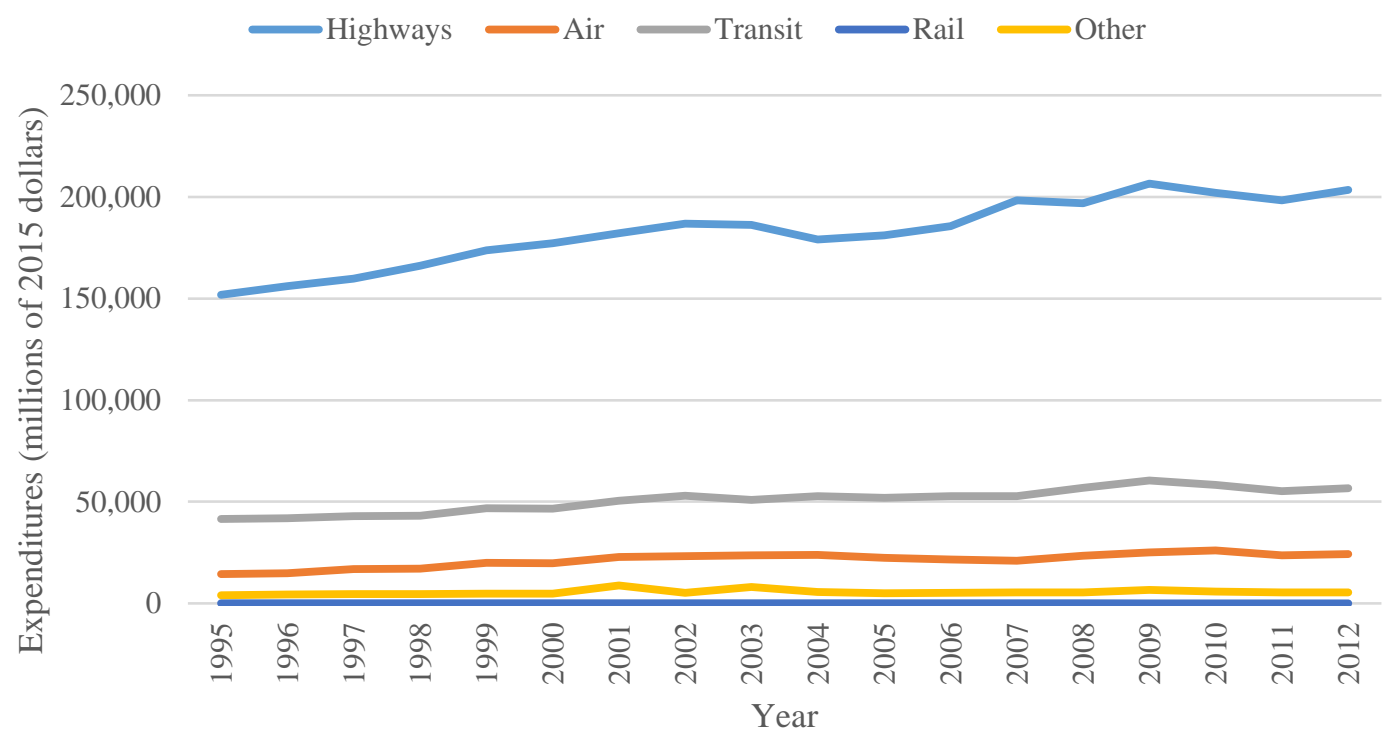

Figure 2.19 State and local transportation expenditures by mode and year. "Other" includes figures for "Water," "Pipeline," and "General” transportation modes. (DOT, 2016b; Federal Reserve Bank of Minneapolis, 2016).

The percent of state and local transportation expenditures by mode is shown in Figure 2.20 from 1995 to 2012. As was indicated by the patterns in Figure 2.19, highways got the largest percentage of state and local transportation funding, claiming about 70 percent of the funds over the presented timeframe. Transit, air, rail, and other transportation modes received about 20 percent, zero percent, and two percent of state and local transportation funds, respectively. 


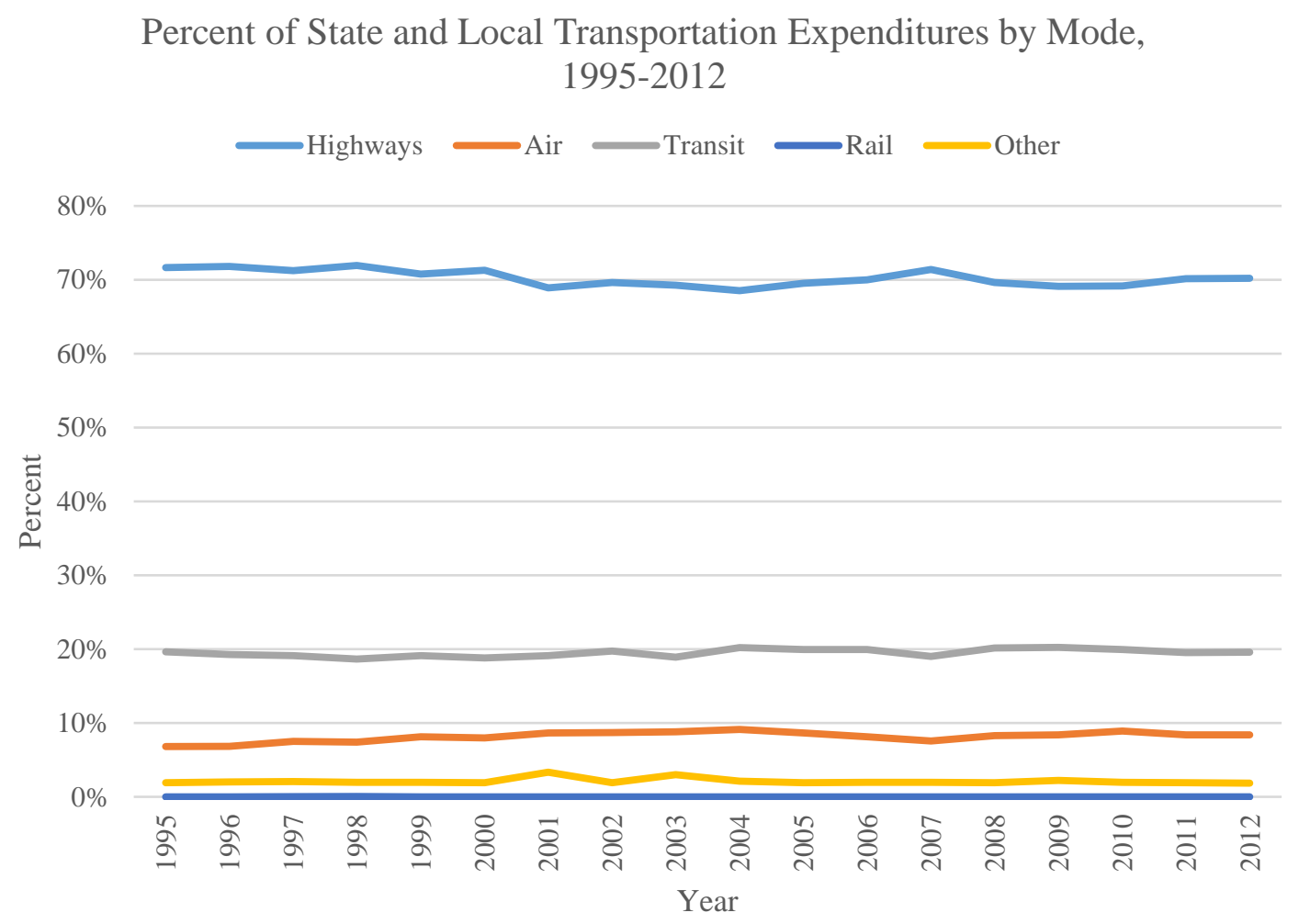

Figure 2.20 Percent of state and local transportation expenditures by mode and by year. "Other" includes figures for "Water," "Pipeline," and "General" transportation modes. (DOT, 2016b; Federal Reserve Bank of Minneapolis, 2016).

A major contributor for the low patronage of transit systems in the United States is the omnipresence of suburban development, which is not conducive to generating ridership for transit. While the ubiquity of suburbs in the United States is attributable to many reasons, the three main reasons include the end of wartime rationing, and the promotion of suburbanization through national housing policy, and national transportation policy. Firstly, the end of wartime rationing and the infusion of federal funds to promote production and consumption through the "permanent war economy" led to higher standards of living and brought automobile ownership within reach of many Americans (Thompson, 2008, p. 1; Noble, n.d.). Figure 2.21 shows one such standard of 
living, real gross domestic product per capita, beginning its rapid rise right around the end of the Second World War.

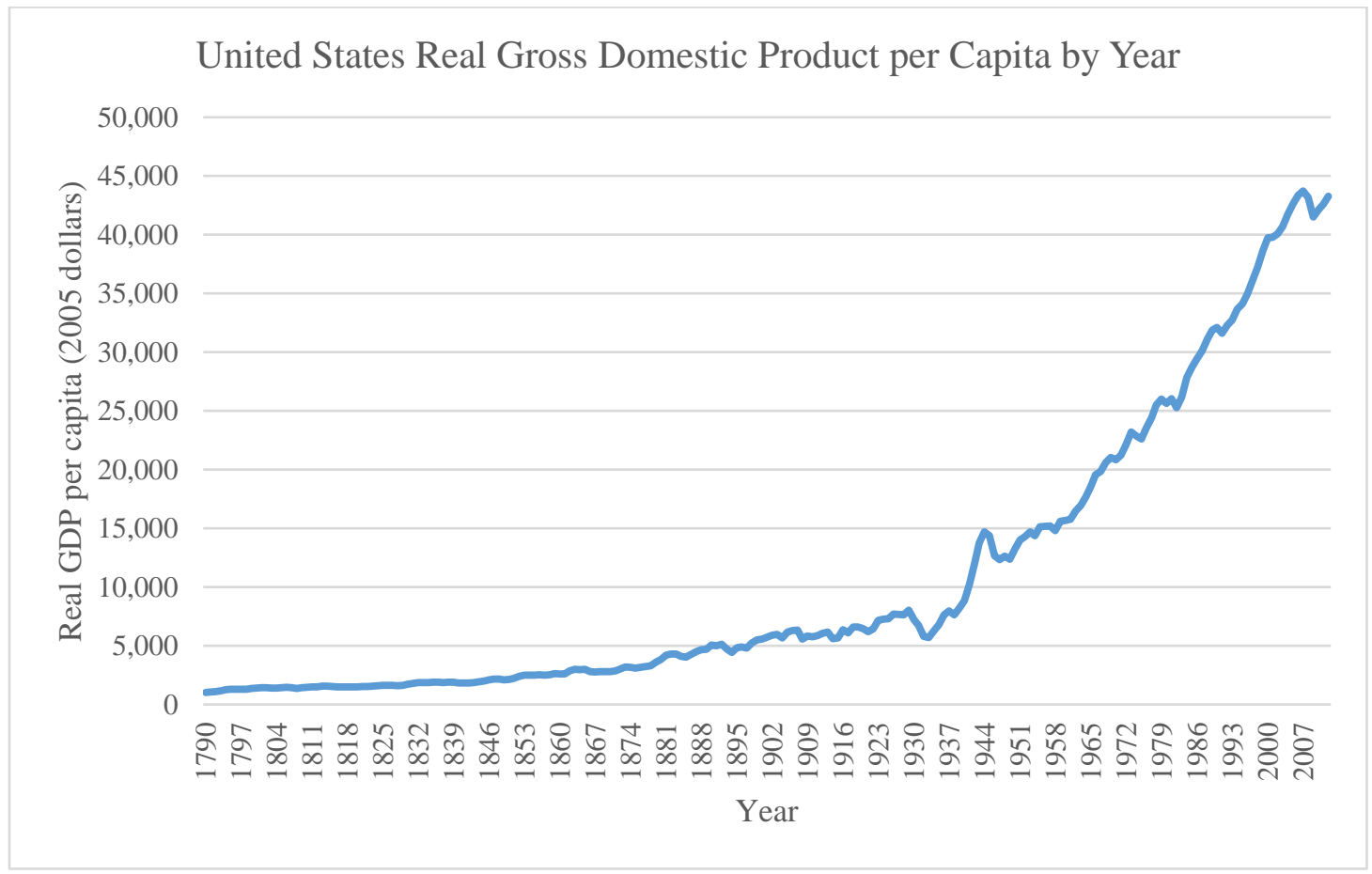

Figure 2.21 United States real gross domestic product per capita per year in 2005 dollars. (Johnston \& Williamson, 2017).

Secondly, while the population in the United States is urbanized, most of the "urban” population lives and works in suburbs (Thompson, 2008, p. 2). National housing policy encourages homeownership through institutions such as the Federal Home Loan Bank Act of 1932, the Federal National Mortgage Association of 1938 (also known as "Fannie Mae"), and the Federal Home Loan Mortgage Corporation (also known as "Freddie Mac") that make up the secondary capital market for mortgages (Investopedia.com, 2017). These institutions "buy mortgages from lenders and either hold these mortgages in their portfolios or package the loans into mortgage-backed securities ... that may be sold" to additional investors (Federal Housing Finance Agency, 
2017). In this way, the pool of liquidity available for mortgages increases because investors are encouraged to provide financing due to the lower risk provided by government-sponsored enterprises as opposed to private financial institutions (Federal Housing Finance Agency, 2017). The larger pool of liquidity means that a greater number of mortgages can be made and allow more citizens to finance the purchase of their homes (Federal Housing Finance Agency, 2017). Thus, the rate of suburban homeownership increases (Federal Housing Finance Agency, 2017). Finally, the construction of major freeways and circumferential expressways in urban areas was stimulated by the National Interstate and Defense Highways Act of 1956 (Muller, 1995, p. 43). The conditions were ripe for suburbanization to take off at unprecedented levels, as shown in Figure 2.22 (Muller, 1995, p. 43). Muller (1995, pp. 43-45) notes that the freeway system eliminated the regionwide centrality advantage of the central city's [central business district]. Now any location on the expressway network could easily be reached by motor vehicle, and intraurban accessibility swiftly became an all-but-ubiquitous spatial good. Ironically, large central cities had encouraged the construction of radial expressways in the 1950s and 1960s because they appeared to enable downtown to remain accessible to the swiftly dispersing suburban population. As one economic activity after another discovered its new locational foot looseness in the freeway metropolis, however, nonresidential deconcentration greatly accelerated. Much of this suburban growth has gravitated toward beltway corridors ...., originally designed to allow long-distance interstate highways to bypass the congested urban core.... 
As high-speed expressways expanded the radius of commuting to encompass the entire dispersed metropolis, residential locational constraints were relaxed as well. No longer were most urbanites required to live within a short distance of their job. Instead, the workplace had now become a locus of opportunity offering access to the best possible residence that a household could afford anywhere within the urbanized area.

Suburbs are generally characterized by low density development, auto-centric transportation infrastructure, and a pronounced separation of land uses by type. These characteristics are not conducive for the provision of effective transit services and, thus, leave most of the population unable to access an efficient modal alternative to the automobile. 


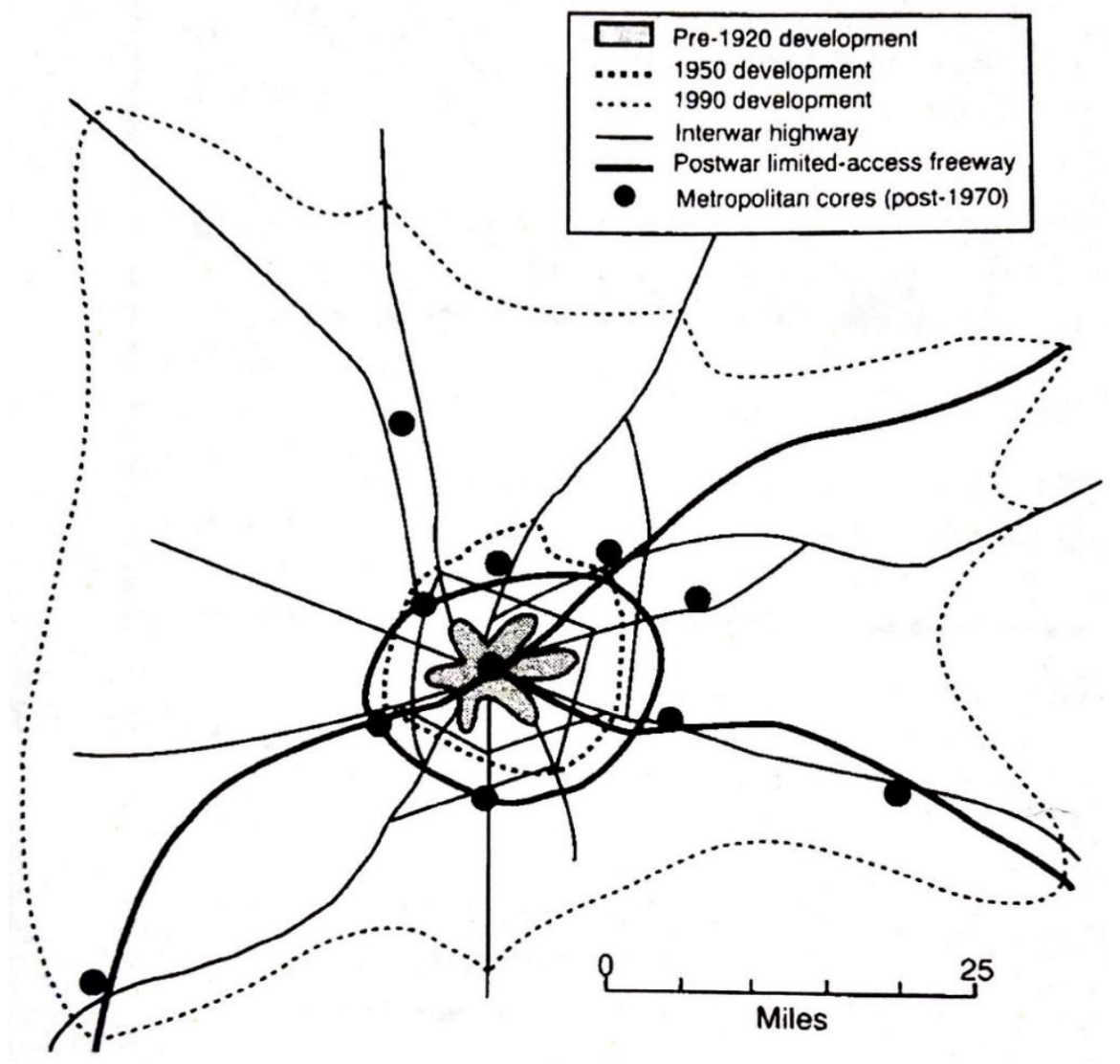

Figure 2.22 Spatial pattern of urban growth around the automobile and highways. (Muller, 1995, p. 43).

The relatively low utilization of transit services in the United States is indicated by the low farebox recovery rates, or ratio of farebox revenues over operating expenses, as shown in Table 2.10 and Table 2.11. Not a single transit agency can be seen to recover its operating expenses from its farebox recovery rates. Since transit agencies in the United States do not engage in business diversification or property development to the level exhibited by Japanese railway company groups, they must rely on state and federal subsidies on an annual basis to keep operations ongoing. Because state and federal subsidies to support transit are subject to the political process, the level of support that transit agencies receive varies depending on the political climate at any given time, leaving transit users with varying and inconsistent levels of transit service. 
Table 2.10 Top 50 Transit Agencies in Terms of Farebox Recovery Rate in the National Transit Database. Note: Yellow cells indicate transit agencies that operate in California. (National Transit Database [NTD], 2015a; NTD, 2015b; NTD, 2016).

\begin{tabular}{|c|c|c|c|c|}
\hline \multicolumn{5}{|c|}{ Top 50 Transit Agencies in Terms of Farebox Recovery Rate in the National Transit Database } \\
\hline Rank & Agency & $\begin{array}{l}\text { Fare Revenues } \\
\text { (millions \$US) }\end{array}$ & $\begin{array}{l}\text { Operating Expenses } \\
\text { (millions \$US) }\end{array}$ & Ratio \\
\hline 1 & MTA New York City Transit (NY) & $\$ 4,291.8$ & $\$ 8,609.9$ & 0.50 \\
\hline 2 & New Jersey Transit Corporation (NJ) & $\$ 935.8$ & $\$ 2,042.4$ & 0.46 \\
\hline 3 & $\begin{array}{l}\text { Washington Metropolitan Area Transit } \\
\text { Authority (DC) }\end{array}$ & $\$ 782.5$ & $\$ 1,722.4$ & 0.45 \\
\hline 4 & MTA Long Island Rail Road (NY) & $\$ 700.7$ & $\$ 1,290.6$ & 0.54 \\
\hline 5 & $\begin{array}{l}\text { Metro-North Commuter Railroad Company } \\
\text { (NY) }\end{array}$ & $\$ 678.3$ & $\$ 1,140.5$ & 0.59 \\
\hline 6 & $\begin{array}{l}\text { Massachusetts Bay Transportation Authority } \\
\text { (MA) }\end{array}$ & $\$ 602.8$ & $\$ 1,490.3$ & 0.40 \\
\hline 7 & Chicago Transit Authority (IL) & $\$ 591.4$ & $\$ 1,363.4$ & 0.43 \\
\hline 8 & $\begin{array}{l}\text { Southeastern Pennsylvania Transportation } \\
\text { Authority (PA) }\end{array}$ & $\$ 481.6$ & $\$ 1,218.8$ & 0.40 \\
\hline 9 & $\begin{array}{l}\text { San Francisco Bay Area Rapid Transit } \\
\text { District (CA) }\end{array}$ & $\$ 462.8$ & $\$ 580.2$ & 0.80 \\
\hline 10 & $\begin{array}{l}\text { Los Angeles County Metropolitan } \\
\text { Transportation Authority (CA) }\end{array}$ & $\$ 368.4$ & $\$ 1,404.8$ & 0.26 \\
\hline 11 & Metra Rail (IL) & $\$ 337.4$ & $\$ 706.7$ & 0.48 \\
\hline 12 & San Francisco Municipal Railway (CA) & $\$ 214.7$ & $\$ 744.9$ & 0.29 \\
\hline 13 & MTA Bus Company (NY) & $\$ 210.3$ & $\$ 642.2$ & 0.33 \\
\hline 14 & $\begin{array}{l}\text { Port Authority Trans-Hudson Corporation } \\
\text { (NJ) }\end{array}$ & $\$ 181.7$ & $\$ 397.3$ & 0.46 \\
\hline 15 & King County Metro (WA) & $\$ 168.4$ & $\$ 591.1$ & 0.28 \\
\hline 16 & $\begin{array}{l}\text { Metropolitan Atlanta Rapid Transit Authority } \\
\text { (GA) }\end{array}$ & $\$ 143.7$ & $\$ 459.3$ & 0.31 \\
\hline 17 & Maryland Transit Administration (MD) & $\$ 136.0$ & $\$ 651.8$ & 0.21 \\
\hline 18 & $\begin{array}{l}\text { Tri-County Metropolitan Transportation } \\
\text { District of Oregon (OR) }\end{array}$ & $\$ 122.7$ & $\$ 391.6$ & 0.31 \\
\hline 19 & Denver Regional Transportation District (CO) & $\$ 121.2$ & $\$ 471.3$ & 0.26 \\
\hline 20 & Miami-Dade Transit (FL) & $\$ 119.9$ & $\$ 517.9$ & 0.23 \\
\hline 21 & Port Authority of Allegheny County (PA) & $\$ 102.4$ & $\$ 377.2$ & 0.27 \\
\hline 22 & San Diego Metropolitan Transit System (CA) & $\$ 97.6$ & $\$ 240.7$ & 0.41 \\
\hline 23 & Metro Transit (MN) & $\$ 95.0$ & $\$ 376.9$ & 0.25 \\
\hline 24 & $\begin{array}{l}\text { Peninsula Corridor Joint Powers Board, dba } \\
\text { Caltrain (CA) }\end{array}$ & $\$ 83.4$ & $\$ 119.5$ & 0.70 \\
\hline 25 & $\begin{array}{l}\text { Southern California Regional Rail Authority, } \\
\text { dba Metrolink (CA) }\end{array}$ & $\$ 83.1$ & $\$ 207.6$ & 0.40 \\
\hline 26 & $\begin{array}{l}\text { Metropolitan Transit Authority of Harris } \\
\text { County, Texas (TX) }\end{array}$ & $\$ 75.0$ & $\$ 489.7$ & 0.15 \\
\hline
\end{tabular}


Table 2.11 Top 50 Transit Agencies in Terms of Farebox Recovery Rate in the National Transit Database (cont.). Note: Yellow cells indicate transit agencies that operate in California. (National Transit Database [NTD], 2015a; NTD, 2015b; NTD, 2016).

\begin{tabular}{|c|c|c|c|c|}
\hline \multicolumn{5}{|c|}{ Top 50 Transit Agencies in Terms of Farebox Recovery Rate in the National Transit Database (contd.) } \\
\hline Rank & Agency & $\begin{array}{l}\text { Fare Revenues } \\
\text { (millions \$US) }\end{array}$ & $\begin{array}{l}\text { Operating Expenses } \\
\text { (millions \$US) }\end{array}$ & Ratio \\
\hline 27 & $\begin{array}{l}\text { Regional Transportation Commission of } \\
\text { Southern Nevada (NV) }\end{array}$ & $\$ 74.0$ & $\$ 190.4$ & 0.39 \\
\hline 28 & Alameda-Contra Costa Transit District (CA) & $\$ 69.9$ & $\$ 358.7$ & 0.20 \\
\hline 29 & Dallas Area Rapid Transit (TX) & $\$ 69.6$ & $\$ 464.2$ & 0.15 \\
\hline 30 & Sound Transit (WA) & $\$ 65.4$ & $\$ 215.2$ & 0.30 \\
\hline 31 & $\begin{array}{l}\text { Orange County Transportation Authority } \\
\text { (CA) }\end{array}$ & $\$ 59.9$ & $\$ 273.8$ & 0.22 \\
\hline 32 & $\begin{array}{l}\text { City and County of Honolulu Department of } \\
\text { Transportation Services (HI) }\end{array}$ & $\$ 56.9$ & $\$ 232.3$ & 0.25 \\
\hline 33 & St. Louis Metro (MO) & $\$ 52.7$ & $\$ 250.8$ & 0.21 \\
\hline 34 & Utah Transit Authority (UT) & $\$ 52.1$ & $\$ 234.3$ & 0.22 \\
\hline 35 & Westchester County Bee-Line System (NY) & $\$ 49.4$ & $\$ 145.1$ & 0.34 \\
\hline 36 & $\begin{array}{l}\text { The Greater Cleveland Regional Transit } \\
\text { Authority }(\mathrm{OH})\end{array}$ & $\$ 47.6$ & $\$ 240.0$ & 0.20 \\
\hline 37 & Nassau Inter County Express (NY) & $\$ 46.3$ & $\$ 128.0$ & 0.36 \\
\hline 38 & $\begin{array}{l}\text { Santa Clara Valley Transportation Authority } \\
\text { (CA) }\end{array}$ & $\$ 42.4$ & $\$ 342.7$ & 0.12 \\
\hline 39 & Pace - Suburban Bus Division (IL) & $\$ 39.4$ & $\$ 200.7$ & 0.20 \\
\hline 40 & $\begin{array}{l}\text { Puerto Rico Highway and Transportation } \\
\text { Authority (PR) }\end{array}$ & $\$ 37.7$ & $\$ 38.6$ & 0.98 \\
\hline 41 & $\begin{array}{l}\text { Niagara Frontier Transportation Authority } \\
\text { (NY) }\end{array}$ & $\$ 37.4$ & $\$ 127.5$ & 0.29 \\
\hline 42 & Milwaukee County Transit System (WI) & $\$ 36.8$ & $\$ 142.2$ & 0.26 \\
\hline 43 & Broward County Transit Division (FL) & $\$ 35.0$ & $\$ 128.1$ & 0.27 \\
\hline 44 & $\begin{array}{l}\text { City of Phoenix Public Transit Department } \\
\text { (AZ) }\end{array}$ & $\$ 34.2$ & $\$ 163.5$ & 0.21 \\
\hline 45 & Sacramento Regional Transit District (CA) & $\$ 29.5$ & $\$ 135.4$ & 0.22 \\
\hline 46 & Charlotte Area Transit System (NC) & $\$ 29.0$ & $\$ 113.1$ & 0.26 \\
\hline 47 & $\begin{array}{l}\text { Central Florida Regional Transportation } \\
\text { Authority (FL) }\end{array}$ & $\$ 28.5$ & $\$ 113.1$ & 0.25 \\
\hline 48 & VIA Metropolitan Transit (TX) & $\$ 25.5$ & $\$ 198.8$ & 0.13 \\
\hline 49 & $\begin{array}{l}\text { Capital Metropolitan Transportation } \\
\text { Authority (TX) }\end{array}$ & $\$ 24.0$ & $\$ 194.6$ & 0.12 \\
\hline 50 & Ride-On Montgomery County Transit (MD) & $\$ 23.2$ & $\$ 112.2$ & 0.21 \\
\hline 51 & $\begin{array}{l}\text { City of Detroit Department of Transportation } \\
\text { (MI) }\end{array}$ & $\$ 19.7$ & $\$ 102.0$ & 0.19 \\
\hline 52 & Long Beach Transit (CA) & $\$ 17.3$ & $\$ 83.0$ & 0.21 \\
\hline
\end{tabular}

In conclusion, transit services began in many American cities during the $19^{\text {th }}$

Century, and were originally provided by private enterprises. Since ticket fares were

regulated, many transit companies were forced to expand their services to attract more

customers and generate additional revenue. This model proved to be financially 
unsustainable and led to the municipalization of transit services in many American cities. As ridership declined sharply after the post-World War II peak in the United States, Congress and the Federal Government gradually acted from the 1960s onward to prevent the further deterioration of transit services as a national priority. Yet, these policies were in contradiction with other national priorities, such as federal policies and funding to support suburban homeownership as well as freeway and airport expansion. Thus, while government support for transit has increased over the last few decades, it has not been met with proportional increases in ridership.

\subsection{Comparison between Japan and the United States}

This section compares the differences in the transit industries in Japan and the United States. The intent is to provide an understanding of the dynamics of the two industrial models, and to analyze why Japan's appears to be more conducive to enabling high passenger ridership as opposed to that of the United States.

Two key functions that the Japanese private railway groups engage in to maximize their long-term success are to plan and implement developments in an integrated fashion, and to do so along railway corridors.

On the first point about planning land developments in an integrated fashion, Cervero and Murakami (2008), and Tang, Chiang, Baldwin, and Yeung (2005) discuss transit-oriented developments in the context of institutional economics. In their study of Hong Kong's Mass Transit Railway Corporation (MTRC), Cervero and Murakami (2008) explain an institutional system that allows MTRC to capitalize on the rise of land values near its rail lines after construction (much like Japanese private railway groups do). Cervero and Murakami (2008) dubbed this system Rail + Property (R + P) 
Development. Tang et al. (2005) focus on the institutional benefits of integration by contrasting the $\mathrm{R}+\mathrm{P}$ model with a transit-oriented development model like that of the United States. In Figure 2.23, Model A represents the traditional model of rail and property developments, or transit-oriented developments, where the transit operator is relegated to just the role of transit operations. Model $\mathrm{B}$ depicts the $\mathrm{R}+\mathrm{P}$ model used in Japan and Hong Kong, in which the transit operator takes the lead in master planning the station area. In Model B, the transit operator works in tandem with local governments to change policies that maximize the success of the station area development. Whenever the development company is not owned by the transit operator, the transit operator also has developers accommodate its master plan during the design stage of the entire station area development. This is in contrast to Model A where developers begin designing their own separate developments near transit stations after the transit infrastructure has been built. Whereas Model A focuses on the coordination of the roles of planning, constructing, and operating a transit-oriented development between different entities, Model B allows for the integration of select roles to a single entity. An example of the components and roles of stakeholders in a typical MTRC development is shown in Figure 2.24, Table 2.12, Figure 2.25, Table 2.13. Note that Figure 2.24, Table 2.12, Figure 2.25, and Table 2.13 display just one example of the components and roles of stakeholders in a station area development. The roles of stakeholders may be different in separate station area developments. 


\section{MODEL A}

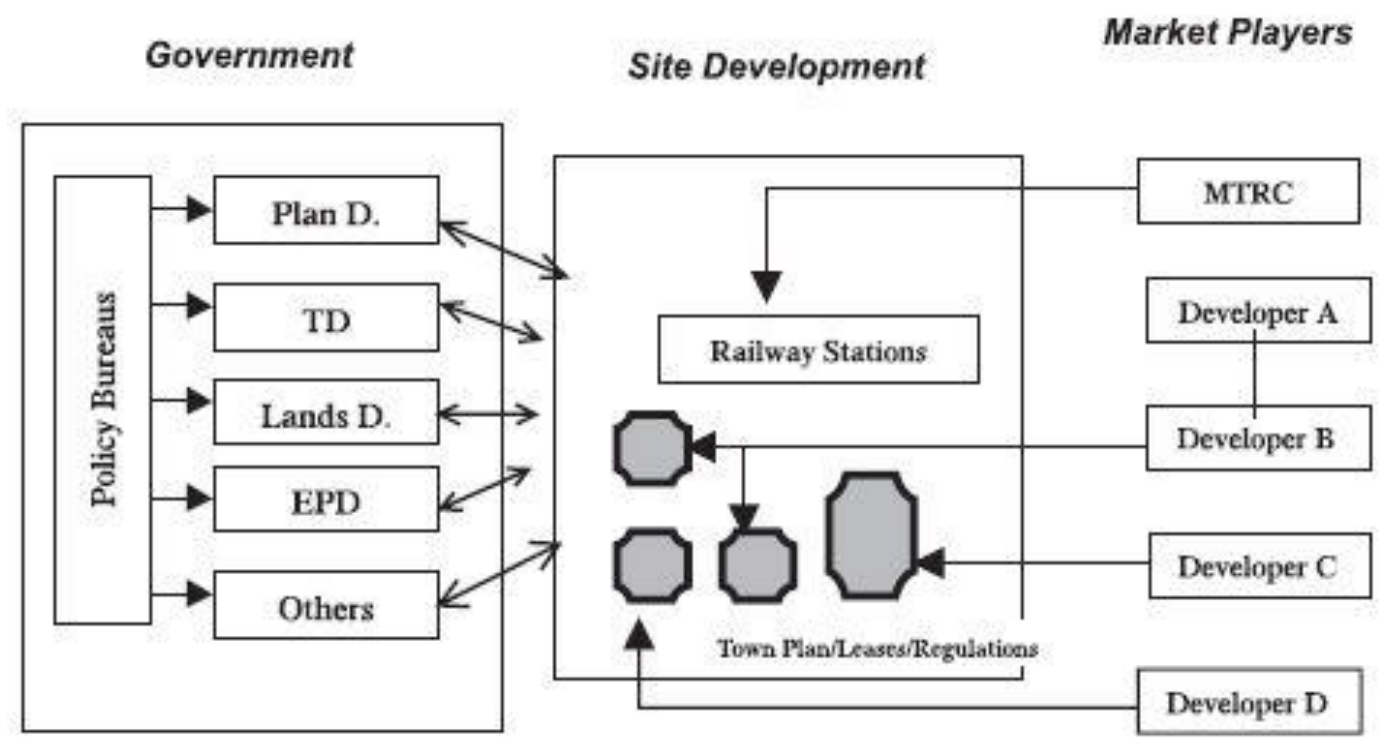

\section{MODEL B}

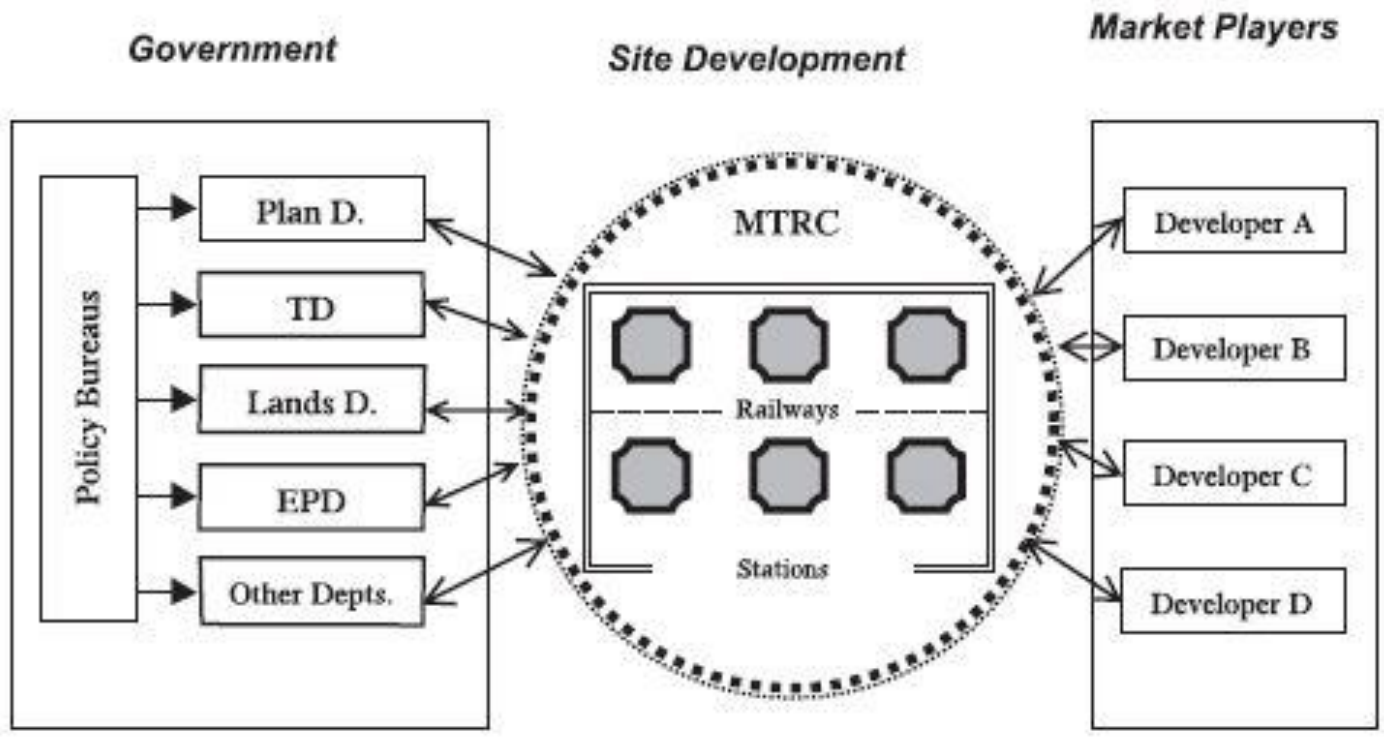

Figure 2.23 Two institutional models for rail and property developments. (Tang et al., 2005, p. 8). 


\section{Residential}

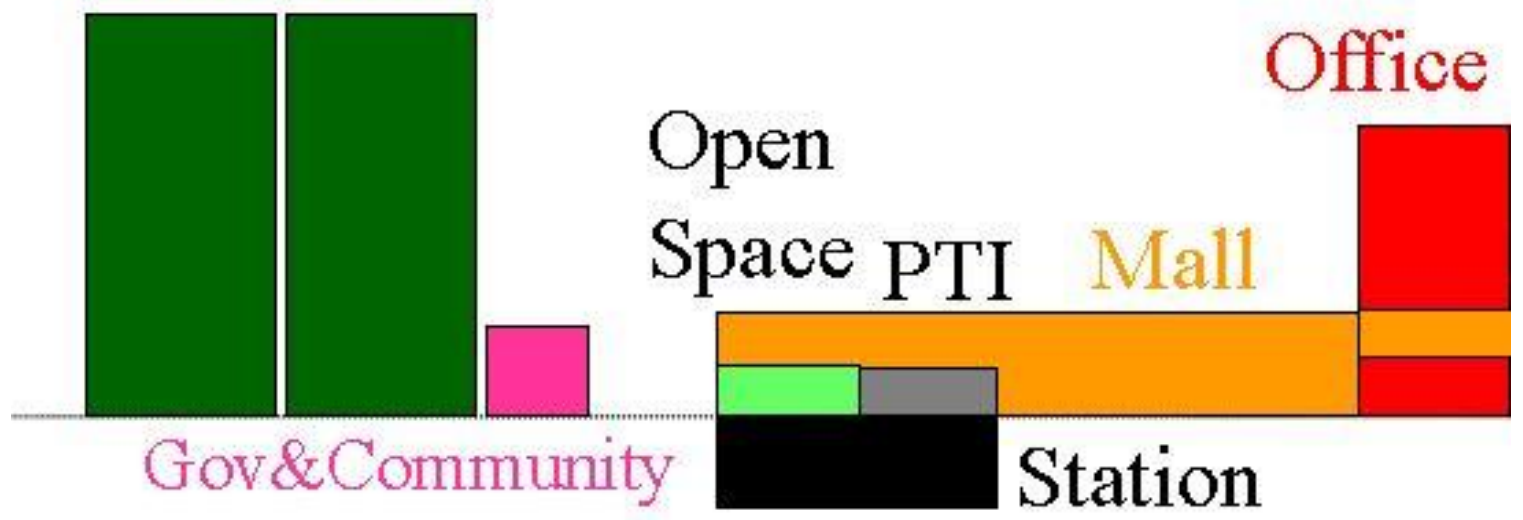

Figure 2.24 The components of a station area development with MTRC. (Cervero \& Murakami, 2008, p. 72).

Table 2.12 The partnership responsibilities in a station area development project. Modified from (Cervero \& Murakami, 2008, p. 72).

\begin{tabular}{|l|l|l|l|l|}
\hline \multicolumn{1}{|c|}{ Component } & \multicolumn{1}{|c|}{$\begin{array}{c}\text { Residential } \\
\text { Towers }\end{array}$} & \multicolumn{1}{|c|}{$\begin{array}{c}\text { Mall and Retail } \\
\text { Bridge }\end{array}$} & Office & Hotel \\
\hline 1) Construction & $\begin{array}{l}\text { Developer based on railway/development coordinated design; enabling works } \\
\text { provided by MTRC (multiple packages) }\end{array}$ & \\
\hline $\begin{array}{l}\text { 2) Mechanism } \\
\text { for sharing costs } \\
\text { and profit }\end{array}$ & $\begin{array}{l}\text { Developer paid land premium and development cost } \\
\text { Investment return split by upfront profit and end profit sharing }\end{array}$ \\
\hline $\begin{array}{l}\text { 3) Ownership of } \\
\text { asset }\end{array}$ & $\begin{array}{l}\text { Individual flat } \\
\text { owners }\end{array}$ & Developer & Hotel operator \\
\hline 4) Management & MTRC & Developer \\
\hline
\end{tabular}




\section{Residential}
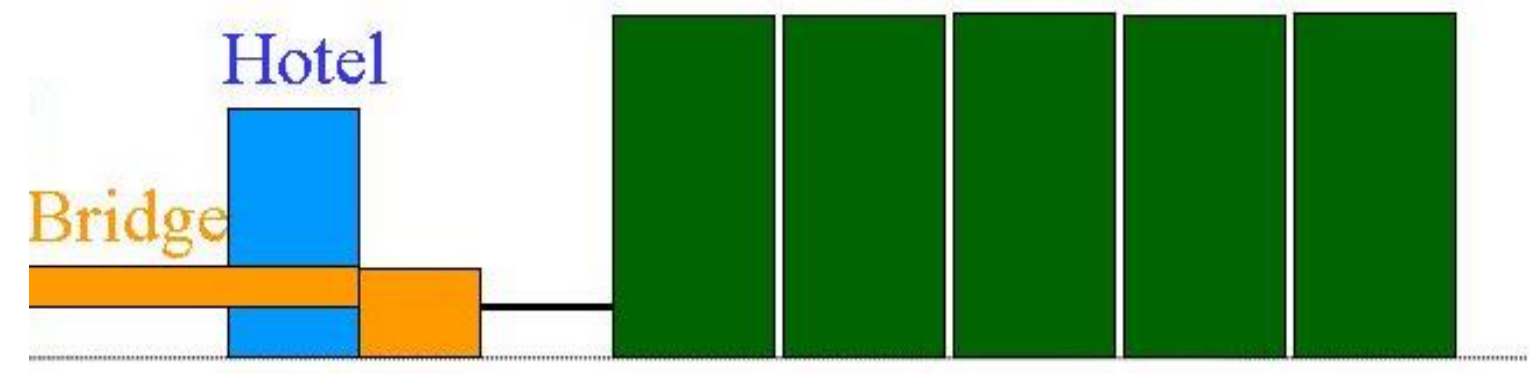

Figure 2.25 The components of a station area development with MTRC (cont.). (Cervero \& Murakami, 2008, p. 72).

Table 2.13 The partnership responsibilities in a station area development project (cont.). Modified from (Cervero \& Murakami, 2008, p. 72).

\begin{tabular}{|l|l|l|l|}
\hline \multicolumn{1}{|c|}{ Component } & \multicolumn{1}{|c|}{ Town Square } & $\begin{array}{c}\text { Tovernment and } \\
\text { Community (Post } \\
\text { Office and Day } \\
\text { Nursery) }\end{array}$ & $\begin{array}{c}\text { Public Transport } \\
\text { Interchange } \\
\text { (Train Station) }\end{array}$ \\
\hline $\begin{array}{l}\text { 1) Construction } \\
\text { 2) Mechanism for } \\
\text { sharing costs and } \\
\text { profit }\end{array}$ & $\begin{array}{l}\text { Developer based on railway/development coordinated design; enabling works } \\
\text { provided by MTRC (multiple packages) }\end{array}$ \\
\hline 3) Ownership of asset & $\begin{array}{l}\text { Part of the property design } \\
\text { and PTI }\end{array}$ & Conditions in land grant \\
\hline 4) Management & Developer & Government \\
\hline
\end{tabular}


The relationships shown in Figure 2.23, Figure 2.24, Table 2.12, Figure 2.25 and Table 2.13 allows the transit operator to reduce transaction costs of planning the different components of a transportation project and optimally designing the station area according to the characteristics of the transit system and intensity of surrounding property developments. Tang et al. (2005, p. 15) explain the idea of transaction costs further, noting that "conflicting objectives can be more effectively resolved when the decisions are put under a company hierarchy," turning a "zero-sum game" between two conflicting parties into a "trade-offs" decision within a single firm. For example, in a complex that includes a transit station and shopping mall, property planners would want to design pathways so that as many pedestrians pass by and are retained by as many retail shops as possible (Tang et al., 2005, p. 14). On the other hand, transportation planners would want to design pathways that provide for the smooth and quick flow of pedestrians as much as possible (Tang et al., 2005, p. 14). If the two types of planning are done by different organizations, the costs of planning property and transportation would be greater than if the two types of planning were done by the same organization (Tang et al., 2005, p. 14). In another example, Mizutani and Nakamura (2004, p. 308) discuss the reasons that Japan did not opt to vertically separate its railways during the privatization of Japan National Railways. Vertical separation of railways, a policy that the European Union promotes through EU Directive 91/440, generally refers to the separation of responsibilities of train operations and right-of-way maintenance to different entities and allows for the open access of train operations in order to entice competition (First Railway Directive, 2017). Instead, Japan opted to vertically integrate its railways (i.e., trains are operated and the right-of-way is maintained by the same entity). 
[A]s the case of British Rail indicates, the division of track from trains becomes problematic because an adversarial relationship has developed between the central track authorities and the train-operating companies. Problems associated with vertical separation include high transaction costs, a need for monitoring of the other's performance, the difficulty in creating complex performance schedules, and the stimulation of incentives for the track authority to invest in new facilities to increase efficiency and improve safety (Mizutani \& Nakamura, 2004, p. 308).

While vertical separation is intended to encourage railway operators to reduce their costs from competition with other operators, the high transaction costs of vertical separation may actually diminish some of the savings from competition. In general, "[t]he transaction costs in reaching a settlement within a firm are much lower than between separate companies," and $\mathrm{R}+\mathrm{P}$ manages to reduce the transaction costs between different entities involved in a transit and property development project (Tang et al., 2005, p. 37).

The integration of planning the different roles involved in transit-oriented developments also has implications for the design and urban orientation of station areas. Because the station and the surrounding land parcels fall under the ownership and management of the transit operator, the operator has an incentive to maintain and improve the spaces surrounding the station to keep their commercial value intact. This concept is further discussed by Arcady, quoted by Tillier (2009), in a socio-architectural analysis of European and American station design: 
There's a big difference in philosophy between European and American station design. In Europe, the trains are within the overall architectural space defined by the station, in the grandest examples a big steel and glass arch covering the tracks and platforms. In America, the station is separate and distinct from the tracks, which are off to the side in what is basically a train yard. In Europe, passengers wait on the platform, and it's not unusual to see, say, a coffee shop right on the platform. In America, probably because of the tradition of low platforms and train-yard style stations, trains and passengers are kept separate until it's actually time for boarding, at which point the passengers go out of the station and to the train, oftentimes walking directly across other tracks. Hence, in even the grandest of US stations (Grand Central for example), the track area is generally ugly and utilitarian.

Figure 2.26 illustrates the point above. Berlin's main railway station evokes a sense of incorporating trains and the supporting infrastructure within the commercial and social space of the entire station complex. 


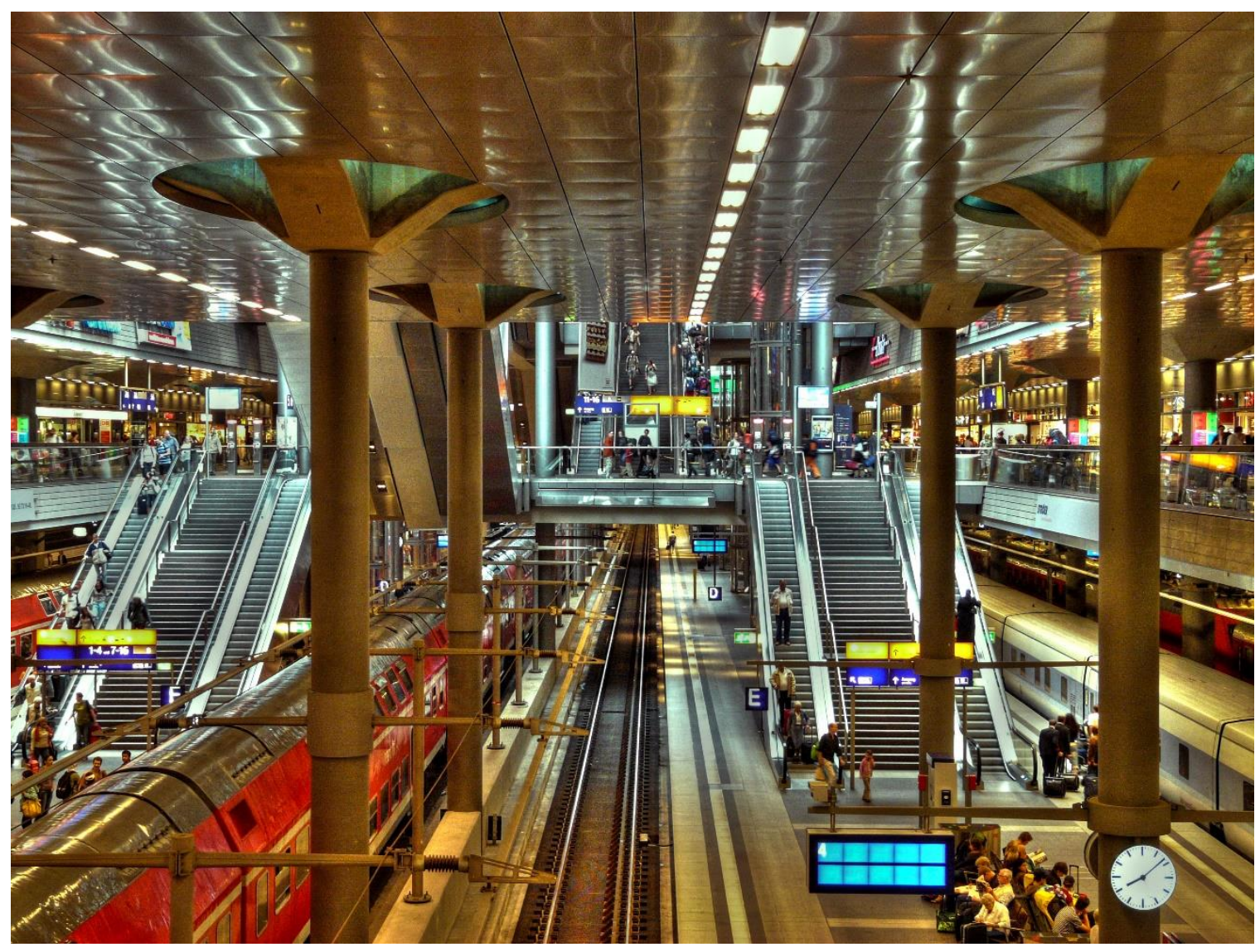

Figure 2.26 Berlin's main railway station. (Tillier, 2009).

Figure 2.27 and Figure 2.28, on the other hand, show examples in North America where there is a complete lack of effort to combine trains with the surrounding urban environment. Commercial and social spaces are compartmentalized from the surrounding parking areas and roadways. 

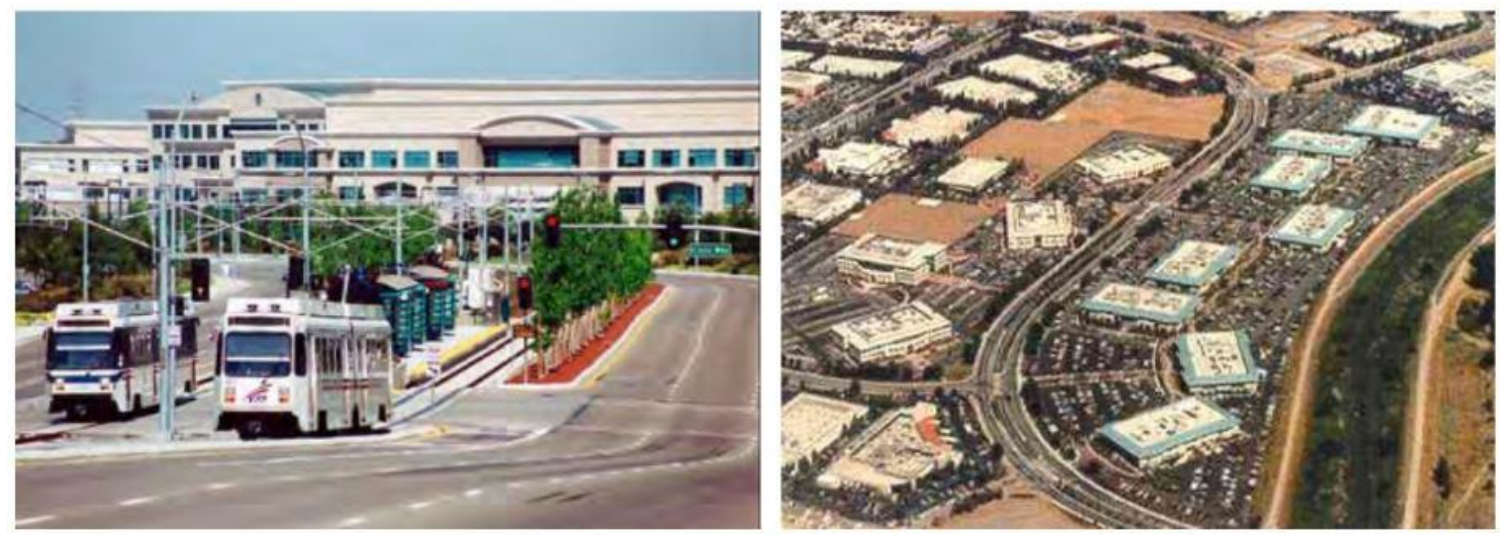

Figure 2.27 "Transit-Adjacent Development" around Valley Transit Authority light rail in San Jose, California. (Cervero \& Murakami, 2008, p. 27).

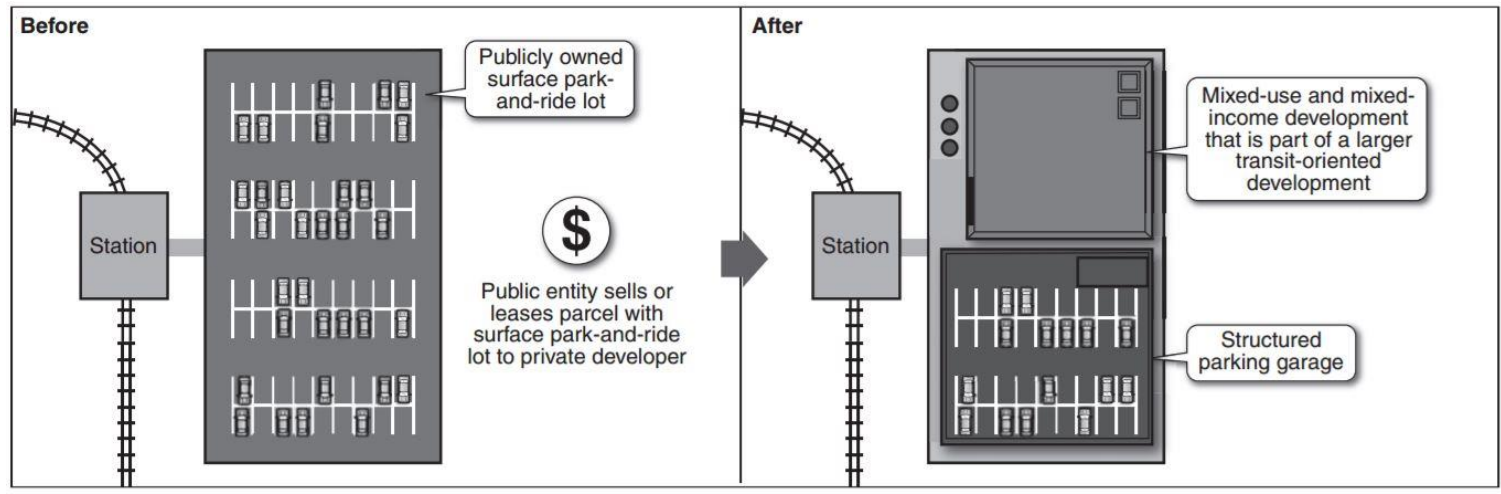

Figure 2.28 Example of a North American joint development project. (Government Accountability Office [GAO], 2010, p. 6).

Zacharias, Zhang, and Nakajima (2011, p. 245) note, however, that Japanese railway companies go beyond the European examples of station design to incorporate their commercial areas into the surrounding urban fabric.

The investment policies of the French, Dutch and German railway companies emphasize services related to travel and the improvement of the ambience of the station. The European railway station is increasingly an important place in the city, a destination in its own right and a magnet for related investment 
(Reusser et al, 2008). Commercial space nevertheless remains highly oriented to travel, whereas in Japan the station hosts a comprehensive set of services and products, equivalent to city core shopping districts. The highly integrated development of real estate with railway services in the Japanese cases is in part due to structural differences in the railway companies. The French, Dutch and German railway companies have distinct and relatively autonomous real estate divisions (Priemus and Konings, 2001). The European practice has been to hive off real estate no longer required for the core transport operations of the railway companies. The real estate developments on former railways ['] lands are urban districts in their own right, accessible to the railway station but primarily a component of the city fabric. Developments have been designed to revitalize station-adjacent areas that suffer from poor connections to the rest of the city and a negative image (Staudacher, 2001). In Japan, however, the railway lines are an integral component of the city fabric, as are the stations. As a consequence, the real estate operations are an increasingly important part of railway activity, within the stations, on lands owned by railway companies and in the immediately adjacent urban space. In this respect, the redevelopment of stations is equivalent to city center revitalization.

Figure 2.29 illustrates this concept by highlighting land plots owned by the Tokyu Group, one of Japan's largest private railway companies, in the Shibuya district in Tokyo. Shibuya Station is located at the terminus of Tokyu's lines and is a major subcenter within the Tokyo Metropolitan Area. 


\section{Status of Property Ownership Around Shibuya Station}

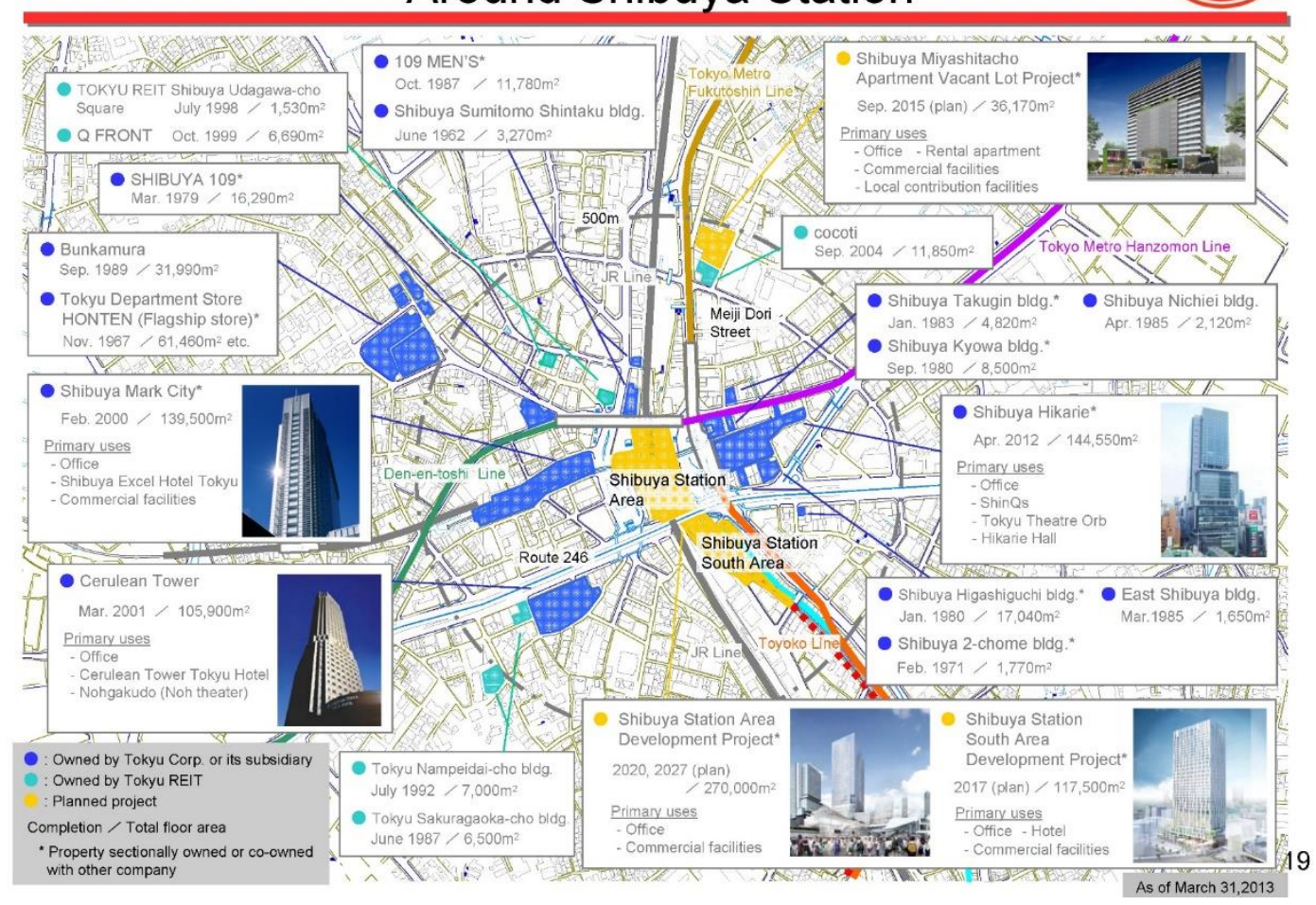

Figure 2.29 Status of property ownership around Shibuya Station. (Tokyu Group, 2013).

As for the second point, railway company groups are able to plan their developments along a railway corridor. A good example of this is the Tokyu Group's "PEAs" Strategy, as shown in Figure 2.30.

\section{"PEAs" Strategy}

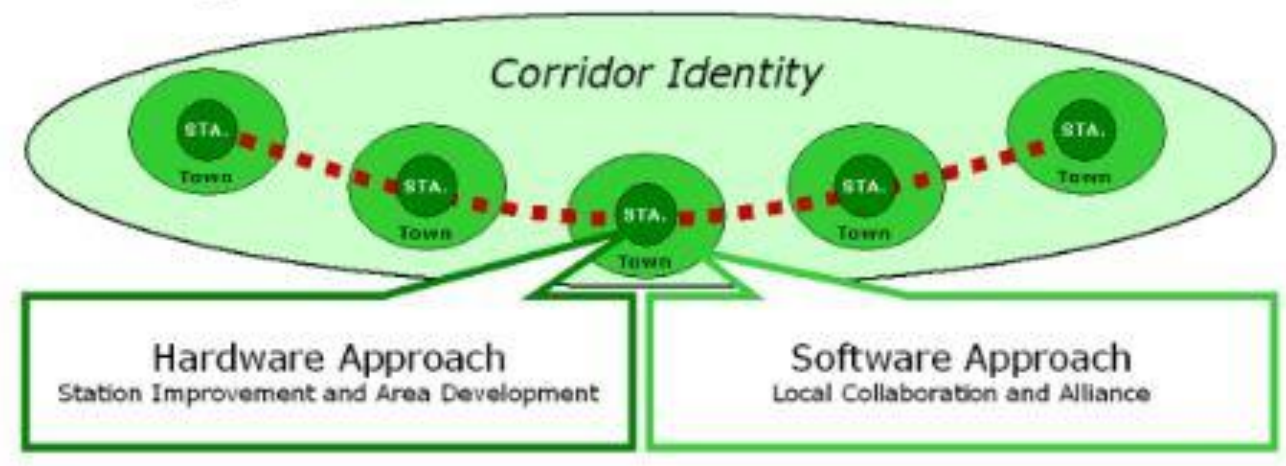

Figure 2.30 Tokyu Group's “PEAs” Strategy. (Cervero \& Murakami, 2008, p. 151). 
Under the "PEAs" Strategy, each station along a railway line is considered to be "pea," and the land area around the railway corridor is considered to be "bean" (Chorus, 2012, p. 151). For each railway corridor, the railway company analyzes the age structure, income, population growth, consumption, and expenditures of the residents and passengers to draw up an appropriate business strategy (Chorus, 2012, p. 151). In partnership with government policies, the Tokyu Group tries to decentralize development from one end of its line to throughout its line in order to generate traffic flows throughout the day and in the reverse direction of major commuter flows (Chorus, 2012, p. 151).

\section{Station + town + railroad network}

Station development is planned from the multidimensional perspective of town development

Especially in the Tokyo metropolitan area, station design strategy is planned to make maximum use of the each site's location as well as to endow each station with multiple functions

Stations are designed to add to the value of the connecting raill ine line and to the entirre rail system

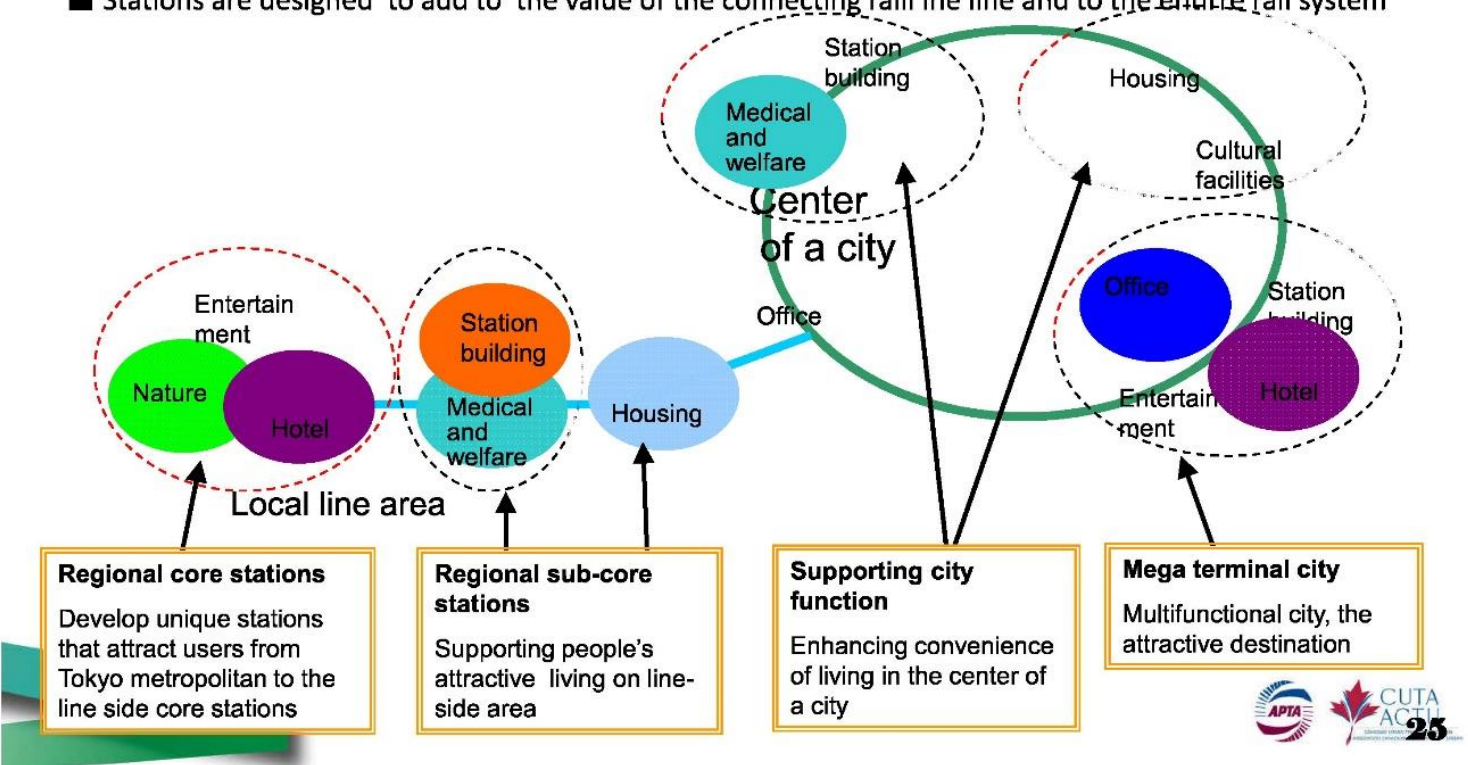

Figure 2.31 Corridor planning by the East Japan Railway Company. (Sayama, n.d., pdf-p. 25). 
Figure 2.31 shows an example of corridor planning by the East Japan Railway Company, or JR East. The plan shows that different combinations of land use activities are to be concentrated within the different station areas.

After a review of the literature on value capture, joint development and transitoriented developments in North America, it became evident that most of the literature does not discuss the integration of transit operations and property development to the extent of the $\mathrm{R}+\mathrm{P}$ process, but rather focused on coordination (Wolf \& Symington, 2009; GAO, 2010; FTA, 2014; Becker, Bernstein, \& Young, 2013; Central Puget Sound Regional Transit Authority [Sound Transit], 2014). The GAO stated that "[s]pecifically, transit agencies are responsible for building, maintaining, and operating transit, but need to coordinate with local and state governments that generally have authority over taxation, land use, and development" (2010, p. 23). Wolfe and Symington (2009) noted that one of the challenges to implementation of transit projects is the lack of common interests from various stakeholders. It was suggested that in large regions a consolidation of multiple agencies that have the authority to issue permits into one regional government might improve coordination between the sub-regions (Wolfe \& Symington, 2009, p. 33). Wolfe and Symington (2009, p. 33) also proposed that a "greater level of regional coordination or consolidation" of seven transit agencies in the four-county Seattle metropolitan region "could improve service, planning and reduce overhead costs." However, Wolfe and Symington (2009) did not mention combining the different types of roles (e.g., transportation, real-estate development, land ownership, real-estate management) into one entity. Most of the literature assumed that the transit agency is relegated to just the responsibilities of ownership and operation of transit facilities. Also, 
design of station areas was master planned not by the transit agency, but by local governments. Finally, property development and investment were left to private developers and property owners. As a note, coordination between agencies with different roles may not be as effective as integrating select roles into a single agency because of transaction costs, as discussed above. On a 2014 tour of Sound Transit's light rail extension projects in the Seattle, Washington, area (i.e. East Link and University Link), a representative of Sound Transit was asked if Sound Transit would engage in management and investment of property developed around the new transit stations. The representative responded that "We like to stick with doing the 'T' in TOD" and that it would not be in the interest of Sound Transit as a public agency to engage in property development or investment. Furthermore, the representative stated that property development and investment should be left to the private sector. From this answer, there seems to be a general reluctance of transit agencies in North America to admittedly engage in commercial activities and privatization. The source of this reluctance is not known. A review of an FTA circular on guiding joint development for transit agencies contained no restrictions of transit agencies engaging in commercial activities, minus using FTAawarded funds for specifically supporting commercial activities. In fact, the circular appeared to encourage private stakeholder involvement in joint development projects. The FTA circular states:

While the statute prohibits FTA from outfitting a commercial space, FTA funds may be used to construct the "shell" of a facility that will be occupied by a commercial entity, as long as the statutory eligibility criteria are met. To illustrate, 
FTA funds could be used to construct a facility that would be occupied by a coffee shop or news stand in exchange for rent payments. FTA could assist in the construction of the overall facility that includes the commercial space but could not pay for seating in the commercial areas, shelving, countertops, or other commercial equipment. (Note: as discussed above, occupants of a facility must pay a fair share of the costs of the facility through rental payments or other means) (2014, p. III-9).

Clearly, FTA does not discourage commercialization. Shoji (n.d., pp. 2-3), however, provides the following analysis:

A public transport system has two basic objectives that it is expected to achieve simultaneously - to serve the public interest and to be profitable [(or, at least to be cost effective given the public investment)]. However, the two objectives can sometimes be in conflict. In such cases, the policy must focus either on the public interest or on profitability. The choice significantly determines how the system evolves because any improvements will be based on the chosen principle. For example, the operator may choose to promote mobility and accessibility by striving to develop and maintain a system that is fair to society as a whole while respecting budgetary limitations. Or the operator may promote commercial objectives according to the self-supporting principle while making exceptions in special cases. 
As described above, the general worldwide trend has been for urban public transit systems to take the first approach. This has helped maintain public transit systems that offer relatively low fares and generate large networks. However, the public-interest approach has led to several problems such as inefficiencies in management and operations, and inefficiencies in services. Today, far-reaching reforms are being introduced worldwide to correct these problems. Such reforms have been made necessary by budgetary restrictions to control excess subsidies, worsening government finances, and a change in public opinion especially among taxpayers.

In regard to joint development and value capture in North America, experience has shown that the revenue generated by actual projects has not lived up to potential. The GAO (2010, p. 15) found that "[a]lthough several transit agencies have generated millions of dollars in annual revenue from joint development, this annual revenue is generally small when compared with an agency's annual operating expenses." In fact, revenue from joint developments for the three North American transit agencies with the most experience in joint developments_-Los Angeles Metro, Washington Metro, and Metropolitan Atlanta Rapid Transit_amounted to at most one percent of their operating expenses in 2008 (GAO, 2010, pp. 15-16). What could be the cause of this? One possible reason is that transit agencies are not allowed by law to own commercial pieces of property. Washington Metro officials noted that they do not have the authority to own land where condominiums are sold and would rather opt to selling the land in that scenario (GAO, 2010, p. 17). Another reason is that because of local resistance to 
increasing density, joint developments cannot be built to their full potential and, thus, generate less revenue. Finally, value capture was often discussed in the form of joint development, special assessment districts, tax increment financing, and development impact fees (GAO, 2010, pp. 5-8); with these methods, the added value of the land from accessibility to transit often goes to the local government, rather than the transit agency (GAO, 2010, p. 17). Any amount that the transit agency receives is only a portion of that originally generated, while the rest is used for other public infrastructure improvements (GAO, 2010, p. 17). These conditions limit transit's ability to benefit from value capture and reach its full potential in North America.

Calimente (2009, pp. 9-10) also states:

It is somewhat surprising that a city with a metro population of 35.7 million (UN, 2007) in which fewer than $30 \%$ of the people commute by automobile (Ministry of Land, Infrastructure, Transport, and Tourism, 1999) has received comparatively little attention for its station area developments. Research to date has been overwhelmingly focused on the United States, Canada, Australia, or the countries of Western Europe. Perhaps this is due to the perception that Japanese society is fundamentally different from that of other countries, so it is assumed that its successes cannot be replicated elsewhere. Or it may simply be [sic] the general tendency of researchers to look at countries they are more familiar with. In any case, much can be learned from the way that private railway companies in Japan have been able to maintain consistent profitability, something 
unheard of for most other transit operators, save a few agencies like the Hong Kong MTR subway.

Whatever the reason is for transit operators in the United States not engaging in business diversification and land development, there are huge opportunities to be taken advantage of as the case of Japanese railway company groups have shown. The benefits include higher revenues, higher ridership, and higher-density station areas with a diversity of land uses, among many others.

The California High-Speed Rail Authority has taken specific steps to move towards the institutional model used in Japan. In its 2016 Business Plan, the Authority (2016, p. 30) stated that it has entered into station area planning agreements with the cities of San Jose, Gilroy, Merced, Fresno, Bakersfield, Palmdale, and Burbank "to advance strategies that promote economic development, encourage station area development and enhance multi-modal connections between the cities and stations."

The Authority has also hired a Director of Planning and Integration and established a Transit-Land Use Committee to coordinate station area development policies and integrate service agreements with other rail providers (Authority, 2014b; Authority, 2017d).

The Authority (2016, p. 42) adopted a delivery model for high-speed rail that emphasizes "long-term, safe and commercially viable operations." An illustration of the model is shown in Figure 2.32. 


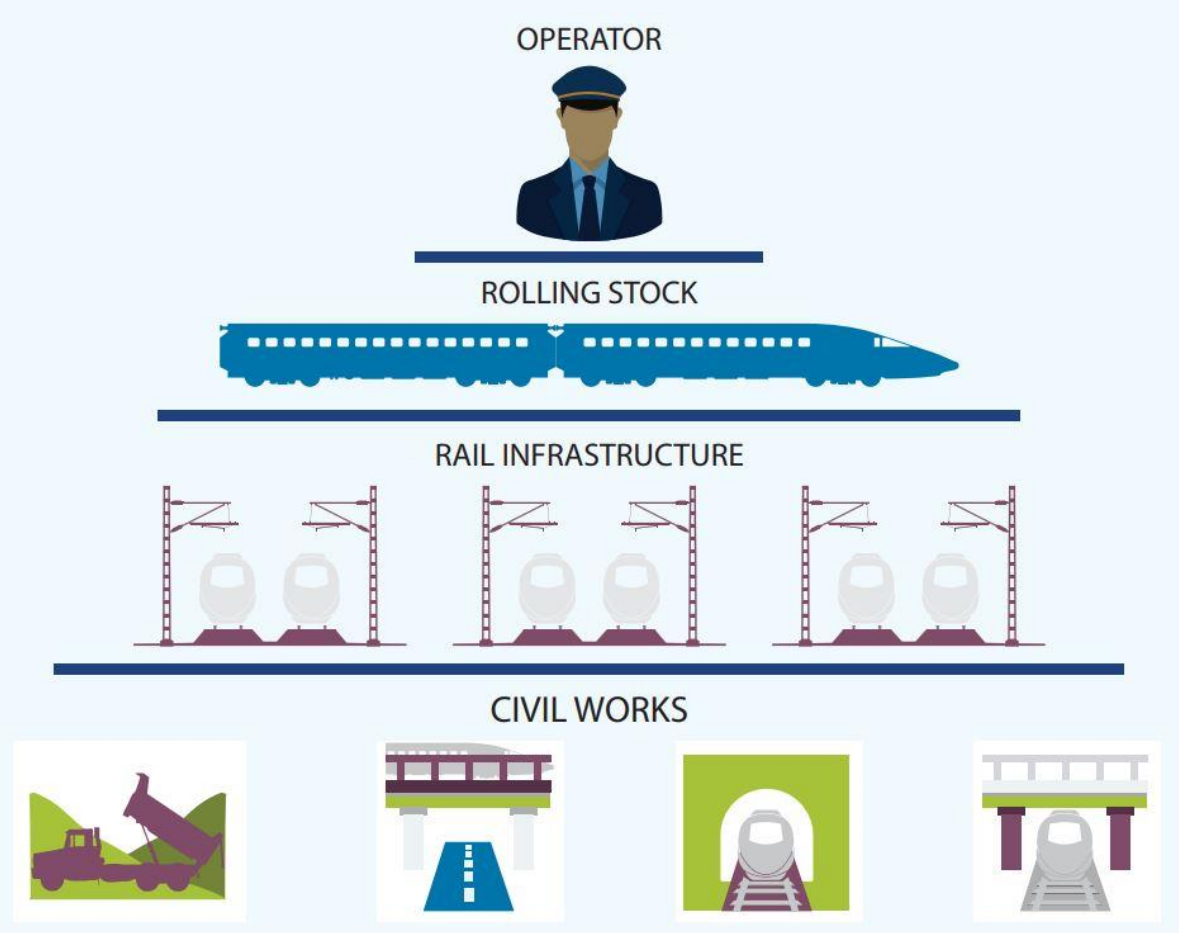

Figure 2.32 Delivery model of California High-Speed Rail. (Authority, 2018a, p. 26).

Within the delivery model, a train operator with demonstrated experience in highspeed rail operations is to partner with the Authority (2016, p. 42) to make key decisions regarding the choice and design of rolling stock and rail infrastructure. The train operator would provide advice during three phases of operations, which are listed below, to "increase asset performance and revenues while reducing costs:"

- Pre-Operations - Operational aspects of the system must be incorporated into the planning, design and construction of the system to ensure commercial viability. 
- Ramp-Up - California high-speed rail brand is built and users begin adopting a new mode of transportation. The phase is critical to the success of the system.

- Mature Operations - "Steady state" operations represent the core operations phase and generates the most revenue after travelers adapt to the system and view it as one of the State's transportation options (Authority, 2016, p. 42).

After a competitive procurement process that involved four international teams, the Authority (2018b, p. 30) selected and placed under contract German-based DB Engineering and Consulting USA as the Early Train Operator in December 2017.

At the time of this writing, the Early Train Operator has provided comment on the 2018 Draft Business Plan and has confirmed that the procurement strategy outlined in Figure 2.32 is consistent with the long-term objectives of the program (Authority, 2018b, p. 30).

The Early Train Operator is currently assisting the Authority (2018b, p. 30) with an analysis of the interim services that will operate between Madera and Bakersfield and between San Francisco and Gilroy, conducting an independent construction cost estimate review to further refine cost projections, is reviewing the Authority's travel demand forecasting model, is commenting on draft rail procurement documents, and providing input to service planning.

The Early Train Operator will later provide input on station design, fare policy and integration, marketing and system branding, and operations and maintenance costing (Authority, 2018b, p. 30). 
All in all, the California High-Speed Rail Authority is taking the appropriate steps to make the high-speed rail system a commercial enterprise and to develop its station areas to build up the potential for higher revenues and ridership. These efforts will serve the high-speed rail system well in the future. 


\section{Study Background}

\subsection{Problem}

As discussed in Section 2.4.3, transit service in the United States continues to suffer from low ridership and negative operating margins despite growing government support. When compared to highway and air modes, transit attracts only a tiny fraction of the passenger-miles that the other modes attract on an annual basis. These findings naturally lead to concern about the prospects of the California High-Speed Rail System, which would have accessibility characteristics similar to that of urban transit modes.

Additionally, it was found that while American transit companies historically encouraged land development near their lines, they did not directly engage in land development like those in Japan did. Land development and retail operations always seemed to be left to external players, leaving transit companies unable to enjoy the revenues and profits that could have been captured to support their transit services. This left transit companies financially weak and eventually subject to municipalization by local and state governments. This has left a legacy of transit services in the United States where the full potential of service is never reached due to budgetary constraints, and that funding for transit services is often made to compete with other public investments through the political process. The institutions of transit in the United States are essentially kept weak.

\subsection{Study Purpose}

The purpose of this study is to examine the current conditions of the areas around the proposed stations of the California High-Speed Rail System and to assess their potential in serving as significant nodes and places within their contextual transportation 
networks and urban fabrics, respectively. By conducting this examination, a better understanding of the potential functions of the different stations along the System can be developed.

This understanding may then be used along with the background information of the institutional frameworks of transit and passenger railways in Japan and the United States discussed in Section 2 to answer the following questions:

1. To what extent are the locations of the California High-Speed Rail System's planned stations currently attractive to development within their respective contexts?

2. Given the information gathered from the study, what policies should be taken to enhance the future development potential of the California High-Speed Rail System's planned stations as activity centers within their respective station areas? 


\section{Study Methodology}

This section explains the methodology used to collect and analyze data for the purposes of this study. The application of the gravity model to replicate the accessibility of station catchment areas is discussed in Section 4.1. Section 4.2 discusses how the size of station catchment areas were determined. The process used to define the locations of the actual high-speed rail stations themselves is elaborated on in Section 4.3. The methodology of collecting data and preparing the data for input into the gravity model is discussed in Sections 4.4, 4.5, 4.6, and 4.7.

\subsection{Defining the Accessibility of Station Catchment Areas}

In order to find out the current attractiveness to development of the planned station locations of the California High-Speed Rail System, a methodology similar to that of Fang's (2009) study of the accessibility of rail transit stations in the San Francisco Bay Area was employed. Fang's (2009, p. 62) study utilized a modified version of Isaac Newton's Law of Universal Gravitation to compute the relative accessibility of rail transit stations in the San Francisco Bay Area. Newton's Law of Universal Gravitation “states that the force of gravity between two bodies is proportional to their mass and inversely proportional to their distance. The greater the gravitational force between the masses, the grater the attraction that exists between them" (Fang, 2009, p. 62). The law is shown in formulaic form below in Figure 4.1:

$F_{g}=G \frac{m_{1} m_{2}}{r}$

Figure 4.1 Newton's Law of Universal Gravitation. (Sir Isaac Newton The Universal Law of Gravitation, n.d.). 
Where:

$$
\begin{aligned}
& F_{\mathrm{g}}=\text { Gravitational force } \\
& \mathrm{G}=\text { Universal gravitational constant } \\
& \mathrm{m}_{1}=\text { Mass of object } 1 \\
& \mathrm{~m}_{2}=\text { Mass of object } 2 \\
& \mathrm{r}=\text { Separation or distance between the two objects }
\end{aligned}
$$

In the field of transportation, Newton's Law of Universal Gravitation is modified to generate the number of trips between defined origins and destinations. "The attraction between two locations is proportional to the size of the locations and inversely proportional to" the distance between them (Fang, 2009, p. 62). "The greater the attraction between the two places, the more trips there are between them, and thus the more accessible the two places can be considered to each other" (Fang, 2009, p. 62). The gravity model used in the transportation field is shown in Figure 4.2:

$$
T_{i j}=P_{i} \frac{A_{j} F_{i j}}{\sum_{k} A_{k} F_{i k}}
$$

Figure 4.2 Gravity model used in the transportation field.

Where:

$$
\begin{aligned}
& T_{i j}=\text { Number of trips from origin } i \text { to destination } j \\
& P_{i}=\text { Number of trips produced from origin } i \\
& A_{j}=\text { Number of trips attracted to destination } j \\
& F_{i j}=\text { Friction factor between origin } i \text { and destination } j
\end{aligned}
$$




$$
\begin{aligned}
& \sum_{k} A_{k} F_{i k}=\text { Summation of the product of the number of trips attracted to } \\
& \text { destination } k \text { and the friction factor of destination } k \text { to each origin } i
\end{aligned}
$$

Like Fang (2009, p. 62), this study utilizes the general relationship of accessibility of a station area to the size of its attractions and the distance between itself and other station areas, as presented below in Figure 4.3:

Accessibility $=\frac{\text { Size of Attraction }}{\text { Distance }}$

Figure 4.3 Accessibility of station areas in relation to the size of its attractions and its distance to relevant points.

\subsection{Determining the Size of Station Catchment Areas}

For the size of attractions at each station area, the population, the number of jobs, and the number of housing units located within each station area were utilized. Several sources were reviewed to determine the size of each station area for study. Considering the general acceptance of the half-mile radius catchment area for transit-oriented developments in the United States, Guerra, Cervero, and Tischler (2011, p. 1) tested the predictive power of a ridership model against one-quarter mile and half-mile radius catchment areas. Guerra, Cervero, and Tischler (2011, p. 11) found that for the purposes of predicting ridership, "little [was] gained from using a particular station catchment area or type over another. The marginal gains from using a quarter-mile or half-mile circle [were] quite small." There was some evidence that the quarter-mile radius catchment area should be used for jobs while the half-mile radius catchment area should be used for population (Guerra, Cervero, \& Tischler, 2011, p. 11). Nuworsoo, Cooper, Cushing, and Jud (2012, pdf-p. 1) studied the characteristics of programs and infrastructure meant to 
promote the use of walking and bicycling to find out what features were most preferred by users. Nuworsoo et al. (2012, pdf-p. 2) found that for the trip purpose of "work," users were willing to walk and cycle up to 13 minutes and 19 minutes, respectively. Combining these figures with the recommended pedestrian speed of 4.0 feet per second from the Manual on Uniform Traffic Control Devices for Streets and Highways (MUTCD) and the Highway Capacity Manual's Level of Service "B" and Level of Service "C" average bicycle travel speeds of 15 kilometers per hour and 11 kilometers per hour, the travel distances of 0.6 miles for walking, and 3.0 miles and 2.2 miles for bicycles were yielded, respectively (FHWA, 1998; FHWA, 2006). The calculations are shown below:

\author{
Walking Distance $=(13 \text { mintes } / 60 \text { mantes } / 1 \text { m })^{*}(4.0$ t $/ 1$ s00 \\ seconds $/ 1$ hour $/ 5280$ feet $/ 1$ mile $)=0.59$ miles $\approx 0.6 \rightarrow 0.5$ miles \\ Cycling Distance ${ }_{\text {LOS }}$ "C" $=(19$ minutes $/ 60$ minutes $/ 1$ hour $) *(11$ \\ kilometers/hour $/ 1.60934$ kilometers $/ 1$ mile $)=2.16$ miles $\approx 2.2$ miles $\rightarrow$ \\ 2.0 miles \\ Cycling Distance ${ }_{L O S}$ “B” $=(19 \text { minutes } / 60 \text { minutes } / 1 \text { hour })^{*}(15$ \\ kilometers/houf $/ 1.60934$ kilometers $/ 1$ mile $)=2.95$ miles $\approx 3.0$ miles
}

Finally, in their study of the spatially redistributive economic effects of highspeed rail, Cervero and Murakami (2010, p. 6) used a radius of five kilometers, or 3.1 miles, for catchment areas around stations along Japan's Shinkansen and California's planned high-speed rail system. Cervero and Murakami (2010, p. 6) justify this catchment area radius by noting that high-speed rail's economic and social effects will be 
larger compared to those of a local transit system because of its greater size and statewide significance. Additionally, since the exact locations of the California High-Speed Rail System's stations are still subject to environmental review and have not been finalized, a larger catchment area creates a sort of umbrella area where the station may be in even after its future location is shifted from its currently proposed location (Cervero \& Murakami, 2010, p. 6). This study also utilized a five-mile radius catchment area to accommodate for attractions that are beyond the reach of pedestrians and cyclists but are within reach of motorized modes. The catchment area radii for station areas used in this study are listed as follows:

- Quarter Mile

- Half Mile

- One Mile

- Two Miles

- Three Miles

- Five Miles

While the results of the analyses for all the catchment sizes are available in the Appendix of this study, the half-mile, three-mile, and five-mile results are discussed within the body of this study. The half-mile radius catchment area is presented because it has become the industry standard for measuring the predictive ridership of transitoriented developments in the United States (Guerra, Cervero, \& Tischler, 2011, p. 1). The three-mile radius catchment area is shown because the distance captures the extent that 
pedestrians and cyclists are willing to travel to and from a transit node (Nuworsoo et al., 2012, pdf-p. 2; FHWA 2012, pdf-p. 2; FHWA, 1998; FHWA, 2006). Finally, the fivemile radius catchment area is discussed because the distance captures trips that are beyond the reach of non-motorized modes of transportation but are within the reach of motorized modes of transportation, such as automobiles and other forms of transit.

\subsection{Defining the Station Locations with Google My Maps}

Data for the population, the number of jobs, and the number of housing units located within each station area were collected using a few tools. The locations of each station were determined by placing points at the most up-to-date locations of stations along the California High-Speed Rail System using Google My Maps. Maps of proposed station locations available from the California High-Speed Rail Authority's (2017c) website were referred to when determining the general locations of stations. Additionally, in cases where multiple station locations were being considered for a particular station area (e.g., Gilroy, Bakersfield, and Burbank), local news articles were referred to in order to identify which station location would be the politically preferred alternative (Barousse, 2012; Hernandez-Cattani, 2017; Douglas, 2016; Carpio, 2017). The station locations studied were limited to those along the segments of the high-speed rail line that encompass Phase 1 of the Project. These include the following from north to south:

1. (San Francisco Transbay) Salesforce Transit Center

2. Millbrae Intermodal Station

3. San Jose Diridon Station

4. (Downtown) Gilroy 
5. Merced

6. Madera

7. Fresno

8. Kings Tulare Regional Station

9. (F Street) Bakersfield

10. Palmdale Transportation Center

11. (Platform Option A) Burbank

12. Los Angeles Union Station

13. Anaheim Regional Transportation Intermodal Center

The station location points in Google My Maps are shown in Map 4.1.

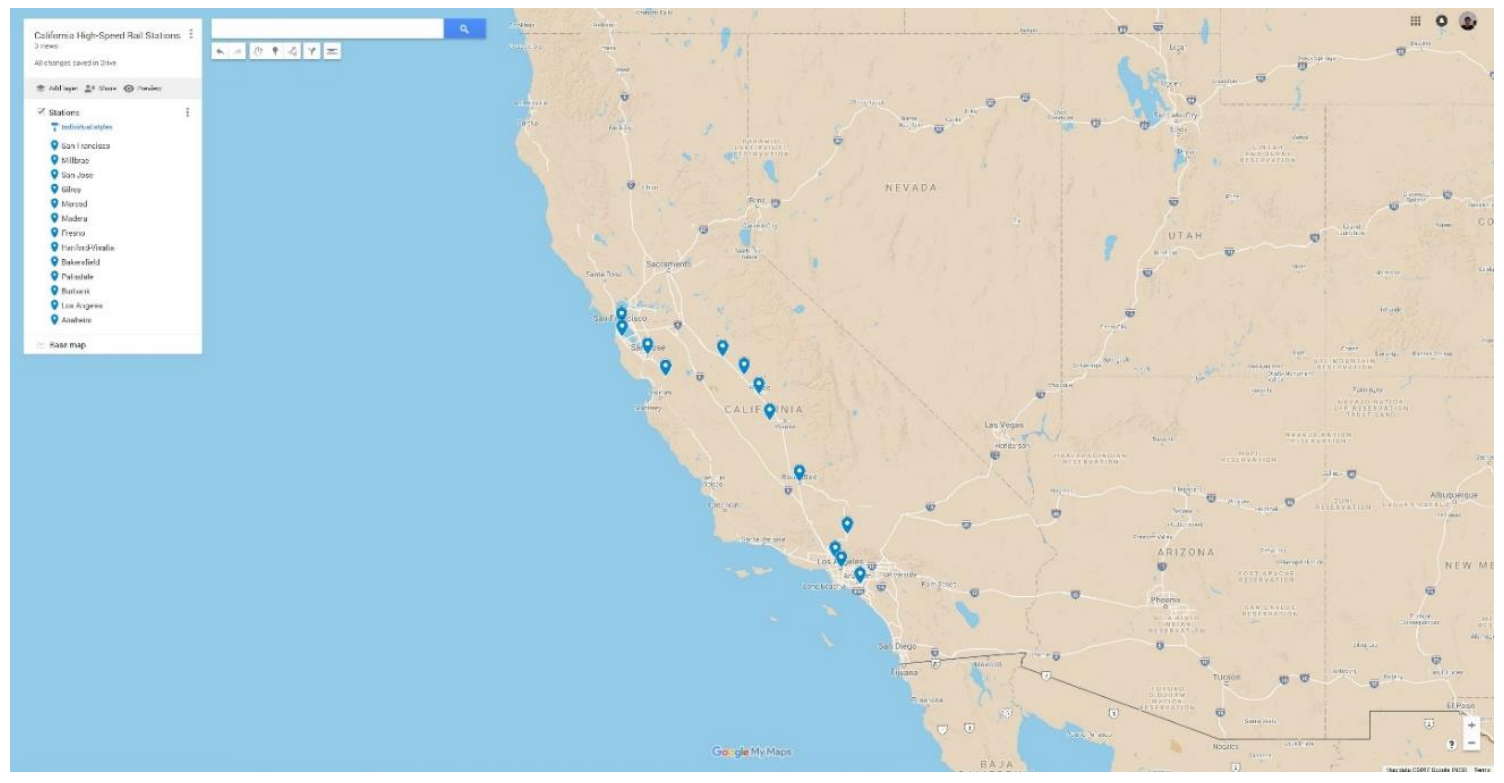

Map 4.1 Station locations of the California High-Speed Rail System. Created using Google My Maps (2017).

After the station locations were inputted into Google My Maps, the data were saved and exported as a Keyhole Markup Language $(\mathrm{kml})$ formatted file. Using the $\mathrm{kml}$ file with the station location data created with Google My Maps, the data were 
subsequently converted to a shapefile using the ArcMap GIS tool "KML to Layer," which is available by navigating the following path: ArcToolbox $>>$ Conversion Tools >> From KML >> KML to Layer. The station location shapefile was imported and overlaid atop a layer of the territory of the United States of America, as shown in Map 4.2 to provide geographic context. Map 4.2 also shows the status of the station facilities that will be used as part of the California High-Speed Rail System. 


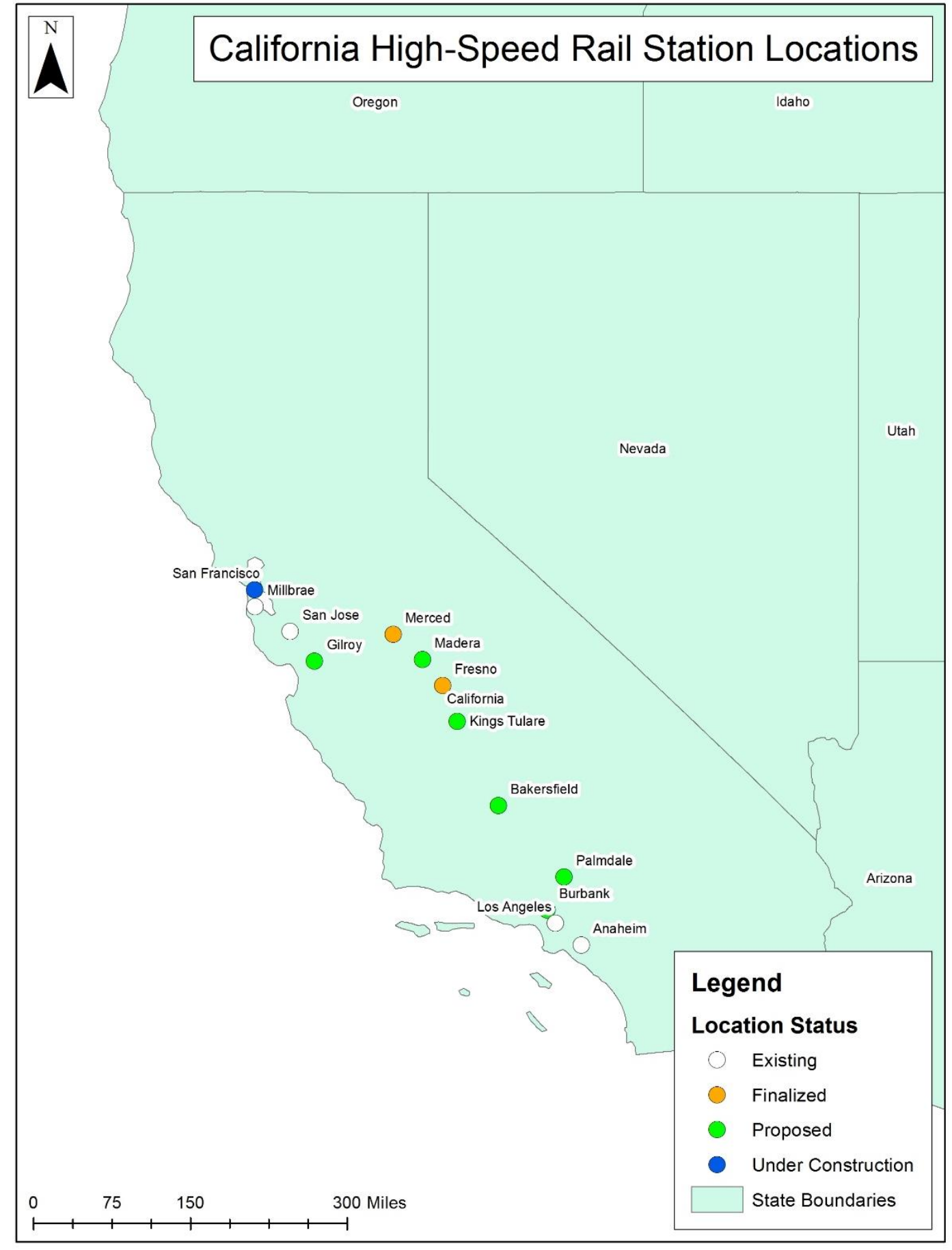

Map 4.2 Status of the stations of California High-Speed Rail. Existing: Future high-speed rail service will utilize existing facilities. Finalized: Future station locations have been determined under the environmental review process. Proposed: Future station locations have been identified, but not yet finalized under the environmental review process. Under Construction: Future high-speed rail service will utilize facilities that are under construction at the time of this writing. 


\subsection{Retrieving Jobs Data with OnTheMap}

The next step involved retrieving the number of jobs within the catchment areas of each station area using OnTheMap, which is an online application available from the United States Census Longitudinal Employer-Household Dynamics (LEHD) program. The default screen of OnTheMap is shown in Appendix Figure A.1. The "Import from KML" link was used to browse to the kml file with the station locations that was saved from Google My Maps. The relevant file was selected and imported onto the OnTheMap display. A picture of the OnTheMap display zoomed in to the imported shapes is displayed in Appendix Figure A.2. To illustrate the process of retrieving data from a single station, the point located at the future San Francisco Transbay Transit Center was selected (by clicking on the point). The "Continue with Selected Features" link was clicked on to proceed to the data retrieval toolbar. The "Simple/Ring" buffer with a definable radius was selected to create the station catchment area. Appendix Figure A.3 shows a radius input of three miles. The "Confirm Selection" button was selected afterwards to generate the radius, as shown in Appendix Figure A.4. The "Perform Analysis on Selection Area" link was selected to prompt the analysis settings, as shown in Appendix Figure A.5. The following settings were used for the analysis of each station catchment area in this study:

- Home/Work Area: "Work"

- Analysis Type: "Area Profile - Labor Market Segment - All Workers"

- Year: "2014"

- Job Type: “All Jobs" 
Note that 2014 was the latest year that jobs data could be retrieved. With the analysis performed, the selection area graphically showed the number of jobs within a three-mile buffer of the station location, as presented in Appendix Figure A.6. The "Detailed Report" link was clicked on to show the retrieved data, including the number of jobs within the station catchment area. This is shown in Appendix Figure A.7. The data were exported to xls format for import into Microsoft Excel. The same process was used to collect jobs data of various station catchment area radii at each station location. Table 4.1 summarizes the raw job figures collected for each station and each station catchment area radius. Figure 4.4 illustrates the data.

In order to provide additional insight of the station catchment areas, the normalized values of jobs were calculated from the raw values, as shown in Table 4.2, Table 4.3, and Figure 4.5. This step was performed to account for differences in the units or geographic attributes of each station catchment area. For example, the geography, transportation network, and zoning regulations in San Francisco would result in an urban form with raw job figures that are different and not directly comparable to those of Madera. Normalization of population and housing unit figures was also performed. As Figure 4.4 shows, the stations within the major metropolitan areas of California dominate in terms of number of jobs near stations. San Francisco and Los Angeles have the greatest number of jobs out of all the other stations along the alignment. It should be noted, however, that at the smaller station catchment area radii, Los Angeles's job numbers are not as great as that of San Francisco's. This suggests that Los Angeles's density of jobs near Los Angeles Union Station is not as high as that of San Francisco's Transbay Salesforce Transit Center. The next tier of job centers along the 
alignment consists of Millbrae, San Jose, Fresno, Bakersfield, Burbank, and Anaheim. Like Los Angeles, the next tier of job centers does not have dramatic job concentrations when the station catchment areas are limited to walking or cycling distances (i.e., up to three miles). Beyond three miles, these stations have relatively significant job concentrations, suggesting that the use of motorized modes may play an important part in accessing these stations. The rest of the stations, including Gilroy, Merced, Madera, Kings Tulare, and Palmdale have very little job concentration around their station areas across the spectrum of catchment area radii.

When looking at the normalized job values in Figure 4.5, a similar pattern appears. San Francisco and Los Angeles overall dominate as job centers among the stations along the alignment. San Francisco has a strong job concentration across all station catchment area radii, while the other stations do not. This time, San Jose, Burbank, and Anaheim are the only stations that make up the next tier of stations with relatively significant job concentrations, and even then, only at the three-mile radius and five-mile radius. The rest of the stations have negative normalized values for all station catchment area radii. 
Table 4.1 Raw job numbers by station catchment area radius, 2014. Courtesy of the United States Census Bureau $(2017 c)$.

\begin{tabular}{|l|r|r|r|r|r|r|}
\hline \multicolumn{7}{|c|}{ Job near Stations, 2014 } \\
\hline & $\begin{array}{c}\text { Quarter-Mile } \\
\text { Buffer }\end{array}$ & \multicolumn{1}{c|}{$\begin{array}{c}\text { Half-Mile } \\
\text { Buffer }\end{array}$} & \multicolumn{1}{c|}{$\begin{array}{l}\text { 1-Mile } \\
\text { Buffer }\end{array}$} & \multicolumn{1}{c|}{$\begin{array}{l}\text { 2-Mile } \\
\text { Buffer }\end{array}$} & \multicolumn{1}{c|}{$\begin{array}{l}\text { 3-Mile } \\
\text { Buffer }\end{array}$} & \multicolumn{1}{c|}{$\begin{array}{c}\text { 5-Mile } \\
\text { Buffer }\end{array}$} \\
\hline $\begin{array}{l}\text { San } \\
\text { Francisco }\end{array}$ & 63,994 & 217,489 & 332,612 & 479,236 & 542,128 & 628,673 \\
\hline Millbrae & 878 & 3,991 & 21,020 & 40,611 & 64,989 & 126,872 \\
\hline San Jose & 2,448 & 8,772 & 34,881 & 86,998 & 169,321 & 353,319 \\
\hline Gilroy & 386 & 1,554 & 6,623 & 15,053 & 17,956 & 19,813 \\
\hline Merced & 456 & 3,121 & 9,823 & 20,839 & 26,122 & 29,603 \\
\hline Madera & 2 & 125 & 323 & 807 & 2,620 & 13,100 \\
\hline Fresno & 2,697 & 6,121 & 34,818 & 48,061 & 70,641 & 106,550 \\
\hline Kings & 0 & 428 & 511 & 1,771 & 5,682 & 18,645 \\
Tulare & 487 & 2,143 & 12,248 & 46,308 & 68,879 & 124,931 \\
\hline Bakersfield & 169 & 695 & 4,262 & 11,235 & 20,594 & 29,666 \\
\hline Palmdale & 479 & 5,380 & 64,954 & 107,473 & 167,304 & 330,895 \\
\hline Burbank & 2,965 & 34,550 & 169,362 & 365,658 & 457,178 & 692,836 \\
\hline $\begin{array}{l}\text { Los } \\
\text { Angeles }\end{array}$ & 1,154 & 7,715 & 35,733 & 113,588 & 191,352 & 387,069 \\
\hline Anaheim & & &
\end{tabular}

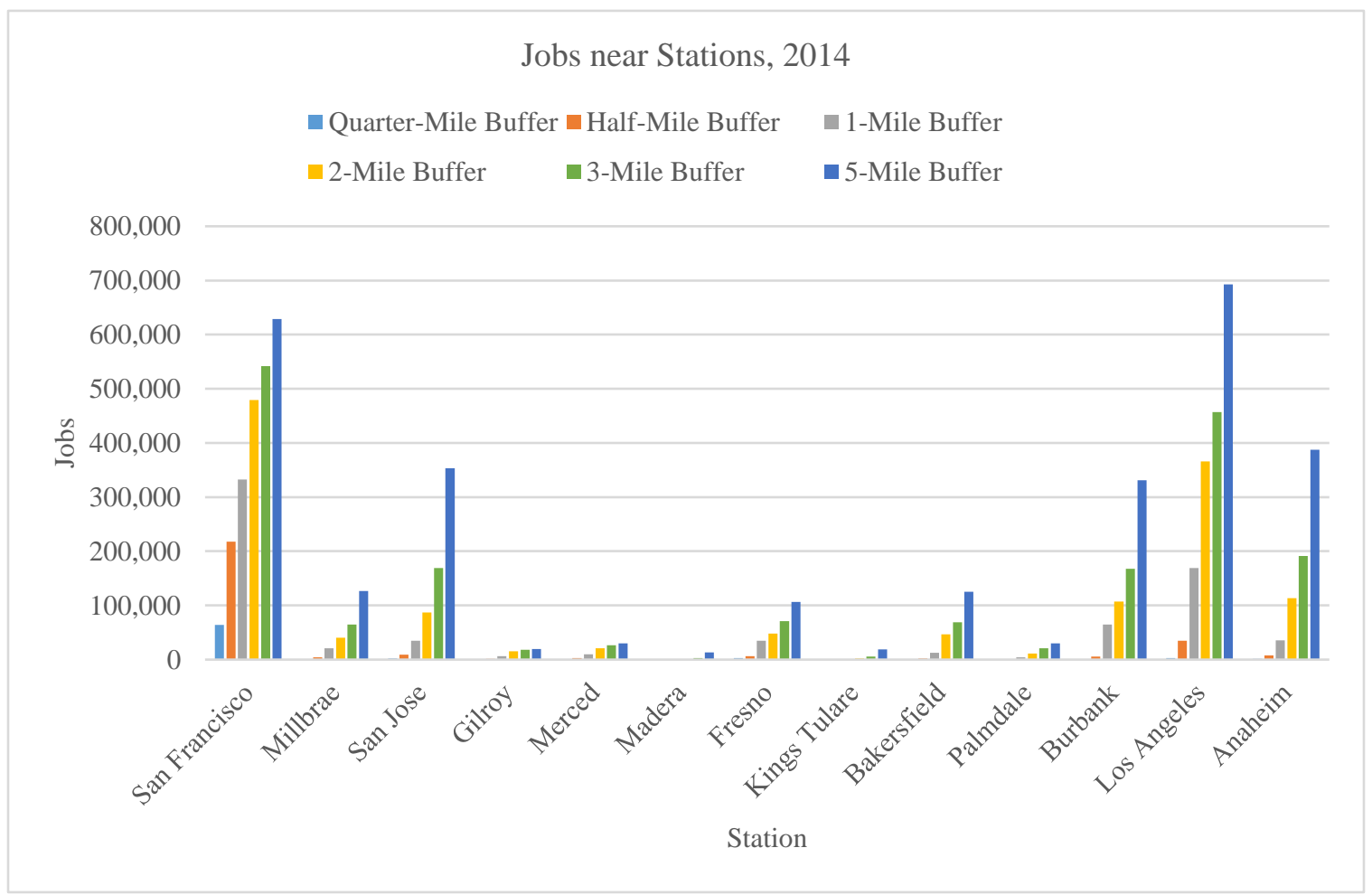

Figure 4.4 Column chart of raw job numbers by station catchment area radius, 2014. Courtesy of the United States Census Bureau (2017c). 
Table 4.2 Descriptive statistics of jobs by station catchment area radius, 2014. Courtesy of the United States Census Bureau (2017c).

\begin{tabular}{|l|c|c|c|c|c|c|}
\hline \multicolumn{7}{|c|}{ Descriptive Statistics of Jobs near Stations, 2014 } \\
\hline & $\begin{array}{c}\text { Quarter-Mile } \\
\text { Buffer }\end{array}$ & $\begin{array}{c}\text { Half-Mile } \\
\text { Buffer }\end{array}$ & $\begin{array}{c}\text { 1-Mile } \\
\text { Buffer }\end{array}$ & $\begin{array}{c}\text { 2-Mile } \\
\text { Buffer }\end{array}$ & $\begin{array}{c}\text { 3-Mile } \\
\text { Buffer }\end{array}$ & $\begin{array}{c}\text { 5-Mile } \\
\text { Buffer }\end{array}$ \\
\hline Average & 5,855 & 22,468 & 55,936 & 102,895 & 138,828 & 220,152 \\
\hline $\begin{array}{l}\text { Standard } \\
\text { Deviation }\end{array}$ & 16,813 & 56,954 & 90,857 & 142,681 & 166,656 & 227,876 \\
\hline
\end{tabular}

Table 4.3 Normalized job numbers by station catchment area radius, 2014. Courtesy of the United States Census Bureau (2017c).

\begin{tabular}{|l|r|r|r|r|r|r|}
\hline \multicolumn{7}{|c|}{ Normalized Values of Jobs near Stations, 2014 } \\
\hline & $\begin{array}{c}\text { Quarter-Mile } \\
\text { Buffer }\end{array}$ & $\begin{array}{c}\text { Half-Mile } \\
\text { Buffer }\end{array}$ & \multicolumn{1}{c|}{$\begin{array}{c}\text { 1-Mile } \\
\text { Buffer }\end{array}$} & \multicolumn{1}{c|}{$\begin{array}{c}\text { 2-Mile } \\
\text { Buffer }\end{array}$} & $\begin{array}{c}\text { 3-Mile } \\
\text { Buffer }\end{array}$ & \multicolumn{1}{c|}{$\begin{array}{c}\text { 5-Mile } \\
\text { Buffer }\end{array}$} \\
\hline $\begin{array}{l}\text { San } \\
\text { Francisco }\end{array}$ & 3.46 & 3.42 & 3.05 & 2.64 & 2.42 & 1.79 \\
\hline Millbrae & -0.30 & -0.32 & -0.38 & -0.44 & -0.44 & -0.41 \\
\hline San Jose & -0.20 & -0.24 & -0.23 & -0.11 & 0.18 & 0.58 \\
\hline Gilroy & -0.33 & -0.37 & -0.54 & -0.62 & -0.73 & -0.88 \\
\hline Merced & -0.32 & -0.34 & -0.51 & -0.58 & -0.68 & -0.84 \\
\hline Madera & -0.35 & -0.39 & -0.61 & -0.72 & -0.82 & -0.91 \\
\hline Fresno & -0.19 & -0.29 & -0.23 & -0.38 & -0.41 & -0.50 \\
\hline Kings & -0.35 & -0.39 & -0.61 & -0.71 & -0.80 & -0.88 \\
Tulare & -0.32 & -0.36 & -0.48 & -0.40 & -0.42 & -0.42 \\
\hline Bakersfield & -0.34 & -0.38 & -0.57 & -0.64 & -0.71 & -0.84 \\
\hline Palmdale & -0.32 & -0.30 & 0.10 & 0.03 & 0.17 & 0.49 \\
\hline Burbank & -0.17 & 0.21 & 1.25 & 1.84 & 1.91 & 2.07 \\
\hline $\begin{array}{l}\text { Los } \\
\text { Angeles }\end{array}$ & -0.28 & -0.26 & -0.22 & 0.07 & 0.32 & 0.73 \\
\hline Anaheim & & & & & &
\end{tabular}




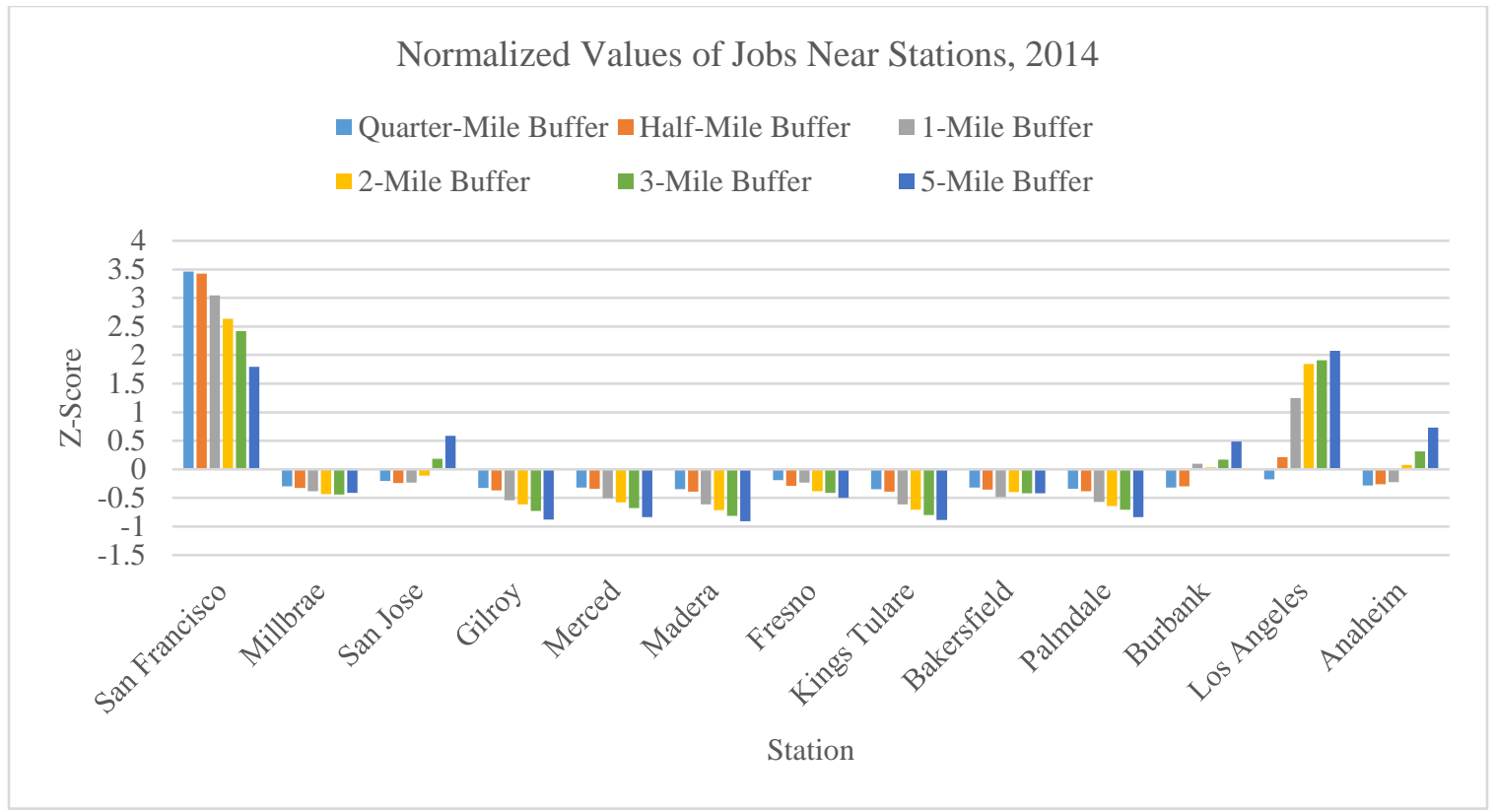

Figure 4.5 Column chart of normalized job numbers by station catchment area radius, 2014. Courtesy of the United States Census Bureau (2017c).

\subsection{Retrieving Population and Housing Data with TIGER and GIS}

Appendix Map A.2 was overlaid with the boundaries of United States Census Bureau Block Group geographic units. The Census block group shapefile was downloaded from the Topologically Integrated Geographic Encoding and Referencing (TIGER) database (United States Census Bureau, 2017d). This means that the shapefile comes as a part of a geodatabase that incorporates selected demographic and economic data for each block group. Since 2014 was the latest year that jobs data from OnTheMap was available, 2014 TIGER data for population and housing unit data was also used to maintain consistency between the data.

To match the station catchment areas with the block group data, the "Buffer" tool, located at the following path within ArcMap GIS: Geoprocessing >> Buffer, was utilized to generate shapefiles of circular station catchment areas with radii specified within Section 4.2. The buffer tool window is shown in Appendix Figure A.8. 
Once the station catchment areas with various radii were recreated as buffers, the "Select By Location" tool, shown in Appendix Figure A.9, was used to select the block groups that intersected with each buffer. New shapefiles were then created with the selected block groups by right-clicking on the block group layer, navigating the following path: Selection >> Create a layer with the selected features, and then exporting the new layers as shapefiles. An example of a new layer for the three-mile radius, named "Intersection," and the corresponding buffer layer, is shown in Appendix Map A.3.

The block group shapefiles were not directly connected with the demographic and economic data of interest. As such, a tabular join of the metadata from the TIGER geodatabase of the block group and the attribute table of each block group shapefile by the various station catchment area radii was performed. This step allowed the relevant demographic and economic data of each selected block group within each station catchment area to be incorporated within the block group shapefiles. The attribute tables for each block group shapefile was downloaded and converted to xls format for incorporation into Microsoft Excel.

Table 4.4 and Figure 4.6 provide a summary of the raw population data in tabular and chart form. Table 4.5, Table 4.6, and Figure 4.7 show the normalized values of population data in tabular and chart form. The same is shown for housing unit data in Table 4.7, Figure 4.8, Table 4.8, Table 4.9 and Figure 4.9.

From Figure 4.6, the raw population concentrations around stations are greatest in the San Francisco Bay Area and the Los Angeles Metropolitan Area. San Francisco no longer has as dominant a position in population concentration as it did with job concentration. Up to the two-mile catchment area radius, no station appears to have a 
relatively large population concentration. Beyond the two-mile buffer, the stations that stand out include San Francisco, Millbrae, San Jose, Fresno, Bakersfield, Burbank, Los Angeles, and Anaheim. Los Angeles has the highest population concentration at the fivemile buffer, while San Jose and San Francisco have the second and third highest, respectively. Anaheim and Burbank are the next two stations with relatively high population concentrations. Fresno and Bakersfield also have relatively high population concentrations, especially when compared to other stations located in the San Joaquin Valley.

When the population numbers are normalized (Table 4.6), the picture is much more varied between stations and catchment area radii. At the quarter-mile distance, it is not San Francisco or Los Angeles that enjoy relatively high population concentrations, but Millbrae, San Jose, Merced, Palmdale, and Burbank. The stations with the greatest normalized values of population concentration, but in the negative direction, are Fresno, Kings Tulare, and Bakersfield. At the half-mile distance, the stations with relatively high population concentrations include San Francisco, Merced, Bakersfield, and Los Angeles. The stations with relatively low population concentrations at the half-mile distance include San Jose, Madera, Fresno, and Anaheim. For the one-mile buffer, the stations with relatively large population concentrations include San Francisco, San Jose, and Los Angeles. Gilroy, Madera, Kings Tulare, and Anaheim have relatively little population concentrations at the one-mile buffer. For station catchment area radii that were two miles or more, the direction and size of the normalized values were much more consistent between stations. The stations with relatively large population concentrations with the two-mile buffer or greater were San Francisco, San Jose, and Los Angeles. Interestingly, 
San Francisco's relatively high population concentration diminishes as the catchment area radii increases. This may be attributable to the fact that San Francisco is bordered by the San Francisco Bay, where no one lives. As the catchment area increases to cover more space where no one lives, it makes sense that San Francisco's relative population concentration decreases. By contrast, Los Angeles's dominance in population concentration increases as the catchment area increases. This is likely because Los Angeles is surrounded by urban areas that are inhabited. For San Jose, as the catchment area increases, there is no increase in population concentration.

From Figure 4.8, one can see that the pattern of raw housing units at stations along the alignment is similar to that of raw population numbers in Figure 4.6. Since the population needs housing units to live in, it makes sense that population and housing units are closely associated. No station stands out in terms of the number of housing units at the quarter-mile and half-mile buffer. When the buffer is one mile or greater, several stations begin to stand out with a relatively high number of housing units. The stations that stand out are San Francisco, Millbrae, San Jose, Fresno, Bakersfield, Burbank, Los Angeles, and Anaheim. Not surprisingly, these are stations located in metropolitan areas. Los Angeles has the highest number of housing units at the five-mile buffer, followed by San Jose, and San Francisco.

The normalized housing unit values are illustrated in Figure 4.9. The illustration resembles the variety that was also shown by visualizing the normalized values for population around each station. In general, the higher normalized housing unit values tend to be located within the major metropolitan areas of California, such as the San Francisco Bay Area and the Los Angeles Metropolitan Area. By contrast, stations located 
in the outskirts of the major metropolitan areas or that are in the San Joaquin Valley tended to have relatively lower normalized housing unit values. 
Table 4.4 Raw population numbers by station catchment area radius, 2014. Courtesy of the United States Census Bureau (2017d).

\begin{tabular}{|l|r|r|r|r|r|r|}
\hline \multicolumn{7}{|c|}{ Population near Stations, 2014} \\
\hline $\begin{array}{l}\text { Quarter-Mile } \\
\text { Buffer }\end{array}$ & \multicolumn{1}{c|}{$\begin{array}{c}\text { Half-Mile } \\
\text { Buffer }\end{array}$} & \multicolumn{1}{c|}{$\begin{array}{l}\text { 1-Mile } \\
\text { Buffer }\end{array}$} & \multicolumn{1}{c|}{$\begin{array}{l}\text { 2-Mile } \\
\text { Buffer }\end{array}$} & \multicolumn{1}{c|}{$\begin{array}{l}\text { 3-Mile } \\
\text { Buffer }\end{array}$} & \multicolumn{1}{c|}{$\begin{array}{c}\text { 5-Mile } \\
\text { Buffer }\end{array}$} \\
\hline $\begin{array}{l}\text { San } \\
\text { Francisco }\end{array}$ & 5,800 & 18,531 & 80,084 & 218,258 & 418,465 & 720,040 \\
\hline Millbrae & 7,732 & 10,526 & 27,962 & 71,210 & 111,383 & 269,136 \\
\hline San Jose & 8,910 & 9,921 & 51,004 & 167,747 & 310,995 & 834,692 \\
\hline Gilroy & 7,180 & 11,670 & 18,059 & 31,430 & 38,404 & 47,851 \\
\hline Merced & 9,070 & 15,392 & 37,544 & 70,940 & 82,193 & 91,984 \\
\hline Madera & 5,036 & 6,355 & 7,668 & 8,932 & 16,684 & 64,907 \\
\hline Fresno & 4,077 & 8,578 & 28,025 & 90,871 & 161,041 & 318,485 \\
\hline Kings & 0 & 4,283 & 5,168 & 15,153 & 36,815 & 80,610 \\
Tulare & 4,757 & 13,417 & 24,343 & 79,855 & 150,335 & 319,140 \\
\hline Bakersfield & 7,776 & 11,761 & 22,541 & 53,246 & 78,816 & 114,650 \\
\hline Palmdale & 8,840 & 11,656 & 30,595 & 113,691 & 255,999 & 615,680 \\
\hline Burbank & 6,841 & 20,263 & 55,752 & 194,244 & 485,451 & $1,325,105$ \\
\hline $\begin{array}{l}\text { Los } \\
\text { Angeles }\end{array}$ & 6,377 & 6,377 & 11,394 & 83,129 & 229,084 & 652,354 \\
\hline Anaheim & & \multicolumn{7}{|c|}{} &
\end{tabular}

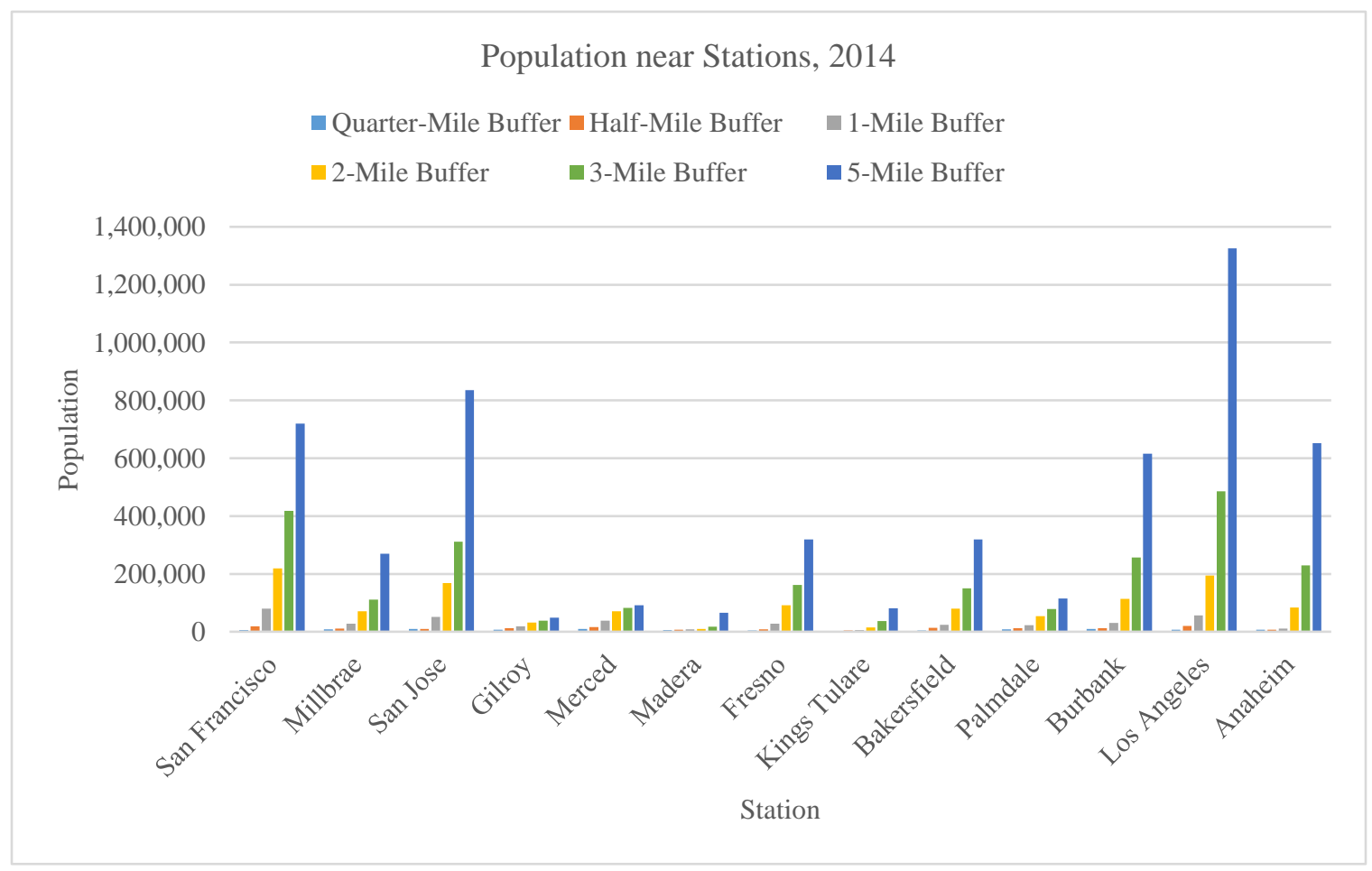

Figure 4.6 Column chart of raw population numbers by station catchment area radius, 2014. Courtesy of the United States Census Bureau (2017d). 
Table 4.5 Descriptive statistics of population by station catchment area radius, 2014. Courtesy of the United States Census Bureau (2017d).

\begin{tabular}{|l|c|c|c|c|c|c|}
\hline \multicolumn{7}{|c|}{ Descriptive Statistics of Population near Stations, 2014} \\
\hline & $\begin{array}{c}\text { Quarter-Mile } \\
\text { Buffer }\end{array}$ & $\begin{array}{c}\text { Half-Mile } \\
\text { Buffer }\end{array}$ & $\begin{array}{c}\text { 1-Mile } \\
\text { Buffer }\end{array}$ & $\begin{array}{c}\text { 2-Mile } \\
\text { Buffer }\end{array}$ & $\begin{array}{c}\text { 3-Mile } \\
\text { Buffer }\end{array}$ & $\begin{array}{c}\text { 5-Mile } \\
\text { Buffer }\end{array}$ \\
\hline Average & 6,338 & 11,441 & 30,780 & 92,208 & 182,743 & 419,587 \\
\hline $\begin{array}{l}\text { Standard } \\
\text { Deviation }\end{array}$ & 2,403 & 4,488 & 20,309 & 63,052 & 143,685 & 371,828 \\
\hline
\end{tabular}

Table 4.6 Normalized population numbers by station catchment area radius, 2014. Courtesy of the United States Census Bureau (2017d).

\begin{tabular}{|l|r|r|r|r|r|r|}
\hline \multicolumn{7}{|c|}{ Normalized Values of Population near Stations, 2014 } \\
\hline & $\begin{array}{c}\text { Quarter-Mile } \\
\text { Buffer }\end{array}$ & $\begin{array}{c}\text { Half-Mile } \\
\text { Buffer }\end{array}$ & \multicolumn{1}{c|}{$\begin{array}{l}\text { 1-Mile } \\
\text { Buffer }\end{array}$} & $\begin{array}{c}\text { 2-Mile } \\
\text { Buffer }\end{array}$ & $\begin{array}{c}\text { 3-Mile } \\
\text { Buffer }\end{array}$ & $\begin{array}{c}\text { 5-Mile } \\
\text { Buffer }\end{array}$ \\
\hline $\begin{array}{l}\text { San } \\
\text { Francisco }\end{array}$ & -0.22 & 1.58 & 2.43 & 2.00 & 1.64 & 0.81 \\
\hline Millbrae & 0.58 & -0.20 & -0.14 & -0.33 & -0.50 & -0.40 \\
\hline San Jose & 1.07 & -0.34 & 1.00 & 1.20 & 0.89 & 1.12 \\
\hline Gilroy & 0.35 & 0.05 & -0.63 & -0.96 & -1.00 & -1.00 \\
\hline Merced & 1.14 & 0.88 & 0.33 & -0.34 & -0.70 & -0.88 \\
\hline Madera & -0.54 & -1.13 & -1.14 & -1.32 & -1.16 & -0.95 \\
\hline Fresno & -0.94 & -0.64 & -0.14 & -0.02 & -0.15 & -0.27 \\
\hline Kings & -2.64 & -1.59 & -1.26 & -1.22 & -1.02 & -0.91 \\
Tulare & -0.66 & 0.44 & -0.32 & -0.20 & -0.23 & -0.27 \\
\hline Bakersfield & 0.60 & 0.07 & -0.41 & -0.62 & -0.72 & -0.82 \\
\hline Palmdale & 1.04 & 0.05 & -0.01 & 0.34 & 0.51 & 0.53 \\
\hline Burbank & 0.21 & 1.97 & 1.23 & 1.62 & 2.11 & 2.44 \\
\hline $\begin{array}{l}\text { Los } \\
\text { Angeles }\end{array}$ & 0.02 & -1.13 & -0.95 & -0.14 & 0.32 & 0.63 \\
\hline Anaheim & & & & & & \\
\hline
\end{tabular}




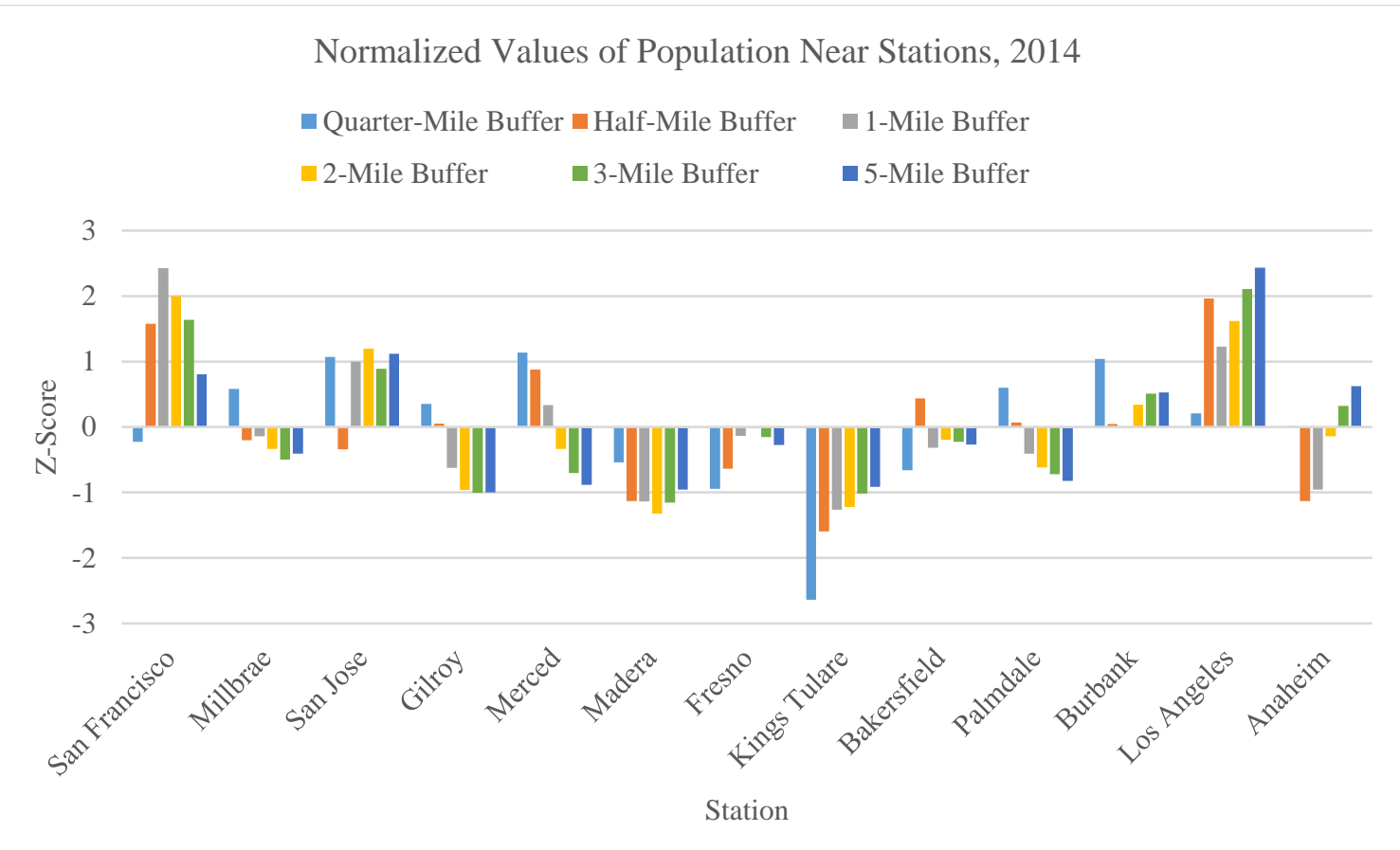

Figure 4.7 Column chart of normalized population numbers by station catchment area radius, 2014. Courtesy of the United States Census Bureau (2017d).

Table 4.7 Raw housing unit numbers by station catchment area radius, 2014. Courtesy of the United States Census Bureau (2017d).

\begin{tabular}{|l|r|r|r|r|r|r|}
\hline \multicolumn{7}{|c|}{ Housing Units near Stations, 2014} \\
\hline $\begin{array}{l}\text { Quarter-Mile } \\
\text { Buffer }\end{array}$ & $\begin{array}{c}\text { Half-Mile } \\
\text { Buffer }\end{array}$ & \multicolumn{1}{c|}{$\begin{array}{l}\text { 1-Mile } \\
\text { Buffer }\end{array}$} & \multicolumn{1}{c|}{$\begin{array}{l}\text { 2-Mile } \\
\text { Buffer }\end{array}$} & $\begin{array}{c}\text { 3-Mile } \\
\text { Buffer }\end{array}$ & \multicolumn{1}{c|}{$\begin{array}{c}\text { 5-Mile } \\
\text { Buffer }\end{array}$} \\
\hline $\begin{array}{l}\text { San } \\
\text { Francisco }\end{array}$ & 2,097 & 6,075 & 29,646 & 78,843 & 151,892 & 271,026 \\
\hline Millbrae & 3,469 & 4,349 & 10,017 & 24,181 & 38,776 & 90,784 \\
\hline San Jose & 2,517 & 2,788 & 15,675 & 57,001 & 111,074 & 295,779 \\
\hline Gilroy & 2,099 & 3,911 & 6,034 & 10,967 & 13,628 & 16,948 \\
\hline Merced & 3,304 & 5,620 & 13,750 & 24,739 & 28,387 & 32,104 \\
\hline Madera & 1,482 & 1,888 & 2,439 & 2,783 & 5,450 & 20,392 \\
\hline Fresno & 1,518 & 3,710 & 11,446 & 37,054 & 64,870 & 120,250 \\
\hline $\begin{array}{l}\text { Kings } \\
\text { Tulare }\end{array}$ & 5 & 1,171 & 1,639 & 3,871 & 9,955 & 24,784 \\
\hline Bakersfield & 1,350 & 5,593 & 9,088 & 27,791 & 54,410 & 110,427 \\
\hline Palmdale & 2,638 & 3,662 & 8,413 & 18,598 & 28,191 & 44,623 \\
\hline Burbank & 3,378 & 4,160 & 11,730 & 42,037 & 94,709 & 221,720 \\
\hline $\begin{array}{l}\text { Los } \\
\text { Angeles }\end{array}$ & 2,056 & 7,907 & 20,232 & 80,788 & 187,045 & 479,563 \\
\hline Anaheim & 2,571 & 2,571 & 4,249 & 29,774 & 82,779 & 234,845 \\
\hline
\end{tabular}




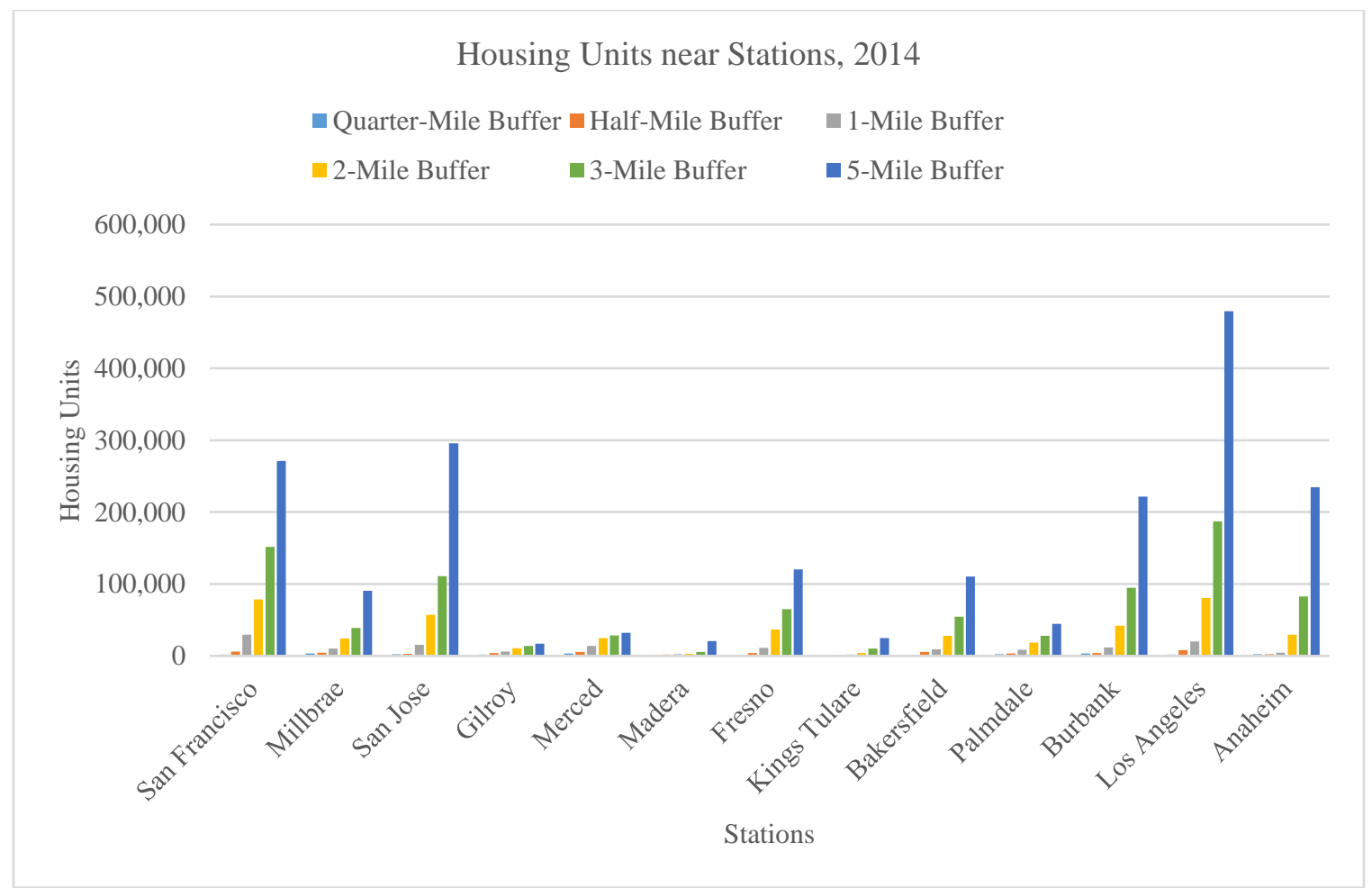

Figure 4.8 Column chart of raw housing unit numbers by station catchment area radius, 2014. Courtesy of the United States Census Bureau (2017d).

Table 4.8 Descriptive statistics of housing units by station catchment area radius, 2014. Courtesy of the United States Census Bureau (2017d).

\begin{tabular}{|l|r|r|r|r|r|c|}
\hline \multicolumn{7}{|c|}{ Descriptive Statistics of Housing Units near Stations, 2014 } \\
\hline & $\begin{array}{c}\text { Quarter-Mile } \\
\text { Buffer }\end{array}$ & $\begin{array}{c}\text { Half-Mile } \\
\text { Buffer }\end{array}$ & $\begin{array}{c}\text { 1-Mile } \\
\text { Buffer }\end{array}$ & $\begin{array}{c}\text { 2-Mile } \\
\text { Buffer }\end{array}$ & $\begin{array}{c}\text { 3-Mile } \\
\text { Buffer }\end{array}$ & $\begin{array}{c}\text { 5-Mile } \\
\text { Buffer }\end{array}$ \\
\hline Average & 2,191 & 4,108 & 11,104 & 33,725 & 67,013 & 151,019 \\
\hline $\begin{array}{l}\text { Standard } \\
\text { Deviation }\end{array}$ & 929 & 1,774 & 7,366 & 24,322 & 54,367 & 135,301 \\
\hline
\end{tabular}


Table 4.9 Normalized housing unit numbers by station catchment area radius, 2014. Courtesy of the United States Census Bureau (2017d).

\begin{tabular}{|l|r|r|r|r|r|r|}
\hline \multicolumn{7}{|c|}{ Normalized Values of Housing Units near Stations, 2014} \\
\hline $\begin{array}{l}\text { Quarter-Mile } \\
\text { Buffer }\end{array}$ & $\begin{array}{c}\text { Half-Mile } \\
\text { Buffer }\end{array}$ & \multicolumn{1}{c|}{$\begin{array}{l}\text { 1-Mile } \\
\text { Buffer }\end{array}$} & $\begin{array}{c}\text { 2-Mile } \\
\text { Buffer }\end{array}$ & $\begin{array}{c}\text { 3-Mile } \\
\text { Buffer }\end{array}$ & $\begin{array}{c}\text { 5-Mile } \\
\text { Buffer }\end{array}$ \\
\hline Francisco & -0.10 & 1.11 & 2.52 & 1.85 & 1.56 & 0.89 \\
\hline Millbrae & 1.38 & 0.14 & -0.15 & -0.39 & -0.52 & -0.45 \\
San Jose & 0.35 & -0.74 & 0.62 & 0.96 & 0.81 & 1.07 \\
\hline Gilroy & -0.10 & -0.11 & -0.69 & -0.94 & -0.98 & -0.99 \\
\hline Merced & 1.20 & 0.85 & 0.36 & -0.37 & -0.71 & -0.88 \\
\hline Madera & -0.76 & -1.25 & -1.18 & -1.27 & -1.13 & -0.97 \\
\hline Fresno & -0.72 & -0.22 & 0.05 & 0.14 & -0.04 & -0.23 \\
\hline $\begin{array}{l}\text { Kings } \\
\text { Tulare }\end{array}$ & -2.35 & -1.66 & -1.28 & -1.23 & -1.05 & -0.93 \\
\hline Bakersfield & -0.91 & 0.84 & -0.27 & -0.24 & -0.23 & -0.30 \\
\hline Palmdale & 0.48 & -0.25 & -0.37 & -0.62 & -0.71 & -0.79 \\
\hline Burbank & 1.28 & 0.03 & 0.08 & 0.34 & 0.51 & 0.52 \\
\hline Los & -0.15 & 2.14 & 1.24 & 1.93 & 2.21 & 2.43 \\
\hline Angeles & 0.41 & -0.87 & -0.93 & -0.16 & 0.29 & 0.62 \\
\hline Anaheim & & & & & & \\
\hline
\end{tabular}




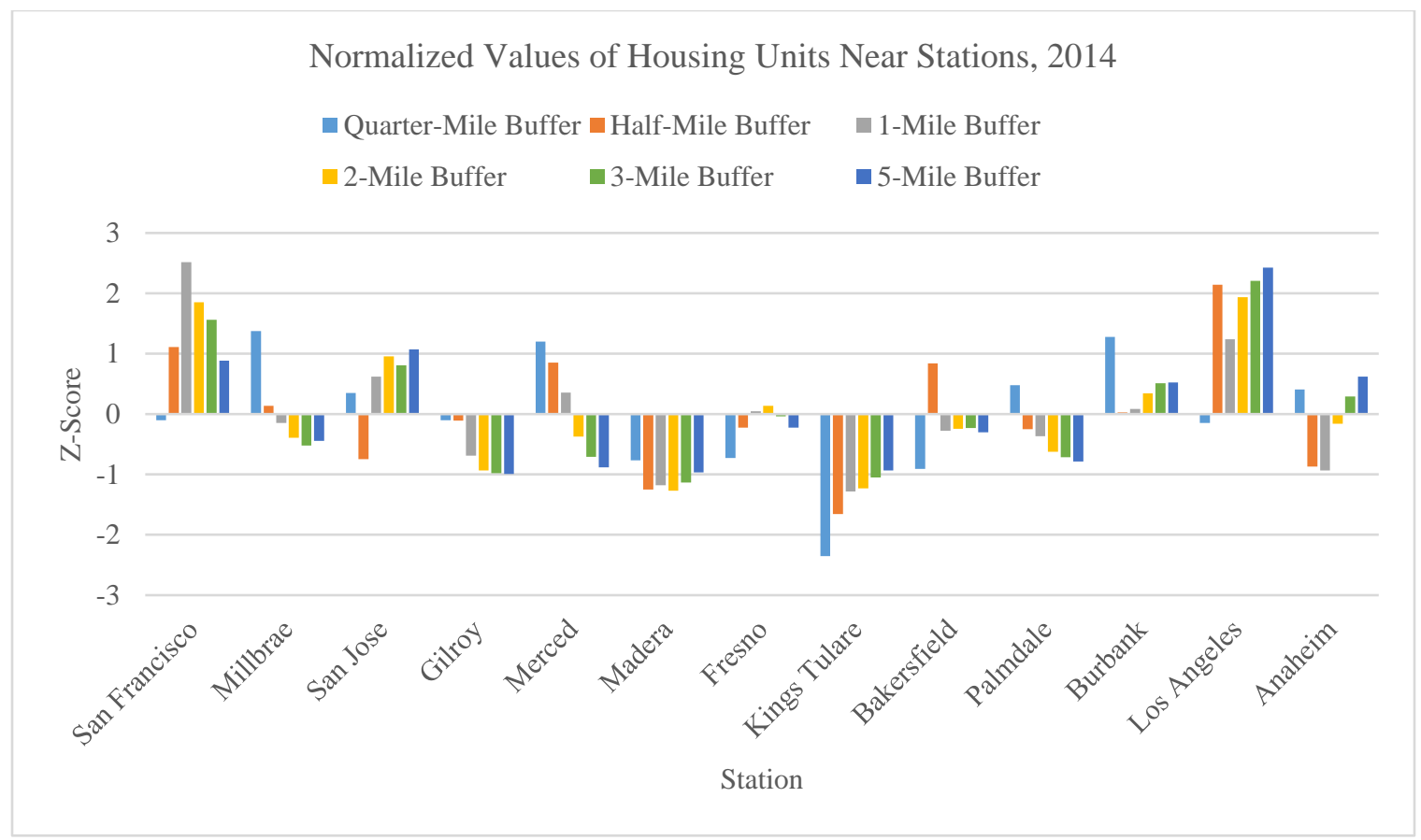

Figure 4.9 Column chart of normalized housing unit numbers by station catchment area radius, 2014. Courtesy of the United States Census Bureau (2017d). 


\subsection{Distance between Stations}

The impedance used in the gravity model incorporates the distance between each of the stations along the alignment of the high-speed rail system. A shapefile of the California High-Speed Rail System alignment was downloaded from Duncan (2014) and projected with the station locations in ArcMap GIS, as shown in Map 4.3. 


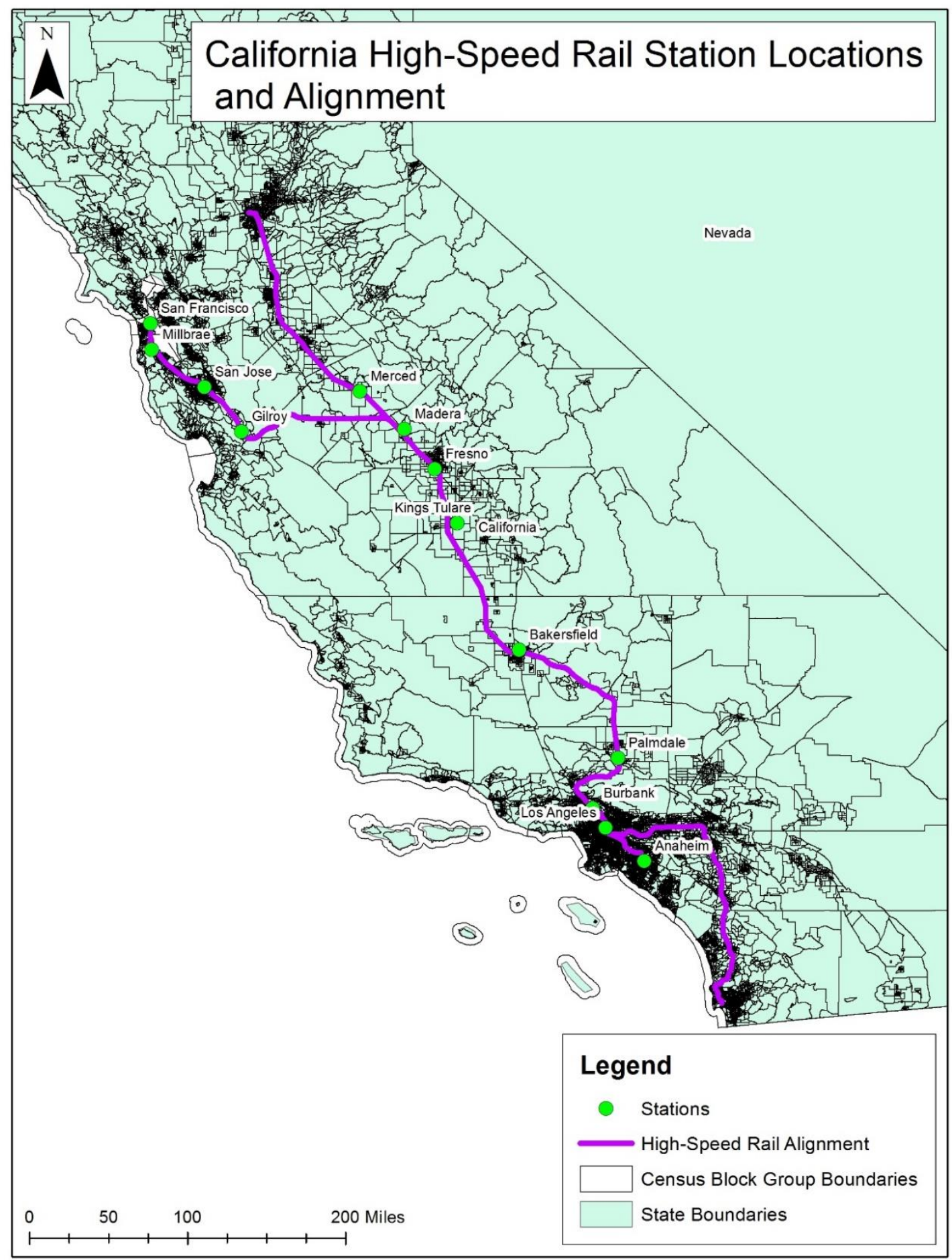

Map 4.3 California High-Speed Rail station locations and alignment. Created using ArcMap GIS (2017). (United States Census Bureau, 2017b; Duncan, 2017). 
Note that the alignment from Duncan (2014) was created in 2004. Since then, the alignment of the System has undergone numerous changes under the environmental review process. As the station locations are more up-to-date compared to the alignment, some stations do not fall directly on top of the alignment (e.g., Kings Tulare). An approximation of the closest point of the alignment to the station location was made to determine the distance between stations. Despite the lack of precision, the approximation seems reasonable because multiple portions of the alignment of the California HighSpeed Rail System are still currently undergoing the environmental review process at the time of this writing and are likely to experience additional shifts in position as the process continues.

The alignment from Duncan (2014) was broken into separate polylines, or links, using the "Editor" toolbar in ArcMap GIS, where the breakpoints were the approximate locations of the closest points of the alignment to each station location. Once all of the links between each station were created, the length of each link was calculated in ArcMap GIS by creating a new field within the attribute table of the alignment layer and using the "Calculate Geometry" tool for the field. The distances between each link are shown in Table 4.10. The yellow cells in Table 4.10 denote the links that connect to or bypass Merced, which is a station that is located at one branch of a "wye" in the middle of the high-speed rail alignment. 
Table 4.10 Distances of links between stations along the high-speed rail alignment.

\begin{tabular}{|c|c|c|c|}
\hline Station & Label & Link & Distance (mi) \\
\hline San Francisco & A & A-B & 18.0 \\
\hline Millbrae & B & B-C & 41.9 \\
\hline San Jose & $\mathrm{C}$ & C-D & 37.6 \\
\hline Gilroy & $\mathrm{D}$ & D-E & 118.4 \\
\hline Merced & $\mathrm{E}$ & E-F & 35.9 \\
\hline Madera & $\mathrm{F}$ & F-G & 32.4 \\
\hline Fresno & G & G-H & 36.0 \\
\hline Kings Tulare & $\mathrm{H}$ & H-I & 100.2 \\
\hline Bakersfield & $\mathrm{I}$ & $\mathrm{I}-\mathrm{J}$ & 105.2 \\
\hline Palmdale & $\mathrm{J}$ & $\mathrm{J}-\mathrm{K}$ & 55.4 \\
\hline Burbank & K & K-L & 16.6 \\
\hline Los Angeles & $\mathrm{L}$ & L-M & 36.1 \\
\hline Anaheim & $M$ & D-F & 111.6 \\
\hline \multicolumn{3}{|c|}{ Total minus Merced Wye } & 590.9 \\
\hline & & Total & 745.2 \\
\hline
\end{tabular}

\subsection{Application of the Gravity Model}

With all the required data collected, the gravity model could be applied. The

distance between each station was tabulated as shown in Table 4.11.

Table 4.11 The distance between each station along the California High-Speed Rail line.

\begin{tabular}{|c|c|c|c|c|c|c|c|c|c|c|c|c|c|}
\hline \multicolumn{14}{|c|}{ Distance between Stations (mi) } \\
\hline Label & $\mathrm{A}$ & B & C & $\mathrm{D}$ & $\mathrm{E}$ & $\mathrm{F}$ & $\mathrm{G}$ & $\mathrm{H}$ & I & $\mathrm{J}$ & $\mathrm{K}$ & $\mathrm{L}$ & $\mathrm{M}$ \\
\hline A & 3 & 18 & 60 & 97 & 216 & 209 & 241 & 277 & 378 & 483 & 538 & 555 & 591 \\
\hline $\mathrm{B}$ & 18 & 3 & 42 & 79 & 198 & 191 & 223 & 259 & 360 & 465 & 520 & 495 & 573 \\
\hline $\mathrm{C}$ & 60 & 42 & 3 & 38 & 156 & 149 & 182 & 218 & 318 & 423 & 478 & 495 & 531 \\
\hline $\mathrm{D}$ & 97 & 79 & 38 & 3 & 118 & 112 & 144 & 277 & 280 & 385 & 441 & 457 & 493 \\
\hline $\mathrm{E}$ & 216 & 198 & 156 & 118 & 3 & 36 & 68 & 104 & 205 & 310 & 365 & 382 & 418 \\
\hline $\mathrm{F}$ & 209 & 191 & 149 & 112 & 36 & 3 & 32 & 68 & 169 & 274 & 329 & 346 & 382 \\
\hline G & 241 & 223 & 182 & 144 & 68 & 32 & 3 & 36 & 136 & 241 & 297 & 313 & 349 \\
\hline $\mathrm{H}$ & 277 & 259 & 218 & 180 & 104 & 68 & 36 & 3 & 100 & 205 & 261 & 277 & 313 \\
\hline I & 378 & 360 & 318 & 280 & 205 & 169 & 136 & 100 & 3 & 105 & 161 & 177 & 213 \\
\hline $\mathbf{J}$ & 483 & 465 & 423 & 385 & 310 & 274 & 241 & 205 & 105 & 3 & 55 & 72 & 108 \\
\hline $\bar{K}$ & 538 & 520 & 478 & 441 & 365 & 329 & 297 & 261 & 161 & 55 & 3 & 17 & 108 \\
\hline $\mathrm{L}$ & 555 & 537 & 495 & 457 & 382 & 346 & 313 & 277 & 177 & 72 & 17 & 3 & 36 \\
\hline $\mathrm{M}$ & 591 & 573 & 531 & 493 & 418 & 382 & 349 & 313 & 213 & 108 & 53 & 36 & 3 \\
\hline
\end{tabular}

The gravity model in the form shown in Figure 4.10 was applied to each station area pair and to each station catchment area radius. 


$$
I_{i j}=\frac{A_{j} F_{i j}}{\sum_{k} A_{k} F_{i k}}
$$

Figure 4.10 Formula for accessibility index of station origin-destination pairs.

Where:

$I_{i j}=$ Accessibility index from origin $\mathrm{i}$ to destination $\mathrm{j}$

$A_{j}=$ Attraction of origin $\mathrm{i}$ (raw or normalized values of jobs, population, or housing units)

$\mathrm{F}_{\mathrm{ij}}=$ Impedance factor from origin $\mathrm{i}$ to destination $\mathrm{j}\left(\right.$ distance $\left.^{-1}\right)$

$\Sigma \mathrm{A}_{\mathrm{k}} \mathrm{F}_{\mathrm{ik}}=$ Summation of the product of attractions to destination $\mathrm{k}$ and the friction factor of destination $\mathrm{k}$ to each origin $\mathrm{i}$

Note that in Figure 4.10, there is no production operand as there is in the typical gravity model used in transportation applications like that shown in Figure 4.2. This reflects the fact that this study is observing the relative attraction between station origindestination pairs using indices, rather than observing the number of trips that will occur between station origin-destination pairs. Since the production operand, which acts as the origin operand in transportation models, is absent from the model in Figure 4.10, the values generated from the model will be dimensionless with respect to the origin. 


\section{$5 \quad$ Findings}

This section discusses the findings of the application of the gravity model to the raw and normalized values of job, population, and housing unit data collected for each station at different catchment area radii. The inputs of jobs, population, and housing unit data into the model were independent, meaning for example that jobs data was never combined with housing unit data when inputted into the model. As noted under Section 4.2, the half-mile radius, three-mile radius, and five-mile radius are analyzed within the body of this study. Data for the other catchment area radii are available within the Appendix to this study.

\subsection{Half-Mile Radius Results}

This section analyzes the results of the gravity model of various attraction variables at the half-mile radius. The half-mile radius represents the industry standard used in projecting transit ridership from transit-oriented developments (Guerra, Cervero, \& Tischler, 2011, p. 1) and the extent that pedestrians are willing to walk to access transit nodes (Nuworsoo et al., 2012, pdf-p. 2; FHWA, 2006), as noted in Section 4.2.

\subsubsection{Raw Job Figures}

The results of the raw job numbers for the half mile radius station catchment area are shown in Table 5.1. San Francisco and Los Angeles appear to have the greatest accessibility indices compared to all the other stations. This makes sense because San Francisco and Los Angeles are major employment centers on a statewide basis. Both San Francisco and Los Angeles are attractive to each other as well because of the high number of jobs at each location. San Francisco's attractiveness as a destination remains strong throughout the entire corridor of the high-speed rail alignment, although it 
dwindles as the distance to another station increases. This is consistent with the fact that distance acts as an impedance factor in the model shown in Figure 4.10. Los Angeles's attractiveness as a destination, however, decreases more rapidly as the distance between itself and other stations decreases. This suggests that Los Angeles is not as significant as a job center to the entire corridor as San Francisco is.

Another pattern to note is the attractiveness of each station area to its host station, as demonstrated by the diagonally aligned series of green cells. For example, Fresno's station area has a relatively high attraction index of 0.910 to Fresno Station. This pattern demonstrates the high accessibility that results between spaces that have little distance between each other. Within the diagonally aligned series of green cells, Millbrae, Gilroy, Madera, Kings Tulare, and Palmdale have relatively low attraction indices. This reflects the relatively low number of jobs within the station areas of these stations within the corridor.

The stations that performed poorly overall were Madera, Kings Tulare, and Palmdale. Madera fared poorly in particular since its station area of a half mile radius has a very low number of jobs. 
Table 5.1 Accessibility indices for origin-destination pairs from raw job figures for half-mile buffer. Green, yellow, and red cells denote relatively high, medium, and low values, respectively. Blue cells denote row or column totals.

\begin{tabular}{|c|c|c|c|c|c|c|c|c|c|c|c|c|c|c|c|}
\hline \multirow{14}{*}{ 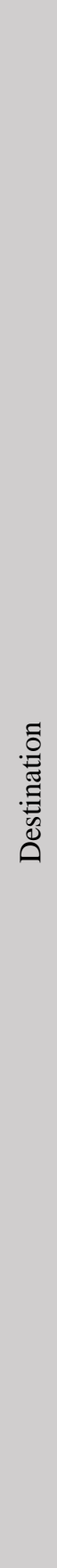 } & $\stackrel{\bar{ే}}{0}$ & $\stackrel{8}{8}$ & $\stackrel{8}{8}$ & $\underset{8}{\stackrel{8}{8}}$ & $\underset{8}{8}$ & $\underset{8}{8}$ & $\underset{8}{8}$ & $\underset{8}{8}$ & $\underset{8}{8}$ & $\underset{8}{8}$ & $\underset{8}{8}$ & $\underset{8}{8}$ & $\underset{-}{8}$ & $\underset{8}{8}$ & $\begin{array}{l}8 \\
\dot{8} \\
\dot{\imath}\end{array}$ \\
\hline & $\Sigma$ & $\begin{array}{l}8 \\
8 \\
0\end{array}$ & $\begin{array}{l}\overline{8} \\
\dot{0}\end{array}$ & $\overline{8}$ & 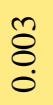 & $\stackrel{8}{8}$ & $\vec{\sigma}$ & $\begin{array}{l}\text { ̊े } \\
\stackrel{0}{0}\end{array}$ & $\stackrel{\sim}{0}$ & $\stackrel{8}{8}$ & $\begin{array}{l}\infty \\
\stackrel{\infty}{O} \\
\stackrel{0}{0}\end{array}$ & $\begin{array}{l}n \\
8 \\
0\end{array}$ & $\stackrel{8}{8}$ & $\frac{N}{\sigma}$ & $\begin{array}{l}\qquad 0 \\
ٌ \\
0 \\
0\end{array}$ \\
\hline & 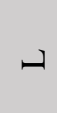 & $\stackrel{8}{8}$ & $\begin{array}{l}\text { ô } \\
0\end{array}$ & $\begin{array}{l}\text { ô } \\
0\end{array}$ & $\stackrel{m}{0}$ & $\stackrel{\sim}{O}$ & 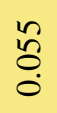 & $\stackrel{\infty}{\circ}$ & है & ô & $\frac{\infty}{\stackrel{\infty}{0}}$ & 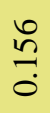 & $\begin{array}{l}\stackrel{0}{\infty} \\
\stackrel{0}{0}\end{array}$ & $\begin{array}{l}\hat{n} \\
0 \\
0\end{array}$ & 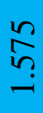 \\
\hline & $\forall$ & $\begin{array}{l}8 \\
8 \\
0\end{array}$ & $\overline{8}$ & $\begin{array}{l}\overline{8} \\
\stackrel{0}{0}\end{array}$ & $\begin{array}{l}\text { ¿े } \\
\stackrel{0}{0}\end{array}$ & $\begin{array}{l}\widetilde{\delta} \\
\stackrel{0}{0}\end{array}$ & $\begin{array}{l}8 \\
\stackrel{0}{0} \\
\stackrel{0}{0}\end{array}$ & $\begin{array}{l}\overline{8} \\
0\end{array}$ & $\begin{array}{l}\circ \\
0 \\
0\end{array}$ & $\begin{array}{l}8 \\
8 \\
0\end{array}$ & $\begin{array}{l}\infty \\
\tilde{O} \\
\stackrel{0}{0}\end{array}$ & $\begin{array}{l}\tilde{O} \\
\infty \\
0 \\
0\end{array}$ & $\begin{array}{l}\mathscr{o} \\
\ddot{0} \\
\dot{0}\end{array}$ & $\begin{array}{l}\stackrel{8}{0} \\
\stackrel{0}{0}\end{array}$ & $\begin{array}{l}\text { M } \\
\infty \\
\infty \\
0\end{array}$ \\
\hline & 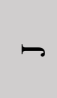 & $\begin{array}{l}8 \\
8 \\
0\end{array}$ & $\begin{array}{l}8 \\
8 \\
0\end{array}$ & $\begin{array}{l}8 \\
8\end{array}$ & $\begin{array}{l}8 \\
8 \\
0\end{array}$ & $\begin{array}{l}8 \\
8 \\
0\end{array}$ & $\overrightarrow{8}$ & $\begin{array}{l}8 \\
8 \\
0\end{array}$ & 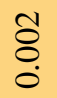 & $\overrightarrow{8}$ & ڤ్ & $\overline{8}$ & \begin{tabular}{l}
8 \\
\hdashline
\end{tabular} & $\begin{array}{l}8 \\
8 \\
0\end{array}$ & $\begin{array}{l}n \\
\text { ñ } \\
0\end{array}$ \\
\hline & - & $\begin{array}{l}8 \\
8 \\
0\end{array}$ & \begin{tabular}{l}
8 \\
\hdashline \\
0
\end{tabular} & $\begin{array}{l}8 \\
0 \\
0\end{array}$ & $\stackrel{\overline{8}}{\circ}$ & ¿্口 & $\stackrel{8}{8}$ & 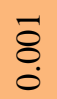 & $\begin{array}{l}0 \\
0 \\
0\end{array}$ & $\begin{array}{l}\infty \\
\infty \\
0\end{array}$ & $\begin{array}{l}\infty \\
\stackrel{0}{0}\end{array}$ & ס्ष & $\stackrel{8}{8}$ & $\stackrel{\overline{8}}{\circ}$ & $\begin{array}{l}\stackrel{a}{+} \\
\infty \\
\stackrel{0}{\circ}\end{array}$ \\
\hline & $I$ & $\begin{array}{l}8 \\
8 \\
0\end{array}$ & $\underset{8}{8}$ & $\begin{array}{l}8 \\
8 \\
\circ\end{array}$ & \begin{tabular}{l}
8 \\
8 \\
\hdashline
\end{tabular} & $\overline{8}$ & $\stackrel{8}{8}$ & $\begin{array}{l}\overline{8} \\
0\end{array}$ & $\stackrel{\infty}{\stackrel{+}{+}}$ & $\stackrel{\overline{8}}{\circ}$ & $\begin{array}{l}\overline{8} \\
\dot{0}\end{array}$ & $\begin{array}{l}8 \\
8 \\
0\end{array}$ & \begin{tabular}{l}
8 \\
$\varnothing$ \\
\hdashline
\end{tabular} & $\begin{array}{l}8 \\
8 \\
0\end{array}$ & $\stackrel{n}{f}$ \\
\hline & 0 & $\begin{array}{l}8 \\
8 \\
0\end{array}$ & $\begin{array}{l}\overline{8} \\
0\end{array}$ & $\begin{array}{l}\text { ¿ै } \\
\text { ¿ }\end{array}$ & $\stackrel{\hat{8}}{0}$ & $\stackrel{\sim}{O}$ & $\frac{d}{\stackrel{+}{0}}$ & $\frac{0}{a}$ & $\begin{array}{l}\infty \\
0 \\
0\end{array}$ & $\stackrel{8}{\circ}$ & $\begin{array}{l}\circ \\
0 \\
0\end{array}$ & $\begin{array}{l}\text { ㅇ } \\
\stackrel{8}{0}\end{array}$ & $\begin{array}{l}8 \\
8\end{array}$ & $\begin{array}{l}\overline{8} \\
\ddot{0}\end{array}$ & 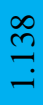 \\
\hline & 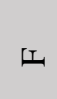 & 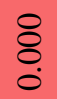 & $\begin{array}{l}8 \\
\vdots \\
0\end{array}$ & \begin{tabular}{l}
8 \\
\hdashline \\
0
\end{tabular} & \begin{tabular}{l}
8 \\
\hdashline
\end{tabular} & \begin{tabular}{l}
8 \\
\hdashline \\
0
\end{tabular} & $\frac{\infty}{\stackrel{\infty}{!}}$ & $\stackrel{8}{8}$ & $\begin{array}{l}\overline{8} \\
\stackrel{0}{0}\end{array}$ & $\begin{array}{l}8 \\
:\end{array}$ & $\stackrel{8}{8}$ & \begin{tabular}{l}
8 \\
\hdashline \\
0
\end{tabular} & $\stackrel{8}{8}$ & \begin{tabular}{l}
8 \\
\hdashline \\
0
\end{tabular} & $\frac{f}{0}$ \\
\hline & (1) & $\begin{array}{l}8 \\
8 \\
0\end{array}$ & $\overline{8}$ & $\begin{array}{l}\overline{8} \\
0\end{array}$ & $\begin{array}{l}n \\
8\end{array}$ & $\begin{array}{l}\underset{\infty}{J} \\
\infty \\
0\end{array}$ & $\begin{array}{l}\infty \\
\stackrel{\infty}{0} \\
0\end{array}$ & $\stackrel{\tilde{8}}{0}$ & $\stackrel{\Delta}{0}$ & $\begin{array}{l}\text { } \\
\tilde{0}\end{array}$ & $\begin{array}{l}\stackrel{t}{8} \\
0\end{array}$ & $\overline{8}$ & $\begin{array}{l}8 \\
8\end{array}$ & $\stackrel{8}{8}$ & $\begin{array}{l}\text { ț } \\
\text { م. }\end{array}$ \\
\hline & D & \begin{tabular}{l}
8 \\
\hdashline \\
0
\end{tabular} & $\stackrel{\overline{8}}{\circ}$ & $\begin{array}{l}\text { ò } \\
\text { o }\end{array}$ & $\tilde{n}$ & 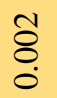 & $\begin{array}{l}\infty \\
\stackrel{8}{0}\end{array}$ & $\overline{8}$ & 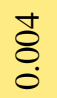 & ¿্口 & 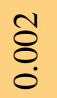 & \begin{tabular}{l}
8 \\
\hdashline \\
0
\end{tabular} & $\begin{array}{l}8 \\
0\end{array}$ & \begin{tabular}{l}
8 \\
\hdashline \\
0
\end{tabular} & $\begin{array}{l}\stackrel{2}{n} \\
n \\
?\end{array}$ \\
\hline & $u$ & $\begin{array}{l}8 \\
0 \\
0\end{array}$ & $\begin{array}{l}\stackrel{0}{0} \\
\stackrel{0}{0}\end{array}$ & $\begin{array}{l}\frac{\pi}{\infty} \\
0 \\
0\end{array}$ & $\begin{array}{l}\text { Pे } \\
\text { ț } \\
0\end{array}$ & $\begin{array}{l}\hat{8} \\
0\end{array}$ & $\begin{array}{l}\text { है } \\
\text { ல }\end{array}$ & $\begin{array}{l}+ \\
8\end{array}$ & $\frac{a}{0}$ & $\begin{array}{l}n \\
\tilde{o} \\
0\end{array}$ & $\begin{array}{l}\infty \\
\stackrel{\infty}{0} \\
0\end{array}$ & s. & $\begin{array}{l}8 \\
8\end{array}$ & $\overrightarrow{8}$ & $\begin{array}{l}\text { \& } \\
\text { Lे } \\
0\end{array}$ \\
\hline & $\infty$ & $\begin{array}{l}\overline{8} \\
\dot{0}\end{array}$ & ळे & $\begin{array}{l}\text { ¿ } \\
\stackrel{0}{0}\end{array}$ & $\begin{array}{l}8 \\
\stackrel{8}{0} \\
0\end{array}$ & $\begin{array}{l}\text { ஜ̊ } \\
\stackrel{0}{0}\end{array}$ & $\underset{0}{\bar{\sigma}}$ & $\begin{array}{l}\overline{8} \\
\stackrel{0}{0}\end{array}$ & $\begin{array}{l}\hat{8} \\
0 \\
0\end{array}$ & $\begin{array}{l}\text { ô } \\
\stackrel{0}{0} \\
0\end{array}$ & $\begin{array}{l}\text { ఠ̊ } \\
0\end{array}$ & $\begin{array}{l}\overline{8} \\
\circ \\
0\end{array}$ & $\begin{array}{l}8 \\
8 \\
0\end{array}$ & $\begin{array}{l}8 \\
8 \\
\circ\end{array}$ & $\stackrel{+}{\stackrel{+}{0}}$ \\
\hline & $\ll$ & ळ. & है? & $\frac{\mathfrak{b}}{0}$ & 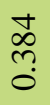 & $\frac{m}{0}$ & $\stackrel{N}{n}$ & $\begin{array}{l}\widehat{0} \\
\stackrel{0}{0}\end{array}$ & $\stackrel{n}{n}$ & $\begin{array}{l}\stackrel{0}{\exists} \\
0\end{array}$ & $\frac{ \pm}{\frac{I}{0}}$ & గొ & $\begin{array}{l}8 \\
\stackrel{0}{0} \\
0\end{array}$ & $\begin{array}{l}\text { ঠ̦ } \\
\stackrel{0}{0}\end{array}$ & 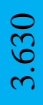 \\
\hline & $\begin{array}{l}\overline{\mathbb{D}} \\
\bar{\Xi}\end{array}$ & $\ll$ & $\infty$ & $u$ & $\theta$ & 디 & 山 & 0 & \pm & - & $\sim$ & $\mathscr{V}$ & \lrcorner & $\Sigma$ & స్ \\
\hline & & & & & & & & & & & & & & & \\
\hline
\end{tabular}




\subsubsection{Normalized Job Figures}

The results of the gravity model when applied to the normalized job figures for the half-mile station catchment area are shown in Table 5.2. Compared to the raw job figures from Table 5.1, the normalized job figures appear to be much less varied and extreme. The pattern of station areas being highly attracted to their host stations still appears, again highlighting the effect of low distance on accessibility.

Interestingly, San Francisco as a destination is relatively unattractive to Millbrae or to San Jose. Also, in terms of total attractiveness, San Francisco only has an index score of 0.32 , which is very low compared to those of the other station areas along the corridor. 
Table 5.2 Accessibility indices for origin-destination pairs from normalized job figures for half-mile buffer. Green, yellow, and red cells denote relatively high, medium, and low values, respectively. Blue cells denote row or column totals.

\begin{tabular}{|c|c|c|c|c|c|c|c|c|c|c|c|c|c|c|c|}
\hline \multirow{14}{*}{ 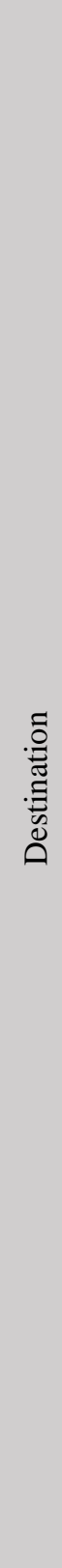 } & 풍 & $\underset{-}{8}$ & $\underset{8}{8}$ & $\underset{-}{8}$ & $\underset{-}{8}$ & $\underset{.}{8}$ & $\underset{-}{8}$ & $\stackrel{8}{8}$ & $\underset{-}{8}$ & $\underset{.}{8}$ & $\underset{-}{8}$ & $\underset{.}{8}$ & $\underset{-}{8}$ & $\underset{-}{8}$ & $\begin{array}{l}8 \\
\dot{\imath}\end{array}$ \\
\hline & $\Sigma$ & $\stackrel{8}{8}$ & $\stackrel{8}{8}$ & $\stackrel{8}{8}$ & $\stackrel{8}{8}$ & $\stackrel{8}{8}$ & $\stackrel{8}{8}$ & $\stackrel{8}{\circ}$ & $\stackrel{8}{8}$ & $\stackrel{8}{8}$ & $\begin{array}{l}8 \\
\end{array}$ & $\stackrel{8}{8}$ & $\begin{array}{l}\text { Oे } \\
\dot{\varphi}\end{array}$ & $\stackrel{\circ}{\circ}$ & ڤे \\
\hline & \lrcorner & $\stackrel{8}{\circ}$ & $\stackrel{8}{\circ}$ & $\stackrel{8}{\circ}$ & $\stackrel{8}{\circ}$ & $\stackrel{8}{\circ}$ & $\stackrel{8}{\circ}$ & $\stackrel{8}{\circ}$ & $\stackrel{8}{\circ}$ & $\stackrel{8}{8}$ & $\stackrel{8}{\circ}$ & 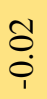 & $\stackrel{\infty}{\stackrel{\infty}{-}}$ & ¿ạ. & $\stackrel{t}{\longrightarrow}$ \\
\hline & $\mathscr{V}$ & $\stackrel{8}{8}$ & $\stackrel{8}{8}$ & $\stackrel{8}{\circ}$ & $\stackrel{8}{8}$ & $\stackrel{8}{8}$ & $\stackrel{8}{8}$ & $\stackrel{8}{\circ}$ & $\stackrel{8}{8}$ & $\stackrel{8}{\circ}$ & o. & ه. & \begin{tabular}{l}
2 \\
\hdashline \\
0 \\
0
\end{tabular} & $\stackrel{\sigma}{0}$ & $\stackrel{\text { gे }}{\circ}$ \\
\hline & $\neg$ & $\stackrel{8}{8}$ & $\stackrel{8}{8}$ & $\stackrel{8}{8}$ & $\stackrel{8}{8}$ & $\underset{0}{8}$ & $\stackrel{8}{0}$ & $\stackrel{8}{\circ}$ & $\stackrel{8}{8}$ & ¿. & gे & $\begin{array}{l}\overline{0} \\
0\end{array}$ & ర్. & $\stackrel{0}{0}$ & ö \\
\hline & $\neg$ & $\stackrel{8}{8}$ & $\stackrel{8}{8}$ & $\stackrel{8}{8}$ & $\stackrel{8}{\circ}$ & $\stackrel{8}{\circ}$ & $\stackrel{8}{\circ}$ & $\stackrel{8}{\circ}$ & $\stackrel{8}{8}$ & $\stackrel{\circ}{\circ}$ & $\stackrel{8}{8}$ & $\stackrel{8}{8}$ & $\begin{array}{l}\sigma \\
0 \\
\end{array}$ & $\stackrel{8}{\circ}$ & $\stackrel{\sigma}{-}$ \\
\hline & $I$ & $\stackrel{8}{\circ}$ & $\stackrel{8}{8}$ & $\stackrel{8}{\circ}$ & $\stackrel{8}{\circ}$ & ¿্口 & ¿্. & $\stackrel{\text { ô }}{\circ}$ & $\stackrel{\infty}{\circ}$ & ¿ర̣ & \&. & \begin{tabular}{l}
8 \\
\hdashline \\
0
\end{tabular} & ஓ. & $\stackrel{8}{\circ}$ & $\stackrel{\text { o. }}{-}$ \\
\hline & ט & $\stackrel{8}{8}$ & $\stackrel{8}{8}$ & $\stackrel{8}{8}$ & $\stackrel{8}{\circ}$ & $\stackrel{\sigma}{0}$ & $\ddot{0}$ & $\stackrel{\circ}{\circ}$ & $\ddot{0}$ & $\stackrel{8}{8}$ & $\stackrel{8}{\circ}$ & $\stackrel{8}{8}$ & $\stackrel{8}{\circ}$ & $\stackrel{8}{\circ}$ & $\underset{8}{\stackrel{8}{2}}$ \\
\hline & IL & $\stackrel{8}{8}$ & $\stackrel{8}{8}$ & $\stackrel{0}{0}$ & $\stackrel{8}{\circ}$ & 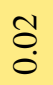 & $\stackrel{\infty}{\circ}$ & $\stackrel{\Omega}{\circ}$ & $\ddot{0}$ & $\stackrel{8}{8}$ & $\stackrel{8}{8}$ & 8 & $\stackrel{8}{8}$ & $\stackrel{8}{\circ}$ & $\stackrel{t}{\mathrm{O}}$ \\
\hline & 山् & $\stackrel{8}{\circ}$ & $\stackrel{8}{8}$ & $\stackrel{8}{\circ}$ & $\stackrel{8}{\circ}$ & $\begin{array}{l}\infty \\
\stackrel{0}{0}\end{array}$ & $\ddot{0}$ & 웅 & $\stackrel{8}{\circ}$ & $\stackrel{8}{8}$ & $\stackrel{8}{8}$ & \& & $\stackrel{8}{\circ}$ & $\stackrel{8}{\circ}$ & $\underset{\sigma}{\sigma}$ \\
\hline & D & $\stackrel{8}{8}$ & $\stackrel{\overline{0}}{\circ}$ & 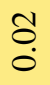 & $\underset{\mathrm{\delta}}{\mathrm{\delta}}$ & $\stackrel{8}{8}$ & $\stackrel{8}{8}$ & $\stackrel{8}{\circ}$ & $\stackrel{8}{8}$ & $\begin{array}{l}8 \\
\\
0\end{array}$ & $\begin{array}{l}8 \\
\end{array}$ & $\begin{array}{l}8 \\
\\
\end{array}$ & $\begin{array}{l}8 \\
\\
\end{array}$ & $\stackrel{8}{8}$ & $\stackrel{0}{-}$ \\
\hline & $u$ & $\stackrel{8}{\circ}$ & $\stackrel{0}{0}$ & $\stackrel{\circ}{\circ}$ & $\stackrel{0}{0}$ & $\stackrel{8}{\circ}$ & $\stackrel{8}{\circ}$ & $\stackrel{8}{\circ}$ & $\stackrel{8}{\circ}$ & $\stackrel{8}{8}$ & $\stackrel{8}{8}$ & $\stackrel{8}{8}$ & $\stackrel{8}{8}$ & $\stackrel{8}{\circ}$ & $\stackrel{g}{\circ}$ \\
\hline & $\infty$ & $\stackrel{8}{8}$ & ?ొ & 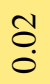 & $\stackrel{0}{0}$ & $\stackrel{8}{\circ}$ & $\stackrel{8}{0}$ & $\stackrel{8}{\circ}$ & $\stackrel{8}{\circ}$ & $\stackrel{8}{8}$ & $\stackrel{8}{8}$ & 8. & $\stackrel{8}{8}$ & $\stackrel{8}{\circ}$ & ले \\
\hline & $\ll$ & ō & $\begin{array}{l}\text { +̦ } \\
\text { i }\end{array}$ & $\frac{m}{\dot{0}}$ & $\begin{array}{l}n \\
0 \\
\stackrel{\varphi}{0}\end{array}$ & 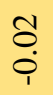 & $\begin{array}{l}\text { ô } \\
\stackrel{\varphi}{1}\end{array}$ & $\begin{array}{l}\text { ô } \\
\stackrel{0}{0}\end{array}$ & 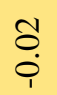 & $\begin{array}{l}\overline{0} \\
\dot{0}\end{array}$ & $\begin{array}{l}\overline{0} \\
0\end{array}$ & $\begin{array}{l}\overline{0} \\
\dot{0}\end{array}$ & $\begin{array}{l}\sigma_{0} \\
\stackrel{0}{0}\end{array}$ & $\stackrel{\overrightarrow{0}}{0}$ & $\stackrel{\widetilde{N}}{0}$ \\
\hline & $\begin{array}{l}\bar{\Xi} \\
\text { ప్త }\end{array}$ & $\ll$ & $\infty$ & $u$ & D & 山ు & L & 0 & $I$ & - & $\neg$ & $\forall$ & ــ & $\Sigma$ & స్త్రే \\
\hline & & & & & & & & & & & & & & & \\
\hline
\end{tabular}




\subsubsection{Raw Population Figures}

In Table 5.3, the gravity model produced results of raw population figures for the half-mile buffer. The same diagonally aligned pattern of station areas attracted to their host stations is evident once again. It should also be noted that station area origindestination pairs that are at opposite ends of the corridor from each other tend to have lower attractiveness indices. For example, destinations in the San Francisco Bay Area tended to be unattractive to origins in the Los Angeles Metropolitan Area, as shown in the lower left portion of Table 5.3. Likewise, destinations in the Los Angeles Metropolitan Area were unattractive to origins in the San Francisco Bay Area, as shown in the upper right portion of Table 5.3. 
Table 5.3 Accessibility indices for origin-destination pairs from raw population figures for half-mile buffer. Green, yellow, and red cells denote relatively high, medium, and low values, respectively. Blue cells denote row or column totals.

\begin{tabular}{|c|c|c|c|c|c|c|c|c|c|c|c|c|c|c|c|}
\hline \multirow{14}{*}{ 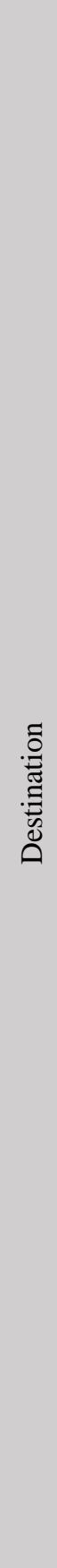 } & స్ & $\underset{8}{8}$ & $\underset{8}{8}$ & $\underset{8}{8}$ & 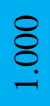 & $\underset{8}{8}$ & $\underset{8}{8}$ & \&̊ & $\underset{8}{8}$ & $\underset{ْ}{8}$ & $\underset{8}{8}$ & $\underset{8}{8}$ & $\underset{8}{8}$ & $\underset{8}{8}$ & $\begin{array}{l}\delta \\
\delta \\
\ddot{\imath} \\
\end{array}$ \\
\hline & $\Sigma$ & $\begin{array}{l}8 \\
8 \\
0\end{array}$ & $\begin{array}{l}8 \\
8 \\
0\end{array}$ & $\overline{8}$ & $\begin{array}{l}\overline{8} \\
\dot{0}\end{array}$ & $\begin{array}{l}8 \\
0 \\
0\end{array}$ & 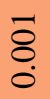 & s. & 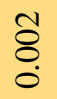 & $\overline{8}$ & $\begin{array}{l}\text { ô } \\
\text {. }\end{array}$ & 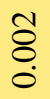 & $\begin{array}{l}+ \\
8 \\
0\end{array}$ & $\frac{\infty}{a}$ & \\
\hline & \lrcorner & $\stackrel{\overline{8}}{\circ}$ & $\begin{array}{l}\tilde{\delta} \\
\stackrel{0}{0}\end{array}$ & $\begin{array}{l}\widetilde{\delta} \\
\stackrel{0}{0}\end{array}$ & $\begin{array}{l}\text { ठै } \\
0 \\
0\end{array}$ & $\begin{array}{l}\tilde{8} \\
\stackrel{0}{0}\end{array}$ & $\begin{array}{l}+ \\
\stackrel{0}{0}\end{array}$ & $\begin{array}{l}+ \\
\stackrel{0}{0}\end{array}$ & $\begin{array}{l}\infty \\
8 \\
0\end{array}$ & $\begin{array}{l}+ \\
8 \\
\stackrel{0}{\circ}\end{array}$ & 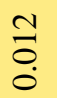 & $\begin{array}{l}a \\
0 \\
\stackrel{0}{0}\end{array}$ & $\begin{array}{l}\infty \\
\stackrel{0}{0} \\
\stackrel{0}{0}\end{array}$ & $\begin{array}{l}\text { o } \\
0 \\
0\end{array}$ & ô \\
\hline & $\forall$ & $\overrightarrow{8}$ & $\begin{array}{l}\overline{8} \\
\dot{0}\end{array}$ & $\begin{array}{l}\overline{8} \\
\dot{0}\end{array}$ & $\begin{array}{l}\overline{8} \\
\dot{0}\end{array}$ & $\begin{array}{l}\overline{8} \\
\dot{0}\end{array}$ & $\begin{array}{l}\tilde{8} \\
\dot{0}\end{array}$ & 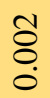 & $\stackrel{n}{8}$ & ڤి & $\stackrel{8}{0}$ & ๙े & $\stackrel{0}{0}$ & $\begin{array}{l}0 \\
0 \\
0\end{array}$ & $\begin{array}{l}\hat{\infty} \\
0 \\
0\end{array}$ \\
\hline & $\neg$ & $\overrightarrow{8}$ & $\overrightarrow{8}$ & $\overline{8}$ & $\overline{8}$ & $\overline{8}_{0}$ & $\begin{array}{l}\text { } \\
\tilde{0}\end{array}$ & 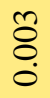 & $\begin{array}{l}0 \\
8 \\
0\end{array}$ & $\stackrel{+}{8}$ & $\begin{array}{l}\text { ڤू } \\
\stackrel{0}{0}\end{array}$ & $\stackrel{\infty}{8}$ & $\begin{array}{l}\text { ț } \\
0\end{array}$ & $\begin{array}{l}\infty \\
\stackrel{0}{0} \\
0\end{array}$ & $\underset{\mathrm{g}}{\stackrel{t}{0}}$ \\
\hline & - & $\begin{array}{l}\overline{8} \\
\dot{0}\end{array}$ & 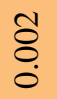 & $\begin{array}{l}\text { ô } \\
\stackrel{0}{0}\end{array}$ & $\begin{array}{l}\tilde{8} \\
\dot{0}\end{array}$ & $\begin{array}{l}1 \\
\tilde{8}\end{array}$ & \begin{tabular}{l}
8 \\
\hdashline \\
0
\end{tabular} & $\begin{array}{l}\mathscr{8} \\
\dot{0}\end{array}$ & $\stackrel{\Delta}{\circ}$ & $\frac{n}{\hat{a}}$ & $\stackrel{n}{8}$ & $\stackrel{8}{0}$ & $\begin{array}{l}0 \\
\tilde{o}\end{array}$ & $\begin{array}{l}\mathscr{8} \\
\tilde{0}\end{array}$ & ֶి \\
\hline & $I$ & $\begin{array}{l}8 \\
0 \\
0\end{array}$ & $\overrightarrow{8}$ & 追 & 훙 & $\begin{array}{l}\overline{8} \\
0\end{array}$ & $\begin{array}{l}\text { t) } \\
0 \\
0\end{array}$ & $\stackrel{0}{0}$ & $\begin{array}{l}\text { Oे } \\
\infty \\
0\end{array}$ & $\begin{array}{l}\text { ô } \\
0 \\
0\end{array}$ & $\overrightarrow{8}$ & 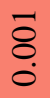 & $\begin{array}{l}8 \\
0 \\
0\end{array}$ & 追 & $\frac{\sim}{a}$ \\
\hline & 0 & $\begin{array}{l}\overline{8} \\
\stackrel{0}{0}\end{array}$ & $\begin{array}{l}\text { ô } \\
\stackrel{0}{0}\end{array}$ & 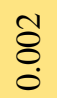 & 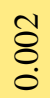 & $\begin{array}{l}+ \\
\stackrel{0}{0} \\
0\end{array}$ & $\stackrel{a}{\partial}$ & $\begin{array}{l}\bar{\sigma} \\
\stackrel{0}{0}\end{array}$ & 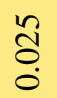 & $\begin{array}{l}\text { ơ } \\
\stackrel{0}{0}\end{array}$ & $\stackrel{\overline{8}}{\circ}$ & $\begin{array}{l}\overline{8} \\
\dot{0}\end{array}$ & $\begin{array}{l}\overline{8} \\
\stackrel{0}{0}\end{array}$ & 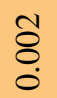 & 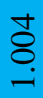 \\
\hline & IL & $\begin{array}{l}\overline{8} \\
\stackrel{0}{0}\end{array}$ & $\stackrel{\overline{8}}{\circ}$ & 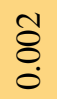 & 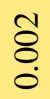 & $\begin{array}{l}8 \\
\vdots \\
0\end{array}$ & ڤి & $\bar{\sigma}$ & $\stackrel{0}{\circ}$ & 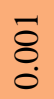 & $\stackrel{\overline{8}}{\circ}$ & ¿্ & \begin{tabular}{l}
8 \\
\hdashline \\
0
\end{tabular} & $\overline{8}$ & \begin{tabular}{l}
\multirow{J}{*}{} \\
$\stackrel{0}{0}$
\end{tabular} \\
\hline & 피 & $\begin{array}{l}\text { ఠ̊ } \\
\stackrel{0}{0}\end{array}$ & $\begin{array}{l}\tilde{8} \\
\stackrel{0}{0}\end{array}$ & $\begin{array}{l}\mathscr{o} \\
\stackrel{0}{0}\end{array}$ & $\begin{array}{l}\mathscr{0} \\
\stackrel{0}{0} \\
0\end{array}$ & $\stackrel{\Re}{\hat{\alpha}}$ & ळ̋. & $\stackrel{\sim}{0}$ & $\stackrel{n}{0}$ & $\begin{array}{l}\text { ô } \\
\stackrel{0}{0}\end{array}$ & $\underset{\delta}{\tilde{O}}$ & 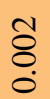 & $\begin{array}{l}\overline{8} \\
\stackrel{0}{0}\end{array}$ & 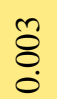 & ह̂. \\
\hline & D & $\begin{array}{l}\text { ôे } \\
0\end{array}$ & $\begin{array}{l}8 \\
8 \\
0 \\
0\end{array}$ & $\frac{n}{0}$ & $\begin{array}{l}\stackrel{\infty}{2} \\
\stackrel{0}{0}\end{array}$ & $\begin{array}{l}0 \\
\stackrel{0}{0}\end{array}$ & $\stackrel{0}{0}$ & $\begin{array}{l}+ \\
\stackrel{0}{0} \\
0\end{array}$ & $\begin{array}{l}\hat{8} \\
0\end{array}$ & 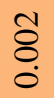 & $\begin{array}{l}\overline{8} \\
\stackrel{0}{0}\end{array}$ & $\begin{array}{l}\overline{8} \\
\stackrel{0}{0}\end{array}$ & $\begin{array}{l}\overline{8} \\
\stackrel{0}{0}\end{array}$ & $\begin{array}{l}\text { ô } \\
\stackrel{0}{0}\end{array}$ & $\bar{\sigma}$ \\
\hline & $u$ & $\begin{array}{l}\text { ¿ } \\
\stackrel{0}{0}\end{array}$ & $\begin{array}{l}\circ \\
0 \\
0\end{array}$ & $\begin{array}{l}\text { Iै } \\
\text { oे }\end{array}$ & $\vec{\sigma}$ & $\begin{array}{l}\text { ô } \\
\stackrel{0}{0}\end{array}$ & $\begin{array}{l}\mathscr{8} \\
\varnothing \\
0\end{array}$ & $\begin{array}{l}\tilde{\delta} \\
\stackrel{0}{0}\end{array}$ & $\begin{array}{l}n \\
8 \\
0\end{array}$ & $\begin{array}{l}\overline{8} \\
\stackrel{0}{0}\end{array}$ & $\begin{array}{l}\overline{8} \\
\end{array}$ & $\begin{array}{l}\overline{8} \\
\stackrel{0}{0}\end{array}$ & $\begin{array}{l}8 \\
8 \\
0\end{array}$ & $\begin{array}{l}\overline{8} \\
\stackrel{0}{0}\end{array}$ & 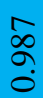 \\
\hline & 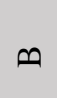 & $\begin{array}{l}n \\
0 \\
0\end{array}$ & 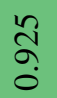 & 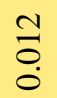 & $\begin{array}{l}\mathscr{8} \\
\dot{0}\end{array}$ & $\begin{array}{l}\tilde{\delta} \\
\stackrel{0}{0}\end{array}$ & $\begin{array}{l}+ \\
\stackrel{0}{0}\end{array}$ & $\stackrel{\overbrace{}}{8}$ & $\begin{array}{l}+ \\
8 \\
0\end{array}$ & $\begin{array}{l}\overline{8} \\
\dot{0}\end{array}$ & $\stackrel{\overline{8}}{0}$ & $\begin{array}{l}\overline{8} \\
\dot{0}\end{array}$ & $\begin{array}{l}8 \\
8 \\
0\end{array}$ & $\begin{array}{l}\overline{8} \\
\dot{0}\end{array}$ & $\frac{\Delta}{\hat{a}}$ \\
\hline & $\ll$ & $\begin{array}{l}\stackrel{2}{a} \\
\text { o. }\end{array}$ & 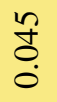 & $\frac{n}{0}$ & $\begin{array}{l}\infty \\
\stackrel{8}{0} \\
0\end{array}$ & $\begin{array}{l}0 \\
0 \\
0\end{array}$ & \begin{tabular}{l}
8 \\
\hdashline \\
\hdashline
\end{tabular} & $\begin{array}{l}+ \\
8 \\
0\end{array}$ & $\begin{array}{l}\hat{8} \\
0\end{array}$ & 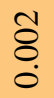 & 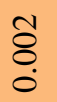 & $\begin{array}{l}\overline{8} \\
\stackrel{0}{0}\end{array}$ & $\begin{array}{l}\overline{8} \\
\stackrel{0}{0}\end{array}$ & $\begin{array}{l}\text { ô } \\
\stackrel{0}{0}\end{array}$ & 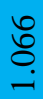 \\
\hline & $\begin{array}{l}\bar{\Xi} \\
\text { ప్త }\end{array}$ & $\ll$ & $\varphi$ & $u$ & D & 디 & II & ט & $I$ & $\neg$ & $\sim$ & 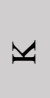 & \lrcorner & $\Sigma$ & $\begin{array}{l}\frac{\pi}{0} \\
\stackrel{0}{0}\end{array}$ \\
\hline & & & & & & & & & & & & & & & \\
\hline
\end{tabular}




\subsubsection{Normalized Population Figures}

Table 5.4 shows the results of the gravity model of normalized population figures at the half-mile buffer. When compared to the results shown in Table 5.3, the values are not as pronounced on a relative basis. Besides the stations within their own station areas, most stations have relatively equal attractiveness to each other as destinations. Like in Table 5.2, however, San Francisco as a destination is unattractive to Millbrae as an origin. Besides a few other station area origin-destination pairs that have relatively lower accessibility indices, Table 5.4 has an identical pattern to that of Table 5.2. 
Table 5.4 Accessibility indices for origin-destination pairs from normalized population figures for half mile buffer. Green, yellow, and red cells denote relatively high, medium, and low values, respectively. Blue cells denote row or column totals.

\begin{tabular}{|c|c|c|c|c|c|c|c|c|c|c|c|c|c|c|c|}
\hline \multirow{14}{*}{ 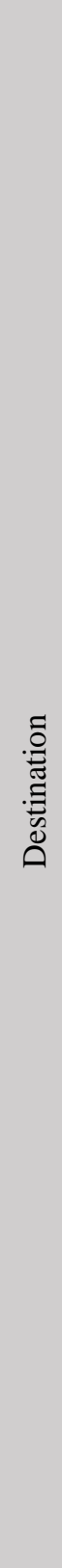 } & $\underset{\widetilde{0}}{\tilde{\theta}}$ & $\stackrel{8}{8}$ & $\stackrel{8}{8}$ & $\stackrel{8}{8}$ & $\stackrel{8}{8}$ & $\stackrel{8}{-}$ & $\underset{-}{8}$ & $\stackrel{8}{-}$ & $\stackrel{8}{8}$ & $\stackrel{8}{8}$ & $\underset{-}{\stackrel{8}{-}}$ & $\underset{-}{8}$ & $\underset{-}{8}$ & 8 & $\begin{array}{l}8 \\
\stackrel{\leftrightarrow}{\longrightarrow}\end{array}$ \\
\hline & $\Sigma$ & $\stackrel{8}{\circ}$ & $\stackrel{\overline{0}}{\circ}$ & $\stackrel{8}{\circ}$ & 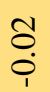 & $\stackrel{8}{\circ}$ & $\stackrel{8}{8}$ & $\stackrel{8}{\circ}$ & $\stackrel{8}{\circ}$ & o. & $\stackrel{0}{0}$ & $\begin{array}{l}\because 0 \\
\stackrel{0}{0}\end{array}$ & $\overline{0}_{0}$ & کૃ. & $\begin{array}{l}\infty \\
\infty \\
\infty\end{array}$ \\
\hline & 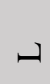 & $\stackrel{8}{8}$ & $\begin{array}{l}\overline{0} \\
0\end{array}$ & $\begin{array}{l}\sigma \\
0 \\
0\end{array}$ & $\stackrel{\Delta}{0}$ & $\stackrel{8}{\circ}$ & : & $\stackrel{8}{\circ}$ & $\stackrel{8}{\circ}$ & $\stackrel{\overline{0}}{\circ}$ & $\frac{\infty}{0}$ & ڤึ) & $\underset{-}{0}$ & $\begin{array}{l}\text { ô } \\
0 \\
\end{array}$ & $\stackrel{\infty}{\stackrel{\infty}{\sim}}$ \\
\hline & 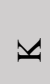 & $\stackrel{8}{8}$ & $\stackrel{8}{\circ}$ & $\stackrel{8}{8}$ & $\stackrel{8}{8}$ & $\stackrel{8}{\circ}$ & $\stackrel{8}{8}$ & $\stackrel{8}{\circ}$ & $\stackrel{8}{\circ}$ & 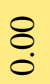 & ö. & 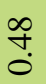 & $\stackrel{8}{\circ}$ & $\stackrel{8}{8}$ & $\begin{array}{l}\infty \\
\stackrel{+}{0}\end{array}$ \\
\hline & $\neg$ & $\stackrel{8}{8}$ & $\stackrel{8}{8}$ & $\stackrel{8}{8}$ & $\stackrel{8}{8}$ & $\stackrel{8}{\circ}$ & $\stackrel{8}{8}$ & $\stackrel{8}{\circ}$ & $\stackrel{8}{\circ}$ & $\stackrel{8}{\circ}$ & گ̆ & ठே. & $\underset{0}{8}$ & $\stackrel{8}{8}$ & $\hat{\sigma}$ \\
\hline & - & $\begin{array}{l}8 \\
0\end{array}$ & $\stackrel{8}{8}$ & $\begin{array}{l}8 \\
0\end{array}$ & 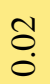 & $\underset{0}{8}$ & $\stackrel{8}{8}$ & $\stackrel{8}{8}$ & $\stackrel{8}{8}$ & 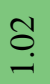 & $\stackrel{\wp}{0}$ & $\tilde{O}_{0}$ & $\stackrel{8}{8}$ & 8 & ְִ \\
\hline & $I$ & $\stackrel{8}{8}$ & 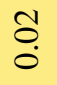 & $\stackrel{\circ}{0}$ & $\begin{array}{l}8 \\
0 \\
\dot{0}\end{array}$ & $\begin{array}{l}0 \\
\stackrel{0}{0}\end{array}$ & $\stackrel{\Xi}{\circ}$ & $\stackrel{0}{0}$ & $\stackrel{8}{8}$ & $\begin{array}{l}\text { Oे } \\
\stackrel{0}{0}\end{array}$ & $\begin{array}{l}\mathscr{0} \\
\stackrel{0}{0}\end{array}$ & $\begin{array}{l}\text { Oo } \\
\dot{\varphi}\end{array}$ & $\underset{8}{8}$ & : & $\begin{array}{l}\stackrel{2}{\circ} \\
\text { }\end{array}$ \\
\hline & 0 & $\stackrel{8}{8}$ & $\ddot{\circ}$ & $\stackrel{\circ}{\circ}$ & $\begin{array}{l}n \\
\stackrel{0}{0} \\
\dot{p}\end{array}$ & $\begin{array}{l}0 \\
\dot{0}\end{array}$ & $\stackrel{\circ}{\circ}$ & ஜ̊ & $\stackrel{\circ}{\circ}$ & $\begin{array}{l}\overline{0} \\
\stackrel{\varphi}{\varphi}\end{array}$ & $\begin{array}{c}\text { ô } \\
\stackrel{\varphi}{1}\end{array}$ & $\begin{array}{l}0 \\
\dot{0}\end{array}$ & $\stackrel{8}{8}$ & ¿. & ஓ̊. \\
\hline & $L$ & $\stackrel{8}{8}$ & $\stackrel{\leftrightarrow}{0}$ & $\stackrel{0}{0}$ & $\frac{0}{0}$ & $\begin{array}{l}\text { ¿̂. } \\
\text {. }\end{array}$ & $\stackrel{8}{8}$ & $\stackrel{0}{0}$ & $\stackrel{\sigma}{0}$ & o. & $\begin{array}{l}0 \\
0 \\
0\end{array}$ & $\begin{array}{l}0 \\
0 \\
0\end{array}$ & $\stackrel{8}{8}$ & $\stackrel{8}{8}$ & $\begin{array}{l}\infty \\
\infty \\
\infty \\
0\end{array}$ \\
\hline & 피 & $\stackrel{8}{8}$ & $\begin{array}{l}\sigma \\
0 \\
0\end{array}$ & ō. & $\stackrel{\infty}{\stackrel{0}{0}}$ & $\stackrel{\infty}{0}$ & ō. & ¿̄. & $\stackrel{8}{\circ}$ & $\stackrel{8}{8}$ & $\underset{0}{\delta}$ & ठ․ & $\stackrel{8}{8}$ & $\stackrel{8}{0}$ & oे \\
\hline & D & $\stackrel{8}{8}$ & $\stackrel{8}{\circ}$ & $\stackrel{8}{8}$ & $\underset{\text { ¿ }}{\text {. }}$ & $\stackrel{8}{\circ}$ & $\stackrel{8}{8}$ & $\stackrel{8}{\circ}$ & $\stackrel{8}{8}$ & $\stackrel{8}{\circ}$ & $\stackrel{8}{\circ}$ & $\stackrel{8}{8}$ & $\stackrel{8}{\circ}$ & $\stackrel{8}{8}$ & 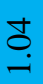 \\
\hline & $u$ & $\stackrel{8}{8}$ & 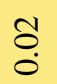 & Oָ & $\stackrel{\text { ọ }}{\circ}$ & $\stackrel{8}{\circ}$ & $\stackrel{8}{8}$ & $\stackrel{8}{\circ}$ & $\stackrel{8}{\circ}$ & $\stackrel{8}{8}$ & ö. & $\stackrel{8}{0}$ & $\stackrel{8}{\circ}$ & $\stackrel{8}{0}$ & o. \\
\hline & 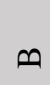 & $\stackrel{8}{\circ}$ & $\stackrel{\text { กิ }}{\text { I }}$ & $\stackrel{0}{0}$ & ڤై & $\stackrel{8}{\circ}$ & $\stackrel{8}{\circ}$ & $\stackrel{8}{\circ}$ & $\stackrel{8}{\circ}$ & $\stackrel{8}{\circ}$ & $\stackrel{8}{\circ}$ & $\stackrel{8}{8}$ & $\stackrel{8}{\circ}$ & $\stackrel{8}{\circ}$ & $\stackrel{9}{\longrightarrow}$ \\
\hline & $\varangle$ & ō. & $\begin{array}{l}\stackrel{0}{1} \\
\stackrel{1}{1}\end{array}$ & $\begin{array}{l}\dot{0} \\
\stackrel{0}{i}\end{array}$ & $\frac{1}{0}$ & $\stackrel{8}{\circ}$ & $\stackrel{8}{\circ}$ & $\stackrel{8}{\circ}$ & $\stackrel{8}{\circ}$ & $\stackrel{8}{\circ}$ & 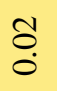 & $\sigma_{0}$ & $\stackrel{8}{\circ}$ & $\stackrel{8}{\circ}$ & $\bar{a}$ \\
\hline & $\begin{array}{l}\bar{\Xi} \\
\bar{\Xi} \\
\end{array}$ & $\varangle$ & $\infty$ & $U$ & D & ㅍ & L & ט & $I$ & - & $\sim$ & $\checkmark$ & ــ & $\Sigma$ & $\stackrel{\overline{\tilde{\theta}}}{\ominus}$ \\
\hline & & & & & & & & & & & & & & & \\
\hline
\end{tabular}




\subsubsection{Raw Housing Unit Figures}

Table 5.5 shows the results of the gravity model for raw housing unit figures at the half-mile distance. The relative pattern of station area origin-destination pair attractiveness in Table 5.5 resembles that of Table 5.4. This highlights the close relationship between population and housing. That is, for there to be people, there needs to be housing. Stations in the San Francisco Bay Area tended to be relatively less attracted to stations in the Los Angeles Metropolitan Area, and stations in the Los Angeles Metropolitan Area tended to be relatively less attracted to stations in the San Francisco Bay Area. This relationship is likely a result of the distance between the two groups of stations. On the other hand, stations in the San Joaquin Valley that had relatively sizeable housing and population clusters (e.g., Fresno and Bakersfield) were attractive to stations in both the San Francisco Bay and the Los Angeles Metropolitan Area. This is likely because of a combination of their relatively large housing and population clusters, and because they are located midway between the two major metropolitan areas (meaning that the distance to each is only half the length of the entire corridor. 
Table 5.5 Accessibility indices for origin-destination pairs from raw housing unit figures for half-mile buffer. Green, yellow, and red cells denote relatively high, medium, and low values, respectively. Blue cells denote row or column totals.

\begin{tabular}{|c|c|c|c|c|c|c|c|c|c|c|c|c|c|c|c|}
\hline \multirow{14}{*}{ 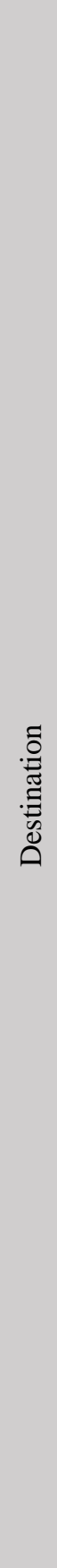 } & $\begin{array}{l}\frac{\pi}{0} \\
\stackrel{0}{0}\end{array}$ & $\underset{8}{8}$ & $\underset{8}{8}$ & $\underset{\text { \& }}{8}$ & $\underset{-}{8}$ & $\underset{-}{8}$ & $\stackrel{8}{8}$ & $\stackrel{8}{8}$ & $\stackrel{8}{8}$ & $\underset{8}{8}$ & $\underset{-}{8}$ & $\underset{8}{8}$ & $\underset{-}{\&}$ & $\underset{8}{8}$ & $\begin{array}{l}\stackrel{8}{8} \\
\stackrel{2}{2}\end{array}$ \\
\hline & $\Sigma$ & $\begin{array}{l}8 \\
8 \\
0\end{array}$ & $\begin{array}{l}8 \\
\stackrel{0}{0}\end{array}$ & $\begin{array}{l}\overline{8} \\
\dot{0}\end{array}$ & $\begin{array}{l}\overline{8} \\
\stackrel{0}{0}\end{array}$ & $\begin{array}{l}\overline{8} \\
\end{array}$ & 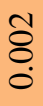 & $\begin{array}{l}\overline{8} \\
0\end{array}$ & $\tilde{\delta}_{0}$ & $\begin{array}{l}\overline{8} \\
\stackrel{0}{0}\end{array}$ & $\begin{array}{l}\text { ஜ } \\
\text { }\end{array}$ & $\begin{array}{l}\mathscr{8} \\
\stackrel{0}{0}\end{array}$ & $\begin{array}{l}\text { ঠे } \\
\text {. }\end{array}$ & 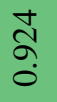 & \begin{tabular}{l}
\multirow{J}{*}{} \\
ò
\end{tabular} \\
\hline & - & $\begin{array}{l}\overline{8} \\
\stackrel{0}{0}\end{array}$ & $\stackrel{\text { ô }}{\circ}$ & $\stackrel{\text { }}{0}$ & $\stackrel{\text { ̊े }}{\circ}$ & 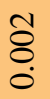 & $\stackrel{8}{8}$ & $\stackrel{0}{0}$ & $\stackrel{0}{\circ}$ & $\stackrel{+}{\stackrel{0}{0}}$ & $\stackrel{\Delta}{\circ}$ & $\stackrel{\tilde{n}}{\mathscr{0}}$ & $\hat{a}$ & ભે & $\begin{array}{l}\varrho \\
ٍ\end{array}$ \\
\hline & 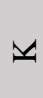 & వ্. & $\begin{array}{l}\overline{8} \\
\dot{0}\end{array}$ & $\begin{array}{l}\overline{8} \\
0 \\
0\end{array}$ & ठ্ & $\stackrel{\overline{8}}{\circ}$ & $\begin{array}{l}\tilde{\delta} \\
0\end{array}$ & 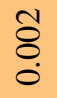 & $\begin{array}{l}8 \\
\vdots \\
0\end{array}$ & 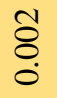 & $\stackrel{0}{\circ}$ & $\begin{array}{l}\tilde{2} \\
\text { ô }\end{array}$ & $\stackrel{n}{a}$ & $\underset{0}{\stackrel{J}{0}}$ & 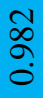 \\
\hline & $\sim$ & $\begin{array}{l}\overline{8} \\
\dot{0}\end{array}$ & $\begin{array}{l}\overline{8} \\
0\end{array}$ & $\begin{array}{l}\overline{8} \\
\dot{0}\end{array}$ & ¿ & $\begin{array}{l}\overline{8} \\
0\end{array}$ & $\stackrel{\wp}{8}$ & 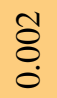 & $\hat{8}$ & $\begin{array}{l}0 \\
\delta\end{array}$ & 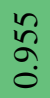 & $\begin{array}{l}\hat{8} \\
0\end{array}$ & $\stackrel{\tilde{\delta}}{0}$ & $\begin{array}{l}8 \\
8 \\
0\end{array}$ & ă \\
\hline & - & $\stackrel{\overline{8}}{0}$ & $\begin{array}{l}\text { ò } \\
\stackrel{0}{0}\end{array}$ & $\begin{array}{l}\tilde{8} \\
0\end{array}$ & §̊ & 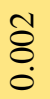 & $\begin{array}{l}\stackrel{8}{8} \\
\stackrel{0}{\circ}\end{array}$ & $\stackrel{\wp}{8}$ & 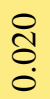 & $\begin{array}{l}\infty \\
\hat{a} \\
0\end{array}$ & $\begin{array}{l}1 \\
8 \\
0\end{array}$ & $\begin{array}{l}+ \\
\stackrel{0}{0}\end{array}$ & 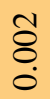 & $\begin{array}{l}n \\
:\end{array}$ & 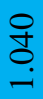 \\
\hline & $\Psi$ & \begin{tabular}{l}
8 \\
\hdashline \\
0
\end{tabular} & \begin{tabular}{l}
8 \\
\hdashline \\
0
\end{tabular} & $\begin{array}{l}\overline{8} \\
0\end{array}$ & $\begin{array}{l}\overline{8} \\
0\end{array}$ & $\begin{array}{l}\overline{8} \\
\dot{0}\end{array}$ & $\begin{array}{l}\text { t) } \\
\stackrel{0}{0}\end{array}$ & $\begin{array}{l}\mathbb{8} \\
\stackrel{8}{0}\end{array}$ & $\begin{array}{l}\hat{\sigma} \\
\infty \\
0 \\
0\end{array}$ & $\begin{array}{l}\overline{8} \\
\dot{0}\end{array}$ & $\bar{\delta}_{0}$ & $\begin{array}{l}8 \\
8 \\
0\end{array}$ & \begin{tabular}{l}
8 \\
\hdashline \\
0
\end{tabular} & $\stackrel{\overline{8}}{\circ}$ & $\begin{array}{c}\underset{\Delta}{\infty} \\
0 \\
0\end{array}$ \\
\hline & 0 & $\underset{8}{\overline{8}}$ & 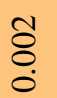 & $\begin{array}{l}\text { ̊̊ } \\
0\end{array}$ & $\begin{array}{l}\text { } \\
0 \\
0\end{array}$ & $\stackrel{n}{8}$ & 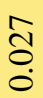 & $\begin{array}{l}\hat{n} \\
\hat{o}\end{array}$ & $\begin{array}{l}\infty \\
\stackrel{\infty}{0} \\
\dot{0}\end{array}$ & $\begin{array}{l}\tilde{\delta} \\
\stackrel{0}{0}\end{array}$ & $\begin{array}{l}\widehat{\delta} \\
\stackrel{0}{0}\end{array}$ & $\begin{array}{l}\overline{8} \\
0\end{array}$ & $\underset{8}{\overline{8}}$ & $\begin{array}{l}\tilde{\delta} \\
\stackrel{0}{0}\end{array}$ & $\underset{\square}{\vec{g}}$ \\
\hline & I & $\stackrel{\overline{8}}{\circ}$ & $\begin{array}{l}\overline{8} \\
\dot{0}\end{array}$ & 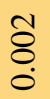 & ô & $\stackrel{\wp}{8}$ & $\begin{array}{c}\hat{\infty} \\
\infty \\
0 \\
0\end{array}$ & $\stackrel{8}{8}$ & $\begin{array}{l}\circ \\
0 \\
0\end{array}$ & $\stackrel{\overline{8}}{\circ}$ & $\begin{array}{l}\overline{8} \\
\dot{0}\end{array}$ & $\begin{array}{l}\overline{8} \\
\stackrel{0}{0}\end{array}$ & \begin{tabular}{l}
8 \\
\hdashline \\
0
\end{tabular} & ¿̈. & $\frac{a}{a}$ \\
\hline & 以工 & 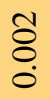 & $\begin{array}{l}0 \\
\tilde{0}\end{array}$ & $\begin{array}{l}8 \\
8 \\
0\end{array}$ & $\begin{array}{l}8 \\
8 \\
\circ\end{array}$ & $\begin{array}{l}t \\
\hat{a} \\
0\end{array}$ & ס̊ & $\begin{array}{l}\bar{\sigma} \\
0 \\
0\end{array}$ & 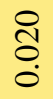 & $\begin{array}{l}\text { ô } \\
\text {. }\end{array}$ & $\begin{array}{l}\text { ठิ } \\
\dot{0}\end{array}$ & $\begin{array}{l}\tilde{\delta} \\
\stackrel{0}{0}\end{array}$ & $\overline{8}$ & $\begin{array}{l}\text { ô } \\
\text {. }\end{array}$ & 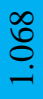 \\
\hline & ค & $\stackrel{8}{8}$ & $\stackrel{n}{8}$ & $\stackrel{0}{0}$ & 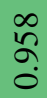 & $\stackrel{8}{8}$ & $\begin{array}{l}\stackrel{8}{8} \\
\stackrel{0}{\circ}\end{array}$ & $\stackrel{0}{0}$ & $\stackrel{\circ}{8}$ & ¿্口 & ¿े & $\stackrel{\overline{8}}{\circ}$ & $\begin{array}{l}\overline{8} \\
\stackrel{0}{0}\end{array}$ & $\overline{8}$ & $\bar{\sigma}$ \\
\hline & U & $\underset{8}{\stackrel{t}{8}}$ & $\hat{8}$ & $\hat{\widehat{\sigma}}$ & $\stackrel{8}{8}$ & $\begin{array}{l}\text { ¿ै } \\
\stackrel{0}{0}\end{array}$ & $\begin{array}{l}\stackrel{+}{8} \\
\stackrel{0}{\circ}\end{array}$ & $\begin{array}{l}1 \\
\stackrel{8}{0} \\
\stackrel{0}{0}\end{array}$ & $\ddot{8}$ & $\stackrel{\overline{8}}{0}$ & ¿े & $\stackrel{\overline{8}}{0}$ & $\begin{array}{l}8 \\
8\end{array}$ & $\overrightarrow{8}$ & $\begin{array}{l}\text { ֶ̊ } \\
\stackrel{2}{0}\end{array}$ \\
\hline & 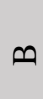 & $\stackrel{0}{0}$ & ळે & $\stackrel{0}{0}$ & $\stackrel{8}{\circ}$ & 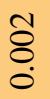 & $\stackrel{1}{8}$ & $\stackrel{8}{8}$ & $\begin{array}{l}8 \\
8 \\
0\end{array}$ & $\stackrel{\overline{8}}{\circ}$ & 官 & $\stackrel{\overline{8}}{\circ}$ & \begin{tabular}{l}
8 \\
\hdashline
\end{tabular} & $\overline{8}$ & $\overbrace{\tilde{\theta}}$ \\
\hline & $\ll$ & $\begin{array}{l}\circ \\
\stackrel{0}{0} \\
\stackrel{0}{0}\end{array}$ & 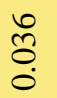 & $\frac{1}{0}$ & $\stackrel{\infty}{\stackrel{8}{\circ}}$ & $\begin{array}{l}\text { ô } \\
\stackrel{0}{0}\end{array}$ & $\hat{8}$ & $\begin{array}{l}\tilde{8} \\
\stackrel{0}{0}\end{array}$ & $\stackrel{\infty}{\stackrel{8}{0}}$ & $\begin{array}{l}\overline{8} \\
\stackrel{0}{0}\end{array}$ & 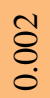 & $\begin{array}{l}\overline{8} \\
\stackrel{0}{0}\end{array}$ & $\begin{array}{l}\overline{8} \\
\stackrel{0}{0}\end{array}$ & $\begin{array}{l}\text { ò } \\
\stackrel{0}{0}\end{array}$ & t. \\
\hline & $\begin{array}{l}\bar{D} \\
\text { త్ }\end{array}$ & $\ll$ & 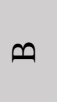 & U & D & 디 & $\amalg$ & 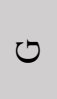 & $I$ & - & $\neg$ & 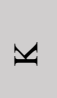 & \lrcorner & $\Sigma$ & 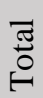 \\
\hline & & & & & & & & & & & & & & & \\
\hline
\end{tabular}




\subsubsection{Normalized Housing Unit Figures}

Table 5.6 shows the results of the gravity model for normalized housing unit values at the half-mile radius. As with Table 5.2 and Table 5.4 showing normalized values, the differences in attractiveness between stations is less pronounced compared with their corresponding raw values, save for the few outliers. In Table 5.6, the outliers are origin-destination pairs, including Gilroy-to-San Francisco, Millbrae-to-San Jose, Burbank-to-Kings Tulare, Palmdale-to-Los Angeles, Anaheim-to-Los Angeles, and Burbank-to-Anaheim. One station that had a particularly low accessibility index was Burbank, with a total score of 0.34 . 
Table 5.6 Accessibility indices for origin-destination pairs from normalized housing unit figures for halfmile buffer. Green, yellow, and red cells denote relatively high, medium, and low values, respectively. Blue cells denote row or column totals.

\begin{tabular}{|c|c|c|c|c|c|c|c|c|c|c|c|c|c|c|c|}
\hline \multirow{14}{*}{ 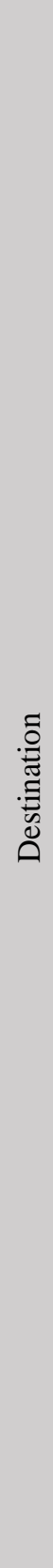 } & సٓ & $\stackrel{8}{8}$ & $\stackrel{8}{8}$ & $\stackrel{8}{8}$ & $\stackrel{8}{8}$ & $\stackrel{8}{8}$ & $\underset{-}{8}$ & $\underset{8}{8}$ & $\stackrel{8}{8}$ & $\underset{-}{8}$ & $\underset{-}{8}$ & $\stackrel{8}{8}$ & $\underset{-}{8}$ & $\underset{-}{8}$ & $\begin{array}{l}8 \\
\ddot{2}\end{array}$ \\
\hline & $\Sigma$ & $\stackrel{8}{\circ}$ & $\stackrel{8}{8}$ & $\stackrel{8}{8}$ & $\stackrel{\overline{0}}{\circ}$ & $\stackrel{8}{8}$ & $\stackrel{8}{8}$ & $\stackrel{8}{8}$ & $\stackrel{8}{8}$ & $\stackrel{8}{8}$ & $\stackrel{\leftrightarrow}{0}$ & $\begin{array}{l}n \\
0 \\
0\end{array}$ & $\begin{array}{l}\overline{0} \\
\stackrel{0}{1}\end{array}$ & $\stackrel{0}{0}$ & $\stackrel{8}{\circ}$ \\
\hline & \lrcorner & $\stackrel{8}{0}$ & $\stackrel{0}{0}$ & $\stackrel{8}{0}$ & $\begin{array}{l}\text { ô. } \\
0\end{array}$ & $\stackrel{8}{\circ}$ & $\stackrel{8}{\circ}$ & $\begin{array}{l}0 \\
0 \\
0\end{array}$ & $\stackrel{8}{\circ}$ & $\ddot{0}$ & $\begin{array}{l}8 \\
0 \\
\end{array}$ & $\stackrel{n}{\mathfrak{0}}$ & $\underset{0}{0}$ & $\begin{array}{l} \pm \\
0 \\
\end{array}$ & \\
\hline & $\mathscr{V}$ & $\stackrel{8}{8}$ & $\stackrel{8}{8}$ & $\stackrel{8}{8}$ & $\stackrel{8}{8}$ & $\stackrel{8}{8}$ & $\stackrel{8}{8}$ & $\stackrel{8}{8}$ & $\stackrel{8}{8}$ & $\stackrel{8}{8}$ & $\stackrel{8}{8}$ & $\stackrel{+}{m}$ & $\stackrel{8}{8}$ & $\stackrel{8}{8}$ & 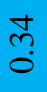 \\
\hline & $\sim$ & $\stackrel{8}{0}$ & $\stackrel{8}{8}$ & $\stackrel{8}{8}$ & $\stackrel{8}{8}$ & $\stackrel{8}{8}$ & $\stackrel{8}{\circ}$ & $\stackrel{8}{8}$ & $\stackrel{8}{8}$ & $\stackrel{8}{\circ}$ & $\underset{-}{\stackrel{t}{0}}$ & $\begin{array}{l}\text { ô. } \\
0 \\
i\end{array}$ & $\stackrel{8}{8}$ & $\stackrel{8}{0}$ & סִ \\
\hline & $\neg$ & $\stackrel{8}{\circ}$ & $\ddot{\circ}$ & $\stackrel{8}{\circ}$ & $\begin{array}{l}0 \\
0 \\
i\end{array}$ & $\stackrel{8}{\circ}$ & $\stackrel{8}{\circ}$ & ō. & $\stackrel{8}{\circ}$ & $\underset{\sigma}{\sigma}$ & $\begin{array}{l}\text { ô } \\
\stackrel{0}{0}\end{array}$ & $\stackrel{\overbrace{}}{0}$ & $\stackrel{8}{\circ}$ & $\stackrel{8}{\circ}$ & $\stackrel{8}{\circ}$ \\
\hline & $I$ & $\stackrel{8}{8}$ & $\begin{array}{l}0 \\
\stackrel{0}{0}\end{array}$ & $\tilde{O}_{0}$ & $\stackrel{\text { Oे. }}{0}$ & $\begin{array}{l}0 \\
0 \\
0\end{array}$ & $\stackrel{0}{0}$ & $\stackrel{\circ}{\circ}$ & $\stackrel{8}{\stackrel{8}{-}}$ & $\underset{\dot{\varphi}}{\ddot{0}}$ & $\stackrel{1}{0}$ & 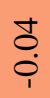 & $\stackrel{8}{8}$ & $\stackrel{8}{\circ}$ & $\hat{o}$ \\
\hline & ט & $\stackrel{8}{\circ}$ & $\stackrel{8}{\circ}$ & $\stackrel{8}{\circ}$ & $\stackrel{\overline{0}}{\circ}$ & $\stackrel{8}{\circ}$ & $\stackrel{8}{\circ}$ & $\begin{array}{l}\infty \\
\infty \\
0\end{array}$ & $\stackrel{8}{\circ}$ & $\stackrel{8}{\circ}$ & $\stackrel{8}{\circ}$ & $\stackrel{8}{\circ}$ & $\stackrel{8}{\circ}$ & $\stackrel{8}{\circ}$ & $\begin{array}{c}\infty \\
\infty \\
\infty \\
0\end{array}$ \\
\hline & L & $\stackrel{8}{8}$ & 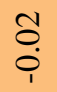 & ठ̄. & $\stackrel{\curvearrowleft}{0}$ & $\begin{array}{l}\text { ô } \\
\stackrel{\leftrightarrow}{1}\end{array}$ & $\stackrel{8}{8}$ & $\stackrel{\infty}{\stackrel{0}{0}}$ & $\ddot{\sigma}$ & $\stackrel{8}{8}$ & $\ddot{0}$ & $\begin{array}{l}\text { ô } \\
\text { ị }\end{array}$ & $\stackrel{8}{8}$ & $\stackrel{8}{8}$ & $\stackrel{5}{-}$ \\
\hline & 디 & $\stackrel{8}{8}$ & $\stackrel{\overrightarrow{0}}{\circ}$ & $\stackrel{8}{8}$ & $\begin{array}{l}\text { Oे } \\
\stackrel{0}{1}\end{array}$ & $\stackrel{\theta}{0}$ & $\begin{array}{l}0 \\
0 \\
0\end{array}$ & $\begin{array}{l}\text { ô } \\
\dot{0}\end{array}$ & $\stackrel{8}{8}$ & $\stackrel{8}{8}$ & $\begin{array}{l}\overline{0} \\
\dot{p}\end{array}$ & $\stackrel{0}{0}$ & $\stackrel{8}{8}$ & $\stackrel{8}{8}$ & $\begin{array}{l}\stackrel{2}{\circ} \\
\stackrel{0}{0}\end{array}$ \\
\hline & D & $\stackrel{8}{8}$ & $\stackrel{8}{8}$ & $\begin{array}{l}8 \\
\stackrel{0}{0}\end{array}$ & $\begin{array}{l}\dot{a} \\
\text { o }\end{array}$ & $\stackrel{8}{8}$ & $\stackrel{8}{8}$ & $\stackrel{8}{8}$ & $\stackrel{8}{8}$ & $\stackrel{8}{8}$ & $\stackrel{8}{8}$ & $\stackrel{8}{8}$ & $\stackrel{8}{8}$ & $\stackrel{8}{8}$ & ț \\
\hline & $u$ & $\begin{array}{l}0 \\
0 \\
\end{array}$ & $\begin{array}{l}8 \\
\stackrel{0}{0}\end{array}$ & 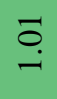 & $\stackrel{\infty}{\circ}$ & $\stackrel{8}{8}$ & $\stackrel{8}{8}$ & $\stackrel{\square}{\circ}$ & $\stackrel{8}{\circ}$ & 8 & 8 & $\begin{array}{l}0 \\
0 \\
\end{array}$ & 8 & $\stackrel{8}{\circ}$ & $\stackrel{\overbrace{}}{0}$ \\
\hline & $\infty$ & 8: & $\begin{array}{l}\infty \\
\infty \\
0\end{array}$ & $\stackrel{8}{8}$ & $\begin{array}{l}\sigma \\
\dot{0}\end{array}$ & $\stackrel{8}{8}$ & $\stackrel{8}{8}$ & $\stackrel{8}{8}$ & $\stackrel{8}{8}$ & $\stackrel{8}{8}$ & $\stackrel{8}{8}$ & $\stackrel{8}{8}$ & $\stackrel{8}{\circ}$ & $\stackrel{8}{8}$ & $\begin{array}{c}\infty \\
0 \\
0\end{array}$ \\
\hline & $\varangle$ & $\underset{8}{8}$ & ণి & $\begin{array}{l}\overline{0} \\
\dot{0}\end{array}$ & $\begin{array}{l}n \\
\stackrel{2}{0} \\
\stackrel{1}{1}\end{array}$ & $\stackrel{8}{\circ}$ & $\stackrel{8}{8}$ & $\begin{array}{l}\overline{0} \\
\dot{\varphi}\end{array}$ & $\stackrel{8}{8}$ & $\stackrel{8}{8}$ & $\stackrel{8}{8}$ & ō & $\stackrel{8}{8}$ & $\stackrel{8}{8}$ & $\stackrel{ \pm}{\Xi}$ \\
\hline & $\begin{array}{l}\bar{\Xi} \\
\text { స్తి }\end{array}$ & $\ll$ & 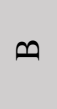 & $U$ & 0 & 피 & IL & 0 & $I$ & - & $\sim$ & $\forall$ & \lrcorner & $\Sigma$ & 茔 \\
\hline & & & & & & & & & & & & & & & \\
\hline
\end{tabular}




\subsection{Three-Mile Radius Results}

This section discusses the results of the gravity model applied to various attraction indicators at the three-mile catchment area radius. This distance represents the extent that cyclists are willing to travel to access transit nodes at Level of Service "C" (Nuworsoo et al., 2012, pdf-p. 2; FHWA, 1998), as stated in Section 4.2. The distance is also inclusive of pedestrians that are willing to walk half of a mile to access transit nodes.

\subsubsection{Raw Job Figures}

Table 5.7 displays the results of the gravity model of raw job numbers at the three-mile radius. The pattern shows that stations located at the ends of the corridor in the major metropolitan areas of California enjoy the highest attraction values as destinations. For example, the stations of San Francisco, Millbrae and San Jose enjoy attractiveness to other stations in the Bay Area and the San Joaquin Valley, while the stations of Burbank, Los Angeles, and Anaheim enjoy attractiveness to other stations in the Los Angeles Metropolitan Area and the San Joaquin Valley. San Francisco and Los Angeles enjoy the highest overall attraction values as destinations at 2.653 and 2.230 , respectively.

The stations from Gilroy to Bakersfield enjoy a relatively lower attractiveness to the rest of the corridor, however. These stations appear to be attractive to other stations that relatively close to them. For example, Gilroy is attractive to stations ranging from its own station area to Kings Tulare. Merced, Fresno, and Bakersfield were attractive to a larger range of stations compared to Gilroy. In Bakersfield's case, the attraction was north towards the San Joaquin Valley. Madera and Kings Tulare had virtually no attractiveness to other station areas, likely because of a lack of jobs within their station areas. 
Table 5.7 Accessibility indices for origin-destination pairs from raw job figures for three-mile buffer.

Green, yellow, and red cells denote relatively high, medium, and low values, respectively. Blue cells denote row or column totals.

\begin{tabular}{|c|c|c|c|c|c|c|c|c|c|c|c|c|c|c|c|}
\hline \multirow{14}{*}{ 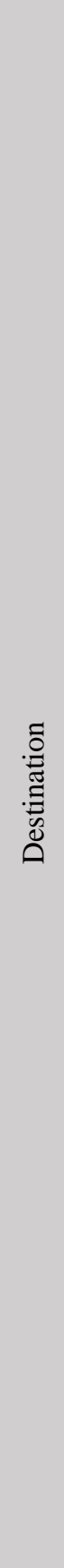 } & 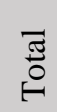 & $\underset{8}{8}$ & 8 & $\underset{-}{8}$ & $\underset{8}{8}$ & $\stackrel{8}{8}$ & $\underset{8}{8}$ & $\underset{8}{8}$ & $\underset{8}{8}$ & $\underset{8}{8}$ & 8 & $\underset{8}{8}$ & 8 & $\underset{-}{8}$ & $\begin{array}{l}\stackrel{8}{8} \\
\ddot{\imath}\end{array}$ \\
\hline & $\Sigma$ & $\begin{array}{l}\text { ठ̊ } \\
\text {. }\end{array}$ & $\begin{array}{l}8 \\
8 \\
0\end{array}$ & $\stackrel{n}{8}$ & 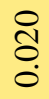 & 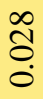 & $\begin{array}{l}0 \\
0 \\
0 \\
0\end{array}$ & $\stackrel{\infty}{\stackrel{\infty}{0}}$ & $\begin{array}{l}0 \\
\qquad \\
0 \\
0\end{array}$ & $\begin{array}{l}\text { ठे. } \\
\text { ¿े }\end{array}$ & $\begin{array}{l}20 \\
0 \\
0\end{array}$ & 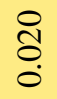 & $\begin{array}{l}\bar{\delta} \\
\dot{0}\end{array}$ & $\frac{\infty}{\stackrel{\infty}{\circ}}$ & $\stackrel{\ddots}{I}$ \\
\hline & \lrcorner & $\begin{array}{l}\text { ¿̊ } \\
\stackrel{0}{0}\end{array}$ & $\begin{array}{l}0 \\
0 \\
0\end{array}$ & $\stackrel{m}{0}$ & $\begin{array}{l}\bar{n} \\
0 \\
0\end{array}$ & 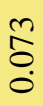 & $\frac{\vec{I}}{\overrightarrow{0}}$ & $\begin{array}{l}\text { fo } \\
\stackrel{0}{0}\end{array}$ & $\frac{\vec{n}}{\overrightarrow{0}}$ & $\begin{array}{l}\stackrel{+}{\infty} \\
\stackrel{0}{0} \\
0\end{array}$ & 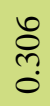 & $\frac{\Delta}{\infty}$ & $\begin{array}{l}n \\
\infty \\
0 \\
0\end{array}$ & $\frac{n}{0}$ & 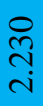 \\
\hline & 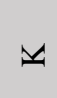 & $\begin{array}{l}\text { ơ } \\
\text { }\end{array}$ & $\begin{array}{l}8 \\
8 \\
0\end{array}$ & \begin{tabular}{l}
$\mathscr{8}$ \\
\hdashline
\end{tabular} & $\stackrel{a}{a}$ & $\begin{array}{l}\stackrel{\Xi}{\tilde{O}} \\
\stackrel{0}{0}\end{array}$ & $\begin{array}{l}\text { fo } \\
0\end{array}$ & $\stackrel{\infty}{0}$ & $\begin{array}{l}\stackrel{\partial}{0} \\
\stackrel{0}{0}\end{array}$ & 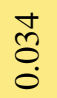 & $\frac{n}{9}$ & $\begin{array}{l}\text { బె } \\
\stackrel{0}{0}\end{array}$ & 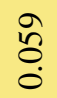 & હे & o̊ \\
\hline & $r$ & $\begin{array}{l}8 \\
8 \\
0\end{array}$ & $\begin{array}{l}\overline{8} \\
0\end{array}$ & $\overline{8}$ & $\begin{array}{l}\tilde{8} \\
0\end{array}$ & $\begin{array}{l}+ \\
\stackrel{8}{0}\end{array}$ & $\hat{8}$ & $\stackrel{\tilde{8}}{0}$ & $\begin{array}{l}\text { } \\
\text { : }\end{array}$ & $\begin{array}{l}8 \\
8 \\
0\end{array}$ & లి & $\begin{array}{l}+ \\
8 \\
0\end{array}$ & $\begin{array}{l}\tilde{\delta} \\
\stackrel{0}{0}\end{array}$ & $\begin{array}{l}\tilde{\delta} \\
\stackrel{0}{0}\end{array}$ & $\underset{\substack{N \\
0}}{0}$ \\
\hline & - & $\begin{array}{l}\overline{8} \\
\dot{0}\end{array}$ & $\begin{array}{l}0 \\
\delta\end{array}$ & $\begin{array}{l}0 \\
\delta\end{array}$ & $\stackrel{2}{3}$ & 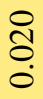 & ڤ̂́. & $\stackrel{0}{0}$ & $\begin{array}{l}\hat{\delta} \\
0\end{array}$ & $\frac{n}{\stackrel{n}{0}}$ & $\begin{array}{l}\bar{\delta} \\
\text { ○. }\end{array}$ & ஜे & $\begin{array}{l}\text { ठ̊ } \\
\text {. }\end{array}$ & $\stackrel{+}{8}$ & $\begin{array}{l}\text { ñ } \\
\text { on }\end{array}$ \\
\hline & $I$ & $\begin{array}{l}8 \\
0 \\
0\end{array}$ & $\begin{array}{l}8 \\
8 \\
0\end{array}$ & \&ి & $\begin{array}{l}\overline{8} \\
0\end{array}$ & 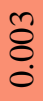 & $\begin{array}{l}\infty \\
8 \\
\stackrel{8}{0}\end{array}$ & $\begin{array}{l}\mathscr{8} \\
\ddot{0}\end{array}$ & $\frac{ \pm}{ \pm}$ & $\begin{array}{l}\text { ô } \\
\stackrel{0}{0}\end{array}$ & $\overline{8}$ & $\begin{array}{l}8 \\
8 \\
0\end{array}$ & $\begin{array}{l}8 \\
8 \\
0\end{array}$ & $\begin{array}{l}8 \\
8 \\
8\end{array}$ & $\begin{array}{l}\stackrel{2}{a} \\
\stackrel{0}{0}\end{array}$ \\
\hline & 0 & $\begin{array}{l}\tilde{\delta} \\
\stackrel{0}{0}\end{array}$ & $\begin{array}{l}n \\
\dot{8} \\
0\end{array}$ & $\begin{array}{l}8 \\
8 \\
0\end{array}$ & 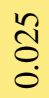 & ?ֶ. & 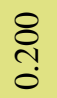 & 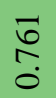 & $\frac{\infty}{\stackrel{0}{0}}$ & $\stackrel{0}{0}$ & $\stackrel{+}{0}$ & $\stackrel{\tilde{8}}{0}$ & $\overline{8}$ & 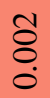 & $\stackrel{\overbrace{}}{\stackrel{\overbrace{}}{\rightarrow}}$ \\
\hline & I & $\begin{array}{l}8 \\
8 \\
0\end{array}$ & $\begin{array}{l}8 \\
8 \\
0\end{array}$ & $\begin{array}{l}8 \\
8 \\
0\end{array}$ & $\overline{8}$ & $\begin{array}{l}\text { t) } \\
\stackrel{0}{\circ}\end{array}$ & $\begin{array}{l}\infty \\
\stackrel{0}{0} \\
0\end{array}$ & $\stackrel{0}{0}$ & $\begin{array}{l}\stackrel{+}{0} \\
\stackrel{0}{0}\end{array}$ & $\overline{8}$ & $\begin{array}{l}8 \\
8 \\
0\end{array}$ & \&̊ & $\begin{array}{l}8 \\
8 \\
0\end{array}$ & \begin{tabular}{l}
8 \\
\hdashline \\
0
\end{tabular} & $\begin{array}{l}\text { to } \\
\stackrel{0}{0}\end{array}$ \\
\hline & 피 & $\begin{array}{l}\overline{8} \\
0 \\
0\end{array}$ & $\begin{array}{l}\text { ô } \\
\dot{0}\end{array}$ & $\begin{array}{l}\text { ठิ } \\
\stackrel{0}{0}\end{array}$ & $\begin{array}{l}\bar{\sigma} \\
0 \\
0\end{array}$ & $\begin{array}{l}\text { ते } \\
\text { त्र }\end{array}$ & $\begin{array}{l}\hat{\delta} \\
\ddot{0}\end{array}$ & $\stackrel{\sim}{\dddot{0}}$ & $\underset{\widetilde{\Xi}}{\stackrel{0}{0}}$ & $\begin{array}{l}+ \\
8 \\
0\end{array}$ & $\begin{array}{l}+ \\
8 \\
0\end{array}$ & $\begin{array}{l}\overline{8} \\
\dot{0}\end{array}$ & $\begin{array}{l}8 \\
8 \\
0\end{array}$ & $\begin{array}{l}\overline{8} \\
0\end{array}$ & \begin{tabular}{l}
$\infty$ \\
\multirow{2}{0}{} \\
0 \\
0
\end{tabular} \\
\hline & $\theta$ & $\begin{array}{l}\overline{8} \\
\dot{0}\end{array}$ & $\begin{array}{l}\text { to } \\
\stackrel{0}{0}\end{array}$ & oे & $\begin{array}{l}\text { ț } \\
\text { ֻn }\end{array}$ & छे & $\begin{array}{l}n \\
0 \\
0\end{array}$ & ¿ & $\begin{array}{l}\ddot{8} \\
0 \\
0\end{array}$ & 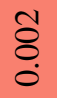 & $\begin{array}{l}\delta \\
\delta \\
0\end{array}$ & $\begin{array}{l}8 \\
0 \\
0\end{array}$ & $\begin{array}{l}8 \\
8 \\
0\end{array}$ & \&̊. & 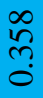 \\
\hline & $U$ & $\begin{array}{l}n \\
0 \\
0\end{array}$ & $\begin{array}{l}0 \\
\dot{0}\end{array}$ & $\begin{array}{l}0 \\
\infty \\
0 \\
0\end{array}$ & $\begin{array}{l}\text { ते } \\
\text { ¿े }\end{array}$ & $\begin{array}{l}\stackrel{0}{\circ} \\
\stackrel{0}{0}\end{array}$ & $\begin{array}{l}\stackrel{t}{0} \\
\end{array}$ & $\begin{array}{l}0 \\
\stackrel{\infty}{0} \\
\stackrel{0}{0}\end{array}$ & $\stackrel{5}{0}$ & $\stackrel{\overline{0}}{0}$ & $\stackrel{0}{a}$ & $\begin{array}{l}+ \\
8\end{array}$ & $\begin{array}{l}\text { ठ̊ } \\
\stackrel{0}{0}\end{array}$ & 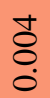 & 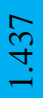 \\
\hline & 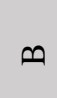 & $\stackrel{\circ}{0}$ & हn & $\begin{array}{l}\text { तิ } \\
\text {. }\end{array}$ & 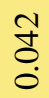 & 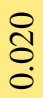 & $\begin{array}{l}\bar{m} \\
0\end{array}$ & $\stackrel{8}{0}$ & $\begin{array}{c}\text { ડ̦ } \\
\stackrel{0}{0}\end{array}$ & $\begin{array}{l}8 \\
\vdots \\
0\end{array}$ & $\begin{array}{l}\hat{8} \\
0\end{array}$ & ¿̊ & 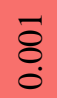 & 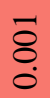 & $\begin{array}{l}\text { to } \\
n \\
n\end{array}$ \\
\hline & $\ll$ & 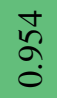 & $\frac{0}{n}$ & $\frac{\grave{N}}{0}$ & 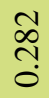 & $\frac{n}{2}$ & 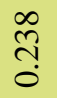 & 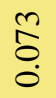 & $\frac{2}{0}$ & $\begin{array}{l}\text { Oे } \\
\text { Oे }\end{array}$ & 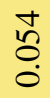 & $\underset{\sigma}{\sigma}$ & $\begin{array}{l}8 \\
8 \\
0\end{array}$ & $\underset{0}{\sigma}$ & $\begin{array}{l}\tilde{n} \\
\hat{\sigma} \\
i\end{array}$ \\
\hline & $\begin{array}{l}\bar{\Xi} \\
\bar{\Xi} \\
\end{array}$ & $\ll$ & $\varphi$ & $u$ & D & [I] & I & 0 & $I$ & - & $\sim$ & $\forall$ & $\omega$ & $\Sigma$ & $\stackrel{\widetilde{\pi}}{0}$ \\
\hline & & & & & & & & & & & & & & & \\
\hline
\end{tabular}




\subsubsection{Normalized Job Figures}

Table 5.8 shows the results of the gravity model for normalized job figures at the three-mile radius. The results of the normalized values are not as varied or extreme as the results for the raw job figures from Table 5.7. San Francisco as a destination is very unattractive to Millbrae as an origin. The diagonally aligned green pattern of cells indicates that station areas are attracted to their host stations, although faintly.

Interestingly, the Millbrae station area is very attracted to itself. Overall, Millbrae has the highest station area attraction index of 4.99, while San Francisco has a negative value of 3.21 . 
Table 5.8 Accessibility indices for origin-destination pairs from normalized job figures for three-mile buffer. Green, yellow, and red cells denote relatively high, medium, and low values, respectively. Blue cells denote row or column totals.

\begin{tabular}{|c|c|c|c|c|c|c|c|c|c|c|c|c|c|c|c|}
\hline \multirow{14}{*}{ 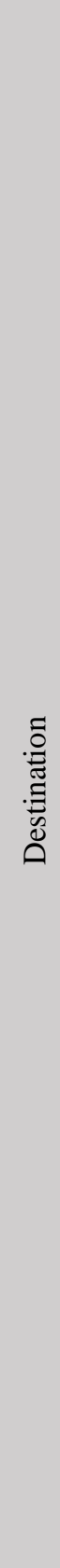 } & 풍 & $\underset{-}{8}$ & $\underset{8}{8}$ & $\stackrel{8}{.}$ & $\underset{-}{8}$ & $\underset{.}{8}$ & $\underset{-}{8}$ & $\underset{-}{8}$ & $\underset{-}{8}$ & $\stackrel{8}{8}$ & $\underset{.}{8}$ & $\underset{-}{8}$ & $\underset{-}{8}$ & $\stackrel{8}{-}$ & $\begin{array}{l}\stackrel{8}{0} \\
\stackrel{-}{2}\end{array}$ \\
\hline & $\Sigma$ & $\stackrel{8}{\circ}$ & 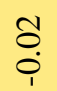 & $\stackrel{\overline{0}}{\circ}$ & $\stackrel{8}{\circ}$ & $\stackrel{8}{8}$ & $\stackrel{8}{\circ}$ & $\stackrel{8}{\circ}$ & $\stackrel{8}{\circ}$ & $\begin{array}{l}\overline{0} \\
\stackrel{0}{\varphi}\end{array}$ & $\begin{array}{l}\sigma \\
\stackrel{0}{0}\end{array}$ & 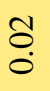 & ö. & $\vec{t}$ & $\stackrel{?}{\stackrel{0}{\circ}}$ \\
\hline & \lrcorner & $\stackrel{8}{\circ}$ & $\stackrel{m}{\frac{m}{1}}$ & $\stackrel{1}{0}$ & $\begin{array}{l}\text { ơ } \\
0\end{array}$ & $\begin{array}{l}\text { Oे } \\
\stackrel{0}{0}\end{array}$ & $\begin{array}{l}\text { ô } \\
\stackrel{0}{1}\end{array}$ & $\begin{array}{l}0 \\
0 \\
\dot{0}\end{array}$ & $\begin{array}{l}\text { ô } \\
\stackrel{0}{0}\end{array}$ & $\begin{array}{l}5 \\
0 \\
0\end{array}$ & $\frac{\mathfrak{T}}{\dot{p}}$ & $\stackrel{n}{\stackrel{0}{0}}$ & $\underset{-}{8}$ & 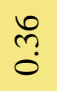 & $\underset{i}{\stackrel{t}{*}}$ \\
\hline & 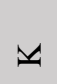 & $\stackrel{8}{8}$ & $\begin{array}{l}\overline{0} \\
0 \\
\end{array}$ & $\stackrel{\overline{0}}{\circ}$ & $\stackrel{8}{\circ}$ & $\stackrel{8}{8}$ & $\stackrel{8}{\circ}$ & $\stackrel{8}{\circ}$ & $\stackrel{8}{\circ}$ & ọ. & o. & $\hat{n}$ & $\begin{array}{l}\sigma_{0} \\
\stackrel{0}{0}\end{array}$ & $\stackrel{\leftrightarrow}{0}$ & $\stackrel{n}{0}$ \\
\hline & $\neg$ & $\stackrel{8}{\circ}$ & $\stackrel{n}{0}$ & $\stackrel{0}{0}$ & $\stackrel{0}{0}$ & $\overline{0}$ & ö. & $\stackrel{\leftrightarrow}{0}$ & $\ddot{0}$ & $\stackrel{n}{\circ}$ & $\stackrel{\text { og }}{\text {. }}$ & $\begin{array}{l}\infty \\
\stackrel{0}{0} \\
0\end{array}$ & 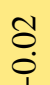 & $\stackrel{+}{0}$ & $\widehat{o}$ \\
\hline & - & $\stackrel{8}{8}$ & $\stackrel{t}{0}$ & $\begin{array}{l}\text { Oे } \\
0\end{array}$ & $\underset{0}{\sigma}$ & $\overline{0}$ & $\stackrel{\sigma}{0}$ & $\underset{0}{0}$ & $\underset{0}{0}$ & $\stackrel{+}{0}$ & ठ̊. & రి. & $\stackrel{8}{8}$ & ठ․ & ò \\
\hline & $I$ & $\stackrel{8}{8}$ & 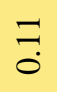 & $\begin{array}{l}\stackrel{0}{0} \\
\stackrel{0}{i}\end{array}$ & $\stackrel{\bar{\sigma}}{\circ}$ & $\stackrel{\text { Oִ }}{0}$ & $\stackrel{+}{0}$ & $\stackrel{1}{\circ}$ & $\bar{\sigma}$ & $\stackrel{n}{\circ}$ & $\begin{array}{l}\text { Oे. } \\
\stackrel{0}{0}\end{array}$ & 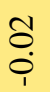 & $\stackrel{8}{\circ}$ & $\begin{array}{l}0 \\
0 \\
0\end{array}$ & $\stackrel{\infty}{\rightleftarrows}$ \\
\hline & ט & $\stackrel{8}{8}$ & $\stackrel{\circ}{\circ}$ & $\stackrel{\text { ț }}{0}$ & $\stackrel{\sigma}{\circ}$ & 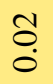 & $\stackrel{\text { ț }}{\circ}$ & $\stackrel{N}{\circ}$ & $\stackrel{+}{\circ}$ & 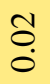 & ō & $\begin{array}{l}\overline{0} . \\
0\end{array}$ & $\stackrel{8}{\circ}$ & ö. & $\begin{array}{c}\hat{\infty} \\
0 \\
0\end{array}$ \\
\hline & IL & ō. & $\frac{n}{0}$ & $\begin{array}{l}0 \\
\stackrel{0}{0}\end{array}$ & $\stackrel{\overbrace{}}{0}$ & $\stackrel{8}{\circ}$ & $\begin{array}{l}\infty \\
\infty \\
0\end{array}$ & $\frac{m}{0}$ & $\stackrel{+}{0}$ & $\stackrel{0}{0}$ & $\stackrel{0}{0}$ & 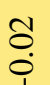 & $\stackrel{8}{8}$ & $\ddot{0}$ & $\stackrel{\text { I }}{\longrightarrow}$ \\
\hline & 피 & $\stackrel{8}{8}$ & $\frac{1}{0}$ & $\stackrel{\infty}{\circ}$ & $\underset{0}{0}$ & $\begin{array}{l}\infty \\
\infty \\
0\end{array}$ & $\stackrel{0}{\circ}$ & $\stackrel{n}{0}$ & ô. & $\underset{0}{0}$ & ō & ప. & $\stackrel{8}{8}$ & $\ddot{0}$ & $\stackrel{g}{g}$ \\
\hline & D & $\begin{array}{l}0 \\
0 \\
0\end{array}$ & $\stackrel{\text { ?ె }}{0}$ & $\begin{array}{l}+ \\
\text { ma } \\
0\end{array}$ & $\stackrel{\wp}{\text { ọ }}$ & 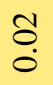 & 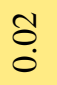 & $\stackrel{\Theta}{0}$ & $\ddot{\circ}$ & 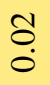 & ō & $\begin{array}{l}\sigma \\
0 \\
0\end{array}$ & $\stackrel{8}{\circ}$ & ọ. & $\stackrel{\text { oे }}{-}$ \\
\hline & $u$ & $\stackrel{8}{8}$ & $\frac{n}{0}$ & $\stackrel{8}{\varnothing}$ & $\begin{array}{l}0 \\
0 \\
0\end{array}$ & $\stackrel{8}{\circ}$ & $\stackrel{8}{\circ}$ & $\begin{array}{l}0 \\
0 \\
\end{array}$ & $\stackrel{8}{8}$ & $\stackrel{8}{\circ}$ & $\stackrel{8}{8}$ & $\begin{array}{l}8 \\
0\end{array}$ & $\stackrel{8}{\circ}$ & $\stackrel{8}{8}$ & $\begin{array}{l}\hat{\infty} \\
0\end{array}$ \\
\hline & $\infty$ & ڤై & $\frac{n}{n}$ & $\frac{\infty}{0}$ & 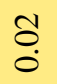 & $\underset{0}{0}$ & $\stackrel{\sigma}{0}$ & $\ddot{0}$ & $\ddot{\circ}$ & ¿̄o & $\stackrel{8}{8}$ & o. & $\stackrel{8}{\circ}$ & ö. & $\underset{+}{\stackrel{\sigma}{r}}$ \\
\hline & $\varangle$ & $\stackrel{n}{\varrho}$ & $\begin{array}{l}\text { bे } \\
\dot{+}\end{array}$ & $\stackrel{?}{0}$ & $=$ & $\begin{array}{l}\dot{D} \\
\stackrel{0}{i}\end{array}$ & $\begin{array}{l}\dot{0} \\
\dot{0}\end{array}$ & $\begin{array}{l}2 \\
0 \\
\dot{\varphi}\end{array}$ & $\begin{array}{l}0 \\
\dot{\varphi}\end{array}$ & $\begin{array}{l}\dot{0} \\
\stackrel{0}{i}\end{array}$ & $\begin{array}{l}\text { ô } \\
\text { ị }\end{array}$ & ֶ̊. & $\stackrel{\Xi}{\circ}$ & $\stackrel{\overbrace{}}{0}$ & $\stackrel{\vec{\sim}}{\stackrel{r}{r}}$ \\
\hline & $\begin{array}{l}\bar{\Xi} \\
\text { త్తి }\end{array}$ & $\varangle$ & $\infty$ & $U$ & D & 디 & L & 0 & 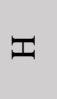 & - & $\neg$ & $\forall$ & \lrcorner & $\Sigma$ & $\stackrel{\bar{\sigma}}{0}$ \\
\hline & & & & & & & & & & & & & & & \\
\hline
\end{tabular}




\subsubsection{Raw Population Figures}

Table 5.9 shows the results of the gravity model for raw population figures at the three-mile radius. As expected, station areas are most strongly attracted to themselves since the distance to themselves is only the radius of the station area. As the distance between station area origin-destination pairs increases, corresponding attraction indices tend to decrease. Also, station areas with greater population clusters were attractive to a greater number of other station areas and were more attractive overall. The pattern shown in Table 5.9 is like that of Table 5.7. 
Table 5.9 Accessibility indices for origin-destination pairs from raw population figures for three-mile buffer. Green, yellow, and red cells denote relatively high, medium, and low values, respectively. Blue cells denote row or column totals

\begin{tabular}{|c|c|c|c|c|c|c|c|c|c|c|c|c|c|c|c|}
\hline \multirow{14}{*}{ 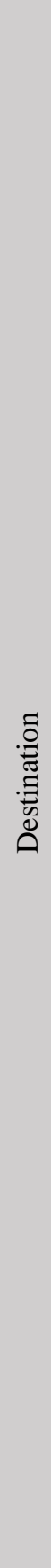 } & స్ & $\underset{-}{8}$ & $\underset{8}{8}$ & $\underset{-}{8}$ & $\underset{8}{8}$ & 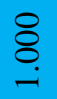 & 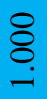 & 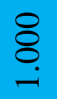 & $\underset{-}{8}$ & $\underset{8}{8}$ & 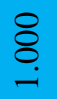 & 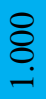 & 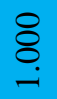 & $\underset{-}{8}$ & $\begin{array}{l}\stackrel{8}{0} \\
\ddot{n}\end{array}$ \\
\hline & $\Sigma$ & ô & $\begin{array}{l}8 \\
8 \\
0\end{array}$ & $\begin{array}{l}+ \\
8 \\
0\end{array}$ & $\frac{n}{0}$ & $\stackrel{\Delta}{0}$ & $\stackrel{\widehat{\sigma}}{\stackrel{0}{0}}$ & $\stackrel{0}{\circ}$ & $\begin{array}{l}\hat{\sigma} \\
\stackrel{0}{0}\end{array}$ & $\stackrel{\infty}{\circ}$ & 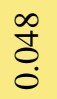 & $\frac{1}{0}$ & $\begin{array}{l}\text { के } \\
\stackrel{0}{0}\end{array}$ & 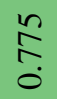 & ळे \\
\hline & \lrcorner & $\begin{array}{l}8 \\
8 \\
0\end{array}$ & $\begin{array}{l}\Delta \\
0 \\
0\end{array}$ & $\stackrel{\infty}{8}$ & ֶ̊. & ֻे & $\hat{\mathscr{\delta}}$ & $\begin{array}{l}\stackrel{\Delta}{\Delta} \\
\stackrel{0}{0}\end{array}$ & $\begin{array}{l}\circ \\
\stackrel{0}{0}\end{array}$ & 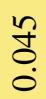 & $\frac{\tilde{n}}{0}$ & 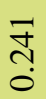 & $\begin{array}{l}\stackrel{8}{0} \\
\infty \\
0\end{array}$ & $\frac{\hat{m}}{0}$ & 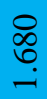 \\
\hline & 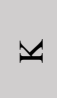 & $\underset{8}{0}$ & $\begin{array}{l}\hat{8} \\
0\end{array}$ & $\stackrel{8}{8}$ & $\stackrel{\infty}{\circ}$ & $\stackrel{\infty}{\stackrel{\infty}{0}} \stackrel{0}{\circ}$ & గ̂. & $\stackrel{m}{0}$ & ô & $\begin{array}{l}\text { İ } \\
\stackrel{0}{0}\end{array}$ & $\frac{d}{0}$ & $\stackrel{\bar{尺}}{\stackrel{0}{\circ}}$ & $\begin{array}{l}\text { Oै } \\
0 \\
0 \\
0\end{array}$ & $\begin{array}{l}\stackrel{Q}{O} \\
\dot{0}\end{array}$ & $\begin{array}{l}\infty \\
\stackrel{0}{0}\end{array}$ \\
\hline & $\neg$ & $\overline{8}$ & $\begin{array}{l}\text { o̊ } \\
\text {. }\end{array}$ & $\begin{array}{l}\text { ठ̊ } \\
\dot{0}\end{array}$ & $\begin{array}{l}8 \\
\stackrel{0}{0}\end{array}$ & $\hat{8}$ & $\stackrel{\frac{m}{\sigma}}{\circ}$ & $\begin{array}{l}\mathscr{8} \\
\dot{0}\end{array}$ & $\stackrel{\Delta}{\circ}$ & $\stackrel{\sim}{\circ}$ & $\begin{array}{l}n \\
\tilde{n} \\
0\end{array}$ & $\frac{1}{0}$ & $\begin{array}{l}8 \\
8 \\
0\end{array}$ & $\hat{8}$ & $\begin{array}{l}\stackrel{0}{\infty} \\
\stackrel{0}{0} \\
\stackrel{0}{0}\end{array}$ \\
\hline & - & $\begin{array}{l}0 \\
\delta \\
0\end{array}$ & $\begin{array}{l}8 \\
8 \\
0\end{array}$ & $\begin{array}{l}+ \\
8 \\
0\end{array}$ & $\stackrel{ }{\circ}$ & $\frac{a}{0}$ & $\begin{array}{l}\stackrel{9}{+} \\
\stackrel{0}{\circ}\end{array}$ & $\stackrel{5}{0}$ & $\begin{array}{l}0 \\
\stackrel{2}{0} \\
0\end{array}$ & $\begin{array}{l}\text { ڤે } \\
\infty \\
0\end{array}$ & ஸै & $\begin{array}{l}\stackrel{8}{8} \\
\stackrel{0}{\circ}\end{array}$ & $\begin{array}{l}\mathscr{8} \\
\stackrel{0}{0}\end{array}$ & $\begin{array}{l}\hat{8} \\
0\end{array}$ & 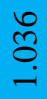 \\
\hline & $I$ & $\overline{8}$ & $\begin{array}{l}\tilde{\delta} \\
\dot{0}\end{array}$ & $\overline{8}$ & $\begin{array}{l}+ \\
8\end{array}$ & $\stackrel{8}{8}$ & $\begin{array}{c}\overleftarrow{\Delta} \\
\stackrel{0}{0}\end{array}$ & $\begin{array}{l}0 \\
0 \\
0\end{array}$ & $\begin{array}{l}8 \\
\stackrel{0}{0} \\
0\end{array}$ & $\begin{array}{l}\stackrel{8}{8} \\
\stackrel{0}{0}\end{array}$ & $\begin{array}{l}+ \\
8 \\
0\end{array}$ & $\overline{8}$ & $\begin{array}{l}\overline{8} \\
\dot{0}\end{array}$ & $\begin{array}{l}\overline{8} \\
\dot{0}\end{array}$ & $\begin{array}{l}\text { ñ } \\
\text { ñ }\end{array}$ \\
\hline & 0 & $\begin{array}{l}+ \\
8 \\
0\end{array}$ & $\begin{array}{l}0 \\
0 \\
0\end{array}$ & $\hat{8}$ & ஜ̊ & $\begin{array}{l}\overrightarrow{8} \\
\stackrel{0}{0}\end{array}$ & ָָ & 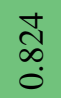 & $\frac{\hat{0}}{0}$ & $\frac{\circ}{\circ}$ & $\stackrel{n}{0}$ & 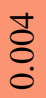 & $\stackrel{0}{8}$ & $\begin{array}{l}n \\
8\end{array}$ & $\stackrel{\infty}{n} \underset{n}{n}$ \\
\hline & IL & $\overline{8}$ & $\begin{array}{l}\overline{8} \\
0\end{array}$ & $\begin{array}{l}\overline{8} \\
0\end{array}$ & $\stackrel{8}{8}$ & 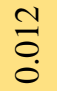 & 웜 & $\begin{array}{l}\infty \\
8 \\
0\end{array}$ & $\stackrel{8}{8}$ & $\stackrel{8}{8}$ & $\overline{8}$ & $\stackrel{8}{8}$ & $\begin{array}{l}8 \\
8 \\
0\end{array}$ & $\begin{array}{l}8 \\
8 \\
0\end{array}$ & $\begin{array}{l}\text { oे } \\
\text { 1̦ }\end{array}$ \\
\hline & 工 & $\underset{\delta}{\delta}$ & $\begin{array}{l}8 \\
8 \\
0\end{array}$ & $\begin{array}{l}+ \\
8 \\
0\end{array}$ & $\begin{array}{l}\text { ธิ } \\
\text { ல }\end{array}$ & $\begin{array}{l}\stackrel{+}{?} \\
0\end{array}$ & $\frac{m}{0}$ & $\stackrel{\infty}{\stackrel{\infty}{0}}$ & $\begin{array}{l}0 \\
\stackrel{\delta}{0} \\
0\end{array}$ & $\hat{8}$ & $\begin{array}{l}0 \\
8 \\
0\end{array}$ & $\begin{array}{l}\tilde{\delta} \\
\stackrel{0}{\circ}\end{array}$ & $\overrightarrow{8}$ & $\begin{array}{l}\text { ठิ } \\
\text {. }\end{array}$ & $\begin{array}{l}\hat{\alpha} \\
\hat{o}\end{array}$ \\
\hline & ค & ô & $\stackrel{8}{8}$ & $\underset{8}{0}$ & $\begin{array}{l}\text { ț } \\
\stackrel{+}{0}\end{array}$ & $\stackrel{\infty}{8}$ & $\begin{array}{l}\frac{n}{o} \\
\stackrel{0}{0}\end{array}$ & $\underset{8}{\stackrel{t}{0}}$ & $\stackrel{\infty}{8}$ & $\underset{\delta}{\tilde{O}}$ & $\stackrel{1}{8}$ & $\overline{8}$ & $\stackrel{8}{8}$ & $\begin{array}{l}\overline{8} \\
0\end{array}$ & \begin{tabular}{l} 
to \\
\multirow{+}{*}{} \\
0
\end{tabular} \\
\hline & $u$ & $\begin{array}{l}+ \\
\tilde{0} \\
0\end{array}$ & $\begin{array}{l}0 \\
0 \\
0\end{array}$ & $\begin{array}{l}+\underset{\infty}{\infty} \\
0 \\
0\end{array}$ & 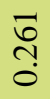 & है & ô & $\begin{array}{l}0 \\
\text { ô. } \\
0\end{array}$ & 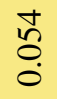 & $\begin{array}{l}0 \\
\stackrel{0}{0} \\
0\end{array}$ & 궁. & $\stackrel{8}{8}$ & $\stackrel{8}{8}$ & $\begin{array}{l}8 \\
8 \\
0\end{array}$ & $\stackrel{\substack{+n}}{n}$ \\
\hline & 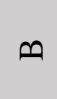 & $\begin{array}{l}\text { o } \\
\text { t. } \\
0\end{array}$ & $\frac{n}{n}$ & $\begin{array}{l}\tilde{\Xi} \\
\text { ல̊ }\end{array}$ & $\begin{array}{l}\text { I } \\
\stackrel{0}{\circ}\end{array}$ & $\stackrel{\Delta}{0}$ & 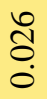 & $\begin{array}{l}\infty \\
8 \\
0\end{array}$ & $\stackrel{0}{0}$ & $\stackrel{n}{8}$ & $\stackrel{n}{8}$ & $\stackrel{\text { ̊े }}{\circ}$ & $\overrightarrow{8}$ & $\begin{array}{l}\text { ठ̊ } \\
\text {. }\end{array}$ & $\stackrel{\overrightarrow{0}}{\circ}$ \\
\hline & $\ll$ & $\begin{array}{l}\overline{8} \\
\text { o }\end{array}$ & 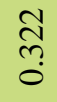 & हैं & $\stackrel{n}{n}$ & $\begin{array}{l}0 \\
0 \\
0 \\
0\end{array}$ & $\begin{array}{l}8 \\
8 \\
0\end{array}$ & $\begin{array}{l}\widehat{\sigma} \\
\text { Oे }\end{array}$ & $\begin{array}{l}0 \\
\text { ஜे } \\
0\end{array}$ & $\stackrel{\infty}{\circ}$ & 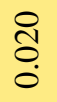 & 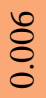 & $\begin{array}{l}+ \\
8 \\
0\end{array}$ & $\hat{8}$ & $\stackrel{n}{\hat{o}}$ \\
\hline & $\begin{array}{l}\bar{\nabla} \\
\text { ज्ञ }\end{array}$ & $\varangle$ & $\infty$ & $u$ & 0 & 피 & I & 0 & $I$ & $\varpi$ & $\neg$ & $\forall$ & \lrcorner & $\Sigma$ & 苟 \\
\hline & & & & & & & & & & & & & & & \\
\hline
\end{tabular}




\subsubsection{Normalized Population Figures}

When looking at the results of the gravity model for normalized population figures within the three-mile catchment area radius, shown in Table 5.10, almost all of the values of attraction for each station origin-destination pair appear to be relatively close to each other, save for a few outliers. San Francisco as a destination is unattractive to Millbrae as an origin. The same is true of San Jose as a destination and Millbrae as an origin, although to a lesser extent. 
Table 5.10 Accessibility indices for origin-destination pairs from normalized population figures for threemile buffer. Green, yellow, and red cells denote relatively high, medium, and low values, respectively. Blue cells denote row or column totals.

\begin{tabular}{|c|c|c|c|c|c|c|c|c|c|c|c|c|c|c|c|}
\hline \multirow{14}{*}{ 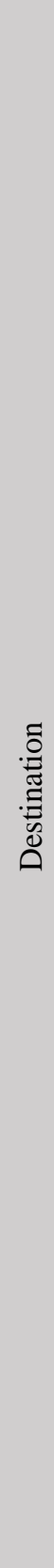 } & $\stackrel{\pi}{\frac{\pi}{0}}$ & $\underset{-}{8}$ & $\underset{-}{8}$ & $\underset{-}{8}$ & $\underset{-}{8}$ & $\underset{-}{8}$ & $\underset{\text { \& }}{8}$ & $\stackrel{8}{-}$ & $\stackrel{8}{8}$ & $\underset{-}{8}$ & $\underset{-}{8}$ & $\underset{-}{8}$ & $\underset{-}{8}$ & $\stackrel{8}{-}$ & $\begin{array}{l}8 \\
\dot{2}\end{array}$ \\
\hline & $\Sigma$ & $\stackrel{8}{8}$ & $\begin{array}{l}\overline{0} \\
\stackrel{p}{\varphi}\end{array}$ & $\begin{array}{l}8 \\
\stackrel{0}{0}\end{array}$ & $\stackrel{8}{8}$ & $\stackrel{8}{8}$ & $\stackrel{8}{8}$ & $\begin{array}{l}\overline{0} \\
\stackrel{p}{\varphi}\end{array}$ & $\stackrel{8}{8}$ & $\begin{array}{l}\text { ô } \\
\stackrel{\leftrightarrow}{\varphi}\end{array}$ & $\begin{array}{l}\overline{0} \\
\stackrel{0}{0}\end{array}$ & $\overline{0}$ & $\stackrel{\circ}{0}$ & స్ర. & $\begin{array}{l}\text { ț } \\
\stackrel{0}{0}\end{array}$ \\
\hline & 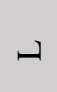 & ○’ & $\begin{array}{l}8 \\
0 \\
\end{array}$ & 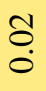 & $\begin{array}{l}\overrightarrow{0} \\
\dot{\varphi}\end{array}$ & $\begin{array}{l}\text { ô } \\
\stackrel{\leftrightarrow}{1}\end{array}$ & $\begin{array}{l}\overline{0} \\
\dot{0}\end{array}$ & $\begin{array}{l}0 \\
\stackrel{0}{0} \\
1\end{array}$ & $\begin{array}{l}\text { Lे } \\
\stackrel{0}{0}\end{array}$ & $\frac{\Delta}{\dot{\varphi}}$ & $\frac{ \pm}{\dot{\varphi}}$ & $\stackrel{0}{+}$ & à & గొ & $\stackrel{n}{n}$ \\
\hline & $\mathscr{V}$ & $\stackrel{8}{8}$ & $\begin{array}{l}\overline{0} \\
\stackrel{0}{1}\end{array}$ & $\stackrel{8}{8}$ & $\stackrel{8}{8}$ & $\begin{array}{l}0 \\
0 \\
0\end{array}$ & $\stackrel{8}{8}$ & 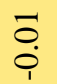 & $\begin{array}{l}\overline{0} \\
0 \\
\end{array}$ & $\begin{array}{l}\dot{0} \\
\dot{0}\end{array}$ & $\begin{array}{l}\text { d } \\
\dot{0}\end{array}$ & $\begin{array}{l}\sigma \\
\stackrel{0}{0}\end{array}$ & $\stackrel{+}{0}$ & $\stackrel{8}{\circ}$ & กิ \\
\hline & $r$ & $\stackrel{8}{8}$ & 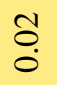 & $\begin{array}{l}\overline{0} \\
0 \\
0\end{array}$ & $\stackrel{\Xi}{0}$ & $\stackrel{\tilde{o}}{0}$ & $\stackrel{\overline{0}}{\circ}$ & 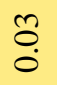 & $\overline{0}$ & $\stackrel{\infty}{\circ}$ & $\stackrel{ \pm}{ \pm}$ & $\begin{array}{l}n \\
0 \\
0\end{array}$ & ö. & $\begin{array}{l}\text { t) } \\
0 \\
\end{array}$ & $\stackrel{\infty}{\rightleftarrows}$ \\
\hline & $\neg$ & $\stackrel{8}{\circ}$ & 뭉 & $\stackrel{8}{8}$ & $\stackrel{8}{\circ}$ & $\stackrel{8}{8}$ & $\stackrel{8}{\circ}$ & ö & ¿. & $\begin{array}{l}\infty \\
0 \\
0\end{array}$ & o. & o. & $\stackrel{8}{0}$ & ō. & ふু \\
\hline & $I$ & $\begin{array}{l}0 \\
0\end{array}$ & $\stackrel{n}{\circ}$ & 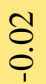 & $\stackrel{\overline{0}}{\circ}$ & $\stackrel{+}{0}$ & $\stackrel{+}{\stackrel{O}{0}}$ & $\stackrel{\mathbb{্}}{0}$ & ఫু & $\frac{\stackrel{1}{0}}{0}$ & $\begin{array}{l}\text { Oे } \\
\stackrel{0}{0}\end{array}$ & $\begin{array}{l}\sigma \\
0 \\
0\end{array}$ & $\begin{array}{l}0 \\
\stackrel{0}{0}\end{array}$ & 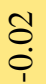 & $\stackrel{\text { + }}{\stackrel{+}{.}}$ \\
\hline & 0 & $\stackrel{8}{8}$ & $\stackrel{\circ}{\circ}$ & $\begin{array}{l}8 \\
\stackrel{0}{0}\end{array}$ & $\stackrel{8}{8}$ & $\stackrel{0}{0}$ & $\stackrel{\circ}{0}$ & $\stackrel{?}{\stackrel{0}{0}}$ & ¿. & $\ddot{\circ}$ & $\begin{array}{l}8 \\
\stackrel{0}{0} \\
\end{array}$ & $\begin{array}{l}8 \\
\stackrel{0}{0}\end{array}$ & $\stackrel{8}{8}$ & $\begin{array}{l}8 \\
\stackrel{0}{0}\end{array}$ & $\stackrel{\infty}{+}$ \\
\hline & IL & $\begin{array}{l}\text { ọ } \\
\text { ị }\end{array}$ & $\stackrel{\infty}{\circ}$ & $\begin{array}{l}\text { O̊. } \\
\stackrel{i}{1}\end{array}$ & $\stackrel{0}{0}$ & $\frac{1}{0}$ & مू & ஜి & $\stackrel{\overbrace{}}{0}$ & $\stackrel{\infty}{\circ}$ & $\begin{array}{l}\Omega \\
\stackrel{0}{0} \\
\stackrel{0}{0}\end{array}$ & ö. & $\stackrel{8}{8}$ & $\begin{array}{l}\text { ơ } \\
\stackrel{\leftrightarrow}{0}\end{array}$ & กี \\
\hline & 피 & $\begin{array}{l}\text { ọ } \\
\text { i }\end{array}$ & $\stackrel{n}{\circ}$ & $\begin{array}{l}\text { ô. } \\
\stackrel{0}{0}\end{array}$ & $\begin{array}{l}1 \\
\stackrel{0}{0}\end{array}$ & $\begin{array}{l}0 \\
\infty \\
0\end{array}$ & $\stackrel{n}{o}$ & $\stackrel{8}{\circ}$ & 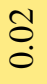 & $\begin{array}{l}\dot{0} \\
\stackrel{0}{0}\end{array}$ & ö. & o. & $\stackrel{8}{8}$ & $\begin{array}{l}\sigma \\
0 \\
0\end{array}$ & $\stackrel{0}{\circ}$ \\
\hline & ค & $\begin{array}{l}\text { ơ } \\
\text { ọ }\end{array}$ & $\frac{5}{0}$ & $\begin{array}{l}0 \\
\text { !) }\end{array}$ & $\stackrel{n}{o}$ & $\stackrel{\oplus}{0}$ & 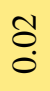 & $\begin{array}{l}\stackrel{0}{0} \\
\stackrel{0}{0}\end{array}$ & 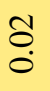 & $\begin{array}{l}\dot{0} \\
\stackrel{0}{0}\end{array}$ & $\stackrel{\overline{0}}{0}$ & $\begin{array}{l}\overline{0} \\
0 \\
\end{array}$ & $\stackrel{8}{\circ}$ & $\begin{array}{l}\overline{0} \\
0 \\
0\end{array}$ & ণి \\
\hline & $u$ & $\stackrel{\text { ô. }}{0}$ & 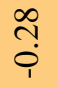 & $\stackrel{8}{\text { a }}$ & ô. & $\begin{array}{l}0 \\
0 \\
0\end{array}$ & ọ & $\begin{array}{l}\dot{I} \\
0 \\
\end{array}$ & $\begin{array}{l}0 \\
\\
\end{array}$ & $\begin{array}{l}0 \\
0 \\
0\end{array}$ & $\begin{array}{l}0 \\
\stackrel{0}{0}\end{array}$ & $\bar{O}$ & $\stackrel{8}{\circ}$ & ¿. & $\begin{array}{l}\stackrel{8}{0} \\
\stackrel{0}{0}\end{array}$ \\
\hline & 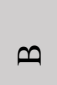 & $\begin{array}{l}n \\
0 \\
0\end{array}$ & $\frac{\bar{c}}{i}$ & $\begin{array}{l}\dot{0} \\
\stackrel{0}{0}\end{array}$ & 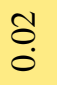 & $\stackrel{\circ}{\circ}$ & $\stackrel{\overline{0}}{\circ}$ & 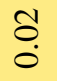 & $\ddot{\circ}$ & $\stackrel{1}{0}$ & ठே. & $\stackrel{8}{\circ}$ & 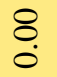 & ¿े. & $\underset{i}{ \pm}$ \\
\hline & $\varangle$ & . & $\frac{9}{7}$ & $\begin{array}{l}\stackrel{0}{\circ} \\
0\end{array}$ & $\begin{array}{l}n \\
0 \\
0\end{array}$ & $\begin{array}{l}0 \\
0 \\
0\end{array}$ & $\begin{array}{l}0 \\
\stackrel{0}{0}\end{array}$ & $\begin{array}{l}0 \\
\stackrel{0}{0} \\
\end{array}$ & $\begin{array}{l}0 \\
0 \\
\stackrel{1}{0}\end{array}$ & $\begin{array}{l}n \\
0 \\
0\end{array}$ & 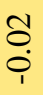 & $\overline{0}$ & $\stackrel{8}{8}$ & $\begin{array}{l}\text { Oे } \\
\stackrel{0}{0}\end{array}$ & 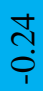 \\
\hline & $\begin{array}{l}\bar{\Xi} \\
\text { 苂 }\end{array}$ & $\ll$ & $ص$ & U & ค & 디 & IL & ن & I & - & $\neg$ & $\forall$ & \lrcorner & $\Sigma$ & 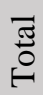 \\
\hline & & & & & & & & & & & & & & & \\
\hline
\end{tabular}




\subsubsection{Raw Housing Unit Figures}

Table 5.11 shows the accessibility indices for origin-destination pairs using raw housing unit numbers at the three-mile buffer. Like Table 5.9, which shows the accessibility indices for raw population numbers at the three-mile buffer, the data in Table 5.11 exhibits a pattern where stations that have a higher number of housing units within their catchment areas have higher attraction values. Also, the attraction value tends to decrease as the distance between origins and destinations increases. 
Table 5.11 Accessibility indices for origin-destination pairs from raw housing unit figures for three-mile buffer. Green, yellow, and red cells denote relatively high, medium, and low values, respectively. Blue cells denote row or column totals.

\begin{tabular}{|c|c|c|c|c|c|c|c|c|c|c|c|c|c|c|c|}
\hline \multirow{14}{*}{ 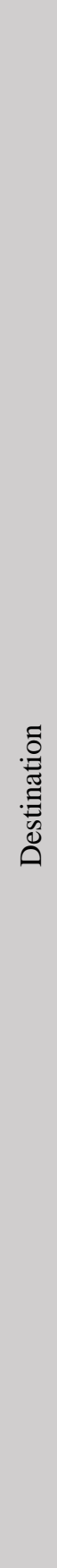 } & స్ & $\underset{8}{8}$ & $\underset{8}{8}$ & 8 & 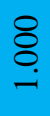 & $\underset{8}{8}$ & $\underset{8}{8}$ & $\underset{-}{8}$ & $\stackrel{8}{8}$ & $\underset{-}{8}$ & $\underset{ن}{8}$ & $\underset{-}{8}$ & $\underset{-}{8}$ & $\underset{-}{8}$ & $\begin{array}{l}\dot{8} \\
\dot{0} \\
\ddot{\eta}\end{array}$ \\
\hline & $\Sigma$ & $\begin{array}{l}\text { ̊̊ } \\
\text {. }\end{array}$ & \begin{tabular}{l}
$\&$ \\
\hdashline
\end{tabular} & $\begin{array}{l}+ \\
8 \\
0\end{array}$ & $\frac{n}{0}$ & $\stackrel{\Delta}{\Delta}$ & $\begin{array}{c}\widehat{\widehat{\sigma}} \\
\stackrel{0}{0}\end{array}$ & $\stackrel{8}{8}$ & ஜ & $\stackrel{\infty}{\circ}$ & $\stackrel{\infty}{\stackrel{\infty}{0}}$ & $\stackrel{0}{0}$ & ชै & $\begin{array}{l}\hat{0} \\
\stackrel{0}{0}\end{array}$ & $\begin{array}{l}\stackrel{\infty}{\infty} \\
\stackrel{0}{0}\end{array}$ \\
\hline & \lrcorner & $\begin{array}{l}8 \\
8 \\
8\end{array}$ & $\stackrel{n}{0}$ & $\begin{array}{l}8 \\
\text { } \\
0\end{array}$ & $\begin{array}{l}0 \\
\text { లి } \\
0\end{array}$ & $\begin{array}{l}0 \\
\text { Oூ } \\
\stackrel{0}{0}\end{array}$ & $\begin{array}{l}\widehat{\delta} \\
\stackrel{0}{0}\end{array}$ & $\begin{array}{l}\overparen{O} \\
\stackrel{0}{0}\end{array}$ & $\stackrel{\hat{o}}{0}$ & $\stackrel{\substack{\infty\\
}}{\stackrel{0}{0}}$ & $\begin{array}{l}\overrightarrow{0} \\
\overrightarrow{0}\end{array}$ & 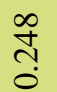 & $\begin{array}{l}\text { ठ } \\
\infty \\
0\end{array}$ & $\begin{array}{l}\stackrel{J}{ \pm} \\
\end{array}$ & $\stackrel{n}{\underline{r}}$ \\
\hline & $\forall$ & $\stackrel{8}{8}$ & $\stackrel{0}{0}$ & $\begin{array}{l}\mathscr{8} \\
\dot{0}\end{array}$ & $\stackrel{a}{0}$ & $\stackrel{\circ}{\circ}$ & $\begin{array}{l}0 \\
\stackrel{0}{0} \\
\stackrel{0}{0}\end{array}$ & $\stackrel{2}{\circ}$ & $\stackrel{\text { It }}{0}$ & $\begin{array}{l}\hat{\sigma} \\
\stackrel{0}{0}\end{array}$ & $\begin{array}{l}8 \\
\stackrel{1}{0}\end{array}$ & $\begin{array}{l}\mathscr{\sigma} \\
\stackrel{0}{0}\end{array}$ & ô & $\begin{array}{l}\stackrel{0}{0} \\
\stackrel{0}{0}\end{array}$ & $\stackrel{8}{8}$ \\
\hline & $\neg$ & $\begin{array}{l}\overline{8} \\
\dot{0}\end{array}$ & $\begin{array}{l}\text { ô } \\
\text {. }\end{array}$ & $\begin{array}{l}\widetilde{\delta} \\
\dot{0}\end{array}$ & $\begin{array}{l}8 \\
8 \\
0\end{array}$ & $\hat{8}$ & $\stackrel{m}{0}$ & $\begin{array}{l}n \\
\tilde{o}\end{array}$ & $\stackrel{0}{0}$ & 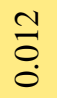 & $\begin{array}{l}0 \\
\infty \\
n \\
0\end{array}$ & $\begin{array}{l}\overrightarrow{0} \\
0 \\
0\end{array}$ & $\stackrel{n}{\tilde{o}}$ & $\hat{8}$ & $\begin{array}{l}\stackrel{R}{6} \\
\stackrel{0}{0}\end{array}$ \\
\hline & - & $\begin{array}{l}\text { ̊̊ } \\
0\end{array}$ & $\begin{array}{l}\mathscr{8} \\
\vdots \\
0\end{array}$ & $\begin{array}{l}+ \\
\stackrel{0}{0} \\
0\end{array}$ & $\frac{1}{0}$ & $\stackrel{\circ}{\circ}$ & $\begin{array}{l}\stackrel{9}{0} \\
0 \\
0\end{array}$ & $\begin{array}{l}0 \\
0 \\
0\end{array}$ & 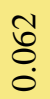 & $\begin{array}{c}\bar{\sigma} \\
\infty \\
0\end{array}$ & $\stackrel{\text { ڤै }}{0}$ & $\stackrel{8}{8}$ & $\begin{array}{l}+ \\
\stackrel{0}{0}\end{array}$ & $\stackrel{8}{0}$ & હે \\
\hline & $I$ & סे. & $\begin{array}{l}\overline{8} \\
\dot{0}\end{array}$ & $\begin{array}{l}\overline{8} \\
0\end{array}$ & 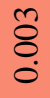 & ڤ్ & $\stackrel{\infty}{0}$ & $\begin{array}{l}\bar{\sigma} \\
0 \\
0\end{array}$ & 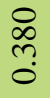 & 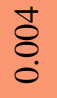 & $\begin{array}{l}\tilde{\delta} \\
0\end{array}$ & $\begin{array}{l}\overline{8} \\
\dot{0}\end{array}$ & \begin{tabular}{l}
8 \\
\hdashline \\
0
\end{tabular} & $\overline{8}$ & $\stackrel{\widetilde{f}}{\stackrel{f}{0}}$ \\
\hline & 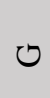 & $\stackrel{n}{8}$ & $\begin{array}{l}\bar{\sigma} \\
\ddot{0}\end{array}$ & $\begin{array}{l}\infty \\
\stackrel{8}{0} \\
0\end{array}$ & $\begin{array}{l}\text { P } \\
\text { Oे }\end{array}$ & $\begin{array}{l}\mathscr{0} \\
\dot{0}\end{array}$ & 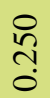 & $\begin{array}{l}m \\
\text { +े } \\
\infty \\
\dot{0}\end{array}$ & 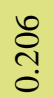 & $\begin{array}{l}\widetilde{\Xi} \\
\stackrel{0}{0}\end{array}$ & $\stackrel{r}{0}$ & $\begin{array}{l}\mathscr{8} \\
\ddot{0}\end{array}$ & $\begin{array}{l}\text { \&̊ } \\
0\end{array}$ & $\begin{array}{l}\mathscr{8} \\
\ddot{0}\end{array}$ & $\begin{array}{l}\text { } \\
\stackrel{\infty}{+} \\
-\end{array}$ \\
\hline & $L$ & $\stackrel{8}{8}$ & $\overrightarrow{8}$ & $\begin{array}{l}\overline{8} \\
\dot{0}\end{array}$ & $\begin{array}{l}+ \\
8 \\
0\end{array}$ & $\ddot{\sigma}$ & $\begin{array}{l}\text { ते } \\
\text { ऽ. }\end{array}$ & $\begin{array}{l}\hat{8} \\
\stackrel{0}{0}\end{array}$ & $\begin{array}{l}8 \\
\stackrel{8}{0} \\
0\end{array}$ & $\begin{array}{l}\overline{8} \\
\stackrel{0}{0}\end{array}$ & $\begin{array}{l}\overline{8} \\
\dot{0}\end{array}$ & $\begin{array}{l}8 \\
8 \\
0\end{array}$ & $\begin{array}{l}8 \\
8 \\
0\end{array}$ & $\begin{array}{l}8 \\
8 \\
\end{array}$ & $\begin{array}{l}\text { ț } \\
\text { ̦. }\end{array}$ \\
\hline & 山) & $\begin{array}{l}\widetilde{\delta} \\
\text {. }\end{array}$ & $\begin{array}{l}0 \\
8 \\
0\end{array}$ & $\begin{array}{l}+ \\
8 \\
0\end{array}$ & $\begin{array}{l}\bar{\delta} \\
\stackrel{0}{0}\end{array}$ & $\begin{array}{l}\bar{\sigma} \\
0 \\
0\end{array}$ & $\begin{array}{l}\text { } \\
\dot{0}\end{array}$ & $\begin{array}{l}0 \\
0 \\
0\end{array}$ & ס̊ & $\begin{array}{l}8 \\
8 \\
0\end{array}$ & $\begin{array}{l}8 \\
8 \\
0\end{array}$ & $\begin{array}{l}\tilde{\delta} \\
\stackrel{0}{0}\end{array}$ & $\overline{8}$ & $\begin{array}{l}0 \\
\delta\end{array}$ & $\begin{array}{c}\infty \\
\infty \\
\infty \\
0\end{array}$ \\
\hline & D & $\begin{array}{l}\text { ô } \\
\stackrel{0}{0}\end{array}$ & $\begin{array}{l}\hat{8} \\
\stackrel{0}{0}\end{array}$ & $\begin{array}{l}8 \\
\dot{8} \\
0\end{array}$ & $\begin{array}{l}\text { के } \\
\text { है }\end{array}$ & $\begin{array}{l}\infty \\
\stackrel{8}{0} \\
\dot{0}\end{array}$ & $\stackrel{n}{0}$ & $\begin{array}{l}\stackrel{+}{8} \\
\stackrel{0}{0}\end{array}$ & $\begin{array}{l}8 \\
\stackrel{8}{0} \\
\dot{0}\end{array}$ & $\begin{array}{l}\text { ô } \\
\stackrel{0}{0}\end{array}$ & 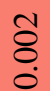 & $\begin{array}{l}\overline{8} \\
\stackrel{0}{0}\end{array}$ & $\begin{array}{l}8 \\
8 \\
8\end{array}$ & ¿্口 & 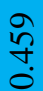 \\
\hline & $u$ & ભ̂? & 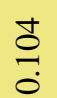 & 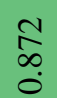 & $\begin{array}{l}0 \\
\text { ํ. } \\
0\end{array}$ & $\begin{array}{l}\text { है } \\
\text { o. } \\
0\end{array}$ & 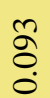 & $\begin{array}{l}\stackrel{+}{0} \\
\stackrel{0}{0}\end{array}$ & \begin{tabular}{l}
$\infty$ \\
\multirow{0}{0}{} \\
0
\end{tabular} & $\begin{array}{l}0 \\
\stackrel{0}{0} \\
\stackrel{0}{0}\end{array}$ & $\begin{array}{l}0 \\
0 \\
0\end{array}$ & $\stackrel{n}{8}$ & $\begin{array}{l}\text { } \\
0\end{array}$ & $\begin{array}{l}\text { \& } \\
\stackrel{0}{0}\end{array}$ & $\stackrel{\text { Ĩ }}{n}$ \\
\hline & $\infty$ & $\stackrel{\infty}{\infty}$ & $\begin{array}{l}n \\
n \\
0 \\
0\end{array}$ & $\begin{array}{l}\tilde{\Xi} \\
\text { ¿ุ. }\end{array}$ & $\stackrel{?}{\stackrel{f}{0}}$ & $\stackrel{\Delta}{\circ}$ & $\stackrel{\text { ô }}{\circ}$ & $\stackrel{8}{\circ}$ & $\stackrel{0}{\circ}$ & 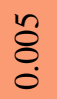 & $\begin{array}{l}\mathscr{8} \\
\stackrel{0}{0} \\
\end{array}$ & $\begin{array}{l}\widetilde{\delta} \\
\stackrel{0}{0}\end{array}$ & $\begin{array}{l}\overline{8} \\
\dot{0}\end{array}$ & $\begin{array}{l}\text { ठ̀ } \\
\stackrel{0}{0}\end{array}$ & $\begin{array}{l}\stackrel{0}{0} \\
\& \\
0 \\
0\end{array}$ \\
\hline & $\varangle$ & 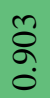 & $\begin{array}{l}\text { ते } \\
\text { ڤై }\end{array}$ & $\begin{array}{l}: \\
: \\
0\end{array}$ & $\frac{\hat{m}}{0}$ & $\begin{array}{l}\bar{n} \\
0 \\
0\end{array}$ & $\begin{array}{l}\bar{g} \\
\dot{0}\end{array}$ & 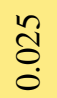 & $\begin{array}{l}\text { ஜ̊ } \\
\stackrel{0}{0}\end{array}$ & $\stackrel{\infty}{\stackrel{0}{0}}$ & 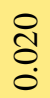 & \begin{tabular}{l}
$\stackrel{8}{\circ}$ \\
\hdashline \\
0
\end{tabular} & $\begin{array}{l}+ \\
\stackrel{0}{0}\end{array}$ & $\stackrel{5}{0}$ & $\stackrel{m}{\approx}$ \\
\hline & $\begin{array}{l}\bar{\Xi} \\
\text { ]्ञ }\end{array}$ & $\ll$ & 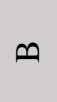 & $u$ & D & 디 & I & 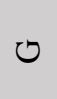 & $I$ & - & $\neg$ & 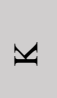 & \lrcorner & $\Sigma$ & 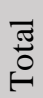 \\
\hline & & & & & & & & & & & & & & & \\
\hline
\end{tabular}




\subsubsection{Normalized Housing Unit Figures}

Table 5.12 shows the accessibility indices for origin-destination pairs with normalized housing unit figures at the three-mile buffer. There is little variation between most accessibility indices for origin-destination pairs, except for the Millbrae-San Francisco origin-destination pair. The other origin-destination pairs with relatively high accessibility indices in the negative direction are Millbrae-San Jose, Bakersfield-Los Angeles, Palmdale-Los Angeles, and San Jose-Gilroy. Millbrae as a destination has the highest overall attraction index at 1.91, while San Francisco has the lowest at -0.01. 
Table 5.12 Accessibility indices for origin-destination pairs from normalized housing unit figures for threemile buffer. Green, yellow, and red cells denote relatively high, medium, and low values, respectively. Blue cells denote row or column totals.

\begin{tabular}{|c|c|c|c|c|c|c|c|c|c|c|c|c|c|c|c|}
\hline \multirow{14}{*}{ 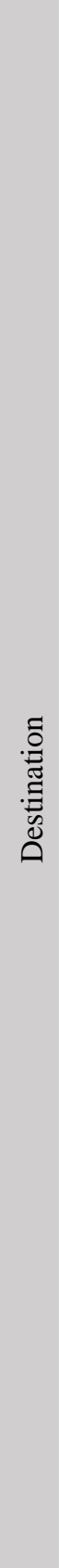 } & స్ & $\stackrel{8}{8}$ & $\underset{-}{8}$ & $\underset{-}{8}$ & $\underset{.}{8}$ & $\stackrel{8}{8}$ & $\underset{-}{8}$ & $\underset{-}{8}$ & $\stackrel{8}{8}$ & $\stackrel{8}{8}$ & $\underset{-}{8}$ & $\stackrel{8}{8}$ & $\stackrel{8}{8}$ & $\underset{-}{8}$ & $\begin{array}{l}8 \\
\dot{\imath} \\
\text { - }\end{array}$ \\
\hline & $\Sigma$ & $\stackrel{8}{8}$ & $\begin{array}{l}\overline{0} \\
\dot{\varphi}\end{array}$ & $\stackrel{8}{8}$ & $\stackrel{8}{8}$ & $\stackrel{8}{8}$ & $\stackrel{8}{8}$ & 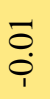 & $\stackrel{8}{\circ}$ & 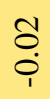 & 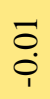 & $\stackrel{\overrightarrow{0}}{0}$ & $\underset{0}{0}$ & $\stackrel{\Re}{0}$ & $\begin{array}{l}\stackrel{8}{0} \\
:\end{array}$ \\
\hline & \lrcorner & $\stackrel{0}{0}$ & $\begin{array}{l}2 \\
0 \\
0\end{array}$ & 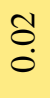 & 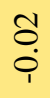 & $\begin{array}{l}0 \\
\stackrel{1}{i}\end{array}$ & 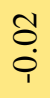 & $\begin{array}{l}\text { oे } \\
\text { i }\end{array}$ & 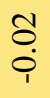 & $\frac{ \pm}{\dot{0}}$ & $\frac{n}{i}$ & f̊. & $\hat{a}$ & $\stackrel{q}{+}$ & $\stackrel{n}{n}$ \\
\hline & 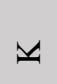 & $\stackrel{8}{8}$ & $\begin{array}{l}\overrightarrow{0} \\
\stackrel{0}{0}\end{array}$ & $\stackrel{8}{8}$ & $\begin{array}{l}8 \\
\stackrel{0}{0}\end{array}$ & $\begin{array}{l}\overline{0} \\
\stackrel{0}{0}\end{array}$ & $\stackrel{8}{8}$ & $\begin{array}{l}\text { ô } \\
0 \\
\end{array}$ & $\begin{array}{l}\overline{0} \\
\dot{0}\end{array}$ & $\begin{array}{l}\dot{0} \\
\dot{0} \\
\end{array}$ & $\begin{array}{l}\text { to. } \\
\stackrel{1}{0}\end{array}$ & $\begin{array}{l}\stackrel{8}{0} \\
\stackrel{0}{0}\end{array}$ & $\stackrel{t}{0}$ & $\stackrel{\circ}{\circ}$ & $\begin{array}{l}\infty \\
n \\
n\end{array}$ \\
\hline & $r$ & $\stackrel{8}{8}$ & $\underset{o}{O}$ & $\begin{array}{l}\overline{0} \\
\stackrel{\varphi}{1}\end{array}$ & $\tilde{o}_{0}$ & $\stackrel{\overline{0}}{\circ}$ & $\stackrel{\tilde{0}}{0}$ & $\underset{\dot{0}}{\stackrel{t}{0}}$ & $\stackrel{\overline{0}}{\circ}$ & $\stackrel{\infty}{\circ}$ & $\stackrel{n}{=}$ & $\begin{array}{l}n \\
0 \\
i\end{array}$ & $\begin{array}{l}0 \\
0\end{array}$ & $\begin{array}{l}\dot{0} \\
0 \\
\end{array}$ & $\stackrel{\text { ণิ }}{-}$ \\
\hline & $\neg$ & $\stackrel{8}{\circ}$ & $\ddot{0}$ & $\stackrel{8}{\circ}$ & $\stackrel{8}{8}$ & $\stackrel{8}{8}$ & $\stackrel{8}{8}$ & 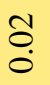 & $\stackrel{0}{0}$ & ஓ̊ & $\stackrel{\overline{0}}{\circ}$ & ¿̄. & $\stackrel{8}{8}$ & 立. & $\hat{\sigma}$ \\
\hline & $I$ & $\begin{array}{l}00 \\
0\end{array}$ & $\stackrel{n}{\varrho}$ & $\begin{array}{l}\text { O̦ } \\
\stackrel{0}{1}\end{array}$ & $\stackrel{\square}{0}$ & $\stackrel{+}{0}$ & $\stackrel{+}{0}$ & లొ & $\hat{\sigma}$ & $\stackrel{\sim}{\stackrel{0}{0}}$ & $\overbrace{0}^{\circ}$ & $\begin{array}{l}\tilde{0} \\
\stackrel{0}{0}\end{array}$ & $\begin{array}{l}0 \\
0 \\
0\end{array}$ & $\begin{array}{l}\text { O̦. } \\
\text { Q }\end{array}$ & กิ \\
\hline & 0 & $\stackrel{8}{8}$ & $\stackrel{8}{\circ}$ & $\stackrel{8}{\circ}$ & $\stackrel{8}{\circ}$ & $\stackrel{8}{\circ}$ & $\stackrel{8}{\circ}$ & $\stackrel{0}{\stackrel{0}{0}}$ & $\stackrel{8}{\circ}$ & $\stackrel{8}{\circ}$ & $\stackrel{8}{\circ}$ & $\stackrel{8}{\circ}$ & $\stackrel{8}{\circ}$ & $\stackrel{8}{\circ}$ & $\frac{1}{0}$ \\
\hline & I & $\begin{array}{l}\overline{0} \\
\stackrel{\varphi}{1}\end{array}$ & $\stackrel{5}{0}$ & $\begin{array}{l}\text { Ô. } \\
\stackrel{\varphi}{1}\end{array}$ & 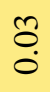 & $\stackrel{1}{\circ}$ & $\stackrel{\text { ô }}{\circ}$ & $\stackrel{\text { If. }}{\circ}$ & $\stackrel{\text { ?े }}{0}$ & $\stackrel{\infty}{\circ}$ & $\stackrel{\text { ô }}{0}$ & $\begin{array}{l}\tilde{0} \\
0 \\
\end{array}$ & $\stackrel{8}{8}$ & $\begin{array}{l}0 \\
0 \\
1\end{array}$ & \\
\hline & 디 & $\begin{array}{l}0 \\
0 \\
0\end{array}$ & $\stackrel{\Delta}{0}$ & 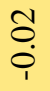 & 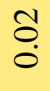 & $\stackrel{\infty}{\infty}$ & $\stackrel{\text { ஜ̊ }}{\circ}$ & $\frac{m}{0}$ & $\stackrel{\text { ô }}{\circ}$ & $\begin{array}{l}\text { ț } \\
\dot{0}\end{array}$ & $\stackrel{\circ}{\circ}$ & 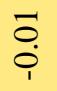 & $\stackrel{8}{8}$ & $\begin{array}{l}0 \\
0 \\
\end{array}$ & $\stackrel{m}{=}$ \\
\hline & 0 & $\begin{array}{l}\text { ô } \\
\text { in }\end{array}$ & $\stackrel{ \pm}{0}$ & $=$ & $\stackrel{?}{\mathscr{C}}$ & $\stackrel{0}{0}$ & $\stackrel{\text { ô }}{\circ}$ & $\begin{array}{l}\infty \\
\stackrel{0}{0} \\
\stackrel{0}{0}\end{array}$ & $\stackrel{0}{0}$ & $\stackrel{t}{0}$ & $\stackrel{\circ}{0}$ & $\begin{array}{l}0 \\
0 \\
\end{array}$ & $\stackrel{8}{8}$ & $\begin{array}{l}\overline{0} \\
\dot{\varphi}\end{array}$ & 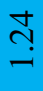 \\
\hline & $u$ & $\stackrel{\text { Oo }}{\circ}$ & $\begin{array}{l}\text { ก̦ } \\
\stackrel{1}{1}\end{array}$ & $\exists$ & $\begin{array}{l}\hat{0} \\
\dot{0}\end{array}$ & $\begin{array}{l}0 \\
0 \\
\stackrel{1}{1}\end{array}$ & $\begin{array}{l}0 \\
0 \\
\dot{\varphi}\end{array}$ & $\begin{array}{l}\stackrel{0}{\circ} \\
\stackrel{0}{0}\end{array}$ & $\begin{array}{l}0 \\
\dot{\varphi}\end{array}$ & $\begin{array}{l}0 \\
0 \\
\dot{\varphi}\end{array}$ & $\begin{array}{l}0 \\
\stackrel{0}{0}\end{array}$ & ö. & $\stackrel{8}{\circ}$ & ö. & $\stackrel{m}{\tilde{0}}$ \\
\hline & $\infty$ & $\begin{array}{l}8 \\
0 \\
0\end{array}$ & $\stackrel{\Delta}{\text { Sa }}$ & $\begin{array}{l}n \\
0 \\
\dot{0}\end{array}$ & $\stackrel{\text { ô }}{0}$ & $\stackrel{\Xi}{\circ}$ & $\stackrel{\Xi}{0}$ & ஜ̊. & $\stackrel{0}{0}$ & 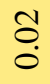 & ¿. & $\stackrel{8}{8}$ & $\stackrel{8}{8}$ & $\begin{array}{l}0 \\
0\end{array}$ & $\bar{\sigma}$ \\
\hline & $\varangle$ & ô. & ầ & $\overline{0}$ & $\begin{array}{l}n \\
0 \\
\dot{\varphi}\end{array}$ & $\begin{array}{l}\text { O̦ } \\
\text { ọ }\end{array}$ & $\begin{array}{l}\text { ơ } \\
\text { ஸे }\end{array}$ & $\begin{array}{l}\infty \\
\stackrel{0}{+} \\
\stackrel{1}{0}\end{array}$ & $\begin{array}{l}0 \\
0 \\
0\end{array}$ & $\begin{array}{l}n \\
0 \\
0\end{array}$ & $\begin{array}{l}0 \\
0 \\
\stackrel{1}{ }\end{array}$ & ö. & $\stackrel{8}{8}$ & 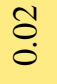 & ö \\
\hline & 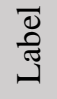 & $\varangle$ & $\varphi$ & $u$ & 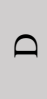 & 디 & IL & 0 & $I$ & - & $\neg$ & 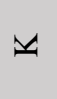 & \lrcorner & $\Sigma$ & 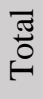 \\
\hline & & & & & & & & & & & & & & & \\
\hline
\end{tabular}




\subsection{Five Mile Radius Results}

This section discusses the accessibility indices of station catchment areas at the five-mile radius. This radius represents a distance that extends beyond the range of pedestrians and cyclists to access a transit node. Trips traveling beyond three miles to access a transit node are likely to utilize motorized modes of transportation, such as automobiles, or other forms of transit, as noted in Section 4.2. The five-mile catchment area radius is inclusive of trips that are shorter in distance and, hence, still accessible to pedestrians and cyclists.

\subsubsection{Raw Job Figures}

Table 5.13 shows the accessibility indices for station origin-destination pairs using raw job figures with a five-mile buffer. Like Table 5.1 and Table 5.7, which respectively show the accessibility indices with raw job figures at the half-mile radius and the three-mile radius, respectively, the pattern shown in Table 5.13 shows that station areas are most attracted to their themselves because of the low distance. Also, station origin-destination pairs tend to lose attraction to each other as the distance between them increases. Station areas with higher absolute jobs numbers have the highest overall attraction indices. 
Table 5.13 Accessibility indices for origin-destination pairs from raw job figures for five-mile buffer.

Green, yellow, and red cells denote relatively high, medium, and low values, respectively. Blue cells denote row or column totals.

\begin{tabular}{|c|c|c|c|c|c|c|c|c|c|c|c|c|c|c|c|}
\hline \multirow{14}{*}{ 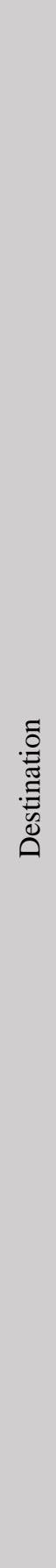 } & స్ّ & $\underset{8}{8}$ & $\underset{8}{8}$ & $\underset{\sim}{8}$ & 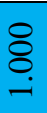 & $\underset{8}{8}$ & $\underset{-}{8}$ & $\underset{-}{8}$ & $\underset{-}{8}$ & 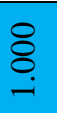 & $\underset{-}{8}$ & 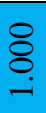 & $\underset{\square}{8}$ & 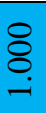 & 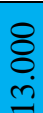 \\
\hline & $\Sigma$ & $\begin{array}{l}n \\
\delta \\
0\end{array}$ & $\begin{array}{l}\text { } \\
\text { : }\end{array}$ & $\begin{array}{l}\infty \\
\stackrel{8}{8} \\
\stackrel{0}{0}\end{array}$ & 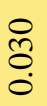 & $\begin{array}{l}\stackrel{0}{2} \\
\stackrel{0}{0} \\
\end{array}$ & $\begin{array}{l}\stackrel{0}{2} \\
\stackrel{2}{0} \\
\stackrel{0}{0}\end{array}$ & $\stackrel{m}{\dddot{m}}$ & $\begin{array}{l}\infty \\
\stackrel{8}{0} \\
\stackrel{0}{0}\end{array}$ & $\begin{array}{l}\stackrel{\infty}{+} \\
\stackrel{0}{0}\end{array}$ & $\frac{\mathbb{N}}{0}$ & $\begin{array}{l}\bar{\sigma} \\
\stackrel{0}{0}\end{array}$ & 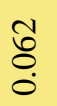 & 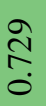 & กี \\
\hline & \lrcorner & $\stackrel{8}{8}$ & $\stackrel{\circ}{\partial}$ & $\begin{array}{l}0 \\
\stackrel{0}{0} \\
\stackrel{0}{0}\end{array}$ & $\begin{array}{l}\infty \\
2 \\
0 \\
0\end{array}$ & $\stackrel{\text { oे }}{0}$ & $\exists$ & $\stackrel{8}{\circ}$ & $\frac{\infty}{\stackrel{\infty}{0}}$ & $\frac{d}{0}$ & $\begin{array}{c}\hat{N} \\
\stackrel{\tilde{O}}{0}\end{array}$ & 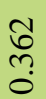 & $\begin{array}{l}\bar{\infty} \\
\infty \\
0\end{array}$ & $\frac{\bar{\infty}}{\overrightarrow{0}}$ & i্ \\
\hline & $\forall$ & $\begin{array}{l}+ \\
8\end{array}$ & $\stackrel{8}{\circ}$ & $\stackrel{\infty}{8}$ & ڤે & $\begin{array}{l}\stackrel{\vartheta}{0} \\
\stackrel{0}{0}\end{array}$ & $\begin{array}{l}0 \\
\qquad \\
0 \\
0\end{array}$ & $\stackrel{m}{\tilde{O}}$ & $\begin{array}{l}\stackrel{0}{0} \\
0 \\
0\end{array}$ & $\begin{array}{l}n \\
\tilde{o} \\
0\end{array}$ & $\begin{array}{l}\text { ڤે } \\
\text { ஸे }\end{array}$ & 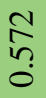 & $\begin{array}{l}\stackrel{n}{=} \\
0\end{array}$ & $\begin{array}{l}\hat{8} \\
\text { हे }\end{array}$ & 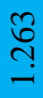 \\
\hline & $r$ & $\begin{array}{l}8 \\
8 \\
0\end{array}$ & $\begin{array}{l}\overline{8} \\
0\end{array}$ & $\begin{array}{l}\overline{8} \\
\dot{0}\end{array}$ & $\stackrel{8}{8}$ & $\begin{array}{l}\mathscr{8} \\
\ddot{0}\end{array}$ & $\begin{array}{l}8 \\
8 \\
0\end{array}$ & 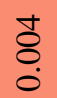 & $\begin{array}{l}\infty \\
\stackrel{8}{0}\end{array}$ & $\begin{array}{l}\infty \\
\stackrel{8}{0} \\
\stackrel{0}{0}\end{array}$ & $\begin{array}{l}\overline{\text { }} \\
\text { ọ }\end{array}$ & \begin{tabular}{l}
$\mathscr{8}$ \\
$\delta$ \\
\hdashline
\end{tabular} & $\begin{array}{l}\tilde{\delta} \\
\stackrel{0}{0}\end{array}$ & 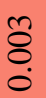 & $\underset{\text { İ }}{\stackrel{5}{0}}$ \\
\hline & - & $\begin{array}{l}\tilde{\delta} \\
\stackrel{0}{0}\end{array}$ & $\stackrel{n}{8}$ & $\begin{array}{l}+ \\
8\end{array}$ & $\stackrel{r}{0}$ & $\stackrel{\text { }}{0}$ & $\begin{array}{l}\vec{J} \\
\dot{0}\end{array}$ & $\begin{array}{l}\hat{\delta} \\
\stackrel{0}{0}\end{array}$ & $\begin{array}{l}\hat{8} \\
\stackrel{0}{0}\end{array}$ & $\begin{array}{l}\hat{\delta} \\
\stackrel{0}{0}\end{array}$ & $\begin{array}{l}\stackrel{0}{0} \\
\text { : }\end{array}$ & $\hat{8}$ & $\stackrel{+}{8}$ & $\begin{array}{l}8 \\
8 \\
0\end{array}$ & \\
\hline & $I$ & $\begin{array}{l}8 \\
8 \\
0\end{array}$ & $\stackrel{\overline{8}}{\circ}$ & $\stackrel{\overline{8}}{\circ}$ & $\stackrel{8}{0}$ & $\begin{array}{l}0 \\
0 \\
0\end{array}$ & $\stackrel{n}{a}$ & $\stackrel{n}{a}$ & 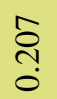 & $\begin{array}{l}n \\
\tilde{0}\end{array}$ & 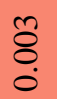 & $\overline{8}$ & $\stackrel{8}{8}$ & $\overline{8}$ & $\begin{array}{l}\text { ָे } \\
\text { సै }\end{array}$ \\
\hline & 0 & $\begin{array}{l}\tilde{8} \\
\stackrel{0}{0}\end{array}$ & $\stackrel{0}{8}$ & $\stackrel{5}{0}$ & $\begin{array}{l}\infty \\
\stackrel{\infty}{0} \\
\stackrel{0}{0}\end{array}$ & $\begin{array}{l}\mathscr{0} \\
0 \\
0 \\
0\end{array}$ & $\frac{\infty}{0}$ & $\begin{array}{l}\infty \\
\widetilde{b} \\
\stackrel{0}{0}\end{array}$ & $\frac{t}{0}$ & $\begin{array}{l}\overline{\widehat{\sigma}} \\
\stackrel{0}{0}\end{array}$ & $\begin{array}{l}n \\
0 \\
0\end{array}$ & $\begin{array}{l}\text { } \\
\stackrel{8}{0}\end{array}$ & $\begin{array}{l}\text { ò } \\
\text { ठ }\end{array}$ & 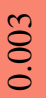 & 古 \\
\hline & LI & $\stackrel{8}{8}$ & $\stackrel{\overline{8}}{\circ}$ & $\overline{8}$ & $\begin{array}{l}\stackrel{+}{8} \\
\stackrel{0}{0}\end{array}$ & 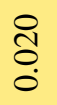 & $\frac{n}{ \pm}$ & $\stackrel{\sim}{0}$ & $\bar{\sigma}$ & $\stackrel{1}{\delta}$ & §̊ & \begin{tabular}{l}
8 \\
8 \\
\hdashline
\end{tabular} & $\stackrel{8}{8}$ & $\begin{array}{l}8 \\
8 \\
0\end{array}$ & $\begin{array}{l}\stackrel{2}{\circ} \\
\frac{0}{2}\end{array}$ \\
\hline & 니 & ¿্. & 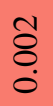 & 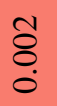 & $\begin{array}{l}\stackrel{0}{0} \\
\stackrel{0}{0}\end{array}$ & $\begin{array}{l}\text { तै } \\
\text { తి }\end{array}$ & \begin{tabular}{l}
0 \\
\multirow{0}{0}{} \\
0
\end{tabular} & $\stackrel{m}{0}$ & $\begin{array}{l}0 \\
0 \\
0\end{array}$ & $\begin{array}{l}+ \\
8 \\
0\end{array}$ & $\stackrel{\wp}{8}$ & $\overline{8}$ & \begin{tabular}{l}
8 \\
\hdashline \\
0
\end{tabular} & $\overrightarrow{8}$ & \begin{tabular}{l} 
ণิ \\
\multirow{\jmath}{0}{}
\end{tabular} \\
\hline & D & $\overline{8}$ & $\stackrel{8}{8}$ & $\begin{array}{l}8 \\
8 \\
0 \\
0\end{array}$ & $\frac{\bar{n}}{0}$ & $\stackrel{8}{\circ}$ & $\stackrel{0}{\circ}$ & 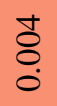 & \begin{tabular}{l}
8 \\
8 \\
\hdashline
\end{tabular} & $\stackrel{1}{8}$ & $\begin{array}{l}1 \\
\delta \\
0\end{array}$ & \begin{tabular}{l}
8 \\
\hdashline
\end{tabular} & $\begin{array}{l}8 \\
\stackrel{8}{0}\end{array}$ & $\begin{array}{l}8 \\
8 \\
0\end{array}$ & $\frac{\circ}{\circ}$ \\
\hline & $u$ & $\begin{array}{l}\bar{\theta} \\
\stackrel{0}{0}\end{array}$ & $\begin{array}{l}\stackrel{0}{=} \\
\dot{0}\end{array}$ & $\frac{t}{2}$ & $\begin{array}{l}\stackrel{a}{n} \\
\text { ֻे }\end{array}$ & $\frac{\overparen{I}}{0}$ & $\frac{\vec{m}}{0}$ & $\begin{array}{l}\infty \\
ٌ \\
0\end{array}$ & \begin{tabular}{l}
8 \\
8 \\
\hdashline
\end{tabular} & Oે & 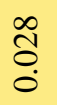 & \begin{tabular}{l}
8 \\
8 \\
\hdashline
\end{tabular} & $\begin{array}{l}\dot{0} \\
\stackrel{0}{0}\end{array}$ & 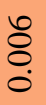 & $\begin{array}{l}\infty \\
\stackrel{\infty}{\rightleftharpoons} \\
\end{array}$ \\
\hline & $\infty$ & $\begin{array}{l}\stackrel{g}{0} \\
\stackrel{0}{0}\end{array}$ & $\stackrel{\infty}{\stackrel{\infty}{m}}$ & $\begin{array}{l}\dot{0} \\
\stackrel{0}{0}\end{array}$ & $\vec{\circ}$ & $\stackrel{n}{\tilde{o}}$ & $\stackrel{0}{0}$ & $\stackrel{0}{0}$ & $\begin{array}{l}\hat{\sigma} \\
\stackrel{0}{0}\end{array}$ & ठे. & ठे. & 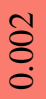 & $\stackrel{\overline{8}}{\circ}$ & $\begin{array}{l}\text { ô } \\
\stackrel{0}{\circ}\end{array}$ & ભొర్ \\
\hline & $\varangle$ & $\begin{array}{l}0 \\
\infty \\
\infty \\
0\end{array}$ & 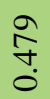 & $\stackrel{\infty}{=}$ & 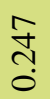 & $\frac{\mathfrak{n}}{0}$ & $\frac{8}{0}$ & 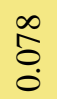 & $\frac{\mathscr{1}}{\stackrel{1}{0}}$ & $\begin{array}{l}\text { J } \\
\stackrel{0}{0}\end{array}$ & $\begin{array}{l}\text { J } \\
\stackrel{0}{0}\end{array}$ & $\begin{array}{l}0 \\
0 \\
0\end{array}$ & $\stackrel{5}{0}$ & \begin{tabular}{l}
$\circ$ \\
\hdashline \\
0
\end{tabular} & 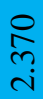 \\
\hline & $\begin{array}{l}\bar{D} \\
\text { ]्ञ }\end{array}$ & $\ll$ & 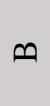 & $u$ & D & 피 & L & 0 & $I$ & - & $\neg$ & 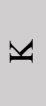 & \lrcorner & $\Sigma$ & 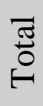 \\
\hline & & & & & & & & & & & & & & & \\
\hline
\end{tabular}




\subsubsection{Normalized Job Figures}

Table 5.14 shows the accessibility indices of station origin-destination pairs for normalized job figures with the five-mile buffer. There is very little variation in attraction between the station areas. In fact, compared to Table 5.8, which shows the accessibility indices of station origin-destination pairs for normalized job figures with the three-mile buffer, Table 5.14 shows less variation overall. Station areas are still most attracted to themselves, but to a lesser extent than in previous tables with normalized job values. Also, the station area origin-destination pair of Millbrae-to-Millbrae stands in contrast to the other station areas being attracted to themselves. Millbrae-to-San Francisco is also an outlier as it is the one station area origin-destination pair that shows a high level of attraction. 
Table 5.14 Accessibility indices for origin-destination pairs from normalized job figures for five-mile buffer. Green, yellow, and red cells denote relatively high, medium, and low values, respectively. Blue cells denote row or column totals.

\begin{tabular}{|c|c|c|c|c|c|c|c|c|c|c|c|c|c|c|c|}
\hline \multirow{14}{*}{ 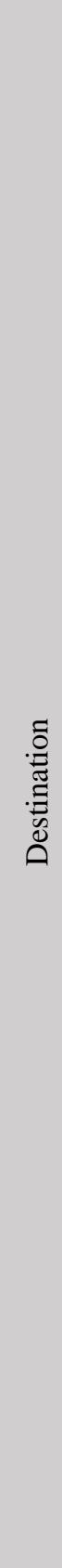 } & 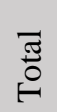 & $\stackrel{8}{8}$ & $\stackrel{8}{8}$ & $\underset{-}{8}$ & $\underset{-}{\stackrel{8}{2}}$ & $\stackrel{8}{8}$ & $\stackrel{8}{8}$ & $\stackrel{8}{\circ}$ & 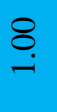 & $\stackrel{8}{8}$ & $\underset{-}{\stackrel{8}{0}}$ & $\stackrel{8}{8}$ & $\stackrel{8}{8}$ & $\underset{-}{\stackrel{8}{2}}$ & $\begin{array}{l}8 \\
\stackrel{8}{2}\end{array}$ \\
\hline & $\Sigma$ & $\stackrel{8}{\circ}$ & $\frac{ \pm}{0}$ & $\ddot{0}$ & $\begin{array}{l}\sigma \\
0 \\
\end{array}$ & $\underset{0}{0}$ & $\begin{array}{l}0 \\
\dot{\varphi}\end{array}$ & $\begin{array}{l}0 \\
\dot{\varphi}\end{array}$ & $\begin{array}{l}0 \\
\dot{\varphi}\end{array}$ & $\begin{array}{l}\dot{J} \\
0 \\
\end{array}$ & $\begin{array}{l}n \\
0 \\
\grave{1}\end{array}$ & $\stackrel{\leftrightarrow}{0}$ & $\stackrel{n}{0}$ & $\frac{n}{0}$ & $\begin{array}{l}\stackrel{+}{\infty} \\
\stackrel{0}{0}\end{array}$ \\
\hline & \lrcorner & $\begin{array}{l}\overline{0} \\
0\end{array}$ & $\stackrel{n}{\circ}$ & $\stackrel{+}{\stackrel{D}{0}}$ & $\begin{array}{l}\text { Oo. } \\
\stackrel{0}{+}\end{array}$ & $\begin{array}{l}\text { Oo. } \\
\dot{0}\end{array}$ & $\begin{array}{l}0 \\
0 \\
\dot{\varphi}\end{array}$ & $\begin{array}{l}\text { to } \\
\stackrel{0}{1}\end{array}$ & $\begin{array}{l}\dot{T} \\
\stackrel{0}{i}\end{array}$ & $\frac{m}{i}$ & $\begin{array}{l}\bar{N} \\
\stackrel{1}{1}\end{array}$ & రై & $\stackrel{+}{\sigma}$ & ָे & $\stackrel{\infty}{\infty}$ \\
\hline & $\forall$ & $\stackrel{8}{8}$ & $\stackrel{\circ}{\circ}$ & $\stackrel{\overline{0}}{0}$ & $\begin{array}{l}\overline{0} \\
\stackrel{0}{0}\end{array}$ & $\begin{array}{l}\overline{0} \\
0 \\
0\end{array}$ & $\begin{array}{l}0 \\
0 \\
0\end{array}$ & $\begin{array}{l}0 \\
0 \\
0\end{array}$ & $\begin{array}{l}\overline{0} \\
\dot{0}\end{array}$ & $\begin{array}{l}\text { O̦ } \\
\text { }\end{array}$ & $\begin{array}{l}0 \\
\stackrel{0}{0}\end{array}$ & $\stackrel{\infty}{+}$ & $\stackrel{1}{0}$ & $\stackrel{n}{\circ}$ & ñ \\
\hline & $\neg$ & $\ddot{0}_{0}^{0}$ & $\frac{9}{\dot{p}}$ & 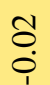 & $\stackrel{0}{0}$ & $\overline{0}_{0}^{0}$ & $\ddot{0}$ & $\stackrel{1}{0}$ & 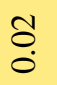 & $\stackrel{8}{8}$ & 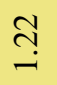 & tọ. & ڤె. & $\begin{array}{l}\dot{0} \\
\stackrel{0}{0}\end{array}$ & $\stackrel{\overbrace{}}{0}$ \\
\hline & $\neg$ & $\stackrel{8}{8}$ & $\stackrel{?}{\frac{1}{i}}$ & $\begin{array}{l}\overline{0} \\
\stackrel{0}{\varphi}\end{array}$ & $\stackrel{\overline{0}}{\circ}$ & $\stackrel{\overline{0}}{\circ}$ & $\stackrel{0}{0}$ & $\stackrel{\sigma}{0}$ & 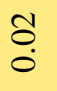 & $\stackrel{8}{\circ}$ & $\stackrel{\overbrace{}}{0}$ & $\begin{array}{l}\overline{0} \\
\stackrel{0}{0}\end{array}$ & $\begin{array}{l}\overline{0} \\
\stackrel{0}{i}\end{array}$ & $\begin{array}{l}\overline{0} \\
\stackrel{0}{0}\end{array}$ & $\begin{array}{l}\mathscr{\infty} \\
\stackrel{\infty}{0}\end{array}$ \\
\hline & $I$ & $\begin{array}{l}0 \\
0\end{array}$ & $\begin{array}{l}0 \\
\text { ?} \\
\text { in }\end{array}$ & $\begin{array}{l}\dot{U} \\
\stackrel{0}{\varphi}\end{array}$ & $\begin{array}{l}0 \\
\stackrel{0}{0}\end{array}$ & $\stackrel{+}{0}$ & $\stackrel{\circ}{\circ}$ & $\begin{array}{l}0 \\
0 \\
0\end{array}$ & $\begin{array}{l}\stackrel{0}{\infty} \\
\stackrel{0}{0}\end{array}$ & $\stackrel{\text { oे }}{0}$ & $\stackrel{0}{0}$ & $\begin{array}{l}0 \\
0 \\
\stackrel{1}{1}\end{array}$ & ọ. & $\begin{array}{l}0 \\
0\end{array}$ & $\begin{array}{l}\bar{\infty} \\
\stackrel{0}{0}\end{array}$ \\
\hline & ט & $\begin{array}{l}0 \\
0 \\
0\end{array}$ & 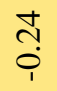 & $\begin{array}{l}m \\
0 \\
0\end{array}$ & $\stackrel{\sigma}{0}$ & $\stackrel{+}{0}$ & $\stackrel{0}{0}$ & $\begin{array}{l}n \\
0 \\
0\end{array}$ & ô. & $\stackrel{+}{0}$ & $\stackrel{\sigma}{0}$ & $\begin{array}{l}0 \\
0 \\
0\end{array}$ & $\stackrel{8}{\circ}$ & $\begin{array}{l}0 \\
0 \\
\end{array}$ & ڤั? \\
\hline & I & 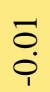 & $\begin{array}{l}\bar{n} \\
\stackrel{p}{1}\end{array}$ & $\stackrel{l}{8}$ & $\stackrel{n}{0}$ & $\frac{m}{0}$ & $\stackrel{\infty}{\infty}$ & $\frac{\infty}{0}$ & $\stackrel{\leftrightarrow}{\circ}$ & $\stackrel{\circ}{\circ}$ & 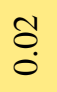 & $\begin{array}{l}\overline{0} \\
\stackrel{0}{1}\end{array}$ & $\begin{array}{l}0 \\
\stackrel{0}{\varphi}\end{array}$ & $\begin{array}{l}\overline{0} \\
\stackrel{0}{0}\end{array}$ & $\begin{array}{l}\infty \\
\stackrel{0}{0}\end{array}$ \\
\hline & 디 & $\begin{array}{l}0 \\
0 \\
0\end{array}$ & $\begin{array}{l}n \\
\stackrel{n}{+} \\
+\end{array}$ & $\begin{array}{l}n \\
0 \\
0\end{array}$ & $\stackrel{+}{0}$ & $\begin{array}{l}\mathscr{\infty} \\
\dot{0}\end{array}$ & $\stackrel{\circ}{\stackrel{0}{0}}$ & $\stackrel{\infty}{\circ}$ & $\begin{array}{l}\dot{0} \\
\stackrel{0}{0}\end{array}$ & $\stackrel{+}{\stackrel{0}{0}}$ & 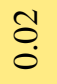 & $\begin{array}{l}0 \\
0 \\
0\end{array}$ & $\stackrel{8}{8}$ & $\begin{array}{l}\overline{0} \\
\dot{0}\end{array}$ & $\begin{array}{l}\overline{0} \\
\stackrel{0}{0}\end{array}$ \\
\hline & D & $\begin{array}{l}\text { ô. } \\
\stackrel{0}{0}\end{array}$ & $\stackrel{\infty}{\stackrel{\infty}{\longrightarrow}}$ & 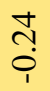 & 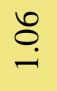 & $\stackrel{\Delta}{0}$ & $\stackrel{0}{0}$ & $\stackrel{+}{0}$ & $\stackrel{\text { ô }}{\circ}$ & $\stackrel{\leftrightarrow}{0}$ & $\underset{\leftrightarrow}{0}$ & 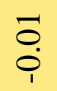 & $\stackrel{8}{8}$ & $\begin{array}{l}\overrightarrow{0} \\
\stackrel{p}{\varphi}\end{array}$ & $\begin{array}{l}\text { ה̃ } \\
\text { }\end{array}$ \\
\hline & $u$ & ô. & $\stackrel{\text { q }}{-}$ & $\stackrel{\infty}{=}$ & $\begin{array}{l}8 \\
0 \\
\end{array}$ & $\begin{array}{l}0 \\
0 \\
\stackrel{\varphi}{0}\end{array}$ & $\begin{array}{l}1 \\
\text { ọ } \\
\stackrel{1}{0}\end{array}$ & $\begin{array}{l}\text { ô } \\
\stackrel{1}{0}\end{array}$ & $\begin{array}{l}\overrightarrow{0} \\
\dot{\varphi}\end{array}$ & $\begin{array}{l}\text { Õ } \\
\dot{\varphi}\end{array}$ & $\begin{array}{l}\overrightarrow{0} \\
\stackrel{0}{0}\end{array}$ & $\stackrel{\circ}{0}$ & $\stackrel{8}{8}$ & $\stackrel{\overrightarrow{0}}{\circ}$ & $\stackrel{n}{n}$ \\
\hline & $\infty$ & $\begin{array}{l}\hat{0} \\
0 \\
\end{array}$ & $\underset{\infty}{\stackrel{+}{\infty}}$ & $\begin{array}{l}0 \\
\stackrel{1}{0}\end{array}$ & $\stackrel{\text { Oे }}{0}$ & $\stackrel{\Xi}{0}$ & $\stackrel{\Xi}{\circ}$ & $\stackrel{\circ}{\circ}$ & $\stackrel{\overline{0}}{\circ}$ & o. & $\stackrel{\overrightarrow{0}}{\circ}$ & $\stackrel{8}{8}$ & $\stackrel{8}{8}$ & $\stackrel{8}{\circ}$ & $\begin{array}{l}\infty \\
\infty \\
\infty \\
\infty \\
1\end{array}$ \\
\hline & $\ll$ & $\stackrel{0}{=}$ & $\begin{array}{l}\text { శூ } \\
\stackrel{0}{0}\end{array}$ & @ి & $=$ & $\begin{array}{l}\text { ț } \\
\stackrel{\varphi}{1}\end{array}$ & $\begin{array}{l}\dot{0} \\
\stackrel{\varphi}{1}\end{array}$ & $\begin{array}{l}n \\
\stackrel{0}{0} \\
1\end{array}$ & $\stackrel{\text { ô }}{\dot{\varphi}}$ & $\begin{array}{l}\because \\
\stackrel{0}{0}\end{array}$ & $\stackrel{0}{0}$ & $\stackrel{\text { ô }}{0}$ & $\stackrel{\overline{0}}{\circ}$ & 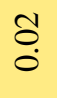 & $\stackrel{\overbrace{}}{\stackrel{\Xi}{\Xi}}$ \\
\hline & $\begin{array}{l}\bar{D} \\
\text { ] } \\
\text { త్ }\end{array}$ & $\ll$ & $\infty$ & $u$ & $\theta$ & 디 & L & ט & $I$ & - & $r$ & 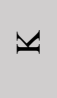 & \lrcorner & $\Sigma$ & 氶 \\
\hline & & & & & & & & & & & & & & & \\
\hline
\end{tabular}




\subsubsection{Raw Population Figures}

Table 5.15 shows the accessibility indices of origin-destination pairs for raw population figures at the five-mile distance. Table 5.9 shows a similar pattern to that shown in Table 5.15, which presents similar data but with a three-mile buffer. Beyond the patterns described in tables above, no remarkable difference in patterns is exhibited. 
Table 5.15 Accessibility indices for origin-destination pairs from raw population figures for five-mile buffer. Green, yellow, and red cells denote relatively high, medium, and low values, respectively. Blue cells denote row or column totals.

\begin{tabular}{|c|c|c|c|c|c|c|c|c|c|c|c|c|c|c|c|}
\hline \multirow{14}{*}{ 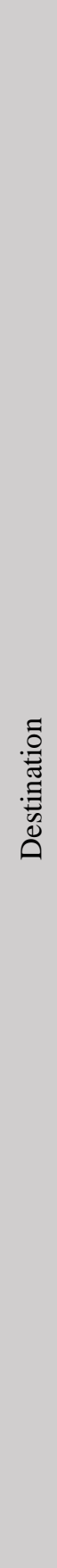 } & $\begin{array}{l}\bar{\pi} \\
0 \\
0\end{array}$ & $\underset{8}{8}$ & $\underset{-}{8}$ & $\underset{8}{8}$ & $\underset{8}{8}$ & $\underset{-}{8}$ & $\underset{8}{8}$ & $\underset{8}{8}$ & $\underset{-}{8}$ & $\underset{8}{8}$ & $\underset{-}{8}$ & $\underset{-}{8}$ & $\underset{-}{8}$ & $\underset{-}{8}$ & $\begin{array}{l}8 \\
\vdots \\
\ddot{2}\end{array}$ \\
\hline & $\Sigma$ & $\begin{array}{l}8 \\
8 \\
0\end{array}$ & छे & \begin{tabular}{l}
8 \\
\hdashline \\
0
\end{tabular} & 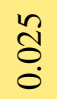 & 饣̂́ & $\begin{array}{l}0 \\
\text { ֻூ } \\
\stackrel{0}{0}\end{array}$ & $\begin{array}{l}\bar{\delta} \\
\stackrel{0}{0}\end{array}$ & $\begin{array}{l}\text { J } \\
\stackrel{0}{0}\end{array}$ & $\begin{array}{l}\dot{T} \\
\stackrel{0}{0}\end{array}$ & $\stackrel{\mathscr{o}}{0}$ & $\begin{array}{l}\infty \\
\stackrel{0}{0} \\
\stackrel{0}{0}\end{array}$ & $\begin{array}{l}n \\
0 \\
0\end{array}$ & $\stackrel{8}{\stackrel{8}{\circ}}$ & $\begin{array}{l}\infty \\
\infty \\
0 \\
0\end{array}$ \\
\hline & \lrcorner & $\stackrel{m}{0}$ & $\begin{array}{l}\text { ปิ } \\
\text { Oे }\end{array}$ & $\stackrel{\Delta}{\stackrel{\Xi}{0}}$ & $\begin{array}{l}\stackrel{+}{0} \\
\stackrel{0}{0}\end{array}$ & 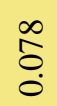 & $\begin{array}{l}\vec{\infty} \\
\stackrel{0}{0} \\
0\end{array}$ & $\begin{array}{l}\hat{J} \\
\stackrel{0}{0}\end{array}$ & $\stackrel{\overrightarrow{0}}{\overrightarrow{0}}$ & $\begin{array}{l}\underset{+}{+} \\
0 \\
0\end{array}$ & 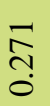 & 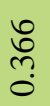 & $\begin{array}{l}8 \\
\infty \\
\infty \\
0\end{array}$ & $\frac{\hat{a}}{0}$ & $\frac{m}{\vec{n}}$ \\
\hline & $\forall$ & $\begin{array}{l}\mathscr{8} \\
8 \\
0\end{array}$ & $\begin{array}{l}\circ \\
0 \\
0\end{array}$ & $\begin{array}{l}\hat{8} \\
0 \\
0\end{array}$ & 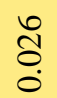 & 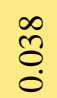 & $\begin{array}{l}\stackrel{P}{0} \\
\stackrel{0}{0}\end{array}$ & $\underset{\widehat{O}}{0}$ & $\begin{array}{l}8 \\
\ddot{0} \\
0\end{array}$ & $\begin{array}{l}\text { Oִ } \\
\stackrel{0}{0}\end{array}$ & $\begin{array}{l}\vec{t} \\
\stackrel{0}{0}\end{array}$ & $\begin{array}{l}\tilde{b} \\
\tilde{0}\end{array}$ & $\stackrel{m}{=}$ & $\begin{array}{l}\hat{b} \\
\stackrel{0}{0}\end{array}$ & $\underset{\Xi}{\exists}$ \\
\hline & $\neg$ & $\begin{array}{l}\overline{8} \\
\dot{0}\end{array}$ & $\begin{array}{l}\text { ठै } \\
\text { ¿ }\end{array}$ & $\begin{array}{l}\overline{8} \\
\dot{0}\end{array}$ & $\begin{array}{l}\mathscr{8} \\
\stackrel{0}{0}\end{array}$ & $\begin{array}{l}\infty \\
\stackrel{8}{0} \\
0\end{array}$ & $\begin{array}{l}\text { ठे } \\
\text { ¿ }\end{array}$ & 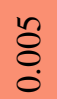 & $\begin{array}{l}\stackrel{1}{0} \\
0 \\
0\end{array}$ & $\stackrel{\sim}{\check{0}}$ & $\stackrel{\tilde{m}}{0}$ & $\begin{array}{l}\text { } \\
\dot{0}\end{array}$ & $\stackrel{\wp}{8}$ & \begin{tabular}{l}
$\mathscr{8}$ \\
8 \\
\hdashline
\end{tabular} & 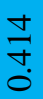 \\
\hline & - & $\begin{array}{l}\mathscr{8} \\
\dot{0}\end{array}$ & $\begin{array}{l}\hat{8} \\
0\end{array}$ & $\begin{array}{l}\mathscr{8} \\
0\end{array}$ & $\begin{array}{l}\overline{\widehat{\sigma}} \\
\dot{0}\end{array}$ & $\begin{array}{l}n \\
\text { n̊ } \\
0\end{array}$ & $\begin{array}{l}\stackrel{9}{0} \\
0 \\
0\end{array}$ & 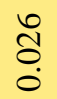 & $\stackrel{0}{\circ}$ & $\frac{\partial}{\hat{\sigma}}$ & $\begin{array}{l}\text { In } \\
0\end{array}$ & $\begin{array}{l}8 \\
\stackrel{8}{0}\end{array}$ & $\stackrel{\wp}{\varrho}$ & 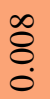 & گૂ \\
\hline & 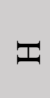 & $\begin{array}{l}\text { ठิ } \\
\text { }\end{array}$ & $\begin{array}{l}\text { ஜ } \\
0 \\
0\end{array}$ & $\begin{array}{l}0 \\
\delta \\
0\end{array}$ & $\begin{array}{l}\mathscr{8} \\
\dot{0}\end{array}$ & $\stackrel{5}{0}$ & 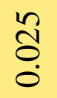 & 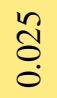 & ले & ஜे & \begin{tabular}{l}
8 \\
\hdashline \\
0
\end{tabular} & $\begin{array}{l}\overline{8} \\
0 \\
0\end{array}$ & $\begin{array}{l}\overline{8} \\
\dot{0}\end{array}$ & $\begin{array}{l}\overline{8} \\
0\end{array}$ & 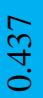 \\
\hline & 0 & $\stackrel{8}{8}$ & $\stackrel{N}{\stackrel{2}{0}}$ & $\begin{array}{l}\text { ठे } \\
\dot{0}\end{array}$ & $\begin{array}{l}\text { Jo } \\
\stackrel{0}{0}\end{array}$ & $\begin{array}{l}\text { to } \\
0 \\
0\end{array}$ & 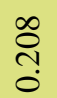 & $\frac{m}{i}$ & $\begin{array}{l}\infty \\
\infty \\
\stackrel{0}{0}\end{array}$ & $\begin{array}{l}\stackrel{2}{ } \\
\check{0} \\
\stackrel{0}{0}\end{array}$ & $\stackrel{\partial}{0}$ & $\begin{array}{l}n \\
8 \\
0\end{array}$ & $\begin{array}{l}\tilde{\delta} \\
\dot{0}\end{array}$ & $\stackrel{n}{\mathscr{8}}$ & ले \\
\hline & LI & $\begin{array}{l}\text { ô } \\
\text { }\end{array}$ & 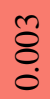 & 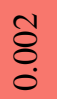 & $\bar{\sigma}$ & $\begin{array}{l}\stackrel{9}{0} \\
0 \\
0\end{array}$ & 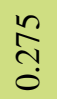 & $\begin{array}{l}\text { তิ } \\
\text {. }\end{array}$ & 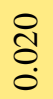 & $\begin{array}{l}\stackrel{t}{\circ} \\
\stackrel{0}{0}\end{array}$ & $\stackrel{0}{8}$ & $\begin{array}{l}\overline{8} \\
\dot{0}\end{array}$ & $\begin{array}{l}\overline{8} \\
\stackrel{0}{0}\end{array}$ & $\begin{array}{l}\overline{8} \\
\stackrel{0}{0}\end{array}$ & 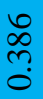 \\
\hline & 디 & $\begin{array}{l}\text { ठ̊ } \\
\stackrel{0}{0}\end{array}$ & $\begin{array}{l}\text { ț } \\
\stackrel{0}{0}\end{array}$ & $\begin{array}{l}\tilde{8} \\
\stackrel{0}{0}\end{array}$ & $\frac{n}{0}$ & $\underset{\nabla}{J}$ & $\begin{array}{l}\stackrel{+}{0} \\
O \\
0\end{array}$ & $\frac{n}{0}$ & $\stackrel{a}{0}$ & $\begin{array}{l}\mathscr{8} \\
\ddot{0} \\
\ddot{0}\end{array}$ & 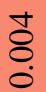 & $\begin{array}{l}\overline{8} \\
0 \\
0\end{array}$ & $\begin{array}{l}\overline{8} \\
\stackrel{0}{0}\end{array}$ & $\begin{array}{l}\overline{8} \\
\stackrel{0}{0}\end{array}$ & $\begin{array}{l}\tilde{n} \\
\tilde{n} \\
\tilde{n}\end{array}$ \\
\hline & D & $\stackrel{\tilde{8}}{0}$ & $\begin{array}{l}n \\
8 \\
0\end{array}$ & $\begin{array}{l}\mathscr{8} \\
\stackrel{0}{0}\end{array}$ & $\frac{2}{0}$ & $\begin{array}{l}\text { } \\
\dot{0}\end{array}$ & $\stackrel{8}{\circ}$ & $\underset{8}{\stackrel{\Xi}{0}}$ & \begin{tabular}{l}
8 \\
$\&$ \\
\hdashline
\end{tabular} & $\begin{array}{l}\tilde{8} \\
\stackrel{0}{0}\end{array}$ & 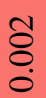 & $\begin{array}{l}8 \\
8 \\
0\end{array}$ & \begin{tabular}{l}
8 \\
8 \\
\hdashline
\end{tabular} & $\overline{8}$ & 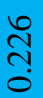 \\
\hline & $u$ & 今o & $\frac{\widehat{\sigma}}{0}$ & $\begin{array}{l}\bar{\curvearrowleft} \\
\infty \\
0\end{array}$ & $\frac{n}{\ddagger}$ & $\frac{\stackrel{\overbrace{}}{1}}{0}$ & $\stackrel{a}{=}$ & $\begin{array}{l}\bar{n} \\
ٌ \\
0\end{array}$ & $\begin{array}{l}\bar{\infty} \\
\stackrel{0}{0}\end{array}$ & $\begin{array}{l}\stackrel{\overbrace{}}{0} \\
\stackrel{0}{0}\end{array}$ & ָे. & $\begin{array}{l}\stackrel{0}{8} \\
\stackrel{0}{0}\end{array}$ & $\begin{array}{l}\mathscr{\delta} \\
\varnothing \\
0\end{array}$ & 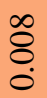 & $\tilde{n}$ \\
\hline & 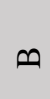 & $\begin{array}{l}\stackrel{0}{0} \\
\stackrel{0}{0}\end{array}$ & $\stackrel{\infty}{\stackrel{\infty}{+}} \underset{0}{0}$ & $\stackrel{\tilde{O}}{0}$ & $\begin{array}{l}\tilde{\delta} \\
\stackrel{0}{0}\end{array}$ & 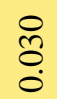 & $\begin{array}{l}\text { Oి } \\
\stackrel{0}{0}\end{array}$ & $\stackrel{m}{0}$ & $\begin{array}{l}\text { ते } \\
\stackrel{0}{0}\end{array}$ & $\begin{array}{l}\infty \\
\stackrel{0}{0} \\
\stackrel{0}{0}\end{array}$ & 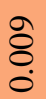 & 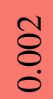 & 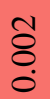 & $\begin{array}{l}\text { } \\
\stackrel{8}{0}\end{array}$ & 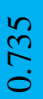 \\
\hline & $\varangle$ & 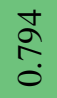 & $\begin{array}{l}\tilde{n} \\
\tilde{n} \\
0\end{array}$ & $\begin{array}{l}\overrightarrow{0} \\
0\end{array}$ & $\stackrel{\substack{m \\
0}}{\square}$ & $\begin{array}{l}n \\
0 \\
0\end{array}$ & 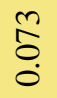 & 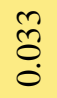 & $\begin{array}{l}n \\
\tilde{o} \\
0\end{array}$ & $\begin{array}{l}\bar{\delta} \\
\stackrel{0}{0}\end{array}$ & 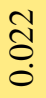 & $\begin{array}{l}8 \\
0 \\
0\end{array}$ & $\begin{array}{l}\text { t) } \\
\stackrel{0}{0}\end{array}$ & s. & $\underset{\sigma}{ \pm}$ \\
\hline & $\begin{array}{l}\overline{\mathcal{D}} \\
\bar{\Xi} \\
\end{array}$ & $\ll$ & 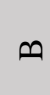 & $u$ & D & 工ు & L & ט & $I$ & $\neg$ & $\neg$ & $\mathscr{V}$ & \lrcorner & $\Sigma$ & 퐁 \\
\hline & & & & & & & & & & & & & & & \\
\hline
\end{tabular}




\subsubsection{Normalized Population Figures}

Table 5.16 shows the accessibility indices of origin-destination pairs for normalized population figures at the five-mile distance. Whereas most accessibility indices for station origin-destination pairs fall within a relatively close range to one another, some pairs associated with specific stations do not. For example, Millbrae as an origin to the destinations of San Francisco, itself, and San Jose, show relatively large deviations from the rest of the station area origin-destination pairs in the negative, positive, and negative directions, respectively. San Francisco is also relatively attracted to itself. 
Table 5.16 Accessibility indices for origin-destination pairs from normalized population figures for fivemile buffer. Green, yellow, and red cells denote relatively high, medium, and low values, respectively. Blue cells denote row or column totals.

\begin{tabular}{|c|c|c|c|c|c|c|c|c|c|c|c|c|c|c|c|}
\hline \multirow{14}{*}{ 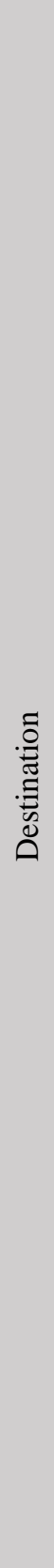 } & 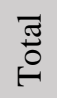 & $\underset{-}{8}$ & $\underset{-}{8}$ & $\underset{-}{8}$ & $\stackrel{8}{8}$ & $\stackrel{8}{-}$ & $\underset{-}{8}$ & $\stackrel{8}{8}$ & $\underset{-}{8}$ & $\underset{-}{8}$ & $\underset{-}{8}$ & $\underset{-}{8}$ & $\underset{-}{8}$ & $\underset{-}{8}$ & $\begin{array}{l}\underset{2}{8} \\
\stackrel{2}{2}\end{array}$ \\
\hline & $\Sigma$ & $\stackrel{0}{0}$ & $\begin{array}{l}\text { ô. } \\
\stackrel{+}{1}\end{array}$ & $\ddot{\circ}$ & ọ. & ठ̊. & $\begin{array}{l}\overline{0} \\
\stackrel{0}{0}\end{array}$ & $\begin{array}{l}\text { Oे } \\
\stackrel{\leftrightarrow}{0}\end{array}$ & $\begin{array}{l}\text { o. } \\
\text { i }\end{array}$ & $\stackrel{n}{\circ}$ & $\begin{array}{l}n \\
\stackrel{0}{0} \\
\dot{1}\end{array}$ & 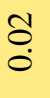 & $\stackrel{0}{0}$ & $\begin{array}{l}\hat{\sigma} \\
\stackrel{0}{0}\end{array}$ & $\tilde{n}$ \\
\hline & \lrcorner & $\stackrel{\text { Oొ }}{0}$ & $\frac{0}{0}$ & $\stackrel{0}{0}$ & 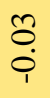 & 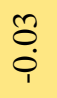 & $\begin{array}{l}\text { ô. } \\
\stackrel{+}{1}\end{array}$ & ô. & $\begin{array}{l}\text { ț } \\
\dot{0}\end{array}$ & $\begin{array}{l}\text { N̦ } \\
\text { ì }\end{array}$ & $\begin{array}{l}\stackrel{0}{1} \\
\text { ị }\end{array}$ & 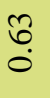 & $\stackrel{n}{o}$ & 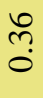 & $\stackrel{0}{\stackrel{1}{=}}$ \\
\hline & $\mathscr{V}$ & $\stackrel{\overline{0}}{\dot{0}}$ & $\begin{array}{l}\text { ô } \\
\dot{0}\end{array}$ & $\stackrel{0}{0}$ & $\begin{array}{l}\overrightarrow{0} \\
\dot{0}\end{array}$ & 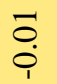 & $\begin{array}{l}\overline{0} \\
\dot{\varphi}\end{array}$ & $\begin{array}{l}\text { Oे } \\
\stackrel{0}{0}\end{array}$ & 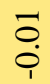 & $\begin{array}{l}n \\
0 \\
\end{array}$ & ô. & $\stackrel{n}{\stackrel{n}{0}}$ & $\stackrel{\circ}{\stackrel{\circ}{\circ}}$ & $\stackrel{2}{\stackrel{0}{0}}$ & $\begin{array}{c}\infty \\
\stackrel{m}{0}\end{array}$ \\
\hline & $\neg$ & $\begin{array}{l}0 \\
0 \\
0\end{array}$ & $\stackrel{\circ}{\circ}$ & $\begin{array}{l}0 \\
0 \\
0\end{array}$ & $\stackrel{\overline{0}}{\circ}$ & $\stackrel{\overline{0}}{\circ}$ & $\stackrel{\overline{0}}{\circ}$ & $\overbrace{0}^{\infty}$ & 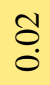 & $\frac{m}{0}$ & $\stackrel{\infty}{\stackrel{\infty}{\sim}}$ & $\begin{array}{l}8 \\
\stackrel{0}{0} \\
1\end{array}$ & $\begin{array}{l}\text { ô } \\
0 \\
0\end{array}$ & $\begin{array}{l}\text { ț } \\
\stackrel{0}{0}\end{array}$ & $\stackrel{o}{+}$ \\
\hline & 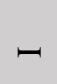 & $\begin{array}{l}\overrightarrow{0} \\
\dot{0}\end{array}$ & $\begin{array}{l}\text { Oे } \\
\stackrel{0}{0}\end{array}$ & $\stackrel{8}{8}$ & $\stackrel{\Xi}{\circ}$ & $\stackrel{\Xi}{0}$ & $\stackrel{\Xi}{\circ}$ & Oे. & $\stackrel{0}{0}$ & $\stackrel{\infty}{\infty}$ & 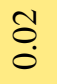 & $\begin{array}{l}\overline{0} \\
\dot{0}\end{array}$ & $\stackrel{8}{8}$ & $\begin{array}{l}\overline{0} \\
\dot{0}\end{array}$ & ț \\
\hline & $I$ & $\begin{array}{l}\text { ô } \\
\stackrel{0}{0}\end{array}$ & $=$ & $\begin{array}{l}\text { ô } \\
\text { ọ }\end{array}$ & 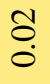 & $\stackrel{+}{0}$ & $\stackrel{\circ}{\circ}$ & กิ & $\stackrel{0}{\infty}$ & $\frac{n}{0}$ & $\stackrel{0}{0}$ & $\begin{array}{l}1 \\
0 \\
0\end{array}$ & $\begin{array}{l}0 \\
0\end{array}$ & $\begin{array}{l}\text { ô. } \\
\stackrel{0}{0}\end{array}$ & $\stackrel{?}{\stackrel{?}{-}}$ \\
\hline & 0 & ö & $\stackrel{+}{0}$ & oم & $\ddot{\circ}$ & $\stackrel{\sigma}{0}$ & $\stackrel{+}{0}$ & †े & ¿̊. & $\stackrel{0}{0}$ & ¿̈. & $\stackrel{8}{8}$ & $\stackrel{8}{8}$ & $\stackrel{8}{8}$ & శூర \\
\hline & II & $\begin{array}{l}\text { Oo } \\
\dot{\varphi}\end{array}$ & $\frac{0}{0}$ & $\stackrel{0}{0}$ & $\stackrel{n}{0}$ & $\frac{m}{0}$ & $\stackrel{\infty}{\infty}$ & ֶֻ & ¿̊. & $\stackrel{8}{\circ}$ & $\stackrel{0}{0}$ & $\begin{array}{l}0 \\
\dot{0}\end{array}$ & $\begin{array}{l}\overline{0} \\
\stackrel{\varphi}{\varphi}\end{array}$ & $\begin{array}{l}\overline{0} \\
\dot{\varphi}\end{array}$ & $\stackrel{?}{n}$ \\
\hline & 디 & $\begin{array}{l}0 \\
0 \\
0\end{array}$ & $\frac{ \pm}{0}$ & $\begin{array}{l}0 \\
0 \\
0\end{array}$ & $\stackrel{+}{0}$ & $\begin{array}{l}\dot{\infty} \\
\stackrel{0}{0}\end{array}$ & $=$ & $=$ & $\begin{array}{l}\dot{0} \\
\dot{0}\end{array}$ & $\stackrel{0}{0}$ & $\begin{array}{l}\text { O̦. } \\
\text {. }\end{array}$ & $\begin{array}{l}\tilde{0} \\
\stackrel{\varphi}{1}\end{array}$ & $\stackrel{8}{8}$ & $\begin{array}{l}0 \\
\dot{\varphi}\end{array}$ & సે \\
\hline & $\theta$ & $\begin{array}{l}0 \\
0 \\
0\end{array}$ & $\stackrel{+}{+}$ & $\frac{ \pm}{\dot{0}}$ & $\stackrel{\text { ga }}{.}$ & $\stackrel{+}{0}$ & $\stackrel{+}{0}$ & $\stackrel{8}{\circ}$ & $\stackrel{0}{0}$ & $\stackrel{8}{\circ}$ & $\stackrel{\sigma}{\circ}$ & $\begin{array}{l}\ddot{0} \\
\stackrel{0}{0}\end{array}$ & $\stackrel{8}{8}$ & $\begin{array}{l}\overline{0} \\
\dot{0}\end{array}$ & $\stackrel{g}{g}$ \\
\hline & $u$ & $\frac{m}{0}$ & $\begin{array}{l}+ \\
\infty \\
0 \\
0\end{array}$ & $\stackrel{9}{\leftrightarrows}$ & $\frac{0}{0}$ & $\begin{array}{l}0 \\
0 \\
0\end{array}$ & ộ & $\begin{array}{l}\text { ?o } \\
\stackrel{1}{1}\end{array}$ & $\begin{array}{l}0 \\
0 \\
0\end{array}$ & $\begin{array}{l}8 \\
\stackrel{0}{0} \\
\end{array}$ & $\begin{array}{l}0 \\
0 \\
\stackrel{1}{0}\end{array}$ & ö & $\stackrel{8}{8}$ & ¿. & $\frac{m}{0}$ \\
\hline & $\infty$ & $\frac{0}{0}$ & $\begin{array}{l}\stackrel{\circ}{\sim} \\
\stackrel{1}{n}\end{array}$ & $\begin{array}{l}n \\
0 \\
\dot{\varphi}\end{array}$ & $\stackrel{0}{0}$ & $\ddot{0}$ & $\stackrel{0}{0}$ & ¿̊. & o. & $\stackrel{\sigma}{o}$ & $\ddot{0}$ & $\stackrel{8}{8}$ & $\stackrel{8}{\circ}$ & $\stackrel{8}{8}$ & $\stackrel{\text { f }}{i}$ \\
\hline & $\ll$ & $\underline{=}$ & $\stackrel{\stackrel{?}{\leftarrow}}{\rightarrow}$ & $\stackrel{0}{0}$ & $\begin{array}{l}n \\
\stackrel{0}{0}\end{array}$ & $\begin{array}{l}0 \\
\stackrel{0}{0} \\
\stackrel{1}{1}\end{array}$ & مَ & $\begin{array}{l}\text { Oo. } \\
\stackrel{+}{+}\end{array}$ & 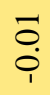 & $\begin{array}{l}\text { Oọ } \\
\stackrel{+}{0}\end{array}$ & ö & రై & $\stackrel{8}{\circ}$ & $\begin{array}{l}\sigma \\
\stackrel{0}{0}\end{array}$ & ڤે? \\
\hline & $\begin{array}{l}\bar{\Xi} \\
\text { ] } \\
\text { ప }\end{array}$ & $\ll$ & $\sim$ & $u$ & Q & 디 & I & ט & $I$ & - & $\sim$ & $\forall$ & \lrcorner & $\Sigma$ & 吾 \\
\hline & & & & & & & & & & & & & & & \\
\hline
\end{tabular}




\subsubsection{Raw Housing Unit Figures}

Table 5.17 displays the accessibility indices of station origin-destination pairs of raw housing unit figures with a five-mile buffer. The pattern shown in Table 5.17 resembles that of Table 5.5 and Table 5.11 showing the results of raw housing unit figures. The stations at the ends of the alignment are within metropolitan areas and have higher housing unit numbers compared to stations in the center of the alignment. As a result, they tend to have higher accessibility indices compared to stations in the center of the alignment. Additionally, the greater the distance between stations, the lower the attraction between them tend to be. 
Table 5.17 Accessibility indices for origin-destination pairs from raw housing unit figures for five-mile buffer. Green, yellow, and red cells denote relatively high, medium, and low values, respectively. Blue cells denote row or column totals.

\begin{tabular}{|c|c|c|c|c|c|c|c|c|c|c|c|c|c|c|c|}
\hline \multirow{14}{*}{ 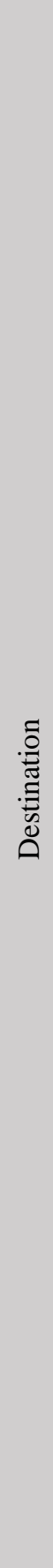 } & సٓ & 8 & $\underset{8}{8}$ & $\stackrel{8}{8}$ & $\underset{-}{8}$ & $\underset{-}{8}$ & $\underset{8}{8}$ & 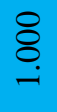 & $\underset{8}{8}$ & $\underset{8}{8}$ & $\underset{8}{8}$ & $\underset{-}{8}$ & $\underset{8}{8}$ & $\underset{-}{8}$ & $\begin{array}{l}8 \\
\delta \\
\ddot{\imath}\end{array}$ \\
\hline & $\Sigma$ & $\begin{array}{l}8 \\
8 \\
0\end{array}$ & $\stackrel{8}{\circ}$ & $\begin{array}{l}8 \\
8 \\
0\end{array}$ & 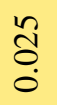 & $\hat{n}$ & م̂ & $\begin{array}{l}\text { ல̊ } \\
\stackrel{0}{0}\end{array}$ & $\begin{array}{l}\text { Oे } \\
0 \\
0\end{array}$ & م̂ & $\begin{array}{l}\widehat{\infty} \\
\stackrel{0}{0} \\
0\end{array}$ & 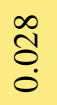 & $\begin{array}{l}n \\
ٌ \\
0\end{array}$ & $\begin{array}{l}\text { वे. } \\
\text { ठ․ }\end{array}$ & $\begin{array}{l}\stackrel{\circ}{\circ} \\
\stackrel{-}{-}\end{array}$ \\
\hline & \lrcorner & $\stackrel{m}{0}$ & $\begin{array}{l}\text { ป̦ } \\
\text { Oे }\end{array}$ & $\stackrel{\Delta}{0}$ & $\begin{array}{l}\tilde{n} \\
\tilde{0} \\
0\end{array}$ & $\stackrel{\hat{\sigma}}{0}$ & $\begin{array}{l}+ \\
\stackrel{\infty}{0} \\
\stackrel{0}{0}\end{array}$ & $\stackrel{0}{0}$ & $\frac{8}{0}$ & $\begin{array}{l}\hat{\infty} \\
\stackrel{0}{0} \\
0\end{array}$ & $\begin{array}{l}\text { ปे } \\
\text { ֶै }\end{array}$ & $\begin{array}{l}\tilde{0} \\
\text { గn? }\end{array}$ & 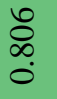 & $\stackrel{\infty}{\stackrel{2}{0}}$ & $\underset{\sim}{\stackrel{P}{\sim}}$ \\
\hline & $\mathscr{V}$ & $\begin{array}{l}8 \\
8 \\
0 \\
0\end{array}$ & $\begin{array}{l}0 \\
0 \\
0\end{array}$ & 용 & $\begin{array}{l}\text { Dे } \\
\text { ọ. } \\
\stackrel{0}{0}\end{array}$ & 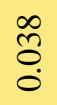 & $\begin{array}{l}\text { ঔ } \\
\stackrel{0}{0}\end{array}$ & 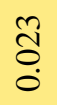 & है & $\underset{\dot{O}}{\stackrel{J}{0}}$ & $\frac{i}{0}$ & $\begin{array}{l}\text { तै } \\
\stackrel{n}{0} \\
0\end{array}$ & $\underset{O}{\stackrel{J}{J}}$ & $\begin{array}{l}\text { ఠ̊ } \\
0\end{array}$ & $\begin{array}{l}\stackrel{J}{ \pm} \\
\stackrel{-}{*}\end{array}$ \\
\hline & $r$ & $\overline{8}$ & $\begin{array}{l}\text { ô } \\
\stackrel{0}{0}\end{array}$ & $\begin{array}{l}\text { \&̊ } \\
\text { }\end{array}$ & \begin{tabular}{l}
8 \\
8 \\
\hdashline
\end{tabular} & $\stackrel{8}{8}$ & $\begin{array}{l}0 \\
0 \\
0\end{array}$ & $\begin{array}{l}8 \\
\&\end{array}$ & $\stackrel{m}{0}$ & $\stackrel{\Delta}{0}$ & $\begin{array}{l}\tilde{n} \\
\text { nn? } \\
0\end{array}$ & $\begin{array}{l}0 \\
0 \\
0\end{array}$ & $\stackrel{8}{8}$ & $\begin{array}{l}8 \\
8 \\
0\end{array}$ & $\underset{f}{\stackrel{f}{f}}$ \\
\hline & 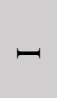 & $\begin{array}{l}+ \\
8 \\
0\end{array}$ & $\begin{array}{l}\hat{8} \\
0\end{array}$ & $\begin{array}{l}\mathscr{8} \\
\stackrel{0}{0}\end{array}$ & $\begin{array}{l}\vec{\delta} \\
\stackrel{0}{0}\end{array}$ & $\begin{array}{l}\text { లి } \\
\stackrel{0}{0}\end{array}$ & $\begin{array}{l}\text { Pे } \\
\text { ¿ }\end{array}$ & 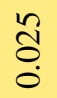 & $\begin{array}{l}\infty \\
\stackrel{8}{\circ} \\
\stackrel{0}{0}\end{array}$ & $\underset{7}{\vec{Z}}$ & 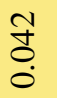 & $\begin{array}{l}\text { ठे } \\
\text { : }\end{array}$ & $\begin{array}{l}\ddot{8} \\
\ddot{\circ}\end{array}$ & $\stackrel{\infty}{\stackrel{0}{0}}$ & م̂. \\
\hline & $I$ & $\begin{array}{l}\overline{8} \\
\dot{0}\end{array}$ & 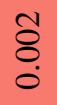 & $\begin{array}{l}\text { ô } \\
\text { ¿ }\end{array}$ & 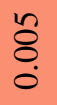 & $\frac{n}{0}$ & 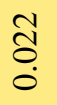 & $\begin{array}{l}\bar{\sigma} \\
\stackrel{0}{0}\end{array}$ & 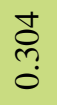 & $\begin{array}{l}\infty \\
\stackrel{0}{0} \\
0\end{array}$ & $\begin{array}{l}\mathscr{8} \\
\stackrel{0}{0}\end{array}$ & $\begin{array}{l}\overline{8} \\
\stackrel{0}{0}\end{array}$ & $\begin{array}{l}\overline{8} \\
\stackrel{0}{0}\end{array}$ & $\stackrel{\circ}{\circ}$ & $\begin{array}{l}\hat{\infty} \\
\stackrel{0}{0}\end{array}$ \\
\hline & 0 & $\hat{8}$ & $\stackrel{\mathrm{N}}{0}$ & $\begin{array}{l}8 \\
\dot{0}\end{array}$ & $\begin{array}{l}\stackrel{J}{d} \\
\stackrel{0}{0}\end{array}$ & $\exists$ & $\begin{array}{l}\stackrel{0}{ } \\
\text { N̦} \\
0\end{array}$ & 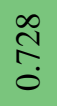 & 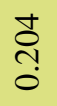 & $\begin{array}{l}\stackrel{\infty}{O} \\
\stackrel{O}{0} \\
\stackrel{0}{0}\end{array}$ & $\begin{array}{l}\text { ठิ } \\
\text { ठ̊. }\end{array}$ & $\stackrel{2}{8}$ & $\begin{array}{l}\text { } \\
\tilde{0}\end{array}$ & $\stackrel{2}{8}$ & 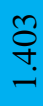 \\
\hline & IL & $\begin{array}{l}\overline{8} \\
\dot{0}\end{array}$ & $\begin{array}{l}\text { ô } \\
\stackrel{8}{0} \\
0\end{array}$ & $\begin{array}{l}\text { Õ } \\
\text { ¿ } \\
0\end{array}$ & $\begin{array}{l}\stackrel{0}{0} \\
\stackrel{0}{0}\end{array}$ & $\begin{array}{l}0 \\
\text { రి } \\
0 \\
0\end{array}$ & 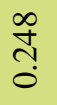 & $\stackrel{\circ}{\circ}$ & $\stackrel{\infty}{\circ}$ & $\begin{array}{l}\mathbb{8} \\
\stackrel{0}{0}\end{array}$ & $\underset{8}{0}$ & $\begin{array}{l}\overline{8} \\
\stackrel{0}{0}\end{array}$ & $\begin{array}{l}8 \\
8 \\
0\end{array}$ & $\stackrel{\overline{8}}{\circ}$ & $\begin{array}{l}n \\
? \\
0\end{array}$ \\
\hline & 피 & 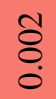 & $\stackrel{+}{8}$ & $\stackrel{8}{8}$ & $\stackrel{\Delta}{\Delta}$ & $\begin{array}{l}\stackrel{n}{o} \\
\stackrel{0}{0}\end{array}$ & $\begin{array}{l}+ \\
ٌ \\
0\end{array}$ & $\stackrel{\Delta}{\circ}$ & $\stackrel{0}{\circ}$ & $\stackrel{\wp}{8}$ & $\begin{array}{l}+ \\
8\end{array}$ & $\stackrel{\overline{8}}{0}$ & $\overline{8}$ & $\overline{8}$ & \begin{tabular}{l}
$\infty$ \\
\multirow{n}{n}{} \\
0
\end{tabular} \\
\hline & D & $\begin{array}{l}0 \\
\delta \\
0\end{array}$ & 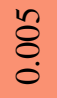 & $\begin{array}{l}8 \\
8 \\
0\end{array}$ & $\stackrel{ }{\stackrel{ }{0}}$ & $\begin{array}{l}\stackrel{0}{0} \\
\stackrel{0}{0}\end{array}$ & $\begin{array}{l}\stackrel{0}{0} \\
\dot{0}\end{array}$ & $\begin{array}{l}\text { ¿̊. } \\
\stackrel{0}{0}\end{array}$ & \begin{tabular}{l}
8 \\
\hdashline \\
0
\end{tabular} & 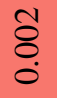 & $\begin{array}{l}\text { ô } \\
\text { ¿ }\end{array}$ & $\begin{array}{l}8 \\
0 \\
0\end{array}$ & $\begin{array}{l}8 \\
\stackrel{0}{0}\end{array}$ & $\begin{array}{l}\overline{8} \\
\dot{0}\end{array}$ & तิ \\
\hline & $u$ & 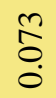 & $\frac{\hat{\sigma}}{0}$ & $\begin{array}{l}\infty \\
\stackrel{+}{0} \\
0\end{array}$ & 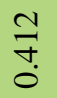 & $\frac{\stackrel{\overbrace{}}{(1}}{0}$ & $\frac{\vec{I}}{0}$ & $\begin{array}{l}\stackrel{q}{+} \\
\stackrel{0}{0}\end{array}$ & $\begin{array}{l}0 \\
\mathscr{0} \\
0 \\
0\end{array}$ & 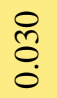 & $\begin{array}{l}\infty \\
\stackrel{\infty}{0} \\
0\end{array}$ & $\stackrel{\infty}{8}$ & $\begin{array}{l}\mathscr{8} \\
\stackrel{0}{0}\end{array}$ & $\stackrel{\infty}{8}$ & $\stackrel{+}{\mathcal{J}}$ \\
\hline & $n$ & $\frac{n}{0}$ & $\stackrel{-}{\nabla}$ & ఠூ & $\begin{array}{l}8 \\
\stackrel{0}{0} \\
0\end{array}$ & $\begin{array}{l}\text { ठै. } \\
\text { ¿े }\end{array}$ & ठे & $\stackrel{\mathrm{O}}{0}$ & $\begin{array}{l}\bar{\delta} \\
\stackrel{0}{0}\end{array}$ & $\begin{array}{l}\infty \\
8 \\
0\end{array}$ & $\stackrel{\infty}{8}$ & $\underset{8}{\tilde{8}}$ & $\begin{array}{l}\overline{8} \\
0\end{array}$ & $\underset{8}{\tilde{8}}$ & $\begin{array}{l}\stackrel{0}{0} \\
\text { రे } \\
0\end{array}$ \\
\hline & $\ll$ & $\begin{array}{l}0 \\
\infty \\
0 \\
0\end{array}$ & $\begin{array}{l}n \\
\text { ma } \\
0\end{array}$ & $\begin{array}{l}n \\
\varnothing \\
0\end{array}$ & $\frac{\text { D }}{\stackrel{0}{0}}$ & 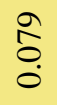 & $\begin{array}{l}\stackrel{\vartheta}{0} \\
\stackrel{0}{0}\end{array}$ & 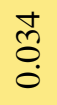 & $\begin{array}{l}8 \\
\stackrel{8}{0} \\
0\end{array}$ & $\begin{array}{l}\overparen{O} \\
\stackrel{\delta}{0}\end{array}$ & $\underset{\delta}{\tilde{O}}$ & $\begin{array}{l}8 \\
8 \\
0\end{array}$ & $\begin{array}{l}\text { ¿ } \\
8 \\
0\end{array}$ & $\stackrel{8}{8}$ & $\begin{array}{l}\stackrel{\circ}{6} \\
\stackrel{-}{*}\end{array}$ \\
\hline & $\begin{array}{l}\bar{\Xi} \\
\text { ]્త }\end{array}$ & $\ll$ & 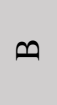 & $u$ & $\theta$ & 피 & LI & 0 & $I$ & - & $\sim$ & $\forall$ & \lrcorner & $\Sigma$ & 馬 \\
\hline & & & & & & & & & & & & & & & \\
\hline
\end{tabular}




\subsubsection{Normalized Housing Unit Figures}

Table 5.18 shows the accessibility indices of station origin-destination pairs for normalized housing unit figures at the five-mile buffer. The numbers are less varied compared to the raw housing unit figures from Table 5.17. Also, certain stations stick out as particularly attractive or unattractive to portions of the corridor. Millbrae-to-Millbrae enjoys relatively high attraction, while Millbrae-to-San Francisco and Millbrae-to-San Jose have very low attraction. 
Table 5.18 Accessibility indices for origin-destination pairs from normalized housing unit figures for fivemile buffer. Green, yellow, and red cells denote relatively high, medium, and low values, respectively. Blue cells denote row or column totals.

\begin{tabular}{|c|c|c|c|c|c|c|c|c|c|c|c|c|c|c|c|}
\hline \multirow{14}{*}{ 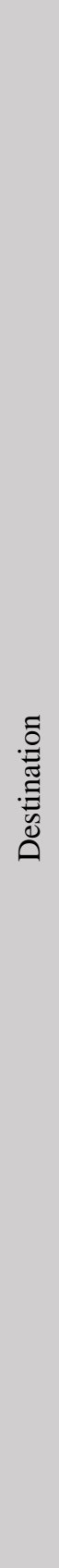 } & స్ & $\stackrel{8}{8}$ & $\stackrel{8}{8}$ & $\underset{.}{8}$ & $\underset{-}{8}$ & $\underset{-}{8}$ & $\underset{-}{8}$ & $\underset{.}{8}$ & $\stackrel{8}{8}$ & $\underset{-}{8}$ & $\underset{-}{8}$ & $\underset{-}{8}$ & $\underset{-}{8}$ & $\underset{-}{8}$ & $\begin{array}{l}8 \\
\dot{\imath} \\
\text { - }\end{array}$ \\
\hline & $\Sigma$ & $\stackrel{0}{0}$ & $\begin{array}{l}m \\
0 \\
\stackrel{\varphi}{1}\end{array}$ & $\stackrel{\overline{0}}{\circ}$ & ö & $\begin{array}{l}0 \\
0 \\
0\end{array}$ & ठ̊. & $\begin{array}{l}\text { ò } \\
\stackrel{\leftrightarrow}{\circ}\end{array}$ & ö & $\begin{array}{l}\text { ț } \\
\stackrel{\varphi}{1}\end{array}$ & $\stackrel{n}{\circ}$ & $\stackrel{\sigma}{0}$ & $\stackrel{\text { O̊ }}{\circ}$ & $\stackrel{\hat{\sigma}}{0}$ & $\begin{array}{l}\infty \\
n \\
n \\
0\end{array}$ \\
\hline & \lrcorner & $\stackrel{0}{\circ}$ & $\frac{m}{\dot{0}}$ & $\stackrel{\text { Oొ }}{0}$ & $\begin{array}{l}0 \\
\stackrel{\varphi}{i}\end{array}$ & Oొ & 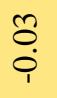 & $\begin{array}{l}5 \\
0 \\
0\end{array}$ & $\begin{array}{l}\text { to } \\
\stackrel{+}{i}\end{array}$ & $\begin{array}{l}\text { ָ̦ } \\
\text { }\end{array}$ & \begin{tabular}{l}
$\infty$ \\
\multirow{i}{1}{} \\
$\stackrel{1}{1}$
\end{tabular} & $\stackrel{\wp}{0}$ & $\stackrel{n}{o}$ & లి & $\stackrel{\infty}{=}$ \\
\hline & 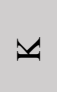 & $\stackrel{\sigma}{0}$ & $\begin{array}{l}\text { Oọ } \\
\stackrel{\varphi}{1}\end{array}$ & ¿م. & $\begin{array}{l}\overline{0} \\
\stackrel{0}{1}\end{array}$ & $\begin{array}{l}0 \\
0 \\
\end{array}$ & $\begin{array}{l}0 \\
0 \\
\end{array}$ & $\begin{array}{l}\text { ơ } \\
\stackrel{\leftrightarrow}{0}\end{array}$ & $\begin{array}{l}0 \\
0 \\
\end{array}$ & $\begin{array}{l}n \\
0 \\
\stackrel{\varphi}{0}\end{array}$ & $\begin{array}{l}\infty \\
0 \\
\stackrel{0}{1}\end{array}$ & $\stackrel{f}{\stackrel{0}{\circ}}$ & 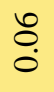 & $\stackrel{\bullet}{\circ}$ & 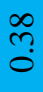 \\
\hline & $r$ & $\begin{array}{l}0 \\
0 \\
\end{array}$ & $\stackrel{n}{\circ}$ & $\begin{array}{l}\tilde{O} \\
\dot{\varphi}\end{array}$ & $\ddot{\circ}$ & ö & $\stackrel{\sigma}{0}$ & $\stackrel{\text { }}{\circ}$ & $\stackrel{1}{0}$ & $\exists$ & సิ & $\begin{array}{l}0 \\
\stackrel{0}{0} \\
0\end{array}$ & $\begin{array}{l}\text { O̦ } \\
\text { ị }\end{array}$ & \begin{tabular}{l}
\multirow{0}{0}{} \\
$\stackrel{0}{1}$
\end{tabular} & શે \\
\hline & $\neg$ & ọ & $\stackrel{\sigma}{o}$ & ọ & $\stackrel{\circ}{\circ}$ & ○. & ö & $\stackrel{\sigma}{0}$ & ö & $\begin{array}{l}2 \\
\dot{0}\end{array}$ & $\stackrel{\sigma}{0}$ & ö & $\stackrel{8}{8}$ & ö & ஃ̊ \\
\hline & $I$ & $\begin{array}{l}\text { ô } \\
\stackrel{0}{0}\end{array}$ & $\begin{array}{l}\stackrel{0}{\circ} \\
0\end{array}$ & 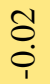 & 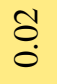 & $\stackrel{+}{0}$ & $\stackrel{\circ}{\circ}$ & $\stackrel{+}{\sim}$ & $\begin{array}{l}\infty \\
\stackrel{0}{0}\end{array}$ & $\frac{ \pm}{0}$ & $\stackrel{\Xi}{0}$ & $\begin{array}{l}\text { İ } \\
0 \\
\end{array}$ & $\begin{array}{l}\ddot{0} \\
\stackrel{0}{0}\end{array}$ & $\begin{array}{l}\text { Iै } \\
\stackrel{0}{0}\end{array}$ & $\underset{\sim}{\stackrel{f}{*}}$ \\
\hline & $\cup$ & $\begin{array}{l}0 \\
0\end{array}$ & 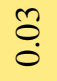 & $\begin{array}{l}0 \\
0 \\
\end{array}$ & $\stackrel{\Xi}{0}$ & 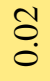 & $\stackrel{\circledast}{0}$ & $\stackrel{\text { I }}{\circ}$ & $\stackrel{0}{0}$ & $\underset{0}{0}$ & $\ddot{0}$ & $\stackrel{8}{8}$ & $\stackrel{8}{0}$ & 8 & ñ \\
\hline & I & $\begin{array}{l}\text { Oọ } \\
\text { }\end{array}$ & $\frac{ \pm}{0}$ & 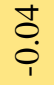 & $\stackrel{n}{\circ}$ & $\frac{m}{0}$ & $\stackrel{\infty}{\infty}$ & 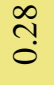 & ¿̊. & $\stackrel{\infty}{\circ}$ & $\stackrel{\text { Oִ. }}{0}$ & $\begin{array}{l}\tilde{O} \\
\stackrel{0}{i}\end{array}$ & $\begin{array}{l}\text { O̦ } \\
\dot{0}\end{array}$ & 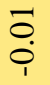 & $\sqrt[\sim]{\underline{-}}$ \\
\hline & 工ు & $\begin{array}{l}m \\
0 \\
0\end{array}$ & $\frac{N}{0}$ & $\begin{array}{l}0 \\
0 \\
0\end{array}$ & $\stackrel{\Xi}{0}$ & $\begin{array}{l}+ \\
\infty \\
0\end{array}$ & $=$ & $\stackrel{\sim}{\stackrel{0}{0}}$ & $\stackrel{+}{\stackrel{+}{0}}$ & $\stackrel{\circ}{\circ}$ & 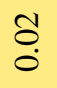 & $\begin{array}{l}\overline{0} \\
\stackrel{0}{1}\end{array}$ & $\stackrel{8}{8}$ & $\begin{array}{l}- \\
0 \\
\end{array}$ & 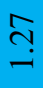 \\
\hline & 0 & $\stackrel{0}{0}$ & $\stackrel{+}{m}$ & $\frac{n}{\dot{p}}$ & $\stackrel{g}{\circ}$ & $\stackrel{\Xi}{0}$ & $\stackrel{+}{0}$ & $\stackrel{\circ}{\circ}$ & $\stackrel{\text { ô }}{0}$ & 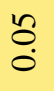 & 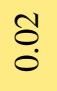 & $\begin{array}{l}\tilde{0} \\
\end{array}$ & $\stackrel{8}{\circ}$ & $\begin{array}{l}\tilde{0} \\
\stackrel{0}{0}\end{array}$ & $\stackrel{m}{\sim}$ \\
\hline & $u$ & $\frac{1}{0}$ & $\frac{?}{\stackrel{0}{i}}$ & $\stackrel{\text { ঙ̣ }}{-}$ & $\begin{array}{l}0 \\
\stackrel{0}{1}\end{array}$ & 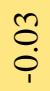 & $\begin{array}{l}0 \\
\stackrel{0}{0}\end{array}$ & $\begin{array}{l}n \\
0 \\
\stackrel{p}{p}\end{array}$ & $\begin{array}{l}\text { ô } \\
\stackrel{\leftrightarrow}{1}\end{array}$ & $\begin{array}{l}n \\
\stackrel{0}{0}\end{array}$ & $\begin{array}{l}0 \\
0 \\
\end{array}$ & $\stackrel{\bar{\sigma}}{\circ}$ & $\stackrel{8}{8}$ & $\ddot{\circ}$ & ָิ \\
\hline & $\infty$ & $\frac{0}{0}$ & 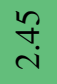 & $\begin{array}{l}8 \\
0 \\
0\end{array}$ & $\stackrel{\overbrace{}}{0}$ & $\stackrel{\sigma}{0}$ & $\stackrel{\Xi}{\circ}$ & 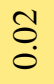 & $\stackrel{\sigma}{\circ}$ & 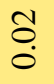 & $\stackrel{\overline{0}}{\circ}$ & $\stackrel{8}{8}$ & $\stackrel{8}{8}$ & $\stackrel{8}{\circ}$ & $\stackrel{\overbrace{}}{i}$ \\
\hline & $\ll$ & $\stackrel{\Xi}{\Xi}$ & $\stackrel{n}{?}$ & $\stackrel{\infty}{\circ}$ & $\begin{array}{l}n \\
0 \\
0\end{array}$ & $\begin{array}{l}\text { ô. } \\
\text { ị }\end{array}$ & $\begin{array}{l}1 \\
\text { ọ } \\
\stackrel{1}{0}\end{array}$ & $\begin{array}{l}0 \\
0 \\
0\end{array}$ & $\begin{array}{l}1 \\
0 \\
0\end{array}$ & $\begin{array}{l}0 \\
0\end{array}$ & $\begin{array}{l}\text { ợ } \\
\text { Q }\end{array}$ & ठ઼. & $\begin{array}{l}8 \\
0\end{array}$ & ¿. & $\begin{array}{l}\hat{N} \\
\text { }\end{array}$ \\
\hline & 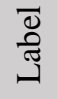 & $\ll$ & 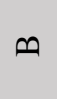 & $U$ & $\theta$ & 디 & IL & ט & I & - & $\neg$ & 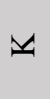 & \lrcorner & $\Sigma$ & స్ّँّ \\
\hline & & & & & & & & & & & & & & & \\
\hline
\end{tabular}




\subsection{Corridor Level Results}

Shortly after concluding the analysis of the attractiveness of station area pairs with origin-destination tables in Sections 5.1 through 5.3, further analysis was carried out by rearranging the data as shown in Table 5.19.

The rearrangement of the data allowed station area pairs to be analyzed at the corridor level. By observing the data at the corridor level, broader generalizations of the results could be made. In the case of San Francisco as an origin, the station was most attracted to itself in terms of the raw number of jobs, regardless of the size of the catchment area. Other stations that San Francisco was attracted to at the 2-mile radius or greater catchment area include Millbrae, San Jose, and Los Angeles to a minute extent.

Table 5.19 Accessibility indices for San Francisco and other stations from raw job figures for all catchment area radii. Green, yellow, and red cells denote relatively high, medium, and low values, respectively.

\begin{tabular}{|c|l|r|r|r|r|r|r|}
\hline \multirow{2}{*}{ From } & \multirow{2}{*}{ To } & \multicolumn{7}{|c|}{ Number of Jobs } \\
\cline { 3 - 9 } & & Quarter-Mile & Half-Mile & 1-Mile & 2-Mile & 3-Mile & 5-Mile \\
\hline San Francisco & San Francisco & 1.00 & 1.00 & 0.99 & 0.98 & 0.95 & 0.88 \\
\hline San Francisco & Millbrae & 0.00 & 0.00 & 0.00 & 0.01 & 0.02 & 0.05 \\
\hline San Francisco & San Jose & 0.00 & 0.00 & 0.00 & 0.01 & 0.01 & 0.04 \\
\hline San Francisco & Gilroy & 0.00 & 0.00 & 0.00 & 0.00 & 0.00 & 0.00 \\
\hline San Francisco & Merced & 0.00 & 0.00 & 0.00 & 0.00 & 0.00 & 0.00 \\
\hline San Francisco & Madera & 0.00 & 0.00 & 0.00 & 0.00 & 0.00 & 0.00 \\
\hline San Francisco & Fresno & 0.00 & 0.00 & 0.00 & 0.00 & 0.00 & 0.00 \\
\hline San Francisco & Kings Tulare & 0.00 & 0.00 & 0.00 & 0.00 & 0.00 & 0.00 \\
\hline San Francisco & Bakersfield & 0.00 & 0.00 & 0.00 & 0.00 & 0.00 & 0.00 \\
\hline San Francisco & Palmdale & 0.00 & 0.00 & 0.00 & 0.00 & 0.00 & 0.00 \\
\hline San Francisco & Burbank & 0.00 & 0.00 & 0.00 & 0.00 & 0.00 & 0.00 \\
\hline San Francisco & Los Angeles & 0.00 & 0.00 & 0.00 & 0.00 & 0.00 & 0.01 \\
\hline San Francisco & Anaheim & 0.00 & 0.00 & 0.00 & 0.00 & 0.00 & 0.00 \\
\hline
\end{tabular}

Table 5.19 was expanded to show the relationship of all stations as origins with the rest of the corridor, as shown in Table 5.20. The red square shows the extent of Table 5.19 within Table 5.20. Note also that Table 5.20 is intended to show the pattern of 
attractiveness along the corridor between jobs, population, and housing units with the use of colored cells and not through the values shown in each cell. 
Table 5.20 Accessibility indices for all stations along the corridor comparing raw figures for jobs, population, and housing units for all catchment area radii. Green, yellow, and red cells denote relatively high, medium, and low values, respectively.

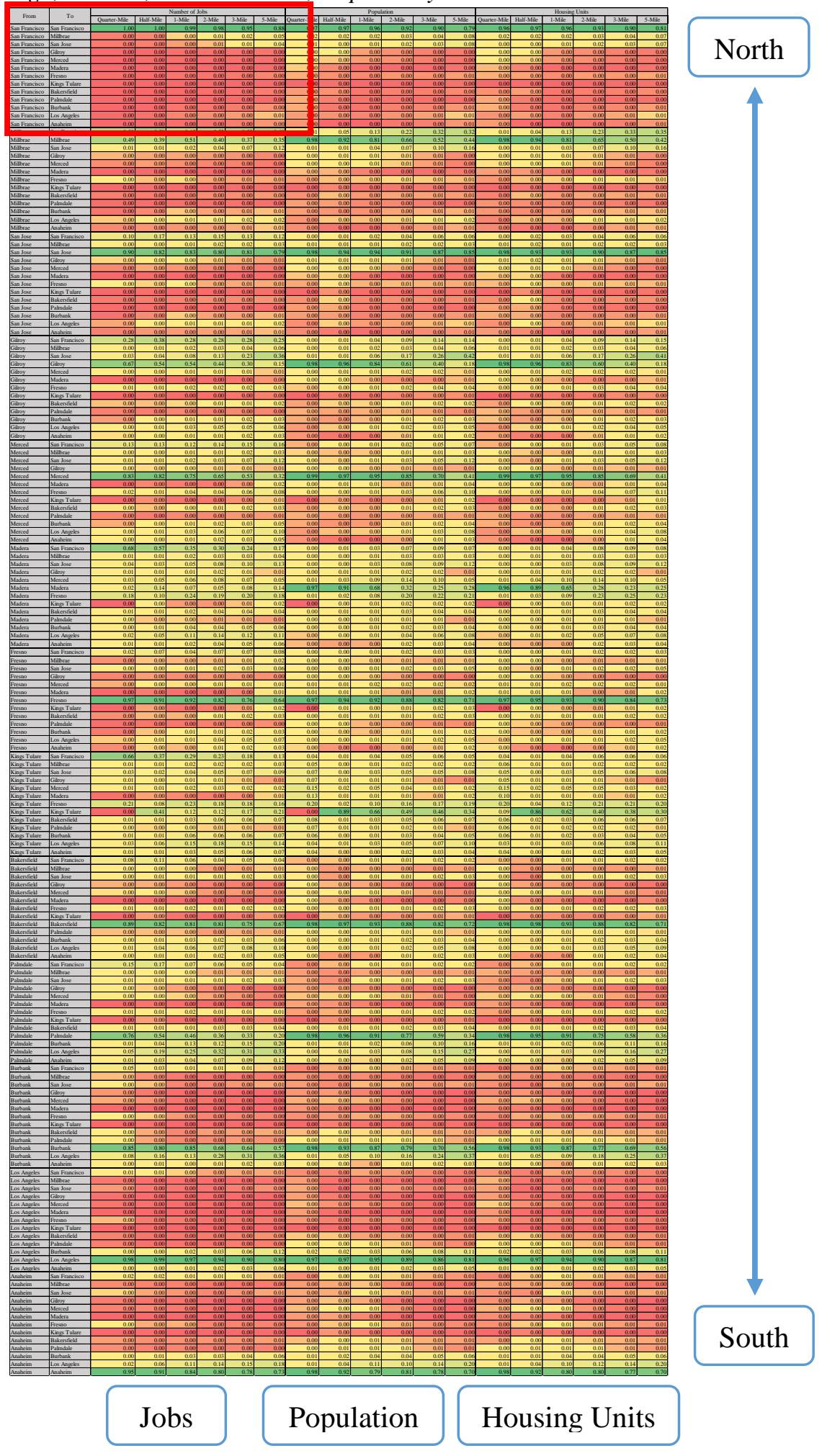


As shown in Table 5.20, a pattern appears within the accessibility indices of station areas. Firstly, regardless of the type of attractor (i.e., jobs, population, or housing units), the relative attractiveness of a station as an origin to other stations remains consistent. For example, San Francisco is attractive as an origin to itself and stations in the San Francisco Bay Area whether the attractor used to calculate the accessibility index is the number of jobs, population, or the number of housing units.

Secondly, the level of attractiveness for stations generally remains the same across the different station area catchment sizes, with some exceptions.

Thirdly, the attractiveness of station areas appeared to be related to its relative location along the corridor. To illustrate, station areas in the northern end of the corridor tended to be attracted to station areas in the northern end of the corridor. The same relationship also appeared to exist for station areas in the southern end of the corridor.

Station areas in the San Joaquin Valley tended to be attracted to station areas in the San Joaquin Valley, as well as to stations in the San Francisco Bay Area and to stations in the Los Angeles Metropolitan Area, though this varied depending on the relative location of the origin along the corridor. For example, a station that is in the northern San Joaquin Valley, such as Merced, was overall more attracted to stations in the San Francisco Bay Area than to stations in the Los Angeles Metropolitan Area. Similarly, a station in the southern San Joaquin Valley, like Bakersfield, was attracted more to station areas in the Los Angeles Metropolitan Area than to station areas in the San Francisco Bay Area. Kings Tulare Station, which is in the center of the corridor, was attracted to station areas in both directions and at relatively equal distances. Station areas 
in the San Joaquin Valley were generally unattractive to the entire corridor, with Madera and Kings Tulare leading in this respect.

\subsection{Categorization of Station Area Synergy by Distance}

The results found in Section 5.4 intrigued further investigation into the attractiveness of station areas in relation to the distances between pairs. The first step in this effort involved selecting station area pairs that had particularly high attraction. Raw jobs data at the three-mile radius were used for the investigation. While Section 5 revealed that station areas were most attracted to themselves, those station pairs could not be used in the investigation because the interest was in studying the attraction of station pairs that had distances beyond their immediate station areas. As such, station area pairs where the origins and destinations were the same were discounted from the analysis, as shown in Table 5.21 
Table 5.21 Accessibility indices for origin-destination pairs from raw job figures for three-mile buffer, less pairs where the origin and destination are the same. Green, yellow, and red cells denote relatively high, medium, and low values, respectively. Blue cells denote row or column totals.

\begin{tabular}{|c|c|c|c|c|c|c|c|c|c|c|c|c|c|c|c|}
\hline \multirow{14}{*}{ 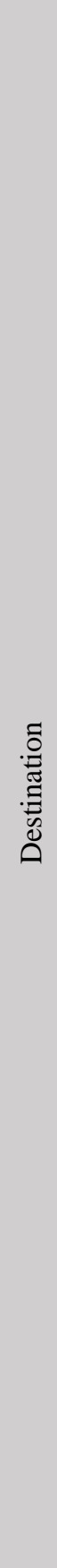 } & 苞 & $\begin{array}{l}l \\
0 \\
0 \\
0\end{array}$ & $\begin{array}{l}\text { त్రి } \\
0\end{array}$ & $\frac{+}{\frac{5}{0}}$ & $\begin{array}{l}\text { o̊ } \\
\text { ! }\end{array}$ & $\underset{+}{\vec{f}}$ & $\begin{array}{l}\text { ૂ̆ } \\
\text { o }\end{array}$ & $\begin{array}{l}\text { ते } \\
\text { ڤิ }\end{array}$ & $\begin{array}{l}\text { I } \\
\infty \\
0 \\
0\end{array}$ & $\begin{array}{l}\stackrel{8}{n} \\
\\
0\end{array}$ & $\begin{array}{l}\stackrel{R}{b} \\
0 \\
0\end{array}$ & $\begin{array}{l}n \\
\tilde{0} \\
\tilde{0}\end{array}$ & $\begin{array}{l}\frac{n}{0} \\
0\end{array}$ & $\begin{array}{l}\text { तิ } \\
\text { ஸे }\end{array}$ & $\begin{array}{l}\overline{\widehat{\sigma}} \\
\dot{\varphi}\end{array}$ \\
\hline & $\Sigma$ & $\begin{array}{l}\tilde{\delta} \\
\stackrel{0}{0}\end{array}$ & $\begin{array}{l}8 \\
8 \\
0\end{array}$ & $\stackrel{n}{8}$ & $\begin{array}{l}\text { ठิ } \\
\stackrel{0}{0}\end{array}$ & $\begin{array}{l}\infty \\
\stackrel{0}{0} \\
0\end{array}$ & $\begin{array}{l}0 \\
\text { ț. } \\
0\end{array}$ & $\stackrel{\infty}{\stackrel{0}{0}}$ & $\begin{array}{l}\mathscr{0} \\
\qquad \\
0\end{array}$ & ठิ & $\begin{array}{l}\mathscr{0} \\
\stackrel{0}{0} \\
\stackrel{+}{0}\end{array}$ & $\begin{array}{l}\stackrel{\Pi}{0} \\
\stackrel{0}{0}\end{array}$ & $\begin{array}{l}\bar{\delta} \\
\dot{0}\end{array}$ & & $\begin{array}{l}0 \\
\text { mे } \\
\text { m. }\end{array}$ \\
\hline & 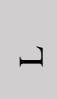 & 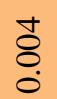 & $\stackrel{0}{0}$ & $\stackrel{m}{0}$ & 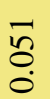 & 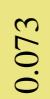 & 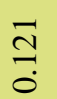 & $\begin{array}{l}\text { fo } \\
\stackrel{0}{0}\end{array}$ & $\frac{\vec{n}}{0}$ & $\begin{array}{l}\stackrel{+}{\infty} \\
\stackrel{0}{0}\end{array}$ & 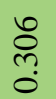 & $\frac{\Delta}{\tilde{m}}$ & & $\frac{n}{n}$ & $\stackrel{m}{m}$ \\
\hline & 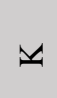 & 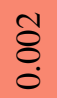 & $\begin{array}{l}8 \\
8 \\
0\end{array}$ & $\stackrel{\wp}{\varrho}$ & $\stackrel{0}{0}$ & $\begin{array}{l}\stackrel{0}{0} \\
\stackrel{0}{0}\end{array}$ & $\begin{array}{l}\text { fo } \\
0\end{array}$ & $\stackrel{\infty}{0}$ & 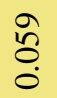 & 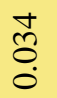 & $\frac{\mathfrak{n}}{0}$ & & $\begin{array}{l}\stackrel{0}{0} \\
0 \\
0\end{array}$ & ڤે & $\begin{array}{l}8 \\
\vdots \\
0\end{array}$ \\
\hline & $\sim$ & $\begin{array}{l}8 \\
8 \\
0\end{array}$ & $\begin{array}{l}\overline{8} \\
0\end{array}$ & $\begin{array}{l}\overline{8} \\
0\end{array}$ & $\stackrel{\wp}{8}$ & $\begin{array}{l}+ \\
8 \\
0\end{array}$ & $\stackrel{5}{8}$ & $\begin{array}{l}\tilde{8} \\
\stackrel{0}{0}\end{array}$ & $\begin{array}{l}\text { oे } \\
\ddot{0}\end{array}$ & $\begin{array}{l}\stackrel{8}{0} \\
\stackrel{0}{0}\end{array}$ & & $\begin{array}{l}\stackrel{+}{8} \\
\stackrel{0}{0}\end{array}$ & $\begin{array}{l}\tilde{\delta} \\
\stackrel{0}{0}\end{array}$ & $\begin{array}{l}\tilde{\delta} \\
\stackrel{0}{0}\end{array}$ & $\begin{array}{l}\mathcal{T} \\
\text { ț } \\
\stackrel{0}{0}\end{array}$ \\
\hline & - & $\begin{array}{l}\overline{8} \\
0 \\
0\end{array}$ & $\stackrel{8}{8}$ & $\stackrel{\text { }}{0}$ & $\stackrel{\sim}{O}$ & $\begin{array}{l}\text { तิ } \\
\text {. }\end{array}$ & $\hat{o}$ & $\begin{array}{l}0 \\
\stackrel{0}{0} \\
0\end{array}$ & $\stackrel{\mathscr{b}}{0}$ & & 官 & ڤ̊ & $\underset{\delta}{\tilde{O}}$ & $\begin{array}{l}\stackrel{+}{8} \\
\stackrel{0}{\circ}\end{array}$ & 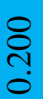 \\
\hline & $I$ & $\begin{array}{l}8 \\
8 \\
0\end{array}$ & $\begin{array}{l}8 \\
8 \\
0\end{array}$ & \begin{tabular}{l}
8 \\
\hdashline \\
0
\end{tabular} & $\overline{8}$ & $\begin{array}{l}\tilde{8} \\
0\end{array}$ & $\stackrel{\infty}{8}$ & $\begin{array}{l}0 \\
\ddot{8}\end{array}$ & & $\begin{array}{l}0 \\
\delta\end{array}$ & $\overrightarrow{8}$ & $\begin{array}{l}8 \\
8 \\
0\end{array}$ & $\begin{array}{l}8 \\
8\end{array}$ & $\begin{array}{l}8 \\
8\end{array}$ & $\begin{array}{l}\tilde{\Xi} \\
\stackrel{0}{\circ}\end{array}$ \\
\hline & 0 & $\begin{array}{l}\text { ơ } \\
\stackrel{0}{0}\end{array}$ & $\begin{array}{l}\mathscr{8} \\
\dot{0}\end{array}$ & $\begin{array}{l}8 \\
8 \\
0\end{array}$ & 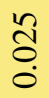 & $\begin{array}{l}n \\
\stackrel{8}{0}\end{array}$ & $\begin{array}{l}\stackrel{8}{1} \\
\text { }\end{array}$ & & $\frac{\infty}{\circ}$ & $\stackrel{5}{0}$ & $\stackrel{\Delta}{\stackrel{\Delta}{0}}$ & $\begin{array}{l}\text { } \\
\ddot{0}\end{array}$ & $\overrightarrow{8}$ & $\stackrel{1}{8}$ & $\frac{n}{n}$ \\
\hline & $I$ & $\begin{array}{l}8 \\
\& \\
0\end{array}$ & $\begin{array}{l}8 \\
8 \\
0\end{array}$ & \begin{tabular}{l}
8 \\
\hdashline \\
0
\end{tabular} & $\begin{array}{l}\overline{8} \\
\circ\end{array}$ & $\begin{array}{l}+ \\
8 \\
0\end{array}$ & & $\begin{array}{l}\tilde{8} \\
\stackrel{0}{0}\end{array}$ & $\begin{array}{l}+ \\
\stackrel{0}{0} \\
0\end{array}$ & $\begin{array}{l}\overline{8} \\
0\end{array}$ & $\begin{array}{l}8 \\
\vdots \\
0\end{array}$ & $\begin{array}{l}8 \\
\& \\
0\end{array}$ & $\begin{array}{l}8 \\
0 \\
0\end{array}$ & \begin{tabular}{l}
8 \\
8 \\
\hdashline
\end{tabular} & $\frac{m}{a}$ \\
\hline & 山 & $\begin{array}{l}\overline{8} \\
\dot{0}\end{array}$ & 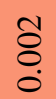 & $\begin{array}{l}\widetilde{\delta} \\
\stackrel{0}{0}\end{array}$ & $\begin{array}{l}\bar{\sigma} \\
0 \\
0\end{array}$ & & $\begin{array}{l}\hat{\delta} \\
\ddot{0}\end{array}$ & $\stackrel{0}{\Xi}$ & $\begin{array}{c}\widetilde{\Xi} \\
\stackrel{0}{0}\end{array}$ & $\begin{array}{l}\stackrel{+}{8} \\
\stackrel{0}{0}\end{array}$ & $\begin{array}{l}\dot{8} \\
\stackrel{8}{0}\end{array}$ & $\begin{array}{l}\overline{8} \\
\dot{0}\end{array}$ & $\begin{array}{l}8 \\
8 \\
0\end{array}$ & $\begin{array}{l}\overline{8} \\
0\end{array}$ & $\frac{\text { ते }}{{ }_{0}}$ \\
\hline & ค & 훙 & $\begin{array}{l}+ \\
\stackrel{0}{0}\end{array}$ & $\hat{8}$ & . & $\begin{array}{l}8 \\
8 \\
0\end{array}$ & $\frac{n}{0}$ & $\begin{array}{l}+ \\
8 \\
0\end{array}$ & $\begin{array}{l}\text { } \\
\stackrel{0}{0}\end{array}$ & 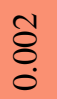 & $\begin{array}{l}\text { ¿̊ } \\
\stackrel{0}{0}\end{array}$ & \begin{tabular}{l}
8 \\
\hdashline \\
0
\end{tabular} & $\begin{array}{l}8 \\
8 \\
0 \\
0\end{array}$ & $\begin{array}{l}8 \\
\stackrel{8}{0}\end{array}$ & 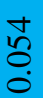 \\
\hline & $u$ & $\stackrel{n}{0}$ & $\underset{\dot{\theta}}{0}$ & & స్ & $\begin{array}{l}0 \\
\stackrel{8}{0} \\
0\end{array}$ & $\begin{array}{l}\stackrel{d}{O} \\
\stackrel{0}{0}\end{array}$ & $\begin{array}{l}\text { O্ } \\
\text { Oे } \\
0\end{array}$ & $\stackrel{5}{0}$ & $\stackrel{ }{0}$ & $\stackrel{a}{0}$ & $\stackrel{\square}{8}$ & $\begin{array}{l}\tilde{8} \\
\stackrel{0}{\circ}\end{array}$ & $\begin{array}{l}\stackrel{+}{8} \\
\stackrel{0}{0}\end{array}$ & $\begin{array}{l}\overline{\widehat{\sigma}} \\
\stackrel{0}{0}\end{array}$ \\
\hline & 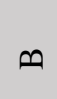 & $\stackrel{\circ}{0}$ & & 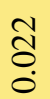 & $\begin{array}{l}\mathcal{T} \\
\stackrel{0}{0}\end{array}$ & $\begin{array}{l}\text { ते } \\
\text {. }\end{array}$ & $\begin{array}{l}\overrightarrow{\tilde{o}} \\
\stackrel{0}{0}\end{array}$ & $\begin{array}{l}\stackrel{8}{0} \\
\stackrel{0}{0}\end{array}$ & $\stackrel{\widetilde{\Omega}}{\stackrel{0}{0}}$ & $\begin{array}{l}\stackrel{8}{0} \\
\stackrel{0}{0}\end{array}$ & $\stackrel{5}{0}$ & $\begin{array}{l}\overline{8} \\
\stackrel{0}{0}\end{array}$ & $\begin{array}{l}\overline{8} \\
\stackrel{0}{\circ}\end{array}$ & ¿̊. & $\begin{array}{l}\tilde{\infty} \\
\stackrel{\infty}{0}\end{array}$ \\
\hline & $\ll$ & & $\begin{array}{l}0 \\
n \\
0\end{array}$ & $\stackrel{\text { సे }}{\stackrel{0}{0}}$ & $\begin{array}{l}\text { I } \\
\stackrel{1}{0}\end{array}$ & $\frac{n}{0}$ & $\begin{array}{l}\infty \\
\stackrel{\sim}{0} \\
\stackrel{0}{0}\end{array}$ & $\stackrel{n}{0}$ & $\frac{2}{0}$ & $\underset{\dot{f}}{\stackrel{f}{0}}$ & $\begin{array}{l}\text { Uै } \\
\text { ô } \\
0\end{array}$ & $\vec{\sigma}$ & 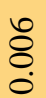 & $\bar{\sigma}$ & बे. \\
\hline & $\begin{array}{l}\bar{D} \\
\bar{\Xi} \\
\Xi\end{array}$ & $\varangle$ & $ص$ & U & D & II & L & ט & $I$ & - & $\sim$ & $\searrow$ & دـ & $\Sigma$ & $\stackrel{\widetilde{ే ే ర}}{0}$ \\
\hline & & & & & & & & & & & & & & & \\
\hline
\end{tabular}


Using the results shown in Table 5.21, the eleven station-area origin-destination pairs with the highest attraction were selected by ranking them with respect to all other station area origin-destination pairs. The results are shown in Table 5.22. 
Table 5.22 Rank of origin-destination pairs based on accessibility indices from raw job figures for threemile buffer, less pairs where the origin and destination are the same. The eleven station-area origin destination pairs with the highest ranks are highlighted in yellow.

\begin{tabular}{|c|c|c|c|c|c|c|c|c|c|c|c|c|c|c|}
\hline & 5 & ్ㅣ & ذ & $\infty$ & in & fo & $\stackrel{n}{m}$ & in & ৯े & Ұ & I & กี & $\stackrel{\mathcal{F}}{ }$ & \\
\hline & ] & 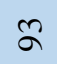 & $\hat{6}$ & $\hat{\sigma}$ & $\bar{m}$ & 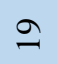 & $\bumpeq$ & లె & $\simeq$ & $\stackrel{\infty}{-}$ & $n$ & $N$ & & 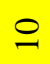 \\
\hline & $\checkmark$ & $\approx$ & $\infty$ & \& & $n$ & $\stackrel{\wp}{f}$ & mे & $\stackrel{\infty}{n}$ & $\stackrel{\sim}{\sim}$ & ले & $\stackrel{m}{2}$ & & $\hat{\sim}$ & $\hat{n}$ \\
\hline & $\sim$ & $\underset{g}{g}$ & 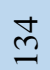 & $\underset{\sim}{\stackrel{2}{2}}$ & $\stackrel{\infty}{\stackrel{0}{0}}$ & $\hat{a}$ & $\stackrel{\infty}{\sim}$ & $\underline{\underline{\sigma}}$ & 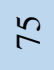 & $\vec{\infty}$ & & J & $\overline{\mathrm{N}}$ & $\stackrel{n}{=}$ \\
\hline & - & $\bar{m}$ & $\stackrel{\varrho}{\varrho}$ & $\stackrel{\varrho}{0}$ & $\infty$ & $\bar{n}$ & $\stackrel{\infty}{m}$ & ชె & $\ddot{\sim}$ & & 우 & $\bar{\sigma}$ & $\Xi$ & 8 \\
\hline & $I$ & $\tilde{n}$ & $\stackrel{\mathscr{f}}{\mathcal{I}}$ & $\underset{\Xi}{J}$ & $\stackrel{\text { ป }}{ }$ & $\underset{\Xi}{ }$ & 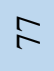 & ஓ & & $\stackrel{\varrho}{=}$ & 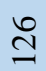 & $\stackrel{f}{ \pm}$ & $\bar{n}$ & $\stackrel{n}{n}$ \\
\hline & ט & 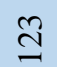 & $\hat{\infty}$ & $\infty$ & ซ & $\stackrel{\sim}{\sim}$ & $r$ & 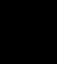 & $\infty$ & $\bar{\sigma}$ & $\bullet$ & $\stackrel{8}{ }$ & $\grave{\cong}$ & $\Xi$ \\
\hline 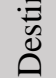 & 工 & $\approx$ & 导 & $\stackrel{\Re}{\underset{f}{f}}$ & $\stackrel{\infty}{\underset{工}{\sim}}$ & $\sigma$ & . & $\stackrel{\varrho}{=}$ & $\hat{0}$ & $\stackrel{\infty}{\sim}$ & 오 & $\hat{n}$ & $\stackrel{\circ}{\curvearrowleft}$ & $\stackrel{+}{n}$ \\
\hline & 工 & $\hat{n}$ & $\cong$ & $\cong$ & $\mathbb{N}$ & 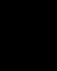 & $\tilde{\lambda}$ & oิ & g & $\curvearrowleft$ & ஃ & 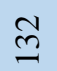 & $\stackrel{\stackrel{\sim}{ \pm}}{ }$ & 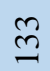 \\
\hline & $\theta$ & 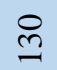 & 으 & 욤 & 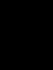 & $\underset{\sim}{ \pm}$ & 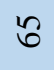 & $\propto$ & 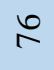 & $\Xi$ & $\stackrel{ }{=}$ & $\stackrel{\text { m }}{-}$ & 京 & ઇ \\
\hline & 0 & $\vec{b}$ & $\approx$ & 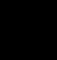 & 0 & $\stackrel{\sim}{d}$ & $\stackrel{0}{-}$ & $\stackrel{\mathscr{q}}{\forall}$ & $\bar{\sim}$ & 8 & $\stackrel{i}{n}$ & જे & $\stackrel{\infty}{ \pm}$ & $\overline{0}$ \\
\hline & 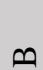 & in & & in & $\stackrel{m}{r}$ & $n$ & ஏ & 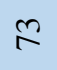 & $\stackrel{\infty}{\forall}$ & 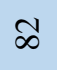 & $\triangleright$ & $\underset{工}{\stackrel{J}{J}}$ & $\stackrel{n}{\varrho}$ & $\cong$ \\
\hline & $\ll$ & & - & \pm & $\forall$ & $=$ & in & ๙ి & $a$ & $m$ & ஓ & $尺$ & $\infty$ & $\nabla$ \\
\hline & $\begin{array}{l}\bar{\Xi} \\
\text { है }\end{array}$ & $\ll$ & 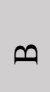 & $U$ & D & 피 & L & 0 & $I$ & - & $\neg$ & $\searrow$ & - & $\Sigma$ \\
\hline & & & & & & & 音 & & & & & & & \\
\hline
\end{tabular}


The characteristics of the eleven station-area origin-destination pairs, including rank, total number of jobs, and distance, are shown in Table 5.23.

Table 5.23 Characteristics of top eleven station area origin-destination pairs at the three-mile radius.

\begin{tabular}{|c|l|c|r|r|}
\hline Rank & \multicolumn{1}{|c|}{ Station Pair } & Label-Pair & Total Number of Jobs & Distance (mi) \\
\hline 1 & Millbrae to San Francisco & B to A & 607,117 & 18 \\
\hline 2 & Burbank to Los Angeles & K to L & 624,482 & 17 \\
\hline 3 & Palmdale to Los Angeles & J to L & 477,772 & 72 \\
\hline 4 & Gilroy to San Francisco & D to A & 560,084 & 97 \\
\hline 5 & Madera to San Francisco & F to A & 544,748 & 209 \\
\hline 6 & Gilroy to San Jose & D to C & 187,277 & 38 \\
\hline 7 & Madera to Fresno & F to G & 73,261 & 32 \\
\hline 8 & Kings Tulare to Fresno & H to G & 76,323 & 36 \\
\hline 9 & Kings Tulare to San Francisco & H to A & 547,810 & 277 \\
\hline 10 & Anaheim to Los Angeles & M to L & 648,530 & 36 \\
\hline 11 & Merced to San Francisco & E to A & 568,250 & 216 \\
\hline
\end{tabular}

The total number of jobs within the station areas of each origin-destination pair and the distance between each station area pair were then used to create the plot in Figure 5.1. 


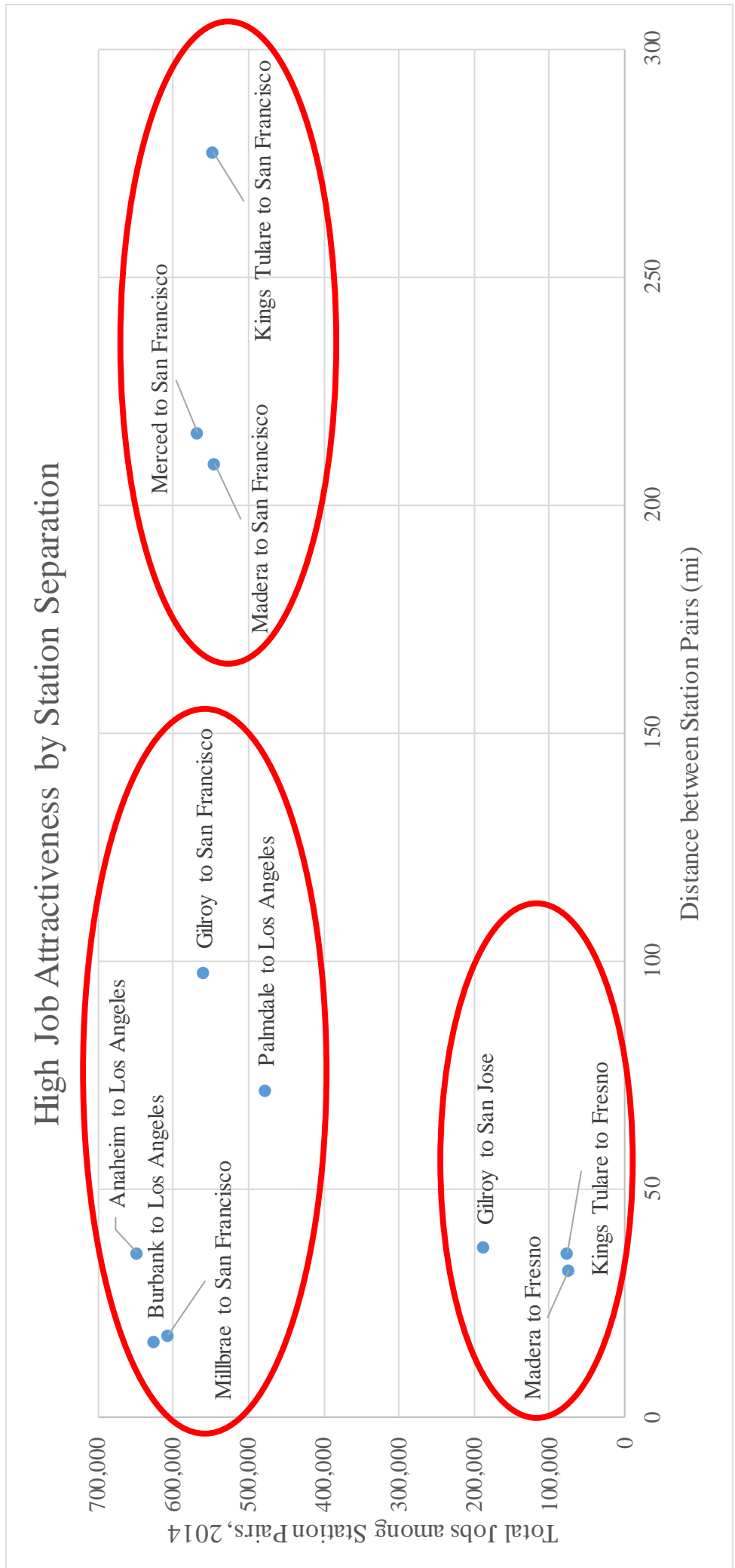

Figure 5.1 High job attractiveness by station separation. 
As Figure 5.1 shows, three clusters of station pairs emerged based on the total number of jobs within three miles of the station and the distance between stations. The clusters were categorized based on the type of passengers that would likely utilize the high-speed rail service within them.

\section{i. Short-Distance urban commuters}

The cluster that would accommodate short-distance urban commuters includes the station pairs of Gilroy to San Jose, Madera to Fresno, and Kings Tulare to Fresno. The travelers within this cluster would originate their trips within the commuter shed of the nearest central business district. Since the trip is short-distance, the travelers would not have to take high-speed rail for their commutes because the time savings would not be great over alternative modes of travel. Nevertheless, high-speed rail provides just enough travel time savings and accessibility to the station areas that makes it convenient for urban commuters to use.

\section{ii. Second-Tier City commuters and travelers}

The cluster that would accommodate ex-urban commuters and travelers includes the station pairs of Anaheim to Los Angeles, Burbank to Los Angeles, Millbrae to San Francisco, Gilroy to San Francisco, and Palmdale to Los Angeles. The travelers within this cluster would originate their trips within second-tier job centers and would commute to the primary job center of their respective metropolitan area. The commuting distance for these travelers is essentially the same as short-distance urban commuters. Yet, the main distinction between the second-tier city commuters and the short-distance urban commuters is that the origins of second-tier city commuters are already relatively 
attractive job centers. This would indicate that some of the commuters are business people traveling between a satellite office in the second-tier city and the main office in the primary job center.

\section{iii. Long-Distance business and leisure travelers}

The final cluster would accommodate long-distance business and leisure travelers, and includes the station pairs of Merced to San Francisco, Madera to San Francisco, and Kings Tulare to San Francisco. The origins of such travelers would be outside the commuter shed of the primary job center of the metropolitan area that the travelers are traveling to. Since the trip distances for these travelers are great, high-speed rail would provide significant advantages in terms of travel time savings and accessibility to faraway job centers. The large trip distances and correspondingly long travel times would be conducive only to travelers who make trips less frequently than every day commuters, such as long-distance business travelers and leisure travelers going on vacation.

It should be noted that the figures shown in Figure 5.1 are unique to the existing conditions of the Phase 1 corridor of the California High-Speed Rail System. The figures are not generalizable and, therefore, should not be applied to other high-speed rail corridors. The procedure used to generate the numbers in Figure 5.1, however, is generalizable and can be applied to other high-speed rail or transit corridors using inputs that are unique to those corridors.

\subsection{Sensitivity Analysis}

A sensitivity analysis was carried out to test the behavior of the accessibility model for validity. The sensitivity analysis was prompted by two reasons. Firstly, by running the accessibility model under alternative scenarios, the behavior of the model 
could be more precisely understood over a wider range of initial conditions. This could allow future users of the model to calibrate parameters accurately and avoid extrapolation of the results.

Secondly, the accessibility model could be used to provide insight into the relationship of station areas along the alignment in the future. The Authority (2015) noted in an economic assessment of the San Joaquin Valley that the high-speed rail system could cause changes in the economic makeup of the station areas once it becomes operational. For example, the increase in accessibility of downtown Fresno and downtown Bakersfield to the San Francisco Bay Area and the Los Angeles Metropolitan Area could allow businesses and their employees to relocate to the San Joaquin Valley. The move could allow businesses and employees to take advantage of the cheaper costof-living (i.e., housing and land values) in the San Joaquin Valley, and could also give the San Joaquin Valley better business opportunities with wealthier areas of the State.

If high-speed rail causes economic changes to the station areas along the alignment, it would likely shift the relative status of business districts on a statewide basis. To illustrate, Figure 4.4 showed that San Francisco and Los Angeles have a disproportionately large share of the jobs in station areas along the entire corridor. This suggests that the two station areas stand out as the primary central business districts not only with respect to their metropolitan areas, but on a statewide basis as well. If Fresno and Bakersfield can capture a larger share of the number of jobs in station areas along the high-speed rail alignment, their regional and statewide importance as central business districts could increase. 
The sensitivity analysis was conducted in two parts. The first part tested the behavior of the model by assuming that the number of jobs of Fresno and Bakersfield's station areas were incrementally increased to match the number of jobs in San Francisco's station area while including all station areas along the corridor. The second part tested the behavior of the model by assuming that the number of jobs of Fresno and Bakersfield's station areas were incrementally increased to match the number of jobs in San Francisco’s station area while including only the stations of Gilroy and Palmdale, and every station in between them. The sensitivity analysis used raw job numbers at the three-mile catchment area radius.

\section{i. $\quad$ Part I}

To begin the analysis, the percent increase in the number of jobs in each of Fresno's and Bakersfield's three-mile radius station areas to match percentages of the number of jobs of San Francisco's three-mile radius station area had to be determined. An example of such a calculation is shown in the following formula:

$$
\begin{aligned}
& \text { Percent Change in Number of Jobs Fresno }=\{[(\text { Percentage } * \text { Number of Jobs } \\
& \text { Francisco })- \text { Number of Jobs } \\
& * 542,128)-70,641] / 70,641\} * 100 \%=284 \%
\end{aligned}
$$

Table 5.24 summarizes the results of calculating the percent change in the number of jobs at Fresno and Bakersfield under different scenarios. 
Table 5.24 Methodology of incrementally increasing Fresno's and Bakersfield's number of jobs to match that of San Francisco's.

\begin{tabular}{|c|c|c|c|c|c|c|}
\hline Scenario & $\begin{array}{l}\text { Selected } \\
\text { City }\end{array}$ & $\begin{array}{c}\text { Number of } \\
\text { Jobs of } \\
\text { Selected } \\
\text { City @ } 3 \\
\text { Mile } \\
\text { Radius } \\
\end{array}$ & $\begin{array}{c}\text { Number of } \\
\text { Jobs of San } \\
\text { Francisco } \\
\text { @ } 3 \text { Mile } \\
\text { Radius }\end{array}$ & Percentages & $\begin{array}{l}\text { Number of } \\
\text { Jobs of San } \\
\text { Francisco @ } \\
3 \text { Mile Radius } \\
\text { by Percentage }\end{array}$ & $\begin{array}{l}\text { Percent Change } \\
\text { in Number of } \\
\text { Jobs of Selected } \\
\text { City @3 Mile } \\
\text { Radius }\end{array}$ \\
\hline A & \multirow{5}{*}{ Fresno } & \multirow{5}{*}{70,641} & \multirow{10}{*}{542,128} & $0 \%$ & 0 & $0 \%$ \\
\hline B & & & & $25 \%$ & 135,532 & $92 \%$ \\
\hline $\mathrm{C}$ & & & & $50 \%$ & 271,064 & $284 \%$ \\
\hline D & & & & $75 \%$ & 406,596 & $476 \%$ \\
\hline E & & & & $100 \%$ & 542,128 & $667 \%$ \\
\hline A & \multirow{5}{*}{ Bakersfield } & \multirow{5}{*}{68,879} & & $0 \%$ & 0 & $0 \%$ \\
\hline B & & & & $25 \%$ & 135,532 & $97 \%$ \\
\hline $\mathrm{C}$ & & & & $50 \%$ & 271,064 & $294 \%$ \\
\hline D & & & & $75 \%$ & 406,596 & $490 \%$ \\
\hline $\mathrm{E}$ & & & & $100 \%$ & 542,128 & $687 \%$ \\
\hline
\end{tabular}

With the percent change in the number of jobs for both Fresno and Bakersfield calculated under various scenarios, the new number of jobs for both Fresno and Bakerfield could be calculated. The computation is defined by the following formula:

New Number of Jobs Fresno $=$ Percent Change in Number of Jobs Fresno $*$ Number of JobSFresno $=284 \% * 70,641=271,064$

Table 5.25 shows the results of the above formula under each scenario and in the context of the entire high-speed rail corridor. 
Table 5.25 Number and percent of jobs at each three-mile radius station area under different scenarios.

\begin{tabular}{|c|c|c|c|c|c|c|c|c|c|c|c|c|c|c|c|}
\hline \multirow{2}{*}{ II } & $\begin{array}{l}\overrightarrow{0} \\
0 \\
\dot{0} \\
2\end{array}$ & $\begin{array}{l}\stackrel{Ð}{N} \\
\stackrel{2}{a}\end{array}$ & $\begin{array}{l}\text { ô } \\
\text { d़ } \\
\text { in }\end{array}$ & $\begin{array}{l}b_{0}^{0} \\
\frac{1}{6}\end{array}$ & $\begin{array}{l}\overbrace{}^{\circ} \\
\qquad 6 \\
\ddot{0}\end{array}$ & $\begin{array}{l}\stackrel{0}{2} \\
\stackrel{2}{0}\end{array}$ & $\begin{array}{l}\stackrel{0}{0} \\
\stackrel{0}{0}\end{array}$ & 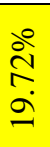 & $\frac{\partial}{\tilde{0}}$ & $\begin{array}{l}\stackrel{\circ}{\stackrel{2}{2}} \\
\stackrel{2}{2}\end{array}$ & $\begin{array}{l}\stackrel{0}{2} \\
\stackrel{2}{0} \\
0\end{array}$ & $\begin{array}{l}0 \\
0 \\
0 \\
0\end{array}$ & $\begin{array}{l}\stackrel{0}{0} \\
\hat{\sigma} \\
0\end{array}$ & $\begin{array}{l}\text { ठ̊ } \\
\text { oे } \\
0\end{array}$ & $\begin{array}{l}\dot{0} \\
8 \\
8 \\
8\end{array}$ \\
\hline & 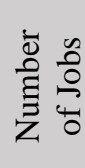 & 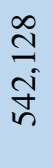 & $\begin{array}{l}\stackrel{2}{\circ} \\
\dot{b}\end{array}$ & $\begin{array}{l}\overline{\tilde{2}} \\
\text { } \\
\hat{\sigma}\end{array}$ & 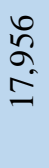 & 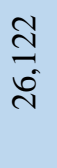 & $\begin{array}{l}\text { त్ } \\
\text { i }\end{array}$ & 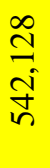 & $\begin{array}{l}\sigma \\
\infty \\
0 \\
\text { in }\end{array}$ & $\frac{\stackrel{\infty}{\text { I }}}{\stackrel{\text { f }}{n}}$ & $\begin{array}{l}\text { ¿े } \\
\text { ñ } \\
\text { ते }\end{array}$ & 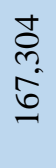 & $\frac{\infty}{\frac{\infty}{n}}$ & $\begin{array}{l}\tilde{n} \\
\stackrel{2}{\sigma}\end{array}$ & 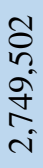 \\
\hline \multirow{2}{*}{$\theta$} & 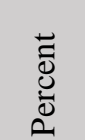 & 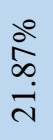 & $\begin{array}{l}\stackrel{0}{ } \\
\text { ర్ } \\
\text { i }\end{array}$ & $\begin{array}{l}\stackrel{0}{0} \\
\infty \\
0 \\
0\end{array}$ & $\stackrel{\stackrel{\circ}{N}}{\stackrel{0}{0}}$ & 告 & $\stackrel{\partial}{=}$ & $\frac{\partial}{\vec{\sigma}}$ & 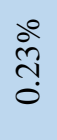 & $\frac{\stackrel{0}{7}}{\stackrel{7}{0}}$ & $\begin{array}{l}\stackrel{0}{ } \\
\infty \\
0 \\
0\end{array}$ & $\stackrel{\frac{8}{n}}{\stackrel{2}{6}}$ & $\begin{array}{l}\stackrel{8}{i n} \\
\stackrel{0}{\infty} \\
\simeq\end{array}$ & $\stackrel{\stackrel{\circ}{N}}{\stackrel{2}{N}}$ & $\begin{array}{l}\delta_{0}^{\circ} \\
8 \\
\dot{8}\end{array}$ \\
\hline & 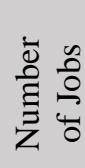 & 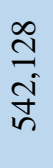 & $\begin{array}{l}2 \\
\text { oे } \\
\dot{b}\end{array}$ & $\begin{array}{l}\overline{\tilde{2}} \\
\text { gे }\end{array}$ & \begin{tabular}{l}
0 \\
\multirow{2}{n}{} \\
\end{tabular} & $\frac{\tilde{N}}{\stackrel{0}{0}}$ & $\begin{array}{l}\text { त్ర } \\
\text { i }\end{array}$ & 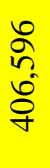 & $\begin{array}{l}\tilde{D} \\
0 \\
0 \\
i\end{array}$ & 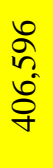 & 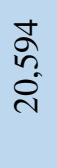 & 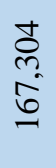 & $\frac{\infty}{\sqrt{n}}$ & $\begin{array}{l}\text { nै } \\
\text { హू }\end{array}$ & \begin{tabular}{l}
$\infty$ \\
\multirow{2}{*}{} \\
$\infty$ \\
$\infty$ \\
\multirow{f}{*}{} \\
$i$
\end{tabular} \\
\hline \multirow[b]{2}{*}{$u$} & $\begin{array}{l}\overrightarrow{0} \\
\dot{0} \\
\dot{0} \\
\text { ص. }\end{array}$ & 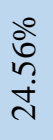 & $\begin{array}{l}\stackrel{0}{0} \\
\overleftarrow{a} \\
\text { ì }\end{array}$ & $\frac{\circ}{\sigma}$ & $\frac{0}{\infty}$ & $\begin{array}{l}\stackrel{0}{\infty} \\
\stackrel{\infty}{\leftrightarrows}\end{array}$ & 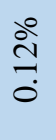 & 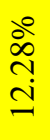 & $\begin{array}{l}\stackrel{0}{0} \\
\stackrel{1}{0}\end{array}$ & 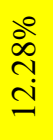 & $\begin{array}{l}\stackrel{0}{a} \\
\grave{0}\end{array}$ & $\begin{array}{l}\infty \\
\infty \\
i \\
r\end{array}$ & $\frac{\partial}{\tilde{i}}$ & $\begin{array}{l}\stackrel{0}{\sigma} \\
\infty \\
\infty\end{array}$ & $\begin{array}{l}80 \\
8 \\
8 \\
8\end{array}$ \\
\hline & 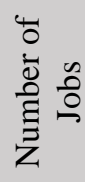 & $\frac{\stackrel{\infty}{\sim}}{\stackrel{f}{\mathcal{H}}}$ & $\begin{array}{l}\stackrel{\alpha}{ } \\
\stackrel{+}{0} \\
\dot{0}\end{array}$ & 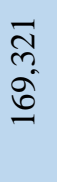 & \begin{tabular}{l}
$\stackrel{0}{n}$ \\
\multirow{2}{\Sigma}{}
\end{tabular} & 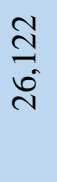 & $\begin{array}{l}\text { त్ } \\
\text { i }\end{array}$ & $\frac{d}{\stackrel{d}{~}}$ & 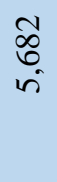 & $\frac{\dot{J}}{\stackrel{\Delta}{\Delta}}$ & $\begin{array}{l}\text { Dे } \\
\text { ñ } \\
\text { है }\end{array}$ & 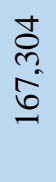 & $\frac{\infty}{\stackrel{\infty}{n}}$ & $\begin{array}{l}\tilde{n} \\
\stackrel{2}{a} \\
\sigma\end{array}$ & 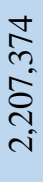 \\
\hline \multirow{2}{*}{ 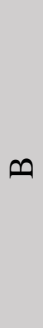 } & $\begin{array}{l}\overrightarrow{0} \\
0 \\
0 \\
0 \\
0 \\
0\end{array}$ & $\begin{array}{l}80 \\
8 \\
0 \\
\infty \\
\text { in }\end{array}$ & $\begin{array}{l}\stackrel{d}{0} \\
\text { ஸे } \\
\text { m. }\end{array}$ & $\frac{\stackrel{0}{+}}{\frac{0}{\infty}}$ & $\stackrel{\circ}{a}$ & $\begin{array}{l}\stackrel{8}{n} \\
\stackrel{n}{n}\end{array}$ & $\frac{\stackrel{d}{ \pm}}{\stackrel{0}{0}}$ & $\frac{8}{8}$ & $\begin{array}{l}\stackrel{0}{\circ} \\
\text { ते }\end{array}$ & $\begin{array}{l}\stackrel{0}{0} \\
\stackrel{8}{0}\end{array}$ & 竎 & $\begin{array}{l}\theta^{0} \\
\underset{b}{0} \\
\infty\end{array}$ & $\begin{array}{l}\frac{0}{6} \\
\ddot{\lambda}\end{array}$ & $\begin{array}{l}\vdots \\
\infty \\
\infty \\
\sigma\end{array}$ & $\begin{array}{l}00 \\
8 \\
8 \\
8 \\
8\end{array}$ \\
\hline & $\begin{array}{l}\overline{\bar{\nu}} \\
\text { है } \\
\bar{\Xi} \\
\bar{z}\end{array}$ & 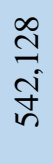 & 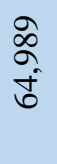 & $\begin{array}{l}\bar{\pi} \\
\text { aे } \\
\text { ô }\end{array}$ & $\begin{array}{l}\stackrel{0}{n} \\
\\
\end{array}$ & 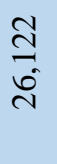 & 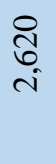 & $\begin{array}{l}\tilde{n} \\
\tilde{n} \\
\tilde{n}\end{array}$ & 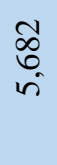 & $\begin{array}{l}n \\
n \\
n \\
n\end{array}$ & 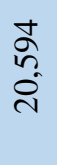 & 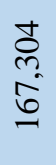 & $\frac{\infty}{\stackrel{n}{n}}$ & $\begin{array}{l}\tilde{n} \\
\stackrel{\sim}{-}\end{array}$ & $\begin{array}{l}0 \\
\text { m. } \\
\sigma^{0} \\
\sigma \\
-\end{array}$ \\
\hline \multirow{2}{*}{$\ll$} & 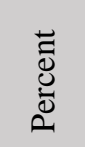 & 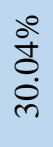 & $\begin{array}{l}\stackrel{0}{0} \\
0 \\
\stackrel{0}{0} \\
\text { r. }\end{array}$ & $\begin{array}{l}\stackrel{0}{0} \\
\infty \\
\\
a\end{array}$ & $\begin{array}{l}\stackrel{2}{\circ} \\
\text { aे }\end{array}$ & 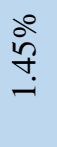 & $\stackrel{\circ}{\frac{1}{0}}$ & $\frac{\partial}{a}$ & $\frac{\partial}{m}$ & $\begin{array}{l}\stackrel{\leftrightarrow}{~} \\
\stackrel{\infty}{0} \\
\dot{m}\end{array}$ & 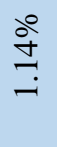 & $\frac{\stackrel{0}{~}}{\stackrel{2}{a}}$ & 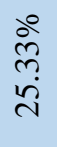 & $\begin{array}{l}\stackrel{0}{0} \\
80 \\
0 \\
0\end{array}$ & $\begin{array}{l}0^{\circ} \\
8 \\
8 \\
8\end{array}$ \\
\hline & 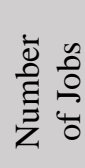 & 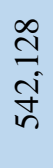 & $\begin{array}{l}\stackrel{\alpha}{ } \\
\stackrel{0}{0}\end{array}$ & 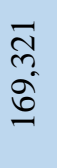 & \begin{tabular}{l}
$\stackrel{0}{2}$ \\
\multirow{2}{n}{}
\end{tabular} & $\frac{\tilde{N}}{\stackrel{0}{0}}$ & $\begin{array}{l}\text { त్ } \\
\text { i } \\
\text { i }\end{array}$ & $\begin{array}{l}\vec{\nabla} \\
\text { Q }\end{array}$ & 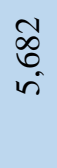 & $\begin{array}{l}\stackrel{2}{0} \\
\infty \\
\infty \\
0\end{array}$ & $\begin{array}{l}+ \\
\text { in } \\
\text { हิ }\end{array}$ & 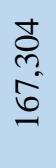 & $\frac{\infty}{\frac{\infty}{n}}$ & $\begin{array}{l}\text { ñ } \\
\text { ๙2}\end{array}$ & 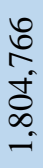 \\
\hline 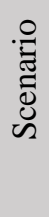 & 营 & 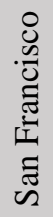 & 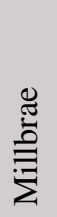 & $\begin{array}{l}0 \\
\stackrel{0}{0} \\
\text { స్ } \\
\text { ผू. }\end{array}$ & 官 & 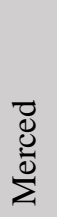 & $\frac{\frac{\pi}{0}}{\frac{\pi}{\pi}}$ & 莺 & 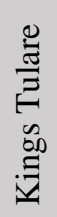 & 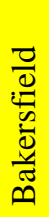 & 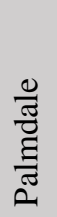 & 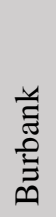 & 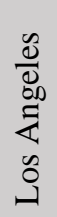 & 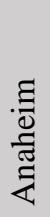 & 氶 \\
\hline
\end{tabular}


With the new job numbers at Fresno and Bakersfield's station areas computed, the gravity model discussed in Section 4.7 was applied to generate accessibility indices for each origin-destination pair. The sum of accessibility indices for each station as a destination is shown in Table 5.26. As expected, the accessibility indices of Fresno and Bakersfield increase as the number of jobs at their station areas increase, while the accessibility indices of the other stations on the corridor decrease. From Scenario A to Scenario E, Fresno's accessibility index (2.76) increases enough to make it the most attractive station area in the corridor, surpassing that of San Francisco's (2.12).

Bakersfield does not experience as great of an increase in its accessibility index as Fresno does. However, Bakersfield (1.77) becomes about as attractive as Los Angeles (1.80). 
Table 5.26 Sum of accessibility indices from raw job figures for half-mile buffer of each station area as a destination by scenario. Green, yellow, and red cells denote relatively high, medium, and low values, respectively. Blue cells denote row or column totals.

\begin{tabular}{|l|c|c|c|c|c|}
\hline \multicolumn{7}{|c|}{ Sum of Accessibility Indices } \\
\hline \multicolumn{1}{|c|}{ Scenario } & A & B & C & D & E \\
\hline San Francisco & 2.65 & 2.50 & 2.31 & 2.20 & 2.12 \\
\hline Millbrae & 0.55 & 0.53 & 0.50 & 0.48 & 0.47 \\
\hline San Jose & 1.44 & 1.36 & 1.27 & 1.21 & 1.17 \\
\hline Gilroy & 0.36 & 0.34 & 0.31 & 0.29 & 0.27 \\
\hline Merced & 0.66 & 0.60 & 0.51 & 0.44 & 0.40 \\
\hline Madera & 0.09 & 0.08 & 0.06 & 0.05 & 0.04 \\
\hline Fresno & 1.28 & 1.69 & 2.20 & 2.52 & 2.76 \\
\hline Kings Tulare & 0.20 & 0.16 & 0.12 & 0.09 & 0.08 \\
\hline Bakersfield & 0.95 & 1.18 & 1.45 & 1.63 & 1.77 \\
\hline Palmdale & 0.37 & 0.35 & 0.32 & 0.29 & 0.27 \\
\hline Burbank & 1.10 & 1.04 & 0.98 & 0.94 & 0.90 \\
\hline Los Angeles & 2.23 & 2.10 & 1.95 & 1.86 & 1.80 \\
\hline Anaheim & 1.13 & 1.08 & 1.02 & 0.98 & 0.95 \\
\hline \multicolumn{2}{|c|}{13.00} & 13.00 & 13.00 & 13.00 & 13.00 \\
\hline
\end{tabular}

A corridor level analysis was performed to observe the relationship of all origindestination pairs with the rest of the corridor. The results are shown in Table 5.27. 
Table 5.27 Comparison of 1) accessibility indices for all station areas along the corridor, 2) percent change of accessibility indices with respect to corresponding origin-destination under Scenario A with conditional formatting by scenario, and 3) percent change of accessibility indices with respect to corresponding origin-destination under Scenario A with conditional formatting of all origin-destination pairs. Green, yellow, and red cells denote relatively high, medium, and low values, respectively.

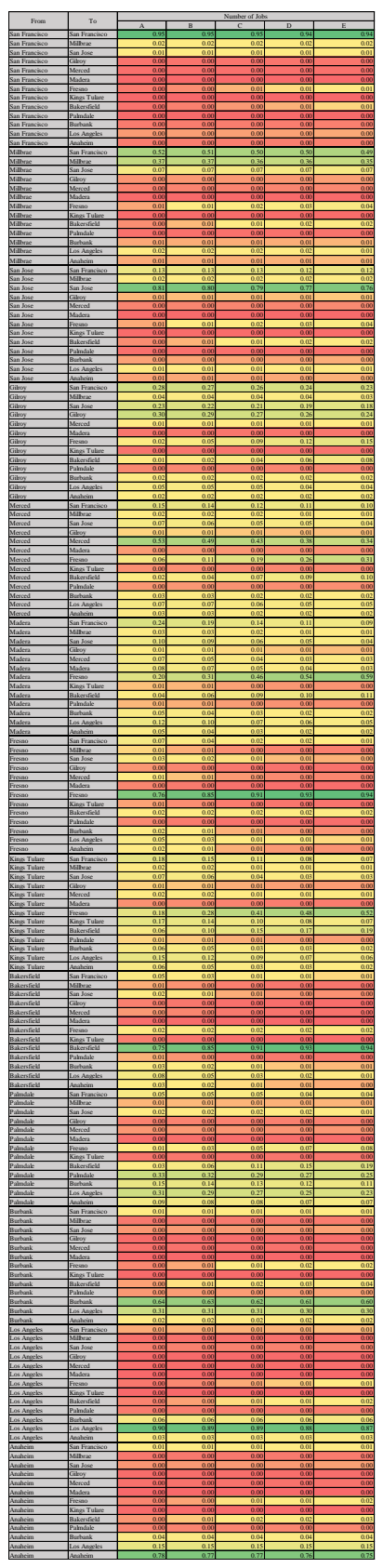

Sub-Table 1

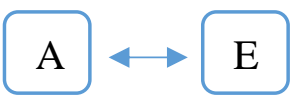

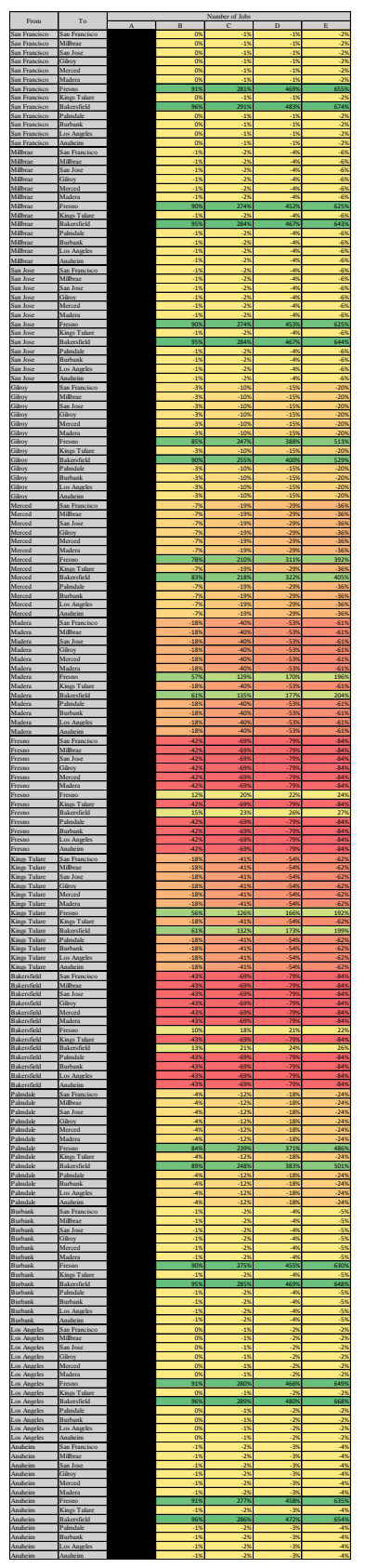

Sub-Table 2

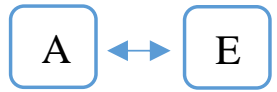

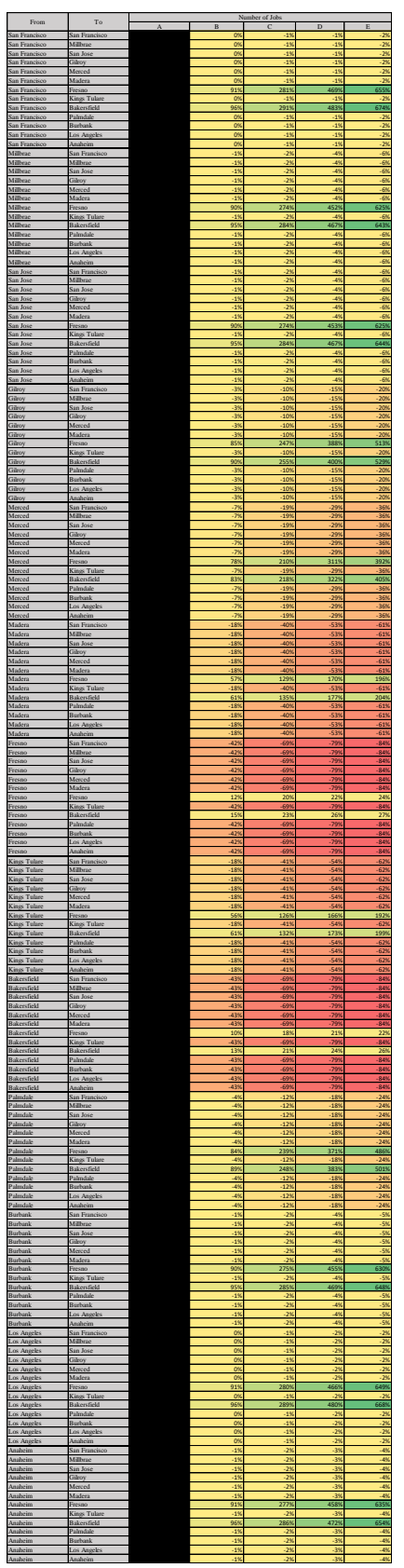

North

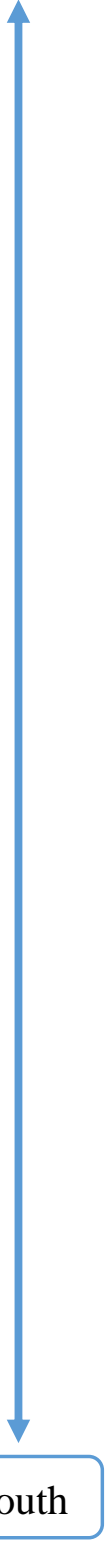

Sub-Table 3

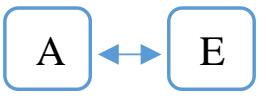


Like Table 5.20, Sub-Table 1 in Table 5.27 compares the accessibility indices of each origin-destination pair by origin (i.e., conditional formatting was used to compare cells by station area origin). Throughout the corridor, San Francisco and Los Angeles still appear to be the most attractive station areas no matter what the scenario. Fresno and Bakersfield increase in accessibility as the Scenario changes from A to E. Each station area is most attractive to itself as expected due to the minute distance.

Sub-Table 2 in Table 5.27 compares the percent change of accessibility indices of all station areas as an origin by scenario (i.e., conditional formatting was used to compare cells by column, or scenario). Fresno and Bakersfield have the highest percent change values regardless of the scenario towards the northern end and southern end of the corridor. Towards the center of the corridor, the percent change values of Fresno and Bakersfield are less pronounced. It appears that because Fresno and Bakersfield are already major job centers in the San Joaquin Valley and are relatively close to other station areas in the San Joaquin Valley, an increase in the number of jobs at Fresno and Bakersfield has relatively little effect on their attractiveness to other stations in the San Joaquin Valley. However, compared to station areas in the San Francisco Bay Area and the Los Angeles Metropolitan Area, the station areas of Fresno and Bakersfield initially do not have a relatively high number of jobs, and are located far away. Thus, the relatively low attractiveness of the station areas of Fresno and Bakersfield to station areas outside of the San Joaquin Valley gives them greater "potential" to increase in relative attractiveness.

Sub-Table 3 in Table 5.27 compares the percent change of accessibility indices of all station areas by origin, regardless of scenario or origin (i.e., conditional formatting 
was used to compare all cells). A similar pattern from Sub-Table 2 appears in Sub-Table 3 regarding the station areas of Fresno and Bakersfield. In contrast to Sub-Table 2, however, Sub-Table 3 exhibits a stronger difference in percent change values by scenario for Fresno and Bakersfield. The percent change values for Fresno and Bakersfield is greatest under Scenario E and weakest under Scenario B.

\section{ii. Part II}

Part II of the sensitivity analysis picks up from Table 5.24 of Part I of the sensitivity analysis, but by analyzing only the station areas of Gilroy and Palmdale, and the station areas in between them. This has the effect of allowing for the observation of the change in attractiveness of the station areas of Fresno and Bakersfield without any interference from the station areas in the much more job-centric San Francisco Bay Area and the Los Angeles Metropolitan Area.

Table 5.28 shows the number and percent of jobs of each station area from Gilroy and Palmdale, and all station areas in between. Note that Fresno and Bakersfield make up a larger portion of the total number of jobs within the corridor in Table 5.28 than in Table 5.25. 
Table 5.28 Number and percent of jobs at each three-mile radius station area from Gilroy to Palmdale under different scenarios.

\begin{tabular}{|c|c|c|c|c|c|c|c|c|c|}
\hline \multirow{2}{*}{ 山 } & 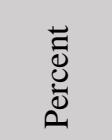 & $\begin{array}{l}\stackrel{0}{n} \\
\stackrel{n}{n}\end{array}$ & $\begin{array}{l}\text { bे } \\
\text { Ni } \\
\text { i }\end{array}$ & $\stackrel{\stackrel{0}{~}}{\tilde{0}}$ & $\begin{array}{l}0^{0} \\
2 \\
\infty \\
\dot{0} \\
\dot{y}\end{array}$ & 官 & $\begin{array}{l}D_{0} \\
20 \\
0 \\
\dot{0}\end{array}$ & $\stackrel{\stackrel{\infty}{\infty}}{\stackrel{\infty}{\leftrightarrows}}$ & $\begin{array}{l}8 \\
8 \\
8 \\
8\end{array}$ \\
\hline & 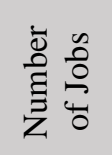 & $\begin{array}{l}\stackrel{2}{2} \\
2 \\
=\end{array}$ & $\frac{\pi}{\text { กิ }}$ & $\begin{array}{l}\text { ర్ } \\
\text { i }\end{array}$ & $\frac{\stackrel{\infty}{\mathfrak{I}}}{\stackrel{\sim}{\sim}}$ & $\begin{array}{l}\tilde{N} \\
\infty \\
0 \\
n\end{array}$ & \begin{tabular}{l}
$\stackrel{\infty}{ \pm}$ \\
\multirow{2}{*}{} \\
in
\end{tabular} & $\begin{array}{l}\text { वे } \\
\text { nे } \\
\text { हे }\end{array}$ & $\begin{array}{l}0 \\
\text { ñ } \\
\text { ñ } \\
=\end{array}$ \\
\hline \multirow{2}{*}{$\theta$} & $\begin{array}{l}\overrightarrow{0} \\
\text { U. } \\
\text { ص. }\end{array}$ & $\begin{array}{l}o ̊ \\
\tilde{O} \\
i\end{array}$ & 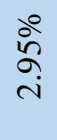 & $\begin{array}{l}0 \\
0 \\
0 \\
0\end{array}$ & 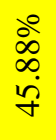 & $\begin{array}{l}b_{0}^{\circ} \\
\dot{0} \\
0\end{array}$ & $\begin{array}{l}\infty \\
\infty \\
\infty \\
\dot{\gamma}\end{array}$ & ڤั & $\begin{array}{l}8 \\
8 \\
8 \\
8\end{array}$ \\
\hline & 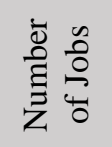 & $\begin{array}{l}\circ \\
2 \\
\Sigma \\
=\end{array}$ & $\frac{\text { I }}{\tilde{d}}$ & $\begin{array}{l}\text { तू } \\
\text { i }\end{array}$ & 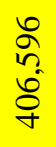 & 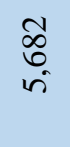 & $\begin{array}{l}8 \\
2 \\
\text { ஜे } \\
8\end{array}$ & $\begin{array}{l}\text { Dे } \\
\text { ñ } \\
\text { हे }\end{array}$ & $\begin{array}{l}8 \\
0 \\
0 \\
\infty \\
\infty\end{array}$ \\
\hline \multirow{2}{*}{$U$} & 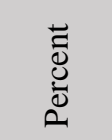 & $\begin{array}{l}\stackrel{\circ}{\alpha े} \\
\text { ते }\end{array}$ & $\begin{array}{l}\stackrel{\circ}{2} \\
\stackrel{\sim}{+}\end{array}$ & $\stackrel{\stackrel{0}{~}}{\stackrel{0}{0}}$ & $\begin{array}{l}\frac{8}{5} \\
0 \\
\dot{J}\end{array}$ & ڤั & $\begin{array}{l}\frac{0}{5} \\
0 \\
\dot{y}\end{array}$ & $\begin{array}{l}\stackrel{0}{2} \\
m \\
m\end{array}$ & $\begin{array}{l}8 \\
8 \\
8 \\
8\end{array}$ \\
\hline & 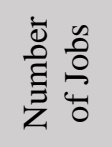 & $\begin{array}{l}2 \\
2 \\
\\
=\end{array}$ & 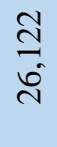 & $\begin{array}{l}\text { त्र } \\
\text { i }\end{array}$ & $\frac{d}{8}$ & $\begin{array}{l}\tilde{N} \\
\infty \\
0 \\
i n\end{array}$ & $\frac{d}{0}$ & $\begin{array}{l}\text { वे } \\
\text { nे } \\
\text { हे }\end{array}$ & 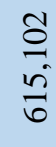 \\
\hline \multirow{2}{*}{ 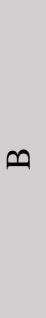 } & $\begin{array}{l}\text { 节 } \\
\text { 苛 }\end{array}$ & $\begin{array}{l}\stackrel{0}{N} \\
\stackrel{n}{n}\end{array}$ & $\begin{array}{l}\stackrel{0}{n} \\
\stackrel{n}{r}\end{array}$ & $\begin{array}{l}\frac{0}{0} \\
\stackrel{0}{0}\end{array}$ & $\begin{array}{l}\stackrel{\circ}{2} \\
\text { ले }\end{array}$ & $\begin{array}{l}\stackrel{0}{0} \\
i 0 \\
i \\
i\end{array}$ & $\begin{array}{l}\text { के } \\
\text { ले } \\
\text { ले }\end{array}$ & $\begin{array}{l}\circ \\
\text { के }\end{array}$ & $\begin{array}{l}8 \\
8 \\
8 \\
8\end{array}$ \\
\hline & 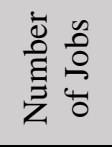 & $\begin{array}{l}\stackrel{2}{2} \\
2 \\
\end{array}$ & $\frac{\widetilde{N}}{\stackrel{0}{0}}$ & $\begin{array}{l}\text { त्र } \\
\text { i }\end{array}$ & $\begin{array}{l}\tilde{n} \\
\tilde{n} \\
n \\
n\end{array}$ & $\begin{array}{l}\mathcal{N} \\
\infty \\
0 \\
i n\end{array}$ & $\begin{array}{l}\text { ñ } \\
n \\
n \\
n\end{array}$ & $\begin{array}{l}+ \\
\text { in } \\
\text { हे }\end{array}$ & 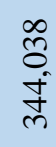 \\
\hline \multirow{2}{*}{$\ll$} & 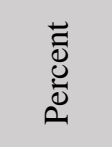 & $\begin{array}{l}\stackrel{0}{n} \\
\stackrel{+}{\infty}\end{array}$ & $\begin{array}{l}\stackrel{\circ}{\Lambda} \\
\text { ป̀ }\end{array}$ & $\stackrel{\stackrel{\leftrightarrow}{+}}{\stackrel{-}{-}}$ & $\begin{array}{l}\stackrel{\circ}{+} \\
\stackrel{+}{m} \\
\text { mे }\end{array}$ & $\begin{array}{l}\frac{0}{0} \\
i \\
i\end{array}$ & $\begin{array}{l}\frac{\partial}{\sigma} \\
\text { cं }\end{array}$ & $\begin{array}{l}\stackrel{\circ}{0} \\
\text { aे }\end{array}$ & $\begin{array}{l}80 \\
8 \\
8 \\
8\end{array}$ \\
\hline & 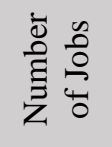 & $\begin{array}{l}\stackrel{2}{2} \\
2 \\
=\end{array}$ & $\frac{\tilde{N}}{\stackrel{0}{0}}$ & $\begin{array}{l}\text { त्र } \\
\text { i }\end{array}$ & $\begin{array}{l}\text { Jु } \\
\stackrel{0}{\circ}\end{array}$ & $\begin{array}{l}\tilde{N} \\
\infty \\
0 \\
i\end{array}$ & $\begin{array}{l}\hat{0} \\
\infty \\
\infty \\
0 \\
0\end{array}$ & $\begin{array}{l}\text { ¿े } \\
\text { ñ. } \\
\text { ते }\end{array}$ & $\begin{array}{l}\text { d } \\
\dot{a} \\
\stackrel{d}{d}\end{array}$ \\
\hline 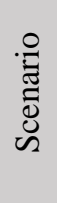 & 苞 & 它 & $\begin{array}{l}\overrightarrow{0} \\
\stackrel{0}{0} \\
\sum_{\Sigma}^{0}\end{array}$ & $\frac{\pi}{\tilde{g}^{\frac{\pi}{\pi}}}$ & 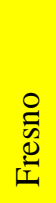 & 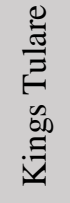 & 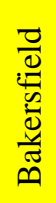 & $\begin{array}{l}\frac{0}{\pi} \\
\frac{\pi}{\tilde{\Xi}} \\
\text { こ }\end{array}$ & స్ \\
\hline
\end{tabular}


The gravity model was applied to the data in Table 5.28 to generate accessibility indices for each origin-destination pair. The sum of accessibility indices for each station as a destination is shown in Table 5.29. Like in Table 5.26, the accessibility indices of Fresno and Bakersfield in Table 5.29 increase as the number of jobs at their station areas increase, while the accessibility indices of the other stations on the corridor decrease. An additional note is that Fresno has a greater increase in its accessibility index compared to that of Bakersfield in Table 5.29, which is like Table 5.26. Fresno is overwhelmingly the most attractive station area in the corridor under all scenarios.

Table 5.29 Sum of accessibility indices from raw job figures for half-mile buffer of each station area from Gilroy to Palmdale as a destination by scenario. Green, yellow, and red cells denote relatively high, medium, and low values, respectively. Blue cells denote row or column totals.

\begin{tabular}{|c|c|c|c|c|c|}
\hline \multicolumn{6}{|c|}{ Sum of Accessibility Indices from Gilroy to Palmdale } \\
\hline Scenario & A & $\mathrm{B}$ & $\mathrm{C}$ & $\mathrm{D}$ & $\mathrm{E}$ \\
\hline Gilroy & 1.72 & 1.36 & 1.01 & 0.82 & 0.70 \\
\hline Merced & 1.45 & 1.16 & 0.86 & 0.70 & 0.59 \\
\hline Madera & 0.25 & 0.17 & 0.10 & 0.07 & 0.06 \\
\hline Fresno & 2.56 & 3.11 & 3.65 & 3.93 & 4.11 \\
\hline Kings Tulare & 0.10 & 0.07 & 0.04 & 0.03 & 0.02 \\
\hline Bakersfield & 0.76 & 1.02 & 1.27 & 1.40 & 1.48 \\
\hline Palmdale & 0.17 & 0.11 & 0.07 & 0.05 & 0.04 \\
\hline Total & 7.00 & 7.00 & 7.00 & 7.00 & 7.00 \\
\hline
\end{tabular}

A corridor level analysis was performed from Gilroy to Palmdale to observe the effects of increasing the number of jobs in the station areas of Fresno and Bakersfield. The results are shown in Table 5.30. 
Table 5.30 Comparison of 1) accessibility indices for all station areas from Gilroy to Palmdale along the corridor, 2) percent change of accessibility indices with respect to corresponding origin-destination under Scenario A with conditional formatting by scenario, and 3) percent change of accessibility indices with respect to corresponding origin-destination under Scenario A with conditional formatting of all origindestination pairs. Green, yellow, and red cells denote relatively high, medium, and low values, respectively.

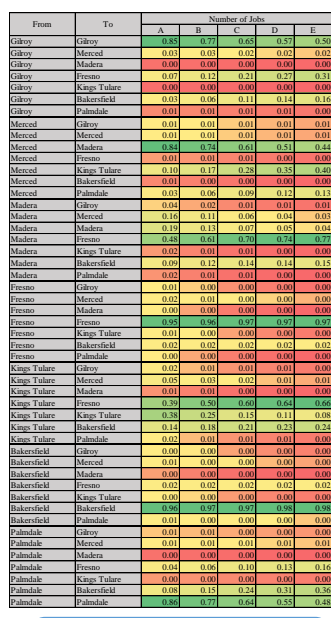

Sub-Table 1

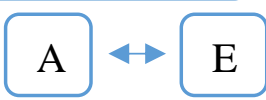

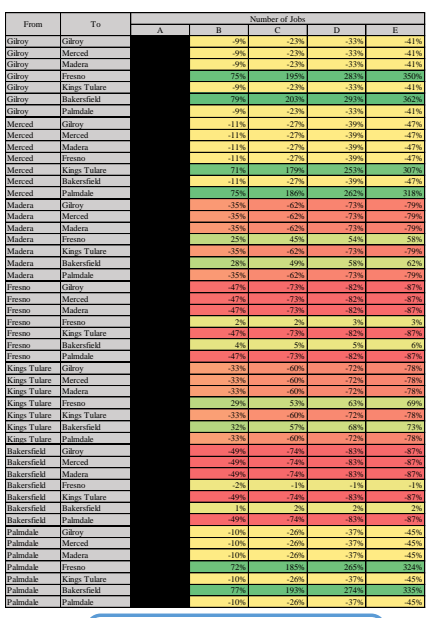

Sub-Table 2

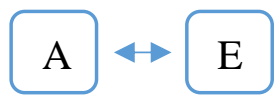

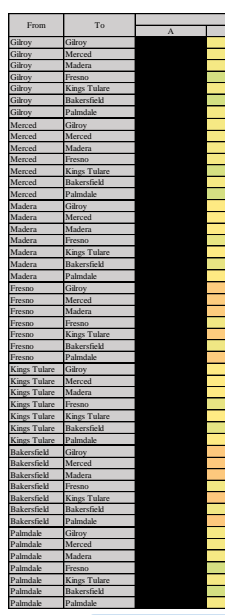

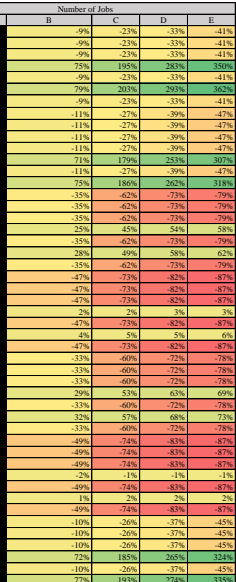

Sub-Table 3

\section{North}

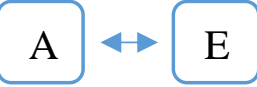

Sub-Table 1 in Table 5.30 compares the accessibility indices of station areas from Gilroy to Palmdale by origin. The origin-destination pairs that enjoy the highest accessibility levels include instances when either Fresno or Bakersfield serve as either origins or destinations to other station areas, or when the origin is the same as the destination (e.g., Gilroy to Gilroy).

As the scenarios change from A to E, the accessibility of Fresno and Bakersfield increase with respect to the rest of the corridor, while the accessibility of other stations decrease with respect to the rest of the corridor.

Sub-Table 2 in Table 5.30 compares the accessibility indices of station areas from Gilroy to Palmdale by scenario. Fresno and Bakersfield enjoy relatively high percent change values in the positive direction throughout the corridor. Their high accessibility is 
most pronounced at the ends of the corridor, while it decreases in the middle of the corridor.

Sub-Table 3 in Table 5.30 compares the accessibility indices of all station areas from Gilroy to Palmdale. Like Sub-Table 2, Fresno and Bakersfield enjoy relatively high percent change values in the positive direction throughout the corridor, though this is most pronounced at the ends of the corridor. Fresno and Bakersfield also seem to experience relatively high percent change values in the positive direction as the scenario moves from $\mathrm{A}$ to $\mathrm{E}$-i.e., as the number jobs within their station areas increases. 


\section{Conclusions \& Recommendations}

As the findings from Section 5 indicate, there were patterns that developed within the data. The most noticeable pattern was that the accessibility indices that were generated from raw input figures were more pronounced compared to the accessibility indices that were generated from normalized input figures. This pattern was consistent regardless of the size of the station catchment area. Secondly, the accessibility indices between origin-destination pairs increased when the attractor of the origin or destination

(i.e., the number of jobs, population, or number of housing units) also increased. Thirdly, the attraction between origin-destination pairs decreased when the distance between the origin and destination increased.

These findings are consistent with the construction of the gravity model discussed in Section 4.7. The attractor of an origin or destination would contribute to an increase or a decrease in the accessibility index when the attractor itself increased or decreased, respectively. In other words, the attractor was directly proportional to the accessibility index. Distance, however, was inversely proportional to the accessibility index. As distance increased, the accessibility index decreased. As distance decreased, the accessibility index increased.

A sensitivity analysis was conducted to observe the behavior of the gravity model under a wider range of initial conditions, and to provide insight as to how the accessibility of station areas could change along the high-speed rail corridor once the system is operational.

As to the overall findings of the study, stations on the ends of the line that were in the major metropolitan areas of the San Francisco Bay Area and the Los Angeles 
Metropolitan Area had the highest accessibility values for the raw input figures. This is likely because the major metropolitan areas, by definition, have a relatively high number of jobs, large populations, and many housing units to house the large populations. Fresno and Bakersfield were the stations with the next highest accessibility indices outside of the major metro areas. The rest of the stations, such as Kings Tulare and Madera, almost always had no attraction except in rare instances. The results for Kings Tulare and Madera make sense, as their station locations are basically in undeveloped areas.

The normalized results, while much less pronounced than the results from raw data values, seemed to show that certain stations had attraction or unattraction to other specific stations, regardless of station catchment area size. For example, Millbrae appeared to consistently have a strong relationship with San Francisco either in the positive or the negative direction.

The patterns of accessibility indices for population and housing units were almost identical as well. This is not surprising, however, because there cannot be a population without housing units to live in. It makes sense that there is an association between population and housing units. Since jobs can be located away from where a population lives, there was less association between the job data and the population or housing data. While the accessibility indices indicate that station areas in the San Francisco Bay Area and the Los Angeles Metropolitan Area are likely to benefit the most from connections with the high-speed rail system, the corridor planning practices of Japanese private railway groups also show that station areas located in other parts of the line can benefit as well. This insight was supported by the findings in the sensitivity analysis. If Fresno and Bakersfield, or any of the other station areas in the San Joaquin Valley, can increase their 
job concentrations relative to the rest of the high-speed rail corridor, they could enjoy the status of being a significant central business district on a statewide basis.

These findings could be of interest to a variety of stakeholders. For example, firms that have offices in either San Francisco or Los Angeles may be interested in opening a satellite office in the other major metropolitan area, or other job centers in the San Joaquin Valley, such as Fresno or Bakersfield, to capture new markets. Whereas these origin-destination pairs may have previously been inconvenient to travel along because of long travel times by automobile, or low accessibility and high inconvenience by airline, high-speed rail provides those origin-destination pairs with a higher level of accessibility that allows for single-day long business trips.

In another example, investors in real estate may be interested in developing commercial and residential land uses in station areas. Using the results from Section 5, investors may be able to place investments in station areas that have good accessibility to job centers, that are within commuting distance (or commuting travel time) to job centers, and have adequate space for additional real estate development. It would also be in the train operator's interest to be engaged in station area planning at the corridor level to ensure that travel flows along the line are balanced directionally and temporally.

Given that corridor level planning is conducted, there is a high potential for growth within the station areas of the San Joaquin Valley if certain pre-conditions are met, such as the implementation of supporting infrastructure, changes in development policies by local governments to promote growth, and the creation of a development strategy for each station area. As noted in Section 2.5, the Authority has already partnered with cities along the alignment to create station area plans that account for such 
pre-conditions. The Authority should continue such efforts so that the potential effects of the California High-Speed Rail System benefit station areas along the alignment with a greater potential for development, the surrounding communities with a higher level of accessibility to other areas of the State, and the high-speed rail operator to provide higher ridership and revenues.

It should be noted that the results discussed in this study are only applicable to the existing conditions of the Phase 1 corridor of the California High-Speed Rail System and are not generalizable to other high-speed rail corridors. However, the methodology used to generate the results, as presented in Section 4, is generalizable and can be used to study other transit corridors.

In accordance to the findings of this study, the following recommendations are made:

- Promote the commercialization of train operations and station areas to capitalize on their long-term economic value;

- Integrate the planning, construction, ownership, and management of train operations and station area development and services to reduce transaction costs;

- Develop plans or business strategies for each station area to create roadmaps and timelines for their development;

- And plan for land use activities at station areas on a corridor level to capitalize on specific synergies between station origin-destination pairs (e.g., land use activities that accommodate long-distance travelers between the San Francisco Bay Area and the Los Angeles Metropolitan Area, or those that accommodate 
commuter needs between up-and-coming station areas in the San Joaquin Valley with major job centers). 


\section{References}

American Public Transportation Association. (2015). 2015 public transportation fact book appendix A: Historical tables. Retrieved on March 29, 2017, from https://www.apta.com/resources/statistics/Documents/FactBook/2015-APTAFact-Book-Appendix-A.pdf

Barousse, J. (2012). Council chooses downtown location for Gilroy's high-speed rail station. Retrieved on May 20, 2017, from https://patch.com/california/gilroy/council-selects-downtown-area-for-highspeed-rail-station

Becker, S., Bernstein, S., Young, L. (2013). The new real estate mantra: Location near public transportation. Chicago, IL: The Center for Neighborhood Technology. Bostock, M. (2017). California population density. Retrieved on April 11, 2017, from https://bl.ocks.org/mbostock/5562380

Burk for Akley. (2012). DeSaulnier says “no” to high-speed rail. Retrieved on January 9, 2017, from: https://eastcountytoday.wordpress.com/2012/07/07/desaulniersays-no-to-high-speed-rail/

California High-Speed Rail Authority. (2011). Draft 2012 business plan. Retrieved on June 4, 2017, from http://www.hsr.ca.gov/docs/about/business_plans/BPlan_2012Draft_web.pdf

—. (2012). Revised 2012 business plan. Retrieved on January 9, 2017, from https://www.hsr.ca.gov/docs/about/business_plans/BPlan_2012_rpt.pdf 
-. (2014a). 2014 Business plan. Retrieved on June 4, 2017, from http://www.hsr.ca.gov/docs/about/business_plans/BPlan_2014_Business_Plan_Fi nal.pdf

-. (2014b). High-Speed rail Authority appoints Director of Planning and Integration. Retrieved on June 13, 2017, from https://www.hsr.ca.gov/docs/newsroom/sept_2014_Auth_Appoints_Dir_Planning _and_Integration_092614.pdf

-. (2015). California High-Speed Rail and the Central Valley economy. Retrieved on June 4, 2017, from https://www.hsr.ca.gov/docs/Newsroom/reports/2015/FINAL_FULL_CENTRAL _VALLEY_ECONOMIC_STUDY_REPORT_020515.pdf

-. (2016). 2016 Business plan. Retrieved on June 4, 2017, from http://www.hsr.ca.gov/docs/about/business_plans/2016_BusinessPlan.pdf

-. (2017a). About California High-Speed Rail Authority. Retrieved on January 9, 2017, from http://www.hsr.ca.gov/About/

—. (2017b). High-Speed rail business plans. Retrieved on June 4, 2017, from http://www.hsr.ca.gov/About/Business_Plans/index.html

-. (2017c). High-Speed rail program maps. Retrieved on May 20, 2017, from http://www.hsr.ca.gov/Newsroom/Multimedia/maps.html

-. (2017d). Transit-Land use committee meetings. Retrieved on June 13, 2017, from http://www.hsr.ca.gov/Board/transit_land_use_committee_meeting.html

—. (2018a). 2018 Draft business plan. Retrieved on May 14, 2018, from http://www.hsr.ca.gov/docs/about/business_plans/Draft_2018_Business_Plan.pdf 
-. (2018b). 2018 Draft revised business plan. Retrieved on May 14, 2018, from http://www.hsr.ca.gov/docs/about/business_plans/Draft_Revised_2018_Business_ Plan.pdf

Calimente, J. (2009). Rail integrated communities in Tokyo. Retrieved on May 31, 2017, from http://summit.sfu.ca/system/files/iritems1/9470/etd4464_JCalimente.pdf

Carpio, A. C. (2017). 'Golden State' plan will guide development near Burbank airport and proposed high-speed rail station. Retrieved on May 20, 2017, from http://www.latimes.com/socal/burbank-leader/news/tn-blr-me-specific-plan20170427-story.html

Central Japan Railway Company. (n.d.). Tokaido-Sanyo Shinkansen timetable (westbound). Retrieved March 29, 2017, from http://english.jrcentral.co.jp/info/timetable/_pdf/westbound.pdf

—. (2008). Data book. Retrieved on January 22, 2017, from http://english.jrcentral.co.jp/company/company/others/data-book/_pdf/2008.pdf

—. (2012). Transportation service. Retrieved on January 22, 2017, from http://english.jrcentral.co.jp/company/ir/annualreport/_pdf/annualreport2012-02.pdf

Central Intelligence Agency. (2017). East \& Southeast Asia: Japan. The World factbook. Retrieved on January 26, 2017, from https://www.cia.gov/library/publications/theworld-factbook/geos/ja.html

Cervero, R. (1998). The Transit metropolis: A Global inquiry. Washington, DC: Island Press.

Cervero, R. \& Murakami, J. (2008). Rail + Property Development: A model of sustainable transit finance and urbanism. Retrieved on April 13, 2017, from 
https://pdfs.semanticscholar.org/ddee/cb08f21dc5f71eba6b2e024d0c0a77d31f01. pdf

Chorus, P. (2012). Station area developments in Tokyo and what the Randstad can learn from it. Retrieved on June 10, 2017, from https://pure.uva.nl/ws/files/1170006/145884_thesis_klein.pdf

Chudacoff, H. P., Smith, J. E., \& Baldwin, P. C. (2010). The Evolution of American urban society (seventh edition). Upper Saddle River, NJ: Prentice Hall.

Douglas, T. (2016). City-Proposed route is new "preferred" path for bullet train. Retrieved on May 20, 2017, from http://www.bakersfield.com/news/cityproposed-route-is-new-preferred-path-for-bullet-train/article_7b650375-b04a527e-be05-182274c877c1.html

Duncan, L. (2014). California High Speed Rail. Retrieved on May 26, 2017, from https://databasin.org/datasets/7a9f1867f2e24a1e97ab10419a73b25a

East Japan Railway Culture Foundation. (n.d.). Scenery_web.pdf. Retrieved on January 9, 2017, from http://www.jrtr.net/jrtr63/pdf/scenery_web.pdf

Fang, K. M. (2009). Accessibility of Bay Area rail transit stations: An Evaluation of opportunities for transit-oriented development. Retrieved on May 17, 2017, from http://digitalcommons.calpoly.edu/cgi/viewcontent.cgi?article=1236\&context=the ses

Federal Aviation Administration. (2016). Overview: What is AIP? Retrieved on March 29, 2017, from https://www.faa.gov/airports/aip/overview/ 
Federal Highway Administration. (1997). State motor vehicle registrations, by years, 1900 - 1995 1/. Retrieved on March 29, 2017, from https://www.fhwa.dot.gov/ohim/summary95/mv200.pdf

-. (1998). Capacity analysis of pedestrian and bicycle facilities: 4. Combined bicycle facilities. Retrieved on May 17, 2017, from https://www.fhwa.dot.gov/publications/research/safety/pedbike/98108/chapter4.cf m

-. (2006). Federal Highway Administration University course on bicycle and pedestrian transportation - Lesson 8: Pedestrian characteristics. Retrieved on May 17, 2017 , from https://www.fhwa.dot.gov/publications/research/safety/pedbike/05085/chapt8.cfm

-. (2015). Quick find: Motor vehicles. Retrieved on March 29, 2017, from https://www.fhwa.dot.gov/policyinformation/quickfinddata/qfvehicles.cfm Federal Housing Finance Agency. (2017). Fannie Mae and Freddie Mac. Retrieved on April 3, 2017, from https://www.fhfa.gov/SupervisionRegulation/FannieMaeandFreddieMac/Pages/A bout-Fannie-Mae---Freddie-Mac.aspx

Federal Reserve Bank of Minneapolis. (2016). Consumer price index, 1913-. Retrieved on April 2, 2017, from https://www.minneapolisfed.org/community/teachingaids/cpi-calculator-information/consumer-price-index-and-inflation-rates-1913

-. (2017). Consumer price index, 1913-. Retrieved on April 13, 2017, from https://www.minneapolisfed.org/community/teaching-aids/cpi-calculatorinformation/consumer-price-index-and-inflation-rates-1913 
Federal Reserve Bank of St. Louis. (2017). Japan / U.S. foreign exchange rate. Retrieved on April 13, 2017, from https://fred.stlouisfed.org/series/DEXJPUS

Federal Transit Administration. (2014). Federal Transit Administration guidance on joint development. Retrieved on June 13, 2017, from https://www.transit.dot.gov/sites/fta.dot.gov/files/docs/FTA_C_7050_1_Guidance _on_Joint_Development_Circular.pdf

-. (2015a). 2015 annual database fare revenue. Retrieved on June 9, 2017, from https://www.transit.dot.gov/sites/fta.dot.gov/files/2015_Fare_Revenue.xlsx

-. (2015b). 2015 annual database operation expense. Retrieved on June 9, 2017 from https://www.transit.dot.gov/sites/fta.dot.gov/files/2015_Operating_Expenses_0.xl SX

-. (2016). Transit profiles: 2015 Top 50 summary. Retrieved on June 9, 2017, from https://www.transit.dot.gov/sites/fta.dot.gov/files/docs/Transit\%20Profiles\%2020 15\%20-\%20Top\%2050\%20Agencies\%20with\%20Summary.pdf

First Railway Directive. (2017). In Wikipedia. Retrieved on June 10, 2017, from https://en.wikipedia.org/wiki/First_Railway_Directive

Funahashi, I. (2009). JR Freight approach to infrastructure development for modal shift. Retrieved on June 3, 2017, from http://www.ejrcf.or.jp/jrtr/jrtr51/pdf/4055_web.pdf

Government Accountability Office. (2010). Federal role in value capture strategies for transit is limited, but additional guidance could help clarify policies. Retrieved on June 11, 2017, from https://www.gao.gov/assets/310/308012.pdf 
Giuliano, G. (2004). Land use impacts of transportation investments. The Geography of urban transportation, third edition, 237-273. New York, NY: Guilford Publications.

Guerra, E., Cervero, R., \& Tischler, D. (2011). The Half-Mile circle: Does it best represent transit station catchments? Retrieved on May 17, 2017, from http://www.its.berkeley.edu/sites/default/files/publications/UCB/2011/VWP/UCB -ITS-VWP-2011-5.pdf

Hernandez-Cattani, R. (2017). High speed rail may go east of outlets. Retrieved on May 20, 2017, from http://www.gilroydispatch.com/news/high-speed-rail-may-go-eastof-outlets/article_f61b97aa-de7b-11e6-85c7-fb625ade001c.html\#user-commentarea

Hosokawa, B. (1997). Old man thunder: Father of the bullet train. Denver, CO: Sogo Way.

Imashiro, M. (1997). Dawn of Japanese National Railways. Japan Railway \& Transport Review, 46-49. Retrieved on June 2, 2017, from http://www.jrtr.net/jrtr10/pdf/history.pdf

Investopedia.com. (2017). Federal Home Loan Bank Act. Retrieved on April 3, 2017, from http://www.investopedia.com/terms/f/federal-home-loan-bank-act.asp Industrial Bank of Japan. (2001). Destruction and creation of business models for railway companies: From a model created by Ichizo Kobayashi to a new model befitting the new age. Retrieved on April 13, 2017, from http://dentetsu.hankyu.co.jp/pdf/IBJreport.pdf 
Japan-Cycling.com. (2017). Japan railway timetable and map. Retrieved on June 3, 2017, from http://japan-cycling.com/japan-railway-timetable-and-map/

The Japan Times. (2016). Three JR train operators report record profits on Shinkansen demand. Retrieved on June 3, 2017, from http://www.japantimes.co.jp/news/2016/04/28/business/corporate-business/threejr-train-operators-report-record-profits-shinkansen-demand/\#.WTNNMmjyvRY

Johnston, L. \& Williamson, S. H. (2017). What was the U.S. GDP then? Retrieved on April 14, 2017, from https://www.measuringworth.com/usgdp/

Krasny, M. (2016). A San Jose detour for California high-speed rail. Retrieved on January 9, 2017, from https://ww2.kqed.org/forum/2016/02/23/a-san-jose-detourfor-california-high-speed-rail/

"List of cities in Japan.” (2017). In Wikipedia. Retrieved on March 29, 2017, from https://en.wikipedia.org/wiki/List_of_cities_in_Japan

Merline, J. (2016). California's $\$ 64$ billion bullet train to nowhere gets delayed ... again. Retrieved on January 9, 2017, from http://www.investors.com/politics/commentary/californias-64-billion-bullet-trainto-nowhere-gets-delayed-again/

Ministry of Land, Infrastructure, Transport and Tourism. (2016). Shinkansen Japanese high-speed rail. Retrieved on January 11, 2017, from https://www.mlit.go.jp/en/tetudo/tetudo_fr2_000000.html

Mizutani, F. \& Nakamura, K. (2004). The Japanese experience with railway restructuring. Retrieved on June 3, 2017, from http://www.nber.org/chapters/c10195.pdf 
Mohl, R. A. (2008). The Interstates and the cities: The U.S. Department of Transportation and the freeway revolt, 1966-1973. Journal of policy history, 20(2), 193-226.

Muller, P. (1995). Transportation and urban form. In Nuworsoo, C. (Eds.), Transportation, theory, policy and practice (92-116). Oakland, CA: Odin Readers.

Murakami, J. \& Cervero, R. (2010). California High-Speed Rail and economic development: Station-Area market profiles and public policy responses. Retrieved on May 17, 2017, from http://www.its.berkeley.edu/sites/default/files/volvocenter/Cervero/California_Hi gh_Speed_Rail_and_Economic_Development_Paper_-murakami_cervero2.pdf

Nakamura, K. (1996). Privatization and beyond: The JR case. Japan Railway \& Transport Review, 4-9. Retrieved on June 3, 2017, from http://www.ejrcf.or.jp/jrtr/jrtr08/pdf/f04_nak.pdf

Newman, P. \& Kenworthy, J. (2006). Urban design to reduce automobile dependence. Opolis: An international journal of suburban and metropolitan studies, 2(1), 3552. Retrieved on February 8, 2016, from http://repositories.cdlib.org/cssd/opolis/vol2/iss1/art3

Nippon.com. (2014). The Shinkansen turns 50: The History and future of Japan's highspeed train. Retrieved on January 10, 2017, from http://www.nippon.com/en/features/h00078/

Noble, S. (n.d.). The Power principle: Part 2. Retrieved on March 29, 2017, from http://metanoia-films.org/the-power-principle/ 
Nuworsoo, C., Cooper, E., Cushing, K., \& Jud, E. (2012). Integration of bicycling and walking facilities into the infrastructure of urban communities. Retrieved on May 17, 2017, from http://transweb.sjsu.edu/PDFs/research/2906-Bicycling-andWalking-Facilities-Urban-Communities-bf.pdf

Nuworsoo, C. \& Deakin, E. (2009). Transforming high-speed rail stations to major activity hubs: Lessons for California. Retrieved on June 26, 2017, from http://digitalcommons.calpoly.edu/cgi/viewcontent.cgi article $=1045 \&$ context $=$ crp _fac

Osamu, S. (2014). Cover story: Olympic legacies. The Japan Journal, 6-12. Retrieved on January 10, 2016, from http://www.japanjournal.jp/img/WP/1409e/1409e_0612_CoverStory.pdf

Publictransit.us. (2010). Japan high-speed rail passenger traffic statistics. Retrieved on January 11, 2017, from http://publictransit.us/ptlibrary/trafficdensity/JapanHSRTrafficDensity2010.pdf

Richman, J. (2014). CA11: Parking Mark DeSaulnier on high-speed rail. Retrieved on January 9, 2017, from http://www.ibabuzz.com/politics/2014/05/20/ca11-parsingmark-desaulnier-on-high-speed-rail/

Rodrigue, J.-P. (2017). The Tokaido Corridor. Retrieved on May 31, 2017, from https://people.hofstra.edu/geotrans/eng/ch6en/appl6en/tokaido.html

Saito, T. (1997). Japanese private railway companies and their business diversification. Japan railway \& transport review, 2-9. Retrieved on April 13, 2017, from http://www.jrtr.net/jrtr10/pdf/f02_sai.pdf 
Sayama, E. (n.d.). JR East: Life-Style business (non-transportation). Retrieved on June 13,2017 , from https://www.apta.com/mc/internationalpracticum/previous/2014/presentations/Pre sentations/Emiko\%20Sayama.pdf

Sheehan, T. (2014). New lawsuit in Fresno challenges cap-and-trade money for highspeed rail. Retrieved on June 4, 2017, from http://www.fresnobee.com/news/local/high-speed-rail/article19521585.html

-. (2015). Gov. Brown, officials gather in Fresno to launch high-speed rail construction. Retrieved on January 2, 2017, from http://www.fresnobee.com/news/local/high-speed-rail/article19529193.html

Shoji, K. (2001). Lessons from Japanese experiences of roles of public and private sectors in urban transport. Japan railway \& transport review, 29, 12-18.

Sir Isaac Newton The Universal Law of Gravitation. (n.d.). Retrieved on May 17, 2017, from http://physics.weber.edu/amiri/physics1010online/WSUonline12w/OnLineCourse Movies/CircularMotion\&Gravity/reviewofgravity/ReviewofGravity.html

Smith, R.A. (2003). The Japanese Shinkansen: Catalyst for the renaissance of rail. The Journal of Transport History, 24(2). Retrieved on January 9, 2017, from http://rodericksmith.synthasite.com/resources/Shinkansen1.pdf

—. (2014). The Shinkansen—World leading high-speed railway system. Japan Railway \& Transport Review, 64, 6-17. Retrieved on January 11, 2017, from http://www.jrtr.net/jrtr64/pdf/6-17_web.pdf 
Statistics Bureau of Japan. (2013). Population density. Retrieved on February 1, 2017, from http://www.stat.go.jp/data/chiri/map/c_koku/mitsudo/pdf/2010.pdf

—. (2017). Japan statistical yearbook 2017. Retrieved on April 8, 2017, from http://www.stat.go.jp/english/data/nenkan/index.htm

Subramani, P. (2008). The Road to California Proposition 1A: A History of the California high-speed rail movement. Retrieved on January 2, 2017, from http://praveens.mit.edu/ praveens/wp/wp-content/uploads/2009/07/CA-Prop1A.pdf

Suyama, Y. (2014). 50 years of Tokaido Shinkansen history. Japan Railway \& Transport Review, 64, 18-27. Retrieved on January 12, 2017, from http://www.ejrcf.or.jp/jrtr/jrtr64/pdf/18-27_web.pdf

Takashima, S. \& Miki, M. (2003). Railway operators in Japan 8: Tokai region. Japan Railway \& Transport Review, 34, 52-63. Retrieved on January 10, 2017, from https://owl.english.purdue.edu/owl/resource/560/07/

Tang, B. S., Chiang, Y. H., Baldwin, A. N., \& Yeung, C. W. (2005). Integration of property and railway development: An Institutional economics analysis. Hong Kong Surveyor, 16(1), 23-40. Retrieved on June 10, 2017, from http://www.hkis.org.hk/hkis/general/journal/2005/200506-bstang.pdf

Terada, K. (2001). Railway operators in Japan 1: Railways in Japan-Public \& private sectors. Japan railway \& transport review, 27, 48-55. Retrieved on April 13, 2017, from http://www.jrtr.net/jrtr27/pdf/s48_ter.pdf

Tillier, C. (2009). Future Transbay? Caltrain HSR compatibility blog. Retrieved on June 11, 2017, from http://caltrain-hsr.blogspot.com/2009/06/future-transbay.html 
Thompson, L. S. (2008). Public transportation in the U.S.: History and current status.

Retrieved on March 29, 2017, from

http://siteresources.worldbank.org/INTURBANTRANSPORT/Resources/Thomps on-PT-history-USA_08.pdf

Tokyu Group. (2013). Status of property ownership around Shibuya Station. Retrieved on July 25, 2014, from

http://www.tokyu.co.jp/ir/upload_file/ENlibrary_06_02/9005_201006091910140

3_P01_.pdf

United States Census Bureau. (1993). Population: 1790 to 1990. Retrieved on March 29, 2017, from https://www.census.gov/population/www/censusdata/files/table-4.pdf

-. (2000). Table P002 - Urban and rural universe: Total population Census 2000

Summary file (SF 1) 100-percent data. Retrieved on March 29, 2017, from

https://factfinder.census.gov/faces/nav/jsf/pages/index.xhtml

-. (2010). Table P2 - Urban and rural universe: Total population 2010 Census

summary file 1. Retrieved on March 29, 2017, from

https://factfinder.census.gov/faces/nav/jsf/pages/index.xhtml

- (2012). State area measurements and internal point coordinates. Retrieved on April

3, 2017, from https://www.census.gov/geo/reference/state-area.html\#n2

-. (2017a). Annual estimates of the resident population for the United States, regions, states, and Puerto Rico: April 1, 2010 to July 1, 2016 (NST-EST2016-01).

Retrieved on April 3, 2017, from

https://www.census.gov/data/tables/2016/demo/popest/state-total.html 
-. (2017b). Cartographic boundary shapefiles - States. Retrieved on May 20, 2017, from https://www.census.gov/geo/maps-data/data/cbf/cbf_state.html

-. (2017c). OnTheMap. Retrieved on May 26, 2017, from https://onthemap.ces.census.gov/

—. (2017d). TIGER/Line with selected demographic and economic data. Retrieved on May 20, 2017, from https://www.census.gov/geo/maps-data/data/tiger-data.html United States Department of Transportation. (2016a). Table 1-40 - U.S. passenger-miles (updated July 2016). Retrieved on March 29, 2017, from https://www.rita.dot.gov/bts/sites/rita.dot.gov.bts/files/publications/national_trans portation_statistics/index.html

-. (2016b). Table 3-36 - Transportation expenditures by mode and level of government from own funds, fiscal year (Chained 2000 \$ millions) (Updated October 2016). Retrieved on April 2, 2017, from https://www.rita.dot.gov/bts/sites/rita.dot.gov.bts/files/publications/national_trans portation_statistics/index.html

Walker, J. (2012). Human transit: How clearer thinking about public transit can enrich our communities and our lives. Washington, DC: Island Press.

Warta, A. (2008). Maps page on Japan. Retrieved on January 31, 2017, from http://maps.unomaha.edu/Peterson/geog1000/MapLinks/Japan.htm

Wolfe, C. R., \& Symington, P. (2009). Urban centers and transit-oriented development in Washington State. Seattle, WA: The Runstad Center for Real Estate Studies.

Zacharias, J., Zhang, T., \& Nakajima, N. (2011). Tokyo station city: The Railway station as urban place. Urban Design International, 16(4), 242-251. 


\section{Appendices}

\section{A. Input data}

\begin{tabular}{|c|c|c|c|c|}
\hline Time & Kodama (All-Stop) & Hikari (Limited-Stop) & Nozomi (Express) & Total \\
\hline Oct 1964 & 32 & 28 & 0 & 60 \\
\hline Oct 1965 & 46 & 40 & 0 & 86 \\
\hline Nov 1965 & 58 & 52 & 0 & 110 \\
\hline Oct 1966 & 65 & 56 & 0 & 121 \\
\hline Oct 1967 & 79 & 64 & 0 & 143 \\
\hline Oct 1968 & 106 & 72 & 0 & 178 \\
\hline Apr 1969 & 114 & 76 & 0 & 190 \\
\hline Oct 1969 & 124 & 78 & 0 & 202 \\
\hline Oct 1970 & 135 & 78 & 0 & 213 \\
\hline Mar 1972 & 123 & 92 & 0 & 215 \\
\hline Oct 1972 & 123 & 92 & 0 & 215 \\
\hline Mar 1973 & 123 & 96 & 0 & 219 \\
\hline Oct 1973 & 124 & 100 & 0 & 224 \\
\hline Mar 1975 & 119 & 116 & 0 & 235 \\
\hline Jul 1976 & 116 & 124 & 0 & 240 \\
\hline Oct 1980 & 98 & 130 & 0 & 228 \\
\hline Mar 1985 & 91 & 140 & 0 & 231 \\
\hline Nov 1986 & 91 & 144 & 0 & 235 \\
\hline Mar 1988 & 93 & 146 & 0 & 239 \\
\hline Mar 1989 & 93 & 158 & 0 & 251 \\
\hline Mar 1990 & 93 & 170 & 0 & 263 \\
\hline Mar 1991 & 96 & 182 & 0 & 278 \\
\hline Mar 1992 & 96 & 188 & 4 & 288 \\
\hline Mar 1993 & 86 & 162 & 34 & 282 \\
\hline Dec 1994 & 85 & 163 & 34 & 282 \\
\hline Mar 1996 & 85 & 164 & 34 & 283 \\
\hline Mar 1997 & 85 & 164 & 34 & 283 \\
\hline Nov 1997 & 85 & 155 & 45 & 285 \\
\hline Mar 1998 & 85 & 155 & 45 & 285 \\
\hline Oct 1998 & 85 & 155 & 45 & 285 \\
\hline Mar 1999 & 87 & 147 & 51 & 285 \\
\hline Oct 1999 & 87 & 147 & 51 & 285 \\
\hline Mar 2000 & 87 & 147 & 51 & 285 \\
\hline Oct 2000 & 87 & 145 & 53 & 285 \\
\hline Apr 2001 & 87 & 145 & 53 & 285 \\
\hline Oct 2001 & 87 & 125 & 75 & 287 \\
\hline Oct 2002 & 87 & 125 & 75 & 287 \\
\hline Jun 2003 & 87 & 125 & 75 & 287 \\
\hline
\end{tabular}

Appendix Table A.1 Number of daily scheduled train services by year and by type on the Tokaido Shinkansen. (Suyama, 2014, p. 19). 


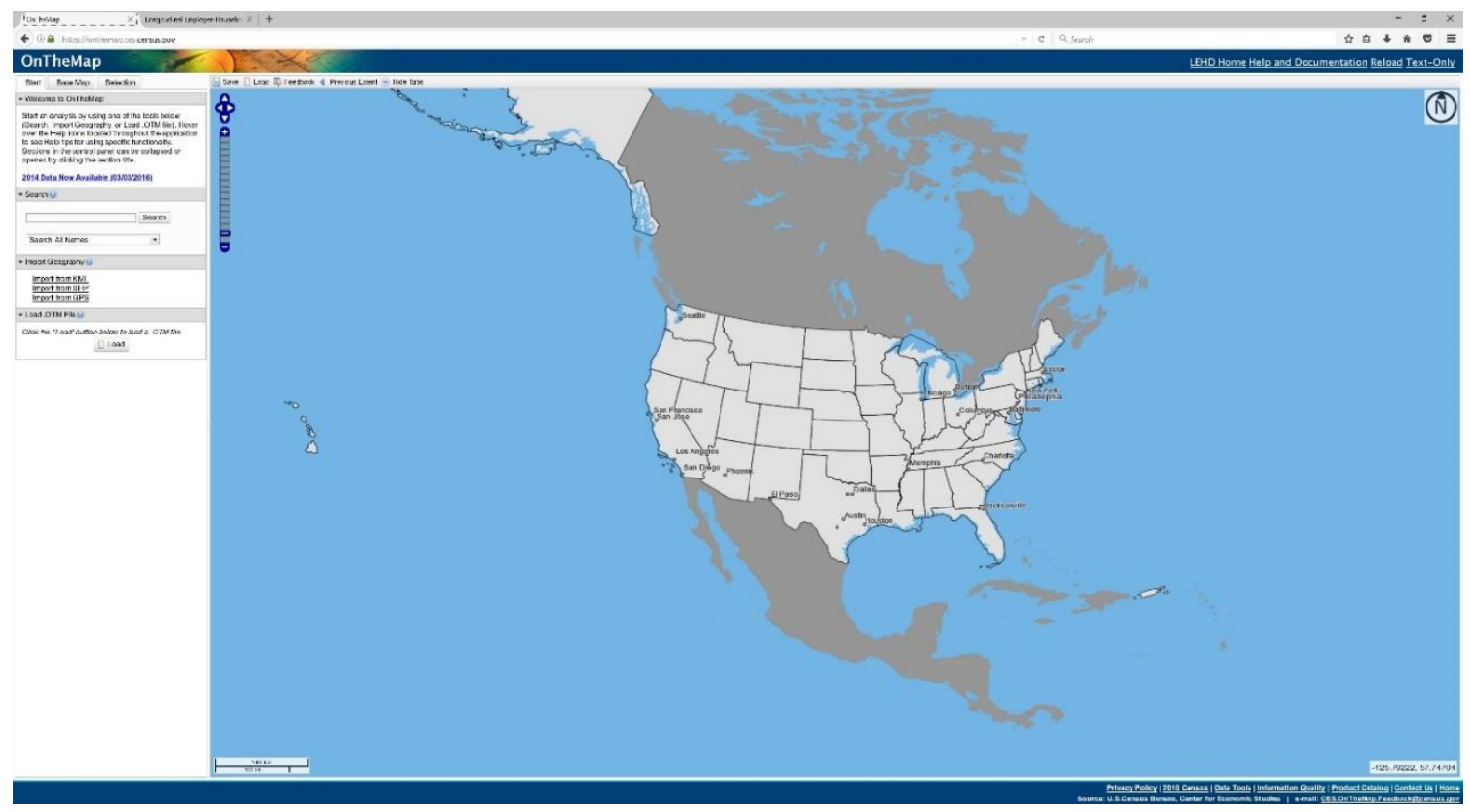

Appendix Figure A.1 Default screen of the LEHD OnTheMap online application. Courtesy of the United States Census Bureau (2017c). 


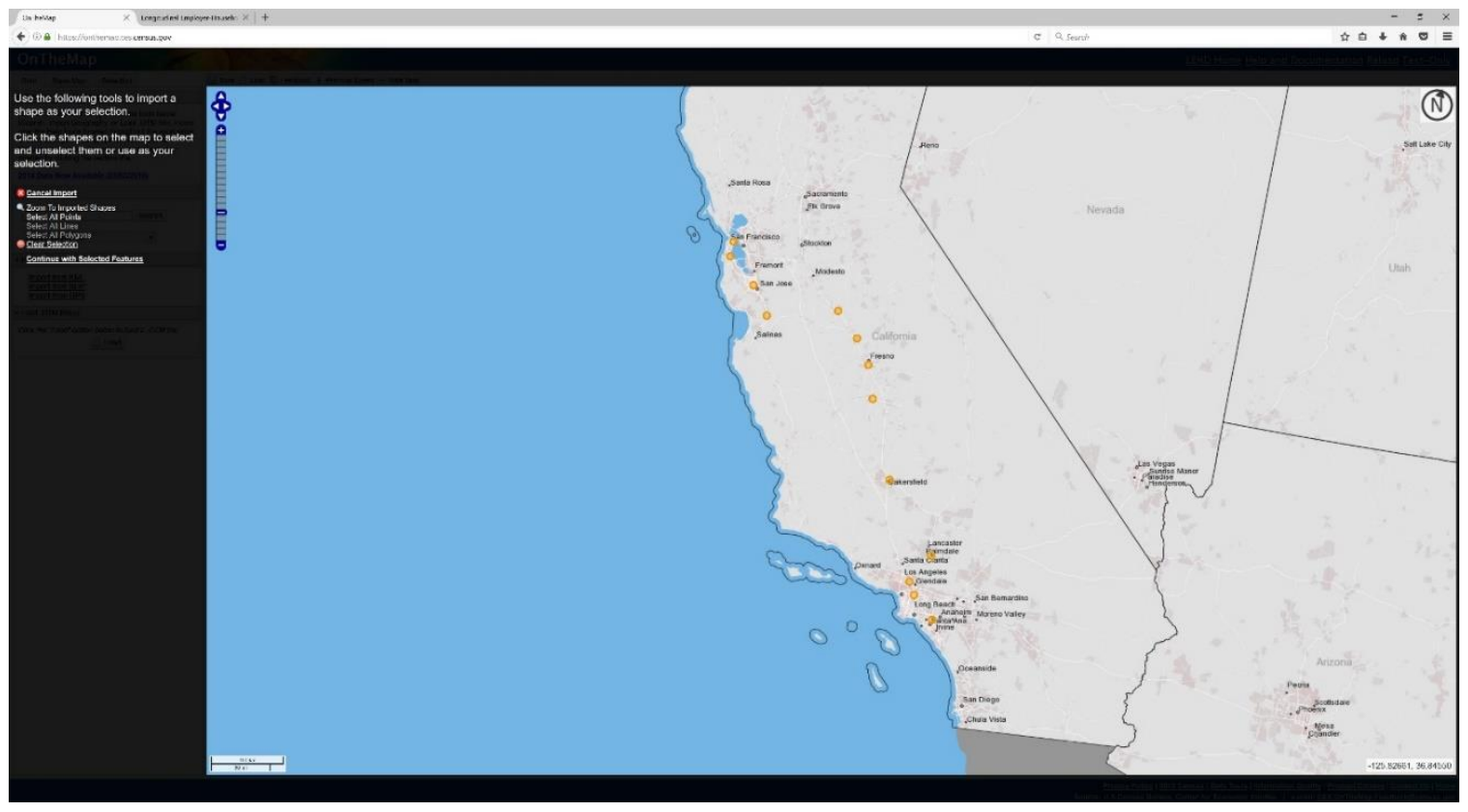

Appendix Figure A.2 Screen of the LEHD OnTheMap online application zoomed in to imported shapes. Courtesy of the United States Census Bureau (2017c). 


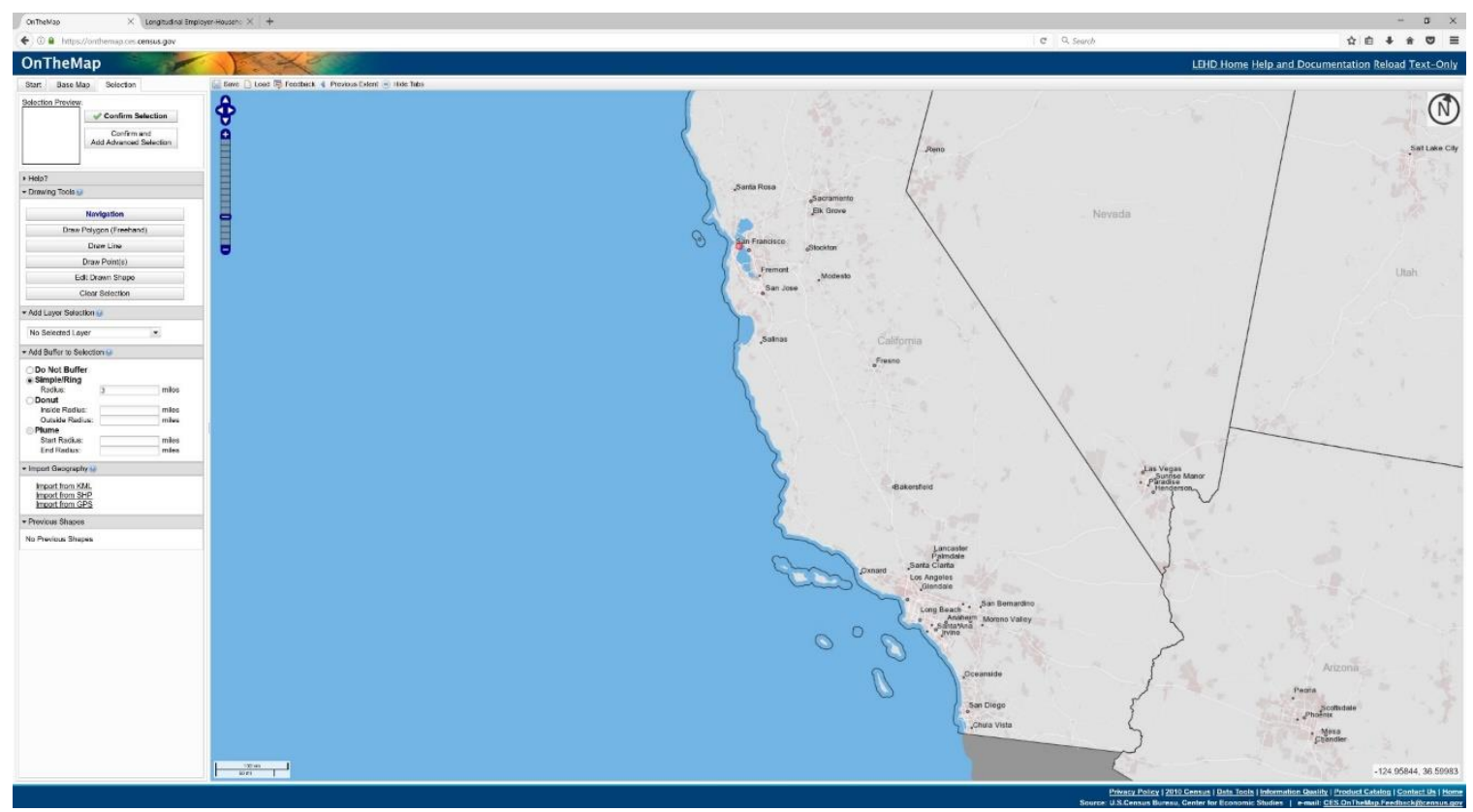

Appendix Figure A.3 Screen of the LEHD OnTheMap online application at the data retrieval toolbar. Courtesy of the United States Census Bureau (2017c). 


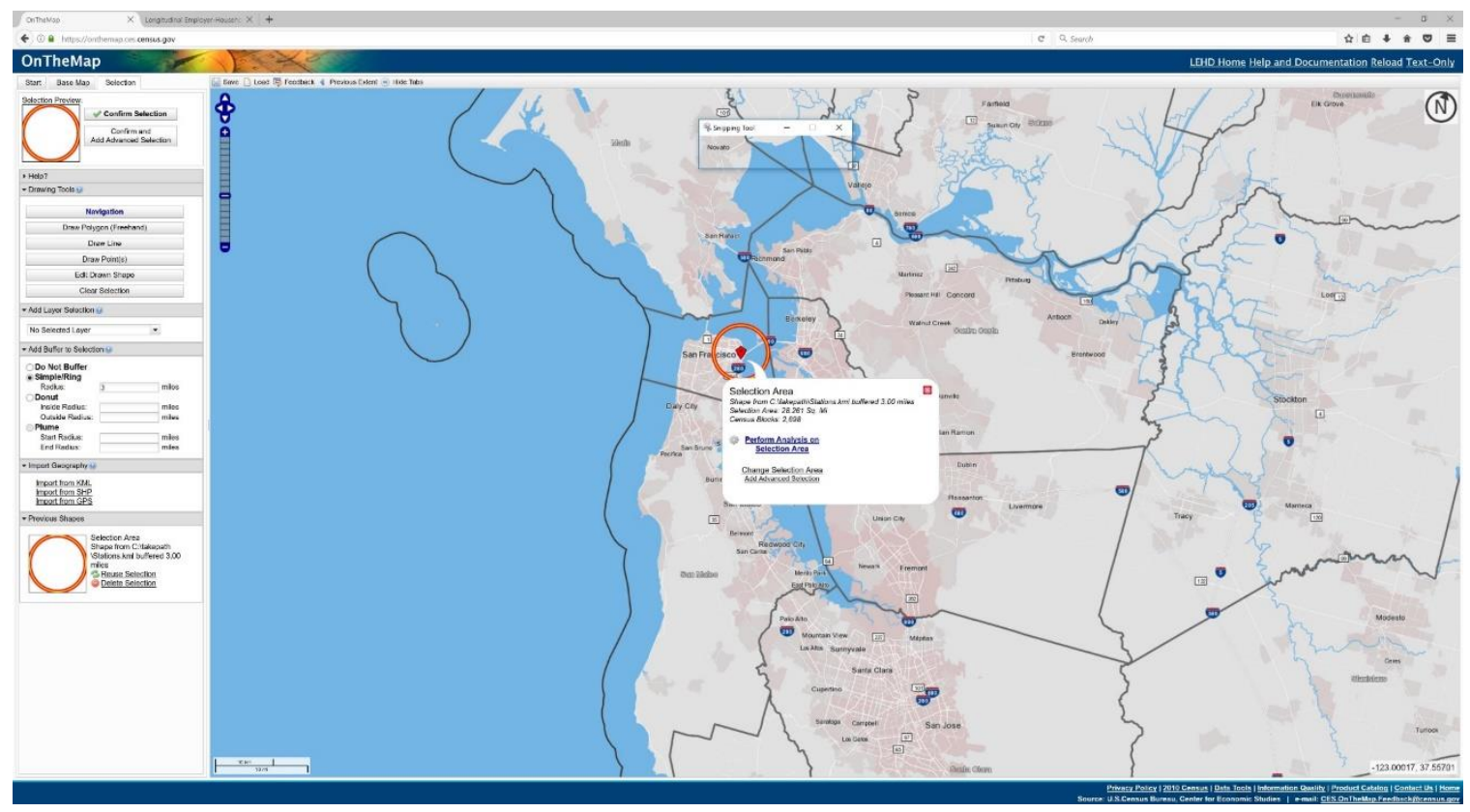

Appendix Figure A.4 Screen of the LEHD OnTheMap online application at "Confirm Selection." Courtesy of the United States Census Bureau (2017c). 


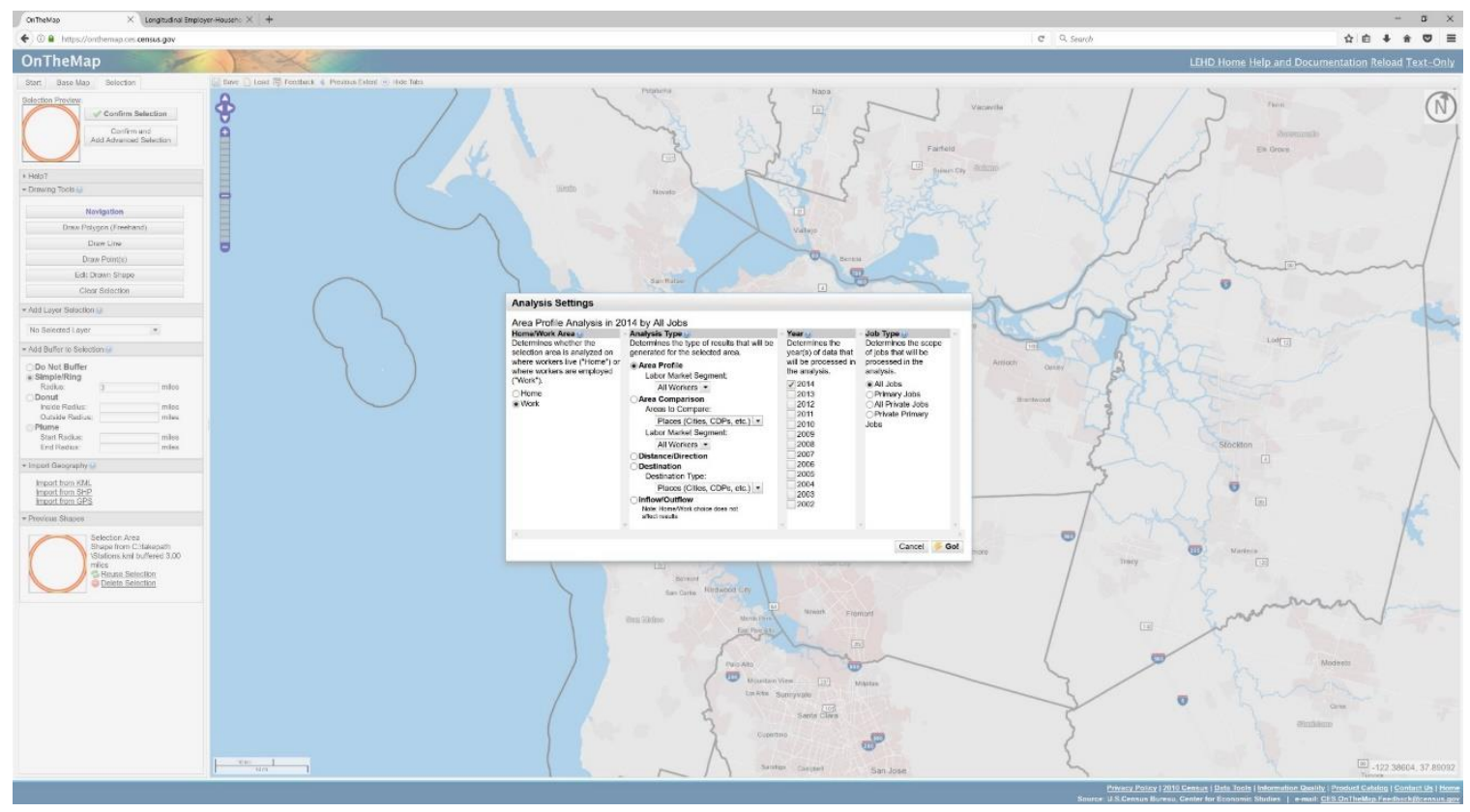

Appendix Figure A.5 Screen of the LEHD OnTheMap online application at "Perform Analysis on Selection Area." Courtesy of the United States Census Bureau (2017c). 


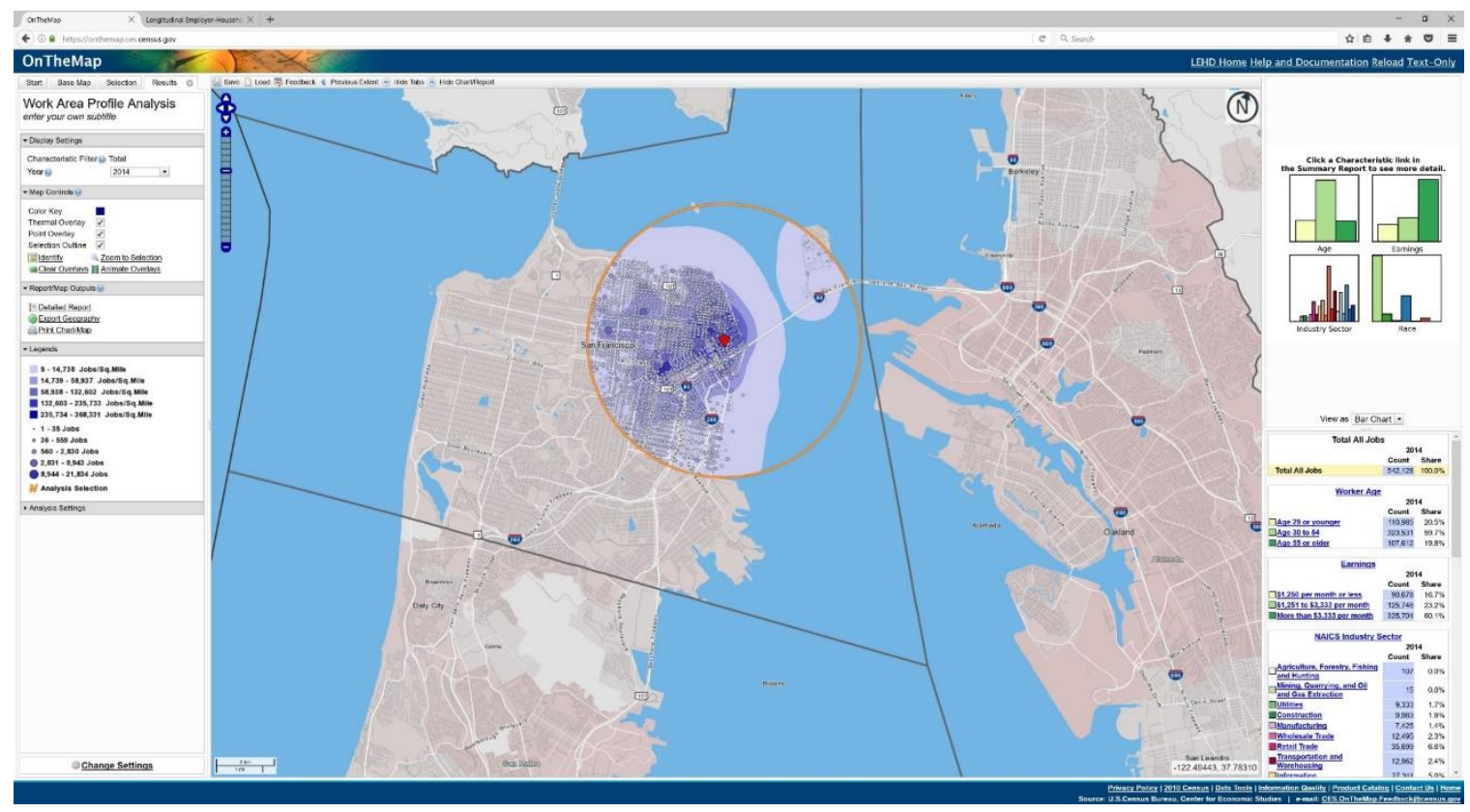

Appendix Figure A.6 Screen of the LEHD OnTheMap online application right after "Perform Analysis on Selection Area." Courtesy of the United States Census Bureau (2017c). 


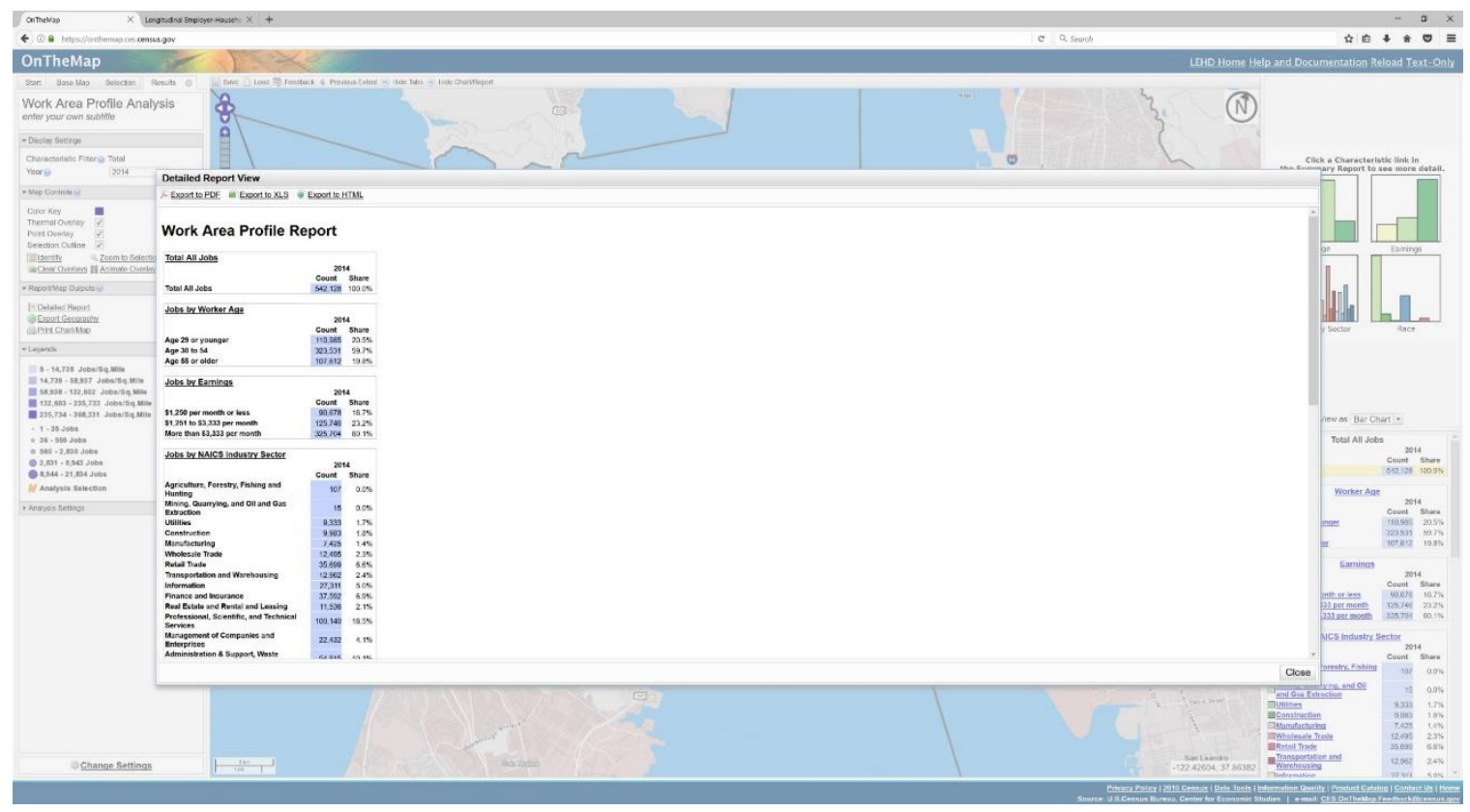

Appendix Figure A.7 Screen of the LEHD OnTheMap online application at "Detailed Report View." Courtesy of the United States Census Bureau (2017c). 


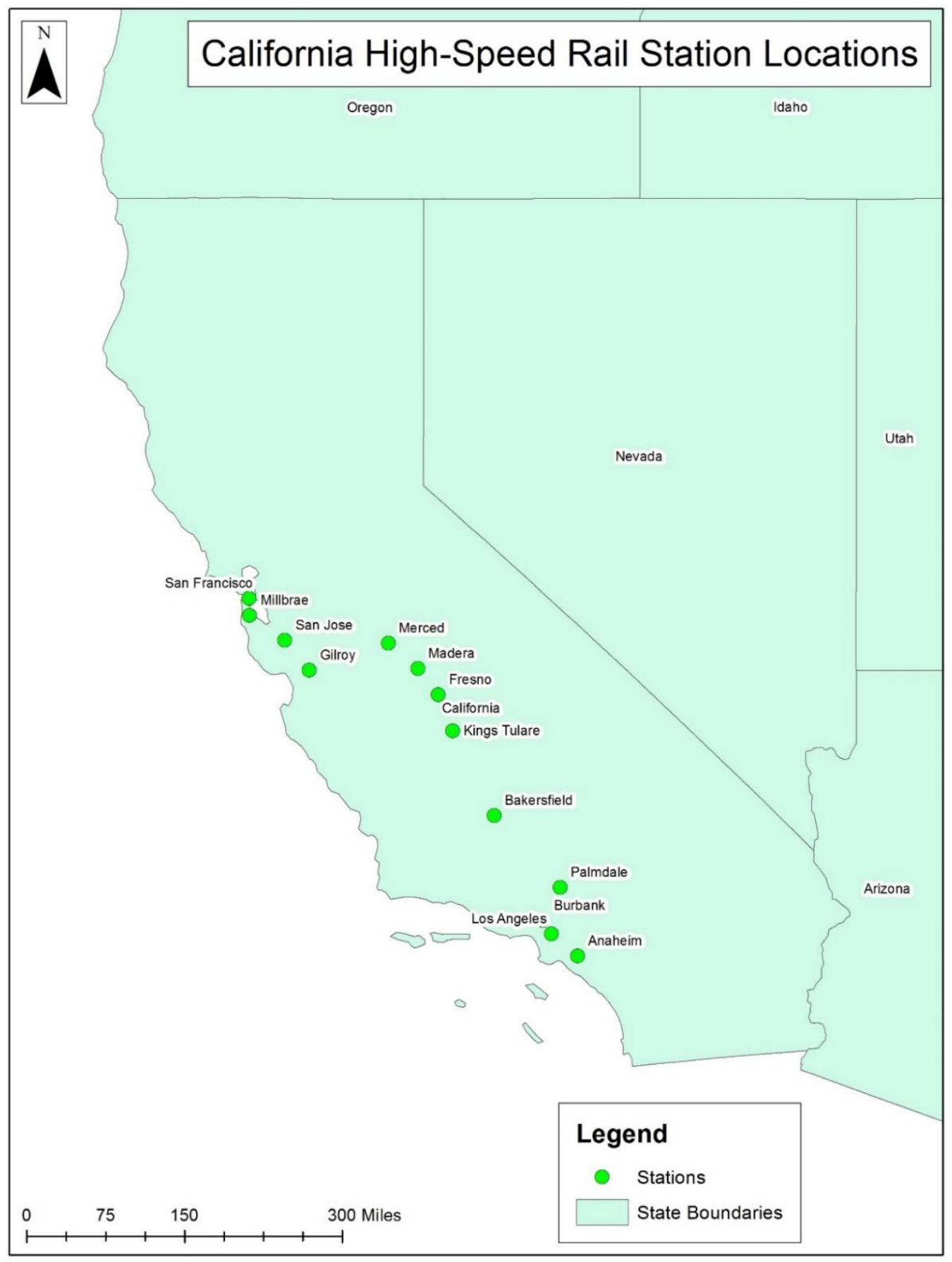

Appendix Map A.1 California High-Speed Rail station locations. (United States Census Bureau, 2017b). 


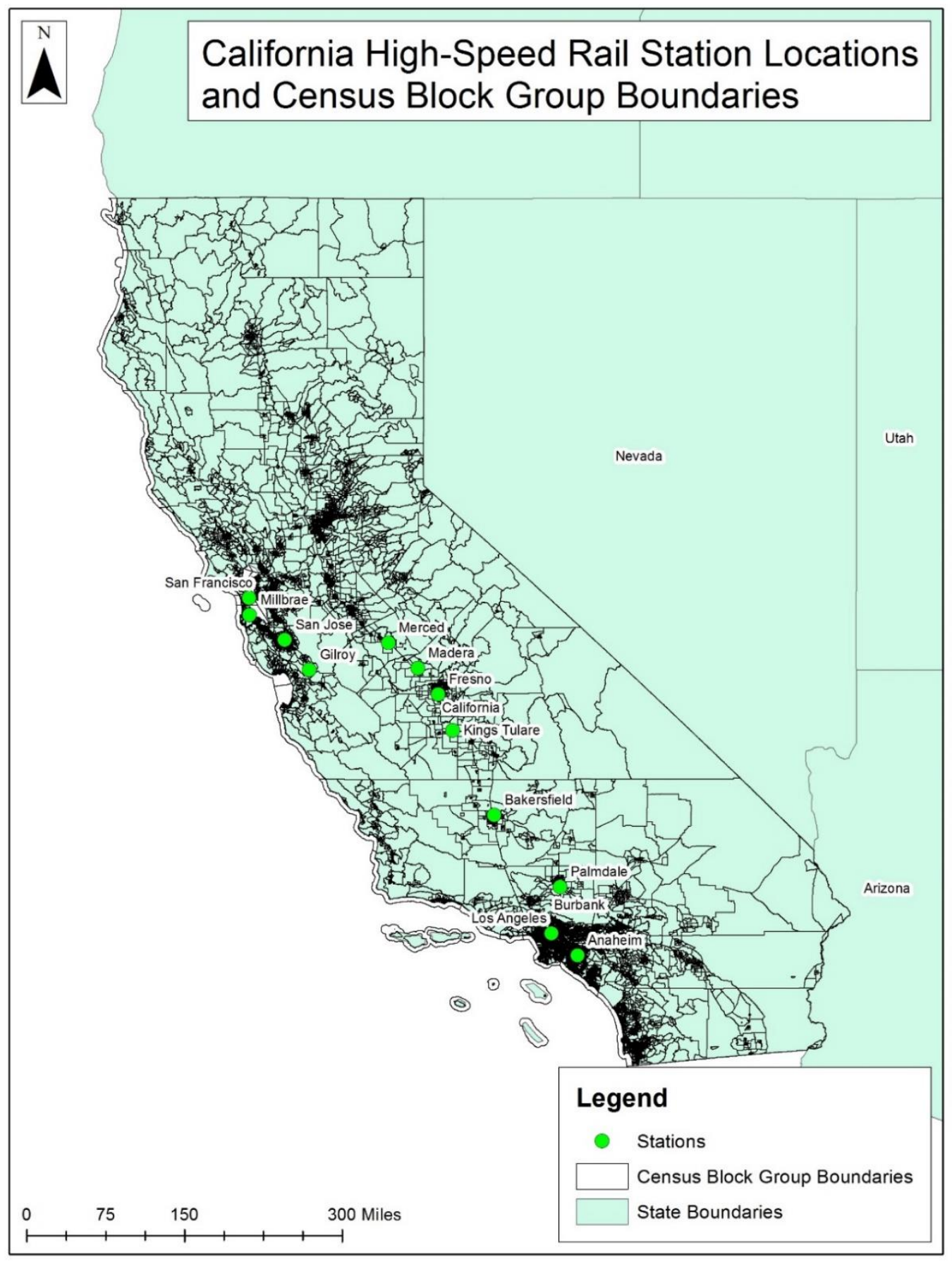

Appendix Map A.2 California High-Speed Rail station locations and Census Block Group boundaries. Created using ArcMap GIS (2017). (United States Census Bureau, 2017b; United States Census Bureau, 2017d). 


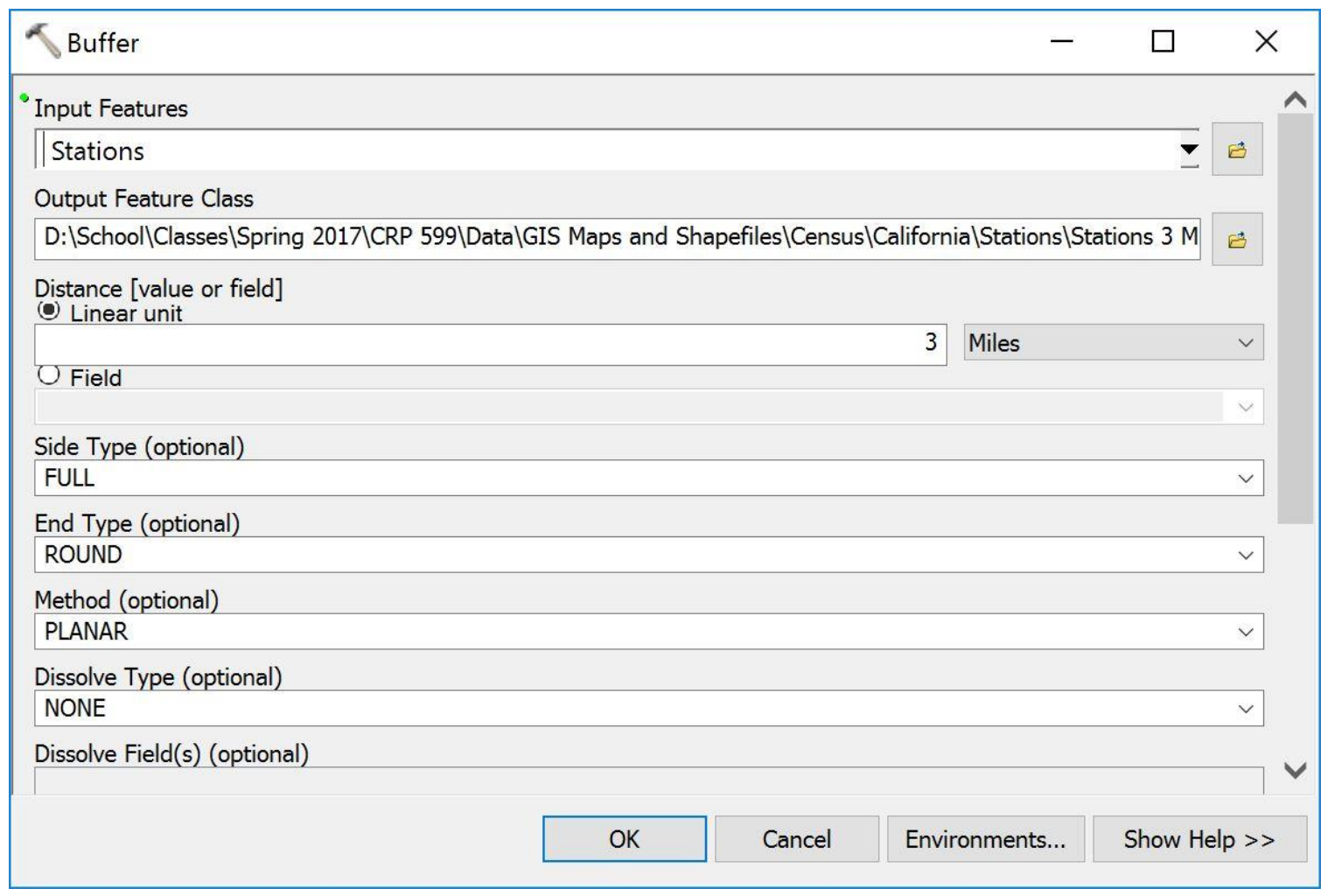

Appendix Figure A.8 Buffer tool in ArcMap GIS. Courtesy of Environmental Systems Research Institute (ESRI) (2017). 


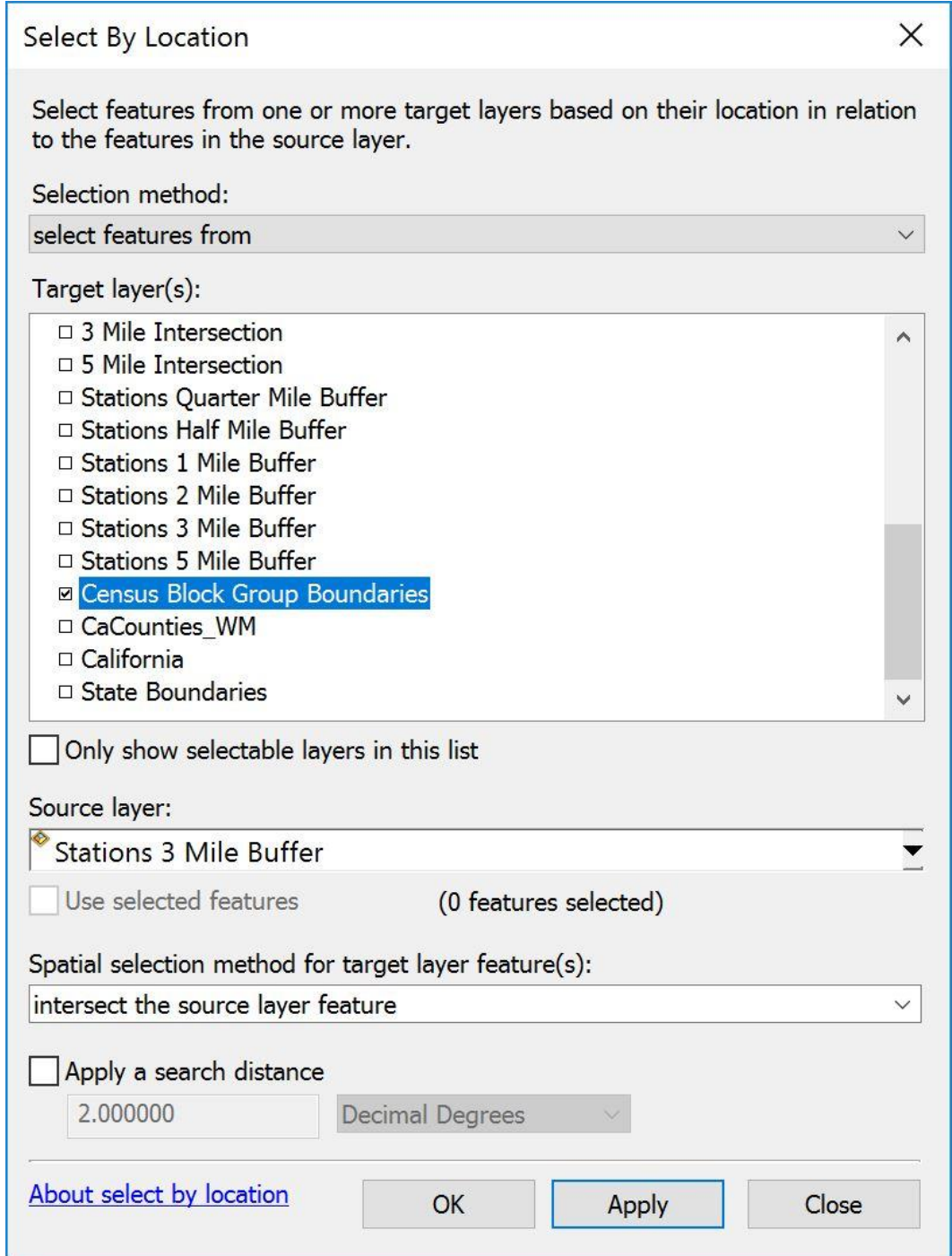

Appendix Figure A.9 Select By Location tool in ArcMap GIS. Courtesy of ESRI (2017). 


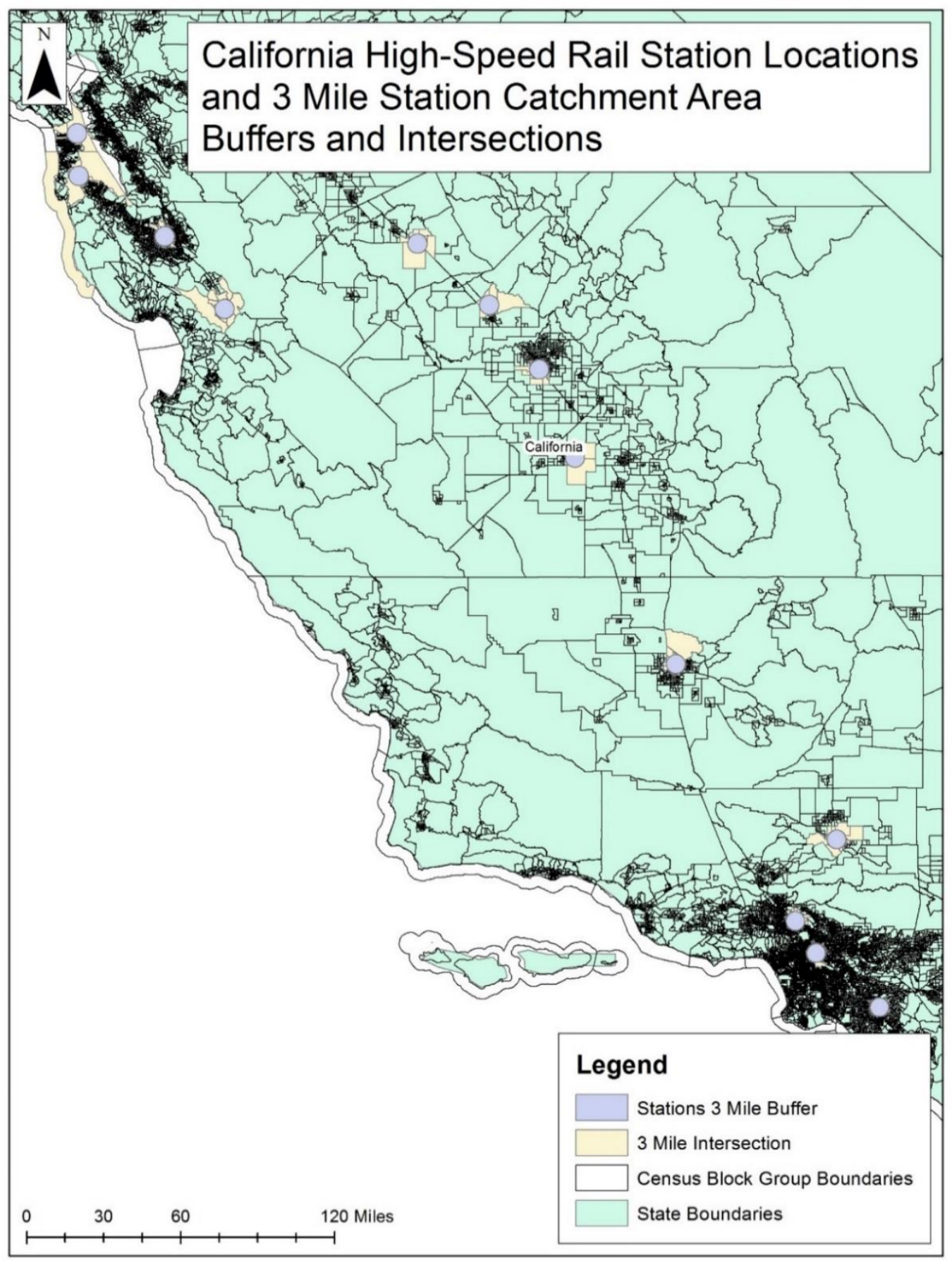

Appendix Map A.3 California High-Speed Rail station locations and Census Block Group boundaries. Created using ArcMap GIS (2017). (United States Census Bureau, 2017b; United States Census Bureau, 2017d). 


\begin{tabular}{|c|c|c|c|c|c|c|}
\hline \multicolumn{7}{|c|}{ Job near Stations, 2014} \\
\hline & $\begin{array}{l}\text { Quarter-Mile } \\
\text { Buffer }\end{array}$ & $\begin{array}{l}\text { Half-Mile } \\
\text { Buffer }\end{array}$ & $\begin{array}{l}\text { 1-Mile } \\
\text { Buffer }\end{array}$ & $\begin{array}{l}\text { 2-Mile } \\
\text { Buffer }\end{array}$ & $\begin{array}{l}\text { 3-Mile } \\
\text { Buffer }\end{array}$ & $\begin{array}{l}\text { 5-Mile } \\
\text { Buffer }\end{array}$ \\
\hline $\begin{array}{l}\text { San } \\
\text { Francisco }\end{array}$ & 63,994 & 217,489 & 332,612 & 479,236 & 542,128 & 628,673 \\
\hline Millbrae & 878 & 3,991 & 21,020 & 40,611 & 64,989 & 126,872 \\
\hline San Jose & 2,448 & 8,772 & 34,881 & 86,998 & 169,321 & 353,319 \\
\hline Gilroy & 386 & 1,554 & 6,623 & 15,053 & 17,956 & 19,813 \\
\hline Merced & 456 & 3,121 & 9,823 & 20,839 & 26,122 & 29,603 \\
\hline Madera & 2 & 125 & 323 & 807 & 2,620 & 13,100 \\
\hline Fresno & 2,697 & 6,121 & 34,818 & 48,061 & 70,641 & 106,550 \\
\hline $\begin{array}{l}\text { Kings } \\
\text { Tulare }\end{array}$ & 0 & 428 & 511 & 1,771 & 5,682 & 18,645 \\
\hline Bakersfield & 487 & 2,143 & 12,248 & 46,308 & 68,879 & 124,931 \\
\hline Palmdale & 169 & 695 & 4,262 & 11,235 & 20,594 & 29,666 \\
\hline Burbank & 479 & 5,380 & 64,954 & 107,473 & 167,304 & 330,895 \\
\hline $\begin{array}{l}\text { Los } \\
\text { Angeles }\end{array}$ & 2,965 & 34,550 & 169,362 & 365,658 & 457,178 & 692,836 \\
\hline Anaheim & 1,154 & 7,715 & 35,733 & 113,588 & 191,352 & 387,069 \\
\hline
\end{tabular}

Appendix Table A.2 Raw job numbers by station catchment area radius, 2014. Courtesy of the United States Census Bureau (2017c). 


\begin{tabular}{|l|c|c|c|c|c|c|}
\hline \multicolumn{7}{|c|}{ Descriptive Statistics of Jobs near Stations, 2014 } \\
\hline & $\begin{array}{c}\text { Quarter-Mile } \\
\text { Buffer }\end{array}$ & $\begin{array}{c}\text { Half-Mile } \\
\text { Buffer }\end{array}$ & $\begin{array}{c}\text { 1-Mile } \\
\text { Buffer }\end{array}$ & $\begin{array}{c}\text { 2-Mile } \\
\text { Buffer }\end{array}$ & $\begin{array}{c}\text { 3-Mile } \\
\text { Buffer }\end{array}$ & $\begin{array}{c}\text { 5-Mile } \\
\text { Buffer }\end{array}$ \\
\hline Average & 5,855 & 22,468 & 55,936 & 102,895 & 138,828 & 220,152 \\
\hline $\begin{array}{l}\text { Standard } \\
\text { Deviation }\end{array}$ & 16,813 & 56,954 & 90,857 & 142,681 & 166,656 & 227,876 \\
\hline
\end{tabular}

Appendix Table A.3 Descriptive statistics of jobs by station catchment area radius, 2014. Courtesy of the United States Census Bureau (2017c).

\begin{tabular}{|l|r|r|r|r|r|r|}
\hline \multicolumn{7}{|c|}{ Normalized Values of Jobs near Stations, 2014 } \\
\hline & $\begin{array}{c}\text { Quarter-Mile } \\
\text { Buffer }\end{array}$ & $\begin{array}{c}\text { Half-Mile } \\
\text { Buffer }\end{array}$ & \multicolumn{1}{c|}{$\begin{array}{c}\text { 1-Mile } \\
\text { Buffer }\end{array}$} & $\begin{array}{c}\text { 2-Mile } \\
\text { Buffer }\end{array}$ & $\begin{array}{c}\text { 3-Mile } \\
\text { Buffer }\end{array}$ & $\begin{array}{r}\text { 5-Mile } \\
\text { Buffer }\end{array}$ \\
\hline $\begin{array}{l}\text { San } \\
\text { Francisco }\end{array}$ & 3.46 & 3.42 & 3.05 & 2.64 & 2.42 & 1.79 \\
\hline Millbrae & -0.30 & -0.32 & -0.38 & -0.44 & -0.44 & -0.41 \\
\hline San Jose & -0.20 & -0.24 & -0.23 & -0.11 & 0.18 & 0.58 \\
\hline Gilroy & -0.33 & -0.37 & -0.54 & -0.62 & -0.73 & -0.88 \\
\hline Merced & -0.32 & -0.34 & -0.51 & -0.58 & -0.68 & -0.84 \\
\hline Madera & -0.35 & -0.39 & -0.61 & -0.72 & -0.82 & -0.91 \\
\hline Fresno & -0.19 & -0.29 & -0.23 & -0.38 & -0.41 & -0.50 \\
\hline $\begin{array}{l}\text { Kings } \\
\text { Tulare }\end{array}$ & -0.35 & -0.39 & -0.61 & -0.71 & -0.80 & -0.88 \\
\hline Bakersfield & -0.32 & -0.36 & -0.48 & -0.40 & -0.42 & -0.42 \\
\hline Palmdale & -0.34 & -0.38 & -0.57 & -0.64 & -0.71 & -0.84 \\
\hline Burbank & -0.32 & -0.30 & 0.10 & 0.03 & 0.17 & 0.49 \\
\hline $\begin{array}{l}\text { Los } \\
\text { Angeles }\end{array}$ & -0.17 & 0.21 & 1.25 & 1.84 & 1.91 & 2.07 \\
\hline Anaheim & -0.28 & -0.26 & -0.22 & 0.07 & 0.32 & 0.73 \\
\hline
\end{tabular}

Appendix Table A.4 Normalized job numbers by station catchment area radius, 2014. Courtesy of the United States Census Bureau (2017c). 


\begin{tabular}{|c|c|c|c|c|c|c|}
\hline \multicolumn{7}{|c|}{ Population near Stations, 2014} \\
\hline & $\begin{array}{l}\text { Quarter-Mile } \\
\text { Buffer }\end{array}$ & $\begin{array}{l}\text { Half-Mile } \\
\text { Buffer }\end{array}$ & $\begin{array}{l}\text { 1-Mile } \\
\text { Buffer }\end{array}$ & $\begin{array}{l}\text { 2-Mile } \\
\text { Buffer }\end{array}$ & $\begin{array}{l}\text { 3-Mile } \\
\text { Buffer }\end{array}$ & $\begin{array}{l}\text { 5-Mile } \\
\text { Buffer }\end{array}$ \\
\hline $\begin{array}{l}\text { San } \\
\text { Francisco }\end{array}$ & 5,800 & 18,531 & 80,084 & 218,258 & 418,465 & 720,040 \\
\hline Millbrae & 7,732 & 10,526 & 27,962 & 71,210 & 111,383 & 269,136 \\
\hline San Jose & 8,910 & 9,921 & 51,004 & 167,747 & 310,995 & 834,692 \\
\hline Gilroy & 7,180 & 11,670 & 18,059 & 31,430 & 38,404 & 47,851 \\
\hline Merced & 9,070 & 15,392 & 37,544 & 70,940 & 82,193 & 91,984 \\
\hline Madera & 5,036 & 6,355 & 7,668 & 8,932 & 16,684 & 64,907 \\
\hline Fresno & 4,077 & 8,578 & 28,025 & 90,871 & 161,041 & 318,485 \\
\hline $\begin{array}{l}\text { Kings } \\
\text { Tulare }\end{array}$ & 0 & 4,283 & 5,168 & 15,153 & 36,815 & 80,610 \\
\hline Bakersfield & 4,757 & 13,417 & 24,343 & 79,855 & 150,335 & 319,140 \\
\hline Palmdale & 7,776 & 11,761 & 22,541 & 53,246 & 78,816 & 114,650 \\
\hline Burbank & 8,840 & 11,656 & 30,595 & 113,691 & 255,999 & 615,680 \\
\hline $\begin{array}{l}\text { Los } \\
\text { Angeles }\end{array}$ & 6,841 & 20,263 & 55,752 & 194,244 & 485,451 & $1,325,105$ \\
\hline Anaheim & 6,377 & 6,377 & 11,394 & 83,129 & 229,084 & 652,354 \\
\hline
\end{tabular}

Appendix Table A.5 Raw population numbers by station catchment area radius, 2014. Courtesy of the United States Census Bureau (2017d). 


\begin{tabular}{|l|c|c|c|c|c|c|}
\hline \multicolumn{7}{|c|}{ Descriptive Statistics of Population near Stations, 2014 } \\
\hline & $\begin{array}{c}\text { Quarter-Mile } \\
\text { Buffer }\end{array}$ & $\begin{array}{c}\text { Half-Mile } \\
\text { Buffer }\end{array}$ & $\begin{array}{l}\text { 1-Mile } \\
\text { Buffer }\end{array}$ & $\begin{array}{c}\text { 2-Mile } \\
\text { Buffer }\end{array}$ & $\begin{array}{l}\text { 3-Mile } \\
\text { Buffer }\end{array}$ & $\begin{array}{c}\text { 5-Mile } \\
\text { Buffer }\end{array}$ \\
\hline Average & 6,338 & 11,441 & 30,780 & 92,208 & 182,743 & 419,587 \\
\hline $\begin{array}{l}\text { Standard } \\
\text { Deviation }\end{array}$ & 2,403 & 4,488 & 20,309 & 63,052 & 143,685 & 371,828 \\
\hline
\end{tabular}

Appendix Table A.6 Descriptive statistics of population by station catchment area radius, 2014. Courtesy of the United States Census Bureau (2017d).

\begin{tabular}{|l|r|r|r|r|r|r|}
\hline \multicolumn{7}{|c|}{ Normalized Values of Population near Stations, 2014 } \\
\hline & $\begin{array}{l}\text { Quarter-Mile } \\
\text { Buffer }\end{array}$ & $\begin{array}{l}\text { Half-Mile } \\
\text { Buffer }\end{array}$ & \multicolumn{1}{l}{$\begin{array}{l}\text { 1-Mile } \\
\text { Buffer }\end{array}$} & \multicolumn{1}{l}{$\begin{array}{l}\text { 2-Mile } \\
\text { Buffer }\end{array}$} & $\begin{array}{l}\text { 3-Mile } \\
\text { Buffer }\end{array}$ & \multicolumn{1}{l|}{$\begin{array}{l}\text { 5-Mile } \\
\text { Buffer }\end{array}$} \\
\hline $\begin{array}{l}\text { San } \\
\text { Francisco }\end{array}$ & -0.22 & 1.58 & 2.43 & 2.00 & 1.64 & 0.81 \\
\hline Millbrae & 0.58 & -0.20 & -0.14 & -0.33 & -0.50 & -0.40 \\
\hline San Jose & 1.07 & -0.34 & 1.00 & 1.20 & 0.89 & 1.12 \\
\hline Gilroy & 0.35 & 0.05 & -0.63 & -0.96 & -1.00 & -1.00 \\
\hline Merced & 1.14 & 0.88 & 0.33 & -0.34 & -0.70 & -0.88 \\
\hline Madera & -0.54 & -1.13 & -1.14 & -1.32 & -1.16 & -0.95 \\
\hline Fresno & -0.94 & -0.64 & -0.14 & -0.02 & -0.15 & -0.27 \\
\hline Kings & -2.64 & -1.59 & -1.26 & -1.22 & -1.02 & -0.91 \\
\hline Tulare & -0.66 & 0.44 & -0.32 & -0.20 & -0.23 & -0.27 \\
\hline Bakersfield & 0.60 & 0.07 & -0.41 & -0.62 & -0.72 & -0.82 \\
\hline Palmdale & 1.04 & 0.05 & -0.01 & 0.34 & 0.51 & 0.53 \\
\hline Burbank & 0.21 & 1.97 & 1.23 & 1.62 & 2.11 & 2.44 \\
\hline $\begin{array}{l}\text { Los } \\
\text { Angeles }\end{array}$ & 0.02 & -1.13 & -0.95 & -0.14 & 0.32 & 0.63 \\
\hline Anaheim & & & & & & \\
\hline
\end{tabular}

Appendix Table A.7 Normalized population numbers by station catchment area radius, 2014. Courtesy of the United States Census Bureau (2017d). 


\begin{tabular}{|c|c|c|c|c|c|c|}
\hline \multicolumn{7}{|c|}{ Housing Units near Stations, 2014} \\
\hline & $\begin{array}{l}\text { Quarter-Mile } \\
\text { Buffer }\end{array}$ & $\begin{array}{l}\text { Half-Mile } \\
\text { Buffer }\end{array}$ & $\begin{array}{l}\text { 1-Mile } \\
\text { Buffer }\end{array}$ & $\begin{array}{l}\text { 2-Mile } \\
\text { Buffer }\end{array}$ & $\begin{array}{l}\text { 3-Mile } \\
\text { Buffer }\end{array}$ & $\begin{array}{l}\text { 5-Mile } \\
\text { Buffer }\end{array}$ \\
\hline $\begin{array}{l}\text { San } \\
\text { Francisco }\end{array}$ & 2,097 & 6,075 & 29,646 & 78,843 & 151,892 & 271,026 \\
\hline Millbrae & 3,469 & 4,349 & 10,017 & 24,181 & 38,776 & 90,784 \\
\hline San Jose & 2,517 & 2,788 & 15,675 & 57,001 & 111,074 & 295,779 \\
\hline Gilroy & 2,099 & 3,911 & 6,034 & 10,967 & 13,628 & 16,948 \\
\hline Merced & 3,304 & 5,620 & 13,750 & 24,739 & 28,387 & 32,104 \\
\hline Madera & 1,482 & 1,888 & 2,439 & 2,783 & 5,450 & 20,392 \\
\hline Fresno & 1,518 & 3,710 & 11,446 & 37,054 & 64,870 & 120,250 \\
\hline $\begin{array}{l}\text { Kings } \\
\text { Tulare }\end{array}$ & 5 & 1,171 & 1,639 & 3,871 & 9,955 & 24,784 \\
\hline Bakersfield & 1,350 & 5,593 & 9,088 & 27,791 & 54,410 & 110,427 \\
\hline Palmdale & 2,638 & 3,662 & 8,413 & 18,598 & 28,191 & 44,623 \\
\hline Burbank & 3,378 & 4,160 & 11,730 & 42,037 & 94,709 & 221,720 \\
\hline $\begin{array}{l}\text { Los } \\
\text { Angeles }\end{array}$ & 2,056 & 7,907 & 20,232 & 80,788 & 187,045 & 479,563 \\
\hline Anaheim & 2,571 & 2,571 & 4,249 & 29,774 & 82,779 & 234,845 \\
\hline
\end{tabular}

Appendix Table A.8 Raw housing unit numbers by station catchment area radius, 2014. Courtesy of the United States Census Bureau (2017d). 


\begin{tabular}{|l|r|r|r|r|r|r|}
\hline \multicolumn{7}{|c|}{ Descriptive Statistics of Housing Units near Stations, 2014 } \\
\hline & $\begin{array}{c}\text { Quarter-Mile } \\
\text { Buffer }\end{array}$ & $\begin{array}{c}\text { Half-Mile } \\
\text { Buffer }\end{array}$ & $\begin{array}{l}\text { 1-Mile } \\
\text { Buffer }\end{array}$ & $\begin{array}{l}\text { 2-Mile } \\
\text { Buffer }\end{array}$ & $\begin{array}{c}\text { 3-Mile } \\
\text { Buffer }\end{array}$ & $\begin{array}{c}\text { 5-Mile } \\
\text { Buffer }\end{array}$ \\
\hline Average & 2,191 & 4,108 & 11,104 & 33,725 & 67,013 & 151,019 \\
\hline $\begin{array}{l}\text { Standard } \\
\text { Deviation }\end{array}$ & 929 & 1,774 & 7,366 & 24,322 & 54,367 & 135,301 \\
\hline
\end{tabular}

Appendix Table A.9 Descriptive statistics of housing units by station catchment area radius, 2014. Courtesy of the United States Census Bureau (2017d).

\begin{tabular}{|c|c|c|c|c|c|c|}
\hline \multicolumn{7}{|c|}{ Normalized Values of Housing Units near Stations, 2014} \\
\hline & $\begin{array}{c}\text { Quarter-Mile } \\
\text { Buffer }\end{array}$ & $\begin{array}{c}\text { Half-Mile } \\
\text { Buffer }\end{array}$ & $\begin{array}{l}\text { 1-Mile } \\
\text { Buffer }\end{array}$ & $\begin{array}{l}\text { 2-Mile } \\
\text { Buffer }\end{array}$ & $\begin{array}{l}\text { 3-Mile } \\
\text { Buffer }\end{array}$ & $\begin{array}{l}\text { 5-Mile } \\
\text { Buffer }\end{array}$ \\
\hline $\begin{array}{c}\text { San } \\
\text { Francisco } \\
\end{array}$ & -0.10 & 1.11 & 2.52 & 1.85 & 1.56 & 0.89 \\
\hline Millbrae & 1.38 & 0.14 & -0.15 & -0.39 & -0.52 & -0.45 \\
\hline San Jose & 0.35 & -0.74 & 0.62 & 0.96 & 0.81 & 1.07 \\
\hline Gilroy & -0.10 & -0.11 & -0.69 & -0.94 & -0.98 & -0.99 \\
\hline Merced & 1.20 & 0.85 & 0.36 & -0.37 & -0.71 & -0.88 \\
\hline Madera & -0.76 & -1.25 & -1.18 & -1.27 & -1.13 & -0.97 \\
\hline Fresno & -0.72 & -0.22 & 0.05 & 0.14 & -0.04 & -0.23 \\
\hline $\begin{array}{l}\text { Kings } \\
\text { Tulare }\end{array}$ & -2.35 & -1.66 & -1.28 & -1.23 & -1.05 & -0.93 \\
\hline Bakersfield & -0.91 & 0.84 & -0.27 & -0.24 & -0.23 & -0.30 \\
\hline Palmdale & 0.48 & -0.25 & -0.37 & -0.62 & -0.71 & -0.79 \\
\hline Burbank & 1.28 & 0.03 & 0.08 & 0.34 & 0.51 & 0.52 \\
\hline $\begin{array}{c}\text { Los } \\
\text { Angeles }\end{array}$ & -0.15 & 2.14 & 1.24 & 1.93 & 2.21 & 2.43 \\
\hline Anaheim & 0.41 & -0.87 & -0.93 & -0.16 & 0.29 & 0.62 \\
\hline
\end{tabular}

Appendix Table A.10 Normalized housing unit numbers by station catchment area radius, 2014. Courtesy of the United States Census Bureau (2017d). 


\begin{tabular}{|l|c|c|r|}
\hline \multicolumn{1}{|c|}{ Station } & Label & Link & Distance (mi) \\
\hline San Francisco & A & A-B & 18.0 \\
\hline Millbrae & B & B-C & 41.9 \\
\hline San Jose & C & C-D & 37.6 \\
\hline Gilroy & D & D-E & 118.4 \\
\hline Merced & E & E-F & 35.9 \\
\hline Madera & F & F-G & 32.4 \\
\hline Fresno & G & G-H & 36.0 \\
\hline Kings Tulare & H & H-I & 100.2 \\
\hline Bakersfield & I & J-J & 105.2 \\
\hline Palmdale & J & K-L & 55.4 \\
\hline Burbank & K & L-M & 16.6 \\
\hline Los Angeles & L & D-F & 36.1 \\
\hline Anaheim & M & Total & 590.9 \\
\hline & & Total minus Merced Wye & 745.2 \\
\hline
\end{tabular}

Appendix Table A.11 Distances of links between stations along the high-speed rail alignment. Yellow cells indicate links that connect to or bypass Merced. 


\begin{tabular}{|c|c|c|c|c|c|c|c|c|c|c|c|c|c|c|}
\hline \multirow{14}{*}{ 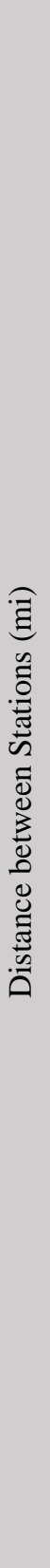 } & $\Sigma$ & $\bar{n}$ & $\stackrel{n}{n}$ & $\bar{n}$ & 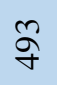 & $\stackrel{\infty}{\vec{\sigma}}$ & $\underset{\infty}{\infty}$ & ले & $\frac{m}{m}$ & $\stackrel{m}{\sim}$ & $\stackrel{\circ}{\circ}$ & $\stackrel{\infty}{\varrho}$ & r & $m$ \\
\hline & \lrcorner & $\begin{array}{l}n \\
n\end{array}$ & $\stackrel{n}{q}$ & $\stackrel{\mathfrak{q}}{q}$ & $\sqrt[i]{f}$ & $\underset{\infty}{\infty}$ & ڤా & $\frac{m}{m}$ & $\stackrel{\curvearrowright}{\approx}$ & 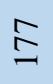 & $\mathbb{N}$ & $\Xi$ & $m$ & ల \\
\hline & $\checkmark$ & $\underset{n}{\infty}$ & iิ & $\stackrel{\infty}{\stackrel{\infty}{\forall}}$ & 尹 & $\stackrel{n}{n}$ & ते & $\hat{\mathrm{\lambda}}$ & $\overline{\mathrm{d}}$ & $\bar{\sigma}$ & $n$ & $m$ & $\beth$ & $n$ \\
\hline & $\neg$ & $\underset{\infty}{\infty}$ & fo & $\stackrel{\overbrace{}}{\mathcal{F}}$ & $\stackrel{n}{\infty}$ & $\stackrel{\circ}{m}$ & $\underset{\sim}{\stackrel{\Delta}{N}}$ & $\underset{\sim}{\vec{J}}$ & 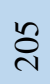 & $\stackrel{n}{\varrho}$ & $m$ & $n$ & $\mathbb{N}$ & $\stackrel{\infty}{\circ}$ \\
\hline & - & $\frac{\infty}{m}$ & 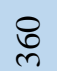 & $\frac{\infty}{m}$ & 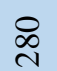 & 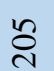 & $\underline{0}$ & 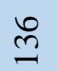 & 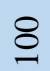 & $m$ & $\stackrel{\varrho}{\varrho}$ & $\overline{0}$ & I & $\stackrel{m}{\sim}$ \\
\hline & $I$ & $\hat{\imath}$ & ฉิ & $\frac{\infty}{\sim}$ & $\hat{\imath}$ & $\stackrel{\Xi}{\Xi}$ & $\infty$ & లి & $m$ & 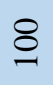 & है & $\bar{乛}$ & $\hat{\imath}$ & $\frac{m}{m}$ \\
\hline & ט & $\vec{J}$ & 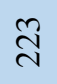 & $\stackrel{\infty}{\infty}$ & 导 & $\ddot{0}$ & $\stackrel{\sim}{n}$ & $m$ & లో & 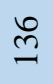 & $\bar{J}$ & $\hat{\mathrm{d}}$ & $\frac{m}{m}$ & $\underset{m}{q}$ \\
\hline & 工 & 유 & $\bar{a}$ & $\stackrel{g}{ \pm}$ & $\stackrel{\simeq}{=}$ & l & $m$ & กี & 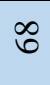 & $\hat{0}$ & $\underset{\sim}{\stackrel{\Delta}{\Delta}}$ & సิ & $\stackrel{\circ}{\stackrel{0}{m}}$ & $\underset{\infty}{\infty}$ \\
\hline & 피 & $\stackrel{0}{\sim}$ & $\stackrel{\infty}{\varrho}$ & $\stackrel{0}{n}$ & $\stackrel{\infty}{=}$ & $m$ & లె & $\infty$ & $\underset{O}{ \pm}$ & 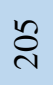 & $\stackrel{\circ}{m}$ & $\mathfrak{\delta}$ & 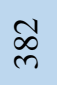 & $\stackrel{\infty}{\forall}$ \\
\hline & D & $\hat{a}$ & $\stackrel{2}{2}$ & $\stackrel{\infty}{m}$ & $m$ & $\stackrel{\infty}{=}$ & $\stackrel{N}{=}$ & $\underset{ \pm}{ \pm}$ & $\stackrel{\infty}{\infty}$ & 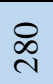 & 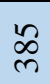 & 尹 & $\tilde{n}$ & $\stackrel{\sigma}{\sigma}$ \\
\hline & $U$ & 8 & F & $m$ & $\stackrel{\infty}{m}$ & $\stackrel{\circ}{n}$ & $\stackrel{g}{ \pm}$ & $\infty$ & $\stackrel{\infty}{\sim}$ & $\frac{\infty}{m}$ & $\stackrel{\overbrace{}}{\sim}$ & $\stackrel{\infty}{\underset{\gamma}{f}}$ & $\stackrel{n}{q}$ & $\bar{n}$ \\
\hline & 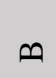 & $\stackrel{\infty}{-}$ & $m$ & F & $\stackrel{2}{2}$ & $\stackrel{\infty}{\varrho}$ & $\bar{\sigma}$ & 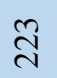 & ڤે & : & $\frac{n}{q}$ & กิ & $\hat{n}$ & $\hat{n}$ \\
\hline & $\varangle$ & $m$ & $\stackrel{\infty}{\sim}$ & 8 & á & $\stackrel{b}{\sim}$ & 유 & $\bar{d}$ & $\stackrel{\widehat{N}}{\sim}$ & $\stackrel{\infty}{\stackrel{\infty}{m}}$ & $\stackrel{\infty}{+}$ & $\underset{n}{n}$ & $\begin{array}{l}n \\
n\end{array}$ & $\bar{n}$ \\
\hline & $\begin{array}{l}\bar{\Xi} \\
\text { ]्ञ } \\
\end{array}$ & $\varangle$ & 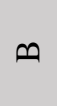 & $u$ & D & 디 & 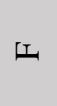 & ט & $I$ & - & $\neg$ & $\forall$ & \lrcorner & $\Sigma$ \\
\hline
\end{tabular}

Appendix Table A.12 The distance between each station along the California High-Speed Rail line. 
$I_{i j}=\frac{A_{j} F_{i j}}{\sum_{k} A_{k} F_{i k}}$

Appendix Figure A.10 Formula for accessibility index of station origin-destination pairs.

Where:

$\mathrm{I}_{\mathrm{ij}}=$ Accessibility index from origin $\mathrm{i}$ to destination $\mathrm{j}$

$A_{j}=$ Attraction of origin $\mathrm{i}$ (raw or normalized values of jobs, population, or housing units)

$\mathrm{F}_{\mathrm{ij}}=$ Impedance factor from origin $\mathrm{i}$ to destination $\mathrm{j}$ (distance)

$\Sigma A_{k} F_{i k}=$ Summation of the product of attractions to destination $\mathrm{k}$ and the friction factor of destination $\mathrm{k}$ to each origin $\mathrm{i}$ 


\section{B. Accessibility Calculations}

\begin{tabular}{|c|c|c|c|c|c|}
\hline Accessibility Index Pairs & $\mathrm{A}_{\mathrm{j}}$ & $F_{i j}$ & $\mathrm{~A}_{\mathrm{j}}^{*} \mathrm{~F}_{\mathrm{ij}}$ & $\sum \mathrm{A}_{\mathrm{k}} * \mathrm{~F}_{\mathrm{ik}}$ & $\mathrm{I}_{\mathrm{ij}}=\left(\mathrm{A}_{\mathrm{j}} * \mathrm{~F}_{\mathrm{ij}} /\left(\Sigma \mathrm{A}_{\mathrm{k}} * \mathrm{~F}_{\mathrm{ik}}\right)\right)$ \\
\hline $\mathrm{I}_{\mathrm{AA}}$ & 217,489 & 2.00 & $434,978.00$ & $435,496.31$ & 1.00 \\
\hline$I_{A B}$ & 3,991 & 0.06 & 221.56 & $435,496.31$ & 0.00 \\
\hline $\mathrm{I}_{\mathrm{AC}}$ & 8,772 & 0.02 & 146.42 & $435,496.31$ & 0.00 \\
\hline $\mathrm{I}_{\mathrm{AD}}$ & 1,554 & 0.01 & 15.94 & $435,496.31$ & 0.00 \\
\hline $\mathrm{I}_{\mathrm{AE}}$ & 3,121 & 0.00 & 14.46 & $435,496.31$ & 0.00 \\
\hline $\mathrm{I}_{\mathrm{AF}}$ & 125 & 0.00 & 0.60 & $435,496.31$ & 0.00 \\
\hline $\mathrm{I}_{\mathrm{AG}}$ & 6,121 & 0.00 & 25.35 & $435,496.31$ & 0.00 \\
\hline $\mathrm{I}_{\mathrm{AH}}$ & 428 & 0.00 & 1.54 & $435,496.31$ & 0.00 \\
\hline $\mathrm{I}_{\mathrm{AI}}$ & 2,143 & 0.00 & 5.67 & $435,496.31$ & 0.00 \\
\hline $\mathrm{I}_{\mathrm{AJ}}$ & 695 & 0.00 & 1.44 & $435,496.31$ & 0.00 \\
\hline $\mathrm{I}_{\mathrm{AK}}$ & 5,380 & 0.00 & 10.00 & $435,496.31$ & 0.00 \\
\hline $\mathrm{I}_{\mathrm{AL}}$ & 34,550 & 0.00 & 62.27 & $435,496.31$ & 0.00 \\
\hline $\mathrm{I}_{\mathrm{AM}}$ & 7,715 & 0.00 & 13.06 & $435,496.31$ & 0.00 \\
\hline $\mathrm{I}_{\mathrm{BA}}$ & 217,489 & 0.06 & $12,073.86$ & $20,431.33$ & 0.59 \\
\hline $\mathrm{I}_{\mathrm{BB}}$ & 3,991 & 2.00 & $7,982.00$ & $20,431.33$ & 0.39 \\
\hline $\mathrm{I}_{\mathrm{BC}}$ & 8,772 & 0.02 & 209.37 & $20,431.33$ & 0.01 \\
\hline $\mathrm{I}_{\mathrm{BD}}$ & 1,554 & 0.01 & 19.55 & $20,431.33$ & 0.00 \\
\hline $\mathrm{I}_{\mathrm{BE}}$ & 3,121 & 0.01 & 15.77 & $20,431.33$ & 0.00 \\
\hline$I_{B F}$ & 125 & 0.01 & 0.65 & $20,431.33$ & 0.00 \\
\hline$I_{B G}$ & 6,121 & 0.00 & 27.39 & $20,431.33$ & 0.00 \\
\hline $\mathrm{I}_{\mathrm{BH}}$ & 428 & 0.00 & 1.65 & $20,431.33$ & 0.00 \\
\hline $\mathrm{I}_{\mathrm{BI}}$ & 2,143 & 0.00 & 5.96 & $20,431.33$ & 0.00 \\
\hline $\mathrm{I}_{\mathrm{BJ}}$ & 695 & 0.00 & 1.50 & $20,431.33$ & 0.00 \\
\hline $\mathrm{I}_{\mathrm{BK}}$ & 5,380 & 0.00 & 10.34 & $20,431.33$ & 0.00 \\
\hline $\mathrm{I}_{\mathrm{BL}}$ & 34,550 & 0.00 & 69.81 & $20,431.33$ & 0.00 \\
\hline$I_{\mathrm{BM}}$ & 7,715 & 0.00 & 13.47 & $20,431.33$ & 0.00 \\
\hline $\mathrm{I}_{\mathrm{CA}}$ & 217,489 & 0.02 & $3,630.28$ & $21,471.39$ & 0.17 \\
\hline $\mathrm{I}_{\mathrm{CB}}$ & 3,991 & 0.02 & 95.26 & $21,471.39$ & 0.00 \\
\hline $\mathrm{I}_{\mathrm{CC}}$ & 8,772 & 2.00 & $17,544.00$ & $21,471.39$ & 0.82 \\
\hline $\mathrm{I}_{\mathrm{CD}}$ & 1,554 & 0.03 & 41.35 & $21,471.39$ & 0.00 \\
\hline $\mathrm{I}_{\mathrm{CE}}$ & 3,121 & 0.01 & 20.01 & $21,471.39$ & 0.00 \\
\hline $\mathrm{I}_{\mathrm{CF}}$ & 125 & 0.01 & 0.84 & $21,471.39$ & 0.00 \\
\hline $\mathrm{I}_{\mathrm{CG}}$ & 6,121 & 0.01 & 33.72 & $21,471.39$ & 0.00 \\
\hline $\mathrm{I}_{\mathrm{CH}}$ & 428 & 0.00 & 1.97 & $21,471.39$ & 0.00 \\
\hline $\mathrm{I}_{\mathrm{CI}}$ & 2,143 & 0.00 & 6.74 & $21,471.39$ & 0.00 \\
\hline $\mathrm{I}_{\mathrm{CJ}}$ & 695 & 0.00 & 1.64 & $21,471.39$ & 0.00 \\
\hline $\mathrm{I}_{\mathrm{CK}}$ & 5,380 & 0.00 & 11.25 & $21,471.39$ & 0.00 \\
\hline $\mathrm{I}_{\mathrm{CL}}$ & 34,550 & 0.00 & 69.81 & $21,471.39$ & 0.00 \\
\hline $\mathrm{I}_{\mathrm{CM}}$ & 7,715 & 0.00 & 14.53 & $21,471.39$ & 0.00 \\
\hline
\end{tabular}

Appendix Table A.1 Accessibility Index Pairs from raw job figures for half mile buffer. 


\begin{tabular}{|c|c|c|c|c|c|}
\hline Accessibility Index Pairs & $\overline{A_{j}}$ & $F_{i j}$ & $\mathrm{~A}_{\mathrm{j}} \mathrm{F}_{\mathrm{ij}}$ & $\sum \mathrm{A}_{\mathrm{k}} * \mathrm{~F}_{\mathrm{ik}}$ & $\mathrm{I}_{\mathrm{ij}}=\left(\mathrm{A}_{\mathrm{j}} * \mathrm{~F}_{\mathrm{ij}} /\left(\Sigma \mathrm{A}_{\mathrm{k}} * \mathrm{~F}_{\mathrm{ik}}\right)\right)$ \\
\hline $\mathrm{I}_{\mathrm{DA}}$ & 217,489 & 0.01 & $2,230.83$ & $5,806.83$ & 0.38 \\
\hline $\mathrm{I}_{\mathrm{DB}}$ & 3,991 & 0.01 & 50.21 & $5,806.83$ & 0.01 \\
\hline $\mathrm{I}_{\mathrm{DC}}$ & 8,772 & 0.03 & 233.40 & $5,806.83$ & 0.04 \\
\hline$I_{D D}$ & 1,554 & 2.00 & $3,108.00$ & $5,806.83$ & 0.54 \\
\hline $\mathrm{I}_{\mathrm{DE}}$ & 3,121 & 0.01 & 26.36 & $5,806.83$ & 0.00 \\
\hline $\mathrm{I}_{\mathrm{DF}}$ & 125 & 0.01 & 1.12 & $5,806.83$ & 0.00 \\
\hline$I_{D G}$ & 6,121 & 0.01 & 42.52 & $5,806.83$ & 0.01 \\
\hline $\mathrm{I}_{\mathrm{DH}}$ & 428 & 0.00 & 1.54 & $5,806.83$ & 0.00 \\
\hline $\mathrm{I}_{\mathrm{DI}}$ & 2,143 & 0.00 & 7.65 & $5,806.83$ & 0.00 \\
\hline $\mathrm{I}_{\mathrm{DJ}}$ & 695 & 0.00 & 1.80 & $5,806.83$ & 0.00 \\
\hline$\overline{I_{D K}}$ & 5,380 & 0.00 & 12.21 & $5,806.83$ & 0.00 \\
\hline $\mathrm{I}_{\mathrm{DL}}$ & 34,550 & 0.00 & 75.55 & $5,806.83$ & 0.01 \\
\hline $\mathrm{I}_{\mathrm{DM}}$ & 7,715 & 0.00 & 15.64 & $5,806.83$ & 0.00 \\
\hline $\mathrm{I}_{\mathrm{EA}}$ & 217,489 & 0.00 & $1,007.42$ & $7,572.66$ & 0.13 \\
\hline $\mathrm{I}_{\mathrm{EB}}$ & 3,991 & 0.01 & 20.17 & $7,572.66$ & 0.00 \\
\hline $\mathrm{I}_{\mathrm{EC}}$ & 8,772 & 0.01 & 56.24 & $7,572.66$ & 0.01 \\
\hline $\mathrm{I}_{\mathrm{ED}}$ & 1,554 & 0.01 & 13.13 & $7,572.66$ & 0.00 \\
\hline $\mathrm{I}_{\mathrm{EE}}$ & 3,121 & 2.00 & $6,242.00$ & $7,572.66$ & 0.82 \\
\hline $\mathrm{I}_{\mathrm{EF}}$ & 125 & 0.03 & 3.48 & $7,572.66$ & 0.00 \\
\hline $\mathrm{I}_{\mathrm{EG}}$ & 6,121 & 0.01 & 89.65 & $7,572.66$ & 0.01 \\
\hline $\mathrm{I}_{\mathrm{EH}}$ & 428 & 0.01 & 4.10 & $7,572.66$ & 0.00 \\
\hline $\mathrm{I}_{\mathrm{EI}}$ & 2,143 & 0.00 & 10.48 & $7,572.66$ & 0.00 \\
\hline $\mathrm{I}_{\mathrm{EJ}}$ & 695 & 0.00 & 2.24 & $7,572.66$ & 0.00 \\
\hline$\overline{\mathrm{I}_{\mathrm{EK}}}$ & 5,380 & 0.00 & 14.74 & $7,572.66$ & 0.00 \\
\hline $\mathrm{I}_{\mathrm{EL}}$ & 34,550 & 0.00 & 90.53 & $7,572.66$ & 0.01 \\
\hline $\mathrm{I}_{\mathrm{EM}}$ & 7,715 & 0.00 & 18.47 & $7,572.66$ & 0.00 \\
\hline$\overline{\mathrm{I}_{\mathrm{FA}}}$ & 217,489 & 0.00 & $1,040.33$ & $1,817.85$ & 0.57 \\
\hline $\mathrm{I}_{\mathrm{FB}}$ & 3,991 & 0.01 & 20.89 & $1,817.85$ & 0.01 \\
\hline $\mathrm{I}_{\mathrm{FC}}$ & 8,772 & 0.01 & 58.81 & $1,817.85$ & 0.03 \\
\hline $\mathrm{I}_{\mathrm{FD}}$ & 1,554 & 0.01 & 13.93 & $1,817.85$ & 0.01 \\
\hline $\mathrm{I}_{\mathrm{FE}}$ & 3,121 & 0.03 & 86.99 & $1,817.85$ & 0.05 \\
\hline $\mathrm{I}_{\mathrm{FF}}$ & 125 & 2.00 & 250.00 & $1,817.85$ & 0.14 \\
\hline $\mathrm{I}_{\mathrm{FG}}$ & 6,121 & 0.03 & 188.92 & $1,817.85$ & 0.10 \\
\hline $\mathrm{I}_{\mathrm{FH}}$ & 428 & 0.01 & 6.25 & $1,817.85$ & 0.00 \\
\hline $\mathrm{I}_{\mathrm{FI}}$ & 2,143 & 0.01 & 12.71 & $1,817.85$ & 0.01 \\
\hline $\mathrm{I}_{\mathrm{FJ}}$ & 695 & 0.00 & 2.54 & $1,817.85$ & 0.00 \\
\hline $\mathrm{I}_{\mathrm{FK}}$ & 5,380 & 0.00 & 16.34 & $1,817.85$ & 0.01 \\
\hline $\mathrm{I}_{\mathrm{FL}}$ & 34,550 & 0.00 & 99.93 & $1,817.85$ & 0.05 \\
\hline $\mathrm{I}_{\mathrm{FM}}$ & 7,715 & 0.00 & 20.21 & $1,817.85$ & 0.01 \\
\hline
\end{tabular}

Appendix Table A.2 Accessibility Index Pairs from raw job figures for half mile buffer (contd.). 


\begin{tabular}{|c|c|c|c|c|c|}
\hline Accessibility Index Pairs & $\overline{A_{j}}$ & $F_{i j}$ & $\overline{\mathrm{A}_{\mathrm{j}} * \mathrm{~F}_{\mathrm{ij}}}$ & $\Sigma \mathrm{A}_{\mathrm{k}} * \mathrm{~F}_{\mathrm{ik}}$ & $\mathrm{I}_{\mathrm{ij}}=\left(\mathrm{A}_{\mathrm{j}} * \mathrm{~F}_{\mathrm{ij}} /\left(\Sigma \mathrm{A}_{\mathrm{k}} * \mathrm{~F}_{\mathrm{ik}}\right)\right)$ \\
\hline $\mathrm{I}_{\mathrm{GA}}$ & 217,489 & 0.00 & 900.73 & $13,450.23$ & 0.07 \\
\hline $\mathrm{I}_{\mathrm{GB}}$ & 3,991 & 0.00 & 17.86 & $13,450.23$ & 0.00 \\
\hline $\mathrm{I}_{\mathrm{GC}}$ & 8,772 & 0.01 & 48.32 & $13,450.23$ & 0.00 \\
\hline $\mathrm{I}_{\mathrm{GD}}$ & 1,554 & 0.01 & 10.79 & $13,450.23$ & 0.00 \\
\hline $\mathrm{I}_{\mathrm{GE}}$ & 3,121 & 0.01 & 45.71 & $13,450.23$ & 0.00 \\
\hline $\mathrm{I}_{\mathrm{GF}}$ & 125 & 0.03 & 3.86 & $13,450.23$ & 0.00 \\
\hline $\mathrm{I}_{\mathrm{GG}}$ & 6,121 & 2.00 & $12,242.00$ & $13,450.23$ & 0.91 \\
\hline $\mathrm{I}_{\mathrm{GH}}$ & 428 & 0.03 & 11.88 & $13,450.23$ & 0.00 \\
\hline $\mathrm{I}_{\mathrm{GI}}$ & 2,143 & 0.01 & 15.73 & $13,450.23$ & 0.00 \\
\hline $\mathrm{I}_{\mathrm{GJ}}$ & 695 & 0.00 & 2.88 & $13,450.23$ & 0.00 \\
\hline $\mathrm{I}_{\mathrm{GK}}$ & 5,380 & 0.00 & 18.13 & $13,450.23$ & 0.00 \\
\hline $\mathrm{I}_{\mathrm{GL}}$ & 34,550 & 0.00 & 110.26 & $13,450.23$ & 0.01 \\
\hline $\mathrm{I}_{\mathrm{GM}}$ & 7,715 & 0.00 & 22.08 & $13,450.23$ & 0.00 \\
\hline $\mathrm{I}_{\mathrm{HA}}$ & 217,489 & 0.00 & 783.77 & $2,100.32$ & 0.37 \\
\hline $\mathrm{I}_{\mathrm{HB}}$ & 3,991 & 0.00 & 15.38 & $2,100.32$ & 0.01 \\
\hline $\mathrm{I}_{\mathrm{HC}}$ & 8,772 & 0.00 & 40.32 & $2,100.32$ & 0.02 \\
\hline $\mathrm{I}_{\mathrm{HD}}$ & 1,554 & 0.01 & 8.63 & $2,100.32$ & 0.00 \\
\hline $\mathrm{I}_{\mathrm{HE}}$ & 3,121 & 0.01 & 29.92 & $2,100.32$ & 0.01 \\
\hline $\mathrm{I}_{\mathrm{HF}}$ & 125 & 0.01 & 1.83 & $2,100.32$ & 0.00 \\
\hline $\mathrm{I}_{\mathrm{HG}}$ & 6,121 & 0.03 & 169.86 & $2,100.32$ & 0.08 \\
\hline $\mathrm{I}_{\mathrm{HH}}$ & 428 & 2.00 & 856.00 & $2,100.32$ & 0.41 \\
\hline $\mathrm{I}_{\mathrm{HI}}$ & 2,143 & 0.01 & 21.39 & $2,100.32$ & 0.01 \\
\hline $\mathrm{I}_{\mathrm{HJ}}$ & 695 & 0.00 & 3.38 & $2,100.32$ & 0.00 \\
\hline $\mathrm{I}_{\mathrm{HK}}$ & 5,380 & 0.00 & 20.63 & $2,100.32$ & 0.01 \\
\hline $\mathrm{I}_{\mathrm{HL}}$ & 34,550 & 0.00 & 124.59 & $2,100.32$ & 0.06 \\
\hline $\mathrm{I}_{\mathrm{HM}}$ & 7,715 & 0.00 & 24.62 & $2,100.32$ & 0.01 \\
\hline $\mathrm{IIA}_{\mathrm{IA}}$ & 217,489 & 0.00 & 575.85 & $5,242.68$ & 0.11 \\
\hline $\mathrm{I}_{\mathrm{IB}}$ & 3,991 & 0.00 & 11.10 & $5,242.68$ & 0.00 \\
\hline $\mathrm{IIC}_{\mathrm{IC}}$ & 8,772 & 0.00 & 27.60 & $5,242.68$ & 0.01 \\
\hline $\mathrm{I}_{\mathrm{ID}}$ & 1,554 & 0.00 & 5.55 & $5,242.68$ & 0.00 \\
\hline $\mathrm{I}_{\mathrm{IE}}$ & 3,121 & 0.00 & 15.26 & $5,242.68$ & 0.00 \\
\hline $\mathrm{I}_{\mathrm{IF}}$ & 125 & 0.01 & 0.74 & $5,242.68$ & 0.00 \\
\hline $\mathrm{I}_{\mathrm{IG}}$ & 6,121 & 0.01 & 44.93 & $5,242.68$ & 0.01 \\
\hline $\mathrm{I}_{\mathrm{IH}}$ & 428 & 0.01 & 4.27 & $5,242.68$ & 0.00 \\
\hline $\mathrm{I}_{\mathrm{II}}$ & 2,143 & 2.00 & $4,286.00$ & $5,242.68$ & 0.82 \\
\hline $\mathrm{I}_{\mathrm{IJ}}$ & 695 & 0.01 & 6.61 & $5,242.68$ & 0.00 \\
\hline $\mathrm{I}_{\mathrm{IK}}$ & 5,380 & 0.01 & 33.51 & $5,242.68$ & 0.01 \\
\hline $\mathrm{I}_{\mathrm{IL}}$ & 34,550 & 0.01 & 195.07 & $5,242.68$ & 0.04 \\
\hline $\mathrm{I}_{\mathrm{IM}}$ & 7,715 & 0.00 & 36.19 & $5,242.68$ & 0.01 \\
\hline
\end{tabular}

Appendix Table A.3 Accessibility Index Pairs from raw job figures for half mile buffer (contd.). 


\begin{tabular}{|c|c|c|c|c|c|}
\hline Accessibility Index Pairs & $A_{j}$ & $F_{i j}$ & $\mathrm{~A}_{\mathrm{j}} * \mathrm{~F}_{\mathrm{ij}}$ & $\Sigma \mathrm{A}_{\mathrm{k}} * \mathrm{~F}_{\mathrm{ik}}$ & $\mathrm{I}_{\mathrm{ij}}=\left(\mathrm{A}_{\mathrm{j}} * \mathrm{~F}_{\mathrm{ij}} /\left(\Sigma \mathrm{A}_{\mathrm{k}} * \mathrm{~F}_{\mathrm{ik}}\right)\right)$ \\
\hline $\mathrm{I}_{\mathrm{JA}}$ & 217,489 & 0.00 & 450.40 & $2,581.11$ & 0.17 \\
\hline $\mathrm{I}_{\mathrm{JB}}$ & 3,991 & 0.00 & 8.59 & $2,581.11$ & 0.00 \\
\hline $\mathrm{I}_{\mathrm{JC}}$ & 8,772 & 0.00 & 20.74 & $2,581.11$ & 0.01 \\
\hline $\mathrm{I}_{\mathrm{JD}}$ & 1,554 & 0.00 & 4.03 & $2,581.11$ & 0.00 \\
\hline $\mathrm{I}_{\mathrm{JE}}$ & 3,121 & 0.00 & 10.08 & $2,581.11$ & 0.00 \\
\hline $\mathrm{I}_{\mathrm{JF}}$ & 125 & 0.00 & 0.46 & $2,581.11$ & 0.00 \\
\hline $\mathrm{I}_{\mathrm{JG}}$ & 6,121 & 0.00 & 25.35 & $2,581.11$ & 0.01 \\
\hline $\mathrm{I}_{\mathrm{JH}}$ & 428 & 0.00 & 2.08 & $2,581.11$ & 0.00 \\
\hline $\mathrm{I}_{\mathrm{JI}}$ & 2,143 & 0.01 & 20.37 & $2,581.11$ & 0.01 \\
\hline $\mathrm{I}_{\mathrm{JJ}}$ & 695 & 2.00 & $1,390.00$ & $2,581.11$ & 0.54 \\
\hline $\mathrm{I}_{\mathrm{JK}}$ & 5,380 & 0.02 & 97.20 & $2,581.11$ & 0.04 \\
\hline $\mathrm{I}_{\mathrm{JL}}$ & 34,550 & 0.01 & 480.39 & $2,581.11$ & 0.19 \\
\hline$I_{J M}$ & 7,715 & 0.01 & 71.43 & $2,581.11$ & 0.03 \\
\hline $\mathrm{I}_{\mathrm{KA}}$ & 217,489 & 0.00 & 404.08 & $13,407.24$ & 0.03 \\
\hline $\mathrm{I}_{\mathrm{KB}}$ & 3,991 & 0.00 & 7.67 & $13,407.24$ & 0.00 \\
\hline $\mathrm{I}_{\mathrm{KC}}$ & 8,772 & 0.00 & 18.34 & $13,407.24$ & 0.00 \\
\hline $\mathrm{I}_{\mathrm{KD}}$ & 1,554 & 0.00 & 3.53 & $13,407.24$ & 0.00 \\
\hline $\mathrm{I}_{\mathrm{KE}}$ & 3,121 & 0.00 & 8.55 & $13,407.24$ & 0.00 \\
\hline $\mathrm{I}_{\mathrm{KF}}$ & 125 & 0.00 & 0.38 & $13,407.24$ & 0.00 \\
\hline $\mathrm{I}_{\mathrm{KG}}$ & 6,121 & 0.00 & 20.63 & $13,407.24$ & 0.00 \\
\hline $\mathrm{I}_{\mathrm{KH}}$ & 428 & 0.00 & 1.64 & $13,407.24$ & 0.00 \\
\hline $\mathrm{I}_{\mathrm{KI}}$ & 2,143 & 0.01 & 13.35 & $13,407.24$ & 0.00 \\
\hline $\mathrm{I}_{\mathrm{KJ}}$ & 695 & 0.02 & 12.56 & $13,407.24$ & 0.00 \\
\hline $\mathrm{I}_{\mathrm{KK}}$ & 5,380 & 2.00 & $10,760.00$ & $13,407.24$ & 0.80 \\
\hline $\mathrm{I}_{\mathrm{KL}}$ & 34,550 & 0.06 & $2,085.09$ & $13,407.24$ & 0.16 \\
\hline $\mathrm{I}_{\mathrm{KM}}$ & 7,715 & 0.01 & 71.43 & $13,407.24$ & 0.01 \\
\hline $\mathrm{I}_{\mathrm{LA}}$ & 217,489 & 0.00 & 392.01 & $70,110.41$ & 0.01 \\
\hline $\mathrm{I}_{\mathrm{LB}}$ & 3,991 & 0.00 & 7.43 & $70,110.41$ & 0.00 \\
\hline $\mathrm{I}_{\mathrm{LC}}$ & 8,772 & 0.00 & 17.73 & $70,110.41$ & 0.00 \\
\hline $\mathrm{I}_{\mathrm{LD}}$ & 1,554 & 0.00 & 3.40 & $70,110.41$ & 0.00 \\
\hline $\mathrm{I}_{\mathrm{LE}}$ & 3,121 & 0.00 & 8.18 & $70,110.41$ & 0.00 \\
\hline $\mathrm{I}_{\mathrm{LF}}$ & 125 & 0.00 & 0.36 & $70,110.41$ & 0.00 \\
\hline $\mathrm{I}_{\mathrm{LG}}$ & 6,121 & 0.00 & 19.53 & $70,110.41$ & 0.00 \\
\hline $\mathrm{I}_{\mathrm{LH}}$ & 428 & 0.00 & 1.54 & $70,110.41$ & 0.00 \\
\hline $\mathrm{I}_{\mathrm{LI}}$ & 2,143 & 0.01 & 12.10 & $70,110.41$ & 0.00 \\
\hline $\mathrm{I}_{\mathrm{LJ}}$ & 695 & 0.01 & 9.66 & $70,110.41$ & 0.00 \\
\hline $\mathrm{I}_{\mathrm{LK}}$ & 5,380 & 0.06 & 324.68 & $70,110.41$ & 0.00 \\
\hline $\mathrm{I}_{\mathrm{LL}}$ & 34,550 & 2.00 & $69,100.00$ & $70,110.41$ & 0.99 \\
\hline $\mathrm{I}_{\mathrm{LM}}$ & 7,715 & 0.03 & 213.78 & $70,110.41$ & 0.00 \\
\hline
\end{tabular}

Appendix Table A.4 Accessibility Index Pairs from raw job figures for half mile buffer (contd.). 


\begin{tabular}{|c|r|c|r|c|r|}
\hline Accessibility Index Pairs & \multicolumn{1}{|c|}{$\mathrm{A}_{\mathrm{j}}$} & $\mathrm{F}_{\mathrm{ij}}$ & $\mathrm{A}_{\mathrm{j}}{ }^{*} \mathrm{~F}_{\mathrm{ij}}$ & $\sum \mathrm{A}_{\mathrm{k}}{ }^{*} \mathrm{~F}_{\mathrm{ik}}$ & $\mathrm{I}_{\mathrm{ij}}=\left(\mathrm{A}_{\mathrm{j}}{ }^{*} \mathrm{~F}_{\mathrm{ij}} /\left(\sum \mathrm{A}_{\mathrm{k}}{ }^{*} \mathrm{~F}_{\mathrm{ik}}\right)\right)$ \\
\hline $\mathrm{I}_{\mathrm{MA}}$ & 217,489 & 0.00 & 368.07 & $16,927.39$ & 0.02 \\
\hline $\mathrm{I}_{\mathrm{MB}}$ & 3,991 & 0.00 & 6.97 & $16,927.39$ & 0.00 \\
\hline $\mathrm{I}_{\mathrm{MC}}$ & 8,772 & 0.00 & 16.52 & $16,927.39$ & 0.00 \\
\hline $\mathrm{I}_{\mathrm{MD}}$ & 1,554 & 0.00 & 3.15 & $16,927.39$ & 0.00 \\
\hline $\mathrm{I}_{\mathrm{ME}}$ & 3,121 & 0.00 & 7.47 & $16,927.39$ & 0.00 \\
\hline $\mathrm{I}_{\mathrm{MF}}$ & 125 & 0.00 & 0.33 & $16,927.39$ & 0.00 \\
\hline $\mathrm{I}_{\mathrm{MG}}$ & 6,121 & 0.00 & 17.52 & $16,927.39$ & 0.00 \\
\hline $\mathrm{I}_{\mathrm{MH}}$ & 428 & 0.00 & 1.37 & $16,927.39$ & 0.00 \\
\hline $\mathrm{I}_{\mathrm{MI}}$ & 2,143 & 0.00 & 10.05 & $16,927.39$ & 0.00 \\
\hline $\mathrm{I}_{\mathrm{MJ}}$ & 695 & 0.01 & 6.43 & $16,927.39$ & 0.01 \\
\hline $\mathrm{I}_{\mathrm{MK}}$ & 5,380 & 0.02 & 102.17 & $16,927.39$ & 0.06 \\
\hline $\mathrm{I}_{\mathrm{ML}}$ & 34,550 & 0.03 & 957.35 & $16,927.39$ & 0.91 \\
\hline $\mathrm{I}_{\mathrm{MM}}$ & 7,715 & 2.00 & $15,430.00$ & $16,927.39$ & \\
\hline
\end{tabular}

Appendix Table A.5 Accessibility Index Pairs from raw job figures for half mile buffer (contd.). 


\begin{tabular}{|c|c|c|c|c|c|}
\hline Accessibility Index Pairs & $\overline{A_{j}}$ & $F_{i j}$ & $\overline{\mathrm{A}_{\mathrm{j}} * \mathrm{~F}_{\mathrm{ij}}}$ & $\Sigma \mathrm{A}_{\mathrm{k}} * \mathrm{~F}_{\mathrm{ik}}$ & $\mathrm{I}_{\mathrm{ij}}=\left(\mathrm{A}_{\mathrm{j}} * \mathrm{~F}_{\mathrm{ij}} /\left(\Sigma \mathrm{A}_{\mathrm{k}} * \mathrm{~F}_{\mathrm{ik}}\right)\right)$ \\
\hline $\mathrm{I}_{\mathrm{AA}}$ & 18,531 & 2.00 & $37,062.00$ & $38,213.16$ & 0.97 \\
\hline $\mathrm{I}_{\mathrm{AB}}$ & 10,526 & 0.06 & 584.35 & $38,213.16$ & 0.02 \\
\hline$\overline{\mathrm{I}_{\mathrm{AC}}}$ & 9,921 & 0.02 & 165.60 & $38,213.16$ & 0.00 \\
\hline $\mathrm{I}_{\mathrm{AD}}$ & 11,670 & 0.01 & 119.70 & $38,213.16$ & 0.00 \\
\hline $\mathrm{I}_{\mathrm{AE}}$ & 15,392 & 0.00 & 71.30 & $38,213.16$ & 0.00 \\
\hline $\mathrm{I}_{\mathrm{AF}}$ & 6,355 & 0.00 & 30.40 & $38,213.16$ & 0.00 \\
\hline $\mathrm{I}_{\mathrm{AG}}$ & 8,578 & 0.00 & 35.53 & $38,213.16$ & 0.00 \\
\hline $\mathrm{I}_{\mathrm{AH}}$ & 4,283 & 0.00 & 15.43 & $38,213.16$ & 0.00 \\
\hline $\mathrm{I}_{\mathrm{AI}}$ & 13,417 & 0.00 & 35.52 & $38,213.16$ & 0.00 \\
\hline $\mathrm{I}_{\mathrm{AJ}}$ & 11,761 & 0.00 & 24.36 & $38,213.16$ & 0.00 \\
\hline $\mathrm{I}_{\mathrm{AK}}$ & 11,656 & 0.00 & 21.66 & $38,213.16$ & 0.00 \\
\hline $\mathrm{I}_{\mathrm{AL}}$ & 20,263 & 0.00 & 36.52 & $38,213.16$ & 0.00 \\
\hline $\mathrm{I}_{\mathrm{AM}}$ & 6,377 & 0.00 & 10.79 & $38,213.16$ & 0.00 \\
\hline $\mathrm{I}_{\mathrm{BA}}$ & 18,531 & 0.06 & $1,028.74$ & $22,767.41$ & 0.05 \\
\hline $\mathrm{I}_{\mathrm{BB}}$ & 10,526 & 2.00 & $21,052.00$ & $22,767.41$ & 0.92 \\
\hline $\mathrm{I}_{\mathrm{BC}}$ & 9,921 & 0.02 & 236.80 & $22,767.41$ & 0.01 \\
\hline$I_{B D}$ & 11,670 & 0.01 & 146.83 & $22,767.41$ & 0.01 \\
\hline $\mathrm{I}_{\mathrm{BE}}$ & 15,392 & 0.01 & 77.79 & $22,767.41$ & 0.00 \\
\hline $\mathrm{I}_{\mathrm{BF}}$ & 6,355 & 0.01 & 33.26 & $22,767.41$ & 0.00 \\
\hline $\mathrm{I}_{\mathrm{BG}}$ & 8,578 & 0.00 & 38.39 & $22,767.41$ & 0.00 \\
\hline $\mathrm{I}_{\mathrm{BH}}$ & 4,283 & 0.00 & 16.51 & $22,767.41$ & 0.00 \\
\hline $\mathrm{I}_{\mathrm{BI}}$ & 13,417 & 0.00 & 37.30 & $22,767.41$ & 0.00 \\
\hline $\mathrm{I}_{\mathrm{BJ}}$ & 11,761 & 0.00 & 25.30 & $22,767.41$ & 0.00 \\
\hline $\mathrm{I}_{\mathrm{BK}}$ & 11,656 & 0.00 & 22.41 & $22,767.41$ & 0.00 \\
\hline $\mathrm{I}_{\mathrm{BL}}$ & 20,263 & 0.00 & 40.94 & $22,767.41$ & 0.00 \\
\hline $\mathrm{I}_{\mathrm{BM}}$ & 6,377 & 0.00 & 11.13 & $22,767.41$ & 0.00 \\
\hline $\mathrm{I}_{\mathrm{CA}}$ & 18,531 & 0.02 & 309.32 & $21,068.64$ & 0.01 \\
\hline $\mathrm{I}_{\mathrm{CB}}$ & 10,526 & 0.02 & 251.24 & $21,068.64$ & 0.01 \\
\hline $\mathrm{I}_{\mathrm{CC}}$ & 9,921 & 2.00 & $19,842.00$ & $21,068.64$ & 0.94 \\
\hline $\mathrm{I}_{\mathrm{CD}}$ & 11,670 & 0.03 & 310.51 & $21,068.64$ & 0.01 \\
\hline $\mathrm{I}_{\mathrm{CE}}$ & 15,392 & 0.01 & 98.68 & $21,068.64$ & 0.00 \\
\hline$I_{C F}$ & 6,355 & 0.01 & 42.61 & $21,068.64$ & 0.00 \\
\hline $\mathrm{I}_{\mathrm{CG}}$ & 8,578 & 0.01 & 47.25 & $21,068.64$ & 0.00 \\
\hline $\mathrm{I}_{\mathrm{CH}}$ & 4,283 & 0.00 & 19.68 & $21,068.64$ & 0.00 \\
\hline $\mathrm{I}_{\mathrm{CI}}$ & 13,417 & 0.00 & 42.22 & $21,068.64$ & 0.00 \\
\hline $\mathrm{I}_{\mathrm{CJ}}$ & 11,761 & 0.00 & 27.81 & $21,068.64$ & 0.00 \\
\hline $\mathrm{I}_{\mathrm{CK}}$ & 11,656 & 0.00 & 24.37 & $21,068.64$ & 0.00 \\
\hline $\mathrm{I}_{\mathrm{CL}}$ & 20,263 & 0.00 & 40.94 & $21,068.64$ & 0.00 \\
\hline $\mathrm{I}_{\mathrm{CM}}$ & 6,377 & 0.00 & 12.01 & $21,068.64$ & 0.00 \\
\hline
\end{tabular}

Appendix Table A.6 Accessibility Index Pairs from raw population figures for half mile buffer. 


\begin{tabular}{|c|c|c|c|c|c|}
\hline Accessibility Index Pairs & $\overline{A_{j}}$ & $F_{i j}$ & $\overline{\mathrm{A}_{\mathrm{j}} * \mathrm{~F}_{\mathrm{ij}}}$ & $\Sigma \mathrm{A}_{\mathrm{k}} * \mathrm{~F}_{\mathrm{ik}}$ & $\mathrm{I}_{\mathrm{ij}}=\left(\mathrm{A}_{\mathrm{j}} * \mathrm{~F}_{\mathrm{ij}} /\left(\Sigma \mathrm{A}_{\mathrm{k}} * \mathrm{~F}_{\mathrm{ik}}\right)\right)$ \\
\hline $\mathrm{I}_{\mathrm{DA}}$ & 18,531 & 0.01 & 190.08 & $24,350.56$ & 0.01 \\
\hline $\mathrm{I}_{\mathrm{DB}}$ & 10,526 & 0.01 & 132.44 & $24,350.56$ & 0.01 \\
\hline $\mathrm{I}_{\mathrm{DC}}$ & 9,921 & 0.03 & 263.98 & $24,350.56$ & 0.01 \\
\hline $\mathrm{I}_{\mathrm{DD}}$ & 11,670 & 2.00 & $23,340.00$ & $24,350.56$ & 0.96 \\
\hline $\mathrm{I}_{\mathrm{DE}}$ & 15,392 & 0.01 & 130.01 & $24,350.56$ & 0.01 \\
\hline $\mathrm{I}_{\mathrm{DF}}$ & 6,355 & 0.01 & 56.96 & $24,350.56$ & 0.00 \\
\hline $\mathrm{I}_{\mathrm{DG}}$ & 8,578 & 0.01 & 59.58 & $24,350.56$ & 0.00 \\
\hline $\mathrm{I}_{\mathrm{DH}}$ & 4,283 & 0.00 & 15.43 & $24,350.56$ & 0.00 \\
\hline $\mathrm{I}_{\mathrm{DI}}$ & 13,417 & 0.00 & 47.89 & $24,350.56$ & 0.00 \\
\hline $\mathrm{I}_{\mathrm{DJ}}$ & 11,761 & 0.00 & 30.52 & $24,350.56$ & 0.00 \\
\hline $\mathrm{I}_{\mathrm{DK}}$ & 11,656 & 0.00 & 26.45 & $24,350.56$ & 0.00 \\
\hline $\mathrm{I}_{\mathrm{DL}}$ & 20,263 & 0.00 & 44.31 & $24,350.56$ & 0.00 \\
\hline $\mathrm{I}_{\mathrm{DM}}$ & 6,377 & 0.00 & 12.92 & $24,350.56$ & 0.00 \\
\hline $\mathrm{I}_{\mathrm{EA}}$ & 18,531 & 0.00 & 85.84 & $31,632.90$ & 0.00 \\
\hline $\mathrm{I}_{\mathrm{EB}}$ & 10,526 & 0.01 & 53.20 & $31,632.90$ & 0.00 \\
\hline $\mathrm{I}_{\mathrm{EC}}$ & 9,921 & 0.01 & 63.61 & $31,632.90$ & 0.00 \\
\hline $\mathrm{I}_{\mathrm{ED}}$ & 11,670 & 0.01 & 98.57 & $31,632.90$ & 0.00 \\
\hline $\mathrm{I}_{\mathrm{EE}}$ & 15,392 & 2.00 & $30,784.00$ & $31,632.90$ & 0.97 \\
\hline $\mathrm{I}_{\mathrm{EF}}$ & 6,355 & 0.03 & 177.13 & $31,632.90$ & 0.01 \\
\hline $\mathrm{I}_{\mathrm{EG}}$ & 8,578 & 0.01 & 125.63 & $31,632.90$ & 0.00 \\
\hline $\mathrm{I}_{\mathrm{EH}}$ & 4,283 & 0.01 & 41.06 & $31,632.90$ & 0.00 \\
\hline $\mathrm{I}_{\mathrm{EI}}$ & 13,417 & 0.00 & 65.61 & $31,632.90$ & 0.00 \\
\hline $\mathrm{I}_{\mathrm{EJ}}$ & 11,761 & 0.00 & 37.98 & $31,632.90$ & 0.00 \\
\hline$\overline{\mathrm{I}_{\mathrm{EK}}}$ & 11,656 & 0.00 & 31.93 & $31,632.90$ & 0.00 \\
\hline $\mathrm{I}_{\mathrm{EL}}$ & 20,263 & 0.00 & 53.10 & $31,632.90$ & 0.00 \\
\hline $\mathrm{I}_{\mathrm{EM}}$ & 6,377 & 0.00 & 15.27 & $31,632.90$ & 0.00 \\
\hline$\overline{\mathrm{I}_{\mathrm{FA}}}$ & 18,531 & 0.00 & 88.64 & $14,014.44$ & 0.01 \\
\hline $\mathrm{I}_{\mathrm{FB}}$ & 10,526 & 0.01 & 55.10 & $14,014.44$ & 0.00 \\
\hline $\mathrm{I}_{\mathrm{FC}}$ & 9,921 & 0.01 & 66.52 & $14,014.44$ & 0.00 \\
\hline $\mathrm{I}_{\mathrm{FD}}$ & 11,670 & 0.01 & 104.60 & $14,014.44$ & 0.01 \\
\hline $\mathrm{I}_{\mathrm{FE}}$ & 15,392 & 0.03 & 429.01 & $14,014.44$ & 0.03 \\
\hline $\mathrm{I}_{\mathrm{FF}}$ & 6,355 & 2.00 & $12,710.00$ & $14,014.44$ & 0.91 \\
\hline $\mathrm{I}_{\mathrm{FG}}$ & 8,578 & 0.03 & 264.76 & $14,014.44$ & 0.02 \\
\hline $\mathrm{I}_{\mathrm{FH}}$ & 4,283 & 0.01 & 62.59 & $14,014.44$ & 0.00 \\
\hline $\mathrm{I}_{\mathrm{FI}}$ & 13,417 & 0.01 & 79.57 & $14,014.44$ & 0.01 \\
\hline $\mathrm{I}_{\mathrm{FJ}}$ & 11,761 & 0.00 & 42.95 & $14,014.44$ & 0.00 \\
\hline $\mathrm{I}_{\mathrm{FK}}$ & 11,656 & 0.00 & 35.41 & $14,014.44$ & 0.00 \\
\hline $\mathrm{I}_{\mathrm{FL}}$ & 20,263 & 0.00 & 58.61 & $14,014.44$ & 0.00 \\
\hline $\mathrm{I}_{\mathrm{FM}}$ & 6,377 & 0.00 & 16.70 & $14,014.44$ & 0.00 \\
\hline
\end{tabular}

Appendix Table A.7 Accessibility Index Pairs from raw population figures for half mile buffer (contd.). 


\begin{tabular}{|c|c|c|c|c|c|}
\hline Accessibility Index Pairs & $\overline{A_{j}}$ & $F_{i j}$ & $\overline{\mathrm{A}_{\mathrm{j}} * \mathrm{~F}_{\mathrm{ij}}}$ & $\Sigma \mathrm{A}_{\mathrm{k}} * \mathrm{~F}_{\mathrm{ik}}$ & $\mathrm{I}_{\mathrm{ij}}=\left(\mathrm{A}_{\mathrm{j}} * \mathrm{~F}_{\mathrm{ij}} /\left(\Sigma \mathrm{A}_{\mathrm{k}} * \mathrm{~F}_{\mathrm{ik}}\right)\right)$ \\
\hline $\mathrm{I}_{\mathrm{GA}}$ & 18,531 & 0.00 & 76.75 & $18,225.39$ & 0.00 \\
\hline $\mathrm{I}_{\mathrm{GB}}$ & 10,526 & 0.00 & 47.11 & $18,225.39$ & 0.00 \\
\hline $\mathrm{I}_{\mathrm{GC}}$ & 9,921 & 0.01 & 54.65 & $18,225.39$ & 0.00 \\
\hline $\mathrm{I}_{\mathrm{GD}}$ & 11,670 & 0.01 & 81.06 & $18,225.39$ & 0.00 \\
\hline $\mathrm{I}_{\mathrm{GE}}$ & 15,392 & 0.01 & 225.43 & $18,225.39$ & 0.01 \\
\hline $\mathrm{I}_{\mathrm{GF}}$ & 6,355 & 0.03 & 196.14 & $18,225.39$ & 0.01 \\
\hline $\mathrm{I}_{\mathrm{GG}}$ & 8,578 & 2.00 & $17,156.00$ & $18,225.39$ & 0.94 \\
\hline $\mathrm{I}_{\mathrm{GH}}$ & 4,283 & 0.03 & 118.86 & $18,225.39$ & 0.01 \\
\hline $\mathrm{I}_{\mathrm{GI}}$ & 13,417 & 0.01 & 98.49 & $18,225.39$ & 0.01 \\
\hline $\mathrm{I}_{\mathrm{GJ}}$ & 11,761 & 0.00 & 48.72 & $18,225.39$ & 0.00 \\
\hline $\mathrm{I}_{\mathrm{GK}}$ & 11,656 & 0.00 & 39.28 & $18,225.39$ & 0.00 \\
\hline $\mathrm{I}_{\mathrm{GL}}$ & 20,263 & 0.00 & 64.67 & $18,225.39$ & 0.00 \\
\hline $\mathrm{I}_{\mathrm{GM}}$ & 6,377 & 0.00 & 18.25 & $18,225.39$ & 0.00 \\
\hline $\mathrm{I}_{\mathrm{HA}}$ & 18,531 & 0.00 & 66.78 & $9,591.54$ & 0.01 \\
\hline $\mathrm{I}_{\mathrm{HB}}$ & 10,526 & 0.00 & 40.57 & $9,591.54$ & 0.00 \\
\hline$\overline{\mathrm{I}_{\mathrm{HC}}}$ & 9,921 & 0.00 & 45.60 & $9,591.54$ & 0.00 \\
\hline $\mathrm{I}_{\mathrm{HD}}$ & 11,670 & 0.01 & 64.83 & $9,591.54$ & 0.01 \\
\hline $\mathrm{I}_{\mathrm{HE}}$ & 15,392 & 0.01 & 147.56 & $9,591.54$ & 0.02 \\
\hline $\mathrm{I}_{\mathrm{HF}}$ & 6,355 & 0.01 & 92.86 & $9,591.54$ & 0.01 \\
\hline $\mathrm{I}_{\mathrm{HG}}$ & 8,578 & 0.03 & 238.05 & $9,591.54$ & 0.02 \\
\hline $\mathrm{I}_{\mathrm{HH}}$ & 4,283 & 2.00 & $8,566.00$ & $9,591.54$ & 0.89 \\
\hline $\mathrm{I}_{\mathrm{HI}}$ & 13,417 & 0.01 & 133.91 & $9,591.54$ & 0.01 \\
\hline $\mathrm{I}_{\mathrm{HJ}}$ & 11,761 & 0.00 & 57.26 & $9,591.54$ & 0.01 \\
\hline $\mathrm{I}_{\mathrm{HK}}$ & 11,656 & 0.00 & 44.70 & $9,591.54$ & 0.00 \\
\hline$\overline{I_{H L}}$ & 20,263 & 0.00 & 73.07 & $9,591.54$ & 0.01 \\
\hline $\mathrm{I}_{\mathrm{HM}}$ & 6,377 & 0.00 & 20.35 & $9,591.54$ & 0.00 \\
\hline $\mathrm{I}_{\mathrm{IA}}$ & 18,531 & 0.00 & 49.06 & $27,532.59$ & 0.00 \\
\hline $\mathrm{I}_{\mathrm{IB}}$ & 10,526 & 0.00 & 29.27 & $27,532.59$ & 0.00 \\
\hline $\mathrm{I}_{\mathrm{IC}}$ & 9,921 & 0.00 & 31.22 & $27,532.59$ & 0.00 \\
\hline $\mathrm{I}_{\mathrm{ID}}$ & 11,670 & 0.00 & 41.65 & $27,532.59$ & 0.00 \\
\hline $\mathrm{I}_{\mathrm{IE}}$ & 15,392 & 0.00 & 75.27 & $27,532.59$ & 0.00 \\
\hline $\mathrm{I}_{\mathrm{IF}}$ & 6,355 & 0.01 & 37.69 & $27,532.59$ & 0.00 \\
\hline $\mathrm{I}_{\mathrm{IG}}$ & 8,578 & 0.01 & 62.97 & $27,532.59$ & 0.00 \\
\hline $\mathrm{I}_{\mathrm{IH}}$ & 4,283 & 0.01 & 42.75 & $27,532.59$ & 0.00 \\
\hline $\mathrm{I}_{\text {II }}$ & 13,417 & 2.00 & $26,834.00$ & $27,532.59$ & 0.97 \\
\hline $\mathrm{I}_{\mathrm{IJ}}$ & 11,761 & 0.01 & 111.80 & $27,532.59$ & 0.00 \\
\hline $\mathrm{I}_{\mathrm{IK}}$ & 11,656 & 0.01 & 72.60 & $27,532.59$ & 0.00 \\
\hline $\mathrm{I}_{\mathrm{IL}}$ & 20,263 & 0.01 & 114.40 & $27,532.59$ & 0.00 \\
\hline $\mathrm{I}_{\mathrm{IM}}$ & 6,377 & 0.00 & 29.91 & $27,532.59$ & 0.00 \\
\hline
\end{tabular}

Appendix Table A.8 Accessibility Index Pairs from raw population figures for half mile buffer (contd.). 


\begin{tabular}{|c|c|c|c|c|c|}
\hline Accessibility Index Pairs & $\overline{A_{j}}$ & $F_{i j}$ & $\overline{\mathrm{A}_{\mathrm{j}} * \mathrm{~F}_{\mathrm{ij}}}$ & $\Sigma \mathrm{A}_{\mathrm{k}} * \mathrm{~F}_{\mathrm{ik}}$ & $\mathrm{I}_{\mathrm{ij}}=\left(\mathrm{A}_{\mathrm{j}} * \mathrm{~F}_{\mathrm{ij}} /\left(\Sigma \mathrm{A}_{\mathrm{k}} * \mathrm{~F}_{\mathrm{ik}}\right)\right)$ \\
\hline $\mathrm{I}_{\mathrm{JA}}$ & 18,531 & 0.00 & 38.38 & $24,444.95$ & 0.00 \\
\hline $\mathrm{I}_{\mathrm{JB}}$ & 10,526 & 0.00 & 22.64 & $24,444.95$ & 0.00 \\
\hline $\mathrm{I}_{\mathrm{JC}}$ & 9,921 & 0.00 & 23.46 & $24,444.95$ & 0.00 \\
\hline $\mathrm{I}_{\mathrm{JD}}$ & 11,670 & 0.00 & 30.28 & $24,444.95$ & 0.00 \\
\hline $\mathrm{I}_{\mathrm{JE}}$ & 15,392 & 0.00 & 49.70 & $24,444.95$ & 0.00 \\
\hline $\mathrm{I}_{\mathrm{JF}}$ & 6,355 & 0.00 & 23.21 & $24,444.95$ & 0.00 \\
\hline $\mathrm{I}_{\mathrm{JG}}$ & 8,578 & 0.00 & 35.53 & $24,444.95$ & 0.00 \\
\hline $\mathrm{I}_{\mathrm{JH}}$ & 4,283 & 0.00 & 20.85 & $24,444.95$ & 0.00 \\
\hline $\mathrm{I}_{\mathrm{II}}$ & 13,417 & 0.01 & 127.54 & $24,444.95$ & 0.01 \\
\hline $\mathrm{I}_{\mathrm{JJ}}$ & 11,761 & 2.00 & $23,522.00$ & $24,444.95$ & 0.96 \\
\hline $\mathrm{I}_{\mathrm{JK}}$ & 11,656 & 0.02 & 210.58 & $24,444.95$ & 0.01 \\
\hline $\mathrm{I}_{\mathrm{JL}}$ & 20,263 & 0.01 & 281.74 & $24,444.95$ & 0.01 \\
\hline $\mathrm{I}_{\mathrm{JM}}$ & 6,377 & 0.01 & 59.04 & $24,444.95$ & 0.00 \\
\hline $\mathrm{I}_{\mathrm{KA}}$ & 18,531 & 0.00 & 34.43 & $25,098.65$ & 0.00 \\
\hline $\mathrm{I}_{\mathrm{KB}}$ & 10,526 & 0.00 & 20.23 & $25,098.65$ & 0.00 \\
\hline$\overline{I_{K C}}$ & 9,921 & 0.00 & 20.74 & $25,098.65$ & 0.00 \\
\hline $\mathrm{I}_{\mathrm{KD}}$ & 11,670 & 0.00 & 26.48 & $25,098.65$ & 0.00 \\
\hline $\mathrm{I}_{\mathrm{KE}}$ & 15,392 & 0.00 & 42.16 & $25,098.65$ & 0.00 \\
\hline $\mathrm{I}_{\mathrm{KF}}$ & 6,355 & 0.00 & 19.31 & $25,098.65$ & 0.00 \\
\hline $\mathrm{I}_{\mathrm{KG}}$ & 8,578 & 0.00 & 28.90 & $25,098.65$ & 0.00 \\
\hline $\mathrm{I}_{\mathrm{KH}}$ & 4,283 & 0.00 & 16.43 & $25,098.65$ & 0.00 \\
\hline $\mathrm{I}_{\mathrm{KI}}$ & 13,417 & 0.01 & 83.57 & $25,098.65$ & 0.00 \\
\hline $\mathrm{I}_{\mathrm{KJ}}$ & 11,761 & 0.02 & 212.48 & $25,098.65$ & 0.01 \\
\hline $\mathrm{I}_{\mathrm{KK}}$ & 11,656 & 2.00 & $23,312.00$ & $25,098.65$ & 0.93 \\
\hline$\overline{\mathrm{I}_{\mathrm{KL}}}$ & 20,263 & 0.06 & $1,222.87$ & $25,098.65$ & 0.05 \\
\hline $\mathrm{I}_{\mathrm{KM}}$ & 6,377 & 0.01 & 59.04 & $25,098.65$ & 0.00 \\
\hline$\overline{\mathrm{I}_{\mathrm{LA}}}$ & 18,531 & 0.00 & 33.40 & $41,845.53$ & 0.00 \\
\hline $\mathrm{I}_{\mathrm{LB}}$ & 10,526 & 0.00 & 19.61 & $41,845.53$ & 0.00 \\
\hline $\mathrm{I}_{\mathrm{LC}}$ & 9,921 & 0.00 & 20.05 & $41,845.53$ & 0.00 \\
\hline $\mathrm{I}_{\mathrm{LD}}$ & 11,670 & 0.00 & 25.52 & $41,845.53$ & 0.00 \\
\hline $\mathrm{I}_{\mathrm{LE}}$ & 15,392 & 0.00 & 40.33 & $41,845.53$ & 0.00 \\
\hline $\mathrm{I}_{\mathrm{LF}}$ & 6,355 & 0.00 & 18.38 & $41,845.53$ & 0.00 \\
\hline $\mathrm{I}_{\mathrm{LG}}$ & 8,578 & 0.00 & 27.38 & $41,845.53$ & 0.00 \\
\hline $\mathrm{I}_{\mathrm{LH}}$ & 4,283 & 0.00 & 15.44 & $41,845.53$ & 0.00 \\
\hline $\mathrm{I}_{\mathrm{LI}}$ & 13,417 & 0.01 & 75.75 & $41,845.53$ & 0.00 \\
\hline $\mathrm{I}_{\mathrm{LJ}}$ & 11,761 & 0.01 & 163.53 & $41,845.53$ & 0.00 \\
\hline $\mathrm{I}_{\mathrm{LK}}$ & 11,656 & 0.06 & 703.44 & $41,845.53$ & 0.02 \\
\hline $\mathrm{I}_{\mathrm{LL}}$ & 20,263 & 2.00 & $40,526.00$ & $41,845.53$ & 0.97 \\
\hline $\mathrm{I}_{\mathrm{LM}}$ & 6,377 & 0.03 & 176.70 & $41,845.53$ & 0.00 \\
\hline
\end{tabular}

Appendix Table A.9 Accessibility Index Pairs from raw population figures for half mile buffer (contd.). 


\begin{tabular}{|c|r|c|r|c|r|}
\hline Accessibility Index Pairs & \multicolumn{1}{|c|}{$\mathrm{A}_{\mathrm{j}}$} & \multicolumn{1}{c|}{$\mathrm{F}_{\mathrm{ij}}$} & \multicolumn{1}{c|}{$\mathrm{A}_{\mathrm{j}}{ }^{*} \mathrm{~F}_{\mathrm{ij}}$} & \multicolumn{1}{c|}{$\sum \mathrm{A}_{\mathrm{k}} * \mathrm{~F}_{\mathrm{ik}}$} & $\mathrm{I}_{\mathrm{ij}}=\left(\mathrm{A}_{\mathrm{j}}{ }^{*} \mathrm{~F}_{\mathrm{ij}} /\left(\Sigma \mathrm{A}_{\mathrm{k}} * \mathrm{~F}_{\mathrm{ik}}\right)\right)$ \\
\hline $\mathrm{I}_{\mathrm{MA}}$ & 18,531 & 0.00 & 31.36 & $13,892.42$ & 0.00 \\
\hline $\mathrm{I}_{\mathrm{MB}}$ & 10,526 & 0.00 & 18.37 & $13,892.42$ & 0.00 \\
\hline $\mathrm{I}_{\mathrm{MC}}$ & 9,921 & 0.00 & 18.68 & $13,892.42$ & 0.00 \\
\hline $\mathrm{I}_{\mathrm{MD}}$ & 11,670 & 0.00 & 23.65 & $13,892.42$ & 0.00 \\
\hline $\mathrm{I}_{\mathrm{ME}}$ & 15,392 & 0.00 & 36.85 & $13,892.42$ & 0.00 \\
\hline $\mathrm{I}_{\mathrm{MF}}$ & 6,355 & 0.00 & 16.64 & $13,892.42$ & 0.00 \\
\hline $\mathrm{I}_{\mathrm{MG}}$ & 8,578 & 0.00 & 24.55 & $13,892.42$ & 0.00 \\
\hline $\mathrm{I}_{\mathrm{MH}}$ & 4,283 & 0.00 & 13.67 & $13,892.42$ & 0.00 \\
\hline $\mathrm{I}_{\mathrm{MI}}$ & 13,417 & 0.00 & 62.93 & $13,892.42$ & 0.01 \\
\hline $\mathrm{I}_{\mathrm{MJ}}$ & 11,761 & 0.01 & 108.89 & $13,892.42$ & 0.02 \\
\hline $\mathrm{I}_{\mathrm{MK}}$ & 11,656 & 0.02 & 221.35 & $13,892.42$ & 0.04 \\
\hline $\mathrm{I}_{\mathrm{ML}}$ & 20,263 & 0.03 & 561.47 & $13,892.42$ & 0.92 \\
\hline $\mathrm{I}_{\mathrm{MM}}$ & 6,377 & 2.00 & $12,754.00$ & $13,892.42$ & \\
\hline
\end{tabular}

Appendix Table A.10 Accessibility Index Pairs from raw population figures for half mile buffer (contd.). 


\begin{tabular}{|c|c|c|c|c|c|}
\hline Accessibility Index Pairs & $\overline{A_{j}}$ & $F_{i j}$ & $\overline{\mathrm{A}_{\mathrm{j}} * \mathrm{~F}_{\mathrm{ij}}}$ & $\Sigma \mathrm{A}_{\mathrm{k}} * \mathrm{~F}_{\mathrm{ik}}$ & $\mathrm{I}_{\mathrm{ij}}=\left(\mathrm{A}_{\mathrm{j}} * \mathrm{~F}_{\mathrm{ij}} /\left(\Sigma \mathrm{A}_{\mathrm{k}} * \mathrm{~F}_{\mathrm{ik}}\right)\right)$ \\
\hline $\mathrm{I}_{\mathrm{AA}}$ & 6,075 & 2.00 & $12,150.00$ & $12,581.46$ & 0.97 \\
\hline $\mathrm{I}_{\mathrm{AB}}$ & 4,349 & 0.06 & 241.43 & $12,581.46$ & 0.02 \\
\hline $\mathrm{I}_{\mathrm{AC}}$ & 2,788 & 0.02 & 46.54 & $12,581.46$ & 0.00 \\
\hline $\mathrm{I}_{\mathrm{AD}}$ & 3,911 & 0.01 & 40.12 & $12,581.46$ & 0.00 \\
\hline $\mathrm{I}_{\mathrm{AE}}$ & 5,620 & 0.00 & 26.03 & $12,581.46$ & 0.00 \\
\hline $\mathrm{I}_{\mathrm{AF}}$ & 1,888 & 0.00 & 9.03 & $12,581.46$ & 0.00 \\
\hline $\mathrm{I}_{\mathrm{AG}}$ & 3,710 & 0.00 & 15.37 & $12,581.46$ & 0.00 \\
\hline $\mathrm{I}_{\mathrm{AH}}$ & 1,171 & 0.00 & 4.22 & $12,581.46$ & 0.00 \\
\hline $\mathrm{I}_{\mathrm{AI}}$ & 5,593 & 0.00 & 14.81 & $12,581.46$ & 0.00 \\
\hline $\mathrm{I}_{\mathrm{AJ}}$ & 3,662 & 0.00 & 7.58 & $12,581.46$ & 0.00 \\
\hline $\mathrm{I}_{\mathrm{AK}}$ & 4,160 & 0.00 & 7.73 & $12,581.46$ & 0.00 \\
\hline $\mathrm{I}_{\mathrm{AL}}$ & 7,907 & 0.00 & 14.25 & $12,581.46$ & 0.00 \\
\hline $\mathrm{I}_{\mathrm{AM}}$ & 2,571 & 0.00 & 4.35 & $12,581.46$ & 0.00 \\
\hline $\mathrm{I}_{\mathrm{BA}}$ & 6,075 & 0.06 & 337.25 & $9,262.30$ & 0.04 \\
\hline $\mathrm{I}_{\mathrm{BB}}$ & 4,349 & 2.00 & $8,698.00$ & $9,262.30$ & 0.94 \\
\hline $\mathrm{I}_{\mathrm{BC}}$ & 2,788 & 0.02 & 66.54 & $9,262.30$ & 0.01 \\
\hline $\mathrm{I}_{\mathrm{BD}}$ & 3,911 & 0.01 & 49.21 & $9,262.30$ & 0.01 \\
\hline $\mathrm{I}_{\mathrm{BE}}$ & 5,620 & 0.01 & 28.40 & $9,262.30$ & 0.00 \\
\hline $\mathrm{I}_{\mathrm{BF}}$ & 1,888 & 0.01 & 9.88 & $9,262.30$ & 0.00 \\
\hline $\mathrm{I}_{\mathrm{BG}}$ & 3,710 & 0.00 & 16.60 & $9,262.30$ & 0.00 \\
\hline $\mathrm{I}_{\mathrm{BH}}$ & 1,171 & 0.00 & 4.51 & $9,262.30$ & 0.00 \\
\hline $\mathrm{I}_{\mathrm{BI}}$ & 5,593 & 0.00 & 15.55 & $9,262.30$ & 0.00 \\
\hline $\mathrm{I}_{\mathrm{BJ}}$ & 3,662 & 0.00 & 7.88 & $9,262.30$ & 0.00 \\
\hline $\mathrm{I}_{\mathrm{BK}}$ & 4,160 & 0.00 & 8.00 & $9,262.30$ & 0.00 \\
\hline $\mathrm{I}_{\mathrm{BL}}$ & 7,907 & 0.00 & 15.98 & $9,262.30$ & 0.00 \\
\hline $\mathrm{I}_{\mathrm{BM}}$ & 2,571 & 0.00 & 4.49 & $9,262.30$ & 0.00 \\
\hline $\mathrm{I}_{\mathrm{CA}}$ & 6,075 & 0.02 & 101.40 & $6,015.55$ & 0.02 \\
\hline $\mathrm{I}_{\mathrm{CB}}$ & 4,349 & 0.02 & 103.80 & $6,015.55$ & 0.02 \\
\hline $\mathrm{I}_{\mathrm{CC}}$ & 2,788 & 2.00 & $5,576.00$ & $6,015.55$ & 0.93 \\
\hline $\mathrm{I}_{\mathrm{CD}}$ & 3,911 & 0.03 & 104.06 & $6,015.55$ & 0.02 \\
\hline $\mathrm{I}_{\mathrm{CE}}$ & 5,620 & 0.01 & 36.03 & $6,015.55$ & 0.01 \\
\hline $\mathrm{I}_{\mathrm{CF}}$ & 1,888 & 0.01 & 12.66 & $6,015.55$ & 0.00 \\
\hline $\mathrm{I}_{\mathrm{CG}}$ & 3,710 & 0.01 & 20.44 & $6,015.55$ & 0.00 \\
\hline $\mathrm{I}_{\mathrm{CH}}$ & 1,171 & 0.00 & 5.38 & $6,015.55$ & 0.00 \\
\hline $\mathrm{I}_{\mathrm{CI}}$ & 5,593 & 0.00 & 17.60 & $6,015.55$ & 0.00 \\
\hline $\mathrm{I}_{\mathrm{CJ}}$ & 3,662 & 0.00 & 8.66 & $6,015.55$ & 0.00 \\
\hline $\mathrm{I}_{\mathrm{CK}}$ & 4,160 & 0.00 & 8.70 & $6,015.55$ & 0.00 \\
\hline $\mathrm{I}_{\mathrm{CL}}$ & 7,907 & 0.00 & 15.98 & $6,015.55$ & 0.00 \\
\hline $\mathrm{I}_{\mathrm{CM}}$ & 2,571 & 0.00 & 4.84 & $6,015.55$ & 0.00 \\
\hline
\end{tabular}

Appendix Table A.11 Accessibility Index Pairs from raw housing unit figures for half mile buffer. 


\begin{tabular}{|c|c|c|c|c|c|}
\hline Accessibility Index Pairs & $A_{j}$ & $F_{i j}$ & $A_{j} * F_{i j}$ & $\Sigma \mathrm{A}_{\mathrm{k}} * \mathrm{~F}_{\mathrm{ik}}$ & $\mathrm{I}_{\mathrm{ij}}=\left(\mathrm{A}_{\mathrm{j}} * \mathrm{~F}_{\mathrm{ij}} /\left(\Sigma \mathrm{A}_{\mathrm{k}} * \mathrm{~F}_{\mathrm{ik}}\right)\right)$ \\
\hline $\mathrm{I}_{\mathrm{DA}}$ & 6,075 & 0.01 & 62.31 & $8,169.00$ & 0.01 \\
\hline $\mathrm{I}_{\mathrm{DB}}$ & 4,349 & 0.01 & 54.72 & $8,169.00$ & 0.01 \\
\hline $\mathrm{I}_{\mathrm{DC}}$ & 2,788 & 0.03 & 74.18 & $8,169.00$ & 0.01 \\
\hline $\mathrm{I}_{\mathrm{DD}}$ & 3,911 & 2.00 & $7,822.00$ & $8,169.00$ & 0.96 \\
\hline $\mathrm{I}_{\mathrm{DE}}$ & 5,620 & 0.01 & 47.47 & $8,169.00$ & 0.01 \\
\hline $\mathrm{I}_{\mathrm{DF}}$ & 1,888 & 0.01 & 16.92 & $8,169.00$ & 0.00 \\
\hline $\mathrm{I}_{\mathrm{DG}}$ & 3,710 & 0.01 & 25.77 & $8,169.00$ & 0.00 \\
\hline $\mathrm{I}_{\mathrm{DH}}$ & 1,171 & 0.00 & 4.22 & $8,169.00$ & 0.00 \\
\hline $\mathrm{I}_{\mathrm{DI}}$ & 5,593 & 0.00 & 19.96 & $8,169.00$ & 0.00 \\
\hline $\mathrm{I}_{\mathrm{DJ}}$ & 3,662 & 0.00 & 9.50 & $8,169.00$ & 0.00 \\
\hline $\mathrm{I}_{\mathrm{DK}}$ & 4,160 & 0.00 & 9.44 & $8,169.00$ & 0.00 \\
\hline $\mathrm{I}_{\mathrm{DL}}$ & 7,907 & 0.00 & 17.29 & $8,169.00$ & 0.00 \\
\hline $\mathrm{I}_{\mathrm{DM}}$ & 2,571 & 0.00 & 5.21 & $8,169.00$ & 0.00 \\
\hline IEA & 6,075 & 0.00 & 28.14 & $11,536.66$ & 0.00 \\
\hline $\mathrm{I}_{\mathrm{EB}}$ & 4,349 & 0.01 & 21.98 & $11,536.66$ & 0.00 \\
\hline $\mathrm{I}_{\mathrm{EC}}$ & 2,788 & 0.01 & 17.87 & $11,536.66$ & 0.00 \\
\hline $\mathrm{I}_{\mathrm{ED}}$ & 3,911 & 0.01 & 33.03 & $11,536.66$ & 0.00 \\
\hline $\mathrm{I}_{\mathrm{EE}}$ & 5,620 & 2.00 & $11,240.00$ & $11,536.66$ & 0.97 \\
\hline $\mathrm{I}_{\mathrm{EF}}$ & 1,888 & 0.03 & 52.62 & $11,536.66$ & 0.00 \\
\hline $\mathrm{I}_{\mathrm{EG}}$ & 3,710 & 0.01 & 54.34 & $11,536.66$ & 0.00 \\
\hline $\mathrm{I}_{\mathrm{EH}}$ & 1,171 & 0.01 & 11.23 & $11,536.66$ & 0.00 \\
\hline $\mathrm{I}_{\mathrm{EI}}$ & 5,593 & 0.00 & 27.35 & $11,536.66$ & 0.00 \\
\hline $\mathrm{I}_{\mathrm{EJ}}$ & 3,662 & 0.00 & 11.82 & $11,536.66$ & 0.00 \\
\hline $\mathrm{I}_{\mathrm{EK}}$ & 4,160 & 0.00 & 11.40 & $11,536.66$ & 0.00 \\
\hline $\mathrm{I}_{\mathrm{EL}}$ & 7,907 & 0.00 & 20.72 & $11,536.66$ & 0.00 \\
\hline $\mathrm{I}_{\mathrm{EM}}$ & 2,571 & 0.00 & 6.15 & $11,536.66$ & 0.00 \\
\hline $\mathrm{I}_{\mathrm{FA}}$ & 6,075 & 0.00 & 29.06 & $4,258.61$ & 0.01 \\
\hline $\mathrm{I}_{\mathrm{FB}}$ & 4,349 & 0.01 & 22.76 & $4,258.61$ & 0.01 \\
\hline $\mathrm{I}_{\mathrm{FC}}$ & 2,788 & 0.01 & 18.69 & $4,258.61$ & 0.00 \\
\hline $\mathrm{I}_{\mathrm{FD}}$ & 3,911 & 0.01 & 35.06 & $4,258.61$ & 0.01 \\
\hline $\mathrm{I}_{\mathrm{FE}}$ & 5,620 & 0.03 & 156.64 & $4,258.61$ & 0.04 \\
\hline $\mathrm{I}_{\mathrm{FF}}$ & 1,888 & 2.00 & $3,776.00$ & $4,258.61$ & 0.89 \\
\hline $\mathrm{I}_{\mathrm{FG}}$ & 3,710 & 0.03 & 114.51 & $4,258.61$ & 0.03 \\
\hline $\mathrm{I}_{\mathrm{FH}}$ & 1,171 & 0.01 & 17.11 & $4,258.61$ & 0.00 \\
\hline $\mathrm{I}_{\mathrm{FI}}$ & 5,593 & 0.01 & 33.17 & $4,258.61$ & 0.01 \\
\hline $\mathrm{I}_{\mathrm{FJ}}$ & 3,662 & 0.00 & 13.37 & $4,258.61$ & 0.00 \\
\hline $\mathrm{I}_{\mathrm{FK}}$ & 4,160 & 0.00 & 12.64 & $4,258.61$ & 0.00 \\
\hline $\mathrm{I}_{\mathrm{FL}}$ & 7,907 & 0.00 & 22.87 & $4,258.61$ & 0.01 \\
\hline $\mathrm{I}_{\mathrm{FM}}$ & 2,571 & 0.00 & 6.73 & $4,258.61$ & 0.00 \\
\hline
\end{tabular}

Appendix Table A.12 Accessibility Index Pairs from raw housing unit figures for half mile buffer (contd.). 


\begin{tabular}{|c|c|c|c|c|c|}
\hline Accessibility Index Pairs & $A_{j}$ & $F_{i j}$ & $A_{j} * F_{i j}$ & $\Sigma \mathrm{A}_{\mathrm{k}} * \mathrm{~F}_{\mathrm{ik}}$ & $\mathrm{I}_{\mathrm{ij}}=\left(\mathrm{A}_{\mathrm{j}} * \mathrm{~F}_{\mathrm{ij}} /\left(\sum \mathrm{A}_{\mathrm{k}} * \mathrm{~F}_{\mathrm{ik}}\right)\right)$ \\
\hline $\mathrm{I}_{\mathrm{GA}}$ & 6,075 & 0.00 & 25.16 & $7,783.06$ & 0.00 \\
\hline $\mathrm{I}_{\mathrm{GB}}$ & 4,349 & 0.00 & 19.46 & $7,783.06$ & 0.00 \\
\hline $\mathrm{I}_{\mathrm{GC}}$ & 2,788 & 0.01 & 15.36 & $7,783.06$ & 0.00 \\
\hline $\mathrm{I}_{\mathrm{GD}}$ & 3,911 & 0.01 & 27.17 & $7,783.06$ & 0.00 \\
\hline $\mathrm{I}_{\mathrm{GE}}$ & 5,620 & 0.01 & 82.31 & $7,783.06$ & 0.01 \\
\hline $\mathrm{I}_{\mathrm{GF}}$ & 1,888 & 0.03 & 58.27 & $7,783.06$ & 0.01 \\
\hline $\mathrm{I}_{\mathrm{GG}}$ & 3,710 & 2.00 & $7,420.00$ & $7,783.06$ & 0.95 \\
\hline $\mathrm{I}_{\mathrm{GH}}$ & 1,171 & 0.03 & 32.50 & $7,783.06$ & 0.00 \\
\hline $\mathrm{I}_{\mathrm{GI}}$ & 5,593 & 0.01 & 41.06 & 7,783.06 & 0.01 \\
\hline $\mathrm{I}_{\mathrm{GJ}}$ & 3,662 & 0.00 & 15.17 & $7,783.06$ & 0.00 \\
\hline $\mathrm{I}_{\mathrm{GK}}$ & 4,160 & 0.00 & 14.02 & $7,783.06$ & 0.00 \\
\hline $\mathrm{I}_{\mathrm{GL}}$ & 7,907 & 0.00 & 25.23 & $7,783.06$ & 0.00 \\
\hline $\mathrm{I}_{\mathrm{GM}}$ & 2,571 & 0.00 & 7.36 & $7,783.06$ & 0.00 \\
\hline $\mathrm{I}_{\mathrm{HA}}$ & 6,075 & 0.00 & 21.89 & $2,725.94$ & 0.01 \\
\hline $\mathrm{I}_{\mathrm{HB}}$ & 4,349 & 0.00 & 16.76 & $2,725.94$ & 0.01 \\
\hline $\mathrm{I}_{\mathrm{HC}}$ & 2,788 & 0.00 & 12.81 & $2,725.94$ & 0.00 \\
\hline $\mathrm{I}_{\mathrm{HD}}$ & 3,911 & 0.01 & 21.73 & $2,725.94$ & 0.01 \\
\hline $\mathrm{I}_{\mathrm{HE}}$ & 5,620 & 0.01 & 53.88 & $2,725.94$ & 0.02 \\
\hline $\mathrm{I}_{\mathrm{HF}}$ & 1,888 & 0.01 & 27.59 & $2,725.94$ & 0.01 \\
\hline $\mathrm{I}_{\mathrm{HG}}$ & 3,710 & 0.03 & 102.96 & $2,725.94$ & 0.04 \\
\hline $\mathrm{I}_{\mathrm{HH}}$ & 1,171 & 2.00 & $2,342.00$ & $2,725.94$ & 0.86 \\
\hline $\mathrm{I}_{\mathrm{HI}}$ & 5,593 & 0.01 & 55.82 & $2,725.94$ & 0.02 \\
\hline $\mathrm{I}_{\mathrm{HJ}}$ & 3,662 & 0.00 & 17.83 & $2,725.94$ & 0.01 \\
\hline $\mathrm{I}_{\mathrm{HK}}$ & 4,160 & 0.00 & 15.95 & $2,725.94$ & 0.01 \\
\hline $\mathrm{I}_{\mathrm{HL}}$ & 7,907 & 0.00 & 28.51 & $2,725.94$ & 0.01 \\
\hline $\mathrm{I}_{\mathrm{HM}}$ & 2,571 & 0.00 & 8.20 & $2,725.94$ & 0.00 \\
\hline $\mathrm{I}_{\mathrm{IA}}$ & 6,075 & 0.00 & 16.08 & $11,431.93$ & 0.00 \\
\hline $\mathrm{I}_{\mathrm{IB}}$ & 4,349 & 0.00 & 12.09 & $11,431.93$ & 0.00 \\
\hline $\mathrm{I}_{\mathrm{IC}}$ & 2,788 & 0.00 & 8.77 & $11,431.93$ & 0.00 \\
\hline $\mathrm{I}_{\mathrm{ID}}$ & 3,911 & 0.00 & 13.96 & $11,431.93$ & 0.00 \\
\hline $\mathrm{I}_{\mathrm{IE}}$ & 5,620 & 0.00 & 27.48 & $11,431.93$ & 0.00 \\
\hline $\mathrm{I}_{\mathrm{IF}}$ & 1,888 & 0.01 & 11.20 & $11,431.93$ & 0.00 \\
\hline $\mathrm{I}_{\mathrm{IG}}$ & 3,710 & 0.01 & 27.23 & $11,431.93$ & 0.00 \\
\hline $\mathrm{I}_{\mathrm{IH}}$ & 1,171 & 0.01 & 11.69 & $11,431.93$ & 0.00 \\
\hline $\mathrm{I}_{\text {II }}$ & 5,593 & 2.00 & $11,186.00$ & $11,431.93$ & 0.98 \\
\hline $\mathrm{I}_{\mathrm{IJ}}$ & 3,662 & 0.01 & 34.81 & $11,431.93$ & 0.00 \\
\hline $\mathrm{I}_{\mathrm{IK}}$ & 4,160 & 0.01 & 25.91 & $11,431.93$ & 0.00 \\
\hline $\mathrm{I}_{\mathrm{IL}}$ & 7,907 & 0.01 & 44.64 & $11,431.93$ & 0.00 \\
\hline $\mathrm{I}_{\mathrm{IM}}$ & 2,571 & 0.00 & 12.06 & $11,431.93$ & 0.00 \\
\hline
\end{tabular}

Appendix Table A.13 Accessibility Index Pairs from raw housing unit figures for half mile buffer (contd.). 


\begin{tabular}{|c|c|c|c|c|c|}
\hline Accessibility Index Pairs & $A_{j}$ & $F_{i j}$ & $A_{j} * F_{i j}$ & $\Sigma \mathrm{A}_{\mathrm{k}} * \mathrm{~F}_{\mathrm{ik}}$ & $\mathrm{I}_{\mathrm{ij}}=\left(\mathrm{A}_{\mathrm{j}} * \mathrm{~F}_{\mathrm{ij}} /\left(\Sigma \mathrm{A}_{\mathrm{k}} * \mathrm{~F}_{\mathrm{ik}}\right)\right)$ \\
\hline $\mathrm{I}_{\mathrm{JA}}$ & 6,075 & 0.00 & 12.58 & $7,670.85$ & 0.00 \\
\hline $\mathrm{I}_{\mathrm{JB}}$ & 4,349 & 0.00 & 9.36 & $7,670.85$ & 0.00 \\
\hline $\mathrm{I}_{\mathrm{JC}}$ & 2,788 & 0.00 & 6.59 & $7,670.85$ & 0.00 \\
\hline $\mathrm{I}_{\mathrm{JD}}$ & 3,911 & 0.00 & 10.15 & $7,670.85$ & 0.00 \\
\hline $\mathrm{I}_{\mathrm{JE}}$ & 5,620 & 0.00 & 18.15 & $7,670.85$ & 0.00 \\
\hline $\mathrm{I}_{\mathrm{JF}}$ & 1,888 & 0.00 & 6.90 & $7,670.85$ & 0.00 \\
\hline $\mathrm{I}_{\mathrm{JG}}$ & 3,710 & 0.00 & 15.37 & $7,670.85$ & 0.00 \\
\hline $\mathrm{I}_{\mathrm{JH}}$ & 1,171 & 0.00 & 5.70 & $7,670.85$ & 0.00 \\
\hline $\mathrm{I}_{\mathrm{JI}}$ & 5,593 & 0.01 & 53.17 & $7,670.85$ & 0.01 \\
\hline $\mathrm{I}_{\mathrm{JJ}}$ & 3,662 & 2.00 & $7,324.00$ & $7,670.85$ & 0.95 \\
\hline $\mathrm{I}_{\mathrm{JK}}$ & 4,160 & 0.02 & 75.16 & $7,670.85$ & 0.01 \\
\hline $\mathrm{I}_{\mathrm{JL}}$ & 7,907 & 0.01 & 109.94 & $7,670.85$ & 0.01 \\
\hline$I_{\mathrm{JM}}$ & 2,571 & 0.01 & 23.80 & $7,670.85$ & 0.00 \\
\hline $\mathrm{I}_{\mathrm{KA}}$ & 6,075 & 0.00 & 11.29 & $8,994.46$ & 0.00 \\
\hline $\mathrm{I}_{\mathrm{KB}}$ & 4,349 & 0.00 & 8.36 & $8,994.46$ & 0.00 \\
\hline $\mathrm{I}_{\mathrm{KC}}$ & 2,788 & 0.00 & 5.83 & $8,994.46$ & 0.00 \\
\hline $\mathrm{I}_{\mathrm{KD}}$ & 3,911 & 0.00 & 8.87 & $8,994.46$ & 0.00 \\
\hline $\mathrm{I}_{\mathrm{KE}}$ & 5,620 & 0.00 & 15.40 & $8,994.46$ & 0.00 \\
\hline $\mathrm{I}_{\mathrm{KF}}$ & 1,888 & 0.00 & 5.74 & $8,994.46$ & 0.00 \\
\hline $\mathrm{I}_{\mathrm{KG}}$ & 3,710 & 0.00 & 12.50 & $8,994.46$ & 0.00 \\
\hline $\mathrm{I}_{\mathrm{KH}}$ & 1,171 & 0.00 & 4.49 & $8,994.46$ & 0.00 \\
\hline $\mathrm{I}_{\mathrm{KI}}$ & 5,593 & 0.01 & 34.84 & $8,994.46$ & 0.00 \\
\hline $\mathrm{I}_{\mathrm{KJ}}$ & 3,662 & 0.02 & 66.16 & $8,994.46$ & 0.01 \\
\hline $\mathrm{I}_{\mathrm{KK}}$ & 4,160 & 2.00 & $8,320.00$ & $8,994.46$ & 0.93 \\
\hline $\mathrm{I}_{\mathrm{KL}}$ & 7,907 & 0.06 & 477.19 & $8,994.46$ & 0.05 \\
\hline $\mathrm{I}_{\mathrm{KM}}$ & 2,571 & 0.01 & 23.80 & $8,994.46$ & 0.00 \\
\hline $\mathrm{I}_{\mathrm{LA}}$ & 6,075 & 0.00 & 10.95 & $16,288.28$ & 0.00 \\
\hline $\mathrm{I}_{\mathrm{LB}}$ & 4,349 & 0.00 & 8.10 & $16,288.28$ & 0.00 \\
\hline $\mathrm{I}_{\mathrm{LC}}$ & 2,788 & 0.00 & 5.63 & $16,288.28$ & 0.00 \\
\hline $\mathrm{I}_{\mathrm{LD}}$ & 3,911 & 0.00 & 8.55 & $16,288.28$ & 0.00 \\
\hline $\mathrm{I}_{\mathrm{LE}}$ & 5,620 & 0.00 & 14.73 & $16,288.28$ & 0.00 \\
\hline $\mathrm{I}_{\mathrm{LF}}$ & 1,888 & 0.00 & 5.46 & $16,288.28$ & 0.00 \\
\hline $\mathrm{I}_{\mathrm{LG}}$ & 3,710 & 0.00 & 11.84 & $16,288.28$ & 0.00 \\
\hline $\mathrm{I}_{\mathrm{LH}}$ & 1,171 & 0.00 & 4.22 & $16,288.28$ & 0.00 \\
\hline $\mathrm{I}_{\mathrm{LI}}$ & 5,593 & 0.01 & 31.58 & $16,288.28$ & 0.00 \\
\hline $\mathrm{I}_{\mathrm{LJ}}$ & 3,662 & 0.01 & 50.92 & $16,288.28$ & 0.00 \\
\hline $\mathrm{I}_{\mathrm{LK}}$ & 4,160 & 0.06 & 251.06 & $16,288.28$ & 0.02 \\
\hline $\mathrm{I}_{\mathrm{LL}}$ & 7,907 & 2.00 & $15,814.00$ & $16,288.28$ & 0.97 \\
\hline $\mathrm{I}_{\mathrm{LM}}$ & 2,571 & 0.03 & 71.24 & $16,288.28$ & 0.00 \\
\hline
\end{tabular}

Appendix Table A.14 Accessibility Index Pairs from raw housing unit figures for half mile buffer (contd.). 


\begin{tabular}{|c|r|r|r|r|r|}
\hline Accessibility Index Pairs & \multicolumn{1}{c|}{$\mathrm{A}_{\mathrm{j}}$} & \multicolumn{1}{c|}{$\mathrm{F}_{\mathrm{ij}}$} & \multicolumn{1}{c|}{$\mathrm{A}_{\mathrm{j}}{ }^{*} \mathrm{~F}_{\mathrm{ij}}$} & \multicolumn{1}{c|}{$\Sigma \mathrm{A}_{\mathrm{k}}{ }^{*} \mathrm{~F}_{\mathrm{ik}}$} & $\mathrm{I}_{\mathrm{ij}}=\left(\mathrm{A}_{\mathrm{j}}{ }^{*} \mathrm{~F}_{\mathrm{ij}} /\left(\Sigma \mathrm{A}_{\mathrm{k}}{ }^{*} \mathrm{~F}_{\mathrm{ik}}\right)\right)$ \\
\hline $\mathrm{I}_{\mathrm{MA}}$ & 6,075 & 0.00 & 10.28 & $5,564.04$ & 0.00 \\
\hline $\mathrm{I}_{\mathrm{MB}}$ & 4,349 & 0.00 & 7.59 & $5,564.04$ & 0.00 \\
\hline $\mathrm{I}_{\mathrm{MC}}$ & 2,788 & 0.00 & 5.25 & $5,564.04$ & 0.00 \\
\hline $\mathrm{I}_{\mathrm{MD}}$ & 3,911 & 0.00 & 7.93 & $5,564.04$ & 0.00 \\
\hline $\mathrm{I}_{\mathrm{ME}}$ & 5,620 & 0.00 & 13.45 & $5,564.04$ & 0.00 \\
\hline $\mathrm{I}_{\mathrm{MF}}$ & 1,888 & 0.00 & 4.94 & $5,564.04$ & 0.00 \\
\hline $\mathrm{I}_{\mathrm{MG}}$ & 3,710 & 0.00 & 10.62 & $5,564.04$ & 0.00 \\
\hline $\mathrm{I}_{\mathrm{MH}}$ & 1,171 & 0.00 & 3.74 & $5,564.04$ & 0.00 \\
\hline $\mathrm{I}_{\mathrm{MI}}$ & 5,593 & 0.00 & 26.23 & $5,564.04$ & 0.01 \\
\hline $\mathrm{I}_{\mathrm{MJ}}$ & 3,662 & 0.01 & 33.90 & $5,564.04$ & 0.01 \\
\hline $\mathrm{I}_{\mathrm{MK}}$ & 4,160 & 0.02 & 79.00 & $5,564.04$ & 0.04 \\
\hline $\mathrm{I}_{\mathrm{ML}}$ & 7,907 & 0.03 & 219.10 & $5,564.04$ & 0.92 \\
\hline $\mathrm{I}_{\mathrm{MM}}$ & 2,571 & 2.00 & $5,142.00$ & $5,564.04$ & \\
\hline
\end{tabular}

Appendix Table A.15 Accessibility Index Pairs from raw housing unit figures for half mile buffer (contd.). 


\begin{tabular}{|c|c|c|c|c|c|}
\hline Accessibility Index Pairs & $\mathrm{A}_{\mathrm{j}}$ & $F_{i j}$ & $\overline{\mathrm{A}_{\mathrm{j}} * \mathrm{~F}_{\mathrm{ij}}}$ & $\Sigma \mathrm{A}_{\mathrm{k}} * \mathrm{~F}_{\mathrm{ik}}$ & $\mathrm{I}_{\mathrm{ij}}=\left(\mathrm{A}_{\mathrm{j}} * \mathrm{~F}_{\mathrm{ij}} /\left(\Sigma \mathrm{A}_{\mathrm{k}} * \mathrm{~F}_{\mathrm{ik}}\right)\right)$ \\
\hline $\mathrm{I}_{\mathrm{AA}}$ & 3.42 & 2.00 & 6.85 & 6.81 & 1.01 \\
\hline $\mathrm{I}_{\mathrm{AB}}$ & -0.32 & 0.06 & -0.02 & 6.81 & 0.00 \\
\hline $\mathrm{I}_{\mathrm{AC}}$ & -0.24 & 0.02 & 0.00 & 6.81 & 0.00 \\
\hline $\mathrm{I}_{\mathrm{AD}}$ & -0.37 & 0.01 & 0.00 & 6.81 & 0.00 \\
\hline $\mathrm{I}_{\mathrm{AE}}$ & -0.34 & 0.00 & 0.00 & 6.81 & 0.00 \\
\hline $\mathrm{I}_{\mathrm{AF}}$ & -0.39 & 0.00 & 0.00 & 6.81 & 0.00 \\
\hline$I_{A G}$ & -0.29 & 0.00 & 0.00 & 6.81 & 0.00 \\
\hline $\mathrm{I}_{\mathrm{AH}}$ & -0.39 & 0.00 & 0.00 & 6.81 & 0.00 \\
\hline $\mathrm{I}_{\mathrm{AI}}$ & -0.36 & 0.00 & 0.00 & 6.81 & 0.00 \\
\hline $\mathrm{I}_{\mathrm{AJ}}$ & -0.38 & 0.00 & 0.00 & 6.81 & 0.00 \\
\hline $\mathrm{I}_{\mathrm{AK}}$ & -0.30 & 0.00 & 0.00 & 6.81 & 0.00 \\
\hline $\mathrm{I}_{\mathrm{AL}}$ & 0.21 & 0.00 & 0.00 & 6.81 & 0.00 \\
\hline$I_{A M}$ & -0.26 & 0.00 & 0.00 & 6.81 & 0.00 \\
\hline$I_{\mathrm{BA}}$ & 3.42 & 0.06 & 0.19 & -0.48 & -0.40 \\
\hline $\mathrm{I}_{\mathrm{BB}}$ & -0.32 & 2.00 & -0.65 & -0.48 & 1.36 \\
\hline$I_{B C}$ & -0.24 & 0.02 & -0.01 & -0.48 & 0.01 \\
\hline$I_{B D}$ & -0.37 & 0.01 & 0.00 & -0.48 & 0.01 \\
\hline $\mathrm{I}_{\mathrm{BE}}$ & -0.34 & 0.01 & 0.00 & -0.48 & 0.00 \\
\hline $\mathrm{I}_{\mathrm{BF}}$ & -0.39 & 0.01 & 0.00 & -0.48 & 0.00 \\
\hline$I_{B G}$ & -0.29 & 0.00 & 0.00 & -0.48 & 0.00 \\
\hline$I_{B H}$ & -0.39 & 0.00 & 0.00 & -0.48 & 0.00 \\
\hline $\mathrm{I}_{\mathrm{BI}}$ & -0.36 & 0.00 & 0.00 & -0.48 & 0.00 \\
\hline $\mathrm{I}_{\mathrm{BJ}}$ & -0.38 & 0.00 & 0.00 & -0.48 & 0.00 \\
\hline$I_{\mathrm{BK}}$ & -0.30 & 0.00 & 0.00 & -0.48 & 0.00 \\
\hline $\mathrm{I}_{\mathrm{BL}}$ & 0.21 & 0.00 & 0.00 & -0.48 & 0.00 \\
\hline$I_{B M}$ & -0.26 & 0.00 & 0.00 & -0.48 & 0.00 \\
\hline $\mathrm{I}_{\mathrm{CA}}$ & 3.42 & 0.02 & 0.06 & -0.45 & -0.13 \\
\hline $\mathrm{I}_{\mathrm{CB}}$ & -0.32 & 0.02 & -0.01 & -0.45 & 0.02 \\
\hline $\mathrm{I}_{\mathrm{CC}}$ & -0.24 & 2.00 & -0.48 & -0.45 & 1.06 \\
\hline $\mathrm{I}_{\mathrm{CD}}$ & -0.37 & 0.03 & -0.01 & -0.45 & 0.02 \\
\hline $\mathrm{I}_{\mathrm{CE}}$ & -0.34 & 0.01 & 0.00 & -0.45 & 0.00 \\
\hline $\mathrm{I}_{\mathrm{CF}}$ & -0.39 & 0.01 & 0.00 & -0.45 & 0.01 \\
\hline $\mathrm{I}_{\mathrm{CG}}$ & -0.29 & 0.01 & 0.00 & -0.45 & 0.00 \\
\hline $\mathrm{I}_{\mathrm{CH}}$ & -0.39 & 0.00 & 0.00 & -0.45 & 0.00 \\
\hline $\mathrm{I}_{\mathrm{CI}}$ & -0.36 & 0.00 & 0.00 & -0.45 & 0.00 \\
\hline $\mathrm{I}_{\mathrm{CJ}}$ & -0.38 & 0.00 & 0.00 & -0.45 & 0.00 \\
\hline $\mathrm{I}_{\mathrm{CK}}$ & -0.30 & 0.00 & 0.00 & -0.45 & 0.00 \\
\hline $\mathrm{I}_{\mathrm{CL}}$ & 0.21 & 0.00 & 0.00 & -0.45 & 0.00 \\
\hline $\mathrm{I}_{\mathrm{CM}}$ & -0.26 & 0.00 & 0.00 & -0.45 & 0.00 \\
\hline
\end{tabular}

Appendix Table A.16 Accessibility Index Pairs from normalized job figures for half mile buffer. 


\begin{tabular}{|c|c|c|c|c|c|}
\hline Accessibility Index Pairs & $\overline{A_{j}}$ & $\mathrm{~F}_{\mathrm{ij}}$ & $\mathrm{A}_{\mathrm{j}} * \mathrm{~F}_{\mathrm{ij}}$ & $\Sigma \mathrm{A}_{\mathrm{k}} * \mathrm{~F}_{\mathrm{ik}}$ & $\mathrm{I}_{\mathrm{ij}}=\left(\mathrm{A}_{\mathrm{j}} * \mathrm{~F}_{\mathrm{ij}} /\left(\Sigma \mathrm{A}_{\mathrm{k}} * \mathrm{~F}_{\mathrm{ik}}\right)\right)$ \\
\hline $\mathrm{I}_{\mathrm{DA}}$ & 3.42 & 0.01 & 0.04 & -0.72 & -0.05 \\
\hline $\mathrm{I}_{\mathrm{DB}}$ & -0.32 & 0.01 & 0.00 & -0.72 & 0.01 \\
\hline $\mathrm{I}_{\mathrm{DC}}$ & -0.24 & 0.03 & -0.01 & -0.72 & 0.01 \\
\hline$I_{D D}$ & -0.37 & 2.00 & -0.73 & -0.72 & 1.02 \\
\hline $\mathrm{I}_{\mathrm{DE}}$ & -0.34 & 0.01 & 0.00 & -0.72 & 0.00 \\
\hline $\mathrm{I}_{\mathrm{DF}}$ & -0.39 & 0.01 & 0.00 & -0.72 & 0.00 \\
\hline $\mathrm{I}_{\mathrm{DG}}$ & -0.29 & 0.01 & 0.00 & -0.72 & 0.00 \\
\hline $\mathrm{I}_{\mathrm{DH}}$ & -0.39 & 0.00 & 0.00 & -0.72 & 0.00 \\
\hline $\mathrm{I}_{\mathrm{DI}}$ & -0.36 & 0.00 & 0.00 & -0.72 & 0.00 \\
\hline $\mathrm{I}_{\mathrm{DJ}}$ & -0.38 & 0.00 & 0.00 & -0.72 & 0.00 \\
\hline $\mathrm{I}_{\mathrm{DK}}$ & -0.30 & 0.00 & 0.00 & -0.72 & 0.00 \\
\hline $\mathrm{I}_{\mathrm{DL}}$ & 0.21 & 0.00 & 0.00 & -0.72 & 0.00 \\
\hline$I_{D M}$ & -0.26 & 0.00 & 0.00 & -0.72 & 0.00 \\
\hline $\mathrm{I}_{\mathrm{EA}}$ & 3.42 & 0.00 & 0.02 & -0.69 & -0.02 \\
\hline $\mathrm{I}_{\mathrm{EB}}$ & -0.32 & 0.01 & 0.00 & -0.69 & 0.00 \\
\hline $\mathrm{I}_{\mathrm{EC}}$ & -0.24 & 0.01 & 0.00 & -0.69 & 0.00 \\
\hline $\mathrm{I}_{\mathrm{ED}}$ & -0.37 & 0.01 & 0.00 & -0.69 & 0.00 \\
\hline $\mathrm{I}_{\mathrm{EE}}$ & -0.34 & 2.00 & -0.68 & -0.69 & 0.98 \\
\hline $\mathrm{I}_{\mathrm{EF}}$ & -0.39 & 0.03 & -0.01 & -0.69 & 0.02 \\
\hline $\mathrm{I}_{\mathrm{EG}}$ & -0.29 & 0.01 & 0.00 & -0.69 & 0.01 \\
\hline $\mathrm{I}_{\mathrm{EH}}$ & -0.39 & 0.01 & 0.00 & -0.69 & 0.01 \\
\hline $\mathrm{I}_{\mathrm{EI}}$ & -0.36 & 0.00 & 0.00 & -0.69 & 0.00 \\
\hline $\mathrm{I}_{\mathrm{EJ}}$ & -0.38 & 0.00 & 0.00 & -0.69 & 0.00 \\
\hline $\mathrm{I}_{\mathrm{EK}}$ & -0.30 & 0.00 & 0.00 & -0.69 & 0.00 \\
\hline $\mathrm{I}_{\mathrm{EL}}$ & 0.21 & 0.00 & 0.00 & -0.69 & 0.00 \\
\hline $\mathrm{I}_{\mathrm{EM}}$ & -0.26 & 0.00 & 0.00 & -0.69 & 0.00 \\
\hline $\mathrm{I}_{\mathrm{FA}}$ & 3.42 & 0.00 & 0.02 & -0.80 & -0.02 \\
\hline $\mathrm{I}_{\mathrm{FB}}$ & -0.32 & 0.01 & 0.00 & -0.80 & 0.00 \\
\hline $\mathrm{I}_{\mathrm{FC}}$ & -0.24 & 0.01 & 0.00 & -0.80 & 0.00 \\
\hline $\mathrm{I}_{\mathrm{FD}}$ & -0.37 & 0.01 & 0.00 & -0.80 & 0.00 \\
\hline $\mathrm{I}_{\mathrm{FE}}$ & -0.34 & 0.03 & -0.01 & -0.80 & 0.01 \\
\hline $\mathrm{I}_{\mathrm{FF}}$ & -0.39 & 2.00 & -0.78 & -0.80 & 0.98 \\
\hline $\mathrm{I}_{\mathrm{FG}}$ & -0.29 & 0.03 & -0.01 & -0.80 & 0.01 \\
\hline $\mathrm{I}_{\mathrm{FH}}$ & -0.39 & 0.01 & -0.01 & -0.80 & 0.01 \\
\hline $\mathrm{I}_{\mathrm{FI}}$ & -0.36 & 0.01 & 0.00 & -0.80 & 0.00 \\
\hline $\mathrm{I}_{\mathrm{FJ}}$ & -0.38 & 0.00 & 0.00 & -0.80 & 0.00 \\
\hline $\mathrm{I}_{\mathrm{FK}}$ & -0.30 & 0.00 & 0.00 & -0.80 & 0.00 \\
\hline $\mathrm{I}_{\mathrm{FL}}$ & 0.21 & 0.00 & 0.00 & -0.80 & 0.00 \\
\hline $\mathrm{I}_{\mathrm{FM}}$ & -0.26 & 0.00 & 0.00 & -0.80 & 0.00 \\
\hline
\end{tabular}

Appendix Table A.17 Accessibility Index Pairs from normalized job figures for half mile buffer (contd.). 


\begin{tabular}{|c|c|c|c|c|c|}
\hline Accessibility Index Pairs & $\overline{A_{j}}$ & $\overline{F_{i j}}$ & $\mathrm{~A}_{\mathrm{j}} * \mathrm{~F}_{\mathrm{ij}}$ & $\Sigma A_{k} * F_{i k}$ & $\mathrm{I}_{\mathrm{ij}}=\left(\mathrm{A}_{\mathrm{j}} * \mathrm{~F}_{\mathrm{ij}} /\left(\Sigma \mathrm{A}_{\mathrm{k}} * \mathrm{~F}_{\mathrm{ik}}\right)\right)$ \\
\hline $\mathrm{I}_{\mathrm{GA}}$ & 3.42 & 0.00 & 0.01 & -0.60 & -0.02 \\
\hline $\mathrm{I}_{\mathrm{GB}}$ & -0.32 & 0.00 & 0.00 & -0.60 & 0.00 \\
\hline $\mathrm{I}_{\mathrm{GC}}$ & -0.24 & 0.01 & 0.00 & -0.60 & 0.00 \\
\hline $\mathrm{I}_{\mathrm{GD}}$ & -0.37 & 0.01 & 0.00 & -0.60 & 0.00 \\
\hline $\mathrm{I}_{\mathrm{GE}}$ & -0.34 & 0.01 & 0.00 & -0.60 & 0.01 \\
\hline $\mathrm{I}_{\mathrm{GF}}$ & -0.39 & 0.03 & -0.01 & -0.60 & 0.02 \\
\hline $\mathrm{I}_{\mathrm{GG}}$ & -0.29 & 2.00 & -0.57 & -0.60 & 0.96 \\
\hline $\mathrm{I}_{\mathrm{GH}}$ & -0.39 & 0.03 & -0.01 & -0.60 & 0.02 \\
\hline $\mathrm{I}_{\mathrm{GI}}$ & -0.36 & 0.01 & 0.00 & -0.60 & 0.00 \\
\hline $\mathrm{I}_{\mathrm{GJ}}$ & -0.38 & 0.00 & 0.00 & -0.60 & 0.00 \\
\hline $\mathrm{I}_{\mathrm{GK}}$ & -0.30 & 0.00 & 0.00 & -0.60 & 0.00 \\
\hline $\mathrm{I}_{\mathrm{GL}}$ & 0.21 & 0.00 & 0.00 & -0.60 & 0.00 \\
\hline$I_{G M}$ & -0.26 & 0.00 & 0.00 & -0.60 & 0.00 \\
\hline $\mathrm{I}_{\mathrm{HA}}$ & 3.42 & 0.00 & 0.01 & -0.79 & -0.02 \\
\hline $\mathrm{I}_{\mathrm{HB}}$ & -0.32 & 0.00 & 0.00 & -0.79 & 0.00 \\
\hline $\mathrm{I}_{\mathrm{HC}}$ & -0.24 & 0.00 & 0.00 & -0.79 & 0.00 \\
\hline $\mathrm{I}_{\mathrm{HD}}$ & -0.37 & 0.01 & 0.00 & -0.79 & 0.00 \\
\hline $\mathrm{I}_{\mathrm{HE}}$ & -0.34 & 0.01 & 0.00 & -0.79 & 0.00 \\
\hline $\mathrm{I}_{\mathrm{HF}}$ & -0.39 & 0.01 & -0.01 & -0.79 & 0.01 \\
\hline $\mathrm{I}_{\mathrm{HG}}$ & -0.29 & 0.03 & -0.01 & -0.79 & 0.01 \\
\hline $\mathrm{I}_{\mathrm{HH}}$ & -0.39 & 2.00 & -0.77 & -0.79 & 0.98 \\
\hline $\mathrm{I}_{\mathrm{HI}}$ & -0.36 & 0.01 & 0.00 & -0.79 & 0.00 \\
\hline $\mathrm{I}_{\mathrm{HJ}}$ & -0.38 & 0.00 & 0.00 & -0.79 & 0.00 \\
\hline $\mathrm{I}_{\mathrm{HK}}$ & -0.30 & 0.00 & 0.00 & -0.79 & 0.00 \\
\hline $\mathrm{I}_{\mathrm{HL}}$ & 0.21 & 0.00 & 0.00 & -0.79 & 0.00 \\
\hline $\mathrm{I}_{\mathrm{HM}}$ & -0.26 & 0.00 & 0.00 & -0.79 & 0.00 \\
\hline $\mathrm{I}_{\mathrm{IA}}$ & 3.42 & 0.00 & 0.01 & -0.72 & -0.01 \\
\hline $\mathrm{I}_{\mathrm{IB}}$ & -0.32 & 0.00 & 0.00 & -0.72 & 0.00 \\
\hline $\mathrm{I}_{\mathrm{IC}}$ & -0.24 & 0.00 & 0.00 & -0.72 & 0.00 \\
\hline $\mathrm{I}_{\mathrm{ID}}$ & -0.37 & 0.00 & 0.00 & -0.72 & 0.00 \\
\hline $\mathrm{I}_{\mathrm{IE}}$ & -0.34 & 0.00 & 0.00 & -0.72 & 0.00 \\
\hline $\mathrm{I}_{\mathrm{IF}}$ & -0.39 & 0.01 & 0.00 & -0.72 & 0.00 \\
\hline $\mathrm{I}_{\mathrm{IG}}$ & -0.29 & 0.01 & 0.00 & -0.72 & 0.00 \\
\hline $\mathrm{I}_{\mathrm{IH}}$ & -0.39 & 0.01 & 0.00 & -0.72 & 0.01 \\
\hline $\mathrm{I}_{\mathrm{II}}$ & -0.36 & 2.00 & -0.71 & -0.72 & 0.99 \\
\hline $\mathrm{I}_{\mathrm{IJ}}$ & -0.38 & 0.01 & 0.00 & -0.72 & 0.01 \\
\hline $\mathrm{I}_{\mathrm{IK}}$ & -0.30 & 0.01 & 0.00 & -0.72 & 0.00 \\
\hline $\mathrm{I}_{\mathrm{IL}}$ & 0.21 & 0.01 & 0.00 & -0.72 & 0.00 \\
\hline $\mathrm{I}_{\mathrm{IM}}$ & -0.26 & 0.00 & 0.00 & -0.72 & 0.00 \\
\hline
\end{tabular}

Appendix Table A.18 Accessibility Index Pairs from normalized job figures for half mile buffer (contd.). 


\begin{tabular}{|c|c|c|c|c|c|}
\hline Accessibility Index Pairs & $\overline{A_{j}}$ & $\overline{F_{i j}}$ & $\mathrm{~A}_{\mathrm{j}} * \mathrm{~F}_{\mathrm{ij}}$ & $\Sigma \mathrm{A}_{\mathrm{k}} * \mathrm{~F}_{\mathrm{ik}}$ & $\mathrm{I}_{\mathrm{ij}}=\left(\mathrm{A}_{\mathrm{j}} * \mathrm{~F}_{\mathrm{ij}} /\left(\Sigma \mathrm{A}_{\mathrm{k}} * \mathrm{~F}_{\mathrm{ik}}\right)\right)$ \\
\hline $\mathrm{I}_{\mathrm{JA}}$ & 3.42 & 0.00 & 0.01 & -0.77 & -0.01 \\
\hline $\mathrm{I}_{\mathrm{JB}}$ & -0.32 & 0.00 & 0.00 & -0.77 & 0.00 \\
\hline $\mathrm{I}_{\mathrm{JC}}$ & -0.24 & 0.00 & 0.00 & -0.77 & 0.00 \\
\hline $\mathrm{I}_{\mathrm{JD}}$ & -0.37 & 0.00 & 0.00 & -0.77 & 0.00 \\
\hline $\mathrm{I}_{\mathrm{JE}}$ & -0.34 & 0.00 & 0.00 & -0.77 & 0.00 \\
\hline $\mathrm{I}_{\mathrm{JF}}$ & -0.39 & 0.00 & 0.00 & -0.77 & 0.00 \\
\hline $\mathrm{I}_{\mathrm{JG}}$ & -0.29 & 0.00 & 0.00 & -0.77 & 0.00 \\
\hline $\mathrm{I}_{\mathrm{JH}}$ & -0.39 & 0.00 & 0.00 & -0.77 & 0.00 \\
\hline $\mathrm{I}_{\mathrm{JI}}$ & -0.36 & 0.01 & 0.00 & -0.77 & 0.00 \\
\hline $\mathrm{I}_{\mathrm{JJ}}$ & -0.38 & 2.00 & -0.76 & -0.77 & 0.99 \\
\hline $\mathrm{I}_{\mathrm{JK}}$ & -0.30 & 0.02 & -0.01 & -0.77 & 0.01 \\
\hline $\mathrm{I}_{\mathrm{JL}}$ & 0.21 & 0.01 & 0.00 & -0.77 & 0.00 \\
\hline$I_{J M}$ & -0.26 & 0.01 & 0.00 & -0.77 & 0.00 \\
\hline $\mathrm{I}_{\mathrm{KA}}$ & 3.42 & 0.00 & 0.01 & -0.60 & -0.01 \\
\hline $\mathrm{I}_{\mathrm{KB}}$ & -0.32 & 0.00 & 0.00 & -0.60 & 0.00 \\
\hline $\mathrm{I}_{\mathrm{KC}}$ & -0.24 & 0.00 & 0.00 & -0.60 & 0.00 \\
\hline$I_{\mathrm{KD}}$ & -0.37 & 0.00 & 0.00 & -0.60 & 0.00 \\
\hline $\mathrm{I}_{\mathrm{KE}}$ & -0.34 & 0.00 & 0.00 & -0.60 & 0.00 \\
\hline $\mathrm{I}_{\mathrm{KF}}$ & -0.39 & 0.00 & 0.00 & -0.60 & 0.00 \\
\hline$I_{\mathrm{KG}}$ & -0.29 & 0.00 & 0.00 & -0.60 & 0.00 \\
\hline$I_{K H}$ & -0.39 & 0.00 & 0.00 & -0.60 & 0.00 \\
\hline $\mathrm{I}_{\mathrm{KI}}$ & -0.36 & 0.01 & 0.00 & -0.60 & 0.00 \\
\hline $\mathrm{I}_{\mathrm{KJ}}$ & -0.38 & 0.02 & -0.01 & -0.60 & 0.01 \\
\hline$I_{K K}$ & -0.30 & 2.00 & -0.60 & -0.60 & 1.00 \\
\hline $\mathrm{I}_{\mathrm{KL}}$ & 0.21 & 0.06 & 0.01 & -0.60 & -0.02 \\
\hline $\mathrm{I}_{\mathrm{KM}}$ & -0.26 & 0.01 & 0.00 & -0.60 & 0.00 \\
\hline $\mathrm{I}_{\mathrm{LA}}$ & 3.42 & 0.00 & 0.01 & 0.39 & 0.02 \\
\hline $\mathrm{I}_{\mathrm{LB}}$ & -0.32 & 0.00 & 0.00 & 0.39 & 0.00 \\
\hline $\mathrm{I}_{\mathrm{LC}}$ & -0.24 & 0.00 & 0.00 & 0.39 & 0.00 \\
\hline $\mathrm{I}_{\mathrm{LD}}$ & -0.37 & 0.00 & 0.00 & 0.39 & 0.00 \\
\hline $\mathrm{I}_{\mathrm{LE}}$ & -0.34 & 0.00 & 0.00 & 0.39 & 0.00 \\
\hline $\mathrm{I}_{\mathrm{LF}}$ & -0.39 & 0.00 & 0.00 & 0.39 & 0.00 \\
\hline $\mathrm{I}_{\mathrm{LG}}$ & -0.29 & 0.00 & 0.00 & 0.39 & 0.00 \\
\hline $\mathrm{I}_{\mathrm{LH}}$ & -0.39 & 0.00 & 0.00 & 0.39 & 0.00 \\
\hline $\mathrm{I}_{\mathrm{LI}}$ & -0.36 & 0.01 & 0.00 & 0.39 & -0.01 \\
\hline $\mathrm{I}_{\mathrm{LJ}}$ & -0.38 & 0.01 & -0.01 & 0.39 & -0.01 \\
\hline $\mathrm{I}_{\mathrm{LK}}$ & -0.30 & 0.06 & -0.02 & 0.39 & -0.05 \\
\hline $\mathrm{I}_{\mathrm{LL}}$ & 0.21 & 2.00 & 0.42 & 0.39 & 1.08 \\
\hline $\mathrm{I}_{\mathrm{LM}}$ & -0.26 & 0.03 & -0.01 & 0.39 & -0.02 \\
\hline
\end{tabular}

Appendix Table A.19 Accessibility Index Pairs from normalized job figures for half mile buffer (contd.). 


\begin{tabular}{|c|r|c|r|r|r|}
\hline Accessibility Index Pairs & \multicolumn{1}{|c|}{$\mathrm{A}_{\mathrm{j}}$} & $\mathrm{F}_{\mathrm{ij}}$ & $\mathrm{A}_{\mathrm{j}}{ }^{*} \mathrm{~F}_{\mathrm{ij}}$ & $\Sigma \mathrm{A}_{\mathrm{k}}{ }^{*} \mathrm{~F}_{\mathrm{ik}}$ & $\mathrm{I}_{\mathrm{ij}}=\left(\mathrm{A}_{\mathrm{j}}{ }^{*} \mathrm{~F}_{\mathrm{ij}} /\left(\Sigma \mathrm{A}_{\mathrm{k}}{ }^{*} \mathrm{~F}_{\mathrm{ik}}\right)\right)$ \\
\hline $\mathrm{I}_{\mathrm{MA}}$ & 3.42 & 0.00 & 0.01 & -0.52 & -0.01 \\
\hline $\mathrm{I}_{\mathrm{MB}}$ & -0.32 & 0.00 & 0.00 & -0.52 & 0.00 \\
\hline $\mathrm{I}_{\mathrm{MC}}$ & -0.24 & 0.00 & 0.00 & -0.52 & 0.00 \\
\hline $\mathrm{I}_{\mathrm{MD}}$ & -0.37 & 0.00 & 0.00 & -0.52 & 0.00 \\
\hline $\mathrm{I}_{\mathrm{ME}}$ & -0.34 & 0.00 & 0.00 & -0.52 & 0.00 \\
\hline $\mathrm{I}_{\mathrm{MF}}$ & -0.39 & 0.00 & 0.00 & -0.52 & 0.00 \\
\hline $\mathrm{I}_{\mathrm{MG}}$ & -0.29 & 0.00 & 0.00 & -0.52 & 0.00 \\
\hline $\mathrm{I}_{\mathrm{MH}}$ & -0.39 & 0.00 & 0.00 & -0.52 & 0.00 \\
\hline $\mathrm{I}_{\mathrm{MI}}$ & -0.36 & 0.00 & 0.00 & -0.52 & 0.01 \\
\hline $\mathrm{I}_{\mathrm{MJ}}$ & -0.38 & 0.01 & 0.00 & -0.52 & 0.01 \\
\hline $\mathrm{I}_{\mathrm{MK}}$ & -0.30 & 0.02 & -0.01 & -0.52 & -0.01 \\
\hline $\mathrm{I}_{\mathrm{ML}}$ & 0.21 & 0.03 & 0.01 & -0.52 & 0.99 \\
\hline $\mathrm{I}_{\mathrm{MM}}$ & -0.26 & 2.00 & -0.52 & -0.52 & \\
\hline
\end{tabular}

Appendix Table A.20 Accessibility Index Pairs from normalized job figures for half mile buffer (contd.). 


\begin{tabular}{|c|c|c|c|c|c|}
\hline Accessibility Index Pairs & $\overline{A_{j}}$ & $F_{i j}$ & $\overline{A_{j} * F_{i j}}$ & $\Sigma \mathrm{A}_{\mathrm{k}} * \mathrm{~F}_{\mathrm{ik}}$ & $\mathrm{I}_{\mathrm{ij}}=\left(\mathrm{A}_{\mathrm{j}} * \mathrm{~F}_{\mathrm{ij}} /\left(\Sigma \mathrm{A}_{\mathrm{k}} * \mathrm{~F}_{\mathrm{ik}}\right)\right)$ \\
\hline $\mathrm{I}_{\mathrm{AA}}$ & 1.58 & 2.00 & 3.16 & 3.14 & 1.01 \\
\hline $\mathrm{I}_{\mathrm{AB}}$ & -0.20 & 0.06 & -0.01 & 3.14 & 0.00 \\
\hline $\mathrm{I}_{\mathrm{AC}}$ & -0.34 & 0.02 & -0.01 & 3.14 & 0.00 \\
\hline $\mathrm{I}_{\mathrm{AD}}$ & 0.05 & 0.01 & 0.00 & 3.14 & 0.00 \\
\hline $\mathrm{I}_{\mathrm{AE}}$ & 0.88 & 0.00 & 0.00 & 3.14 & 0.00 \\
\hline $\mathrm{I}_{\mathrm{AF}}$ & -1.13 & 0.00 & -0.01 & 3.14 & 0.00 \\
\hline $\mathrm{I}_{\mathrm{AG}}$ & -0.64 & 0.00 & 0.00 & 3.14 & 0.00 \\
\hline $\mathrm{I}_{\mathrm{AH}}$ & -1.59 & 0.00 & -0.01 & 3.14 & 0.00 \\
\hline $\mathrm{I}_{\mathrm{AI}}$ & 0.44 & 0.00 & 0.00 & 3.14 & 0.00 \\
\hline $\mathrm{I}_{\mathrm{AJ}}$ & 0.07 & 0.00 & 0.00 & 3.14 & 0.00 \\
\hline $\mathrm{I}_{\mathrm{AK}}$ & 0.05 & 0.00 & 0.00 & 3.14 & 0.00 \\
\hline $\mathrm{I}_{\mathrm{AL}}$ & 1.97 & 0.00 & 0.00 & 3.14 & 0.00 \\
\hline $\mathrm{I}_{\mathrm{AM}}$ & -1.13 & 0.00 & 0.00 & 3.14 & 0.00 \\
\hline $\mathrm{I}_{\mathrm{BA}}$ & 1.58 & 0.06 & 0.09 & -0.33 & -0.26 \\
\hline $\mathrm{I}_{\mathrm{BB}}$ & -0.20 & 2.00 & -0.41 & -0.33 & 1.22 \\
\hline $\mathrm{I}_{\mathrm{BC}}$ & -0.34 & 0.02 & -0.01 & -0.33 & 0.02 \\
\hline $\mathrm{I}_{\mathrm{BD}}$ & 0.05 & 0.01 & 0.00 & -0.33 & 0.00 \\
\hline $\mathrm{I}_{\mathrm{BE}}$ & 0.88 & 0.01 & 0.00 & -0.33 & -0.01 \\
\hline $\mathrm{I}_{\mathrm{BF}}$ & -1.13 & 0.01 & -0.01 & -0.33 & 0.02 \\
\hline $\mathrm{I}_{\mathrm{BG}}$ & -0.64 & 0.00 & 0.00 & -0.33 & 0.01 \\
\hline $\mathrm{I}_{\mathrm{BH}}$ & -1.59 & 0.00 & -0.01 & -0.33 & 0.02 \\
\hline $\mathrm{I}_{\mathrm{BI}}$ & 0.44 & 0.00 & 0.00 & -0.33 & 0.00 \\
\hline $\mathrm{I}_{\mathrm{BJ}}$ & 0.07 & 0.00 & 0.00 & -0.33 & 0.00 \\
\hline $\mathrm{I}_{\mathrm{BK}}$ & 0.05 & 0.00 & 0.00 & -0.33 & 0.00 \\
\hline $\mathrm{I}_{\mathrm{BL}}$ & 1.97 & 0.00 & 0.00 & -0.33 & -0.01 \\
\hline $\mathrm{I}_{\mathrm{BM}}$ & -1.13 & 0.00 & 0.00 & -0.33 & 0.01 \\
\hline $\mathrm{I}_{\mathrm{CA}}$ & 1.58 & 0.02 & 0.03 & -0.66 & -0.04 \\
\hline $\mathrm{I}_{\mathrm{CB}}$ & -0.20 & 0.02 & 0.00 & -0.66 & 0.01 \\
\hline $\mathrm{I}_{\mathrm{CC}}$ & -0.34 & 2.00 & -0.68 & -0.66 & 1.02 \\
\hline $\mathrm{I}_{\mathrm{CD}}$ & 0.05 & 0.03 & 0.00 & -0.66 & 0.00 \\
\hline $\mathrm{I}_{\mathrm{CE}}$ & 0.88 & 0.01 & 0.01 & -0.66 & -0.01 \\
\hline $\mathrm{I}_{\mathrm{CF}}$ & -1.13 & 0.01 & -0.01 & -0.66 & 0.01 \\
\hline $\mathrm{I}_{\mathrm{CG}}$ & -0.64 & 0.01 & 0.00 & -0.66 & 0.01 \\
\hline $\mathrm{I}_{\mathrm{CH}}$ & -1.59 & 0.00 & -0.01 & -0.66 & 0.01 \\
\hline $\mathrm{I}_{\mathrm{CI}}$ & 0.44 & 0.00 & 0.00 & -0.66 & 0.00 \\
\hline $\mathrm{I}_{\mathrm{CJ}}$ & 0.07 & 0.00 & 0.00 & -0.66 & 0.00 \\
\hline $\mathrm{I}_{\mathrm{CK}}$ & 0.05 & 0.00 & 0.00 & -0.66 & 0.00 \\
\hline $\mathrm{I}_{\mathrm{CL}}$ & 1.97 & 0.00 & 0.00 & -0.66 & -0.01 \\
\hline $\mathrm{I}_{\mathrm{CM}}$ & -1.13 & 0.00 & 0.00 & -0.66 & 0.00 \\
\hline
\end{tabular}

Appendix Table A.21 Accessibility Index Pairs from normalized population figures for half mile buffer. 


\begin{tabular}{|c|c|c|c|c|c|}
\hline Accessibility Index Pairs & $A_{j}$ & $F_{i j}$ & $\overline{A_{j} * F_{i j}}$ & $\Sigma \mathrm{A}_{\mathrm{k}} * \mathrm{~F}_{\mathrm{ik}}$ & $\mathrm{I}_{\mathrm{ij}}=\left(\mathrm{A}_{\mathrm{j}} * \mathrm{~F}_{\mathrm{ij}} /\left(\Sigma \mathrm{A}_{\mathrm{k}} * \mathrm{~F}_{\mathrm{ik}}\right)\right)$ \\
\hline $\mathrm{I}_{\mathrm{DA}}$ & 1.58 & 0.01 & 0.02 & 0.10 & 0.17 \\
\hline $\mathrm{I}_{\mathrm{DB}}$ & -0.20 & 0.01 & 0.00 & 0.10 & -0.03 \\
\hline $\mathrm{I}_{\mathrm{DC}}$ & -0.34 & 0.03 & -0.01 & 0.10 & -0.09 \\
\hline $\mathrm{I}_{\mathrm{DD}}$ & 0.05 & 2.00 & 0.10 & 0.10 & 1.04 \\
\hline $\mathrm{I}_{\mathrm{DE}}$ & 0.88 & 0.01 & 0.01 & 0.10 & 0.08 \\
\hline $\mathrm{I}_{\mathrm{DF}}$ & -1.13 & 0.01 & -0.01 & 0.10 & -0.10 \\
\hline $\mathrm{I}_{\mathrm{DG}}$ & -0.64 & 0.01 & 0.00 & 0.10 & -0.05 \\
\hline $\mathrm{I}_{\mathrm{DH}}$ & -1.59 & 0.00 & -0.01 & 0.10 & -0.06 \\
\hline $\mathrm{I}_{\mathrm{DI}}$ & 0.44 & 0.00 & 0.00 & 0.10 & 0.02 \\
\hline $\mathrm{I}_{\mathrm{DJ}}$ & 0.07 & 0.00 & 0.00 & 0.10 & 0.00 \\
\hline $\mathrm{I}_{\mathrm{DK}}$ & 0.05 & 0.00 & 0.00 & 0.10 & 0.00 \\
\hline $\mathrm{I}_{\mathrm{DL}}$ & 1.97 & 0.00 & 0.00 & 0.10 & 0.04 \\
\hline $\mathrm{I}_{\mathrm{DM}}$ & -1.13 & 0.00 & 0.00 & 0.10 & -0.02 \\
\hline $\mathrm{I}_{\mathrm{EA}}$ & 1.58 & 0.00 & 0.01 & 1.71 & 0.00 \\
\hline $\mathrm{I}_{\mathrm{EB}}$ & -0.20 & 0.01 & 0.00 & 1.71 & 0.00 \\
\hline $\mathrm{I}_{\mathrm{EC}}$ & -0.34 & 0.01 & 0.00 & 1.71 & 0.00 \\
\hline $\mathrm{I}_{\mathrm{ED}}$ & 0.05 & 0.01 & 0.00 & 1.71 & 0.00 \\
\hline $\mathrm{I}_{\mathrm{EE}}$ & 0.88 & 2.00 & 1.76 & 1.71 & 1.03 \\
\hline $\mathrm{I}_{\mathrm{EF}}$ & -1.13 & 0.03 & -0.03 & 1.71 & -0.02 \\
\hline $\mathrm{I}_{\mathrm{EG}}$ & -0.64 & 0.01 & -0.01 & 1.71 & -0.01 \\
\hline $\mathrm{I}_{\mathrm{EH}}$ & -1.59 & 0.01 & -0.02 & 1.71 & -0.01 \\
\hline $\mathrm{I}_{\mathrm{EI}}$ & 0.44 & 0.00 & 0.00 & 1.71 & 0.00 \\
\hline $\mathrm{I}_{\mathrm{EJ}}$ & 0.07 & 0.00 & 0.00 & 1.71 & 0.00 \\
\hline $\mathrm{I}_{\mathrm{EK}}$ & 0.05 & 0.00 & 0.00 & 1.71 & 0.00 \\
\hline $\mathrm{I}_{\mathrm{EL}}$ & 1.97 & 0.00 & 0.01 & 1.71 & 0.00 \\
\hline $\mathrm{I}_{\mathrm{EM}}$ & -1.13 & 0.00 & 0.00 & 1.71 & 0.00 \\
\hline $\mathrm{I}_{\mathrm{FA}}$ & 1.58 & 0.00 & 0.01 & -2.27 & 0.00 \\
\hline $\mathrm{I}_{\mathrm{FB}}$ & -0.20 & 0.01 & 0.00 & -2.27 & 0.00 \\
\hline $\mathrm{I}_{\mathrm{FC}}$ & -0.34 & 0.01 & 0.00 & -2.27 & 0.00 \\
\hline $\mathrm{I}_{\mathrm{FD}}$ & 0.05 & 0.01 & 0.00 & -2.27 & 0.00 \\
\hline $\mathrm{I}_{\mathrm{FE}}$ & 0.88 & 0.03 & 0.02 & -2.27 & -0.01 \\
\hline $\mathrm{I}_{\mathrm{FF}}$ & -1.13 & 2.00 & -2.27 & -2.27 & 1.00 \\
\hline $\mathrm{I}_{\mathrm{FG}}$ & -0.64 & 0.03 & -0.02 & -2.27 & 0.01 \\
\hline $\mathrm{I}_{\mathrm{FH}}$ & -1.59 & 0.01 & -0.02 & -2.27 & 0.01 \\
\hline $\mathrm{I}_{\mathrm{FI}}$ & 0.44 & 0.01 & 0.00 & -2.27 & 0.00 \\
\hline $\mathrm{I}_{\mathrm{FJ}}$ & 0.07 & 0.00 & 0.00 & -2.27 & 0.00 \\
\hline $\mathrm{I}_{\mathrm{FK}}$ & 0.05 & 0.00 & 0.00 & -2.27 & 0.00 \\
\hline $\mathrm{I}_{\mathrm{FL}}$ & 1.97 & 0.00 & 0.01 & -2.27 & 0.00 \\
\hline $\mathrm{I}_{\mathrm{FM}}$ & -1.13 & 0.00 & 0.00 & -2.27 & 0.00 \\
\hline
\end{tabular}

Appendix Table A.22 Accessibility Index Pairs from normalized population figures for half mile buffer (contd.). 


\begin{tabular}{|c|c|c|c|c|c|}
\hline Accessibility Index Pairs & $\overline{A_{j}}$ & $F_{i j}$ & $\overline{A_{j} * F_{i j}}$ & $\Sigma \mathrm{A}_{\mathrm{k}} * \mathrm{~F}_{\mathrm{ik}}$ & $\mathrm{I}_{\mathrm{ij}}=\left(\mathrm{A}_{\mathrm{j}} * \mathrm{~F}_{\mathrm{ij}} /\left(\Sigma \mathrm{A}_{\mathrm{k}} * \mathrm{~F}_{\mathrm{ik}}\right)\right)$ \\
\hline $\mathrm{I}_{\mathrm{GA}}$ & 1.58 & 0.00 & 0.01 & -1.33 & 0.00 \\
\hline $\mathrm{I}_{\mathrm{GB}}$ & -0.20 & 0.00 & 0.00 & -1.33 & 0.00 \\
\hline $\mathrm{I}_{\mathrm{GC}}$ & -0.34 & 0.01 & 0.00 & -1.33 & 0.00 \\
\hline $\mathrm{I}_{\mathrm{GD}}$ & 0.05 & 0.01 & 0.00 & -1.33 & 0.00 \\
\hline $\mathrm{I}_{\mathrm{GE}}$ & 0.88 & 0.01 & 0.01 & -1.33 & -0.01 \\
\hline $\mathrm{I}_{\mathrm{GF}}$ & -1.13 & 0.03 & -0.03 & -1.33 & 0.03 \\
\hline $\mathrm{I}_{\mathrm{GG}}$ & -0.64 & 2.00 & -1.28 & -1.33 & 0.96 \\
\hline $\mathrm{I}_{\mathrm{GH}}$ & -1.59 & 0.03 & -0.04 & -1.33 & 0.03 \\
\hline $\mathrm{I}_{\mathrm{GI}}$ & 0.44 & 0.01 & 0.00 & -1.33 & 0.00 \\
\hline $\mathrm{I}_{\mathrm{GJ}}$ & 0.07 & 0.00 & 0.00 & -1.33 & 0.00 \\
\hline $\mathrm{I}_{\mathrm{GK}}$ & 0.05 & 0.00 & 0.00 & -1.33 & 0.00 \\
\hline $\mathrm{I}_{\mathrm{GL}}$ & 1.97 & 0.00 & 0.01 & -1.33 & 0.00 \\
\hline $\mathrm{I}_{\mathrm{GM}}$ & -1.13 & 0.00 & 0.00 & -1.33 & 0.00 \\
\hline $\mathrm{I}_{\mathrm{HA}}$ & 1.58 & 0.00 & 0.01 & -3.20 & 0.00 \\
\hline $\mathrm{I}_{\mathrm{HB}}$ & -0.20 & 0.00 & 0.00 & -3.20 & 0.00 \\
\hline $\mathrm{I}_{\mathrm{HC}}$ & -0.34 & 0.00 & 0.00 & -3.20 & 0.00 \\
\hline $\mathrm{I}_{\mathrm{HD}}$ & 0.05 & 0.01 & 0.00 & -3.20 & 0.00 \\
\hline $\mathrm{I}_{\mathrm{HE}}$ & 0.88 & 0.01 & 0.01 & -3.20 & 0.00 \\
\hline $\mathrm{I}_{\mathrm{HF}}$ & -1.13 & 0.01 & -0.02 & -3.20 & 0.01 \\
\hline $\mathrm{I}_{\mathrm{HG}}$ & -0.64 & 0.03 & -0.02 & -3.20 & 0.01 \\
\hline $\mathrm{I}_{\mathrm{HH}}$ & -1.59 & 2.00 & -3.19 & -3.20 & 1.00 \\
\hline $\mathrm{I}_{\mathrm{HI}}$ & 0.44 & 0.01 & 0.00 & -3.20 & 0.00 \\
\hline $\mathrm{I}_{\mathrm{HJ}}$ & 0.07 & 0.00 & 0.00 & -3.20 & 0.00 \\
\hline $\mathrm{I}_{\mathrm{HK}}$ & 0.05 & 0.00 & 0.00 & -3.20 & 0.00 \\
\hline $\mathrm{I}_{\mathrm{HL}}$ & 1.97 & 0.00 & 0.01 & -3.20 & 0.00 \\
\hline $\mathrm{I}_{\mathrm{HM}}$ & -1.13 & 0.00 & 0.00 & -3.20 & 0.00 \\
\hline $\mathrm{I}_{\mathrm{IA}}$ & 1.58 & 0.00 & 0.00 & 0.87 & 0.00 \\
\hline $\mathrm{I}_{\mathrm{IB}}$ & -0.20 & 0.00 & 0.00 & 0.87 & 0.00 \\
\hline $\mathrm{I}_{\mathrm{IC}}$ & -0.34 & 0.00 & 0.00 & 0.87 & 0.00 \\
\hline $\mathrm{I}_{\mathrm{ID}}$ & 0.05 & 0.00 & 0.00 & 0.87 & 0.00 \\
\hline $\mathrm{I}_{\mathrm{IE}}$ & 0.88 & 0.00 & 0.00 & 0.87 & 0.00 \\
\hline $\mathrm{I}_{\mathrm{IF}}$ & -1.13 & 0.01 & -0.01 & 0.87 & -0.01 \\
\hline $\mathrm{I}_{\mathrm{IG}}$ & -0.64 & 0.01 & 0.00 & 0.87 & -0.01 \\
\hline $\mathrm{I}_{\mathrm{IH}}$ & -1.59 & 0.01 & -0.02 & 0.87 & -0.02 \\
\hline $\mathrm{I}_{\mathrm{II}}$ & 0.44 & 2.00 & 0.88 & 0.87 & 1.02 \\
\hline $\mathrm{I}_{\mathrm{IJ}}$ & 0.07 & 0.01 & 0.00 & 0.87 & 0.00 \\
\hline $\mathrm{I}_{\mathrm{IK}}$ & 0.05 & 0.01 & 0.00 & 0.87 & 0.00 \\
\hline $\mathrm{I}_{\mathrm{IL}}$ & 1.97 & 0.01 & 0.01 & 0.87 & 0.01 \\
\hline $\mathrm{I}_{\mathrm{IM}}$ & -1.13 & 0.00 & -0.01 & 0.87 & -0.01 \\
\hline
\end{tabular}

Appendix Table A.23 Accessibility Index Pairs from normalized population figures for half mile buffer (contd.). 


\begin{tabular}{|c|c|c|c|c|c|}
\hline Accessibility Index Pairs & $A_{j}$ & $F_{i j}$ & $\overline{A_{j} * F_{i j}}$ & $\Sigma \mathrm{A}_{\mathrm{k}} * \mathrm{~F}_{\mathrm{ik}}$ & $\mathrm{I}_{\mathrm{ij}}=\left(\mathrm{A}_{\mathrm{j}} * \mathrm{~F}_{\mathrm{ij}} /\left(\Sigma \mathrm{A}_{\mathrm{k}} * \mathrm{~F}_{\mathrm{ik}}\right)\right)$ \\
\hline $\mathrm{I}_{\mathrm{JA}}$ & 1.58 & 0.00 & 0.00 & 0.16 & 0.02 \\
\hline $\mathrm{I}_{\mathrm{JB}}$ & -0.20 & 0.00 & 0.00 & 0.16 & 0.00 \\
\hline $\mathrm{I}_{\mathrm{JC}}$ & -0.34 & 0.00 & 0.00 & 0.16 & -0.01 \\
\hline $\mathrm{I}_{\mathrm{JD}}$ & 0.05 & 0.00 & 0.00 & 0.16 & 0.00 \\
\hline $\mathrm{I}_{\mathrm{JE}}$ & 0.88 & 0.00 & 0.00 & 0.16 & 0.02 \\
\hline $\mathrm{I}_{\mathrm{JF}}$ & -1.13 & 0.00 & 0.00 & 0.16 & -0.03 \\
\hline $\mathrm{I}_{\mathrm{JG}}$ & -0.64 & 0.00 & 0.00 & 0.16 & -0.02 \\
\hline $\mathrm{I}_{\mathrm{JH}}$ & -1.59 & 0.00 & -0.01 & 0.16 & -0.05 \\
\hline $\mathrm{I}_{\mathrm{JI}}$ & 0.44 & 0.01 & 0.00 & 0.16 & 0.03 \\
\hline $\mathrm{I}_{\mathrm{JJ}}$ & 0.07 & 2.00 & 0.14 & 0.16 & 0.92 \\
\hline $\mathrm{I}_{\mathrm{JK}}$ & 0.05 & 0.02 & 0.00 & 0.16 & 0.01 \\
\hline $\mathrm{I}_{\mathrm{JL}}$ & 1.97 & 0.01 & 0.03 & 0.16 & 0.18 \\
\hline $\mathrm{I}_{\mathrm{JM}}$ & -1.13 & 0.01 & -0.01 & 0.16 & -0.07 \\
\hline $\mathrm{I}_{\mathrm{KA}}$ & 1.58 & 0.00 & 0.00 & 0.20 & 0.01 \\
\hline $\mathrm{I}_{\mathrm{KB}}$ & -0.20 & 0.00 & 0.00 & 0.20 & 0.00 \\
\hline $\mathrm{I}_{\mathrm{KC}}$ & -0.34 & 0.00 & 0.00 & 0.20 & 0.00 \\
\hline $\mathrm{I}_{\mathrm{KD}}$ & 0.05 & 0.00 & 0.00 & 0.20 & 0.00 \\
\hline $\mathrm{I}_{\mathrm{KE}}$ & 0.88 & 0.00 & 0.00 & 0.20 & 0.01 \\
\hline $\mathrm{I}_{\mathrm{KF}}$ & -1.13 & 0.00 & 0.00 & 0.20 & -0.02 \\
\hline $\mathrm{I}_{\mathrm{KG}}$ & -0.64 & 0.00 & 0.00 & 0.20 & -0.01 \\
\hline $\mathrm{I}_{\mathrm{KH}}$ & -1.59 & 0.00 & -0.01 & 0.20 & -0.03 \\
\hline $\mathrm{I}_{\mathrm{KI}}$ & 0.44 & 0.01 & 0.00 & 0.20 & 0.01 \\
\hline $\mathrm{I}_{\mathrm{KJ}}$ & 0.07 & 0.02 & 0.00 & 0.20 & 0.01 \\
\hline $\mathrm{I}_{\mathrm{KK}}$ & 0.05 & 2.00 & 0.10 & 0.20 & 0.48 \\
\hline $\mathrm{I}_{\mathrm{KL}}$ & 1.97 & 0.06 & 0.12 & 0.20 & 0.59 \\
\hline $\mathrm{I}_{\mathrm{KM}}$ & -1.13 & 0.01 & -0.01 & 0.20 & -0.05 \\
\hline $\mathrm{I}_{\mathrm{LA}}$ & 1.58 & 0.00 & 0.00 & 3.90 & 0.00 \\
\hline $\mathrm{I}_{\mathrm{LB}}$ & -0.20 & 0.00 & 0.00 & 3.90 & 0.00 \\
\hline $\mathrm{I}_{\mathrm{LC}}$ & -0.34 & 0.00 & 0.00 & 3.90 & 0.00 \\
\hline $\mathrm{I}_{\mathrm{LD}}$ & 0.05 & 0.00 & 0.00 & 3.90 & 0.00 \\
\hline $\mathrm{I}_{\mathrm{LE}}$ & 0.88 & 0.00 & 0.00 & 3.90 & 0.00 \\
\hline $\mathrm{I}_{\mathrm{LF}}$ & -1.13 & 0.00 & 0.00 & 3.90 & 0.00 \\
\hline $\mathrm{I}_{\mathrm{LG}}$ & -0.64 & 0.00 & 0.00 & 3.90 & 0.00 \\
\hline $\mathrm{I}_{\mathrm{LH}}$ & -1.59 & 0.00 & -0.01 & 3.90 & 0.00 \\
\hline $\mathrm{I}_{\mathrm{LI}}$ & 0.44 & 0.01 & 0.00 & 3.90 & 0.00 \\
\hline $\mathrm{I}_{\mathrm{LJ}}$ & 0.07 & 0.01 & 0.00 & 3.90 & 0.00 \\
\hline $\mathrm{I}_{\mathrm{LK}}$ & 0.05 & 0.06 & 0.00 & 3.90 & 0.00 \\
\hline $\mathrm{I}_{\mathrm{LL}}$ & 1.97 & 2.00 & 3.93 & 3.90 & 1.01 \\
\hline $\mathrm{I}_{\mathrm{LM}}$ & -1.13 & 0.03 & -0.03 & 3.90 & -0.01 \\
\hline
\end{tabular}

Appendix Table A.24 Accessibility Index Pairs from normalized population figures for half mile buffer (contd.). 


\begin{tabular}{|c|r|r|r|r|r|}
\hline Accessibility Index Pairs & \multicolumn{1}{c|}{$\mathrm{A}_{\mathrm{j}}$} & \multicolumn{1}{c|}{$\mathrm{F}_{\mathrm{ij}}$} & $\mathrm{A}_{\mathrm{j}}{ }^{*} \mathrm{~F}_{\mathrm{ij}}$ & $\Sigma \mathrm{A}_{\mathrm{k}}{ }^{*} \mathrm{~F}_{\mathrm{ik}}$ & $\mathrm{I}_{\mathrm{ij}}=\left(\mathrm{A}_{\mathrm{j}}{ }^{*} \mathrm{~F}_{\mathrm{ij}} /\left(\Sigma \mathrm{A}_{\mathrm{k}}{ }^{*} \mathrm{~F}_{\mathrm{ik}}\right)\right)$ \\
\hline $\mathrm{I}_{\mathrm{MA}}$ & 1.58 & 0.00 & 0.00 & -2.20 & 0.00 \\
\hline $\mathrm{I}_{\mathrm{MB}}$ & -0.20 & 0.00 & 0.00 & -2.20 & 0.00 \\
\hline $\mathrm{I}_{\mathrm{MC}}$ & -0.34 & 0.00 & 0.00 & -2.20 & 0.00 \\
\hline $\mathrm{I}_{\mathrm{MD}}$ & 0.05 & 0.00 & 0.00 & -2.20 & 0.00 \\
\hline $\mathrm{I}_{\mathrm{ME}}$ & 0.88 & 0.00 & 0.00 & -2.20 & 0.00 \\
\hline $\mathrm{I}_{\mathrm{MF}}$ & -1.13 & 0.00 & 0.00 & -2.20 & 0.00 \\
\hline $\mathrm{I}_{\mathrm{MG}}$ & -0.64 & 0.00 & 0.00 & -2.20 & 0.00 \\
\hline $\mathrm{I}_{\mathrm{MH}}$ & -1.59 & 0.00 & -0.01 & -2.20 & 0.00 \\
\hline $\mathrm{I}_{\mathrm{MI}}$ & 0.44 & 0.00 & 0.00 & -2.20 & 0.00 \\
\hline $\mathrm{I}_{\mathrm{MJ}}$ & 0.07 & 0.01 & 0.00 & -2.20 & 0.00 \\
\hline $\mathrm{I}_{\mathrm{MK}}$ & 0.05 & 0.02 & 0.00 & -2.20 & 0.00 \\
\hline $\mathrm{I}_{\mathrm{ML}}$ & 1.97 & 0.03 & 0.05 & -2.20 & -0.02 \\
\hline $\mathrm{I}_{\mathrm{MM}}$ & -1.13 & 2.00 & -2.26 & -2.20 & 1.02 \\
\hline
\end{tabular}

Appendix Table A.25 Accessibility Index Pairs from normalized population figures for half mile buffer (contd.). 


\begin{tabular}{|c|c|c|c|c|c|}
\hline Accessibility Index Pairs & $\overline{A_{j}}$ & $F_{i j}$ & $\overline{A_{j} * F_{i j}}$ & $\Sigma \mathrm{A}_{\mathrm{k}} * \mathrm{~F}_{\mathrm{ik}}$ & $\mathrm{I}_{\mathrm{ij}}=\left(\mathrm{A}_{\mathrm{j}} * \mathrm{~F}_{\mathrm{ij}} /\left(\Sigma \mathrm{A}_{\mathrm{k}} * \mathrm{~F}_{\mathrm{ik}}\right)\right)$ \\
\hline $\mathrm{I}_{\mathrm{AA}}$ & 1.11 & 2.00 & 2.22 & 2.21 & 1.00 \\
\hline $\mathrm{I}_{\mathrm{AB}}$ & 0.14 & 0.06 & 0.01 & 2.21 & 0.00 \\
\hline $\mathrm{I}_{\mathrm{AC}}$ & -0.74 & 0.02 & -0.01 & 2.21 & -0.01 \\
\hline $\mathrm{I}_{\mathrm{AD}}$ & -0.11 & 0.01 & 0.00 & 2.21 & 0.00 \\
\hline $\mathrm{I}_{\mathrm{AE}}$ & 0.85 & 0.00 & 0.00 & 2.21 & 0.00 \\
\hline $\mathrm{I}_{\mathrm{AF}}$ & -1.25 & 0.00 & -0.01 & 2.21 & 0.00 \\
\hline $\mathrm{I}_{\mathrm{AG}}$ & -0.22 & 0.00 & 0.00 & 2.21 & 0.00 \\
\hline $\mathrm{I}_{\mathrm{AH}}$ & -1.66 & 0.00 & -0.01 & 2.21 & 0.00 \\
\hline $\mathrm{I}_{\mathrm{AI}}$ & 0.84 & 0.00 & 0.00 & 2.21 & 0.00 \\
\hline $\mathrm{I}_{\mathrm{AJ}}$ & -0.25 & 0.00 & 0.00 & 2.21 & 0.00 \\
\hline $\mathrm{I}_{\mathrm{AK}}$ & 0.03 & 0.00 & 0.00 & 2.21 & 0.00 \\
\hline $\mathrm{I}_{\mathrm{AL}}$ & 2.14 & 0.00 & 0.00 & 2.21 & 0.00 \\
\hline $\mathrm{I}_{\mathrm{AM}}$ & -0.87 & 0.00 & 0.00 & 2.21 & 0.00 \\
\hline $\mathrm{I}_{\mathrm{BA}}$ & 1.11 & 0.06 & 0.06 & 0.31 & 0.20 \\
\hline $\mathrm{I}_{\mathrm{BB}}$ & 0.14 & 2.00 & 0.27 & 0.31 & 0.88 \\
\hline $\mathrm{I}_{\mathrm{BC}}$ & -0.74 & 0.02 & -0.02 & 0.31 & -0.06 \\
\hline $\mathrm{I}_{\mathrm{BD}}$ & -0.11 & 0.01 & 0.00 & 0.31 & 0.00 \\
\hline $\mathrm{I}_{\mathrm{BE}}$ & 0.85 & 0.01 & 0.00 & 0.31 & 0.01 \\
\hline $\mathrm{I}_{\mathrm{BF}}$ & -1.25 & 0.01 & -0.01 & 0.31 & -0.02 \\
\hline $\mathrm{I}_{\mathrm{BG}}$ & -0.22 & 0.00 & 0.00 & 0.31 & 0.00 \\
\hline $\mathrm{I}_{\mathrm{BH}}$ & -1.66 & 0.00 & -0.01 & 0.31 & -0.02 \\
\hline $\mathrm{I}_{\mathrm{BI}}$ & 0.84 & 0.00 & 0.00 & 0.31 & 0.01 \\
\hline $\mathrm{I}_{\mathrm{BJ}}$ & -0.25 & 0.00 & 0.00 & 0.31 & 0.00 \\
\hline $\mathrm{I}_{\mathrm{BK}}$ & 0.03 & 0.00 & 0.00 & 0.31 & 0.00 \\
\hline $\mathrm{I}_{\mathrm{BL}}$ & 2.14 & 0.00 & 0.00 & 0.31 & 0.01 \\
\hline $\mathrm{I}_{\mathrm{BM}}$ & -0.87 & 0.00 & 0.00 & 0.31 & 0.00 \\
\hline $\mathrm{I}_{\mathrm{CA}}$ & 1.11 & 0.02 & 0.02 & -1.48 & -0.01 \\
\hline $\mathrm{I}_{\mathrm{CB}}$ & 0.14 & 0.02 & 0.00 & -1.48 & 0.00 \\
\hline $\mathrm{I}_{\mathrm{CC}}$ & -0.74 & 2.00 & -1.49 & -1.48 & 1.01 \\
\hline $\mathrm{I}_{\mathrm{CD}}$ & -0.11 & 0.03 & 0.00 & -1.48 & 0.00 \\
\hline $\mathrm{I}_{\mathrm{CE}}$ & 0.85 & 0.01 & 0.01 & -1.48 & 0.00 \\
\hline $\mathrm{I}_{\mathrm{CF}}$ & -1.25 & 0.01 & -0.01 & -1.48 & 0.01 \\
\hline $\mathrm{I}_{\mathrm{CG}}$ & -0.22 & 0.01 & 0.00 & -1.48 & 0.00 \\
\hline $\mathrm{I}_{\mathrm{CH}}$ & -1.66 & 0.00 & -0.01 & -1.48 & 0.01 \\
\hline $\mathrm{I}_{\mathrm{CI}}$ & 0.84 & 0.00 & 0.00 & -1.48 & 0.00 \\
\hline $\mathrm{I}_{\mathrm{CJ}}$ & -0.25 & 0.00 & 0.00 & -1.48 & 0.00 \\
\hline $\mathrm{I}_{\mathrm{CK}}$ & 0.03 & 0.00 & 0.00 & -1.48 & 0.00 \\
\hline $\mathrm{I}_{\mathrm{CL}}$ & 2.14 & 0.00 & 0.00 & -1.48 & 0.00 \\
\hline $\mathrm{I}_{\mathrm{CM}}$ & -0.87 & 0.00 & 0.00 & -1.48 & 0.00 \\
\hline
\end{tabular}

Appendix Table A.26 Accessibility Index Pairs from normalized housing unit figures for half mile buffer. 


\begin{tabular}{|c|c|c|c|c|c|}
\hline Accessibility Index Pairs & $\overline{A_{j}}$ & $F_{i j}$ & $\overline{A_{j} * F_{i j}}$ & $\Sigma \mathrm{A}_{\mathrm{k}} * \mathrm{~F}_{\mathrm{ik}}$ & $\mathrm{I}_{\mathrm{ij}}=\left(\mathrm{A}_{\mathrm{j}} * \mathrm{~F}_{\mathrm{ij}} /\left(\Sigma \mathrm{A}_{\mathrm{k}} * \mathrm{~F}_{\mathrm{ik}}\right)\right)$ \\
\hline $\mathrm{I}_{\mathrm{DA}}$ & 1.11 & 0.01 & 0.01 & -0.24 & -0.05 \\
\hline $\mathrm{I}_{\mathrm{DB}}$ & 0.14 & 0.01 & 0.00 & -0.24 & -0.01 \\
\hline $\mathrm{I}_{\mathrm{DC}}$ & -0.74 & 0.03 & -0.02 & -0.24 & 0.08 \\
\hline $\mathrm{I}_{\mathrm{DD}}$ & -0.11 & 2.00 & -0.22 & -0.24 & 0.94 \\
\hline $\mathrm{I}_{\mathrm{DE}}$ & 0.85 & 0.01 & 0.01 & -0.24 & -0.03 \\
\hline $\mathrm{I}_{\mathrm{DF}}$ & -1.25 & 0.01 & -0.01 & -0.24 & 0.05 \\
\hline $\mathrm{I}_{\mathrm{DG}}$ & -0.22 & 0.01 & 0.00 & -0.24 & 0.01 \\
\hline $\mathrm{I}_{\mathrm{DH}}$ & -1.66 & 0.00 & -0.01 & -0.24 & 0.03 \\
\hline $\mathrm{I}_{\mathrm{DI}}$ & 0.84 & 0.00 & 0.00 & -0.24 & -0.01 \\
\hline $\mathrm{I}_{\mathrm{DJ}}$ & -0.25 & 0.00 & 0.00 & -0.24 & 0.00 \\
\hline $\mathrm{I}_{\mathrm{DK}}$ & 0.03 & 0.00 & 0.00 & -0.24 & 0.00 \\
\hline $\mathrm{I}_{\mathrm{DL}}$ & 2.14 & 0.00 & 0.00 & -0.24 & -0.02 \\
\hline $\mathrm{I}_{\mathrm{DM}}$ & -0.87 & 0.00 & 0.00 & -0.24 & 0.01 \\
\hline $\mathrm{I}_{\mathrm{EA}}$ & 1.11 & 0.00 & 0.01 & 1.66 & 0.00 \\
\hline $\mathrm{I}_{\mathrm{EB}}$ & 0.14 & 0.01 & 0.00 & 1.66 & 0.00 \\
\hline $\mathrm{I}_{\mathrm{EC}}$ & -0.74 & 0.01 & 0.00 & 1.66 & 0.00 \\
\hline $\mathrm{I}_{\mathrm{ED}}$ & -0.11 & 0.01 & 0.00 & 1.66 & 0.00 \\
\hline $\mathrm{I}_{\mathrm{EE}}$ & 0.85 & 2.00 & 1.70 & 1.66 & 1.03 \\
\hline $\mathrm{I}_{\mathrm{EF}}$ & -1.25 & 0.03 & -0.03 & 1.66 & -0.02 \\
\hline $\mathrm{I}_{\mathrm{EG}}$ & -0.22 & 0.01 & 0.00 & 1.66 & 0.00 \\
\hline $\mathrm{I}_{\mathrm{EH}}$ & -1.66 & 0.01 & -0.02 & 1.66 & -0.01 \\
\hline $\mathrm{I}_{\mathrm{EI}}$ & 0.84 & 0.00 & 0.00 & 1.66 & 0.00 \\
\hline $\mathrm{I}_{\mathrm{EJ}}$ & -0.25 & 0.00 & 0.00 & 1.66 & 0.00 \\
\hline $\mathrm{I}_{\mathrm{EK}}$ & 0.03 & 0.00 & 0.00 & 1.66 & 0.00 \\
\hline $\mathrm{I}_{\mathrm{EL}}$ & 2.14 & 0.00 & 0.01 & 1.66 & 0.00 \\
\hline $\mathrm{I}_{\mathrm{EM}}$ & -0.87 & 0.00 & 0.00 & 1.66 & 0.00 \\
\hline $\mathrm{I}_{\mathrm{FA}}$ & 1.11 & 0.00 & 0.01 & -2.50 & 0.00 \\
\hline $\mathrm{I}_{\mathrm{FB}}$ & 0.14 & 0.01 & 0.00 & -2.50 & 0.00 \\
\hline $\mathrm{I}_{\mathrm{FC}}$ & -0.74 & 0.01 & 0.00 & -2.50 & 0.00 \\
\hline $\mathrm{I}_{\mathrm{FD}}$ & -0.11 & 0.01 & 0.00 & -2.50 & 0.00 \\
\hline $\mathrm{I}_{\mathrm{FE}}$ & 0.85 & 0.03 & 0.02 & -2.50 & -0.01 \\
\hline $\mathrm{I}_{\mathrm{FF}}$ & -1.25 & 2.00 & -2.50 & -2.50 & 1.00 \\
\hline $\mathrm{I}_{\mathrm{FG}}$ & -0.22 & 0.03 & -0.01 & -2.50 & 0.00 \\
\hline $\mathrm{I}_{\mathrm{FH}}$ & -1.66 & 0.01 & -0.02 & -2.50 & 0.01 \\
\hline $\mathrm{I}_{\mathrm{FI}}$ & 0.84 & 0.01 & 0.00 & -2.50 & 0.00 \\
\hline $\mathrm{I}_{\mathrm{FJ}}$ & -0.25 & 0.00 & 0.00 & -2.50 & 0.00 \\
\hline $\mathrm{I}_{\mathrm{FK}}$ & 0.03 & 0.00 & 0.00 & -2.50 & 0.00 \\
\hline $\mathrm{I}_{\mathrm{FL}}$ & 2.14 & 0.00 & 0.01 & -2.50 & 0.00 \\
\hline $\mathrm{I}_{\mathrm{FM}}$ & -0.87 & 0.00 & 0.00 & -2.50 & 0.00 \\
\hline
\end{tabular}

Appendix Table A.27 Accessibility Index Pairs from normalized housing unit figures for half mile buffer (contd.). 


\begin{tabular}{|c|c|c|c|c|c|}
\hline Accessibility Index Pairs & $A_{j}$ & $F_{i j}$ & $\overline{A_{j} * F_{i j}}$ & $\Sigma \mathrm{A}_{\mathrm{k}} * \mathrm{~F}_{\mathrm{ik}}$ & $\mathrm{I}_{\mathrm{ij}}=\left(\mathrm{A}_{\mathrm{j}} * \mathrm{~F}_{\mathrm{ij}} /\left(\sum \mathrm{A}_{\mathrm{k}} * \mathrm{~F}_{\mathrm{ik}}\right)\right)$ \\
\hline $\mathrm{I}_{\mathrm{GA}}$ & 1.11 & 0.00 & 0.00 & -0.51 & -0.01 \\
\hline $\mathrm{I}_{\mathrm{GB}}$ & 0.14 & 0.00 & 0.00 & -0.51 & 0.00 \\
\hline $\mathrm{I}_{\mathrm{GC}}$ & -0.74 & 0.01 & 0.00 & -0.51 & 0.01 \\
\hline $\mathrm{I}_{\mathrm{GD}}$ & -0.11 & 0.01 & 0.00 & -0.51 & 0.00 \\
\hline $\mathrm{I}_{\mathrm{GE}}$ & 0.85 & 0.01 & 0.01 & -0.51 & -0.02 \\
\hline $\mathrm{I}_{\mathrm{GF}}$ & -1.25 & 0.03 & -0.04 & -0.51 & 0.08 \\
\hline $\mathrm{I}_{\mathrm{GG}}$ & -0.22 & 2.00 & -0.45 & -0.51 & 0.88 \\
\hline $\mathrm{I}_{\mathrm{GH}}$ & -1.66 & 0.03 & -0.05 & -0.51 & 0.09 \\
\hline $\mathrm{I}_{\mathrm{GI}}$ & 0.84 & 0.01 & 0.01 & -0.51 & -0.01 \\
\hline $\mathrm{I}_{\mathrm{GJ}}$ & -0.25 & 0.00 & 0.00 & -0.51 & 0.00 \\
\hline $\mathrm{I}_{\mathrm{GK}}$ & 0.03 & 0.00 & 0.00 & -0.51 & 0.00 \\
\hline $\mathrm{I}_{\mathrm{GL}}$ & 2.14 & 0.00 & 0.01 & -0.51 & -0.01 \\
\hline $\mathrm{I}_{\mathrm{GM}}$ & -0.87 & 0.00 & 0.00 & -0.51 & 0.00 \\
\hline $\mathrm{I}_{\mathrm{HA}}$ & 1.11 & 0.00 & 0.00 & -3.32 & 0.00 \\
\hline $\mathrm{I}_{\mathrm{HB}}$ & 0.14 & 0.00 & 0.00 & -3.32 & 0.00 \\
\hline $\mathrm{I}_{\mathrm{HC}}$ & -0.74 & 0.00 & 0.00 & -3.32 & 0.00 \\
\hline $\mathrm{I}_{\mathrm{HD}}$ & -0.11 & 0.01 & 0.00 & -3.32 & 0.00 \\
\hline $\mathrm{I}_{\mathrm{HE}}$ & 0.85 & 0.01 & 0.01 & -3.32 & 0.00 \\
\hline $\mathrm{I}_{\mathrm{HF}}$ & -1.25 & 0.01 & -0.02 & -3.32 & 0.01 \\
\hline $\mathrm{I}_{\mathrm{HG}}$ & -0.22 & 0.03 & -0.01 & -3.32 & 0.00 \\
\hline $\mathrm{I}_{\mathrm{HH}}$ & -1.66 & 2.00 & -3.31 & -3.32 & 1.00 \\
\hline $\mathrm{I}_{\mathrm{HI}}$ & 0.84 & 0.01 & 0.01 & -3.32 & 0.00 \\
\hline $\mathrm{I}_{\mathrm{HJ}}$ & -0.25 & 0.00 & 0.00 & -3.32 & 0.00 \\
\hline $\mathrm{I}_{\mathrm{HK}}$ & 0.03 & 0.00 & 0.00 & -3.32 & 0.00 \\
\hline $\mathrm{I}_{\mathrm{HL}}$ & 2.14 & 0.00 & 0.01 & -3.32 & 0.00 \\
\hline $\mathrm{I}_{\mathrm{HM}}$ & -0.87 & 0.00 & 0.00 & -3.32 & 0.00 \\
\hline $\mathrm{I}_{\mathrm{IA}}$ & 1.11 & 0.00 & 0.00 & 1.66 & 0.00 \\
\hline $\mathrm{I}_{\mathrm{IB}}$ & 0.14 & 0.00 & 0.00 & 1.66 & 0.00 \\
\hline $\mathrm{I}_{\mathrm{IC}}$ & -0.74 & 0.00 & 0.00 & 1.66 & 0.00 \\
\hline $\mathrm{I}_{\mathrm{ID}}$ & -0.11 & 0.00 & 0.00 & 1.66 & 0.00 \\
\hline $\mathrm{I}_{\mathrm{IE}}$ & 0.85 & 0.00 & 0.00 & 1.66 & 0.00 \\
\hline $\mathrm{I}_{\mathrm{IF}}$ & -1.25 & 0.01 & -0.01 & 1.66 & 0.00 \\
\hline $\mathrm{I}_{\mathrm{IG}}$ & -0.22 & 0.01 & 0.00 & 1.66 & 0.00 \\
\hline $\mathrm{I}_{\mathrm{IH}}$ & -1.66 & 0.01 & -0.02 & 1.66 & -0.01 \\
\hline $\mathrm{I}_{I I}$ & 0.84 & 2.00 & 1.67 & 1.66 & 1.01 \\
\hline $\mathrm{I}_{\mathrm{IJ}}$ & -0.25 & 0.01 & 0.00 & 1.66 & 0.00 \\
\hline $\mathrm{I}_{\mathrm{IK}}$ & 0.03 & 0.01 & 0.00 & 1.66 & 0.00 \\
\hline $\mathrm{I}_{\mathrm{IL}}$ & 2.14 & 0.01 & 0.01 & 1.66 & 0.01 \\
\hline $\mathrm{I}_{\mathrm{IM}}$ & -0.87 & 0.00 & 0.00 & 1.66 & 0.00 \\
\hline
\end{tabular}

Appendix Table A.28 Accessibility Index Pairs from normalized housing unit figures for half mile buffer (contd.). 


\begin{tabular}{|c|c|c|c|c|c|}
\hline Accessibility Index Pairs & $A_{j}$ & $F_{i j}$ & $\overline{A_{j} * F_{i j}}$ & $\Sigma \mathrm{A}_{\mathrm{k}} * \mathrm{~F}_{\mathrm{ik}}$ & $\mathrm{I}_{\mathrm{ij}}=\left(\mathrm{A}_{\mathrm{j}} * \mathrm{~F}_{\mathrm{ij}} /\left(\Sigma \mathrm{A}_{\mathrm{k}} * \mathrm{~F}_{\mathrm{ik}}\right)\right)$ \\
\hline $\mathrm{I}_{\mathrm{JA}}$ & 1.11 & 0.00 & 0.00 & -0.48 & 0.00 \\
\hline $\mathrm{I}_{\mathrm{JB}}$ & 0.14 & 0.00 & 0.00 & -0.48 & 0.00 \\
\hline $\mathrm{I}_{\mathrm{JC}}$ & -0.74 & 0.00 & 0.00 & -0.48 & 0.00 \\
\hline $\mathrm{I}_{\mathrm{JD}}$ & -0.11 & 0.00 & 0.00 & -0.48 & 0.00 \\
\hline $\mathrm{I}_{\mathrm{JE}}$ & 0.85 & 0.00 & 0.00 & -0.48 & -0.01 \\
\hline $\mathrm{I}_{\mathrm{JF}}$ & -1.25 & 0.00 & 0.00 & -0.48 & 0.01 \\
\hline $\mathrm{I}_{\mathrm{JG}}$ & -0.22 & 0.00 & 0.00 & -0.48 & 0.00 \\
\hline $\mathrm{I}_{\mathrm{JH}}$ & -1.66 & 0.00 & -0.01 & -0.48 & 0.02 \\
\hline $\mathrm{I}_{\mathrm{JI}}$ & 0.84 & 0.01 & 0.01 & -0.48 & -0.02 \\
\hline $\mathrm{I}_{\mathrm{JJ}}$ & -0.25 & 2.00 & -0.50 & -0.48 & 1.04 \\
\hline $\mathrm{I}_{\mathrm{JK}}$ & 0.03 & 0.02 & 0.00 & -0.48 & 0.00 \\
\hline $\mathrm{I}_{\mathrm{JL}}$ & 2.14 & 0.01 & 0.03 & -0.48 & -0.06 \\
\hline $\mathrm{I}_{\mathrm{JM}}$ & -0.87 & 0.01 & -0.01 & -0.48 & 0.02 \\
\hline $\mathrm{I}_{\mathrm{KA}}$ & 1.11 & 0.00 & 0.00 & 0.17 & 0.01 \\
\hline $\mathrm{I}_{\mathrm{KB}}$ & 0.14 & 0.00 & 0.00 & 0.17 & 0.00 \\
\hline $\mathrm{I}_{\mathrm{KC}}$ & -0.74 & 0.00 & 0.00 & 0.17 & -0.01 \\
\hline $\mathrm{I}_{\mathrm{KD}}$ & -0.11 & 0.00 & 0.00 & 0.17 & 0.00 \\
\hline $\mathrm{I}_{\mathrm{KE}}$ & 0.85 & 0.00 & 0.00 & 0.17 & 0.01 \\
\hline $\mathrm{I}_{\mathrm{KF}}$ & -1.25 & 0.00 & 0.00 & 0.17 & -0.02 \\
\hline $\mathrm{I}_{\mathrm{KG}}$ & -0.22 & 0.00 & 0.00 & 0.17 & 0.00 \\
\hline $\mathrm{I}_{\mathrm{KH}}$ & -1.66 & 0.00 & -0.01 & 0.17 & -0.04 \\
\hline $\mathrm{I}_{\mathrm{KI}}$ & 0.84 & 0.01 & 0.01 & 0.17 & 0.03 \\
\hline $\mathrm{I}_{\mathrm{KJ}}$ & -0.25 & 0.02 & 0.00 & 0.17 & -0.03 \\
\hline $\mathrm{I}_{\mathrm{KK}}$ & 0.03 & 2.00 & 0.06 & 0.17 & 0.34 \\
\hline $\mathrm{I}_{\mathrm{KL}}$ & 2.14 & 0.06 & 0.13 & 0.17 & 0.75 \\
\hline $\mathrm{I}_{\mathrm{KM}}$ & -0.87 & 0.01 & -0.01 & 0.17 & -0.05 \\
\hline $\mathrm{I}_{\mathrm{LA}}$ & 1.11 & 0.00 & 0.00 & 4.25 & 0.00 \\
\hline $\mathrm{I}_{\mathrm{LB}}$ & 0.14 & 0.00 & 0.00 & 4.25 & 0.00 \\
\hline $\mathrm{I}_{\mathrm{LC}}$ & -0.74 & 0.00 & 0.00 & 4.25 & 0.00 \\
\hline $\mathrm{I}_{\mathrm{LD}}$ & -0.11 & 0.00 & 0.00 & 4.25 & 0.00 \\
\hline $\mathrm{I}_{\mathrm{LE}}$ & 0.85 & 0.00 & 0.00 & 4.25 & 0.00 \\
\hline $\mathrm{I}_{\mathrm{LF}}$ & -1.25 & 0.00 & 0.00 & 4.25 & 0.00 \\
\hline $\mathrm{I}_{\mathrm{LG}}$ & -0.22 & 0.00 & 0.00 & 4.25 & 0.00 \\
\hline $\mathrm{I}_{\mathrm{LH}}$ & -1.66 & 0.00 & -0.01 & 4.25 & 0.00 \\
\hline $\mathrm{I}_{\mathrm{LI}}$ & 0.84 & 0.01 & 0.00 & 4.25 & 0.00 \\
\hline $\mathrm{I}_{\mathrm{LJ}}$ & -0.25 & 0.01 & 0.00 & 4.25 & 0.00 \\
\hline $\mathrm{I}_{\mathrm{LK}}$ & 0.03 & 0.06 & 0.00 & 4.25 & 0.00 \\
\hline $\mathrm{I}_{\mathrm{LL}}$ & 2.14 & 2.00 & 4.28 & 4.25 & 1.01 \\
\hline $\mathrm{I}_{\mathrm{LM}}$ & -0.87 & 0.03 & -0.02 & 4.25 & -0.01 \\
\hline
\end{tabular}

Appendix Table A.29 Accessibility Index Pairs from normalized housing unit figures for half mile buffer (contd.). 


\begin{tabular}{|c|r|r|r|r|r|}
\hline Accessibility Index Pairs & \multicolumn{1}{|c|}{$\mathrm{A}_{\mathrm{j}}$} & \multicolumn{1}{c|}{$\mathrm{F}_{\mathrm{ij}}$} & $\mathrm{A}_{\mathrm{j}}{ }^{*} \mathrm{~F}_{\mathrm{ij}}$ & $\Sigma \mathrm{A}_{\mathrm{k}}{ }^{*} \mathrm{~F}_{\mathrm{ik}}$ & $\mathrm{I}_{\mathrm{ij}}=\left(\mathrm{A}_{\mathrm{j}}{ }^{*} \mathrm{~F}_{\mathrm{ij}} /\left(\Sigma \mathrm{A}_{\mathrm{k}}{ }^{*} \mathrm{~F}_{\mathrm{ik}}\right)\right)$ \\
\hline $\mathrm{I}_{\mathrm{MA}}$ & 1.11 & 0.00 & 0.00 & -1.68 & 0.00 \\
\hline $\mathrm{I}_{\mathrm{MB}}$ & 0.14 & 0.00 & 0.00 & -1.68 & 0.00 \\
\hline $\mathrm{I}_{\mathrm{MC}}$ & -0.74 & 0.00 & 0.00 & -1.68 & 0.00 \\
\hline $\mathrm{I}_{\mathrm{MD}}$ & -0.11 & 0.00 & 0.00 & -1.68 & 0.00 \\
\hline $\mathrm{I}_{\mathrm{ME}}$ & 0.85 & 0.00 & 0.00 & -1.68 & 0.00 \\
\hline $\mathrm{I}_{\mathrm{MF}}$ & -1.25 & 0.00 & 0.00 & -1.68 & 0.00 \\
\hline $\mathrm{I}_{\mathrm{MG}}$ & -0.22 & 0.00 & 0.00 & -1.68 & 0.00 \\
\hline $\mathrm{I}_{\mathrm{MH}}$ & -1.66 & 0.00 & -0.01 & -1.68 & 0.00 \\
\hline $\mathrm{I}_{\mathrm{MI}}$ & 0.84 & 0.00 & 0.00 & -1.68 & 0.00 \\
\hline $\mathrm{I}_{\mathrm{MJ}}$ & -0.25 & 0.01 & 0.00 & -1.68 & 0.00 \\
\hline $\mathrm{I}_{\mathrm{MK}}$ & 0.03 & 0.02 & 0.00 & -1.68 & -0.04 \\
\hline $\mathrm{I}_{\mathrm{ML}}$ & 2.14 & 0.03 & 0.06 & -1.68 & 1.03 \\
\hline $\mathrm{I}_{\mathrm{MM}}$ & -0.87 & 2.00 & -1.73 & -1.68 & \\
\hline
\end{tabular}

Appendix Table A.30 Accessibility Index Pairs from normalized housing unit figures for half mile buffer (contd.). 


\section{Results Matrices}

\section{a. Quarter-Mile Radius}

\begin{tabular}{|c|c|c|c|c|c|c|c|c|c|c|c|c|c|c|c|}
\hline \multirow{14}{*}{ 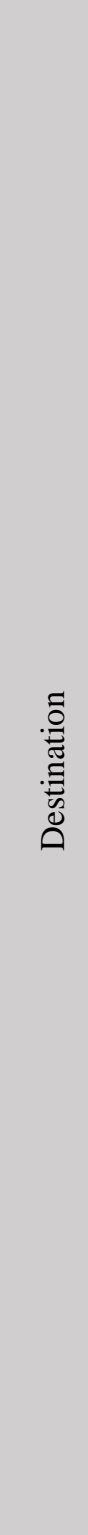 } & 耉 & $\stackrel{8}{\stackrel{-}{*}}$ & $\stackrel{8}{-}$ & $\underset{-}{\stackrel{-}{-}}$ & $\stackrel{8}{\stackrel{-}{-}}$ & $\stackrel{8}{-}$ & $\stackrel{8}{-}$ & $\underset{-}{\stackrel{8}{-}}$ & $\stackrel{8}{-}$ & $\stackrel{8}{8}$ & $\stackrel{8}{-}$ & $\stackrel{8}{-}$ & $\underset{-}{\stackrel{-}{-}}$ & $\stackrel{8}{\stackrel{\leftrightarrow}{-}}$ & $\underset{\sim}{8}$ \\
\hline & $\Sigma$ & $\stackrel{8}{\circ}$ & $\stackrel{8}{\circ}$ & $\stackrel{8}{\circ}$ & $\stackrel{8}{0}$ & $\stackrel{8}{\circ}$ & $\overline{0}$ & $\stackrel{8}{\circ}$ & $\stackrel{\square}{0}$ & $\stackrel{8}{0}$ & $\bar{\circ}$ & $\stackrel{8}{0}$ & $\stackrel{8}{\circ}$ & ŏ & $\underset{-}{\stackrel{8}{-}}$ \\
\hline & \lrcorner & 8 & 8 & 8 & $\stackrel{8}{0}$ & $\stackrel{8}{0}$ & $\stackrel{\mathrm{o}}{\mathrm{O}}$ & $\stackrel{8}{0}$ & $\stackrel{\leftrightarrow}{\circ}$ & $\stackrel{\overline{0}}{\circ}$ & $\stackrel{n}{\circ}$ & $\stackrel{\infty}{\circ}$ & $\begin{array}{l}\infty \\
\stackrel{0}{0}\end{array}$ & $\tilde{O}$ & $\stackrel{9}{\rightrightarrows}$ \\
\hline & $\longleftarrow$ & 8 & $\stackrel{8}{\circ}$ & $\stackrel{8}{0}$ & $\stackrel{8}{0}$ & $\stackrel{8}{0}$ & $\stackrel{8}{0}$ & $\stackrel{8}{8}$ & $\overline{0}$ & $\stackrel{8}{0}$ & $\bar{\circ}$ & $\begin{array}{l}n \\
\infty \\
\infty \\
0\end{array}$ & $\stackrel{8}{0}$ & 8 & $\begin{array}{l}\infty \\
\infty \\
0\end{array}$ \\
\hline & $\sim$ & $\stackrel{8}{\circ}$ & 8 & $\stackrel{8}{0}$ & $\stackrel{8}{0}$ & $\stackrel{8}{0}$ & $\stackrel{8}{0}$ & $\stackrel{8}{0}$ & $\stackrel{8}{0}$ & $\stackrel{8}{0}$ & 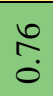 & $\stackrel{8}{\circ}$ & 8 & $\stackrel{8}{0}$ & $\stackrel{?}{0}$ \\
\hline & - & $\stackrel{8}{\circ}$ & $\stackrel{8}{\circ}$ & $\stackrel{8}{\circ}$ & $\stackrel{8}{0}$ & $\stackrel{8}{0}$ & $\stackrel{\square}{0}$ & $\stackrel{8}{\circ}$ & $\stackrel{\circ}{0}$ & $\begin{array}{l}\stackrel{0}{0} \\
0\end{array}$ & : & $\stackrel{8}{0}$ & $\stackrel{8}{0}$ & $\stackrel{8}{\circ}$ & $\tilde{\delta}$ \\
\hline & \pm & $\stackrel{8}{0}$ & $\stackrel{8}{\circ}$ & $\stackrel{8}{0}$ & $\stackrel{8}{0}$ & $\stackrel{8}{0}$ & $\stackrel{8}{0}$ & $\stackrel{8}{0}$ & $\stackrel{8}{0}$ & $\stackrel{8}{0}$ & $\stackrel{8}{\circ}$ & $\stackrel{8}{0}$ & $\stackrel{8}{0}$ & $\stackrel{8}{0}$ & $\stackrel{8}{0}$ \\
\hline & 0 & $\stackrel{8}{\circ}$ & $\stackrel{8}{\circ}$ & $\stackrel{8}{\circ}$ & $\stackrel{\overrightarrow{0}}{\circ}$ & $\stackrel{\tilde{o}}{0}$ & $\frac{\infty}{0}$ & $\hat{a}$ & $\tilde{\widetilde{o}}$ & $\stackrel{\square}{0}$ & : & $\stackrel{8}{0}$ & $\stackrel{8}{0}$ & $\stackrel{8}{0}$ & $\stackrel{f}{\stackrel{9}{q}}$ \\
\hline & 山 & $\stackrel{8}{\circ}$ & $\stackrel{8}{\circ}$ & $\stackrel{8}{0}$ & $\stackrel{8}{0}$ & $\stackrel{8}{0}$ & $\stackrel{\text { ô }}{0}$ & $\stackrel{8}{\circ}$ & $\stackrel{8}{0}$ & $\stackrel{8}{0}$ & $\stackrel{8}{\circ}$ & $\stackrel{8}{\circ}$ & $\stackrel{8}{0}$ & $\stackrel{8}{\circ}$ & 0 \\
\hline & 山 & $\stackrel{8}{\circ}$ & $\stackrel{8}{\circ}$ & $\stackrel{8}{0}$ & $\stackrel{8}{0}$ & $\begin{array}{l}\mathscr{\infty} \\
\stackrel{0}{0}\end{array}$ & $\stackrel{\overbrace{}}{0}$ & $\stackrel{8}{\circ}$ & $\stackrel{\sigma}{0}$ & $\stackrel{8}{0}$ & 8 & 8 & $\stackrel{8}{0}$ & $\stackrel{8}{0}$ & $\begin{array}{l}\infty \\
\infty \\
0\end{array}$ \\
\hline & 0 & $\stackrel{8}{\circ}$ & $\stackrel{8}{\circ}$ & $\stackrel{8}{\circ}$ & $\hat{\sigma}$ & $\stackrel{8}{0}$ & ö. & $\stackrel{8}{\circ}$ & ö. & $\stackrel{8}{0}$ & $\stackrel{8}{\circ}$ & $\stackrel{8}{\circ}$ & $\stackrel{8}{\circ}$ & $\stackrel{8}{\circ}$ & $\stackrel{0}{0}$ \\
\hline & U & $\stackrel{8}{\circ}$ & $\bar{\circ}$ & \&. & $\stackrel{o}{0}$ & $\overrightarrow{0}$ & $\stackrel{t}{\circ}$ & $\stackrel{8}{\circ}$ & $\stackrel{\overbrace{}}{0}$ & 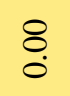 & $\bar{\circ}$ & $\stackrel{8}{0}$ & $\stackrel{8}{\circ}$ & $\stackrel{8}{0}$ & $\widetilde{\varepsilon}$ \\
\hline & $\infty$ & $\stackrel{8}{\circ}$ & $\stackrel{g}{0}$ & $\stackrel{8}{0}$ & $\stackrel{8}{0}$ & $\stackrel{8}{0}$ & $\overrightarrow{0}$ & $\stackrel{8}{0}$ & $\ddot{0}$ & $\stackrel{8}{0}$ & $\stackrel{8}{0}$ & $\stackrel{8}{0}$ & $\stackrel{8}{0}$ & $\stackrel{8}{0}$ & ñ \\
\hline & $\varangle$ & $\stackrel{8}{8}$ & in & $\stackrel{\circ}{\circ}$ & ஸे & $\stackrel{m}{0}$ & $\stackrel{\infty}{0}$ & $\stackrel{d}{0}$ & $\begin{array}{l}0 \\
:\end{array}$ & $\stackrel{\infty}{\circ}$ & $\stackrel{n}{0}$ & $\stackrel{2}{0}$ & $\overline{0}$ & $\stackrel{\mathrm{o}}{\mathrm{O}}$ & $\underset{\dot{r}}{\mathrm{i}}$ \\
\hline & $\begin{array}{l}\overline{\mathrm{d}} \\
\text { ]్త }\end{array}$ & $\varangle$ & $\infty$ & u & 0 & 山 & 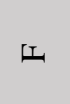 & ט & \pm & - & 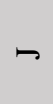 & $\checkmark$ & دـ & $\Sigma$ & J్ \\
\hline & & & & & & & & & & & & & & & \\
\hline
\end{tabular}

Appendix Table A.1 Accessibility indices for origin-destination pairs from raw job figures for quarter-mile buffer. Green, yellow, and red cells denote relatively high, medium, and low values, respectively. Blue cells denote row or column totals. The number of significant figures has been reduced to fit the table within the page. 


\begin{tabular}{|c|c|c|c|c|c|c|c|c|c|c|c|c|c|c|c|}
\hline \multirow{14}{*}{ 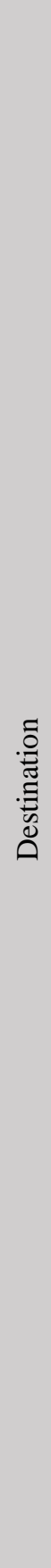 } & 吾 & 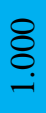 & $\underset{8}{8}$ & $\underset{8}{8}$ & $\underset{8}{8}$ & $\underset{8}{8}$ & $\underset{\&}{\&}$ & $\underset{\&}{\&}$ & $\underset{8}{8}$ & $\underset{-}{8}$ & $\underset{8}{8}$ & $\underset{8}{8}$ & $\underset{8}{8}$ & 8 & $\begin{array}{l}\stackrel{8}{8} \\
\stackrel{m}{2}\end{array}$ \\
\hline & $\Sigma$ & $\begin{array}{l}8 \\
0 \\
0\end{array}$ & $\begin{array}{l}8 \\
0 \\
0\end{array}$ & $\begin{array}{l}8 \\
8 \\
0\end{array}$ & $\begin{array}{l}8 \\
0 \\
0\end{array}$ & $\begin{array}{l}8 \\
0 \\
0\end{array}$ & $\overrightarrow{8}$ & $\begin{array}{l}\overline{8} \\
0\end{array}$ & $\begin{array}{l}0 \\
\text { రి } \\
0\end{array}$ & $\stackrel{0}{0}$ & 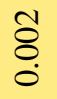 & $\stackrel{\text { ô }}{0}$ & $\begin{array}{l}8 \\
0 \\
0\end{array}$ & $\begin{array}{l}\hat{\hat{O}} \\
\hat{0}\end{array}$ & ర్లి \\
\hline & \lrcorner & $\overline{8}$ & $\begin{array}{l}8 \\
8 \\
0\end{array}$ & $\begin{array}{l}8 \\
8 \\
0\end{array}$ & $\stackrel{\overline{8}}{\circ}$ & \begin{tabular}{l}
8 \\
8 \\
\hdashline
\end{tabular} & $\underset{8}{\overline{8}}$ & $\overline{8}$ & $\stackrel{m}{\stackrel{m}{0}}$ & $\stackrel{\text { ô }}{0}$ & $\begin{array}{l}\text { } \\
\stackrel{0}{0}\end{array}$ & $\bar{\Xi}$ & $\begin{array}{l}\text { ஜ̊ } \\
\stackrel{0}{0}\end{array}$ & \&̊ & $\begin{array}{c}\infty \\
\tilde{\sigma} \\
\stackrel{-}{2}\end{array}$ \\
\hline & 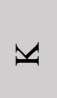 & $\overline{8}$ & 官 & 官 & $\stackrel{8}{8}$ & $\overline{8}$ & $\stackrel{\overline{8}}{0}$ & 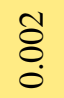 & $\begin{array}{l}8 \\
0 \\
0\end{array}$ & $\stackrel{8}{8}$ & $\begin{array}{l}n \\
8 \\
0\end{array}$ & ڤે & $\frac{a}{0}$ & $\begin{array}{l}8 \\
8 \\
0\end{array}$ & $\stackrel{\infty}{5}$ \\
\hline & $\neg$ & $\bar{\delta}_{\circ}$ & $\bar{\Xi}$ & $\begin{array}{l}\overline{8} \\
8 \\
0\end{array}$ & $\begin{array}{l}\overline{8} \\
\stackrel{0}{0}\end{array}$ & $\begin{array}{l}\overline{8} \\
\stackrel{0}{0}\end{array}$ & $\begin{array}{l}\overline{8} \\
\stackrel{0}{0}\end{array}$ & $\begin{array}{l}\widetilde{\delta} \\
\stackrel{0}{0}\end{array}$ & $\begin{array}{l}\stackrel{8}{8} \\
\stackrel{0}{0}\end{array}$ & $\begin{array}{l}\dot{0} \\
\stackrel{0}{0}\end{array}$ & 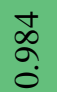 & $\begin{array}{l}\stackrel{+}{8} \\
\stackrel{0}{0}\end{array}$ & $\begin{array}{l}\dot{0} \\
\stackrel{0}{0}\end{array}$ & $\begin{array}{l}0 \\
\stackrel{8}{0}\end{array}$ & $\underset{\mathrm{S}}{\mathrm{N}}$ \\
\hline & - & $\overline{8}$ & $\stackrel{8}{8}$ & 8 & $\stackrel{8}{8}$ & $\stackrel{\overline{8}}{0}$ & $\stackrel{8}{8}$ & $\begin{array}{l}\text { ô } \\
\stackrel{0}{0}\end{array}$ & $\begin{array}{l}\text { Oे } \\
0 \\
0\end{array}$ & 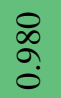 & $\stackrel{8}{8}$ & $\stackrel{\overline{8}}{0}$ & $\overline{8}$ & ș & $\stackrel{\text { }}{\underline{\sigma}}$ \\
\hline & $I$ & $\begin{array}{l}8 \\
\stackrel{0}{0} \\
0\end{array}$ & $\begin{array}{l}8 \\
0 \\
0\end{array}$ & $\begin{array}{l}8 \\
8 \\
0\end{array}$ & $\begin{array}{l}8 \\
8 \\
0\end{array}$ & $\begin{array}{l}8 \\
8 \\
0\end{array}$ & $\begin{array}{l}8 \\
8 \\
0\end{array}$ & $\begin{array}{l}8 \\
0 \\
0\end{array}$ & $\begin{array}{l}8 \\
8 \\
0\end{array}$ & $\begin{array}{l}8 \\
0 \\
0\end{array}$ & \begin{tabular}{l}
8 \\
8 \\
\hdashline
\end{tabular} & $\begin{array}{l}8 \\
8 \\
0\end{array}$ & $\begin{array}{l}8 \\
8 \\
0\end{array}$ & $\begin{array}{l}8 \\
8 \\
0\end{array}$ & $\begin{array}{l}8 \\
8 \\
0\end{array}$ \\
\hline & 0 & $\overline{8}$ & $\begin{array}{l}\overline{8} \\
\stackrel{0}{0}\end{array}$ & $\begin{array}{l}\overline{8} \\
\stackrel{0}{0}\end{array}$ & $\begin{array}{l}\overline{8} \\
\stackrel{0}{0}\end{array}$ & $\begin{array}{l}\text { ô } \\
\stackrel{0}{0}\end{array}$ & \begin{tabular}{l}
8 \\
\hdashline \\
\hdashline
\end{tabular} & $\begin{array}{l}\tilde{2} \\
\stackrel{0}{0}\end{array}$ & $\frac{2}{0}$ & $\begin{array}{l}\text { ô } \\
\stackrel{0}{0}\end{array}$ & $\begin{array}{l}\overline{8} \\
\stackrel{0}{0}\end{array}$ & \begin{tabular}{l}
8 \\
8 \\
\hdashline
\end{tabular} & $\begin{array}{l}8 \\
0 \\
0\end{array}$ & $\begin{array}{l}8 \\
8 \\
0\end{array}$ & $\stackrel{\infty}{=}$ \\
\hline & 【 & $\overline{8}$ & $\overline{8}$ & s. & 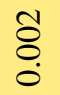 & $\begin{array}{l}+ \\
8\end{array}$ & 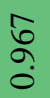 & $\begin{array}{l}\text { } \\
\dot{0}\end{array}$ & $\frac{\stackrel{0}{0}}{0}$ & $\begin{array}{l}\text { ô } \\
\stackrel{0}{0}\end{array}$ & $\begin{array}{l}\overline{8} \\
\stackrel{0}{0}\end{array}$ & $\begin{array}{l}8 \\
8 \\
\end{array}$ & $\begin{array}{l}\overline{8} \\
0\end{array}$ & $\begin{array}{l}\overline{8} \\
\stackrel{0}{0}\end{array}$ & $\Xi$ \\
\hline & 山 & $\begin{array}{l}\tilde{\delta} \\
\stackrel{0}{0}\end{array}$ & $\begin{array}{l}\overline{8} \\
\stackrel{0}{0}\end{array}$ & 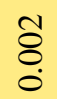 & $\begin{array}{l}\tilde{8} \\
\stackrel{0}{0}\end{array}$ & 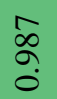 & $\stackrel{1}{\dddot{0}}$ & $\begin{array}{l}\infty \\
\stackrel{8}{0} \\
\stackrel{0}{0}\end{array}$ & $\frac{n}{0}$ & $\begin{array}{l}\tilde{\delta} \\
\stackrel{0}{0}\end{array}$ & ¿্口 & $\stackrel{\overline{8}}{\circ}$ & $\begin{array}{l}\overline{8} \\
\stackrel{0}{0}\end{array}$ & $\begin{array}{l}\overline{8} \\
\stackrel{0}{0}\end{array}$ & $\stackrel{\text { I }}{I}$ \\
\hline & $\theta$ & $\stackrel{8}{8}$ & $\stackrel{8}{8}$ & $\begin{array}{l}n \\
8 \\
0\end{array}$ & $\begin{array}{l}\hat{\widehat{a}} \\
\text { o. }\end{array}$ & $\begin{array}{l}\widetilde{o} \\
\stackrel{0}{0}\end{array}$ & $\begin{array}{l}\tilde{8} \\
\stackrel{0}{0}\end{array}$ & $\begin{array}{l}\tilde{8} \\
\dot{0}\end{array}$ & $\begin{array}{l}\stackrel{0}{0} \\
0 \\
0\end{array}$ & $\overrightarrow{8}$ & $\overline{8}$ & $\stackrel{8}{8}$ & $\overrightarrow{8}$ & 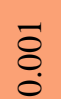 & క్ \\
\hline & $u$ & \begin{tabular}{l}
$\stackrel{8}{0}$ \\
\hdashline
\end{tabular} & $\stackrel{0}{\circ}$ & $\begin{array}{l}\tilde{D} \\
\stackrel{2}{0} \\
\stackrel{2}{0}\end{array}$ & $\stackrel{\infty}{\stackrel{8}{0}}$ & ఠ̊ & $\stackrel{\overbrace{}}{0}$ & $\stackrel{\text { }}{0}$ & 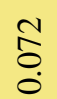 & $\stackrel{\overline{8}}{\circ}$ & $\overrightarrow{8}$ & $\begin{array}{l}\overline{8} \\
\stackrel{0}{0}\end{array}$ & $\overrightarrow{8}$ & ठே. & $\begin{array}{l}\stackrel{0}{ } \\
\stackrel{0}{\circ}\end{array}$ \\
\hline & $\infty$ & $\stackrel{\infty}{\circ}$ & $\frac{n}{\hat{a}}$ & $\begin{array}{l}n \\
8 \\
0\end{array}$ & $\begin{array}{l}\tilde{8} \\
\dot{0}\end{array}$ & $\overline{8}$ & $\underset{\delta}{\tilde{o}}$ & $\begin{array}{l}\tilde{\delta} \\
\stackrel{0}{0}\end{array}$ & \begin{tabular}{l}
$\tilde{\sigma}$ \\
\multirow{0}{0}{}
\end{tabular} & $\overline{8}$ & $\stackrel{\overline{8}}{\circ}$ & $\stackrel{8}{8}$ & $\overrightarrow{8}$ & $\ddot{8}$ & $\widetilde{\sigma}$ \\
\hline & $\ll$ & $\begin{array}{l}\hat{\sigma} \\
\text { ᄋे }\end{array}$ & $\stackrel{0}{\circ}$ & 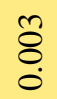 & $\begin{array}{l}\text { \&̊ } \\
\stackrel{0}{0}\end{array}$ & $\begin{array}{l}\overline{8} \\
\stackrel{0}{0}\end{array}$ & $\overline{8}$ & $\begin{array}{l}\overline{8} \\
0\end{array}$ & ô & $\begin{array}{l}\overline{8} \\
0\end{array}$ & $\begin{array}{l}8 \\
\stackrel{8}{0}\end{array}$ & $\stackrel{8}{8}$ & $\begin{array}{l}8 \\
8 \\
0\end{array}$ & $\underset{8}{8}$ & 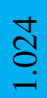 \\
\hline & $\begin{array}{l}\overline{\mathcal{D}} \\
\text { స్తు }\end{array}$ & $\varangle$ & $\infty$ & $u$ & D & 山 & IL & 0 & $I$ & - & $\sim$ & $\checkmark$ & \lrcorner & $\Sigma$ & స్ \\
\hline & & & & & & & & & & & & & & & \\
\hline
\end{tabular}

Appendix Table A.2 Accessibility indices for origin-destination pairs from raw population figures for quarter-mile buffer. Green, yellow, and red cells denote relatively high, medium, and low values, respectively. Blue cells denote row or column totals. 


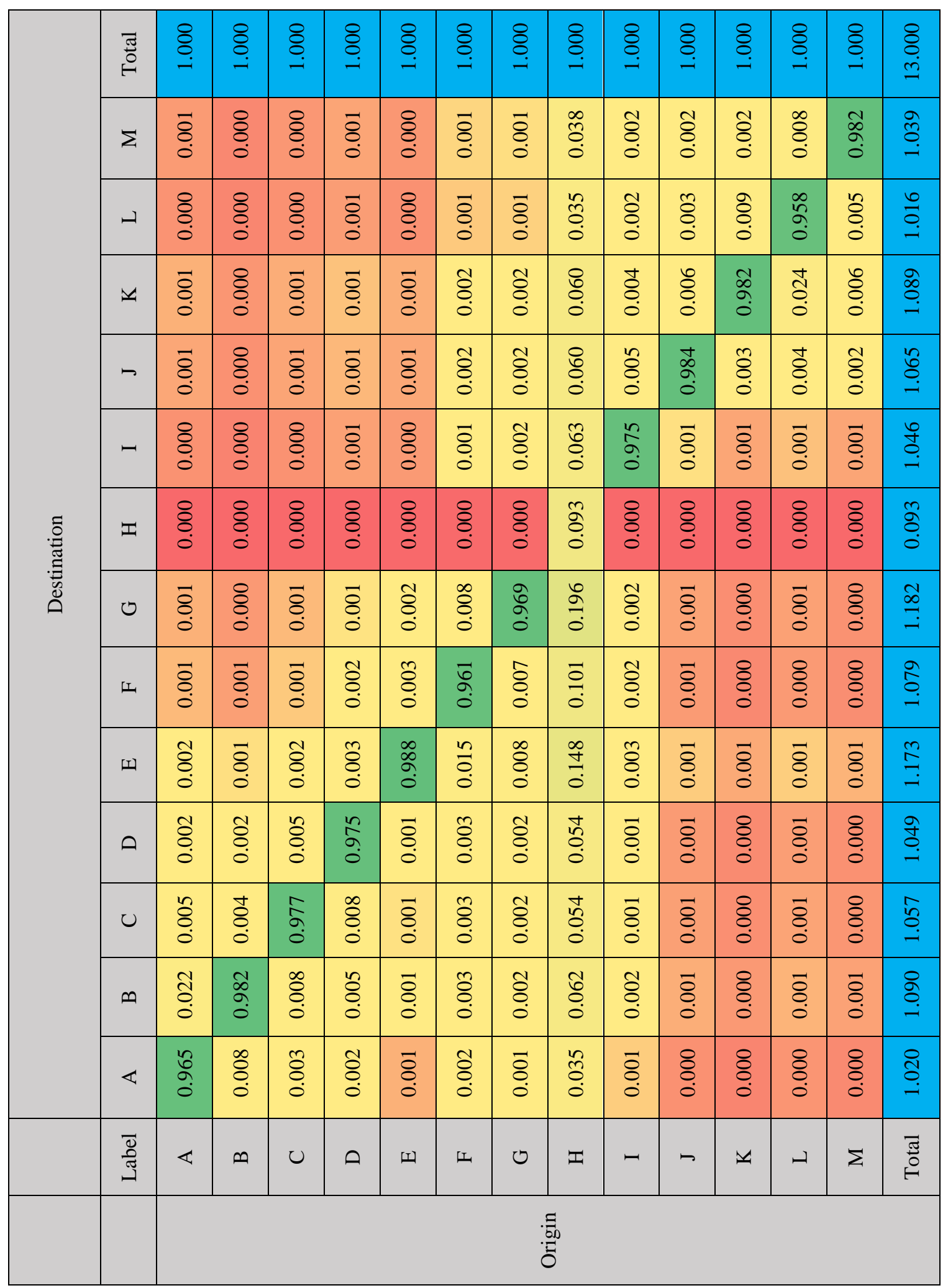

Appendix Table A.3 Accessibility indices for origin-destination pairs from raw housing unit figures for quarter-mile buffer. Green, yellow, and red cells denote relatively high, medium, and low values, respectively. Blue cells denote row or column totals. 


\begin{tabular}{|c|c|c|c|c|c|c|c|c|c|c|c|c|c|c|c|}
\hline \multirow{14}{*}{8} & 嵒 & 8 & $\stackrel{8}{-}$ & 8 & 8 & 8 & $\stackrel{8}{-1}$ & $\stackrel{8}{-}$ & 8 & $\stackrel{8}{-1}$ & 8 & 8 & $\stackrel{8}{-}$ & 8 & $\stackrel{8}{\AA}$ \\
\hline & $\Sigma$ & $\frac{8}{0}$ & 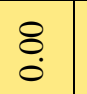 & 8 & $\stackrel{8}{0}$ & 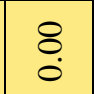 & $\stackrel{0}{0}$ & $\stackrel{8}{0}$ & 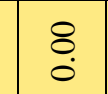 & $\stackrel{0}{0}$ & 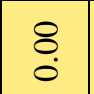 & $\stackrel{8}{0}$ & $\bar{\partial}$ & gे & $\bar{\Xi}$ \\
\hline & 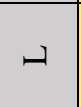 & 8 & $\frac{8}{8}$ & 8 & 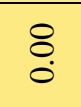 & 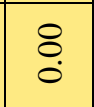 & 8 & 8 & $\begin{array}{l}8 \\
0\end{array}$ & $\stackrel{8}{0}$ & 8 & $\overline{0}$ & $\stackrel{0}{0}$ & $\frac{8}{8}$ & $\bar{s}$ \\
\hline & $\because$ & $\stackrel{8}{0}$ & $\stackrel{8}{8}$ & $\stackrel{8}{8}$ & $\stackrel{8}{0}$ & $\stackrel{8}{0}$ & $\stackrel{8}{0}$ & $\stackrel{8}{0}$ & $\begin{array}{l}8 \\
0\end{array}$ & $\stackrel{8}{0}$ & \begin{tabular}{|l|} 
\\
0
\end{tabular} & $\begin{array}{l}0 \\
\stackrel{\infty}{0} \\
0\end{array}$ & $\stackrel{8}{8}$ & $\bar{\partial}$ & $\stackrel{?}{\stackrel{?}{*}}$ \\
\hline & - & $\stackrel{8}{0}$ & $\stackrel{8}{8}$ & 8 & $\stackrel{8}{0}$ & 8 & $\stackrel{8}{0}$ & 8 & 8 & 8 & g. & $\stackrel{8}{0}$ & $\overline{0}$ & 8 & $\stackrel{\Xi}{-}$ \\
\hline & - & 8 & $\begin{array}{l}8 \\
\end{array}$ & 8 & 8 & 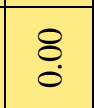 & 8 & 8 & 8 & aे & 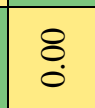 & $\stackrel{8}{8}$ & 8 & 8 & $\bar{a}$ \\
\hline & $I$ & $\stackrel{8}{\circ}$ & $\begin{array}{l} \\
\end{array}$ & $\begin{array}{l}8 \\
\end{array}$ & 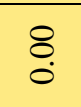 & 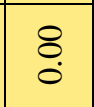 & 8 & $\bar{\sigma}$ & $\dot{a}$ & $\stackrel{8}{0}$ & 号 & $\stackrel{8}{8}$ & 8 & $\stackrel{8}{0}$ & $\stackrel{\sim}{-}$ \\
\hline & 0 & 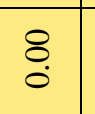 & $\frac{8}{8}$ & 8 & $\stackrel{8}{0}$ & $\begin{array}{l} \\
\end{array}$ & 8 & 5 & $\stackrel{8}{0}$ & $\stackrel{8}{0}$ & : & 8 & 8 & $\stackrel{8}{\circ}$ & aे \\
\hline & $\Psi$ & 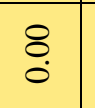 & 8 & $\begin{array}{l}8 \\
0 \\
0\end{array}$ & $\stackrel{8}{0}$ & $\bar{a}$ & oे & $\bar{\partial}$ & 8 & $\stackrel{8}{0}$ & $\%$ & 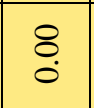 & 8 & $\stackrel{8}{0}$ & $\stackrel{?}{\stackrel{?}{i}}$ \\
\hline & w & 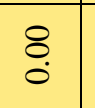 & $\begin{array}{l}8 \\
\end{array}$ & $\stackrel{8}{8}$ & $\stackrel{8}{0}$ & g & $\bar{\partial}$ & $\bar{\partial}$ & 8 & $\stackrel{8}{0}$ & 8 & $\begin{array}{l} \\
\\
\end{array}$ & 8 & 8 & $\stackrel{\Xi}{\Xi}$ \\
\hline & 0 & 8 & 8 & $\bar{\partial}$ & $\stackrel{\bar{\sigma}}{-}$ & 8 & 8 & 8 & $\begin{array}{l}8 \\
0 \\
0\end{array}$ & $\stackrel{8}{0}$ & 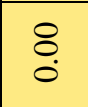 & \begin{tabular}{|l|}
8 \\
0
\end{tabular} & $\stackrel{8}{\circ}$ & 8 & $\underset{+}{\stackrel{t}{*}}$ \\
\hline & 0 & 8 & $\begin{array}{l} \\
\end{array}$ & $\stackrel{t}{+}$ & $\stackrel{8}{0}$ & 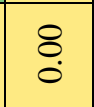 & 8 & 8 & 8 & $\stackrel{8}{0}$ & $\%$ & \begin{tabular}{|l|} 
\\
\end{tabular} & 8 & 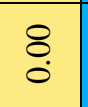 & $\stackrel{\circ}{\leftrightarrow}$ \\
\hline & $\infty$ & $\stackrel{8}{0}$ & $\exists$ & $\bar{D}_{0}$ & $\stackrel{8}{0}$ & 8 & 8 & $\stackrel{8}{\circ}$ & 8 & $\stackrel{8}{\circ}$ & 8 & \begin{tabular}{|l|} 
\\
\end{tabular} & 8 & 8 & $\stackrel{9}{=}$ \\
\hline & $\varangle$ & $\stackrel{8}{-}$ & $\stackrel{9}{0}$ & 它 & 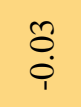 & $\bar{a}_{i}$ & to & 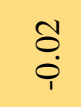 & 官 & $\vec{o}_{\dot{i}}$ & $\bar{a}_{i}$ & $\stackrel{8}{0}$ & ö & ö & : \\
\hline & 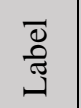 & $\varangle$ & $\infty$ & 0 & 0 & $\omega$ & ш & 0 & \pm & - & - & $\because$ & دـ & $\Sigma$ & 氶 \\
\hline & & & & & & & & & & & & & & & \\
\hline
\end{tabular}

Appendix Table A.4 Accessibility indices for origin-destination pairs from normalized job figures for quarter-mile buffer. Green, yellow, and red cells denote relatively high, medium, and low values, respectively. Blue cells denote row or column totals. 


\begin{tabular}{|c|c|c|c|c|c|c|c|c|c|c|c|c|c|c|c|}
\hline \multirow{14}{*}{ 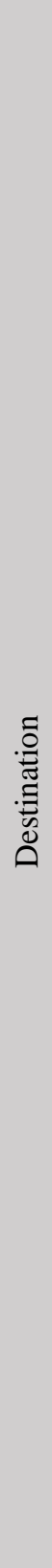 } & స్ & $\stackrel{8}{8}$ & $\stackrel{8}{8}$ & ه. & $\underset{8}{8}$ & $\stackrel{8}{8}$ & $\underset{-}{8}$ & $\underset{-}{8}$ & $\underset{-}{8}$ & $\stackrel{8}{8}$ & $\stackrel{8}{8}$ & $\underset{-}{8}$ & $\stackrel{8}{8}$ & $\stackrel{8}{8}$ & $\begin{array}{l}\stackrel{8}{0} \\
\stackrel{-}{ }\end{array}$ \\
\hline & $\Sigma$ & $\stackrel{8}{0}$ & $\stackrel{8}{8}$ & 8 & $\stackrel{8}{8}$ & $\stackrel{8}{8}$ & $\stackrel{8}{8}$ & $\stackrel{8}{\circ}$ & 8 & $\begin{array}{l}8 \\
0\end{array}$ & $\stackrel{8}{8}$ & $\stackrel{8}{\circ}$ & $\stackrel{8}{\circ}$ & $\frac{n}{\tilde{0}}$ & $\frac{n}{0}$ \\
\hline & $\bullet$ & $\stackrel{8}{\circ}$ & $\stackrel{8}{8}$ & $\begin{array}{l}8 \\
0\end{array}$ & $\stackrel{8}{8}$ & $\stackrel{8}{8}$ & $\stackrel{8}{\circ}$ & $\stackrel{8}{8}$ & : & $\stackrel{8}{8}$ & $\stackrel{8}{8}$ & $\stackrel{8}{\circ}$ & $\stackrel{\Omega}{0}$ & ô. & $\underset{8}{8}$ \\
\hline & $\mathscr{V}$ & $\stackrel{8}{\circ}$ & $\stackrel{8}{\circ}$ & $\stackrel{8}{8}$ & $\stackrel{8}{\circ}$ & $\stackrel{8}{8}$ & $\stackrel{8}{\circ}$ & $\stackrel{8}{\circ}$ & $\stackrel{8}{8}$ & $\stackrel{8}{8}$ & $\stackrel{0}{0}$ & $\stackrel{8}{\circ}$ & ¿̊. & $\stackrel{\overbrace{}}{0}$ & $\stackrel{\overbrace{}}{\dddot{r}}$ \\
\hline & $\neg$ & $\stackrel{8}{\circ}$ & $\stackrel{8}{\circ}$ & $\stackrel{8}{\circ}$ & $\stackrel{8}{8}$ & $\stackrel{8}{0}$ & $\stackrel{8}{\circ}$ & $\stackrel{8}{\circ}$ & $\stackrel{8}{8}$ & $\underset{0}{8}$ & $\stackrel{8}{8}$ & $\stackrel{8}{\circ}$ & $\ddot{\circ}$ & $\stackrel{\text { }}{\circ}$ & ô. \\
\hline & - & $\stackrel{8}{0}$ & $\stackrel{8}{0}$ & $\stackrel{8}{8}$ & 8 & $\stackrel{8}{8}$ & $\stackrel{8}{8}$ & 8 & 8 & $\underset{8}{8}$ & 8 & 8 & 8 & do & $\stackrel{2}{0}$ \\
\hline & $I$ & $\stackrel{\Xi}{0}$ & $\stackrel{8}{8}$ & $\begin{array}{l}8 \\
\stackrel{0}{\circ}\end{array}$ & $\begin{array}{l}0 \\
0 \\
\end{array}$ & $\begin{array}{l}0 \\
0 \\
0\end{array}$ & $\stackrel{1}{0}$ & 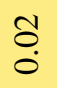 & هُ & $\stackrel{0}{0}$ & $\begin{array}{l}0 \\
0 \\
0\end{array}$ & $\stackrel{8}{\circ}$ & 官. & $\begin{array}{l}0 \\
\frac{0}{0}\end{array}$ & ô \\
\hline & 0 & $\stackrel{8}{\circ}$ & $\stackrel{8}{8}$ & $\begin{array}{l}8 \\
\stackrel{0}{\circ}\end{array}$ & $\stackrel{8}{8}$ & $\stackrel{8}{8}$ & $\stackrel{\circ}{\circ}$ & $\begin{array}{l}\infty \\
\stackrel{0}{0}\end{array}$ & $\begin{array}{l}8 \\
\stackrel{8}{\circ}\end{array}$ & $\stackrel{8}{8}$ & $\stackrel{8}{8}$ & $\stackrel{8}{\circ}$ & $\stackrel{8}{\circ}$ & ô. & $\stackrel{\circ}{\circ}$ \\
\hline & $I$ & $\stackrel{8}{8}$ & $\stackrel{8}{8}$ & $\stackrel{8}{8}$ & $\stackrel{8}{8}$ & $\stackrel{8}{8}$ & ڤ̆ & $\stackrel{8}{8}$ & $\stackrel{8}{8}$ & $\stackrel{8}{8}$ & $\stackrel{8}{\circ}$ & $\stackrel{8}{\circ}$ & $\stackrel{8}{0}$ & 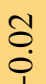 & $\hat{o}$ \\
\hline & 피 & $\begin{array}{l}\ddot{0} \\
\stackrel{\varphi}{\varphi}\end{array}$ & $\stackrel{8}{8}$ & $\begin{array}{l}8 . \\
0\end{array}$ & $\stackrel{0}{0}$ & $\stackrel{\circ}{\circ}$ & $\begin{array}{l}\overline{0} \\
\stackrel{0}{1}\end{array}$ & $\stackrel{8}{\circ}$ & $\stackrel{8}{8}$ & $\stackrel{8}{8}$ & $\stackrel{8}{8}$ & $\stackrel{8}{8}$ & $\stackrel{8}{8}$ & ô. & $\hat{\sigma}$ \\
\hline & D & $\stackrel{8}{\circ}$ & $\stackrel{8}{\circ}$ & $\stackrel{8}{8}$ & $\begin{array}{l}\infty \\
\stackrel{0}{0}\end{array}$ & $\stackrel{8}{8}$ & $\stackrel{8}{\circ}$ & $\stackrel{8}{\circ}$ & $\stackrel{8}{8}$ & $\stackrel{8}{\circ}$ & $\stackrel{8}{8}$ & $\stackrel{\circ}{\circ}$ & $\stackrel{8}{\circ}$ & o. & $\grave{o}$ \\
\hline & $u$ & $\begin{array}{l}1 \\
0 \\
0\end{array}$ & $\ddot{0}$ & $\stackrel{8}{8}$ & Õ & $\stackrel{8}{8}$ & $\stackrel{8}{8}$ & $\stackrel{8}{\circ}$ & 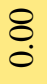 & $\stackrel{8}{8}$ & $\stackrel{8}{8}$ & $\stackrel{8}{\circ}$ & $\stackrel{8}{\circ}$ & ণิ & ộ \\
\hline & $\infty$ & 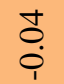 & $\stackrel{8}{8}$ & $\stackrel{8}{8}$ & ö & $\stackrel{8}{8}$ & $\stackrel{8}{\circ}$ & $\stackrel{8}{8}$ & : & $\stackrel{8}{8}$ & $\stackrel{8}{8}$ & $\stackrel{8}{8}$ & $\stackrel{8}{\circ}$ & ¿. & $\begin{array}{l}\infty \\
\stackrel{0}{0}\end{array}$ \\
\hline & $\ll$ & $\stackrel{n}{\varrho}$ & $\begin{array}{l}0 \\
0 \\
\end{array}$ & $\stackrel{8}{8}$ & $\stackrel{8}{8}$ & $\stackrel{8}{8}$ & $\stackrel{8}{8}$ & $\stackrel{8}{\circ}$ & $\begin{array}{l}8 \\
:\end{array}$ & $\stackrel{8}{8}$ & $\stackrel{8}{8}$ & $\stackrel{8}{\circ}$ & $\stackrel{8}{\circ}$ & $\stackrel{8}{8}$ & $\stackrel{+}{0}$ \\
\hline & $\begin{array}{l}\bar{\Xi} \\
\text { 苂 }\end{array}$ & $\varangle$ & 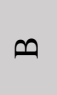 & U & D & 디 & L & 0 & I & - & $r$ & $\forall$ & \lrcorner & $\Sigma$ & 苟 \\
\hline & & & & & & & & & & & & & & & \\
\hline
\end{tabular}

Appendix Table A.5 Accessibility indices for origin-destination pairs from normalized population figures for quarter-mile buffer. Green, yellow, and red cells denote relatively high, medium, and low values, respectively. Blue cells denote row or column totals. 


\begin{tabular}{|c|c|c|c|c|c|c|c|c|c|c|c|c|c|c|c|}
\hline \multirow{14}{*}{ 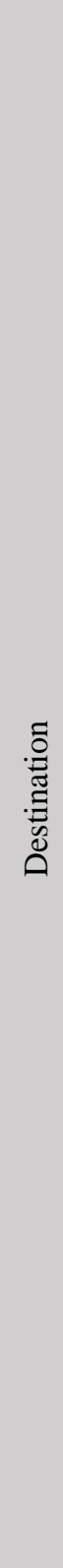 } & 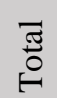 & $\stackrel{8}{8}$ & $\underset{8}{8}$ & $\underset{8}{8}$ & $\underset{-}{8}$ & $\stackrel{8}{8}$ & $\stackrel{8}{8}$ & 8 & $\stackrel{8}{8}$ & $\stackrel{8}{8}$ & $\stackrel{8}{8}$ & $\stackrel{8}{8}$ & $\stackrel{8}{8}$ & $\stackrel{8}{8}$ & $\begin{array}{l}8 \\
\dot{g}\end{array}$ \\
\hline & $\Sigma$ & $\stackrel{8}{8}$ & $\stackrel{8}{\circ}$ & $\stackrel{8}{8}$ & $\stackrel{8}{\circ}$ & $\stackrel{8}{8}$ & : & $\stackrel{8}{8}$ & $\stackrel{8}{\circ}$ & $\stackrel{8}{8}$ & $\stackrel{8}{8}$ & $\stackrel{8}{8}$ & $\begin{array}{l}0 \\
0 \\
0\end{array}$ & $\stackrel{\circ}{\circ}$ & $\hat{a}$ \\
\hline & 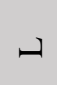 & 8 & $\stackrel{8}{\circ}$ & $\stackrel{8}{8}$ & 8 & $\stackrel{8}{8}$ & $\stackrel{8}{\circ}$ & 8 & $\stackrel{8}{\circ}$ & $\stackrel{8}{8}$ & $\stackrel{8}{8}$ & $\stackrel{8}{8}$ & 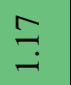 & $\stackrel{8}{8}$ & 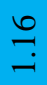 \\
\hline & 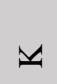 & o. & $\stackrel{8}{\circ}$ & $\stackrel{8}{8}$ & ö. & $\stackrel{8}{\circ}$ & : & $\stackrel{8}{8}$ & $\stackrel{8}{\circ}$ & $\stackrel{8}{8}$ & రై & $\stackrel{8}{8}$ & $\frac{n}{0}$ & $\ddot{0}$ & $\begin{array}{l}\bullet \\
\stackrel{0}{0}\end{array}$ \\
\hline & $\sim$ & $\stackrel{8}{8}$ & $\stackrel{8}{8}$ & $\stackrel{8}{8}$ & $\stackrel{8}{8}$ & $\stackrel{8}{8}$ & $\stackrel{8}{8}$ & $\stackrel{8}{8}$ & $\stackrel{8}{8}$ & $\stackrel{8}{8}$ & $\stackrel{8}{8}$ & $\stackrel{8}{8}$ & ' & $\stackrel{8}{8}$ & $\begin{array}{l}\infty \\
\stackrel{0}{0}\end{array}$ \\
\hline & - & $\overline{0}$ & $\stackrel{8}{8}$ & $\stackrel{8}{8}$ & $\ddot{0}$ & $\stackrel{8}{8}$ & $\stackrel{8}{\circ}$ & 8 & $\stackrel{8}{8}$ & $\underset{8}{8}$ & $\stackrel{8}{8}$ & $\stackrel{8}{8}$ & ō & $\stackrel{8}{8}$ & $\underset{\text { ô }}{ }$ \\
\hline & $I$ & $\stackrel{0}{0}$ & $\stackrel{8}{8}$ & ō & 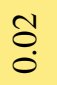 & $\stackrel{8}{8}$ & $\stackrel{\sigma}{0}$ & 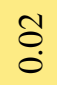 & $\underset{8}{8}$ & $\stackrel{\sigma}{0}$ & ō & $\stackrel{8}{8}$ & $\stackrel{\text { ô }}{0}$ & $\stackrel{8}{8}$ & $\stackrel{\infty}{\stackrel{-}{\circ}}$ \\
\hline & 0 & 웅 & $\stackrel{8}{8}$ & $\stackrel{8}{8}$ & ¿̈. & $\stackrel{8}{8}$ & $\stackrel{0}{0}$ & $\begin{array}{l}\infty \\
0 \\
0\end{array}$ & $\underset{0}{8}$ & $\begin{array}{l}8 \\
0\end{array}$ & $\stackrel{8}{8}$ & $\underset{0}{8}$ & $\underset{0}{8}$ & $\underset{0}{8}$ & $\bar{\sigma}$ \\
\hline & L & ö & 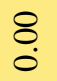 & $\stackrel{8}{8}$ & $\begin{array}{l}0 \\
0 \\
0\end{array}$ & $\stackrel{8}{8}$ & $\underset{-}{8}$ & ō & 8 & 8 & $\stackrel{8}{8}$ & $\stackrel{8}{8}$ & 8 & 8 & $\stackrel{\overbrace{}}{\text { ro }}$ \\
\hline & LI & $\begin{array}{l}0 \\
0 \\
0\end{array}$ & $\stackrel{8}{\circ}$ & $\stackrel{\overline{0}}{0}$ & $\begin{array}{l}0 \\
0 \\
0\end{array}$ & $\underset{-}{0}$ & $\begin{array}{l}0 \\
0 \\
\end{array}$ & $\begin{array}{l}\overline{0} \\
\dot{0}\end{array}$ & $\stackrel{8}{8}$ & $\stackrel{8}{8}$ & $\stackrel{8}{8}$ & $\stackrel{8}{8}$ & 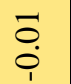 & $\stackrel{8}{8}$ & ڤn \\
\hline & $\theta$ & $\stackrel{8}{\circ}$ & $\stackrel{8}{\circ}$ & $\stackrel{8}{8}$ & $\stackrel{t}{0}$ & $\stackrel{8}{\circ}$ & $\stackrel{8}{0}$ & $\stackrel{8}{\circ}$ & $\stackrel{8}{\circ}$ & $\stackrel{8}{\circ}$ & $\stackrel{8}{\circ}$ & $\stackrel{8}{\circ}$ & $\stackrel{8}{\circ}$ & $\stackrel{8}{\circ}$ & $\stackrel{n}{o}$ \\
\hline & $U$ & $\begin{array}{l}0 \\
0 \\
0\end{array}$ & $\stackrel{8}{8}$ & ঞ̊ & $\begin{array}{l}0 \\
0 \\
0\end{array}$ & $\stackrel{8}{8}$ & $\stackrel{8}{8}$ & $\stackrel{8}{8}$ & $\stackrel{8}{8}$ & $\stackrel{8}{8}$ & $\stackrel{8}{8}$ & $\stackrel{8}{8}$ & $\stackrel{8}{8}$ & $\stackrel{8}{8}$ & $\stackrel{+}{\text { ta }}$ \\
\hline & 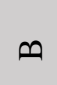 & 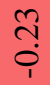 & $\stackrel{8}{8}$ & $\stackrel{\text { O̦ }}{0}$ & $\begin{array}{l}n \\
0 \\
0\end{array}$ & $\stackrel{8}{8}$ & \&̊. & $\begin{array}{l}8 \\
0 \\
0\end{array}$ & $\stackrel{8}{\circ}$ & $\stackrel{8}{8}$ & $\stackrel{8}{8}$ & $\stackrel{8}{8}$ & $\begin{array}{l}0 \\
0 \\
\end{array}$ & $\stackrel{8}{\circ}$ & $\frac{t}{0}$ \\
\hline & $\varangle$ & $\stackrel{\text { స̃ }}{-}$ & $\stackrel{8}{8}$ & $\stackrel{8}{8}$ & $\stackrel{8}{8}$ & $\stackrel{8}{8}$ & $\stackrel{8}{8}$ & $\stackrel{8}{8}$ & $\stackrel{8}{8}$ & $\stackrel{8}{8}$ & $\stackrel{8}{8}$ & $\stackrel{8}{8}$ & $\stackrel{8}{8}$ & $\stackrel{8}{8}$ & $\underset{\sim}{(}$ \\
\hline & $\begin{array}{l}\bar{\Xi} \\
\text { స్త }\end{array}$ & $\varangle$ & 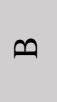 & $U$ & ค & 띠 & 工 & 0 & $I$ & - & $\neg$ & $\mathscr{V}$ & \lrcorner & $\Sigma$ & 丞 \\
\hline & & & & & & & & & & & & & & & \\
\hline
\end{tabular}

Appendix Table A.6 Accessibility indices for origin-destination pairs from normalized housing unit figures for quarter-mile buffer. Green, yellow, and red cells denote relatively high, medium, and low values, respectively. Blue cells denote row or column totals. 


\section{b. Half-Mile Radius}

\begin{tabular}{|c|c|c|c|c|c|c|c|c|c|c|c|c|c|c|c|}
\hline & 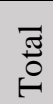 & $\underset{-}{\stackrel{8}{-}}$ & $\underset{-}{\stackrel{8}{-}}$ & $\underset{8}{\stackrel{8}{-}}$ & $\stackrel{8}{-}$ & $\underset{-}{8}$ & $\underset{-}{\stackrel{-}{-}}$ & $\underset{-}{\stackrel{8}{-}}$ & $\underset{-}{\stackrel{8}{-}}$ & $\stackrel{8}{\stackrel{8}{-}}$ & $\underset{-}{\stackrel{8}{-}}$ & $\underset{8}{8}$ & $\underset{-}{\stackrel{8}{-}}$ & $\stackrel{\&}{-}$ & $\begin{array}{l}8 \\
- \\
-\end{array}$ \\
\hline & $\Sigma$ & 8 & $\stackrel{8}{0}$ & $\stackrel{8}{0}$ & 8 & 8 & $\bar{\circ}$ & 8 & $\ddot{0}$ & $\ddot{\circ}$ & $\stackrel{0}{0}$ & $\overline{0}$ & $\stackrel{8}{0}$ & $\bar{a}$ & $\stackrel{\circ}{\circ}$ \\
\hline & $ـ$ & 8 & $\stackrel{8}{\circ}$ & $\stackrel{0}{0}$ & $\stackrel{\overrightarrow{0}}{\circ}$ & $\stackrel{\square}{0}$ & $\stackrel{n}{0}$ & $\stackrel{\square}{\circ}$ & $\stackrel{\circ}{\circ}$ & do & $\frac{9}{0}$ & $\stackrel{\circ}{0}$ & gे & $\stackrel{8}{\circ}$ & \\
\hline & $\checkmark$ & $\stackrel{8}{\circ}$ & $\stackrel{8}{\circ}$ & $\stackrel{8}{0}$ & $\stackrel{8}{\circ}$ & 8 & $\bar{\circ}$ & $\stackrel{8}{\circ}$ & $\vec{\circ}$ & $\overrightarrow{0}$ & $\stackrel{\square}{\circ}$ & 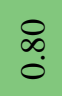 & $\stackrel{8}{0}$ & $\bar{\delta}$ & \\
\hline & $\sim$ & 8 & $\stackrel{8}{0}$ & 8 & 8 & 8 & 8 & 8 & 8 & 8 & in & 8 & $\stackrel{8}{8}$ & 8 & \\
\hline & - & 8 & $\stackrel{8}{0}$ & $\stackrel{8}{0}$ & 8 & 8 & $\bar{\circ}$ & 8 & $\ddot{0}$ & $\begin{array}{l}\infty \\
\infty \\
0\end{array}$ & $\bar{\circ}$ & 8 & $\stackrel{8}{0}$ & 8 & \\
\hline . & \pm & $\stackrel{8}{0}$ & $\stackrel{8}{0}$ & $\stackrel{8}{0}$ & $\stackrel{8}{0}$ & $\stackrel{8}{0}$ & $\stackrel{8}{\circ}$ & $\stackrel{8}{0}$ & J. & $\stackrel{8}{0}$ & $\stackrel{8}{0}$ & $\stackrel{8}{0}$ & $\stackrel{8}{0}$ & $\stackrel{8}{\circ}$ & \\
\hline صे & ט & 8 & $\stackrel{8}{0}$ & 8 & $\stackrel{\vec{\circ}}{\circ}$ & $\overline{0}$ & $\stackrel{\circ}{\circ}$ & $\bar{a}$ & $\stackrel{\infty}{0}$ & $\stackrel{\overline{0}}{0}$ & $\bar{\circ}$ & 8 & $\stackrel{8}{0}$ & $\stackrel{8}{0}$ & \\
\hline & II & $\stackrel{8}{\circ}$ & $\stackrel{8}{0}$ & $\stackrel{8}{8}$ & $\stackrel{8}{\circ}$ & $\stackrel{8}{8}$ & $\stackrel{ \pm}{ \pm}$ & $\stackrel{8}{\circ}$ & $\stackrel{8}{0}$ & $\stackrel{8}{8}$ & $\stackrel{8}{\circ}$ & 8 & $\stackrel{8}{\circ}$ & $\stackrel{8}{\circ}$ & \\
\hline & 피 & $\stackrel{8}{\circ}$ & $\stackrel{8}{0}$ & $\stackrel{8}{0}$ & $\stackrel{8}{0}$ & $\begin{array}{c}0 \\
\infty \\
0\end{array}$ & $\stackrel{0}{\circ}$ & $\stackrel{8}{\circ}$ & $\stackrel{\square}{\circ}$ & $\stackrel{8}{0}$ & $\stackrel{8}{0}$ & $\stackrel{8}{\circ}$ & $\stackrel{8}{\circ}$ & $\stackrel{8}{\circ}$ & \\
\hline & 0 & $\stackrel{8}{\circ}$ & $\stackrel{8}{0}$ & $\stackrel{8}{0}$ & 苦 & 8 & 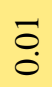 & $\stackrel{8}{\circ}$ & $\stackrel{8}{0}$ & $\stackrel{8}{0}$ & $\stackrel{8}{0}$ & 8 & $\stackrel{8}{\circ}$ & $\stackrel{8}{\circ}$ & \\
\hline & $u$ & 8 & $\ddot{\circ}$ & $\begin{array}{l}\stackrel{0}{\infty} \\
0\end{array}$ & $\stackrel{t}{0}$ & ö & $\stackrel{0}{\circ}$ & 8 & $\stackrel{\sigma}{0}$ & $\ddot{0}$ & $\overline{0}$ & 8 & $\stackrel{8}{0}$ & $\stackrel{8}{0}$ & \\
\hline & $\infty$ & 8 & ले & 8 & : & 8 & $\bar{\circ}$ & $\stackrel{8}{\circ}$ & $\ddot{0}$ & 8 & 8 & 8 & $\stackrel{8}{0}$ & $\stackrel{8}{0}$ & \\
\hline & $\varangle$ & $\stackrel{8}{-}$ & है & $\frac{5}{0}$ & $\stackrel{\infty}{\tilde{0}}$ & $\frac{m}{0}$ & ñ & $\stackrel{5}{0}$ & $\hat{n}$ & $\overline{0}$ & $\stackrel{7}{0}$ & $\stackrel{\leftrightarrow}{0}$ & $\stackrel{0}{\circ}$ & $\stackrel{\tilde{O}}{0}$ & \\
\hline & $\begin{array}{l}\bar{d} \\
\text { ज़ }\end{array}$ & $\ll$ & $\infty$ & $u$ & D & 피 & L & ט & $I$ & - & $\sim$ & $\forall$ & \lrcorner & $\Sigma$ & \\
\hline & & & & & & & & & & & & & & & \\
\hline
\end{tabular}

Appendix Table A.7 Accessibility indices for origin-destination pairs from raw job figures for half-mile buffer. Green, yellow, and red cells denote relatively high, medium, and low values, respectively. Blue cells denote row or column totals. The number of significant figures has been reduced to fit the table within the page. 


\begin{tabular}{|c|c|c|c|c|c|c|c|c|c|c|c|c|c|c|c|}
\hline \multirow{14}{*}{ 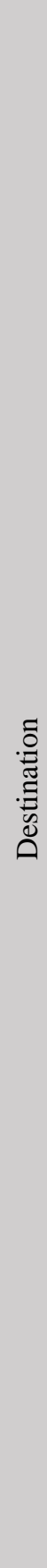 } & : & $\underset{-}{8}$ & $\underset{8}{8}$ & $\underset{8}{8}$ & $\underset{8}{8}$ & $\underset{8}{8}$ & $\underset{8}{8}$ & $\underset{8}{8}$ & 8 & $\underset{8}{8}$ & $\underset{-}{8}$ & $\underset{8}{8}$ & $\underset{8}{8}$ & $\underset{-}{8}$ & $\begin{array}{l}\delta \\
\dot{\delta} \\
\ddot{2}\end{array}$ \\
\hline & $\Sigma$ & $\begin{array}{l}8 \\
0 \\
0\end{array}$ & $\begin{array}{l}8 \\
0 \\
0\end{array}$ & $\overrightarrow{8}$ & $\begin{array}{l}\overline{8} \\
0\end{array}$ & \&̊. & వ্े & $\overrightarrow{8}$ & $\begin{array}{l}\delta \\
\delta \\
0\end{array}$ & 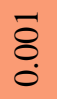 & $\stackrel{\text { ô }}{0}$ & 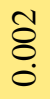 & $\begin{array}{l}\text { to } \\
\stackrel{0}{0}\end{array}$ & $\frac{\infty}{a}$ & $\begin{array}{l}\tilde{\kappa} \\
\hat{\sigma}\end{array}$ \\
\hline & \lrcorner & $\overline{8}$ & $\stackrel{\text { ô }}{0}$ & $\stackrel{\text { ô }}{0}$ & $\stackrel{\text { ô }}{0}$ & $\stackrel{\text { ô }}{0}$ & $\stackrel{t}{8}$ & $\underset{8}{\stackrel{t}{0}}$ & $\stackrel{\infty}{8}$ & $\underset{8}{\stackrel{0}{0}}$ & $\stackrel{2}{0}$ & $\stackrel{\substack{0 \\
0}}{0}$ & $\begin{array}{l}\infty \\
\stackrel{\circ}{0} \\
0\end{array}$ & 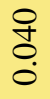 & $\hat{\mathrm{o}}$ \\
\hline & 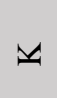 & $\stackrel{8}{8}$ & $\begin{array}{l}\overline{8} \\
0\end{array}$ & $\begin{array}{l}\overline{8} \\
\dot{0}\end{array}$ & $\begin{array}{l}\overline{8} \\
\dot{0}\end{array}$ & $\begin{array}{l}\overline{8} \\
0\end{array}$ & $\stackrel{8}{8}$ & 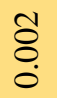 & $\begin{array}{l}\tilde{8} \\
\dot{0}\end{array}$ & $\stackrel{8}{8}$ & $\stackrel{8}{\circ}$ & ふેे & $\stackrel{0}{0}$ & $\stackrel{0}{\circ}$ & $\begin{array}{l}\hat{\infty} \\
0 \\
0\end{array}$ \\
\hline & $r$ & ¿े. & $\begin{array}{l}\overline{8} \\
0\end{array}$ & ¿্口 & $\begin{array}{l}\overline{8} \\
0\end{array}$ & వ̊. & $\begin{array}{l}0 \\
\delta\end{array}$ & $\begin{array}{l}0 \\
8 \\
0\end{array}$ & $\begin{array}{l}8 \\
8 \\
0\end{array}$ & $\begin{array}{l}+ \\
8 \\
0\end{array}$ & $\begin{array}{l}\text { oै } \\
\circ \\
0\end{array}$ & $\begin{array}{l}\infty \\
\stackrel{8}{0}\end{array}$ & $\begin{array}{l}+ \\
8 \\
0\end{array}$ & $\stackrel{\infty}{8}$ & $\underset{\mathrm{Z}}{\stackrel{+}{8}}$ \\
\hline & - & $\stackrel{\overline{8}}{0}$ & $\begin{array}{l}\tilde{8} \\
\stackrel{0}{0}\end{array}$ & 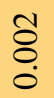 & 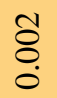 & 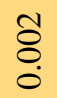 & $\begin{array}{l}8 \\
\&\end{array}$ & $\stackrel{n}{8}$ & $\begin{array}{l}\Delta \\
0 \\
0\end{array}$ & $\begin{array}{l}n \\
\hat{a} \\
0\end{array}$ & $\stackrel{n}{8}$ & $\stackrel{8}{8}$ & $\stackrel{1}{0}$ & $\stackrel{\wp}{8}$ & ڤి \\
\hline & $I$ & $\begin{array}{l}8 \\
0 \\
0\end{array}$ & $\begin{array}{l}\overline{8} \\
0\end{array}$ & $\begin{array}{l}\overline{8} \\
\dot{0}\end{array}$ & $\begin{array}{l}\overline{8} \\
\dot{0}\end{array}$ & $\begin{array}{l}\overline{8} \\
\dot{0}\end{array}$ & $\stackrel{+}{0}$ & $\begin{array}{l}0 \\
0 \\
0\end{array}$ & $\begin{array}{l}\infty \\
\infty \\
0\end{array}$ & 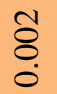 & $\stackrel{\overline{8}}{\circ}$ & $\stackrel{\overline{8}}{\circ}$ & $\begin{array}{l}8 \\
8 \\
0\end{array}$ & $\overline{8}$ & $\frac{\tau}{\alpha}$ \\
\hline & ט & 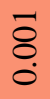 & 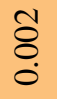 & 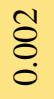 & $\begin{array}{l}\text { ô. } \\
\text { Oे }\end{array}$ & 总 & $\stackrel{a}{\circ}$ & $\begin{array}{l}\vec{J} \\
\text { o }\end{array}$ & ڤ్ & 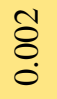 & వ্. & ¿্ণ & $\stackrel{\overline{8}}{\circ}$ & ठ̊. & ¿্. \\
\hline & II & $\stackrel{\overline{8}}{\circ}$ & $\overline{8}$ & $\begin{array}{l}\text { oै } \\
\text { o }\end{array}$ & 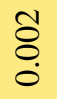 & \&̊ & ڤ̊. & $\vec{\sigma}$ & $\begin{array}{l}0 \\
0 \\
0 \\
0\end{array}$ & $\overline{8}$ & $\overline{8}$ & $\overrightarrow{8}$ & $\begin{array}{l}8 \\
8\end{array}$ & s. & $\begin{array}{l}\text { İ } \\
\text { o. }\end{array}$ \\
\hline & 디 & రి & $\begin{array}{l}\text { ̊̊. } \\
\stackrel{0}{0}\end{array}$ & 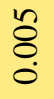 & $\begin{array}{l}n \\
\stackrel{2}{0} \\
0\end{array}$ & 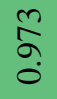 & ळ్ & 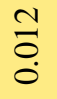 & $\begin{array}{l}n \\
0 \\
0\end{array}$ & $\begin{array}{l}\text { ôे } \\
\text { }\end{array}$ & 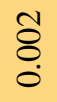 & $\begin{array}{l}\text { ठ̊ } \\
\text {. }\end{array}$ & $\begin{array}{l}\overrightarrow{8} \\
\dot{0}\end{array}$ & $\begin{array}{l}\tilde{\delta} \\
\stackrel{0}{0}\end{array}$ & है \\
\hline & $\theta$ & 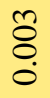 & $\begin{array}{l}8 \\
8 \\
0\end{array}$ & $\stackrel{n}{0}$ & $\begin{array}{l}\infty \\
\swarrow \\
\vdots \\
0\end{array}$ & $\tilde{o}_{0}$ & $\hat{8}$ & $\begin{array}{l}\stackrel{t}{8} \\
0\end{array}$ & $\hat{8}$ & $\begin{array}{l}\text { ô } \\
0\end{array}$ & $\overrightarrow{8}$ & $\overrightarrow{8}$ & $\overrightarrow{8}$ & $\underset{8}{\tilde{8}}$ & $\bar{\sigma}$ \\
\hline & $U$ & $\begin{array}{l}\text { பீ } \\
\text {. }\end{array}$ & $\stackrel{\circ}{\circ}$ & $\stackrel{+}{\stackrel{+}{a}}$ & $\underset{0}{\Xi}$ & 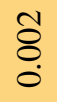 & $\begin{array}{l}\mathscr{8} \\
\stackrel{0}{0}\end{array}$ & $\stackrel{8}{8}$ & $\begin{array}{l}n \\
\delta \\
0\end{array}$ & 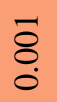 & 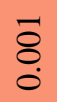 & $\begin{array}{l}\overline{8} \\
0 \\
0\end{array}$ & \begin{tabular}{l}
8 \\
8 \\
\hdashline
\end{tabular} & ¿̊. & 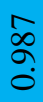 \\
\hline & 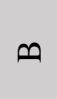 & $\stackrel{n}{0}$ & 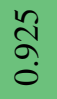 & $\stackrel{2}{\stackrel{0}{0}}$ & $\stackrel{n}{8}$ & $\stackrel{8}{0}$ & $\underset{8}{\stackrel{t}{0}}$ & 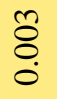 & ठ্ & $\overline{8}$ & $\overline{8}$ & $\overline{8}$ & $\stackrel{8}{8}$ & $\overline{8}$ & $\begin{array}{l}\text { ț } \\
\text { ô }\end{array}$ \\
\hline & $\ll$ & $\begin{array}{l}\stackrel{2}{a} \\
\text { à }\end{array}$ & $\begin{array}{l}\text { ñ } \\
\text { do } \\
0\end{array}$ & $\stackrel{n}{0}$ & $\begin{array}{l}\infty \\
8 \\
0\end{array}$ & $\hat{\delta}_{0}$ & $\begin{array}{l}8 \\
8 \\
0\end{array}$ & $\begin{array}{l}\stackrel{t}{8} \\
0\end{array}$ & $\hat{8}$ & $\begin{array}{l}\text { ô } \\
0\end{array}$ & $\begin{array}{l}\text { ठै } \\
\text { : }\end{array}$ & $\overrightarrow{8}$ & $\overrightarrow{8}$ & $\begin{array}{l}\text { \&े } \\
0\end{array}$ & $\stackrel{8}{\circ}$ \\
\hline & $\begin{array}{l}\bar{\Xi} \\
\text { 苂 }\end{array}$ & $\varangle$ & 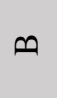 & U & $\theta$ & 디 & IL & 0 & $I$ & - & $\neg$ & $\forall$ & \lrcorner & $\Sigma$ & స్తే \\
\hline & & & & & & & & & & & & & & & \\
\hline
\end{tabular}

Appendix Table A.8 Accessibility indices for origin-destination pairs from raw population figures for halfmile buffer. Green, yellow, and red cells denote relatively high, medium, and low values, respectively. Blue cells denote row or column totals. 


\begin{tabular}{|c|c|c|c|c|c|c|c|c|c|c|c|c|c|c|c|}
\hline \multirow{14}{*}{ 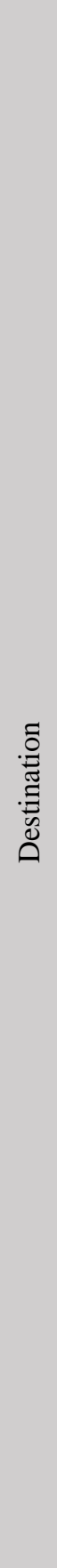 } & స్ّ & $\underset{8}{8}$ & $\underset{8}{8}$ & $\underset{8}{8}$ & $\underset{8}{8}$ & $\underset{8}{8}$ & $\underset{8}{8}$ & 8 & $\underset{8}{8}$ & $\underset{8}{8}$ & $\underset{8}{8}$ & $\underset{8}{8}$ & $\stackrel{8}{8}$ & $\stackrel{8}{8}$ & $\begin{array}{l}\stackrel{8}{8} \\
\dot{\imath} \\
\end{array}$ \\
\hline & $\Sigma$ & \begin{tabular}{l}
8 \\
8 \\
\hdashline
\end{tabular} & $\begin{array}{l}8 \\
8 \\
0\end{array}$ & $\stackrel{\overline{8}}{\circ}$ & $\begin{array}{l}\overline{8} \\
\stackrel{0}{0}\end{array}$ & $\overline{8}$ & 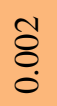 & $\begin{array}{l}\overline{8} \\
\dot{0}\end{array}$ & $\stackrel{\wp}{8}$ & $\overline{8}$ & $\stackrel{8}{8}$ & 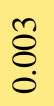 & $\begin{array}{l}\stackrel{d}{8} \\
\stackrel{0}{0}\end{array}$ & $\begin{array}{l}\stackrel{J}{\sigma} \\
\stackrel{\sigma}{0}\end{array}$ & 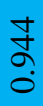 \\
\hline & \lrcorner & $\begin{array}{l}\overline{8} \\
0\end{array}$ & $\begin{array}{l}\text { ô } \\
\stackrel{0}{0}\end{array}$ & 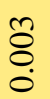 & $\begin{array}{l}\text { oै } \\
\stackrel{0}{0}\end{array}$ & $\stackrel{\text { ô }}{0}$ & $\begin{array}{l}n \\
\delta\end{array}$ & $\begin{array}{l}\text { } \\
\dot{8}\end{array}$ & $\begin{array}{l}\circ \\
0 \\
0\end{array}$ & 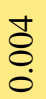 & $\stackrel{\Delta}{\Delta}$ & $\begin{array}{l}\tilde{o} \\
\ddot{0}\end{array}$ & 亏a & ळે. & $\stackrel{O}{=}$ \\
\hline & $\mathscr{V}$ & $\begin{array}{l}\overline{8} \\
\dot{0}\end{array}$ & $\overline{8}$ & $\stackrel{\overline{8}}{\circ}$ & $\begin{array}{l}\overline{8} \\
0\end{array}$ & $\overline{8}$ & $\stackrel{8}{8}$ & 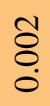 & $\begin{array}{l}0 \\
8 \\
0\end{array}$ & $\begin{array}{l}\text { ㅇ } \\
\stackrel{8}{0} \\
\stackrel{0}{0}\end{array}$ & $\stackrel{0}{\circ}$ & 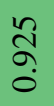 & $\frac{n}{0}$ & $\stackrel{\nabla}{\stackrel{\Xi}{0}}$ & 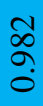 \\
\hline & $\sim$ & $\begin{array}{l}\overline{8} \\
\dot{0}\end{array}$ & $\begin{array}{l}\overline{8} \\
\stackrel{0}{0}\end{array}$ & $\begin{array}{l}\overline{8} \\
\stackrel{0}{0}\end{array}$ & $\begin{array}{l}\overline{8} \\
\stackrel{0}{0}\end{array}$ & $\begin{array}{l}\overline{8} \\
\stackrel{0}{0}\end{array}$ & $\begin{array}{l}\tilde{\delta} \\
\stackrel{0}{0}\end{array}$ & 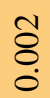 & $\stackrel{0}{0}$ & $\begin{array}{l}\text { } \\
\stackrel{8}{0}\end{array}$ & $\begin{array}{l}\tilde{n} \\
\hat{\sigma}\end{array}$ & $\stackrel{5}{8}$ & $\stackrel{\tilde{o}}{0}$ & \begin{tabular}{l}
$\mathscr{8}$ \\
\hdashline \\
0
\end{tabular} & बू. \\
\hline & - & $\begin{array}{l}\overline{8} \\
\dot{0}\end{array}$ & 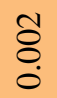 & $\stackrel{8}{8}$ & $\begin{array}{l}\text { ơ } \\
\stackrel{0}{0}\end{array}$ & 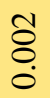 & $\stackrel{\infty}{8}$ & $\stackrel{n}{8}$ & $\begin{array}{l}\stackrel{0}{0} \\
\text { ठ. }\end{array}$ & $\begin{array}{l}\infty \\
\hat{\alpha} \\
0\end{array}$ & $\stackrel{8}{8}$ & $\begin{array}{l}+ \\
8\end{array}$ & $\stackrel{1}{8}$ & $\stackrel{\wp}{8}$ & $\stackrel{\text { fo }}{+}$ \\
\hline & $I$ & $\begin{array}{l}8 \\
8 \\
0\end{array}$ & $\begin{array}{l}8 \\
8 \\
0\end{array}$ & ¿े. & $\begin{array}{l}\overline{8} \\
\dot{0}\end{array}$ & $\stackrel{\overline{8}}{0}$ & $\begin{array}{l}\text { t) } \\
0 \\
0\end{array}$ & $\begin{array}{l}+ \\
8 \\
0\end{array}$ & $\begin{array}{l}\hat{n} \\
\infty \\
0 \\
0\end{array}$ & $\overline{8}$ & $\begin{array}{l}\overline{8} \\
\dot{0}\end{array}$ & $\begin{array}{l}8 \\
0 \\
0\end{array}$ & $\begin{array}{l}8 \\
0 \\
0\end{array}$ & 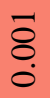 & 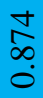 \\
\hline & 0 & 官 & $\begin{array}{l}\text { o̊ } \\
\stackrel{0}{0}\end{array}$ & 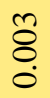 & 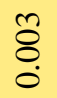 & $\stackrel{n}{o}$ & $\begin{array}{l}\hat{\widehat{O}} \\
\stackrel{0}{0}\end{array}$ & $\begin{array}{l}n \\
\hat{o}\end{array}$ & $\stackrel{\infty}{\infty}$ & 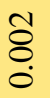 & 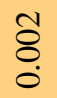 & $\stackrel{\overrightarrow{8}}{\circ}$ & $\overrightarrow{8}$ & 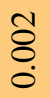 & $\underset{\Xi}{\Xi}$ \\
\hline & L & $\overline{8}$ & $\overline{8}$ & 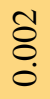 & 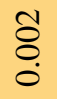 & $\stackrel{n}{0}$ & $\begin{array}{l}\infty \\
\infty \\
\infty \\
0\end{array}$ & $\hat{8}$ & $\begin{array}{l}0 \\
0 \\
0\end{array}$ & $\overline{8}$ & $\overline{8}$ & s. & $\begin{array}{l}8 \\
8 \\
0\end{array}$ & $\overline{8}$ & $\frac{a}{a}$ \\
\hline & 山匚 & $\begin{array}{l}\text { ठิ } \\
\text {. }\end{array}$ & $\begin{array}{l}0 \\
\tilde{o}\end{array}$ & 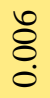 & $\begin{array}{l}8 \\
8 \\
0\end{array}$ & $\frac{t}{\hat{a}}$ & $\begin{array}{l}\hat{\tilde{o}} \\
0 \\
0\end{array}$ & $\bar{\sigma}$ & 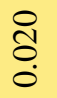 & 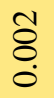 & 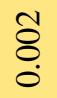 & 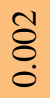 & $\overrightarrow{8}$ & ठ̊. & $\stackrel{\infty}{\stackrel{\circ}{\circ}}$ \\
\hline & 0 & 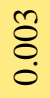 & $\begin{array}{l}n \\
8 \\
\dot{8}\end{array}$ & $\stackrel{0}{0}$ & 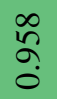 & $\stackrel{8}{0}$ & $\stackrel{\infty}{8}$ & $\stackrel{8}{8}$ & $\stackrel{\infty}{8}$ & $\overline{8}$ & $\overline{8}$ & $\begin{array}{l}\overline{8} \\
\dot{0}\end{array}$ & $\begin{array}{l}\overline{8} \\
0\end{array}$ & $\overline{8}$ & $\bar{\sigma}$ \\
\hline & $u$ & $\begin{array}{l}\text { ¿ } \\
\stackrel{0}{0}\end{array}$ & 용 & $\stackrel{\widehat{\Omega}}{\grave{0}}$ & $\stackrel{8}{\circ}$ & $\begin{array}{l}\text { ㅇ } \\
\stackrel{8}{0}\end{array}$ & $\begin{array}{l}\dot{8} \\
\stackrel{8}{0}\end{array}$ & 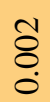 & $\begin{array}{l}\mathscr{8} \\
\stackrel{0}{0} \\
\end{array}$ & ס्ठ & $\begin{array}{l}\overline{8} \\
\stackrel{0}{0}\end{array}$ & $\begin{array}{l}\overline{8} \\
\stackrel{0}{0}\end{array}$ & \begin{tabular}{l}
8 \\
8 \\
\hdashline
\end{tabular} & ¿. & $\begin{array}{l}\text { రి } \\
\stackrel{0}{0}\end{array}$ \\
\hline & $ص$ & $\stackrel{a}{0}$ & ふે & $\frac{1}{0}$ & $\hat{8}$ & $\begin{array}{l}\text { \&̊ } \\
0\end{array}$ & $\stackrel{n}{8}$ & $\begin{array}{l}\tilde{8} \\
0\end{array}$ & $\begin{array}{l}8 \\
8 \\
0\end{array}$ & $\overline{8}$ & $\ddot{8}$ & $\underset{8}{\overline{8}}$ & \begin{tabular}{l}
8 \\
8 \\
\hdashline
\end{tabular} & $\overline{8}$ & $\tilde{\delta}_{0}$ \\
\hline & $\ll$ & $\begin{array}{l}8 \\
\circ \\
0 \\
0\end{array}$ & 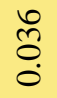 & ô. & $\begin{array}{l}\infty \\
\& \\
0\end{array}$ & $\begin{array}{l}\text { ठै } \\
0\end{array}$ & $\hat{\tilde{8}}$ & $\stackrel{\tilde{\delta}}{0}$ & $\stackrel{\infty}{8}$ & $\overline{8}$ & $\begin{array}{l}\text { ठै } \\
\text { o }\end{array}$ & $\overrightarrow{8}$ & $\overrightarrow{8}$ & $\underset{\delta}{\tilde{8}}$ & है \\
\hline & $\begin{array}{l}\bar{\Xi} \\
\text { త్త }\end{array}$ & $\ll$ & $m$ & $U$ & $\theta$ & 피 & IL & 0 & $I$ & - & $\sim$ & $\forall$ & \lrcorner & $\Sigma$ & (5 \\
\hline & & & & & & & & & & & & & & & \\
\hline
\end{tabular}

Appendix Table A.9 Accessibility indices for origin-destination pairs from raw housing unit figures for half-mile buffer. Green, yellow, and red cells denote relatively high, medium, and low values, respectively. Blue cells denote row or column totals. 


\begin{tabular}{|c|c|c|c|c|c|c|c|c|c|c|c|c|c|c|c|}
\hline & 胥 & $\stackrel{8}{\stackrel{-}{-}}$ & $\stackrel{8}{\stackrel{\leftrightarrow}{-}}$ & $\underset{-}{\stackrel{8}{-}}$ & $\stackrel{8}{-}$ & $\stackrel{8}{-}$ & $\underset{-}{\stackrel{\leftrightarrow}{-}}$ & $\underset{-}{\stackrel{8}{-}}$ & $\underset{-}{\stackrel{\leftrightarrow}{-}}$ & $\stackrel{8}{\rightarrow}$ & $\underset{-}{8}$ & $\underset{-}{\stackrel{8}{-}}$ & $\underset{-}{\stackrel{-}{-}}$ & $\stackrel{8}{\stackrel{\leftrightarrow}{-}}$ & $\begin{array}{l}8 \\
\stackrel{\oplus}{g}\end{array}$ \\
\hline & $\Sigma$ & $\stackrel{8}{0}$ & $\stackrel{8}{0}$ & 8 & 8 & $\stackrel{8}{\circ}$ & $\stackrel{8}{0}$ & 8 & $\stackrel{8}{0}$ & 8 & $\begin{array}{l}8 \\
0 \\
0\end{array}$ & $\stackrel{8}{0}$ & $\stackrel{d}{\delta}$ & oे & gे \\
\hline & \lrcorner & 8 & $\stackrel{8}{0}$ & $\stackrel{8}{\circ}$ & 8 & 8 & $\stackrel{8}{0}$ & 8 & $\stackrel{8}{0}$ & $\stackrel{8}{0}$ & 8 & 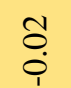 & $\stackrel{\infty}{\stackrel{\leftrightarrow}{\rightarrow}}$ & : & $\stackrel{t}{\longrightarrow}$ \\
\hline & 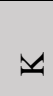 & $\stackrel{8}{0}$ & $\stackrel{8}{0}$ & $\stackrel{8}{\circ}$ & $\stackrel{8}{\circ}$ & $\stackrel{8}{\circ}$ & $\stackrel{8}{\circ}$ & $\stackrel{8}{\circ}$ & $\stackrel{8}{0}$ & $\stackrel{8}{\circ}$ & $\stackrel{0}{\circ}$ & $\underset{-}{8}$ & $\begin{array}{l}n \\
\dot{i} \\
\dot{1}\end{array}$ & $\overline{0}$ & oे \\
\hline & $\sim$ & $\stackrel{8}{0}$ & $\stackrel{8}{0}$ & $\stackrel{8}{0}$ & $\stackrel{8}{\circ}$ & 8 & $\stackrel{8}{0}$ & $\stackrel{8}{\circ}$ & $\stackrel{8}{0}$ & $\bar{\circ}$ & gे & $\overrightarrow{0}$ & $\begin{array}{l}\overrightarrow{0} \\
\dot{1}\end{array}$ & $\overline{0}$ & $\sigma_{-}$ \\
\hline & - & $\stackrel{8}{0}$ & $\stackrel{8}{\circ}$ & $\stackrel{8}{\circ}$ & $\stackrel{8}{0}$ & 8 & $\stackrel{8}{0}$ & $\stackrel{8}{0}$ & $\stackrel{8}{0}$ & ठे. & $\stackrel{8}{8}$ & $\stackrel{8}{0}$ & $\begin{array}{l}\overrightarrow{0} \\
\dot{i}\end{array}$ & 8 & $\vec{\sigma}$ \\
\hline 奇 & $I$ & $\stackrel{8}{0}$ & $\stackrel{8}{0}$ & $\stackrel{8}{0}$ & $\stackrel{8}{0}$ & Б. & $\Xi_{0}$ & $\stackrel{0}{0}$ & $\stackrel{\infty}{\circ}$ & $\stackrel{\overrightarrow{0}}{\circ}$ & $\stackrel{8}{0}$ & 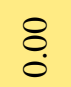 & $\stackrel{8}{0}$ & 8 & $\stackrel{\vartheta}{\ominus}$ \\
\hline ๑ & 0 & 8 & 8 & $\stackrel{8}{0}$ & $\stackrel{8}{8}$ & $\bar{\circ}$ & $\overrightarrow{0}$ & $\stackrel{2}{\circ}$ & $\ddot{0}$ & $\stackrel{8}{0}$ & 8 & $\stackrel{8}{0}$ & $\stackrel{8}{0}$ & 8 & $\stackrel{8}{-}$ \\
\hline & ⿷匚 & $\stackrel{8}{0}$ & $\stackrel{8}{\circ}$ & $\bar{\sigma}_{\circ}$ & $\stackrel{8}{\circ}$ & $\tilde{\delta}$ & $\stackrel{\infty}{\circ}$ & ¿̊. & $\stackrel{0}{0}$ & $\stackrel{8}{0}$ & $\stackrel{8}{\circ}$ & $\stackrel{8}{0}$ & $\stackrel{8}{0}$ & $\stackrel{8}{\circ}$ & $\underset{d}{d}$ \\
\hline & 띠 & $\stackrel{8}{0}$ & $\stackrel{8}{0}$ & $\stackrel{8}{0}$ & $\stackrel{8}{0}$ & $\begin{array}{l}\infty \\
\stackrel{0}{0}\end{array}$ & $\stackrel{\Xi}{\circ}$ & o. & $\stackrel{8}{0}$ & $\stackrel{8}{0}$ & $\stackrel{8}{0}$ & $\stackrel{8}{0}$ & $\stackrel{8}{\circ}$ & $\stackrel{8}{\circ}$ & $\underset{\mathrm{C}}{\mathrm{C}}$ \\
\hline & 0 & 8 & $\overline{0}$ & $\tilde{\sigma}$ & os. & 8 & $\stackrel{8}{0}$ & 8 & 8 & 8 & 8 & $\stackrel{8}{0}$ & $\stackrel{8}{0}$ & 8 & $\stackrel{s}{.}$ \\
\hline & 0 & $\stackrel{8}{0}$ & $\overline{0}$ & $\stackrel{\text { }}{\circ}$ & $\stackrel{0}{\circ}$ & $\stackrel{8}{\circ}$ & $\stackrel{8}{\circ}$ & $\stackrel{8}{\circ}$ & $\stackrel{8}{0}$ & $\stackrel{8}{0}$ & $\stackrel{8}{\circ}$ & $\stackrel{8}{0}$ & $\stackrel{8}{0}$ & $\stackrel{8}{\circ}$ & $\stackrel{\text { oे }}{\text {. }}$ \\
\hline & $\infty$ & 8 & $\stackrel{\overbrace{}}{\rightarrow}$ & $\stackrel{\delta}{0}$ & $\stackrel{\overrightarrow{0}}{0}$ & 8 & $\stackrel{8}{0}$ & $\stackrel{8}{8}$ & 8 & 8 & $\stackrel{8}{8}$ & 8 & $\stackrel{8}{0}$ & 8 & ભે \\
\hline & $\varangle$ & $\stackrel{\square}{-}$ & $\begin{array}{l}q \\
i \\
i\end{array}$ & $\stackrel{m}{0}$ & 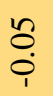 & $\begin{array}{l}\text { ò. } \\
\text { î. }\end{array}$ & o̊ & $\begin{array}{l}\text { ô. } \\
\text { o. }\end{array}$ & $\begin{array}{l}0 \\
\stackrel{i}{i}\end{array}$ & $\begin{array}{l}\overline{0} \\
\dot{i}\end{array}$ & $\begin{array}{l}\overline{0} \\
\\
\end{array}$ & $\begin{array}{l}\overrightarrow{0} \\
\dot{i}\end{array}$ & $\stackrel{\delta}{0}$ & 官 & $\tilde{\check{c}}$ \\
\hline & $\begin{array}{l}\bar{\Xi} \\
\text { J్ }\end{array}$ & $\varangle$ & $\infty$ & U & $\theta$ & $\amalg$ & I & ט & $\Psi$ & $\tau$ & $r$ & $\forall$ & \lrcorner & $\Sigma$ & స్ \\
\hline & & & & & & & & & & & & & & & \\
\hline
\end{tabular}

Appendix Table A.10 Accessibility indices for origin-destination pairs from normalized job figures for halfmile buffer. Green, yellow, and red cells denote relatively high, medium, and low values, respectively. Blue cells denote row or column totals. 


\begin{tabular}{|c|c|c|c|c|c|c|c|c|c|c|c|c|c|c|c|}
\hline \multirow{14}{*}{ 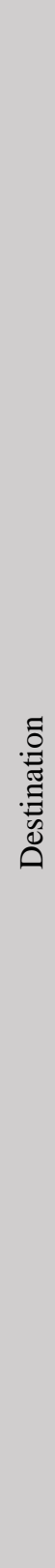 } & $\stackrel{\pi}{0}$ & $\underset{-}{8}$ & $\underset{-}{8}$ & $\underset{-}{8}$ & $\underset{-}{8}$ & $\underset{8}{8}$ & $\stackrel{8}{8}$ & $\underset{-}{8}$ & $\stackrel{8}{.}$ & $\underset{\sim}{8}$ & $\underset{-}{8}$ & $\stackrel{8}{8}$ & $\underset{-}{8}$ & $\stackrel{8}{8}$ & $\begin{array}{l}8 \\
\ddot{g} \\
\ddot{\sim}\end{array}$ \\
\hline & $\Sigma$ & $\stackrel{8}{\circ}$ & $\stackrel{\overline{0}}{\circ}$ & $\stackrel{8}{\circ}$ & $\begin{array}{l}\text { ô } \\
\stackrel{\varphi}{1}\end{array}$ & $\stackrel{8}{\circ}$ & : & $\stackrel{8}{\circ}$ & $\stackrel{8}{8}$ & $\begin{array}{l}0 \\
0 \\
0\end{array}$ & ô. & $\begin{array}{l}n \\
0 \\
0\end{array}$ & $\begin{array}{l}0 \\
0 \\
\end{array}$ & ô & $\begin{array}{l}\infty \\
\infty \\
0 \\
0\end{array}$ \\
\hline & 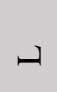 & $\stackrel{8}{8}$ & $\begin{array}{l}0 \\
0 \\
\end{array}$ & $\begin{array}{l}0 \\
0\end{array}$ & $\stackrel{t}{0}$ & $\stackrel{8}{0}$ & $\stackrel{8}{\circ}$ & $\stackrel{8}{\circ}$ & $\stackrel{8}{8}$ & $\stackrel{\sigma}{0}$ & $\stackrel{\infty}{0}$ & กิ? & চِ & ô. & $\stackrel{\infty}{\stackrel{\infty}{\tau}}$ \\
\hline & $\mathscr{V}$ & $\stackrel{8}{8}$ & $\stackrel{8}{8}$ & $\stackrel{8}{8}$ & $\stackrel{8}{8}$ & $\stackrel{8}{8}$ & $\stackrel{8}{\circ}$ & $\stackrel{8}{\circ}$ & $\stackrel{8}{8}$ & $\stackrel{8}{8}$ & $\stackrel{0}{0}$ & $\stackrel{\infty}{+}$ & $\stackrel{8}{8}$ & $\stackrel{8}{\circ}$ & $\stackrel{\infty}{\stackrel{\infty}{0} .}$ \\
\hline & $\neg$ & $\stackrel{8}{8}$ & $\stackrel{8}{8}$ & $\stackrel{8}{8}$ & $\stackrel{8}{8}$ & $\stackrel{8}{8}$ & $\stackrel{8}{8}$ & $\stackrel{8}{8}$ & $\stackrel{8}{8}$ & $\stackrel{8}{8}$ & Oু & $\ddot{0}$ & $\stackrel{8}{0}$ & $\stackrel{8}{\circ}$ & $\hat{\sigma}$ \\
\hline & $\neg$ & 8 & 8 & 8 & $\stackrel{\sigma}{0}$ & 8 & $\stackrel{8}{\circ}$ & $\stackrel{8}{8}$ & $\stackrel{8}{8}$ & $\underset{\text { Sa }}{0}$ & 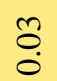 & $\overline{0}$ & $\underset{8}{8}$ & $\stackrel{8}{8}$ & \&ِ \\
\hline & $I$ & $\stackrel{8}{8}$ & 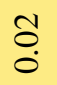 & $\stackrel{\square}{0}$ & $\begin{array}{l}0 \\
\stackrel{0}{0} \\
\end{array}$ & $\begin{array}{l}\overline{0} \\
0 \\
0\end{array}$ & $\stackrel{\overline{0}}{\circ}$ & 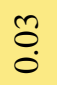 & $\underset{8}{8}$ & ơ & $\stackrel{0}{0}$ & ช̊. & $\stackrel{8}{8}$ & $\stackrel{8}{\circ}$ & ஓ. \\
\hline & 0 & $\stackrel{8}{8}$ & $\stackrel{\overline{0}}{\circ}$ & $\stackrel{\sigma}{\circ}$ & $\begin{array}{l}n \\
0 \\
\dot{p}\end{array}$ & $\begin{array}{l}\overline{0} \\
0\end{array}$ & $\stackrel{\sigma}{\circ}$ & $\stackrel{\circ}{\circ}$ & $\stackrel{\overline{0}}{\dot{0}}$ & $\begin{array}{l}\tilde{0} \\
\dot{p}\end{array}$ & $\begin{array}{l}\text { ô } \\
\dot{0}\end{array}$ & ठ․ & $\stackrel{8}{8}$ & $\stackrel{8}{8}$ & \&̊. \\
\hline & IL & $\stackrel{8}{\circ}$ & $\stackrel{\leftrightarrow}{0}$ & ō & $\frac{0}{0}$ & $\begin{array}{l}\text { O̦ } \\
0 \\
0\end{array}$ & $\stackrel{8}{8}$ & 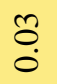 & ¿ִ̣. & $\begin{array}{l}\overline{0} \\
0 \\
0\end{array}$ & $\begin{array}{l}m \\
0 \\
0\end{array}$ & 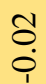 & $\stackrel{8}{\circ}$ & $\stackrel{8}{8}$ & $\begin{array}{l}\infty \\
\infty \\
0\end{array}$ \\
\hline & 피 & $\stackrel{8}{8}$ & $\begin{array}{l}0 \\
\stackrel{0}{0}\end{array}$ & $\begin{array}{l}0 \\
0 \\
0\end{array}$ & $\stackrel{\infty}{\stackrel{\infty}{0}}$ & $\stackrel{\varrho}{0}$ & ¿. & ọ. & $\stackrel{8}{\circ}$ & $\stackrel{8}{\circ}$ & 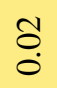 & ㅁ. & $\stackrel{8}{\circ}$ & $\stackrel{8}{\circ}$ & $\stackrel{a}{a}$ \\
\hline & $\theta$ & 8 & 8 & 8 & $\underset{\sim}{\Delta}$ & 8 & 8 & 8 & 8 & 8 & 8 & 8 & 8 & 8 & $\underset{-}{+}$ \\
\hline & $U$ & $\stackrel{8}{8}$ & $\stackrel{\leftrightarrow}{0}$ & $\stackrel{\sigma}{0}$ & $\begin{array}{l}8 \\
\stackrel{0}{0} \\
\end{array}$ & $\stackrel{8}{8}$ & $\stackrel{8}{8}$ & $\stackrel{8}{\circ}$ & $\stackrel{8}{\circ}$ & $\stackrel{8}{8}$ & ọ. & $\stackrel{8}{8}$ & $\stackrel{8}{\circ}$ & 8 & ठே \\
\hline & 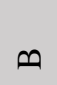 & $\stackrel{8}{8}$ & กิ & $\stackrel{0}{0}$ & $\stackrel{0}{0}$ & $\stackrel{8}{\circ}$ & $\stackrel{8}{8}$ & $\stackrel{8}{\circ}$ & $\stackrel{8}{8}$ & $\stackrel{8}{\circ}$ & $\stackrel{8}{\circ}$ & $\stackrel{8}{\circ}$ & $\stackrel{8}{\circ}$ & 8 & $\stackrel{a}{\rightleftarrows}$ \\
\hline & $\ll$ & $\underline{0}$ & $\begin{array}{l}\stackrel{2}{1} \\
\text { in }\end{array}$ & $\begin{array}{l}\text { to } \\
0 \\
\end{array}$ & $\frac{1}{0}$ & $\stackrel{8}{8}$ & $\stackrel{8}{\circ}$ & $\stackrel{8}{\circ}$ & $\stackrel{8}{8}$ & $\stackrel{8}{8}$ & 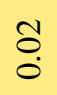 & $\stackrel{\Xi}{0}$ & $\stackrel{8}{8}$ & 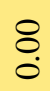 & $\bar{\sigma}$ \\
\hline & $\begin{array}{l}\bar{\Xi} \\
\bar{\Xi} \\
\text { ] }\end{array}$ & $\varangle$ & $ص$ & $u$ & D & 디 & IL & 0 & $I$ & - & $\neg$ & $\forall$ & \lrcorner & $\Sigma$ & 吾 \\
\hline & & & & & & & & & & & & & & & \\
\hline
\end{tabular}

Appendix Table A.11 Accessibility indices for origin-destination pairs from normalized population figures for half-mile buffer. Green, yellow, and red cells denote relatively high, medium, and low values, respectively. Blue cells denote row or column totals. 


\begin{tabular}{|c|c|c|c|c|c|c|c|c|c|c|c|c|c|c|c|}
\hline & స్ & $\stackrel{8}{\stackrel{-}{-}}$ & $\stackrel{8}{8}$ & $\stackrel{8}{-}$ & $\stackrel{8}{\circ}$ & $\underset{8}{\stackrel{8}{-}}$ & $\underset{-}{8}$ & $\underset{8}{\stackrel{-}{-}}$ & $\stackrel{8}{-}$ & $\stackrel{8}{-}$ & $\underset{:}{\stackrel{-}{-}}$ & $\underset{-}{8}$ & $\stackrel{8}{-}$ & $\stackrel{8}{\stackrel{\leftrightarrow}{-}}$ & 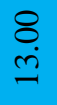 \\
\hline & $\Sigma$ & 8 & 8 & $\stackrel{8}{0}$ & $\overline{0}$ & 8 & $\stackrel{8}{\circ}$ & 8 & $\stackrel{8}{0}$ & $\stackrel{8}{0}$ & $\stackrel{\delta}{0}$ & $\begin{array}{l}n \\
0 \\
0 \\
\dot{1}\end{array}$ & o. & $\stackrel{\overbrace{}}{\stackrel{\leftrightarrow}{-}}$ & $\stackrel{8}{-}$ \\
\hline & ــ & $\stackrel{8}{0}$ & ¿. & $\stackrel{8}{0}$ & 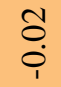 & $\stackrel{8}{0}$ & $\stackrel{8}{\circ}$ & ¿. & $\stackrel{8}{0}$ & $\stackrel{\Xi}{0}$ & 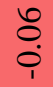 & $\frac{n}{0}$ & $\underset{-}{\sigma}$ & 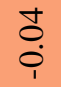 & ț \\
\hline & $\forall$ & $\stackrel{8}{0}$ & \&. & $\stackrel{8}{0}$ & $\stackrel{8}{0}$ & $\stackrel{8}{0}$ & $\stackrel{0}{0}$ & $\stackrel{8}{0}$ & $\stackrel{8}{0}$ & $\stackrel{8}{0}$ & $\stackrel{8}{0}$ & d़ & $\stackrel{8}{0}$ & : & m. \\
\hline & - & $\stackrel{8}{\circ}$ & $\stackrel{8}{\circ}$ & $\stackrel{8}{0}$ & $\stackrel{8}{\circ}$ & $\stackrel{8}{\circ}$ & $\stackrel{0}{\circ}$ & $\stackrel{8}{\circ}$ & $\stackrel{8}{0}$ & $\stackrel{8}{0}$ & $\stackrel{t}{\mathrm{O}}$ & ộ & $\stackrel{8}{\circ}$ & $\stackrel{8}{\circ}$ & $\stackrel{\sigma}{\sigma}$ \\
\hline & - & $\stackrel{8}{\circ}$ & : & $\stackrel{8}{0}$ & o. & $\stackrel{8}{\circ}$ & $\stackrel{8}{\circ}$ & ¿. & $\stackrel{8}{0}$ & $\stackrel{\sigma}{\sigma}$ & ¿̊. & $\stackrel{\leftrightarrow}{0}$ & $\stackrel{8}{\circ}$ & $\stackrel{8}{\circ}$ & $\stackrel{8}{.}$ \\
\hline & \pm & $\stackrel{8}{0}$ & $\begin{array}{l}2 \\
0 \\
0\end{array}$ & $\overrightarrow{0}$ & $\stackrel{\overbrace{}}{0}$ & $\overrightarrow{0}$ & $\vec{\sigma}_{0}$ & oे & $\stackrel{\leftrightarrow}{\leftrightarrow}$ & 항 & $\delta_{0}^{0}$ & ț. & $\stackrel{8}{0}$ & $\stackrel{8}{0}$ & $\stackrel{\sigma}{-}$ \\
\hline$\stackrel{\vec{s}}{\Delta}$ & 0 & $\stackrel{8}{0}$ & $\stackrel{8}{0}$ & $\stackrel{8}{0}$ & $\stackrel{\bar{o}}{0}$ & $\stackrel{8}{0}$ & $\stackrel{8}{0}$ & $\begin{array}{l}\infty \\
\infty \\
\infty\end{array}$ & $\stackrel{8}{0}$ & $\stackrel{8}{0}$ & $\stackrel{8}{0}$ & 8 & $\stackrel{8}{0}$ & $\stackrel{8}{0}$ & $\begin{array}{c}\infty \\
\infty \\
\infty\end{array}$ \\
\hline & L & 8 & $\begin{array}{l}\text { ò } \\
\text { in }\end{array}$ & $\dot{0}$ & $\stackrel{n}{0}$ & ò & $\underset{-}{8}$ & $\stackrel{\circ}{\circ}$ & $\dot{0}$ & 8 & $\overline{0}$ & $\begin{array}{l}\text { ò } \\
\text { i. }\end{array}$ & 8 & 8 & $\stackrel{s}{-}$ \\
\hline & 山् & $\stackrel{8}{\circ}$ & $\Xi$ & $\stackrel{8}{0}$ & $\stackrel{\overbrace{}}{:}$ & $\stackrel{\overbrace{}}{\text { o. }}$ & $\overrightarrow{0}$ & ồ & $\stackrel{8}{0}$ & $\stackrel{8}{0}$ & : & ō & $\stackrel{8}{\circ}$ & $\stackrel{8}{\circ}$ & $\begin{array}{l}\infty \\
\stackrel{0}{0} \\
0\end{array}$ \\
\hline & 0 & $\stackrel{8}{\circ}$ & 8 & $\stackrel{8}{0}$ & to & $\stackrel{8}{\circ}$ & $\stackrel{8}{\circ}$ & $\stackrel{8}{\circ}$ & $\stackrel{8}{0}$ & $\stackrel{8}{0}$ & $\stackrel{8}{0}$ & $\stackrel{8}{8}$ & $\stackrel{8}{\circ}$ & $\stackrel{8}{\circ}$ & ò \\
\hline & u & : & 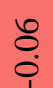 & $\underset{\dot{\sigma}}{-}$ & $\stackrel{\infty}{\circ}$ & $\stackrel{8}{\circ}$ & $\stackrel{8}{\circ}$ & ¿. & $\stackrel{8}{0}$ & $\stackrel{8}{0}$ & $\stackrel{8}{0}$ & ō & $\stackrel{8}{\circ}$ & $\stackrel{8}{\circ}$ & $\stackrel{\tilde{o}}{-}$ \\
\hline & $\infty$ & $\stackrel{8}{0}$ & $\begin{array}{c}\infty \\
\infty \\
0 \\
0\end{array}$ & $\stackrel{8}{\circ}$ & : & $\stackrel{8}{0}$ & $\stackrel{8}{\circ}$ & $\stackrel{8}{0}$ & $\stackrel{8}{0}$ & $\stackrel{8}{0}$ & 8 & 8 & $\stackrel{8}{0}$ & $\stackrel{8}{0}$ & $\begin{array}{c}\infty \\
\infty \\
\infty \\
\infty\end{array}$ \\
\hline & $\ll$ & $\stackrel{8}{8}$ & ते & $\begin{array}{l}\overrightarrow{0} \\
\dot{1}\end{array}$ & ${ }_{0}^{n}$ & 8 & $\stackrel{8}{8}$ & o. & $\stackrel{8}{0}$ & $\stackrel{8}{0}$ & 8 & $\overline{0}$ & 8 & $\stackrel{8}{0}$ & $\stackrel{\Xi}{\Xi}$ \\
\hline & $\begin{array}{l}\bar{D} \\
\text { ज్ }\end{array}$ & $\varangle$ & 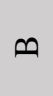 & $u$ & 0 & 山 & 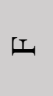 & 0 & $\Psi$ & - & $n$ & $\forall$ & دـ & $\Sigma$ & స్ \\
\hline & & & & & & & & & & & & & & & \\
\hline
\end{tabular}

Appendix Table A.12 Accessibility indices for origin-destination pairs from normalized housing unit figures for half-mile buffer. Green, yellow, and red cells denote relatively high, medium, and low values, respectively. Blue cells denote row or column totals. 


\section{c. One-Mile Radius}

\begin{tabular}{|c|c|c|c|c|c|c|c|c|c|c|c|c|c|c|c|}
\hline \multirow{14}{*}{ 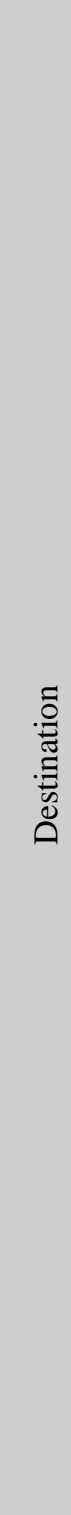 } & 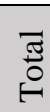 & $\stackrel{8}{\circ}$ & $\underset{-}{8}$ & $\underset{-}{8}$ & $\underset{-}{8}$ & $\underset{-}{8}$ & $\stackrel{8}{8}$ & $\underset{-}{8}$ & $\stackrel{8}{8}$ & $\underset{.}{8}$ & $\stackrel{8}{-}$ & 8 & $\underset{-}{8}$ & $\stackrel{8}{8}$ & $\begin{array}{l}8 \\
\stackrel{8}{2} \\
\ddot{7}\end{array}$ \\
\hline & $\Sigma$ & $\stackrel{8}{8}$ & $\stackrel{8}{8}$ & $\stackrel{8}{\circ}$ & $\underset{0}{0}$ & $\tilde{O}_{0}^{0}$ & 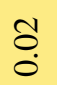 & $\stackrel{8}{8}$ & $\stackrel{\wp}{0}$ & $\overline{0}$ & $\underset{0}{\stackrel{0}{0}}$ & $\stackrel{8}{\circ}$ & $\stackrel{\sigma}{0}$ & $\begin{array}{l}+ \\
\infty \\
0\end{array}$ & $\begin{array}{l}\text { ڤ̊ } \\
\text { o }\end{array}$ \\
\hline & \lrcorner & $\stackrel{8}{8}$ & $\underset{0}{0}$ & $\underset{0}{0}$ & $\stackrel{\wp}{0}$ & $\stackrel{0}{0}$ & $\overrightarrow{0}$ & $\underset{0}{0}$ & $\frac{n}{0}$ & $\stackrel{.}{\circ}$ & $\stackrel{n}{\tilde{c}}$ & $\frac{m}{0}$ & å & $\exists$ & $\begin{array}{l}\infty \\
\stackrel{\infty}{-} \\
\stackrel{-}{2}\end{array}$ \\
\hline & 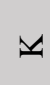 & $\stackrel{8}{\circ}$ & $\stackrel{8}{8}$ & $\stackrel{8}{8}$ & $\stackrel{\overrightarrow{0}}{0}$ & ō & $\stackrel{+}{0}$ & $\stackrel{\square}{\circ}$ & $\stackrel{\bullet}{\circ}$ & $\begin{array}{l}\overbrace{0} \\
\dot{0}\end{array}$ & $\stackrel{m}{0}$ & $\begin{array}{l}\because \\
\infty \\
0\end{array}$ & $\stackrel{\text { ô }}{\circ}$ & $\stackrel{\wp}{0}$ & $\stackrel{9}{\rightleftarrows}$ \\
\hline & 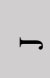 & $\stackrel{8}{8}$ & $\stackrel{8}{8}$ & $\stackrel{8}{8}$ & $\stackrel{8}{\circ}$ & $\stackrel{8}{8}$ & $\stackrel{8}{\circ}$ & $\stackrel{8}{\circ}$ & $\stackrel{8}{0}$ & $\stackrel{8}{8}$ & $\stackrel{0}{+}$ & \&. & $\stackrel{8}{\circ}$ & $\stackrel{8}{\circ}$ & $\stackrel{\infty}{+}$ \\
\hline & $\neg$ & $\stackrel{8}{8}$ & $\begin{array}{l}8 \\
0\end{array}$ & $\stackrel{8}{8}$ & $\begin{array}{l}8 \\
0\end{array}$ & $\stackrel{8}{8}$ & $\underset{0}{0}$ & $\stackrel{8}{8}$ & $\stackrel{0}{0}$ & $\begin{array}{l}\bar{\infty} \\
0\end{array}$ & $\stackrel{\sigma}{0}$ & $\stackrel{8}{8}$ & $\stackrel{8}{\circ}$ & $\begin{array}{l}8 \\
0\end{array}$ & $\begin{array}{l}\infty \\
\infty \\
0 \\
0\end{array}$ \\
\hline & $I$ & $\stackrel{8}{8}$ & $\stackrel{8}{8}$ & $\stackrel{8}{8}$ & $\stackrel{8}{8}$ & $\stackrel{8}{8}$ & $\stackrel{8}{8}$ & $\stackrel{8}{8}$ & $\frac{1}{0}$ & $\stackrel{8}{8}$ & $\underset{0}{8}$ & $\stackrel{8}{8}$ & $\stackrel{8}{\circ}$ & $\stackrel{8}{8}$ & $\frac{m}{0}$ \\
\hline & 0 & $\stackrel{8}{\circ}$ & $\stackrel{8}{\circ}$ & $\stackrel{8}{\circ}$ & $\stackrel{\text { I̦ }}{0}$ & $\stackrel{t}{0}$ & 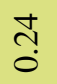 & 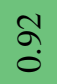 & $\stackrel{\overbrace{}}{0}$ & 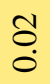 & 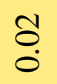 & $\stackrel{8}{8}$ & $\stackrel{8}{\circ}$ & $\stackrel{8}{8}$ & i̊ ?ִ \\
\hline & I & 8 & $\stackrel{8}{0}$ & $\stackrel{8}{8}$ & $\stackrel{8}{8}$ & $\stackrel{8}{8}$ & $\stackrel{0}{0}$ & $\stackrel{8}{\circ}$ & $\stackrel{8}{8}$ & $\stackrel{8}{8}$ & $\stackrel{8}{\circ}$ & $\stackrel{8}{8}$ & $\stackrel{8}{\circ}$ & $\stackrel{8}{8}$ & $\stackrel{1}{0}$ \\
\hline & 山ు & $\stackrel{8}{8}$ & $\stackrel{8}{8}$ & $\stackrel{8}{8}$ & $\stackrel{\overline{0}}{\circ}$ & $\stackrel{n}{i}$ & $\stackrel{\circ}{\circ}$ & $\stackrel{8}{8}$ & 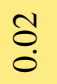 & $\stackrel{8}{8}$ & $\stackrel{8}{\circ}$ & 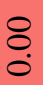 & $\stackrel{8}{0}$ & $\underset{0}{8}$ & $\begin{array}{l}\infty \\
\infty \\
0 \\
0\end{array}$ \\
\hline & D & 8 & $\stackrel{8}{8}$ & $\stackrel{8}{8}$ & $\stackrel{+}{n}$ & $\stackrel{8}{8}$ & $\ddot{0}$ & $\stackrel{8}{8}$ & $\ddot{0}$ & $\stackrel{8}{8}$ & $\stackrel{8}{8}$ & $\begin{array}{l}8 \\
0\end{array}$ & $\stackrel{8}{0}$ & $\stackrel{8}{8}$ & $\begin{array}{c}\infty \\
\stackrel{n}{n}\end{array}$ \\
\hline & $u$ & $\stackrel{8}{\circ}$ & $\underset{0}{0}$ & $\begin{array}{l}\mathscr{m} \\
\infty \\
0\end{array}$ & $\stackrel{\infty}{\stackrel{\infty}{0}}$ & $\underset{0}{0}$ & $\stackrel{n}{\circ}$ & $\ddot{0}$ & $\underset{0}{\stackrel{D}{0}}$ & ö. & $\stackrel{\Xi}{0}$ & $\begin{array}{l}8 \\
\stackrel{0}{0}\end{array}$ & $\stackrel{8}{\circ}$ & $\stackrel{8}{8}$ & \\
\hline & $\infty$ & 8 & $\bar{n}$ & ō & $\stackrel{\text { I̦ }}{0}$ & ō & $\stackrel{\leftrightarrow}{0}$ & $\stackrel{8}{\circ}$ & 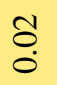 & $\stackrel{8}{\circ}$ & $\stackrel{8}{\circ}$ & $\stackrel{8}{8}$ & $\stackrel{8}{\circ}$ & $\stackrel{8}{8}$ & $\overrightarrow{0}$ \\
\hline & $\varangle$ & $\hat{\sigma}$ & $\stackrel{n}{\circ}$ & $\frac{m}{0}$ & 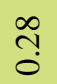 & $\frac{N}{0}$ & $\tilde{n}$ & $\stackrel{+}{0}$ & $\stackrel{\text { సે }}{0}$ & $\begin{array}{l}8 \\
0\end{array}$ & $\stackrel{0}{0}$ & o. & $\stackrel{8}{0}$ & $\stackrel{0}{0}$ & $\begin{array}{l}\stackrel{\infty}{ } \\
\text { i }\end{array}$ \\
\hline & $\begin{array}{l}\overline{\mathbb{D}} \\
\bar{\Xi} \\
\widetilde{J}\end{array}$ & $\varangle$ & $\infty$ & $u$ & $\theta$ & II & IL & ن & $I$ & - & $\neg$ & 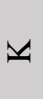 & - & $\Sigma$ & స్తే \\
\hline & & & & & & & & & & & & & & & \\
\hline
\end{tabular}

Appendix Table A.13 Accessibility indices for origin-destination pairs from raw job figures for one-mile buffer. Green, yellow, and red cells denote relatively high, medium, and low values, respectively. Blue cells denote row or column totals. The number of significant figures has been reduced to fit the table within the page. 


\begin{tabular}{|c|c|c|c|c|c|c|c|c|c|c|c|c|c|c|c|}
\hline \multirow{14}{*}{ 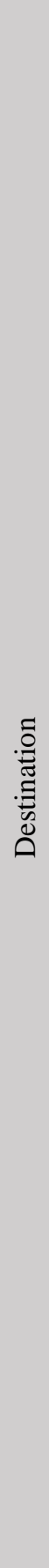 } & 完 & $\underset{8}{8}$ & $\underset{8}{8}$ & $\stackrel{8}{8}$ & $\underset{8}{8}$ & $\stackrel{8}{8}$ & 8 & $\underset{8}{8}$ & $\underset{8}{8}$ & $\underset{8}{8}$ & $\underset{8}{8}$ & $\underset{8}{8}$ & $\underset{8}{8}$ & $\underset{8}{8}$ & $\begin{array}{l}8 \\
\delta \\
\dot{\imath}\end{array}$ \\
\hline & $\Sigma$ & \begin{tabular}{l}
8 \\
\hdashline
\end{tabular} & $\overline{8}$ & \begin{tabular}{l}
8 \\
\hdashline \\
0
\end{tabular} & ¿্口 & ¿̊ & $\hat{8}$ & ¿্口 & $\begin{array}{l}n \\
\delta \\
0\end{array}$ & 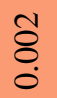 & $\begin{array}{l}+ \\
\stackrel{0}{0} \\
0\end{array}$ & $\hat{8}$ & $\stackrel{n}{0}$ & $\stackrel{2}{\stackrel{0}{0}}$ & $\begin{array}{l}\stackrel{0}{\infty} \\
\stackrel{0}{0}\end{array}$ \\
\hline & \lrcorner & $\underset{8}{\overline{8}}$ & $\begin{array}{l}\text { } \\
\stackrel{0}{0}\end{array}$ & 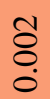 & $\begin{array}{l}8 \\
8 \\
0\end{array}$ & $\underset{8}{\stackrel{0}{0}}$ & $\stackrel{\nabla}{\circ}$ & \begin{tabular}{l}
8 \\
8 \\
\hdashline
\end{tabular} & $\begin{array}{l}\text { I. } \\
\text { ¿ }\end{array}$ & $\stackrel{1}{0}$ & ס̊: & $\begin{array}{l}\text { ¿ } \\
8 \\
0\end{array}$ & \begin{tabular}{l}
0 \\
\multirow{2}{0}{} \\
0
\end{tabular} & $\begin{array}{l}\stackrel{\infty}{\circ} \\
0\end{array}$ & 突 \\
\hline & $\forall$ & $\begin{array}{l}\overline{8} \\
\dot{0}\end{array}$ & 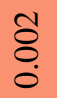 & $\overline{8}$ & $\stackrel{8}{0}$ & $\begin{array}{l}\text { ô } \\
\text {. }\end{array}$ & $\begin{array}{l}\infty \\
\stackrel{8}{0}\end{array}$ & $\stackrel{8}{8}$ & $\frac{n}{0}$ & $\hat{8}$ & $\begin{array}{l}\widetilde{\Xi} \\
\text { Oे }\end{array}$ & $\begin{array}{l}\hat{D} \\
\infty \\
0\end{array}$ & ஜே. & $\begin{array}{l}\text { \& } \\
\stackrel{0}{0}\end{array}$ & $\stackrel{8}{8}$ \\
\hline & $\neg$ & $\underset{8}{\overline{8}}$ & $\begin{array}{l}\overline{8} \\
0\end{array}$ & $\begin{array}{l}\overline{8} \\
0\end{array}$ & $\begin{array}{l}\tilde{\delta} \\
\dot{0}\end{array}$ & $\begin{array}{l}\text { ô } \\
\stackrel{0}{0}\end{array}$ & \&̊. & $\begin{array}{l}\tilde{\delta} \\
\stackrel{0}{0}\end{array}$ & $\begin{array}{l}\vec{\sigma} \\
\dot{0}\end{array}$ & $\begin{array}{l}\infty \\
\stackrel{8}{0} \\
\stackrel{0}{0}\end{array}$ & 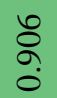 & $\stackrel{ }{\circ}$ & $\begin{array}{l}\mathscr{8} \\
\ddot{0}\end{array}$ & $\stackrel{n}{0}$ & م̂. \\
\hline & - & $\begin{array}{l}\overline{8} \\
\stackrel{0}{0}\end{array}$ & 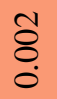 & s. & $\begin{array}{l}+ \\
\stackrel{8}{0}\end{array}$ & $\begin{array}{l}0 \\
\delta\end{array}$ & $\stackrel{m}{0}$ & \begin{tabular}{l}
8 \\
\hdashline \\
0
\end{tabular} & $\begin{array}{l}\bar{\delta} \\
\dot{0}\end{array}$ & $\tilde{\sigma}$ & $\stackrel{8}{\circ}$ & $\begin{array}{l}+ \\
8 \\
0\end{array}$ & 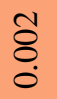 & $\begin{array}{l}\stackrel{0}{8} \\
\stackrel{0}{0}\end{array}$ & $\stackrel{5}{0}$ \\
\hline & $I$ & $\stackrel{8}{8}$ & ¿্ & $\stackrel{8}{8}$ & $\overline{8}$ & $\overline{8}$ & \&̊ & $\stackrel{n}{8}$ & $\begin{array}{l}\infty \\
\hat{0} \\
0\end{array}$ & 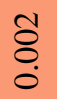 & ¿্ & $\overline{8}$ & $\stackrel{8}{8}$ & $\overline{8}$ & 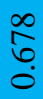 \\
\hline & 0 & $\stackrel{\overline{8}}{\circ}$ & $\stackrel{+}{\stackrel{0}{0}}$ & $\stackrel{\tilde{8}}{0}$ & $\stackrel{\text { }}{0}$ & $\stackrel{0}{\circ}$ & 令 & $\begin{array}{l}\text { ลू } \\
\text { o }\end{array}$ & $\begin{array}{l}\hat{\delta} \\
0\end{array}$ & $\stackrel{\infty}{8}$ & $\stackrel{n}{8}$ & $\begin{array}{l}0 \\
\delta\end{array}$ & 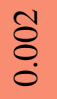 & $\begin{array}{l}8 \\
8 \\
0\end{array}$ & $\stackrel{\infty}{ \pm}$ \\
\hline & IL & \begin{tabular}{l}
8 \\
\hdashline \\
0
\end{tabular} & 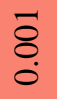 & ¿্口. & $\begin{array}{l}\text { ôे } \\
0\end{array}$ & 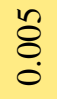 & $\begin{array}{l}n \\
0 \\
0 \\
0\end{array}$ & $\begin{array}{l}\infty \\
\stackrel{0}{0} \\
0\end{array}$ & $\underset{0}{\stackrel{J}{0}}$ & 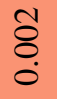 & ¿্口. & চ̊. & $\begin{array}{l}8 \\
0 \\
0\end{array}$ & $\overline{8}$ & $\underset{\overbrace{}}{\stackrel{\overbrace{}}{0}}$ \\
\hline & II & $\stackrel{\text { ô }}{0}$ & $\stackrel{n}{0}$ & $\stackrel{t}{8}$ & $\stackrel{n}{0}$ & İ & $\stackrel{0}{0}$ & $\stackrel{\infty}{\circ}$ & $\begin{array}{l}0 \\
0 \\
0\end{array}$ & $\stackrel{0}{0}$ & $\stackrel{n}{8}$ & $\stackrel{8}{8}$ & $\stackrel{0}{0}$ & $\stackrel{8}{8}$ & $\stackrel{m}{\stackrel{n}{=}}$ \\
\hline & $\theta$ & $\begin{array}{l}\text { ㅇ } \\
\delta \\
\end{array}$ & $\stackrel{8}{8}$ & $\begin{array}{l}8 \\
8 \\
\circ\end{array}$ & $\begin{array}{l}\infty \\
\infty \\
\infty \\
0\end{array}$ & $\begin{array}{l}\text { ¿ } \\
0 \\
0\end{array}$ & $\frac{+}{0}$ & $\underset{8}{\stackrel{8}{8}}$ & $\stackrel{m}{0}$ & 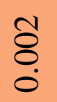 & 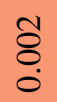 & $\begin{array}{l}\overline{8} \\
\dot{0}\end{array}$ & $\overline{8}$ & $\stackrel{8}{8}$ & $\begin{array}{l}8 \\
ٌ \\
0\end{array}$ \\
\hline & $u$ & $\stackrel{0}{\circ}$ & ڤ̂ & $\begin{array}{l}\text { +̊ } \\
\text { Oे }\end{array}$ & $\begin{array}{l}\tilde{o} \\
0\end{array}$ & $\begin{array}{l}\infty \\
\stackrel{0}{0} \\
0\end{array}$ & চூ & $\stackrel{8}{0}$ & 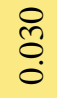 & $\begin{array}{l}8 \\
8 \\
0\end{array}$ & $\begin{array}{l}n \\
8\end{array}$ & $\hat{8}$ & 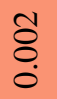 & $\hat{8}$ & $\stackrel{\infty}{ \pm}$ \\
\hline & $\infty$ & $\stackrel{a}{\circ}$ & $\begin{array}{l}0 \\
\substack{\infty \\
0}\end{array}$ & $\stackrel{2}{\circ}$ & $\stackrel{0}{0}$ & $\begin{array}{l}\text { to } \\
\stackrel{0}{0}\end{array}$ & $\stackrel{n}{0}$ & $\begin{array}{l}\stackrel{t}{0} \\
\stackrel{0}{0}\end{array}$ & $\underset{0}{\Delta}$ & $\begin{array}{l}\text { ô } \\
\stackrel{0}{0}\end{array}$ & 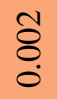 & $\begin{array}{l}\delta \\
\delta \\
0\end{array}$ & $\overrightarrow{8}$ & $\stackrel{8}{8}$ & $\begin{array}{l}\text { ồ } \\
\text { o. }\end{array}$ \\
\hline & $\ll$ & $\begin{array}{l}\overline{0} \\
\stackrel{0}{0}\end{array}$ & $\frac{\stackrel{D}{0}}{0}$ & $\begin{array}{l}\text { aे } \\
\text { ô. } \\
0\end{array}$ & $\stackrel{\infty}{\infty}$ & $\stackrel{8}{0}$ & ڤ్ర & $\begin{array}{l}\bar{\sigma} \\
0 \\
0\end{array}$ & $\hat{\tilde{\delta}}$ & $\begin{array}{l}\infty \\
\stackrel{0}{0} \\
0\end{array}$ & 용. & $\begin{array}{l}+ \\
0 \\
0\end{array}$ & $\begin{array}{l}\text { ̊̊ } \\
\stackrel{0}{0}\end{array}$ & ठे. & 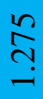 \\
\hline & $\begin{array}{l}\bar{\Xi} \\
\text { త్త }\end{array}$ & $\varangle$ & $ص$ & U & D & 띠 & L & 0 & $I$ & - & $\neg$ & $\mathscr{V}$ & \lrcorner & $\Sigma$ & సేّ \\
\hline & & & & & & & & & & & & & & & \\
\hline
\end{tabular}

Appendix Table A.14 Accessibility indices for origin-destination pairs from raw population figures for onemile buffer. Green, yellow, and red cells denote relatively high, medium, and low values, respectively. Blue cells denote row or column totals. 


\begin{tabular}{|c|c|c|c|c|c|c|c|c|c|c|c|c|c|c|c|}
\hline \multirow{14}{*}{ 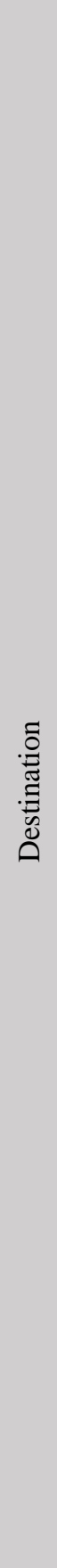 } & స్తే & $\underset{8}{8}$ & $\stackrel{8}{8}$ & $\underset{-}{8}$ & $\underset{8}{8}$ & $\underset{-}{8}$ & $\stackrel{8}{8}$ & $\underset{8}{8}$ & $\underset{8}{8}$ & 8 & 8 & $\underset{8}{8}$ & 8 & $\underset{8}{8}$ & $\begin{array}{l}\stackrel{8}{8} \\
\stackrel{1}{2}\end{array}$ \\
\hline & $\Sigma$ & $\begin{array}{l}8 \\
0 \\
0\end{array}$ & $\overline{8}$ & $\begin{array}{l}8 \\
0 \\
0\end{array}$ & $\overline{8}$ & $\overline{8}$ & $\begin{array}{l}0 \\
\delta \\
0\end{array}$ & $\overline{8}$ & $\stackrel{n}{8}$ & $\begin{array}{l}\delta \\
\delta \\
0\end{array}$ & $\begin{array}{l}+ \\
8 \\
0\end{array}$ & $\begin{array}{l}0 \\
\delta \\
\dot{0}\end{array}$ & $\begin{array}{l}\mathscr{\delta} \\
\dot{0}\end{array}$ & $\begin{array}{l}\stackrel{2}{0} \\
0\end{array}$ & $\begin{array}{l}\tilde{N} \\
\infty \\
0 \\
0\end{array}$ \\
\hline & \lrcorner & $\overline{8}$ & 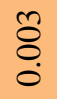 & $\overbrace{0}^{2}$ & $\begin{array}{l}0 \\
8 \\
0\end{array}$ & $\underset{8}{0}$ & $\stackrel{0}{0}$ & $\stackrel{n}{8}$ & 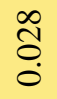 & $\frac{\mathfrak{o}}{0}$ & $\begin{array}{l}0 \\
\text { రి } \\
0\end{array}$ & $\begin{array}{l}\bar{g} \\
\dot{0}\end{array}$ & $\begin{array}{l}\text { \&े } \\
\text { o }\end{array}$ & $\begin{array}{l}\stackrel{n}{0} \\
0\end{array}$ & 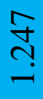 \\
\hline & $\forall$ & $\overline{8}$ & $\begin{array}{l}\text { ¿ै } \\
\text { ¿ }\end{array}$ & $\begin{array}{l}\overline{8} \\
\dot{0}\end{array}$ & $\begin{array}{l}+ \\
8\end{array}$ & $\stackrel{1}{0}$ & $\begin{array}{l}0 \\
0 \\
0\end{array}$ & कृ & $\stackrel{0}{0}$ & $\begin{array}{l}\infty \\
8 \\
0\end{array}$ & $\stackrel{\widetilde{o}}{0}$ & $\begin{array}{l}n \\
\infty \\
\infty \\
0\end{array}$ & గొ & 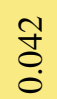 & రి \\
\hline & 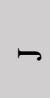 & $\begin{array}{l}\overline{8} \\
\dot{0}\end{array}$ & $\begin{array}{l}\overline{8} \\
0 \\
0\end{array}$ & $\begin{array}{l}\overline{8} \\
\stackrel{0}{0}\end{array}$ & $\begin{array}{l}\tilde{8} \\
\stackrel{0}{0}\end{array}$ & $\begin{array}{l}\text { ¿ै } \\
\stackrel{0}{0}\end{array}$ & $\begin{array}{l}0 \\
\stackrel{8}{0} \\
0\end{array}$ & ô & $\stackrel{0}{0}$ & $\begin{array}{l}\infty \\
\stackrel{8}{0} \\
0\end{array}$ & $\begin{array}{l}\hat{o} \\
\text { o }\end{array}$ & $\begin{array}{l}\overline{0} \\
0 \\
0\end{array}$ & 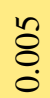 & $\stackrel{n}{0}$ & $\begin{array}{l}\bar{\infty} \\
\stackrel{0}{0}\end{array}$ \\
\hline & - & $\begin{array}{l}\overline{8} \\
\dot{0}\end{array}$ & 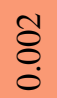 & 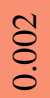 & $\begin{array}{l}+ \\
8 \\
0\end{array}$ & $\stackrel{\overbrace{}}{8}$ & $\begin{array}{l}\vec{\sigma} \\
\stackrel{0}{0}\end{array}$ & $\frac{n}{8}$ & 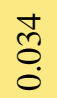 & ळू & $\begin{array}{l}\text { } \\
\dot{0}\end{array}$ & $\begin{array}{l}+ \\
8 \\
0\end{array}$ & $\begin{array}{l}\text { ठ̊ } \\
\text { ¿ }\end{array}$ & $\begin{array}{l}\infty \\
\stackrel{8}{0} \\
\dot{0}\end{array}$ & 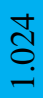 \\
\hline & $I$ & $\begin{array}{l}8 \\
0 \\
0\end{array}$ & $\stackrel{\overline{8}}{\circ}$ & \begin{tabular}{l}
8 \\
\hdashline \\
0
\end{tabular} & $\overrightarrow{8}$ & $\overrightarrow{8}$ & $\begin{array}{l}8 \\
8 \\
0\end{array}$ & $\begin{array}{l}+ \\
0 \\
0\end{array}$ & $\begin{array}{l}\overrightarrow{\widehat{N}} \\
\stackrel{0}{0}\end{array}$ & $\begin{array}{l}\delta \\
\delta \\
0\end{array}$ & $\begin{array}{l}\overline{8} \\
\dot{0}\end{array}$ & $\begin{array}{l}8 \\
8 \\
0\end{array}$ & $\begin{array}{l}8 \\
8 \\
0\end{array}$ & $\begin{array}{l}\overline{8} \\
\dot{0}\end{array}$ & $\begin{array}{l}\text { हे } \\
\text { : }\end{array}$ \\
\hline & 0 & $\begin{array}{l}\text { o̊ } \\
\text {. }\end{array}$ & 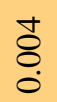 & $\begin{array}{l}\text { ¿̊. } \\
\stackrel{0}{0}\end{array}$ & $\bar{\sigma}$ & $\stackrel{\sim}{0}$ & $\begin{array}{l}\stackrel{+}{0} \\
\text { o }\end{array}$ & ๙ֶ. & $\frac{\stackrel{1}{1}}{0}$ & $\begin{array}{l}0 \\
\dot{0} \\
\dot{0}\end{array}$ & $\begin{array}{l}n \\
\delta \\
0\end{array}$ & $\begin{array}{l}0 \\
\delta \\
0\end{array}$ & $\begin{array}{l}\text { ơ } \\
\text { o }\end{array}$ & $\begin{array}{l}0 \\
8 \\
0\end{array}$ & હે సે \\
\hline & LI & $\begin{array}{l}8 \\
8 \\
0\end{array}$ & $\overline{8}$ & $\overline{8}$ & $\stackrel{8}{8}$ & $\begin{array}{l}n \\
8\end{array}$ & $\begin{array}{l}\tilde{2} \\
0 \\
0\end{array}$ & $\begin{array}{l}8 \\
8 \\
0\end{array}$ & $\stackrel{\Delta}{\circ}$ & $\overline{8}$ & $\overline{8}$ & $\begin{array}{l}\overline{8} \\
0\end{array}$ & $\begin{array}{l}8 \\
8 \\
0\end{array}$ & है & $\begin{array}{l}\stackrel{0}{0} \\
\infty \\
0\end{array}$ \\
\hline & 니 & $\begin{array}{l}\text { ô } \\
\text {. }\end{array}$ & 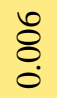 & 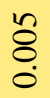 & $\begin{array}{l}0 \\
0 \\
0\end{array}$ & \begin{tabular}{l}
$\infty$ \\
\multirow{2}{0}{} \\
0
\end{tabular} & $\frac{\delta}{0}$ & $\begin{array}{l}0 \\
0 \\
0\end{array}$ & \begin{tabular}{l}
$\mathscr{8}$ \\
\hdashline \\
0
\end{tabular} & $\begin{array}{l}\hat{8} \\
0\end{array}$ & $\begin{array}{l}n \\
\delta \\
0\end{array}$ & $\begin{array}{l}0 \\
\delta \\
0\end{array}$ & $\begin{array}{l}\delta \\
\delta \\
0\end{array}$ & $\begin{array}{l}8 \\
8 \\
0\end{array}$ & 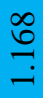 \\
\hline & $\theta$ & $\begin{array}{l}\tilde{\delta} \\
\delta \\
0\end{array}$ & $\begin{array}{l}0 \\
8 \\
0\end{array}$ & $\stackrel{0}{\circ}$ & $\begin{array}{l}\text { के } \\
\infty \\
0\end{array}$ & $\stackrel{+}{8}$ & $\underset{0}{+}$ & $\hat{\delta}$ & $\stackrel{m}{0}$ & $\begin{array}{l}\delta \\
\delta \\
0\end{array}$ & $\begin{array}{l}\tilde{\delta} \\
0\end{array}$ & $\begin{array}{l}\overline{8} \\
0\end{array}$ & $\begin{array}{l}\overline{8} \\
0\end{array}$ & 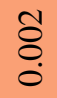 & $\begin{array}{l}\text { ڤે } \\
0 \\
0\end{array}$ \\
\hline & $u$ & $\begin{array}{l}\text { } \\
\text {. }\end{array}$ & $\begin{array}{l}0 \\
\text { Oొ } \\
\stackrel{0}{0}\end{array}$ & ڤે̀ & 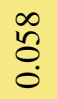 & $\stackrel{0}{0}$ & 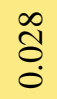 & $\begin{array}{l}\hat{8} \\
0\end{array}$ & $\begin{array}{l}\hat{\widehat{o}} \\
\stackrel{0}{0}\end{array}$ & $\begin{array}{l}n \\
\delta \\
0\end{array}$ & $\begin{array}{l}+ \\
8 \\
0\end{array}$ & $\begin{array}{l}\delta \\
\delta \\
0\end{array}$ & $\begin{array}{l}\overline{8} \\
0\end{array}$ & $\begin{array}{l}8 \\
8 \\
0\end{array}$ & $\stackrel{\Xi}{\Xi}$ \\
\hline & 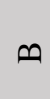 & $\stackrel{\infty}{\stackrel{\infty}{0}} \underset{0}{0}$ & $\begin{array}{l}0 \\
\infty \\
0 \\
0\end{array}$ & $\stackrel{+}{\Delta}$ & $\stackrel{0}{0}$ & $\stackrel{8}{8}$ & $\stackrel{\Delta}{\Delta}$ & $\begin{array}{l}\text { t) } \\
0\end{array}$ & $\stackrel{n}{a}$ & $\stackrel{8}{8}$ & $\stackrel{\text { ㅇ. }}{8}$ & $\overline{8}$ & $\overline{8}$ & 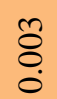 & 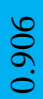 \\
\hline & $\ll$ & $\begin{array}{l}\text { ț } \\
\text { o }\end{array}$ & $\stackrel{m}{\stackrel{m}{0}}$ & ठे. & $\stackrel{\text { It }}{\text { d̦ }}$ & \&े & 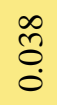 & $\stackrel{0}{0}$ & $\begin{array}{l}\stackrel{+}{+} \\
0 \\
0\end{array}$ & $\begin{array}{l}\infty \\
8 \\
0\end{array}$ & 용 & $\begin{array}{l}\text { t } \\
\dot{0}\end{array}$ & 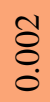 & $\begin{array}{l}\hat{\delta} \\
\dot{0}\end{array}$ & సે \\
\hline & $\begin{array}{l}\bar{\Xi} \\
\bar{\Xi} \\
\text { D. }\end{array}$ & $\ll$ & $\infty$ & $u$ & $\theta$ & 山 & L & 0 & $I$ & - & $\neg$ & 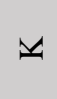 & \lrcorner & $\Sigma$ & స్ \\
\hline & & & & & & & & & & & & & & & \\
\hline
\end{tabular}

Appendix Table A.15 Accessibility indices for origin-destination pairs from raw housing unit figures for one-mile buffer. Green, yellow, and red cells denote relatively high, medium, and low values, respectively. Blue cells denote row or column totals. 


\begin{tabular}{|c|c|c|c|c|c|c|c|c|c|c|c|c|c|c|c|}
\hline \multirow{14}{*}{ 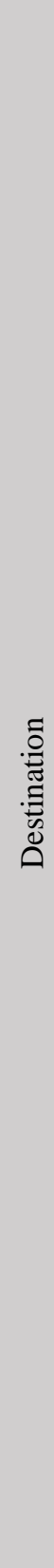 } & $\underset{\mathscr{0}}{\tilde{\theta}}$ & $\underset{-}{8}$ & $\underset{-}{8}$ & $\underset{-}{8}$ & $\underset{\sim}{8}$ & $\underset{-}{8}$ & $\underset{-}{8}$ & $\underset{-}{8}$ & $\underset{-}{8}$ & $\underset{-}{8}$ & $\stackrel{8}{-}$ & $\underset{-}{8}$ & $\stackrel{8}{-}$ & $\underset{-}{8}$ & $\begin{array}{l}\underset{8}{8} \\
\stackrel{m}{2}\end{array}$ \\
\hline & $\Sigma$ & $\stackrel{8}{8}$ & $\stackrel{8}{\circ}$ & $\stackrel{8}{\circ}$ & $\stackrel{8}{8}$ & $\stackrel{8}{8}$ & $\stackrel{8}{\circ}$ & $\stackrel{8}{\circ}$ & $\stackrel{8}{\circ}$ & $\stackrel{8}{\circ}$ & $\stackrel{8}{\circ}$ & ō. & $\stackrel{8}{\circ}$ & $\stackrel{\Xi}{\leftrightarrows}$ & $\stackrel{m}{=}$ \\
\hline & \lrcorner & $\stackrel{8}{8}$ & $\begin{array}{l}\tilde{0} \\
\stackrel{0}{i}\end{array}$ & ${ }_{0} \overline{0}$ & $\begin{array}{l}\text { Oे } \\
\dot{0}\end{array}$ & 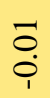 & $\begin{array}{l}\tilde{0} \\
\stackrel{\varphi}{\varphi}\end{array}$ & $\begin{array}{l}\text { Oे } \\
\dot{0}\end{array}$ & $\begin{array}{l}0 \\
0 \\
\dot{\varphi}\end{array}$ & $\begin{array}{l}\ddot{0} \\
\stackrel{\varphi}{i}\end{array}$ & $\begin{array}{l}0 \\
0 \\
\stackrel{1}{0}\end{array}$ & $\stackrel{\infty}{+}$ & $\stackrel{\vec{\sigma}}{-}$ & $\frac{\infty}{0}$ & 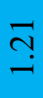 \\
\hline & $\forall$ & $\stackrel{8}{0}$ & $\stackrel{8}{8}$ & $\stackrel{8}{8}$ & $\stackrel{8}{8}$ & $\stackrel{8}{8}$ & $\stackrel{8}{8}$ & $\stackrel{8}{8}$ & $\stackrel{8}{8}$ & $\stackrel{8}{8}$ & $\stackrel{8}{8}$ & $\begin{array}{l}\text { ț } \\
\dot{0}\end{array}$ & $\stackrel{8}{8}$ & ö & $\begin{array}{l}\widetilde{\sigma} \\
0\end{array}$ \\
\hline & $\neg$ & $\stackrel{8}{\circ}$ & $\stackrel{0}{0}$ & $\stackrel{0}{0}$ & $\stackrel{8}{8}$ & $\stackrel{8}{8}$ & $\stackrel{8}{8}$ & $\stackrel{0}{0}$ & $\stackrel{8}{\circ}$ & రె. & $\underset{0}{0}$ & tọ. & ō. & $\stackrel{0}{0}$ & $\underset{\sigma}{0}$ \\
\hline & - & $\stackrel{8}{\circ}$ & $\stackrel{\sigma}{0}$ & ō & $\stackrel{8}{8}$ & $\stackrel{8}{8}$ & $\stackrel{8}{8}$ & $\stackrel{\square}{0}$ & $\stackrel{\overline{0}}{0}$ & $\stackrel{\infty}{\stackrel{0}{0}}$ & $\stackrel{\overline{0}}{\circ}$ & 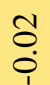 & $\stackrel{8}{8}$ & $\stackrel{0}{0}$ & $\stackrel{\wp}{0}$ \\
\hline & $I$ & $\stackrel{8}{\circ}$ & $\stackrel{\Xi}{0}$ & $\stackrel{\sigma}{0}$ & $\stackrel{8}{8}$ & $\stackrel{\circ}{\circ}$ & $\stackrel{\square}{\circ}$ & $\stackrel{\circ}{8}$ & $\hat{o}$ & $\stackrel{\overline{0}}{\circ}$ & $\stackrel{\Xi}{\circ}$ & $\begin{array}{l}0 \\
0 \\
\end{array}$ & $\stackrel{8}{8}$ & $\stackrel{\overline{0}}{\dot{0}}$ & 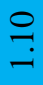 \\
\hline & 0 & $\stackrel{8}{\circ}$ & $\stackrel{8}{8}$ & ō & $\stackrel{8}{8}$ & ō & $\stackrel{\square}{\circ}$ & $\begin{array}{l}\mathscr{n} \\
\infty \\
0\end{array}$ & $\stackrel{\overline{0}}{\circ}$ & $\stackrel{8}{8}$ & $\stackrel{8}{\circ}$ & ọ̄. & $\stackrel{8}{\circ}$ & $\stackrel{8}{\circ}$ & ஓ̊ \\
\hline & 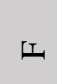 & $\stackrel{8}{8}$ & $\stackrel{0}{0}$ & $\begin{array}{l}\text { Oे } \\
0\end{array}$ & $\stackrel{0}{0}$ & $\stackrel{0}{0}$ & ஃ̊ & $\stackrel{0}{0}$ & $\ddot{0}$ & $\stackrel{0}{0}$ & $\stackrel{8}{8}$ & ō & $\stackrel{8}{8}$ & ㅁ. & $\stackrel{ }{\leftrightarrows}$ \\
\hline & 디 & $\stackrel{8}{\circ}$ & $\stackrel{0}{0}$ & 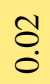 & $\ddot{0}$ & ڤ̊ & 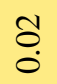 & $\stackrel{\leftrightarrow}{0}$ & $\ddot{0}$ & $\stackrel{0}{0}$ & $\stackrel{8}{\circ}$ & ō. & $\stackrel{8}{\circ}$ & $\ddot{0}$ & on \\
\hline & D & $\stackrel{8}{\circ}$ & 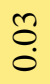 & 웅 & $\underset{\sigma}{\sigma}$ & ō & $\stackrel{\square}{\circ}$ & $\stackrel{\square}{\circ}$ & $\stackrel{8}{\circ}$ & $\stackrel{8}{8}$ & $\stackrel{8}{\circ}$ & $\begin{array}{l}0 \\
0\end{array}$ & $\stackrel{8}{\circ}$ & 뭉 & $\stackrel{\Xi}{\Xi}$ \\
\hline & $u$ & $\stackrel{8}{\circ}$ & 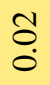 & $\stackrel{5}{0}$ & $\stackrel{\circ}{\circ}$ & $\stackrel{8}{8}$ & $\stackrel{8}{8}$ & $\stackrel{8}{8}$ & $\stackrel{8}{8}$ & $\stackrel{8}{8}$ & $\stackrel{8}{8}$ & $\stackrel{8}{8}$ & $\stackrel{8}{8}$ & $\stackrel{8}{8}$ & $\stackrel{\overbrace{}}{\leftrightarrows}$ \\
\hline & $\infty$ & $\begin{array}{l}0 \\
0 \\
0\end{array}$ & $\underset{\sigma}{\sigma}$ & $\stackrel{+}{0}$ & 훙 & $\stackrel{8}{8}$ & $\stackrel{8}{8}$ & $\stackrel{\circ}{0}$ & $\stackrel{8}{\circ}$ & $\stackrel{8}{8}$ & $\stackrel{8}{\circ}$ & $\stackrel{8}{8}$ & $\stackrel{8}{8}$ & $\stackrel{8}{8}$ & $\begin{array}{l}\infty \\
\stackrel{\infty}{0}\end{array}$ \\
\hline & $\ll$ & 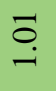 & $\vec{i}$ & 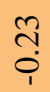 & $\begin{array}{l}\stackrel{8}{0} \\
\stackrel{0}{\varphi}\end{array}$ & $\begin{array}{l}\text { Oొ } \\
\stackrel{0}{\varphi}\end{array}$ & 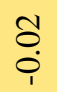 & $\begin{array}{l}n \\
0 \\
\dot{\varphi}\end{array}$ & $\begin{array}{l}0 \\
0 \\
\stackrel{p}{p}\end{array}$ & $\begin{array}{l}\text { ô } \\
0 \\
\end{array}$ & $\begin{array}{l}\tilde{0} \\
\dot{\varphi}\end{array}$ & $\stackrel{t}{0}$ & $\stackrel{8}{\circ}$ & $\begin{array}{l}\text { Oó } \\
0 \\
0\end{array}$ & $\frac{2}{0}$ \\
\hline & 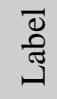 & $\ll$ & 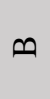 & $U$ & 0 & 띠 & $\Phi$ & 0 & $I$ & 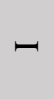 & $\neg$ & $\smile$ & \lrcorner & $\Sigma$ & $\stackrel{\widetilde{\pi}}{0}$ \\
\hline & & & & & & & & & & & & & & & \\
\hline
\end{tabular}

Appendix Table A.16 Accessibility indices for origin-destination pairs from normalized job figures for onemile buffer. Green, yellow, and red cells denote relatively high, medium, and low values, respectively. Blue cells denote row or column totals. 


\begin{tabular}{|c|c|c|c|c|c|c|c|c|c|c|c|c|c|c|c|}
\hline \multirow{14}{*}{ 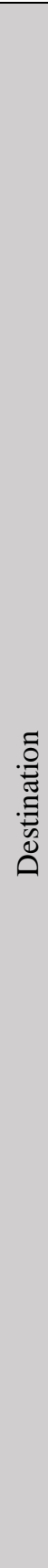 } & $\underset{\tilde{0}}{\overline{0}}$ & $\underset{-}{8}$ & $\underset{-}{8}$ & $\underset{.}{8}$ & $\underset{-}{8}$ & $\underset{\sim}{8}$ & $\underset{8}{8}$ & $\underset{-}{8}$ & $\stackrel{8}{.}$ & $\underset{-}{8}$ & $\underset{-}{8}$ & $\underset{-}{8}$ & $\underset{-}{8}$ & $\underset{-}{8}$ & $\begin{array}{l}8 \\
\stackrel{8}{-}\end{array}$ \\
\hline & $\Sigma$ & $\stackrel{8}{\circ}$ & $\stackrel{\hat{m}}{\rightarrow}$ & $\stackrel{8}{\circ}$ & $\stackrel{8}{\circ}$ & $\begin{array}{l}\overline{0} \\
\dot{\varphi}\end{array}$ & $\stackrel{8}{\circ}$ & $\ddot{\circ}$ & 8 & $\ddot{0}$ & ఠ̊ & $\begin{array}{l}\text { N̦ } \\
\stackrel{1}{1}\end{array}$ & 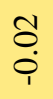 & $\stackrel{\overbrace{}}{0}$ & $\begin{array}{l}\text { ñ } \\
\text { ? }\end{array}$ \\
\hline & \lrcorner & $\stackrel{8}{\circ}$ & $\begin{array}{l}\qquad \\
i \\
i\end{array}$ & $\stackrel{8}{8}$ & $\stackrel{8}{0}$ & $\stackrel{\sigma}{0}$ & $\stackrel{8}{\circ}$ & $\begin{array}{l}\text { ô } \\
\stackrel{\leftrightarrow}{1}\end{array}$ & $\stackrel{8}{8}$ & $\begin{array}{l}\text { ô } \\
\stackrel{\leftrightarrow}{1}\end{array}$ & $\begin{array}{l}\text { to } \\
\dot{0}\end{array}$ & $\stackrel{\text { oे }}{-}$ & $\stackrel{\text { ọ }}{\text {. }}$ & $\begin{array}{l}\text { t) } \\
\stackrel{0}{+}\end{array}$ & $\begin{array}{l}n \\
\dot{\gamma}\end{array}$ \\
\hline & $\mathscr{V}$ & $\stackrel{8}{8}$ & $\begin{array}{l}\overline{0} \\
\stackrel{\varphi}{\varphi}\end{array}$ & $\begin{array}{l}8 \\
0\end{array}$ & $\stackrel{8}{\circ}$ & $\stackrel{8}{\circ}$ & $\stackrel{8}{\circ}$ & $\stackrel{8}{\circ}$ & $\begin{array}{l}8 \\
\end{array}$ & $\stackrel{8}{\circ}$ & $\stackrel{8}{\circ}$ & స̃. & $\stackrel{8}{8}$ & $\stackrel{8}{8}$ & $\begin{array}{l}\text { N̦ } \\
\text { in }\end{array}$ \\
\hline & $\neg$ & $\stackrel{8}{\circ}$ & 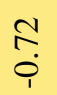 & $\stackrel{8}{\circ}$ & $\stackrel{8}{0}$ & $\stackrel{8}{\circ}$ & $\stackrel{8}{\circ}$ & ō. & $\stackrel{8}{8}$ & $\stackrel{0}{0}$ & $\underset{-}{8}$ & $\stackrel{1}{0}$ & $\stackrel{8}{\circ}$ & $\stackrel{8}{\circ}$ & $\stackrel{ \pm}{0}$ \\
\hline & $\neg$ & $\stackrel{8}{8}$ & $\stackrel{m}{0}$ & $\stackrel{8}{8}$ & $\stackrel{8}{\circ}$ & $\begin{array}{l}0 \\
0 \\
0\end{array}$ & $\stackrel{8}{8}$ & $\stackrel{\overline{0}}{\circ}$ & $\stackrel{8}{8}$ & $\stackrel{\circ}{\circ}$ & jo & $\begin{array}{l}\text { to } \\
\end{array}$ & $\stackrel{8}{\circ}$ & $\stackrel{8}{8}$ & $\overline{\tilde{o}}$ \\
\hline & $I$ & $\stackrel{8}{8}$ & $\begin{array}{l}8 \\
\stackrel{+}{+}\end{array}$ & $\begin{array}{l}\overline{0} \\
\stackrel{0}{0}\end{array}$ & $\ddot{\circ}$ & $\begin{array}{l}\text { Do } \\
\stackrel{+}{1}\end{array}$ & 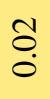 & $\frac{\infty}{0}$ & ڤे & $\stackrel{t}{0}$ & 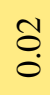 & $\overrightarrow{0}$ & $\stackrel{8}{8}$ & $\stackrel{8}{8}$ & $\bar{a}$ \\
\hline & 0 & $\stackrel{8}{\circ}$ & $\begin{array}{l}\stackrel{0}{n} \\
\text { ? }\end{array}$ & 8 & $\stackrel{8}{0}$ & $\begin{array}{l}\overline{0} \\
\dot{0}\end{array}$ & $\stackrel{8}{8}$ & $\stackrel{?}{\stackrel{0}{0}}$ & : & $\stackrel{8}{8}$ & $\stackrel{8}{8}$ & $\begin{array}{l}\overline{0} \\
\stackrel{0}{0}\end{array}$ & $\stackrel{8}{8}$ & $\begin{array}{l}8 \\
\stackrel{0}{0}\end{array}$ & ָ̊. \\
\hline & IL & $\stackrel{8}{\circ}$ & $\begin{array}{l}\bar{\gamma} \\
\dot{+}\end{array}$ & 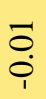 & $\stackrel{\leftrightarrow}{\delta}$ & $\overrightarrow{0}$ & $\underset{-}{8}$ & $\frac{\infty}{0}$ & $\sigma_{0}^{\circ}$ & $\stackrel{\text { ô }}{\circ}$ & o. & $\begin{array}{l}\infty \\
\stackrel{0}{\varphi} \\
\dot{1}\end{array}$ & $\stackrel{8}{\circ}$ & $\begin{array}{l}8 \\
\circ\end{array}$ & $\begin{array}{l}\infty \\
\infty \\
\dot{p}\end{array}$ \\
\hline & 피 & $\stackrel{8}{\circ}$ & ભે & $\stackrel{8}{8}$ & $\stackrel{8}{8}$ & $\stackrel{\cong}{\leftrightarrows}$ & $\begin{array}{l}0 \\
0\end{array}$ & $\begin{array}{l}0 \\
0 \\
\end{array}$ & : & $\stackrel{8}{\circ}$ & $\stackrel{8}{\circ}$ & $\underset{\mathrm{O}}{0}$ & $\stackrel{8}{\circ}$ & $\begin{array}{l}\stackrel{8}{0} \\
\stackrel{0}{0}\end{array}$ & $\stackrel{\infty}{+} \underset{i}{+}$ \\
\hline & 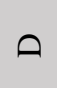 & $\stackrel{8}{8}$ & $\begin{array}{l}\stackrel{f}{+} \\
\stackrel{p}{0}\end{array}$ & $\begin{array}{l}\text { ô } \\
\stackrel{0}{0}\end{array}$ & $\stackrel{8}{8}$ & $\begin{array}{l}0 \\
0 \\
0\end{array}$ & $\stackrel{8}{8}$ & 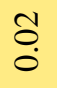 & $\stackrel{8}{8}$ & $\stackrel{\overline{0}}{\circ}$ & $\stackrel{8}{8}$ & $\begin{array}{l}0 \\
\stackrel{0}{0}\end{array}$ & $\stackrel{8}{8}$ & $\begin{array}{l}8 \\
\stackrel{0}{0}\end{array}$ & $\begin{array}{l}\text { o } \\
\stackrel{1}{\text { pr }}\end{array}$ \\
\hline & $u$ & $\ddot{\circ}$ & $\hat{n}$ & $\stackrel{\circ}{\circ}$ & $\begin{array}{l}\Delta \\
\stackrel{0}{0}\end{array}$ & 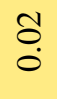 & $\begin{array}{l}0 \\
0 \\
\dot{\varphi}\end{array}$ & $\begin{array}{l}0 \\
\stackrel{\leftrightarrow}{i}\end{array}$ & $\stackrel{8}{8}$ & $\begin{array}{l}0 \\
\stackrel{0}{Q}\end{array}$ & $\begin{array}{l}0 \\
0 \\
\end{array}$ & $\stackrel{n}{0}$ & $\stackrel{8}{8}$ & $\stackrel{8}{\circ}$ & 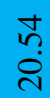 \\
\hline & $\infty$ & $\stackrel{8}{8}$ & $\begin{array}{l}\stackrel{0}{~} \\
\stackrel{ \pm}{=}\end{array}$ & $\stackrel{8}{8}$ & $\stackrel{8}{8}$ & $\stackrel{8}{8}$ & $\stackrel{8}{\circ}$ & $\stackrel{8}{\circ}$ & $\stackrel{8}{8}$ & $\stackrel{8}{\circ}$ & 8 & $\begin{array}{l}0 \\
\stackrel{0}{0}\end{array}$ & $\stackrel{8}{8}$ & $\stackrel{8}{8}$ & $\begin{array}{l}\tilde{N} \\
\pm \\
=\end{array}$ \\
\hline & $\varangle$ & $\underset{-}{8}$ & $\begin{array}{l}\stackrel{\infty}{\varrho} \\
\stackrel{0}{=}\end{array}$ & $\stackrel{\Delta}{0}$ & $\begin{array}{l} \pm \\
\stackrel{0}{0}\end{array}$ & $\stackrel{t}{0}$ & $\begin{array}{l}0 \\
0 \\
0\end{array}$ & $\begin{array}{l}0 \\
0 \\
\dot{\varphi}\end{array}$ & $\begin{array}{l}\overline{0} \\
\stackrel{0}{0}\end{array}$ & 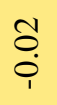 & $\begin{array}{l}\overline{0} \\
\dot{\varphi}\end{array}$ & $\begin{array}{l}\circ \\
\stackrel{0}{0}\end{array}$ & $\stackrel{8}{8}$ & $\stackrel{8}{8}$ & $\begin{array}{l}\tilde{O} \\
\text { I } \\
\end{array}$ \\
\hline & $\begin{array}{l}\bar{\Xi} \\
\text { త్త్త }\end{array}$ & $\ll$ & 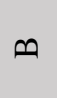 & $U$ & $\theta$ & 디 & I & 0 & $I$ & - & - & $\forall$ & \lrcorner & $\Sigma$ & $\bar{\sigma}$ \\
\hline & & & & & & & & & & & & & & & \\
\hline
\end{tabular}

Appendix Table A.17 Accessibility indices for origin-destination pairs from normalized population figures for one-mile buffer. Green, yellow, and red cells denote relatively high, medium, and low values, respectively. Blue cells denote row or column totals. 


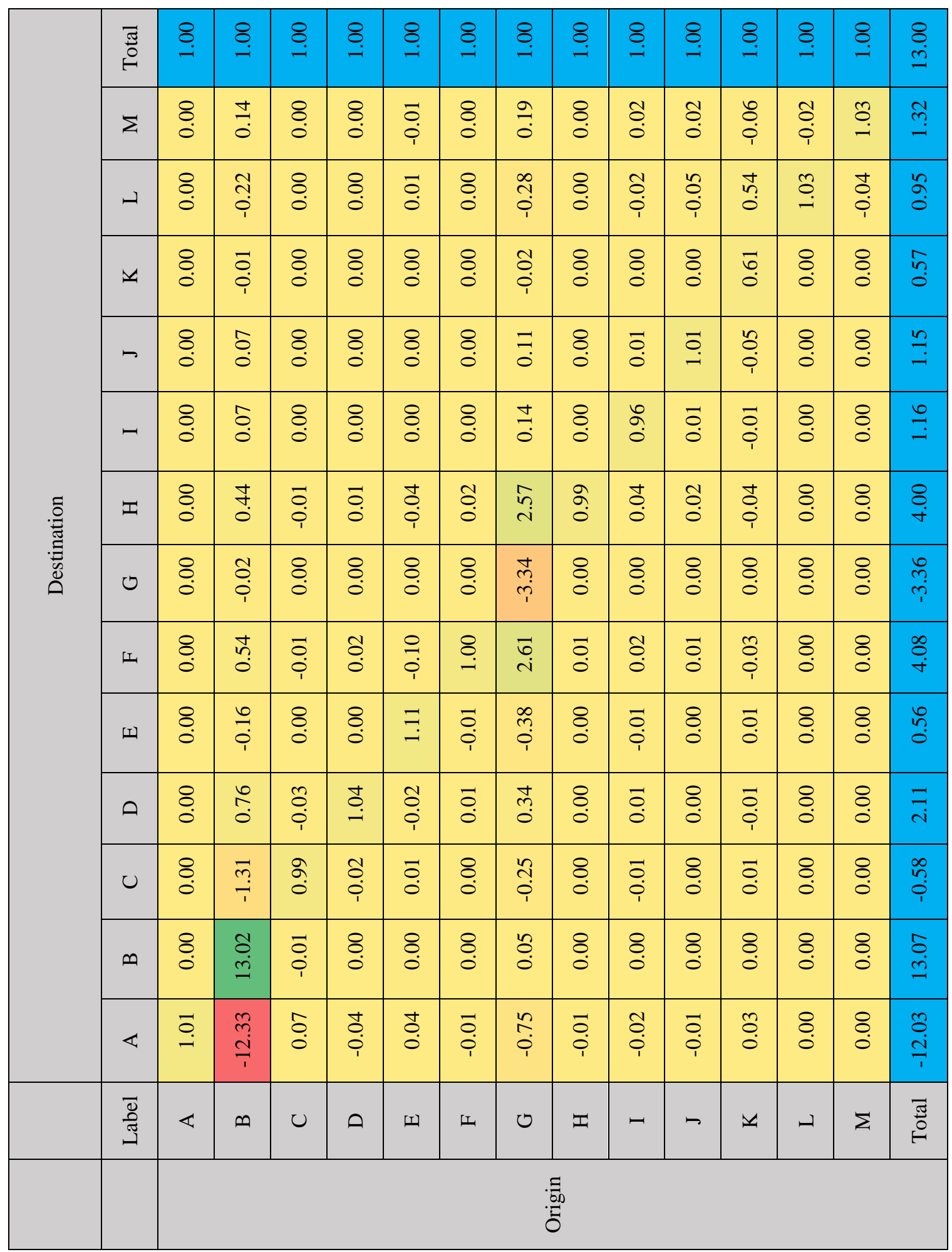

Appendix Table A.18 Accessibility indices for origin-destination pairs from normalized housing unit figures for one-mile buffer. Green, yellow, and red cells denote relatively high, medium, and low values,

respectively. Blue cells denote row or column totals. 


\section{d. Two-Mile Radius}

\begin{tabular}{|c|c|c|c|c|c|c|c|c|c|c|c|c|c|c|c|}
\hline \multirow{14}{*}{ 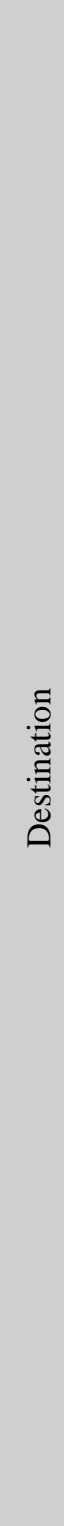 } & స్ & $\underset{-}{8}$ & $\stackrel{8}{8}$ & $\underset{.}{8}$ & $\underset{\text { \& }}{8}$ & $\underset{-}{8}$ & $\underset{-}{8}$ & $\stackrel{8}{8}$ & $\underset{1}{8}$ & $\stackrel{8}{8}$ & $\underset{.}{8}$ & $\underset{-}{8}$ & $\underset{.}{8}$ & $\stackrel{8}{8}$ & $\begin{array}{l}8 \\
\stackrel{0}{2}\end{array}$ \\
\hline & $\Sigma$ & $\stackrel{8}{\circ}$ & $\stackrel{8}{\circ}$ & $\stackrel{8}{8}$ & $\ddot{0}$ & $\stackrel{\text { ô }}{0}$ & $\stackrel{t}{0}$ & $\stackrel{-}{\circ}$ & $\stackrel{2}{0}$ & $\stackrel{\text { ô. }}{0}$ & o. & ¿̋. & $\stackrel{\text { ô. }}{0}$ & $\begin{array}{l}\stackrel{0}{0} \\
0 \\
0\end{array}$ & 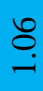 \\
\hline & 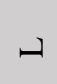 & $\stackrel{8}{8}$ & ö. & $\stackrel{0}{0}$ & $\stackrel{\leftrightarrow}{0}$ & $\begin{array}{l}\circ \\
0\end{array}$ & $\frac{ \pm}{0}$ & $\stackrel{t}{0}$ & $\stackrel{\infty}{\stackrel{0}{0}}$ & $\stackrel{0}{0}$ & $\stackrel{\sim}{3}$ & $\stackrel{\infty}{\stackrel{\infty}{0}}$ & $\stackrel{+}{+}$ & $\stackrel{ \pm}{\overrightarrow{0}}$ & $\underset{\sim}{\sim}$ \\
\hline & $\checkmark$ & $\begin{array}{l}8 \\
0\end{array}$ & $\stackrel{8}{8}$ & $\stackrel{8}{8}$ & $\underset{0}{\tilde{0}}$ & $\begin{array}{l}\text { ô } \\
0\end{array}$ & $\begin{array}{l}\text { U. } \\
0\end{array}$ & $\stackrel{\sigma}{0}$ & $\stackrel{8}{\circ}$ & $\stackrel{\text { Oे }}{0}$ & $\stackrel{1}{0}$ & $\begin{array}{l}\infty \\
\stackrel{\infty}{0} \\
0\end{array}$ & 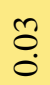 & $\begin{array}{l}\tilde{\theta} \\
0\end{array}$ & $\underset{\text { ¿ }}{\text {. }}$ \\
\hline & $r$ & $\stackrel{8}{\circ}$ & $\stackrel{8}{\circ}$ & $\stackrel{8}{\circ}$ & $\stackrel{8}{\circ}$ & $\stackrel{8}{\circ}$ & ¿̄o & $\stackrel{8}{\circ}$ & ¿. & $\stackrel{8}{\circ}$ & ñ & $\stackrel{8}{\circ}$ & $\stackrel{8}{\circ}$ & $\stackrel{8}{\circ}$ & $\begin{array}{l}\infty \\
\stackrel{0}{0}\end{array}$ \\
\hline & - & $\stackrel{8}{8}$ & $\stackrel{8}{8}$ & $\stackrel{8}{8}$ & $\ddot{0}$ & ō & $\stackrel{+}{0}$ & $\overline{0}$ & $\stackrel{\circ}{\circ}$ & $\begin{array}{c}\bar{\infty} \\
0\end{array}$ & $\stackrel{0}{0}$ & $\stackrel{8}{8}$ & $\stackrel{8}{8}$ & $\stackrel{8}{8}$ & $\stackrel{\infty}{\circ}$ \\
\hline & $I$ & $\stackrel{8}{\circ}$ & $\stackrel{8}{8}$ & $\stackrel{8}{8}$ & $\stackrel{8}{8}$ & $\stackrel{8}{8}$ & $\stackrel{8}{\circ}$ & $\stackrel{8}{\circ}$ & $\frac{I}{0}$ & $\stackrel{8}{8}$ & $\stackrel{8}{8}$ & $\stackrel{8}{\circ}$ & $\stackrel{8}{8}$ & $\stackrel{8}{8}$ & $\frac{m}{0}$ \\
\hline & 0 & $\stackrel{8}{8}$ & $\stackrel{8}{8}$ & $\stackrel{8}{\circ}$ & 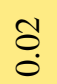 & $\stackrel{+}{0}$ & $\frac{9}{0}$ & 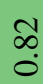 & $\stackrel{\infty}{\overrightarrow{0}}$ & $\stackrel{\overrightarrow{0}}{0}$ & ${ }_{0}^{0}$ & $\begin{array}{l}8 \\
0\end{array}$ & $\stackrel{8}{8}$ & $\stackrel{8}{8}$ & సે \\
\hline & II & $\stackrel{8}{8}$ & $\stackrel{8}{8}$ & $\begin{array}{l}8 \\
\stackrel{0}{0}\end{array}$ & $\stackrel{8}{8}$ & $\stackrel{8}{8}$ & $\stackrel{n}{\circ}$ & $\stackrel{8}{\circ}$ & $\stackrel{8}{\circ}$ & $\stackrel{8}{8}$ & $\stackrel{8}{\circ}$ & $\stackrel{8}{\circ}$ & $\stackrel{8}{8}$ & $\stackrel{8}{8}$ & $\begin{array}{l}\stackrel{\circ}{\circ} \\
\stackrel{0}{0}\end{array}$ \\
\hline & 工 & $\begin{array}{l}8 \\
0\end{array}$ & $\stackrel{8}{8}$ & $\stackrel{8}{8}$ & $\stackrel{\sigma}{0}$ & $\begin{array}{l}n \\
0 \\
0\end{array}$ & $\stackrel{\infty}{\circ}$ & $\stackrel{\Xi}{\circ}$ & $\stackrel{\overbrace{}}{0}$ & $\stackrel{8}{8}$ & $\stackrel{8}{\circ}$ & $\stackrel{8}{\circ}$ & $\stackrel{8}{8}$ & $\stackrel{8}{8}$ & $\stackrel{?}{\circ}$ \\
\hline & $\theta$ & $\stackrel{8}{8}$ & $\stackrel{8}{8}$ & $\overline{0}$ & $\underset{0}{ \pm}$ & ō. & $\begin{array}{l}\tilde{O} \\
\stackrel{0}{0}\end{array}$ & $\stackrel{8}{\circ}$ & $\overline{0}$ & $\stackrel{8}{8}$ & $\stackrel{8}{\circ}$ & $\stackrel{8}{\circ}$ & $\stackrel{8}{\circ}$ & $\stackrel{8}{8}$ & $\stackrel{q}{\stackrel{+}{0}}$ \\
\hline & $u$ & $\ddot{0}$ & $\stackrel{t}{0}$ & $\begin{array}{l}\stackrel{\infty}{\infty} \\
\stackrel{0}{0}\end{array}$ & $\frac{m}{0}$ & $\stackrel{3}{0}$ & $\stackrel{\infty}{0}$ & $\stackrel{\sigma}{0}$ & $\stackrel{2}{0}$ & ō. & 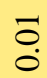 & $\stackrel{8}{8}$ & $\stackrel{8}{0}$ & $\stackrel{8}{8}$ & $\stackrel{9}{=}$ \\
\hline & $\sim$ & $\stackrel{0}{0}$ & ㅇ. & 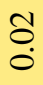 & $\stackrel{\text { Oै }}{0}$ & $\stackrel{0}{0}$ & $\stackrel{0}{0}$ & $\stackrel{\sigma}{\circ}$ & 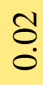 & $\stackrel{8}{8}$ & ठ. & $\stackrel{8}{\circ}$ & $\stackrel{8}{\circ}$ & $\stackrel{8}{8}$ & ñ \\
\hline & $\varangle$ & $\stackrel{\circ}{\circ}$ & $\stackrel{n}{n}$ & $\frac{n}{0}$ & $\begin{array}{l}\infty \\
\stackrel{\infty}{0}\end{array}$ & $\frac{ \pm}{0}$ & లి & $\stackrel{0}{\circ}$ & ֶิ & $\stackrel{t}{0}$ & $\stackrel{\circ}{\circ}$ & 웅 & $\stackrel{8}{\circ}$ & $\stackrel{\circ}{\circ}$ & $\begin{array}{l}\curvearrowright \\
\stackrel{1}{c} \\
\text { i }\end{array}$ \\
\hline & $\begin{array}{l}\bar{\Xi} \\
\text { ज्ञ }\end{array}$ & $\ll$ & 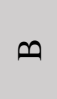 & U & ๑ & 山ు & IL & ט & $\Psi$ & - & $\sim$ & 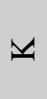 & - & $\Sigma$ & 哥 \\
\hline & & & & & & & & & & & & & & & \\
\hline
\end{tabular}

Appendix Table A.19 Accessibility indices for origin-destination pairs from raw job figures for two-mile buffer. Green, yellow, and red cells denote relatively high, medium, and low values, respectively. Blue cells denote row or column totals. The number of significant figures has been reduced to fit the table within the page. 


\begin{tabular}{|c|c|c|c|c|c|c|c|c|c|c|c|c|c|c|c|}
\hline \multirow{14}{*}{ 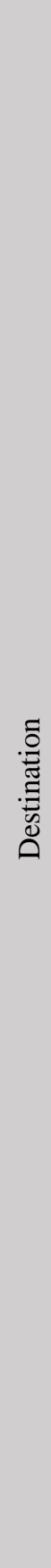 } & 完 & $\underset{8}{8}$ & $\stackrel{8}{8}$ & $\begin{array}{l}8 \\
\varnothing \\
\end{array}$ & $\underset{8}{8}$ & $\underset{8}{8}$ & $\underset{8}{8}$ & $\stackrel{8}{8}$ & $\underset{8}{8}$ & $\underset{8}{8}$ & $\underset{8}{8}$ & $\underset{8}{8}$ & $\underset{8}{8}$ & $\stackrel{8}{8}$ & $\begin{array}{l}8 \\
\dot{\Xi} \\
\dot{\Omega}\end{array}$ \\
\hline & $\Sigma$ & $\begin{array}{l}\overline{8} \\
\end{array}$ & $\begin{array}{l}\tilde{\delta} \\
\dot{0}\end{array}$ & $\begin{array}{l}\text { ㅇ. } \\
\stackrel{0}{0} \\
\text {. }\end{array}$ & $\begin{array}{l}8 \\
8 \\
0 \\
0\end{array}$ & $\begin{array}{l}n \\
8 \\
0\end{array}$ & $\frac{n}{0}$ & $\begin{array}{l}\mathscr{8} \\
\stackrel{0}{0}\end{array}$ & $\frac{\overline{0}}{0}$ & $\begin{array}{l}8 \\
\text { ọ } \\
0\end{array}$ & $\begin{array}{l}\text { ปิ } \\
\text { ல̊ }\end{array}$ & ت্ & $\begin{array}{l}\bar{O} \\
\stackrel{0}{0}\end{array}$ & $\begin{array}{l}\stackrel{\partial}{\infty} \\
\dot{0} \\
0\end{array}$ & $\begin{array}{l}\text { ڤ్ } \\
\text { oे }\end{array}$ \\
\hline & - & $\stackrel{8}{8}$ & 용 & $\begin{array}{l}\stackrel{+}{8} \\
\stackrel{0}{0}\end{array}$ & $\stackrel{0}{\circ}$ & $\stackrel{2}{0}$ & $\begin{array}{l}\stackrel{+}{0} \\
0 \\
0\end{array}$ & $\stackrel{2}{0}$ & $\begin{array}{l}0 \\
\text { o } \\
0\end{array}$ & $\begin{array}{l}\stackrel{+}{\delta} \\
\stackrel{0}{0}\end{array}$ & $\stackrel{\infty}{5}$ & $\frac{\sigma}{\sigma}$ & $\begin{array}{l}\bar{\sigma} \\
\infty \\
0\end{array}$ & $\frac{\dddot{n}}{\stackrel{0}{0}}$ & $\stackrel{\bar{q}}{\stackrel{g}{-}}$ \\
\hline & 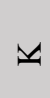 & 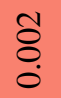 & $\begin{array}{l}+ \\
8 \\
0\end{array}$ & $\stackrel{8}{0}$ & $\begin{array}{l}\circ \\
0 \\
0\end{array}$ & $\begin{array}{l}\infty \\
\stackrel{8}{0} \\
\stackrel{0}{0}\end{array}$ & 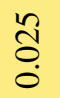 & $\hat{8}$ & $\begin{array}{l}\infty \\
\stackrel{0}{0} \\
\stackrel{0}{0}\end{array}$ & $\begin{array}{l}0 \\
0 \\
0\end{array}$ & 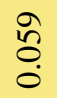 & 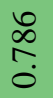 & $\begin{array}{l}0 \\
\mathscr{0}\end{array}$ & $\begin{array}{l}\mathcal{T} \\
\stackrel{5}{0}\end{array}$ & $\tilde{z}$ \\
\hline & $r$ & $\overline{8}$ & $\begin{array}{l}\text { ठ̊ } \\
\text {. }\end{array}$ & $\stackrel{\overline{8}}{\circ}$ & 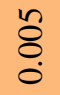 & $\begin{array}{l}\text { to } \\
\stackrel{0}{0}\end{array}$ & $\stackrel{\Delta}{0}$ & $\begin{array}{l}+ \\
8 \\
0\end{array}$ & $\frac{a}{0}$ & $\begin{array}{l}\bar{\sigma} \\
0 \\
0\end{array}$ & $\begin{array}{l}\hat{0} \\
\hat{0}\end{array}$ & $\frac{m}{0}$ & $\stackrel{0}{8}$ & \begin{tabular}{l}
$\stackrel{0}{0}$ \\
\hdashline \\
0
\end{tabular} & $\begin{array}{l}\hat{n} \\
\infty \\
0 \\
0\end{array}$ \\
\hline & - & 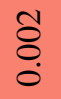 & $\begin{array}{l}+ \\
8 \\
0\end{array}$ & 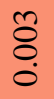 & $\bar{\sigma}$ & $\stackrel{8}{0}$ & 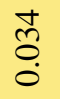 & $\vec{\sigma}$ & $\begin{array}{l}\tilde{n} \\
\text { है } \\
0\end{array}$ & $\begin{array}{l}0 \\
\infty \\
\infty \\
0\end{array}$ & $\begin{array}{l}\text { Sิ } \\
\text { Oे }\end{array}$ & $\hat{8}$ & 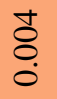 & $\hat{8}$ & $\stackrel{\infty}{\stackrel{\infty}{\dagger}}$ \\
\hline & $I$ & $\begin{array}{l}8 \\
8 \\
0\end{array}$ & $\begin{array}{l}\overline{8} \\
\dot{0}\end{array}$ & $\begin{array}{l}\overline{8} \\
\end{array}$ & 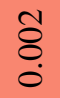 & $\begin{array}{l}+ \\
\stackrel{0}{0} \\
0\end{array}$ & $\begin{array}{l}0 \\
0 \\
0\end{array}$ & $\begin{array}{l}\infty \\
\stackrel{8}{0}\end{array}$ & & $\begin{array}{l}0 \\
\delta \\
0\end{array}$ & $\begin{array}{l}\text { ठ̊ } \\
\text {. }\end{array}$ & $\begin{array}{l}\overline{8} \\
\dot{0}\end{array}$ & $\begin{array}{l}\overline{8} \\
\dot{0}\end{array}$ & $\overline{8}$ & त̂ \\
\hline & 0 & $\begin{array}{l}\text { ôे } \\
0\end{array}$ & 苂 & $\begin{array}{l}n \\
\stackrel{0}{0}\end{array}$ & $\begin{array}{l}\text { d̦ } \\
\text { Oे. }\end{array}$ & है & $\frac{\partial}{3}$ & $\begin{array}{l}\bar{\infty} \\
\infty \\
\infty \\
0\end{array}$ & $\begin{array}{l}+t \\
\stackrel{0}{0}\end{array}$ & $\frac{n}{0}$ & ${ }_{0}^{\bar{\sigma}}$ & $\begin{array}{l}\text { ¿ } \\
\stackrel{0}{0}\end{array}$ & $\begin{array}{l}0 \\
\stackrel{0}{0}\end{array}$ & $\begin{array}{l}n \\
\delta \\
0\end{array}$ & $\begin{array}{l}\stackrel{+}{n} \\
\stackrel{n}{n}\end{array}$ \\
\hline & IL & $\begin{array}{l}8 \\
8 \\
0\end{array}$ & $\begin{array}{l}\overline{8} \\
\dot{0}\end{array}$ & $\overline{8}$ & $\begin{array}{l}\tilde{8} \\
0\end{array}$ & $\begin{array}{l}8 \\
8 \\
0 \\
0\end{array}$ & $\frac{n}{3}$ & $\begin{array}{l}\mathscr{8} \\
8 \\
\dot{0}\end{array}$ & $\begin{array}{l}\infty \\
8 \\
0 \\
0\end{array}$ & চ̊ & ఠ̊ & \begin{tabular}{l}
8 \\
8 \\
\hdashline
\end{tabular} & $\begin{array}{l}8 \\
8 \\
0\end{array}$ & $\begin{array}{l}8 \\
8 \\
0\end{array}$ & $\begin{array}{l}\text { fo } \\
\text { ma }\end{array}$ \\
\hline & 피 & $\stackrel{\wp}{8}$ & $\begin{array}{l}5 \\
0 \\
0\end{array}$ & 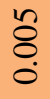 & $\underset{\tilde{o}}{\tilde{O}}$ & $\begin{array}{l}n \\
\infty \\
\infty \\
0\end{array}$ & $\frac{P}{\stackrel{0}{0}}$ & 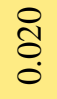 & \begin{tabular}{l}
\multirow{J}{0}{} \\
$\stackrel{0}{0}$
\end{tabular} & $\begin{array}{l}\infty \\
\stackrel{0}{0} \\
0\end{array}$ & $\begin{array}{l}\hat{8} \\
0\end{array}$ & $\begin{array}{l}0 \\
\delta\end{array}$ & $\begin{array}{l}\text { ô } \\
\text { ọ. }\end{array}$ & $\begin{array}{l}\hat{\delta} \\
\stackrel{0}{0}\end{array}$ & $\stackrel{\varrho}{\exists}$ \\
\hline & $\theta$ & 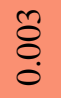 & $\hat{8}$ & $\stackrel{8}{0}$ & $\begin{array}{l}0 \\
\stackrel{0}{0} \\
0\end{array}$ & $\begin{array}{l}8 \\
8\end{array}$ & 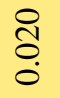 & $\begin{array}{l}\text { ț } \\
0\end{array}$ & $\bar{\sigma}$ & $\begin{array}{l}\text { ठै } \\
\text { o }\end{array}$ & $\begin{array}{l}\text { ठै } \\
\text {. }\end{array}$ & $\overrightarrow{8}$ & $\overrightarrow{8}$ & $\overline{8}$ & 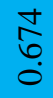 \\
\hline & $u$ & $\begin{array}{l}\stackrel{J}{0} \\
\text { Oִ }\end{array}$ & $\stackrel{+}{0}$ & $\begin{array}{l}\text { ळे } \\
\text { ळे }\end{array}$ & $\frac{N}{0}$ & 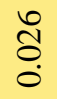 & $\begin{array}{l}0 \\
\stackrel{0}{0} \\
0 \\
0\end{array}$ & $\stackrel{\infty}{\circ}$ & $\begin{array}{l}0 \\
0 \\
0 \\
0\end{array}$ & $\stackrel{2}{0}$ & $\bar{\sigma}$ & $\stackrel{n}{\circ}$ & $\begin{array}{l}\text { ô } \\
\stackrel{0}{0}\end{array}$ & 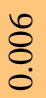 & $\begin{array}{l}\stackrel{\infty}{2} \\
\stackrel{?}{?}\end{array}$ \\
\hline & $\varphi$ & 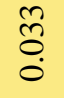 & $\begin{array}{l}\infty \\
\vdots \\
0 \\
0\end{array}$ & $\stackrel{\infty}{\circ}$ & $\stackrel{n}{\tilde{\delta}}$ & $\stackrel{8}{0}$ & $\begin{array}{l}\text { İ } \\
\text { ô. } \\
0\end{array}$ & $\stackrel{8}{8}$ & $\stackrel{\infty}{\circ}$ & $\underset{8}{8}$ & $\underset{8}{\stackrel{\Xi}{0}}$ & $\begin{array}{l}\tilde{8} \\
\stackrel{0}{0}\end{array}$ & $\overrightarrow{8}$ & $\begin{array}{l}\tilde{\delta} \\
\stackrel{0}{\circ}\end{array}$ & $\begin{array}{l}\infty \\
\infty \\
0\end{array}$ \\
\hline & $\varangle$ & $\begin{array}{c}\tilde{a} \\
\text { ô }\end{array}$ & 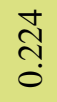 & के & $\begin{array}{l}0 \\
\& \\
0 \\
0\end{array}$ & $\begin{array}{l}\text { ț } \\
\text { O. }\end{array}$ & $\underset{\stackrel{+}{0}}{\stackrel{0}{0}}$ & $\stackrel{\infty}{0}$ & $\begin{array}{l}\bar{n} \\
0 \\
0\end{array}$ & $\stackrel{n}{0}$ & $\stackrel{m}{0}$ & $\begin{array}{l}\mathscr{0} \\
\stackrel{0}{0}\end{array}$ & $\begin{array}{l}\dot{0} \\
\stackrel{0}{0} \\
0\end{array}$ & $\begin{array}{l}\hat{8} \\
0 \\
0\end{array}$ & $\stackrel{+\infty}{\stackrel{+}{+}}$ \\
\hline & $\begin{array}{l}\bar{\Xi} \\
\bar{\Xi}\end{array}$ & $\varangle$ & 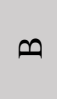 & U & ๑ & 디 & $\Phi$ & 0 & $I$ & - & $\neg$ & $\forall$ & \lrcorner & $\Sigma$ & है \\
\hline & & & & & & & & & & & & & & & \\
\hline
\end{tabular}

Appendix Table A.20 Accessibility indices for origin-destination pairs from raw population figures for twomile buffer. Green, yellow, and red cells denote relatively high, medium, and low values, respectively. Blue cells denote row or column totals. 


\begin{tabular}{|c|c|c|c|c|c|c|c|c|c|c|c|c|c|c|c|}
\hline \multirow{14}{*}{ 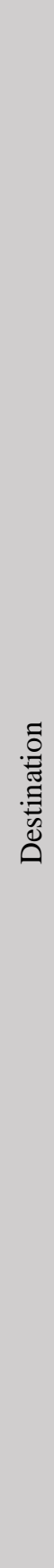 } & 丞 & $\underset{8}{8}$ & $\underset{8}{8}$ & $\underset{\delta}{8}$ & $\underset{-}{8}$ & $\begin{array}{l}8 \\
\delta \\
- \\
-\end{array}$ & $\underset{8}{8}$ & 8 & $\underset{8}{8}$ & $\underset{8}{8}$ & $\underset{8}{8}$ & $\underset{8}{8}$ & $\underset{\overbrace{}}{8}$ & $\stackrel{8}{8}$ & $\begin{array}{l}\stackrel{8}{\&} \\
\stackrel{m}{2}\end{array}$ \\
\hline & $\Sigma$ & $\overline{8}$ & $\stackrel{8}{8}$ & $\begin{array}{l}\text { \&े } \\
\stackrel{8}{0}\end{array}$ & $\stackrel{8}{8}$ & $\begin{array}{l}2 \\
\delta \\
\dot{o}\end{array}$ & $\begin{array}{l}0 \\
0 \\
0\end{array}$ & $\begin{array}{l}\text { ț } \\
\stackrel{8}{0} \\
\end{array}$ & $\begin{array}{l}\stackrel{\Xi}{0} \\
\stackrel{0}{0}\end{array}$ & $\begin{array}{l}8 \\
8 \\
0\end{array}$ & $\begin{array}{l}\text { ঠิ } \\
\stackrel{0}{0}\end{array}$ & $\stackrel{0}{\circ}$ & $\frac{\infty}{0}$ & $\frac{n}{\stackrel{n}{0}}$ & $\frac{2}{a}$ \\
\hline & \lrcorner & $\begin{array}{l}\hat{\delta} \\
\dot{\delta}\end{array}$ & $\begin{array}{l}\text { ठे } \\
\dot{0}\end{array}$ & 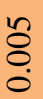 & $\stackrel{\partial}{0}$ & $\begin{array}{l}n \\
\vdots \\
0 \\
0\end{array}$ & $\begin{array}{l}\text { So } \\
\stackrel{0}{0}\end{array}$ & $\stackrel{\sim}{\stackrel{2}{0}}$ & \begin{tabular}{l}
8 \\
\hdashline \\
\hdashline
\end{tabular} & $\stackrel{\text { ָे }}{\stackrel{0}{0}}$ & $\begin{array}{l}\overline{8} \\
\dot{0}\end{array}$ & $\frac{a}{0}$ & $\begin{array}{l}\text { ¿े } \\
\text { }\end{array}$ & $\frac{\stackrel{1}{1}}{0}$ & 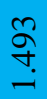 \\
\hline & 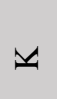 & 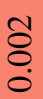 & $\begin{array}{l}\overleftarrow{8} \\
8 \\
0\end{array}$ & $\begin{array}{l}\text { है } \\
\dot{0}\end{array}$ & $\begin{array}{l}\circ \\
0 \\
0\end{array}$ & $\begin{array}{l}\infty \\
8 \\
0 \\
0\end{array}$ & $\begin{array}{l}\text { İ } \\
\stackrel{0}{0}\end{array}$ & $\begin{array}{l}\hat{8} \\
0\end{array}$ & 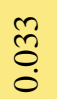 & 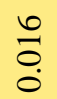 & $\begin{array}{l}\bar{\varnothing} \\
\varnothing \\
0\end{array}$ & 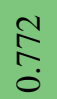 & $\begin{array}{l}\tilde{n} \\
0 \\
0\end{array}$ & $\stackrel{m}{\stackrel{O}{0}}$ & 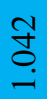 \\
\hline & $\neg$ & $\begin{array}{l}\overline{8} \\
\stackrel{8}{\circ}\end{array}$ & $\begin{array}{l}\tilde{\delta} \\
\stackrel{0}{0}\end{array}$ & $\begin{array}{l}\overline{8} \\
\stackrel{8}{0}\end{array}$ & $\stackrel{n}{\ddot{8}}$ & 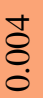 & $\stackrel{\Delta}{\Delta}$ & 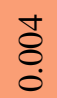 & $\stackrel{\circ}{0}$ & $\bar{\sigma}$ & $\frac{\tilde{n}}{\stackrel{0}{0}}$ & $\stackrel{\mathrm{T}}{0}$ & 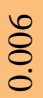 & $\begin{array}{l}\mathscr{8} \\
\stackrel{0}{0}\end{array}$ & $\begin{array}{c}\vec{F} \\
\infty \\
0\end{array}$ \\
\hline & - & 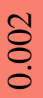 & $\begin{array}{l}\stackrel{+}{8} \\
0\end{array}$ & گ̊. & $\begin{array}{l}\bar{\sigma} \\
0 \\
0\end{array}$ & \&े & ֻे & $\begin{array}{l}0 \\
0 \\
0\end{array}$ & $\begin{array}{l}n \\
0 \\
0\end{array}$ & $\begin{array}{l}n \\
\infty \\
\infty \\
0\end{array}$ & $\overrightarrow{\widehat{s}}$ & $\begin{array}{l}8 \\
\& \\
0\end{array}$ & $\begin{array}{l}+ \\
8 \\
0\end{array}$ & $\stackrel{8}{8}$ & 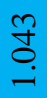 \\
\hline & $I$ & $\begin{array}{l}8 \\
\vdots \\
0\end{array}$ & $\overrightarrow{8}$ & $\overline{8}$ & 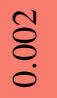 & $\begin{array}{l}\tilde{\delta} \\
0 \\
0\end{array}$ & $\begin{array}{l}\bar{\sigma} \\
0 \\
0\end{array}$ & $\begin{array}{l}n \\
\delta \\
0\end{array}$ & $\begin{array}{l}\stackrel{\infty}{0} \\
\text { ஸे }\end{array}$ & $\begin{array}{l}\text { ठ̊ } \\
\text {. }\end{array}$ & $\begin{array}{l}\text { ㅇ } \\
\stackrel{8}{0} \\
\stackrel{0}{0}\end{array}$ & $\begin{array}{l}\overline{8} \\
\stackrel{0}{0}\end{array}$ & $\begin{array}{l}8 \\
8 \\
0\end{array}$ & $\begin{array}{l}\overline{8} \\
\stackrel{0}{0}\end{array}$ & 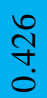 \\
\hline & 0 & 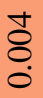 & $\begin{array}{l}\stackrel{8}{0} \\
\stackrel{0}{0}\end{array}$ & 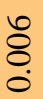 & 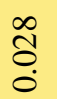 & ô. & ָี & $\begin{array}{l}\text { ๖ } \\
\infty \\
0\end{array}$ & $\frac{\stackrel{N}{\pi}}{0}$ & $\stackrel{r}{0}$ & $\stackrel{\mathfrak{O}}{0}$ & $\begin{array}{l}n \\
8 \\
8\end{array}$ & $\begin{array}{l}\text { ô } \\
\stackrel{0}{0}\end{array}$ & \begin{tabular}{l}
8 \\
8 \\
\hdashline
\end{tabular} & $\begin{array}{l}8 \\
\stackrel{8}{+} \\
+\end{array}$ \\
\hline & IL & $\begin{array}{l}8 \\
8 \\
0\end{array}$ & $\overrightarrow{8}$ & $\overline{8}$ & $\stackrel{0}{8}$ & \begin{tabular}{l}
$\stackrel{n}{8}$ \\
\hdashline \\
0
\end{tabular} & 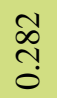 & $\begin{array}{l}+ \\
8 \\
0\end{array}$ & $\begin{array}{l}\infty \\
\stackrel{8}{0} \\
0\end{array}$ & $\overline{8}$ & $\begin{array}{l}\overline{8} \\
0\end{array}$ & $\begin{array}{l}8 \\
\&\end{array}$ & \begin{tabular}{l}
8 \\
8 \\
\hdashline
\end{tabular} & $\begin{array}{l}8 \\
8 \\
0\end{array}$ & 仓े \\
\hline & 디 & $\begin{array}{l}\tilde{\delta} \\
\dot{0}\end{array}$ & $\begin{array}{l}\hat{8} \\
0\end{array}$ & $\begin{array}{l}\dddot{n} \\
\delta \\
0\end{array}$ & $\begin{array}{l}\tilde{\delta} \\
\stackrel{0}{0}\end{array}$ & $\begin{array}{l}\hat{\sigma} \\
\text { o. } \\
0\end{array}$ & $\frac{q}{\stackrel{0}{0}}$ & $\stackrel{\infty}{0}$ & $\begin{array}{l}\stackrel{g}{0} \\
\stackrel{0}{0}\end{array}$ & $\begin{array}{l}\infty \\
\stackrel{8}{0}\end{array}$ & $\begin{array}{l}0 \\
8 \\
0\end{array}$ & $\begin{array}{l}\text { ठ̊ } \\
\stackrel{0}{0}\end{array}$ & $\overline{8}$ & $\begin{array}{l}0 \\
\tilde{o}\end{array}$ & $\begin{array}{l} \pm \\
\Xi\end{array}$ \\
\hline & $\theta$ & $\begin{array}{l}\tilde{8} \\
\dot{8}\end{array}$ & $\hat{8}$ & $\begin{array}{l}\hat{8} \\
\dot{0}\end{array}$ & $\begin{array}{l}0 \\
\stackrel{0}{0} \\
0\end{array}$ & \begin{tabular}{l}
8 \\
8 \\
\hdashline
\end{tabular} & $\begin{array}{l}\stackrel{0}{ } \\
\stackrel{0}{0}\end{array}$ & $\begin{array}{l}+ \\
8 \\
0\end{array}$ & $\stackrel{m}{0}$ & $\begin{array}{l}\widetilde{8} \\
\dot{0}\end{array}$ & $\begin{array}{l}\widetilde{8} \\
\dot{0}\end{array}$ & $\overline{8}$ & $\overline{8}$ & $\overline{8}$ & $\begin{array}{l}\frac{1}{\delta} \\
0 \\
0\end{array}$ \\
\hline & $u$ & $\begin{array}{l}\tilde{\Xi} \\
\text {. }\end{array}$ & $\stackrel{n}{0}$ & 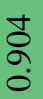 & $\frac{\hat{0}}{0}$ & 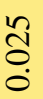 & 今o & $\stackrel{n}{a}$ & $\begin{array}{l}t \\
ٌ \\
0 \\
0\end{array}$ & $\bar{\sigma}$ & $\begin{array}{l}\bar{\sigma} \\
0\end{array}$ & $\begin{array}{l}\text { ¿̊ } \\
\dot{0}\end{array}$ & $\begin{array}{l}\hat{8} \\
\dot{0}\end{array}$ & \begin{tabular}{l} 
\& \\
\hdashline
\end{tabular} & $\stackrel{\overbrace{}}{\stackrel{N}{n}}$ \\
\hline & $ص$ & กิ & $\begin{array}{l}\text { fo } \\
\text { Oे }\end{array}$ & $\frac{\infty}{0}$ & $\stackrel{\text { }}{0}$ & $\begin{array}{l}\infty \\
\stackrel{0}{0} \\
0\end{array}$ & $\begin{array}{l}\text { İ } \\
\stackrel{0}{0}\end{array}$ & $\begin{array}{l}\mathscr{8} \\
\dot{0}\end{array}$ & $\stackrel{0}{0}$ & $\begin{array}{l}+ \\
8 \\
0\end{array}$ & $\begin{array}{l}+ \\
8 \\
0\end{array}$ & $\begin{array}{l}\text { o̊ } \\
\stackrel{0}{0}\end{array}$ & $\overline{8}$ & 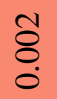 & $\begin{array}{l}\tilde{D} \\
\infty \\
0\end{array}$ \\
\hline & $\ll$ & $\begin{array}{l}\hat{\sigma} \\
\hat{o}\end{array}$ & $\begin{array}{l}\text { तै } \\
\text { ல }\end{array}$ & \begin{tabular}{l} 
Tे \\
\multirow{0}{0}{}
\end{tabular} & $\begin{array}{l}\mathscr{\alpha} \\
\stackrel{0}{0}\end{array}$ & $\begin{array}{l}\text { İ } \\
\text { o. } \\
0\end{array}$ & $\begin{array}{l}0 \\
\vdots \\
0 \\
0\end{array}$ & $\begin{array}{l}0 \\
0 \\
0\end{array}$ & \begin{tabular}{l}
$\infty$ \\
\hdashline \\
0
\end{tabular} & $\stackrel{m}{0}$ & $\stackrel{m}{0}$ & $\begin{array}{l}n \\
\delta\end{array}$ & $\begin{array}{l}\tilde{8} \\
\stackrel{0}{0}\end{array}$ & $\begin{array}{l}\hat{8} \\
0\end{array}$ & $\stackrel{\circ}{\stackrel{n}{n}}$ \\
\hline & $\begin{array}{l}\bar{\Xi} \\
\bar{\Xi} \\
\end{array}$ & $\varangle$ & $\varphi$ & $u$ & ค & 디 & I & 0 & $I$ & - & $\sim$ & $\forall$ & \lrcorner & $\Sigma$ & 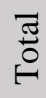 \\
\hline & & & & & & & & & & & & & & & \\
\hline
\end{tabular}

Appendix Table A.21 Accessibility indices for origin-destination pairs from raw housing unit figures for two-mile buffer. Green, yellow, and red cells denote relatively high, medium, and low values, respectively. Blue cells denote row or column totals. 


\begin{tabular}{|c|c|c|c|c|c|c|c|c|c|c|c|c|c|c|c|}
\hline \multirow{14}{*}{ 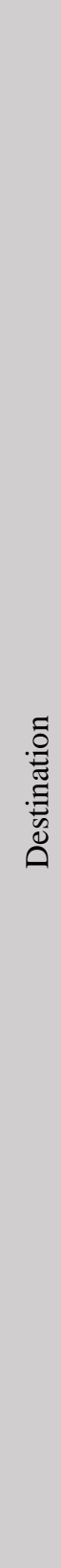 } & 吾 & $\stackrel{8}{8}$ & $\stackrel{8}{8}$ & $\stackrel{8}{8}$ & $\stackrel{8}{8}$ & $\stackrel{8}{8}$ & $\underset{-}{8}$ & $\stackrel{8}{8}$ & $\underset{-}{8}$ & 8 & $\stackrel{8}{-}$ & $\underset{-}{8}$ & $\stackrel{8}{8}$ & $\stackrel{8}{8}$ & $\begin{array}{l}8 \\
\stackrel{\oplus}{=}\end{array}$ \\
\hline & $\Sigma$ & $\stackrel{8}{\circ}$ & $\stackrel{8}{\circ}$ & $\stackrel{8}{\circ}$ & $\stackrel{8}{\circ}$ & $\stackrel{8}{\circ}$ & $\stackrel{8}{\circ}$ & $\stackrel{8}{\circ}$ & $\stackrel{8}{\circ}$ & $\stackrel{8}{\circ}$ & $\stackrel{8}{\circ}$ & ㅇ. & $\stackrel{8}{\circ}$ & 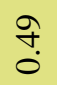 & $\stackrel{\infty}{\stackrel{0}{0}}$ \\
\hline & 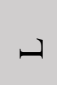 & $\stackrel{8}{8}$ & $\begin{array}{l}\dot{I} \\
\stackrel{0}{0}\end{array}$ & $\begin{array}{l}\hat{0} \\
\stackrel{0}{0}\end{array}$ & $\begin{array}{l}0 \\
0 \\
\end{array}$ & $\begin{array}{l}\text { Oे } \\
\stackrel{0}{0}\end{array}$ & $\begin{array}{l}0 \\
0 \\
0\end{array}$ & $\begin{array}{l}0 \\
0 \\
0\end{array}$ & $\begin{array}{l}0 \\
0 \\
0\end{array}$ & $\begin{array}{l}20 \\
0 \\
0\end{array}$ & $\begin{array}{l}\infty \\
\stackrel{0}{0} \\
1\end{array}$ & ס̊. & 우․ & $\begin{array}{l}8 \\
0 \\
0\end{array}$ & $\hat{\overbrace{}}$ \\
\hline & $\forall$ & 8 & 8 & 8 & $\stackrel{8}{8}$ & 8 & $\stackrel{8}{8}$ & $\stackrel{8}{8}$ & 8 & 8 & 8 & $\frac{n}{0}$ & 8 & $\ddot{0}$ & $\frac{n}{0}$ \\
\hline & $\neg$ & $\stackrel{8}{8}$ & $\stackrel{\text { ô }}{0}$ & 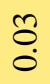 & $\stackrel{\Xi}{0}$ & $\stackrel{\overline{0}}{\circ}$ & $\stackrel{\overline{0}}{\circ}$ & $\stackrel{\overline{0}}{\circ}$ & $\stackrel{\overline{0}}{0}$ & రి & $\stackrel{n}{\circ}$ & $\overline{\dot{0}}$ & $\begin{array}{l}\overline{0} \\
0\end{array}$ & $\begin{array}{l}\infty \\
\stackrel{0}{0} \\
0\end{array}$ & $\hat{a}$ \\
\hline & - & 8 & $\ddot{0}$ & 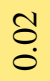 & $\stackrel{8}{8}$ & 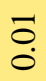 & $\ddot{0}$ & $\ddot{0}$ & $\ddot{0}$ & $\stackrel{\circ}{\circ}$ & $\stackrel{0}{0}$ & 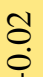 & $\stackrel{8}{\circ}$ & $\begin{array}{l}\sigma \\
0\end{array}$ & $\stackrel{8}{8}$ \\
\hline & $I$ & $\stackrel{8}{8}$ & $\stackrel{0}{0}$ & $\stackrel{0}{\circ}$ & $\ddot{\circ}$ & $\stackrel{\widetilde{\sigma}}{\circ}$ & $\stackrel{0}{0}$ & $\stackrel{\infty}{\stackrel{0}{0}}$ & ¿ே. & ְ̊. & $\ddot{\circ}$ & ô. & $\stackrel{8}{\circ}$ & O̊. & $\stackrel{0}{=}$ \\
\hline & 0 & $\stackrel{8}{\circ}$ & 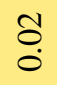 & $\stackrel{\Delta}{0}$ & $\stackrel{\overrightarrow{0}}{\circ}$ & 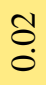 & $\stackrel{\leftrightarrow}{0}$ & $\stackrel{\infty}{\infty}$ & $\stackrel{\circledast}{0}$ & ¿. & $\stackrel{\Xi}{0}$ & 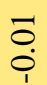 & $\stackrel{8}{\circ}$ & $\begin{array}{l}\overrightarrow{0} \\
\dot{0}\end{array}$ & ț \\
\hline & II & $\stackrel{8}{8}$ & $\stackrel{+}{0}$ & $\stackrel{8}{8}$ & 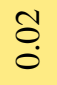 & $\stackrel{8}{\circ}$ & $\bar{\sigma}$ & $\stackrel{\text { ga }}{\circ}$ & $\stackrel{0}{0}$ & $\underset{ْ}{0}$ & ס्. & $\begin{array}{l}\text { So } \\
\stackrel{0}{0}\end{array}$ & $\stackrel{8}{8}$ & $\begin{array}{l}\text { ô } \\
\dot{0}\end{array}$ & $\stackrel{\overbrace{}}{\sim}$ \\
\hline & I & $\stackrel{8}{\circ}$ & 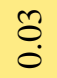 & $\stackrel{0}{0}$ & 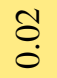 & $\bar{a}$ & $\begin{array}{l}\dot{0} \\
0\end{array}$ & $\begin{array}{l}\dot{D} \\
0\end{array}$ & $\ddot{\circ}$ & $\sigma_{0}^{\circ}$ & $\stackrel{\sigma}{0}$ & ¿̈. & $\stackrel{8}{\circ}$ & Oे. & $\exists$ \\
\hline & ค & $\stackrel{8}{8}$ & $\stackrel{\infty}{\circ}$ & กี & $\underset{-}{\sigma}$ & $\stackrel{0}{0}$ & $\stackrel{\bar{\sigma}}{\circ}$ & 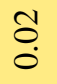 & $\stackrel{\Xi}{\circ}$ & ¿. & $\stackrel{\sigma}{0}$ & $\begin{array}{l}\overline{0} \\
\dot{\rho}\end{array}$ & $\stackrel{8}{\circ}$ & $\begin{array}{l}\text { ô } \\
\dot{0}\end{array}$ & $\stackrel{f}{\stackrel{f}{-}}$ \\
\hline & $U$ & $\begin{array}{l}8 \\
0\end{array}$ & $\stackrel{0}{0}$ & $\stackrel{\text { sa }}{.}$ & $\ddot{\circ}$ & 8 & $\stackrel{8}{8}$ & $\stackrel{8}{8}$ & 8 & : & $\stackrel{8}{8}$ & $\begin{array}{l}8 \\
0 \\
0\end{array}$ & 8 & $\stackrel{8}{8}$ & $\stackrel{\cong}{=}$ \\
\hline & $\sim$ & $\begin{array}{l}0 \\
0 \\
0\end{array}$ & $\hat{n}$ & ڤ్ & $\stackrel{\sigma}{0}$ & ¿. & $\ddot{\circ}$ & $\ddot{\circ}$ & 8 & ö. & $\stackrel{8}{8}$ & $\begin{array}{l}\overline{0} \\
\dot{\rho}\end{array}$ & $\stackrel{8}{\circ}$ & $\begin{array}{l}0 \\
0 \\
0\end{array}$ & in \\
\hline & $\ll$ & $\stackrel{0}{0}$ & $\frac{n}{n}$ & $\begin{array}{l}0 \\
\infty \\
0 \\
1\end{array}$ & $\begin{array}{l}\text { oे } \\
\text { ị }\end{array}$ & $\begin{array}{l}\dot{I} \\
0 \\
\end{array}$ & $\stackrel{0}{0}$ & $\begin{array}{l}n \\
0 \\
1\end{array}$ & $\begin{array}{l}\text { Oे } \\
0\end{array}$ & $\begin{array}{l}\text { Oo } \\
\dot{\varphi}\end{array}$ & $\begin{array}{l}\text { ô } \\
\stackrel{0}{1}\end{array}$ & $\begin{array}{l}\because \\
\stackrel{0}{0} \\
\end{array}$ & ¿ & $\stackrel{\circ}{\stackrel{0}{0}}$ & $\underset{i}{\stackrel{8}{i}}$ \\
\hline & $\begin{array}{l}\overline{\mathbb{D}} \\
\text { ज्ञ }\end{array}$ & $\ll$ & 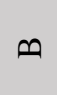 & $u$ & $\theta$ & 피 & IL & 0 & $I$ & - & $\neg$ & 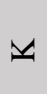 & - & $\Sigma$ & స్ّే \\
\hline & & & & & & & & & & & & & & & \\
\hline
\end{tabular}

Appendix Table A.22 Accessibility indices for origin-destination pairs from normalized job figures for twomile buffer. Green, yellow, and red cells denote relatively high, medium, and low values, respectively. Blue cells denote row or column totals. The number of significant figures has been reduced to fit the table within the page. 


\begin{tabular}{|c|c|c|c|c|c|c|c|c|c|c|c|c|c|c|c|}
\hline \multirow{14}{*}{ 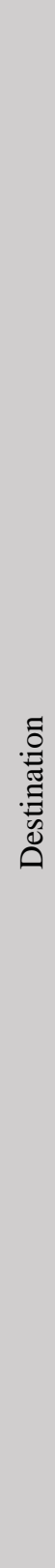 } & $\underset{\tilde{0}}{\overline{0}}$ & $\underset{-}{8}$ & $\underset{-}{8}$ & $\underset{-}{8}$ & $\underset{-}{8}$ & $\underset{\sim}{8}$ & $\stackrel{8}{8}$ & $\underset{-}{8}$ & $\stackrel{8}{.}$ & $\underset{-}{8}$ & $\underset{-}{8}$ & $\underset{.}{8}$ & $\underset{-}{8}$ & $\underset{-}{8}$ & $\begin{array}{l}8 \\
\dot{0} \\
\end{array}$ \\
\hline & $\Sigma$ & $\stackrel{8}{0}$ & $\stackrel{8}{\circ}$ & $\stackrel{8}{8}$ & $\stackrel{8}{\circ}$ & $\stackrel{8}{8}$ & $\stackrel{8}{\circ}$ & ¿̄o & $\stackrel{8}{8}$ & ọ̈. & $\stackrel{8}{\circ}$ & ¿. & $\stackrel{8}{\circ}$ & $\underset{\sim}{\stackrel{N}{N}}$ & $\stackrel{\widetilde{T}}{\stackrel{\sim}{\sim}}$ \\
\hline & \lrcorner & $\stackrel{8}{\circ}$ & $\begin{array}{l}8 \\
\stackrel{0}{0}\end{array}$ & $\stackrel{\sigma}{\circ}$ & $\begin{array}{l}0 \\
\dot{\varphi}\end{array}$ & $\begin{array}{l}\text { O̦ } \\
\stackrel{0}{1}\end{array}$ & $\begin{array}{l}\overline{0} \\
\stackrel{0}{0}\end{array}$ & $\begin{array}{l}8 \\
\stackrel{0}{0}\end{array}$ & $\begin{array}{l}\overline{0} \\
\stackrel{0}{1}\end{array}$ & $\begin{array}{l}\infty \\
\stackrel{0}{\varphi}\end{array}$ & $\begin{array}{l}\infty \\
\stackrel{0}{0}\end{array}$ & ले & $\stackrel{8}{8}$ & 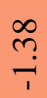 & $\begin{array}{l}\bar{n} \\
0 \\
0\end{array}$ \\
\hline & $\mathscr{V}$ & $\stackrel{8}{8}$ & $\begin{array}{l}\overline{0} \\
\stackrel{\varphi}{\varphi}\end{array}$ & $\stackrel{8}{\circ}$ & $\stackrel{8}{\circ}$ & $\stackrel{8}{\circ}$ & $\begin{array}{l}8 \\
\end{array}$ & $\begin{array}{l}\overline{0} \\
\stackrel{0}{\varphi}\end{array}$ & $\begin{array}{l}8 \\
\end{array}$ & $\begin{array}{l}\text { ô. } \\
0\end{array}$ & $\begin{array}{l}\text { ọ. } \\
\stackrel{0}{0}\end{array}$ & $\stackrel{0}{0}$ & $\stackrel{0}{0}$ & तి & $\underset{0}{+}$ \\
\hline & $\neg$ & $\stackrel{8}{\circ}$ & $\stackrel{0}{0}$ & $\stackrel{8}{\circ}$ & $\stackrel{8}{0}$ & $\stackrel{0}{0}$ & $\stackrel{8}{\circ}$ & $\stackrel{\overbrace{}}{0}$ & $\stackrel{8}{8}$ & $\stackrel{n}{\circ}$ & $\stackrel{\text { }}{\circ}$ & $\stackrel{0}{0}$ & ō. & $\frac{\infty}{0}$ & $\bar{n}$ \\
\hline & $\neg$ & 8 & $\ddot{0}$ & 8 & 8 & 8 & $\stackrel{8}{0}$ & $\underset{0}{0}$ & $\begin{array}{l}8 \\
\\
\end{array}$ & $\stackrel{\text { के }}{\stackrel{0}{0}}$ & ö & $\stackrel{8}{8}$ & $\stackrel{8}{8}$ & 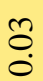 & $\begin{array}{l}n \\
o\end{array}$ \\
\hline & $I$ & $\stackrel{8}{\circ}$ & $\stackrel{8}{\circ}$ & ọ. & $\ddot{0}$ & $\stackrel{0}{\circ}$ & $\stackrel{3}{\circ}$ & $\stackrel{\text { I }}{0}$ & $\stackrel{\infty}{\circ}$ & $=$ & $\stackrel{\sigma}{0}$ & o̊. & $\ddot{0}$ & $\stackrel{\mathcal{I}}{\circ}$ & $\stackrel{9}{\stackrel{2}{Z}}$ \\
\hline & ن & $\stackrel{8}{8}$ & $\stackrel{8}{\circ}$ & $\stackrel{8}{8}$ & $\stackrel{8}{0}$ & $\stackrel{8}{8}$ & $\stackrel{8}{\circ}$ & $\frac{m}{0}$ & 8 & $\stackrel{8}{\circ}$ & $\stackrel{8}{8}$ & $\stackrel{8}{\circ}$ & $\stackrel{8}{8}$ & $\stackrel{8}{8}$ & $\stackrel{ \pm}{\dot{0}}$ \\
\hline & LL & $\begin{array}{l}0 \\
\dot{0} \\
\dot{1}\end{array}$ & $\frac{\Delta}{0}$ & $\begin{array}{l}\Omega \\
0 \\
0 \\
1\end{array}$ & $\stackrel{0}{0}$ & $\frac{\infty}{0}$ & $\hat{a}$ & 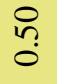 & గ̂. & $\stackrel{5}{0}$ & $\begin{array}{l}\text { ơ } \\
\stackrel{0}{0}\end{array}$ & $\begin{array}{l}\text { ô } \\
\stackrel{\leftrightarrow}{\circ}\end{array}$ & $\stackrel{8}{8}$ & $\overline{0}$ & ๙े \\
\hline & 디 & $\stackrel{8}{8}$ & $\stackrel{\text { Oे }}{0}$ & $\begin{array}{l}8 \\
\dot{0}\end{array}$ & $\stackrel{\sigma}{0}$ & $\stackrel{\infty}{\infty}$ & ¿. & $\begin{array}{l}\stackrel{0}{0} \\
\stackrel{0}{0}\end{array}$ & ¿. & $\stackrel{\overline{0}}{\circ}$ & $\stackrel{8}{8}$ & $\stackrel{8}{8}$ & $\stackrel{8}{8}$ & $\begin{array}{l}\stackrel{1}{0} \\
\stackrel{0}{0}\end{array}$ & ڤ̊ \\
\hline & D & $\begin{array}{l}0 \\
\dot{0} \\
\dot{0}\end{array}$ & $\stackrel{\mathbb{J}}{0}$ & $\begin{array}{l}\text { to } \\
\dot{0}\end{array}$ & $\stackrel{5}{\circ}$ & $\stackrel{\Delta}{0}$ & $\stackrel{\overline{0}}{\circ}$ & $\stackrel{\infty}{\circ}$ & ¿. & $\stackrel{\overbrace{}}{0}$ & $\stackrel{\sigma}{0}$ & 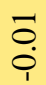 & $\stackrel{8}{\circ}$ & $\begin{array}{l}\stackrel{8}{0} \\
\stackrel{0}{ }\end{array}$ & $\stackrel{\infty}{+}$ \\
\hline & $u$ & 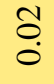 & $\begin{array}{l}0 \\
\stackrel{2}{?} \\
?\end{array}$ & $\stackrel{0}{0}$ & $\begin{array}{l}0 \\
0 \\
0\end{array}$ & $\begin{array}{l}\text { ț } \\
\text { i }\end{array}$ & $\begin{array}{l}0 \\
\dot{0}\end{array}$ & $\begin{array}{l}\infty \\
0 \\
0\end{array}$ & $\begin{array}{l}0 \\
\stackrel{0}{0}\end{array}$ & $\begin{array}{l}0 \\
0 \\
0\end{array}$ & $\begin{array}{l}0 \\
0 \\
0\end{array}$ & ¿. & $\stackrel{8}{8}$ & o̊. & $\frac{1}{0}$ \\
\hline & $\infty$ & $\begin{array}{l}\text { ô } \\
0 \\
\end{array}$ & ஸे & $\begin{array}{l}\overline{0} \\
0 \\
0\end{array}$ & $\stackrel{0}{0}$ & ō & $\stackrel{8}{\circ}$ & 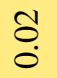 & $\stackrel{8}{\circ}$ & $\ddot{\circ}$ & $\stackrel{8}{\circ}$ & 8 & $\stackrel{8}{8}$ & $\stackrel{\text { ô. }}{\circ}$ & rn \\
\hline & $\ll$ & రి & $\frac{a}{\vec{i}}$ & $\stackrel{8}{8}$ & $\begin{array}{l}n \\
0 \\
\dot{p}\end{array}$ & $\begin{array}{l}\text { to } \\
\stackrel{0}{0}\end{array}$ & $\begin{array}{l}\overline{0} \\
\stackrel{0}{\varphi}\end{array}$ & $\stackrel{0}{\stackrel{0}{0}}$ & $\begin{array}{l}\overline{0} \\
\stackrel{0}{0}\end{array}$ & $\begin{array}{l}\mathscr{0} \\
\stackrel{0}{0}\end{array}$ & $\begin{array}{l}0 \\
0\end{array}$ & $\stackrel{\square}{\circ}$ & $\stackrel{8}{8}$ & $\frac{0}{0}$ & $\stackrel{\infty}{\stackrel{\infty}{+}}$ \\
\hline & $\begin{array}{l}\bar{\Xi} \\
\bar{\Xi} \\
\text { ] }\end{array}$ & $\varangle$ & $ص$ & $u$ & ๑ & 디 & IL & 0 & I & - & $r$ & $\forall$ & \lrcorner & $\Sigma$ & 苞 \\
\hline & & & & & & & & & & & & & & & \\
\hline
\end{tabular}

Appendix Table A.23 Accessibility indices for origin-destination pairs from normalized population figures for two-mile buffer. Green, yellow, and red cells denote relatively high, medium, and low values, respectively. Blue cells denote row or column totals. 


\begin{tabular}{|c|c|c|c|c|c|c|c|c|c|c|c|c|c|c|c|}
\hline & 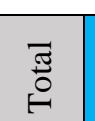 & 8 & 8 & $\stackrel{8}{-}$ & $\stackrel{8}{-}$ & 8 & $\stackrel{8}{-}$ & 8 & 8 & $\stackrel{8}{-1}$ & 8 & 8 & 8 & $\stackrel{8}{\sharp}$ & $\underset{8}{8}$ \\
\hline & $\bar{z}$ & $\stackrel{8}{0}$ & $\stackrel{8}{0}$ & 8 & 8 & 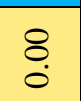 & 8 & $\frac{n}{0}$ & $\stackrel{8}{0}$ & $\overline{0}$ & $\bar{\partial}$ & $\bar{o}$ & 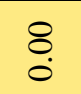 & $\overbrace{\text { d }}$ & वे \\
\hline & لد & 8 & 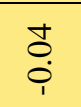 & $\vec{\partial}$ & $\overrightarrow{\vec{i}}$ & $\stackrel{0}{0}$ & $\overline{\dot{\phi}}$ & $\frac{\infty}{\rightarrow+\infty}$ & $\overline{\vec{c}}$ & 离 & oे & 妻 & $\underset{-}{\stackrel{8}{*}}$ & & $\underset{i}{F}$ \\
\hline & 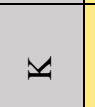 & $\stackrel{8}{0}$ & $\overrightarrow{\vec{i}}$ & $\begin{array}{l}8 \\
0\end{array}$ & 8 & $\stackrel{8}{0}$ & $\stackrel{8}{8}$ & min & $\stackrel{0}{0}$ & $\stackrel{8}{\grave{i}}$ & $\stackrel{\Delta}{i}$ & 㕝 & $\stackrel{0}{0}$ & $\stackrel{9}{\vec{g}}$ & $\stackrel{\circ}{0}$ \\
\hline & - & $\stackrel{8}{0}$ & $\overrightarrow{0}$ & $\begin{array}{l}8 \\
\end{array}$ & 8 & $\bar{\partial}$ & 8 & $\stackrel{\infty}{\infty}$ & $\stackrel{8}{\circ}$ & ta & $\stackrel{a}{-}$ & 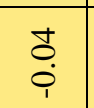 & $\overline{\vec{b}}$ & $\stackrel{7}{0}$ & 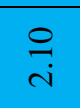 \\
\hline & - & 8 & $\vec{\partial}$ & $\begin{array}{l}8 \\
0\end{array}$ & 8 & $\bar{\partial}$ & 8 & $\stackrel{\infty}{\infty}$ & 8 & : & $\bar{\sigma}$ & $\overline{\sigma_{0}}$ & 8 & $\overbrace{0}^{\circ}$ & $\stackrel{n}{n}$ \\
\hline & \pm & 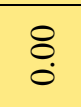 & : & $\begin{array}{l}\vec{i} \\
\dot{i}\end{array}$ & $\vec{\partial}$ & $\stackrel{n}{g}$ & $\stackrel{8}{8}$ & $\begin{array}{l}\text { ta } \\
\stackrel{a}{g}\end{array}$ & $\begin{array}{l}\infty \\
\stackrel{\infty}{0} \\
0\end{array}$ & gे & $\tilde{O}$ & : & 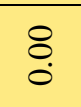 & $\stackrel{9}{0}$ & 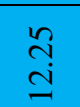 \\
\hline & 0 & 8 & $\overrightarrow{\dot{a}_{i}}$ & \begin{tabular}{|l|}
8 \\
\end{tabular} & 8 & $\overline{\dot{a}_{i}}$ & $\overline{\sigma_{0}}$ & 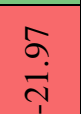 & 产 & $\overline{\dot{o}}$ & $\stackrel{8}{0}$ & $\begin{array}{l}8 \\
0 \\
\end{array}$ & $\stackrel{8}{\circ}$ & & ¿ \\
\hline & د & 京 & $\stackrel{5}{0}$ & : & $\stackrel{\Omega}{8}$ & $\stackrel{0}{0}$ & S. & $\underset{\stackrel{\vec{\sigma}}{\underline{I}}}{ }$ & $\stackrel{\Omega}{8}$ & $\stackrel{8}{0}$ & $\stackrel{\Omega}{0}$ & $\begin{array}{c}\overline{0} \\
\dot{i}\end{array}$ & 8 & $\frac{8}{\circ}$ & $\begin{array}{l}\stackrel{8}{ \pm} \\
\end{array}$ \\
\hline & $\Psi$ & 8 & $\Xi$ & $\overrightarrow{\dot{a}}$ & $\bar{\sigma}$ & $\stackrel{\infty}{\infty}$ & $\stackrel{0}{0}$ & $\underset{t}{t}$ & $\bar{\sigma}$ & $\bar{\delta}$ & 8 & 8 & 8 & $\stackrel{8}{0}$ & 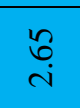 \\
\hline & 0 & $\overline{\dot{i}}$ & $\frac{9}{0}$ & 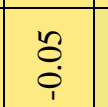 & $\stackrel{n}{\stackrel{n}{\prime}}$ & ta & $\vec{a}$ & $\stackrel{\vec{i}}{\mathrm{i}}$ & $\overline{\dot{o}}$ & 兽 & $\overline{\dot{0}}$ & $\begin{array}{l}\overline{0} \\
\dot{i}\end{array}$ & 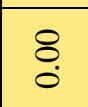 & 8 & 嵭 \\
\hline & 0 & : & 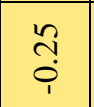 & $\underset{\sim}{\stackrel{t}{*}}$ & $\stackrel{8}{\circ}$ & $\stackrel{8}{i}$ & $\overrightarrow{\dot{\varphi}}$ & $\stackrel{8}{\circ}$ & to & O̊ & $\bar{\phi}_{i}$ & $\begin{array}{l} \\
\dot{0}\end{array}$ & 8 & 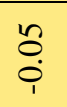 & $\underset{\leftarrow}{-}$ \\
\hline & $\infty$ & 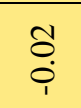 & $\frac{\pi}{\mathrm{N}}$ & $\underset{\stackrel{i}{i}}{i}$ & $\bar{\partial}$ & $\overline{0}$ & $\begin{array}{l}8 \\
\end{array}$ & : & $\stackrel{8}{8}$ & $\overline{0}$ & $\stackrel{8}{0}$ & $\begin{array}{l}8 \\
\end{array}$ & 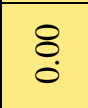 & d: & $\underset{\mathrm{d}}{\mathrm{i}}$ \\
\hline & $\varangle$ & $\stackrel{8}{-}$ & $\bar{F}$ & $\begin{array}{c}5 \\
0 \\
0\end{array}$ & 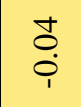 & $\stackrel{t}{\dot{i}}$ & 寄 & 年 & 京 & 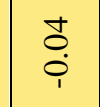 & 衣 & $\bar{o}$ & 8 & $\dot{S}$ & $\underset{i}{\pi}$ \\
\hline & 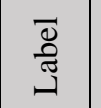 & $\varangle$ & $\infty$ & 0 & 0 & $\omega$ & ш & 0 & \pm & - & - & 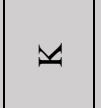 & د & $z^{2}$ & 氶 \\
\hline
\end{tabular}

Appendix Table A.24 Accessibility indices for origin-destination pairs from normalized housing unit figures for two-mile buffer. Green, yellow, and red cells denote relatively high, medium, and low values,

respectively. Blue cells denote row or column totals. 


\section{e. Three-Mile Radius}

\begin{tabular}{|c|c|c|c|c|c|c|c|c|c|c|c|c|c|c|c|}
\hline \multirow{14}{*}{ 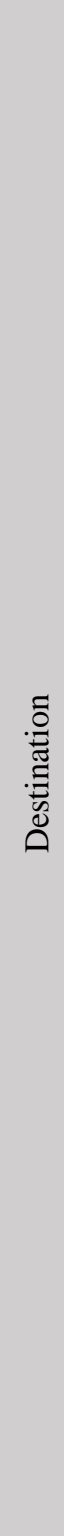 } & స్ & $\stackrel{8}{8}$ & $\stackrel{8}{8}$ & $\underset{.}{8}$ & $\underset{\text { }}{\stackrel{8}{ }}$ & $\underset{-}{8}$ & $\underset{-}{8}$ & $\stackrel{8}{.}$ & $\underset{-}{8}$ & $\underset{-}{8}$ & $\underset{8}{8}$ & $\stackrel{8}{8}$ & $\underset{-}{8}$ & $\underset{-}{8}$ & $\begin{array}{l}8 \\
\dot{2} \\
\ddot{2}\end{array}$ \\
\hline & $\Sigma$ & $\stackrel{8}{\circ}$ & $\stackrel{0}{0}$ & $\tilde{O}_{0}$ & 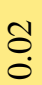 & $\stackrel{\overbrace{}}{\circ}$ & $\stackrel{n}{\circ}$ & ชै & $\begin{array}{l}\circ \\
0\end{array}$ & $\stackrel{\text { Oִ }}{0}$ & $\stackrel{\circ}{\circ}$ & $\stackrel{\text { OL }}{0}$ & $\stackrel{\text { Oִ }}{0}$ & $\frac{\infty}{\stackrel{0}{0}}$ & $\stackrel{m}{\rightleftarrows}$ \\
\hline & - & $\stackrel{8}{\circ}$ & 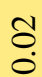 & ¿. & $\begin{array}{l}n \\
\stackrel{0}{0}\end{array}$ & $\stackrel{\circ}{\circ}$ & $\stackrel{\stackrel{2}{7}}{\circ}$ & $\stackrel{\circ}{\circ}$ & $\frac{n}{0}$ & $\stackrel{\infty}{\stackrel{\infty}{0}}$ & $\vec{m}$ & $\vec{m}$ & ڤి & $\frac{n}{0}$ & 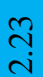 \\
\hline & $\forall$ & $\stackrel{8}{8}$ & $\stackrel{0}{0}$ & 8 & $\begin{array}{l}\text { Oे } \\
\stackrel{0}{0}\end{array}$ & $\stackrel{0}{0}$ & $\stackrel{0}{0}$ & $\stackrel{d}{O}$ & $\stackrel{0}{\circ}$ & $\stackrel{0}{0}$ & $\frac{n}{0}$ & $\begin{array}{l}t \\
0\end{array}$ & $\stackrel{8}{\circ}$ & $\stackrel{+}{0}$ & $\stackrel{0}{\rightleftarrows}$ \\
\hline & $\neg$ & $\stackrel{8}{8}$ & $\stackrel{8}{\circ}$ & $\stackrel{8}{\circ}$ & $\stackrel{8}{8}$ & $\stackrel{8}{8}$ & $\overline{0}$ & $\stackrel{8}{\circ}$ & $\ddot{\sigma}$ & $\ddot{\sigma}$ & $\stackrel{m}{m}$ & $\stackrel{8}{\circ}$ & $\stackrel{8}{\circ}$ & $\stackrel{8}{\circ}$ & $\stackrel{n}{0}$ \\
\hline & $\neg$ & $\stackrel{8}{8}$ & $\stackrel{8}{8}$ & : & $\overline{0}$ & $\stackrel{\text { Oे }}{\circ}$ & $\underset{:}{\stackrel{D}{0}}$ & 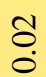 & 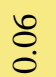 & $\stackrel{n}{\stackrel{n}{0}}$ & $\stackrel{\overbrace{}}{0}$ & $\stackrel{8}{8}$ & $\stackrel{8}{8}$ & $\stackrel{8}{8}$ & ڤn \\
\hline & I & $\stackrel{8}{8}$ & $\stackrel{8}{\circ}$ & 8 & 8 & 8 & $\overline{0}$ & $\overline{0}$ & $\frac{5}{0}$ & $\stackrel{8}{8}$ & $\stackrel{8}{8}$ & 8 & 8 & $\stackrel{8}{8}$ & ָֻ \\
\hline & 0 & $\stackrel{8}{\circ}$ & $\stackrel{0}{0}$ & ¿. & $\begin{array}{l}\widetilde{O} \\
\stackrel{0}{0}\end{array}$ & $\stackrel{8}{\circ}$ & กิ & $\stackrel{\circ}{\stackrel{0}{0}}$ & $\frac{\infty}{0}$ & $\stackrel{\text { O̦ }}{0}$ & $\stackrel{0}{0}$ & $\stackrel{8}{8}$ & $\stackrel{8}{\stackrel{0}{0}}$ & $\stackrel{8}{8}$ & $\stackrel{\infty}{\stackrel{\infty}{̣}}$ \\
\hline & LI & $\stackrel{8}{8}$ & $\stackrel{8}{\circ}$ & $\begin{array}{l}8 \\
0\end{array}$ & $\underset{0}{8}$ & $\stackrel{8}{8}$ & $\stackrel{\infty}{\stackrel{0}{0}}$ & $\stackrel{8}{\circ}$ & $\stackrel{8}{\circ}$ & $\begin{array}{l}8 \\
0\end{array}$ & $\begin{array}{l}8 \\
0\end{array}$ & $\begin{array}{l}8 \\
0 \\
0\end{array}$ & $\begin{array}{l}8 \\
\stackrel{0}{0}\end{array}$ & $\begin{array}{l}8 \\
0\end{array}$ & $\begin{array}{l}\stackrel{0}{0} \\
\dot{0}\end{array}$ \\
\hline & 피 & $\stackrel{8}{8}$ & $\stackrel{8}{\circ}$ & $\begin{array}{l}8 \\
0\end{array}$ & o. & ñ? & ¿̊. & $\stackrel{\sigma}{0}$ & 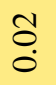 & $\stackrel{8}{8}$ & $\stackrel{8}{8}$ & $\stackrel{8}{8}$ & $\stackrel{8}{\circ}$ & $\stackrel{8}{8}$ & $\begin{array}{l}\stackrel{8}{\circ} \\
\stackrel{0}{0}\end{array}$ \\
\hline & 0 & : & 8 & $\ddot{\circ}$ & లి & 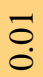 & ¿. & 8 & $\ddot{0}$ & $\stackrel{8}{8}$ & $\stackrel{8}{8}$ & $\stackrel{8}{8}$ & $\stackrel{8}{8}$ & $\stackrel{8}{8}$ & $\begin{array}{l}\text { ְి } \\
\stackrel{0}{0}\end{array}$ \\
\hline & $u$ & $\overline{0}$ & $\stackrel{0}{0}$ & $\stackrel{\infty}{\infty}$ & $\stackrel{\overbrace{}}{\leftrightarrow}$ & o. & $\frac{0}{0}$ & $\stackrel{0}{0}$ & s. & $\begin{array}{l}0 \\
\stackrel{0}{0}\end{array}$ & $\begin{array}{l}0 \\
\stackrel{0}{0}\end{array}$ & 8 & $\stackrel{8}{8}$ & $\stackrel{8}{8}$ & $\underset{-}{\stackrel{\neg}{f}}$ \\
\hline & 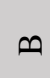 & $\stackrel{0}{0}$ & $\tilde{n}$ & $\stackrel{1}{0}$ & $\begin{array}{l}\text { to } \\
0\end{array}$ & $\stackrel{d}{\sigma}$ & $\stackrel{0}{0}$ & ㅇ. & $\stackrel{\sigma}{0}$ & $\ddot{0}$ & ○. & 8 & 8 & 8 & $\tilde{n}$ \\
\hline & $\varangle$ & مٌ & กี & $\frac{m}{0}$ & 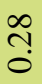 & $\frac{n}{0}$ & $\stackrel{\text { I }}{0}$ & ¿̊. & $\frac{\infty}{0}$ & $\stackrel{2}{0}$ & $\stackrel{2}{0}$ & $\stackrel{0}{0}$ & $\ddot{0}$ & $\stackrel{0}{0}$ & $\begin{array}{l}\sqrt{6} \\
i \\
\text { in }\end{array}$ \\
\hline & $\begin{array}{l}\bar{\Xi} \\
\bar{\Xi} \\
\end{array}$ & $\varangle$ & $\sim$ & U & D & 띠 & L & ט & $I$ & - & $r$ & $\mathscr{V}$ & \lrcorner & $\Sigma$ & స్తేర \\
\hline & & & & & & & & & & & & & & & \\
\hline
\end{tabular}

Appendix Table A.25 Accessibility indices for origin-destination pairs from raw job figures for three-mile buffer. Green, yellow, and red cells denote relatively high, medium, and low values, respectively. Blue cells denote row or column totals. The number of significant figures has been reduced to fit the table within the page. 


\begin{tabular}{|c|c|c|c|c|c|c|c|c|c|c|c|c|c|c|c|}
\hline \multirow{14}{*}{ 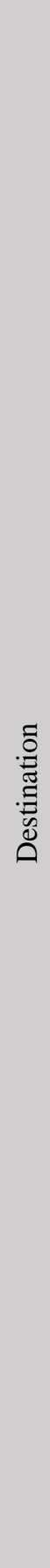 } & 苛 & $\stackrel{8}{8}$ & $\underset{8}{8}$ & $\underset{8}{8}$ & $\underset{8}{8}$ & $\underset{8}{8}$ & $\underset{8}{8}$ & $\underset{8}{8}$ & $\underset{8}{8}$ & $\underset{8}{8}$ & $\underset{8}{8}$ & $\underset{8}{8}$ & $\underset{8}{8}$ & $\underset{8}{8}$ & $\begin{array}{l}8 \\
\dot{\theta}\end{array}$ \\
\hline & $\Sigma$ & 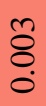 & $\begin{array}{l}8 \\
8 \\
0\end{array}$ & $\begin{array}{l}\text { षे } \\
\stackrel{0}{0}\end{array}$ & $\stackrel{n}{0}$ & $\stackrel{\nabla}{\circ}$ & సิ & $\stackrel{0}{\circ}$ & ত̃ & $\stackrel{\infty}{0}$ & $\stackrel{\infty}{\stackrel{\infty}{0}}$ & $\stackrel{\Gamma}{0}$ & 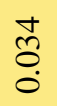 & $\stackrel{n}{\stackrel{n}{\circ}}$ & $\begin{array}{l}\hat{\sigma} \\
\hat{\sigma}\end{array}$ \\
\hline & \lrcorner & $\stackrel{8}{8}$ & $\stackrel{+}{\circ}$ & $\stackrel{\infty}{8}$ & 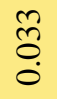 & ஜ̂. & 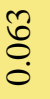 & 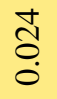 & $\begin{array}{l}8 \\
8\end{array}$ & 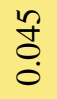 & $\stackrel{\tilde{n}}{0}$ & 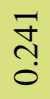 & $\begin{array}{l}8 \\
\infty \\
\infty \\
0\end{array}$ & $\stackrel{\hat{n}}{0}$ & $\begin{array}{l}\stackrel{\circ}{\infty} \\
\stackrel{0}{\circ}\end{array}$ \\
\hline & $\forall$ & $\stackrel{8}{8}$ & $\hat{8}$ & $\begin{array}{l}\mathscr{8} \\
\dot{0}\end{array}$ & $\stackrel{\infty}{\circ}$ & $\stackrel{\infty}{\stackrel{\infty}{0}}$ & $\stackrel{\overbrace{}}{\tilde{o}}$ & $\stackrel{m}{0}$ & $\stackrel{\hat{n}}{0}$ & 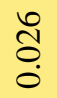 & $\frac{d}{0}$ & $\underset{0}{\stackrel{R}{0}}$ & $\begin{array}{l}\text { Oै } \\
\stackrel{0}{0} \\
\stackrel{0}{0}\end{array}$ & $\begin{array}{l}\stackrel{+}{0} \\
\stackrel{0}{0}\end{array}$ & $\stackrel{\infty}{\circ}$ \\
\hline & $\sim$ & $\overline{8}$ & $\begin{array}{l}\text { ठิ } \\
\text {. }\end{array}$ & $\begin{array}{l}\tilde{\delta} \\
\stackrel{0}{0}\end{array}$ & $\begin{array}{l}8 \\
8 \\
0\end{array}$ & $\hat{8}$ & $\stackrel{m}{0}$ & $\begin{array}{l}\mathscr{8} \\
\tilde{0}\end{array}$ & $\stackrel{\Delta}{\circ}$ & $\stackrel{N}{\circ}$ & $\begin{array}{l}n \\
\tilde{n} \\
\tilde{\sigma}\end{array}$ & $\stackrel{v}{\square}$ & $\begin{array}{l}\mathscr{8} \\
8 \\
0\end{array}$ & $\stackrel{8}{8}$ & $\begin{array}{l}\stackrel{0}{0} \\
\stackrel{0}{0} \\
\stackrel{0}{0}\end{array}$ \\
\hline & - & $\begin{array}{l}0 \\
\delta \\
0\end{array}$ & 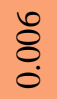 & $\begin{array}{l}+ \\
8 \\
0\end{array}$ & $\stackrel{r}{0}$ & $\frac{a}{0}$ & $\begin{array}{l}\text { Oे } \\
0 \\
0\end{array}$ & $\stackrel{5}{0}$ & $\begin{array}{l}0 \\
\stackrel{2}{0} \\
0\end{array}$ & $\begin{array}{l}\widetilde{\omega} \\
\infty \\
0 \\
0\end{array}$ & ஸै & $\begin{array}{l}\stackrel{0}{8} \\
\stackrel{0}{0}\end{array}$ & $\begin{array}{l}\mathscr{8} \\
\ddot{0}\end{array}$ & $\begin{array}{l}\hat{8} \\
0\end{array}$ & గ్రి \\
\hline & $I$ & 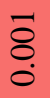 & 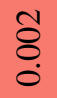 & 훙 & $\begin{array}{l}+ \\
\stackrel{0}{0} \\
0\end{array}$ & $\begin{array}{l}\stackrel{8}{0} \\
\dot{0}\end{array}$ & $\begin{array}{l}\stackrel{+}{0} \\
\text { Oִ } \\
0\end{array}$ & $\begin{array}{l}0 \\
\stackrel{0}{0} \\
0\end{array}$ & $\begin{array}{l}8 \\
\stackrel{0}{0} \\
\stackrel{0}{0}\end{array}$ & 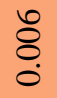 & $\begin{array}{l}\text { t) } \\
\stackrel{0}{0}\end{array}$ & 훙 & $\overrightarrow{8}$ & 훙 & $\begin{array}{l}\text { } \\
\text { ñ. } \\
0\end{array}$ \\
\hline & 0 & $\begin{array}{l}\stackrel{t}{8} \\
\stackrel{0}{0}\end{array}$ & $\begin{array}{l}0 \\
0 \\
0\end{array}$ & $\hat{8}$ & $\begin{array}{l}\text { n̂. } \\
\tilde{\delta} \\
0\end{array}$ & $\begin{array}{l}\overline{8} \\
0\end{array}$ & 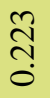 & $\begin{array}{l}\underset{N}{J} \\
0 \\
0\end{array}$ & $\frac{\hat{0}}{0}$ & $\begin{array}{l}\hat{\partial} \\
\dot{0}\end{array}$ & $\begin{array}{l}n \\
0 \\
0\end{array}$ & $\begin{array}{l}\text { ț } \\
0\end{array}$ & $\begin{array}{l}\text { } \\
\tilde{0}\end{array}$ & $\begin{array}{l}n \\
\tilde{o}\end{array}$ & $\stackrel{\infty}{\stackrel{\infty}{n}}$ \\
\hline & I & $\overrightarrow{8}$ & $\overrightarrow{8}$ & $\overline{8}$ & $\begin{array}{l}n \\
\tilde{o}\end{array}$ & $\frac{N}{0}$ & 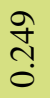 & $\begin{array}{l}\infty \\
\stackrel{8}{0} \\
0\end{array}$ & $\begin{array}{l}\text { } \\
\dot{0}\end{array}$ & $\begin{array}{l}\widetilde{\delta} \\
\stackrel{0}{0}\end{array}$ & $\overrightarrow{8}$ & $\begin{array}{l}8 \\
8 \\
0\end{array}$ & $\begin{array}{l}8 \\
8 \\
0\end{array}$ & $\begin{array}{l}8 \\
8 \\
0\end{array}$ & $\begin{array}{l}\text { के } \\
\text { ஸे }\end{array}$ \\
\hline & 工 & $\begin{array}{l}\widetilde{\delta} \\
\stackrel{0}{0}\end{array}$ & $\begin{array}{l}8 \\
8 \\
0\end{array}$ & $\begin{array}{l}+ \\
8 \\
0\end{array}$ & $\begin{array}{l}\widetilde{\Xi} \\
\text { ல̊ }\end{array}$ & 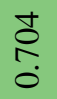 & $\frac{\tilde{O}}{0}$ & $\stackrel{\infty}{\circ}$ & 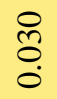 & $\hat{8}$ & $\begin{array}{l}8 \\
8 \\
0\end{array}$ & $\begin{array}{l}\tilde{\delta} \\
\dot{0}\end{array}$ & $\overrightarrow{8}$ & $\begin{array}{l}\tilde{\delta} \\
\text {. }\end{array}$ & $\begin{array}{l}\hat{8} \\
\stackrel{0}{0}\end{array}$ \\
\hline & D & 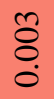 & $\hat{8}$ & $\underset{8}{0}$ & $\begin{array}{l}\text { ț } \\
\stackrel{0}{0}\end{array}$ & $\begin{array}{l}\infty \\
\stackrel{0}{0} \\
0\end{array}$ & $\stackrel{n}{0}$ & $\begin{array}{l}\text { ț } \\
\stackrel{0}{0}\end{array}$ & $\stackrel{\infty}{8}$ & $\begin{array}{l}\text { ठิ } \\
\text {. }\end{array}$ & $\begin{array}{l}\text { ठै } \\
\text { }\end{array}$ & $\overrightarrow{8}$ & $\begin{array}{l}8 \\
8\end{array}$ & $\begin{array}{l}\overline{8} \\
0\end{array}$ & \begin{tabular}{l}
\multirow{0}{0}{} \\
$\stackrel{0}{0}$
\end{tabular} \\
\hline & $u$ & $\begin{array}{l}\text { ஸे } \\
\stackrel{0}{0}\end{array}$ & $\frac{\beta}{0}$ & $\underset{\substack{+0 \\
0}}{0}$ & $\begin{array}{l}\overline{0} \\
\text { ִָ }\end{array}$ & $\begin{array}{l}\bar{n} \\
0 \\
0\end{array}$ & ồ & 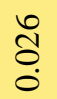 & $\begin{array}{l}\stackrel{+}{0} \\
\stackrel{0}{0}\end{array}$ & $\stackrel{0}{\circ}$ & $\begin{array}{l}- \\
ٍ \\
0\end{array}$ & $\begin{array}{l}n \\
\delta \\
0\end{array}$ & $\stackrel{\text { }}{8}$ & $\begin{array}{l}8 \\
8 \\
0 \\
0\end{array}$ & $\stackrel{?}{n}$ \\
\hline & $n$ & $\begin{array}{l}\text { + } \\
\text { : }\end{array}$ & $\frac{n}{n}$ & $\begin{array}{l}\widetilde{Z} \\
\text { đ̊. }\end{array}$ & $\stackrel{t}{\stackrel{t}{0}}$ & $\stackrel{\Delta}{\circ}$ & $\begin{array}{l}\text { İ } \\
\stackrel{0}{0}\end{array}$ & $\stackrel{\infty}{8}$ & $\begin{array}{l}0 \\
0 \\
0\end{array}$ & $\stackrel{n}{8}$ & $\stackrel{n}{8}$ & 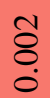 & $\begin{array}{l}\overline{8} \\
\stackrel{0}{0}\end{array}$ & $\begin{array}{l}\text { ô } \\
0 \\
0\end{array}$ & $\begin{array}{l}\overline{0} \\
0\end{array}$ \\
\hline & $\ll$ & হ్̊ి & $\begin{array}{l}\text { तै } \\
\text { ?ุ }\end{array}$ & $\begin{array}{l}\text { है } \\
\text { है }\end{array}$ & $\frac{n}{2}$ & $\begin{array}{l}0 \\
\stackrel{0}{0} \\
0\end{array}$ & $\begin{array}{l}8 \\
\stackrel{8}{\circ} \\
\stackrel{0}{0}\end{array}$ & $\stackrel{\widehat{o}}{\stackrel{0}{0}}$ & $\begin{array}{l}0 \\
\qquad \\
0\end{array}$ & $\stackrel{\infty}{0}$ & 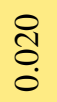 & 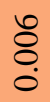 & $\begin{array}{l}\dot{8} \\
\stackrel{8}{0}\end{array}$ & 용 & $\stackrel{\mathfrak{o}}{\stackrel{n}{0}}$ \\
\hline & $\begin{array}{l}\bar{\nabla} \\
\text { త్ }\end{array}$ & $\ll$ & $\infty$ & $u$ & D & 띠 & IL & 0 & 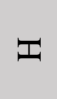 & - & $\sim$ & $\mathscr{V}$ & \lrcorner & $\Sigma$ & 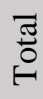 \\
\hline & & & & & & & & & & & & & & & \\
\hline
\end{tabular}

Appendix Table A.26 Accessibility indices for origin-destination pairs from raw population figures for three-mile buffer. Green, yellow, and red cells denote relatively high, medium, and low values, respectively. Blue cells denote row or column totals. 


\begin{tabular}{|c|c|c|c|c|c|c|c|c|c|c|c|c|c|c|c|}
\hline \multirow{14}{*}{ 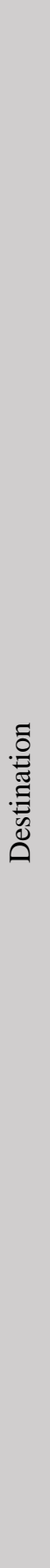 } & 胥 & $\underset{8}{8}$ & $\underset{8}{8}$ & $\stackrel{8}{8}$ & $\underset{-}{8}$ & $\underset{8}{8}$ & $\underset{8}{8}$ & $\underset{8}{8}$ & $\underset{8}{8}$ & $\underset{8}{8}$ & $\underset{8}{8}$ & $\underset{8}{8}$ & $\underset{8}{8}$ & $\underset{8}{8}$ & $\begin{array}{l}\delta \\
\ddot{\delta} \\
\ddot{2}\end{array}$ \\
\hline & $\Sigma$ & $\begin{array}{l}\text { ㅇ. } \\
\stackrel{0}{0} \\
\stackrel{0}{0}\end{array}$ & $\begin{array}{l}8 \\
8 \\
0\end{array}$ & $\begin{array}{l}\stackrel{+}{8} \\
\stackrel{0}{0}\end{array}$ & $\stackrel{n}{0}$ & $\stackrel{ \pm}{\stackrel{\Xi}{0}}$ & $\begin{array}{l}\hat{O} \\
\text {. }\end{array}$ & $\begin{array}{l}8 \\
\text { ọ } \\
\dot{0}\end{array}$ & ஜ্ণ & $\stackrel{\infty}{0}$ & $\stackrel{\substack{+ٍ}}{\stackrel{+}{0}}$ & $\stackrel{0}{\circ}$ & గొ & 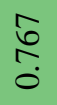 & $\begin{array}{l}\stackrel{0}{\infty} \\
\stackrel{0}{0}\end{array}$ \\
\hline & \lrcorner & $\begin{array}{l}8 \\
8 \\
\stackrel{0}{0}\end{array}$ & $\frac{n}{0}$ & $\begin{array}{l}\stackrel{8}{8} \\
\stackrel{0}{0}\end{array}$ & $\begin{array}{l}0 \\
\text { రి } \\
0 \\
0\end{array}$ & 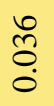 & $\stackrel{0}{\circ}$ & $\stackrel{\overbrace{}}{\tilde{o}}$ & 今̊ & 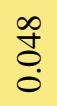 & $\begin{array}{l}\bar{\sigma} \\
\dot{0}\end{array}$ & $\stackrel{\infty}{\stackrel{\infty}{ు}}$ & $\begin{array}{l}\text { ○ } \\
\infty \\
\infty \\
0\end{array}$ & $\frac{\nexists}{\dot{D}}$ & 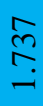 \\
\hline & 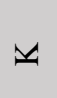 & $\stackrel{8}{8}$ & $\hat{8}$ & $\stackrel{\leftrightarrow}{8}$ & $\stackrel{a}{\circ}$ & $\stackrel{a}{0}$ & $\begin{array}{l}0 \\
\text { On } \\
0\end{array}$ & $\stackrel{\sim}{0}$ & $\begin{array}{l}\text { İ } \\
\text { Oे }\end{array}$ & $\begin{array}{l}\hat{\widehat{O}} \\
\dot{0}\end{array}$ & $\frac{8}{\stackrel{0}{0}}$ & $\begin{array}{l}n \\
\hat{o} \\
0\end{array}$ & مิ & 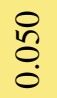 & 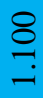 \\
\hline & $\neg$ & $\begin{array}{l}\bar{\delta} \\
\stackrel{0}{0}\end{array}$ & 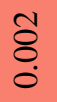 & $\begin{array}{l}0 \\
\delta \\
0\end{array}$ & 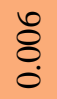 & $\stackrel{0}{8}$ & $\stackrel{m}{0}$ & $\begin{array}{l}\mathscr{8} \\
\delta \\
0\end{array}$ & $\frac{0}{0}$ & $\stackrel{\sim}{\circ}$ & $\begin{array}{l}m \\
\infty \\
n \\
0\end{array}$ & $\bar{\sigma}$ & $\begin{array}{l}\mathscr{8} \\
\stackrel{0}{0}\end{array}$ & $\stackrel{0}{8}$ & $\begin{array}{l}\stackrel{0}{0} \\
\stackrel{0}{0}\end{array}$ \\
\hline & - & $\begin{array}{l}0 \\
\tilde{0}\end{array}$ & $\begin{array}{l}8 \\
\stackrel{0}{0}\end{array}$ & ${ }_{0}^{t}$ & $\stackrel{\sigma}{0}$ & $\stackrel{a}{\partial}$ & $\begin{array}{l}\text { Pे } \\
\stackrel{0}{0} \\
0\end{array}$ & $\begin{array}{l}0 \\
0 \\
0\end{array}$ & $\begin{array}{l}\widetilde{o} \\
\stackrel{0}{0}\end{array}$ & $\begin{array}{l}\vec{\delta} \\
0 \\
0\end{array}$ & ठै. & $\hat{8}$ & $\begin{array}{l}+ \\
8 \\
0\end{array}$ & $\hat{8}$ & ఠે \\
\hline & $I$ & $\begin{array}{l}\overline{8} \\
\dot{0}\end{array}$ & $\overline{8}$ & $\begin{array}{l}\overline{8} \\
\dot{0}\end{array}$ & $\stackrel{8}{8}$ & $\stackrel{8}{8}$ & $\stackrel{\infty}{\circ}$ & $\bar{\sigma}$ & $\begin{array}{l}\stackrel{0}{\infty} \\
\text { ?ִ }\end{array}$ & $\stackrel{+}{8}$ & $\begin{array}{l}\text { } \\
\hat{\delta}\end{array}$ & $\begin{array}{l}\overline{8} \\
0\end{array}$ & $\begin{array}{l}8 \\
8 \\
0\end{array}$ & $\begin{array}{l}\overline{8} \\
0\end{array}$ & $\stackrel{\widetilde{f}}{\stackrel{0}{0}}$ \\
\hline & 0 & $\stackrel{8}{8}$ & $\begin{array}{l}\overline{0} \\
0 \\
0\end{array}$ & $\stackrel{\infty}{8}$ & $\begin{array}{l}\stackrel{9}{0} \\
0 \\
0\end{array}$ & $\stackrel{\leftrightarrow}{0}$ & 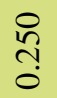 & $\begin{array}{l}m \\
\infty \\
0 \\
0\end{array}$ & 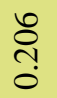 & 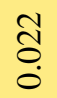 & $\stackrel{1}{0}$ & $\stackrel{n}{8}$ & $\stackrel{8}{8}$ & $\stackrel{n}{8}$ & $\stackrel{\substack{\infty \\
-}}{+}$ \\
\hline & II & $\begin{array}{l}8 \\
0 \\
0\end{array}$ & $\begin{array}{l}\overline{8} \\
\stackrel{0}{0}\end{array}$ & ठ্ণ & $\begin{array}{l}\text { ¿ } \\
\stackrel{0}{0}\end{array}$ & $\overrightarrow{0}$ & $\begin{array}{l}\text { तె } \\
\text { Oे }\end{array}$ & ồ & $\stackrel{8}{0}$ & ¿্口 & ¿̊. & \&: & $\begin{array}{l}8 \\
0 \\
0\end{array}$ & \begin{tabular}{l}
8 \\
\hdashline \\
0
\end{tabular} & $\begin{array}{l}\text { ț } \\
\text { గె }\end{array}$ \\
\hline & 피 & $\stackrel{\text { ô }}{0}$ & $\stackrel{8}{8}$ & $\stackrel{t}{8}$ & $\stackrel{\vec{\delta}}{\stackrel{0}{0}}$ & $\begin{array}{l}\bar{b} \\
\dot{0}\end{array}$ & $\stackrel{\partial}{0}$ & $\begin{array}{l}0 \\
0 \\
0\end{array}$ & চூ & $\stackrel{8}{8}$ & $\stackrel{8}{8}$ & $\stackrel{\text { ô }}{0}$ & $\overline{8}$ & 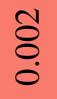 & $\begin{array}{l}\widehat{\infty} \\
\infty \\
\infty \\
0\end{array}$ \\
\hline & D & 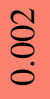 & $\begin{array}{l}\hat{8} \\
0\end{array}$ & 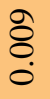 & ले & $\begin{array}{l}\infty \\
\stackrel{0}{0} \\
0\end{array}$ & $\stackrel{n}{a}$ & $\begin{array}{l}\text { ¿ } \\
8 \\
0\end{array}$ & $\stackrel{8}{8}$ & $\begin{array}{l}\text { ô } \\
\text {. }\end{array}$ & $\begin{array}{l}\text { ô } \\
0\end{array}$ & $\overline{8}$ & $\begin{array}{l}8 \\
8 \\
0\end{array}$ & $\overline{8}$ & iे \\
\hline & $u$ & $\stackrel{\mathscr{c}}{\mathscr{\delta}}$ & $\begin{array}{l}\stackrel{d}{0} \\
\stackrel{0}{0}\end{array}$ & $\begin{array}{c}\mathbb{N} \\
\infty \\
0 \\
0\end{array}$ & $\begin{array}{l}\text { ¿े } \\
\text { ị }\end{array}$ & है & $\stackrel{n}{0}$ & $\begin{array}{l}\text { d̦ } \\
\text { Oे }\end{array}$ & $\begin{array}{l}\infty \\
\tilde{o} \\
0 \\
0\end{array}$ & $\stackrel{0}{0}$ & 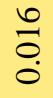 & $\stackrel{n}{0}$ & $\stackrel{8}{0}$ & $\begin{array}{l}8 \\
\& \\
0\end{array}$ & $\stackrel{\text { Ĩ }}{n}$ \\
\hline & $ص$ & $\begin{array}{l}\infty \\
\stackrel{\infty}{0} \\
0\end{array}$ & $\begin{array}{l}n \\
n \\
n \\
0 \\
0\end{array}$ & 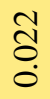 & $\stackrel{?}{\stackrel{O}{0}}$ & $\stackrel{\Delta}{\stackrel{\Delta}{0}}$ & $\begin{array}{l}\text { ڤै } \\
\text { ô. } \\
0\end{array}$ & $\hat{8}$ & $\stackrel{1}{0}$ & $\begin{array}{l}\mathscr{8} \\
\dot{0}\end{array}$ & ஜे & 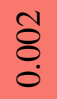 & $\overline{8}$ & 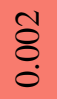 & 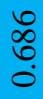 \\
\hline & $\ll$ & $\begin{array}{l}\text { m} \\
\text { ᄋ̆ }\end{array}$ & సે & 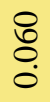 & $\frac{\hat{m}}{0}$ & $\begin{array}{l}\bar{n} \\
\stackrel{0}{0}\end{array}$ & oे & $\begin{array}{l}\tilde{o} \\
\text { ô }\end{array}$ & $\begin{array}{l}\mathscr{b} \\
\ddot{0}\end{array}$ & $\stackrel{\infty}{0}$ & $\begin{array}{l}\stackrel{0}{~} \\
\stackrel{0}{0}\end{array}$ & $\begin{array}{l}8 \\
8 \\
0\end{array}$ & $\begin{array}{l}\stackrel{\Xi}{8} \\
\stackrel{0}{0}\end{array}$ & $\hat{8}$ & $\stackrel{m}{=}$ \\
\hline & $\begin{array}{l}\overline{\mathcal{v}} \\
\text { J్త }\end{array}$ & $\ll$ & 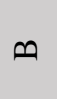 & $U$ & D & 띠 & I & 0 & $I$ & $\neg$ & $\neg$ & 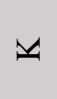 & 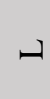 & $\Sigma$ & 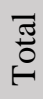 \\
\hline & & & & & & & & & & & & & & & \\
\hline
\end{tabular}

Appendix Table A.27 Accessibility indices for origin-destination pairs from raw housing unit figures for three-mile buffer. Green, yellow, and red cells denote relatively high, medium, and low values, respectively. Blue cells denote row or column totals. 


\begin{tabular}{|c|c|c|c|c|c|c|c|c|c|c|c|c|c|c|c|}
\hline \multirow{14}{*}{ 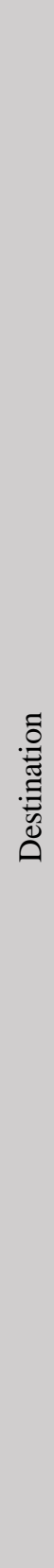 } & $\underset{\tilde{0}}{\tilde{\sigma}}$ & $\underset{8}{8}$ & $\stackrel{8}{8}$ & $\underset{8}{8}$ & $\underset{8}{8}$ & $\stackrel{8}{8}$ & $\underset{8}{8}$ & $\underset{-}{8}$ & $\underset{-}{8}$ & $\underset{8}{8}$ & $\underset{-}{8}$ & $\underset{8}{8}$ & $\underset{-}{8}$ & $\underset{8}{8}$ & $\begin{array}{l}8 \\
\ddot{2}\end{array}$ \\
\hline & $\Sigma$ & $\stackrel{8}{8}$ & $\begin{array}{l}\text { ô } \\
\stackrel{\leftrightarrow}{0}\end{array}$ & $\stackrel{0}{0}$ & $\stackrel{8}{\circ}$ & $\stackrel{8}{8}$ & $\stackrel{8}{\circ}$ & $\stackrel{8}{\circ}$ & $\stackrel{8}{0}$ & $\begin{array}{l}\overrightarrow{0} \\
\dot{0}\end{array}$ & 号 & 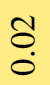 & 뭉 & $\tilde{0}$ & $\stackrel{?}{\circ}$ \\
\hline & 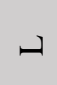 & $\stackrel{8}{8}$ & $\frac{m}{\dot{p}}$ & $\stackrel{0}{0}$ & $\begin{array}{l}\text { ô } \\
\text { Q }\end{array}$ & $\begin{array}{l}1 \\
0 \\
0\end{array}$ & $\begin{array}{l}0 \\
0 \\
\stackrel{p}{0}\end{array}$ & $\begin{array}{l}0 \\
0 \\
0\end{array}$ & $\begin{array}{l}\text { ô } \\
\text { p. }\end{array}$ & $\begin{array}{l}\hat{0} \\
\dot{0}\end{array}$ & $\frac{\text { I }}{\stackrel{1}{0}}$ & $\frac{n}{0}$ & $\underset{-}{8}$ & $\begin{array}{l}\text { ?. } \\
\text { ?’ }\end{array}$ & $\stackrel{ \pm}{\stackrel{t}{*}}$ \\
\hline & $\breve{v}$ & $\stackrel{8}{\circ}$ & $\begin{array}{l}\overline{0} \\
\dot{0}\end{array}$ & $\stackrel{0}{0}$ & $\stackrel{8}{\circ}$ & $\stackrel{8}{8}$ & $\stackrel{8}{\circ}$ & $\stackrel{8}{\circ}$ & $\stackrel{8}{\circ}$ & $\begin{array}{l}0 \\
\dot{0} \\
\end{array}$ & 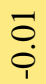 & $\hat{n}$ & $\stackrel{\sigma}{0}$ & $\stackrel{d}{O}$ & $\hat{n}$ \\
\hline & $\sim$ & 8 & $\stackrel{n}{\circ}$ & mọ. & ठㅁ. & $\stackrel{\sigma}{\circ}$ & ठ․ & $\begin{array}{l}\text { Oे. } \\
\text {. }\end{array}$ & $\ddot{\circ}$ & $\stackrel{n}{\circ}$ & 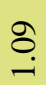 & 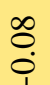 & 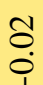 & $\begin{array}{l}I \\
0\end{array}$ & so. \\
\hline & 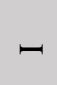 & $\stackrel{8}{\circ}$ & $\stackrel{+}{0}$ & $\begin{array}{l}\text { O̦ } \\
0 \\
\end{array}$ & $\stackrel{\overrightarrow{0}}{0}$ & $\stackrel{\sigma}{\circ}$ & $\stackrel{\sigma}{0}$ & 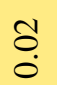 & $\stackrel{\sigma}{0}$ & Oे & $\stackrel{0}{0}$ & $\begin{array}{l}\text { O̦ } \\
0 \\
\end{array}$ & $\stackrel{8}{\circ}$ & ọ. & ڤे \\
\hline & $I$ & $\stackrel{8}{8}$ & 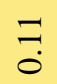 & $\begin{array}{l}8 \\
0 \\
0\end{array}$ & $\ddot{0}$ & $\stackrel{\wp}{0}$ & $\stackrel{t}{0}$ & $\frac{1}{0}$ & $\bar{\sigma}$ & $\stackrel{\leftrightarrow}{0}$ & ס̊ & $\begin{array}{l}\text { ô } \\
\stackrel{0}{0}\end{array}$ & $\stackrel{8}{\circ}$ & $\begin{array}{l}\text { ô } \\
\stackrel{0}{0}\end{array}$ & $\stackrel{\infty}{\rightleftarrows}$ \\
\hline & 0 & $\stackrel{8}{8}$ & $\stackrel{8}{0}$ & $\begin{array}{l}\text { do } \\
\stackrel{0}{1}\end{array}$ & $\underset{0}{\tilde{0}}$ & 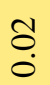 & $\stackrel{+}{0}$ & $\stackrel{\mathbb{N}}{\tilde{0}}$ & $\stackrel{+}{0}$ & 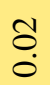 & $\stackrel{0}{0}$ & $\begin{array}{l}0 \\
0 \\
\end{array}$ & $\stackrel{8}{\circ}$ & $\begin{array}{l}0 \\
0 \\
0\end{array}$ & ஸ્ \\
\hline & L & $\begin{array}{l}0 \\
0 \\
0\end{array}$ & $\frac{n}{0}$ & $\frac{0}{\stackrel{0}{p}}$ & $\stackrel{m}{0}$ & $\stackrel{\circ}{\circ}$ & $\begin{array}{l}\infty \\
\infty \\
0\end{array}$ & $\frac{m}{0}$ & $\underset{0}{\stackrel{0}{0}}$ & $\stackrel{\text { ڤె. }}{0}$ & $\sigma_{0}^{0}$ & $\begin{array}{l}\text { ô } \\
0\end{array}$ & $\stackrel{8}{\circ}$ & $\begin{array}{l}0 \\
0 \\
0\end{array}$ & 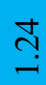 \\
\hline & LI & $\stackrel{8}{8}$ & $\frac{1}{0}$ & $\begin{array}{l}\infty \\
0 \\
0\end{array}$ & $\stackrel{\text { Oे }}{0}$ & $\begin{array}{l}\infty \\
\infty \\
0\end{array}$ & $\stackrel{0}{\circ}$ & $\stackrel{0}{0}$ & $\stackrel{1}{\delta}$ & $\stackrel{\text { Oे }}{0}$ & $\underset{0}{0}$ & $\begin{array}{l}\sigma \\
\stackrel{0}{0}\end{array}$ & $\stackrel{8}{\circ}$ & $\begin{array}{l}0 \\
0 \\
0\end{array}$ & $\stackrel{8}{\text { a }}$ \\
\hline & D & 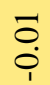 & กֶ? & $\begin{array}{l}+ \\
\text { mo }\end{array}$ & $\stackrel{\wp}{0}$ & 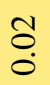 & 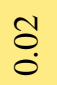 & $\stackrel{8}{0}$ & ¿̈. & 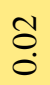 & $\underset{0}{0}$ & ¿. & $\stackrel{8}{\circ}$ & $\begin{array}{l}0 \\
\stackrel{0}{0}\end{array}$ & $\stackrel{8}{\circ}$ \\
\hline & $u$ & $\stackrel{8}{8}$ & $\frac{n}{\dot{p}}$ & $\stackrel{\circ}{\circ}$ & $\begin{array}{l}0 \\
0 \\
\stackrel{\varphi}{0}\end{array}$ & $\stackrel{8}{8}$ & $\stackrel{8}{8}$ & $\begin{array}{l}\overrightarrow{0} \\
\stackrel{\varphi}{1}\end{array}$ & $\stackrel{8}{8}$ & $\stackrel{8}{8}$ & $\stackrel{8}{8}$ & $\stackrel{8}{8}$ & 8 & $\stackrel{8}{8}$ & $\stackrel{\infty}{\infty}$ \\
\hline & $\infty$ & ô. & $\frac{n}{n}$ & $\frac{\infty}{\dot{0}}$ & 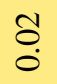 & ō & $\stackrel{\overline{0}}{\circ}$ & $\stackrel{\overline{0}}{\circ}$ & $\stackrel{\overline{0}}{\circ}$ & $\stackrel{\overline{0}}{\circ}$ & $\stackrel{8}{\stackrel{0}{0}}$ & ō. & $\begin{array}{l}8 \\
\stackrel{0}{0}\end{array}$ & oم & $\stackrel{\partial}{\dot{\sigma}}$ \\
\hline & $\ll$ & $\stackrel{n}{0}$ & $\begin{array}{l}\text { bे } \\
\dot{+}\end{array}$ & $\frac{R}{0}$ & $=$ & $\begin{array}{l}\text { ț } \\
\stackrel{0}{1}\end{array}$ & $\begin{array}{l}\dot{0} \\
\stackrel{0}{0}\end{array}$ & $\begin{array}{l}n \\
0 \\
0\end{array}$ & $\begin{array}{l}0 \\
0 \\
\end{array}$ & $\begin{array}{l}\text { ț } \\
\stackrel{0}{1}\end{array}$ & $\begin{array}{l}\text { ô } \\
\text { í }\end{array}$ & $\stackrel{\overbrace{}}{0}$ & $\overline{0}$ & $\stackrel{0}{0}$ & $\underset{\sim}{\vec{i}}$ \\
\hline & $\begin{array}{l}\bar{\Xi} \\
\bar{\Xi} \\
\end{array}$ & $\ll$ & 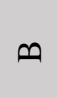 & $u$ & D & L & IL & 0 & 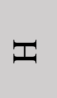 & - & $\neg$ & $\checkmark$ & \lrcorner & $\Sigma$ & స్ّ \\
\hline & & & & & & & & & & & & & & & \\
\hline
\end{tabular}

Appendix Table A.28 Accessibility indices for origin-destination pairs from normalized job figures for

three-mile buffer. Green, yellow, and red cells denote relatively high, medium, and low values, respectively. Blue cells denote row or column totals. 


\begin{tabular}{|c|c|c|c|c|c|c|c|c|c|c|c|c|c|c|c|}
\hline \multirow{14}{*}{ 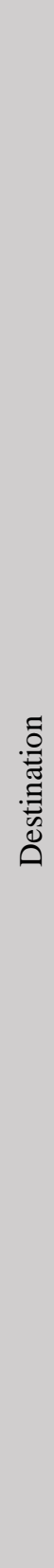 } & 퓽 & $\underset{8}{8}$ & $\stackrel{8}{8}$ & $\stackrel{8}{8}$ & $\stackrel{8}{8}$ & $\stackrel{8}{8}$ & $\underset{8}{8}$ & $\stackrel{8}{8}$ & $\underset{8}{8}$ & $\stackrel{8}{8}$ & $\underset{8}{8}$ & $\underset{\sim}{8}$ & $\underset{-}{8}$ & $\underset{8}{8}$ & $\begin{array}{l}8 \\
\stackrel{0}{2}\end{array}$ \\
\hline & $\Sigma$ & $\stackrel{8}{\circ}$ & $\begin{array}{l}0 \\
0 \\
\end{array}$ & $\stackrel{8}{\circ}$ & $\stackrel{8}{8}$ & $\stackrel{8}{\circ}$ & $\stackrel{8}{\circ}$ & $\begin{array}{l}\overline{0} \\
\stackrel{0}{0}\end{array}$ & $\stackrel{8}{\circ}$ & $\begin{array}{l}0 \\
\text { ô } \\
\stackrel{i}{1}\end{array}$ & $\begin{array}{l}0 \\
\dot{Q}\end{array}$ & $\ddot{\circ}$ & $\ddot{\circ}$ & $\stackrel{\widehat{o}}{\circ}$ & $\begin{array}{l}\stackrel{t}{0} \\
\stackrel{0}{0}\end{array}$ \\
\hline & \lrcorner & $\stackrel{\overline{0}}{\circ}$ & $\begin{array}{l}8 \\
\stackrel{1}{1}\end{array}$ & 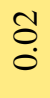 & $\begin{array}{l}\ddot{0} \\
\stackrel{\varphi}{1}\end{array}$ & $\begin{array}{l}0 \\
\stackrel{0}{0} \\
\stackrel{1}{1}\end{array}$ & $\begin{array}{l}0 \\
\dot{\varphi}\end{array}$ & $\begin{array}{l}8 \\
\stackrel{1}{1}\end{array}$ & $\begin{array}{l}0 \\
\stackrel{0}{0}\end{array}$ & $\frac{\Delta}{\dot{P}}$ & $\frac{ \pm}{\dot{Q}}$ & $\stackrel{\text { Oீ. }}{\stackrel{0}{0}}$ & $\hat{a}$ & ?ִ & $\stackrel{m}{\dddot{m}}$ \\
\hline & $\forall$ & $\stackrel{8}{8}$ & $\begin{array}{l}\overline{0} \\
\stackrel{p}{\varphi}\end{array}$ & $\stackrel{8}{8}$ & $\stackrel{8}{8}$ & 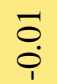 & $\stackrel{8}{8}$ & $\begin{array}{l}\overline{0} \\
\stackrel{0}{\varphi}\end{array}$ & $\begin{array}{l}0 \\
\dot{0}\end{array}$ & $\begin{array}{l}\dot{I} \\
\stackrel{0}{0}\end{array}$ & $\begin{array}{l}\text { ț } \\
\dot{0}\end{array}$ & $\begin{array}{l}\bar{b} \\
\dot{0}\end{array}$ & $\stackrel{\Delta}{0}$ & $\stackrel{\circ}{\circ}$ & ஜุ \\
\hline & $\sim$ & $\stackrel{8}{8}$ & 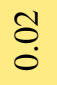 & $\begin{array}{l}0 \\
0 \\
\end{array}$ & $\stackrel{\overrightarrow{0}}{\circ}$ & $\stackrel{0}{0}$ & $\stackrel{\overline{0}}{\circ}$ & $\stackrel{\text { Oి }}{0}$ & $\stackrel{\overline{0}}{\circ}$ & $\stackrel{\infty}{\circ}$ & $\stackrel{\Xi}{\Xi}$ & $\begin{array}{l}n \\
0 \\
\dot{0}\end{array}$ & $\begin{array}{l}\overrightarrow{0} \\
\stackrel{0}{0}\end{array}$ & $\begin{array}{l}\dot{0} \\
\stackrel{0}{0}\end{array}$ & $\stackrel{\infty}{=}$ \\
\hline & $\neg$ & $\stackrel{8}{8}$ & $\stackrel{\overline{0}}{\circ}$ & $\stackrel{8}{8}$ & $\stackrel{8}{8}$ & $\stackrel{8}{8}$ & $\stackrel{8}{8}$ & $\stackrel{\overline{0}}{\circ}$ & $\stackrel{\sigma}{0}$ & $\stackrel{\text { के }}{0}$ & $\stackrel{\square}{0}$ & ọ. & $\stackrel{8}{8}$ & ọ̄. & $\tilde{o}$ \\
\hline & $I$ & $\begin{array}{l}\overline{0} \\
\dot{0}\end{array}$ & $\stackrel{n}{0}$ & 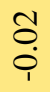 & $\stackrel{\circ}{\circ}$ & $\stackrel{\Delta}{0}$ & $\stackrel{t}{\stackrel{d}{0}}$ & 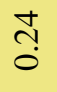 & ठ̀. & $\frac{1}{0}$ & 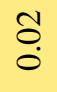 & 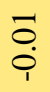 & $\begin{array}{l}0 \\
0 \\
0\end{array}$ & $\begin{array}{l}\text { ô } \\
\text { Q }\end{array}$ & $\stackrel{f}{\rightarrow}$ \\
\hline & 0 & $\stackrel{8}{\circ}$ & $\stackrel{\bar{\sigma}}{\circ}$ & $\stackrel{8}{8}$ & $\stackrel{8}{\circ}$ & $\stackrel{\square}{\circ}$ & ō & $\stackrel{?}{\stackrel{0}{0}}$ & $\stackrel{\overline{0}}{\circ}$ & $\stackrel{\overline{0}}{\circ}$ & $\stackrel{8}{8}$ & $\stackrel{8}{\circ}$ & $\stackrel{8}{\circ}$ & $\stackrel{8}{8}$ & $\stackrel{\infty}{+}$ \\
\hline & IL & $\begin{array}{l}0 \\
0 \\
0\end{array}$ & $\stackrel{\infty}{\stackrel{0}{0}}$ & 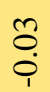 & $\stackrel{3}{0}$ & $\frac{1}{0}$ & ô & ஜ̂. & $\stackrel{2}{2}$ & $\stackrel{\infty}{\stackrel{0}{0}}$ & $\stackrel{\leftrightarrow}{\circ}$ & ọ. & $\stackrel{8}{8}$ & ô. & $\stackrel{n}{n}$ \\
\hline & 디 & $\begin{array}{l}\overline{0} \\
\stackrel{\varphi}{i}\end{array}$ & $\stackrel{n}{\circ}$ & 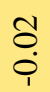 & 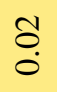 & $\begin{array}{l}\circ \\
\infty \\
0\end{array}$ & $\stackrel{\leftrightarrow}{\circ}$ & $\stackrel{8}{\circ}$ & 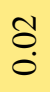 & $\stackrel{t}{0}$ & $\stackrel{\Xi}{0}$ & $\begin{array}{l}0 \\
0\end{array}$ & $\stackrel{8}{\circ}$ & ¿ొ. & $\stackrel{g}{\circ}$ \\
\hline & D & $\begin{array}{l}0 \\
0 \\
\end{array}$ & $\frac{1}{0}$ & $\begin{array}{l}0 \\
0 \\
0\end{array}$ & $\stackrel{n}{\circ}$ & $\stackrel{0}{0}$ & 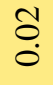 & $\stackrel{\circ}{\circ}$ & $\stackrel{\sigma}{o}$ & $\stackrel{+}{0}$ & $\ddot{\circ}$ & ö & $\stackrel{8}{8}$ & ö & 오 \\
\hline & $u$ & 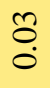 & 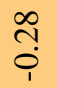 & $\stackrel{8}{g}$ & $\begin{array}{l}0 \\
0 \\
\end{array}$ & $\begin{array}{l}\text { ô } \\
\stackrel{0}{0}\end{array}$ & $\begin{array}{l}\overline{0} \\
\dot{\varphi}\end{array}$ & $\begin{array}{l}\dot{0} \\
\stackrel{0}{0}\end{array}$ & $\begin{array}{l}0 \\
0 \\
0\end{array}$ & $\stackrel{\text { Oִ }}{0}$ & $\begin{array}{l}0 \\
0 \\
0\end{array}$ & $\stackrel{\Xi}{0}$ & $\stackrel{8}{\circ}$ & $\stackrel{\overline{0}}{\circ}$ & $\begin{array}{l}\stackrel{8}{\circ} \\
\stackrel{0}{0}\end{array}$ \\
\hline & 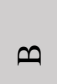 & $\begin{array}{l}n \\
0 \\
0\end{array}$ & $\frac{i}{i}$ & $\begin{array}{l}\text { J } \\
\stackrel{0}{0}\end{array}$ & 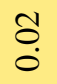 & 뭉 & ō & 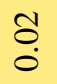 & $\stackrel{\overline{0}}{\circ}$ & 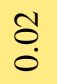 & $\stackrel{\square}{0}$ & $\stackrel{8}{8}$ & $\stackrel{8}{\circ}$ & : & $\stackrel{ \pm}{i}$ \\
\hline & $\ll$ & $\stackrel{\text { }}{\circ}$ & $\frac{9}{7}$ & $\frac{0}{0}$ & $\begin{array}{l}n \\
0 \\
0\end{array}$ & $\begin{array}{l}0 \\
0 \\
0\end{array}$ & $\begin{array}{l}0 \\
0 \\
0\end{array}$ & $\begin{array}{l}0 \\
0 \\
\end{array}$ & 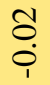 & $\begin{array}{l}n \\
0 \\
\stackrel{1}{0}\end{array}$ & $\begin{array}{l}0 \\
0 \\
0\end{array}$ & ö. & $\stackrel{8}{\circ}$ & ơ & $\begin{array}{l}\stackrel{ \pm}{\sim} \\
\stackrel{1}{1}\end{array}$ \\
\hline & $\begin{array}{l}\overline{\mathcal{D}} \\
\text { త్త్త }\end{array}$ & $\varangle$ & 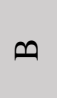 & $u$ & D & 디 & IL & 0 & $I$ & - & $r$ & $\mathscr{V}$ & \lrcorner & $\Sigma$ & $\stackrel{\bar{\sigma}}{\stackrel{5}{\circ}}$ \\
\hline & & & & & & & & & & & & & & & \\
\hline
\end{tabular}

Appendix Table A.29 Accessibility indices for origin-destination pairs from normalized population figures for three-mile buffer. Green, yellow, and red cells denote relatively high, medium, and low values, respectively. Blue cells denote row or column totals. 


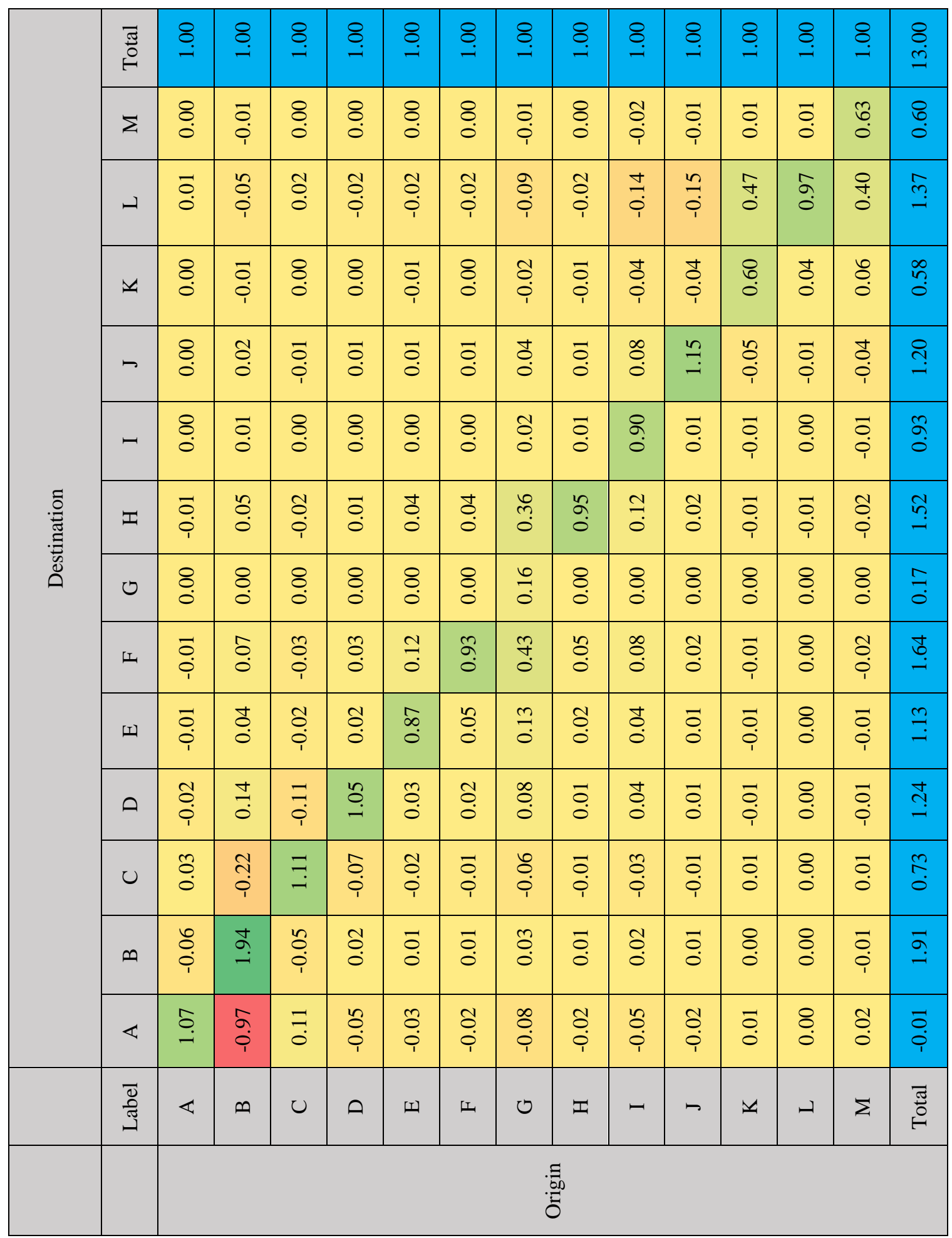

Appendix Table A.30 Accessibility indices for origin-destination pairs from normalized housing unit figures for three-mile buffer. Green, yellow, and red cells denote relatively high, medium, and low values,

respectively. Blue cells denote row or column totals. 


\section{f. Five-Mile Radius}

\begin{tabular}{|c|c|c|c|c|c|c|c|c|c|c|c|c|c|c|c|}
\hline & 丞 & $\underset{\sim}{\stackrel{8}{-}}$ & $\stackrel{8}{\stackrel{8}{-}}$ & $\stackrel{8}{-}$ & $\stackrel{\&}{-}$ & $\underset{i}{\stackrel{8}{-}}$ & $\stackrel{\&}{-}$ & $\stackrel{8}{-}$ & $\stackrel{8}{\circ}$ & $\stackrel{8}{\rightarrow}$ & $\stackrel{8}{-}$ & $\underset{\sim}{\stackrel{8}{-}}$ & $\stackrel{8}{-}$ & $\stackrel{8}{\stackrel{8}{-}}$ & $\underset{\ddot{m}}{\stackrel{2}{2}}$ \\
\hline & $\Sigma$ & $\stackrel{8}{0}$ & ¿্. & ¿্. & $\stackrel{\text { ô }}{\circ}$ & $\stackrel{n}{0}$ & $\stackrel{\circ}{\circ}$ & 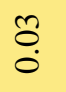 & $\stackrel{0}{0}$ & ֶ̊. & $\stackrel{9}{0}$ & 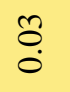 & $\stackrel{8}{\circ}$ & $\stackrel{\overbrace{}}{0}$ & 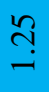 \\
\hline & - & $\ddot{\circ}$ & Ș. & రి & $\stackrel{8}{\circ}$ & $\stackrel{\circ}{0}$ & $=$ & $\stackrel{0}{0}$ & $\underset{0}{ \pm}$ & $\stackrel{\circ}{0}$ & $\stackrel{m}{0}$ & లై & $\stackrel{\triangleright}{\infty}$ & $\stackrel{\infty}{\stackrel{0}{0}}$ & તે \\
\hline & $\forall$ & $\stackrel{8}{0}$ & $\stackrel{\square}{\circ}$ & $\stackrel{\circ}{\circ}$ & $\stackrel{\text { ஜ̊ }}{\circ}$ & $\stackrel{n}{0}$ & $\stackrel{8}{\circ}$ & $\stackrel{\overbrace{}}{0}$ & $\stackrel{0}{0}$ & $\stackrel{0}{0}$ & ণึ) & in & $\stackrel{\stackrel{1}{-}}{\circ}$ & $\stackrel{8}{\circ}$ & 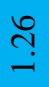 \\
\hline & $\sim$ & $\stackrel{8}{0}$ & $\stackrel{8}{\circ}$ & $\stackrel{8}{0}$ & $\stackrel{8}{\circ}$ & $\stackrel{\vec{\circ}}{\circ}$ & $\bar{o}_{0}$ & $\stackrel{8}{\circ}$ & $\stackrel{\square}{0}$ & $\bar{\sigma}_{0}$ & ָุ & $\stackrel{8}{0}$ & $\stackrel{8}{0}$ & $\stackrel{8}{0}$ & ֶֶ. \\
\hline & - & $\stackrel{8}{0}$ & $\stackrel{8}{0}$ & $\stackrel{0}{0}$ & Oे. & 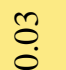 & t. & $\stackrel{8}{0}$ & o. & 5 & $\underset{0}{0}$ & $\stackrel{\tilde{0}}{0}$ & $\stackrel{8}{0}$ & $\ddot{0}$ & کু \\
\hline . & I & $\stackrel{8}{0}$ & $\stackrel{8}{\circ}$ & $\stackrel{8}{0}$ & $\stackrel{8}{\circ}$ & $\stackrel{0}{0}$ & $\stackrel{\tilde{o}}{\circ}$ & $\stackrel{1}{0}$ & $\overline{\tilde{o}}$ & $\stackrel{8}{0}$ & $\stackrel{8}{0}$ & $\stackrel{8}{0}$ & $\stackrel{8}{0}$ & $\stackrel{8}{0}$ & 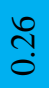 \\
\hline 峞 & 0 & $\stackrel{8}{0}$ & $\stackrel{\overrightarrow{0}}{0}$ & $\stackrel{0}{0}$ & 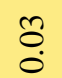 & $\stackrel{\infty}{0}$ & $\stackrel{\infty}{\circ}$ & 芯 & $\stackrel{0}{\circ}$ & $\tilde{\delta}$ & 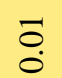 & $\stackrel{8}{0}$ & $\stackrel{0}{0}$ & $\stackrel{8}{0}$ & $\stackrel{0}{=}$ \\
\hline & L & $\stackrel{8}{0}$ & $\stackrel{8}{0}$ & $\stackrel{0}{0}$ & $\stackrel{0}{0}$ & $\stackrel{1}{0}$ & $\stackrel{\Delta}{0}$ & $\stackrel{\overrightarrow{0}}{0}$ & $\ddot{0}$ & $\stackrel{0}{0}$ & $\stackrel{8}{0}$ & $\stackrel{0}{0}$ & $\stackrel{8}{0}$ & $\stackrel{8}{0}$ & तิ \\
\hline & 山 & $\stackrel{8}{0}$ & $\stackrel{8}{0}$ & $\stackrel{0}{0}$ & o. & $\tilde{3}$ & : & $\stackrel{\overrightarrow{0}}{0}$ & O̊. & $\stackrel{0}{0}$ & \&. & 8 & $\stackrel{8}{8}$ & $\stackrel{8}{0}$ & $\stackrel{\text { fa }}{0}$ \\
\hline & 0 & $\stackrel{8}{0}$ & $\stackrel{8}{0}$ & $\overline{0}$ & $\frac{n}{0}$ & $\ddot{0}$ & $\overline{0}$ & $\stackrel{8}{0}$ & $\ddot{\circ}$ & $\stackrel{8}{0}$ & $\stackrel{8}{\circ}$ & $\stackrel{8}{0}$ & $\stackrel{8}{0}$ & $\stackrel{8}{0}$ & ণి ָి \\
\hline & $U$ & $\stackrel{+}{0}$ & $\stackrel{\overbrace{}}{\circ}$ & શે & $\begin{array}{l}0 \\
\text { లె? }\end{array}$ & $\stackrel{1}{0}$ & $\stackrel{m}{0}$ & $\stackrel{\circ}{\circ}$ & $\stackrel{8}{0}$ & $\stackrel{\leftrightarrow}{\circ}$ & $\stackrel{\leftrightarrow}{\circ}$ & $\overrightarrow{0}$ & $\stackrel{8}{0}$ & $\ddot{\circ}$ & $\stackrel{શ}{i}$ \\
\hline & $\infty$ & $\stackrel{n}{0}$ & $\ddot{n}$ & $\stackrel{\leftrightarrow}{\circ}$ & $\stackrel{8}{\circ}$ & $\stackrel{\rho}{0}$ & 离 & $\begin{array}{l}1 \\
0 \\
0\end{array}$ & $\stackrel{\overbrace{}}{0}$ & $\stackrel{\square}{\circ}$ & ō & $\stackrel{8}{0}$ & $\stackrel{8}{0}$ & $\stackrel{8}{0}$ & గో: \\
\hline & $\varangle$ & $\begin{array}{l}\infty \\
\infty \\
0\end{array}$ & $\stackrel{\infty}{\circ}$ & $\frac{7}{0}$ & $\stackrel{n}{\tilde{c}}$ & $\frac{0}{0}$ & 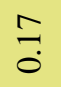 & $\stackrel{\infty}{\circ}$ & $\frac{m}{0}$ & $\stackrel{t}{0}$ & $\stackrel{t}{0}$ & $\ddot{\circ}$ & $\ddot{0}$ & $\ddot{\circ}$ & $\stackrel{\hat{n}}{i}$ \\
\hline & $\begin{array}{l}\bar{\delta} \\
\stackrel{\Xi}{\exists}\end{array}$ & $\varangle$ & $\infty$ & $u$ & D & 山 & 山 & 0 & 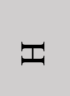 & - & $\sim$ & 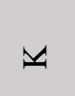 & \lrcorner & $\Sigma$ & 胥 \\
\hline & & & & & & & & & & & & & & & \\
\hline
\end{tabular}

Appendix Table A.31 Accessibility indices for origin-destination pairs from raw job figures for five-mile buffer. Green, yellow, and red cells denote relatively high, medium, and low values, respectively. Blue cells denote row or column totals. The number of significant figures has been reduced to fit the table within the page. 


\begin{tabular}{|c|c|c|c|c|c|c|c|c|c|c|c|c|c|c|c|}
\hline \multirow{14}{*}{ 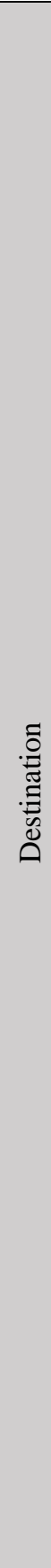 } & 苛 & $\underset{-}{8}$ & $\underset{8}{8}$ & 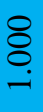 & $\underset{8}{8}$ & $\underset{8}{8}$ & $\underset{-}{8}$ & $\underset{8}{8}$ & 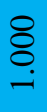 & $\underset{8}{8}$ & $\underset{8}{8}$ & $\underset{8}{8}$ & $\underset{8}{8}$ & $\underset{-}{8}$ & $\begin{array}{l}8 \\
\varnothing \\
\dot{\imath}\end{array}$ \\
\hline & $\Sigma$ & $\begin{array}{l}8 \\
8 \\
\circ\end{array}$ & $\stackrel{8}{\circ}$ & \begin{tabular}{l}
8 \\
\multirow{0}{0}{} \\
0
\end{tabular} & 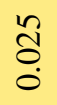 & $\begin{array}{l}n \\
\tilde{0} \\
0\end{array}$ & $\begin{array}{l}0 \\
\text { లె } \\
0\end{array}$ & ত্ণ & 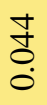 & ֻे & $\begin{array}{l}\infty \\
\stackrel{0}{0} \\
\dot{0}\end{array}$ & 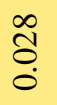 & $\begin{array}{l}n \\
\tilde{o} \\
0\end{array}$ & $\frac{8}{\stackrel{8}{\circ}}$ & 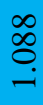 \\
\hline & 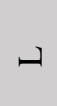 & $\stackrel{m}{0}$ & $\begin{array}{l}\widetilde{\jmath} \\
\text { ठุ. }\end{array}$ & $\stackrel{t}{\circ}$ & 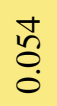 & $\stackrel{\infty}{5}$ & $\begin{array}{l}\bar{\infty} \\
\stackrel{0}{0}\end{array}$ & $\stackrel{\overbrace{}}{O}$ & $\begin{array}{l}\bar{\sigma} \\
\stackrel{0}{0}\end{array}$ & $\begin{array}{l}+ \\
\infty \\
0\end{array}$ & $\underset{\widehat{~}}{0}$ & $\begin{array}{l}\stackrel{0}{0} \\
\text { ஸे } \\
0\end{array}$ & $\begin{array}{l}\circ \\
\infty \\
\infty \\
0\end{array}$ & $\frac{\hat{a}}{0}$ & $\stackrel{m}{\stackrel{m}{c}}$ \\
\hline & $\breve{v}$ & $\begin{array}{l}8 \\
8 \\
0\end{array}$ & $\begin{array}{l}0 \\
0 \\
0\end{array}$ & $\hat{8}$ & $\begin{array}{l}0 \\
\stackrel{1}{0} \\
0\end{array}$ & $\begin{array}{l}\infty \\
\stackrel{\infty}{0} \\
\stackrel{0}{0}\end{array}$ & $\begin{array}{l}\text { +o } \\
\text { : }\end{array}$ & 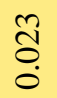 & \begin{tabular}{l}
8 \\
\hdashline \\
\hdashline
\end{tabular} & $\stackrel{?}{\stackrel{O}{0}}$ & $\frac{t}{0}$ & 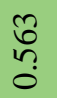 & $\stackrel{m}{=}$ & 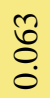 & $\underset{ت}{ \pm}$ \\
\hline & $\neg$ & $\begin{array}{l}\overline{8} \\
\stackrel{0}{0}\end{array}$ & $\begin{array}{l}\text { ô } \\
\stackrel{0}{0}\end{array}$ & $\begin{array}{l}\overline{8} \\
\stackrel{0}{\circ}\end{array}$ & $\begin{array}{l}\mathscr{8} \\
\varnothing \\
0\end{array}$ & $\begin{array}{l}0 \\
\stackrel{8}{0} \\
0\end{array}$ & 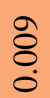 & $\begin{array}{l}\mathscr{\wp} \\
\varnothing \\
0\end{array}$ & $\begin{array}{l}\stackrel{2}{0} \\
\stackrel{0}{0}\end{array}$ & $\stackrel{\sim}{\dddot{0}}$ & 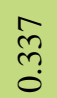 & $\begin{array}{l}\text { ठे } \\
\ddot{0}\end{array}$ & $\begin{array}{l}\mathscr{8} \\
8 \\
0\end{array}$ & $\begin{array}{l}8 \\
8 \\
0\end{array}$ & $\underset{⿱ 亠 凶}{ \pm}$ \\
\hline & - & 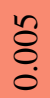 & $\begin{array}{l}\hat{8} \\
0\end{array}$ & $\begin{array}{l}\mathscr{8} \\
\delta \\
0\end{array}$ & $\begin{array}{l}\overline{\widetilde{\sigma}} \\
\dot{0}\end{array}$ & $\begin{array}{l}n \\
\tilde{o} \\
0\end{array}$ & $\begin{array}{l}\stackrel{0}{+} \\
0 \\
0\end{array}$ & $\begin{array}{l}\stackrel{0}{ } \\
\stackrel{0}{0}\end{array}$ & $\begin{array}{l}\hat{\delta} \\
0\end{array}$ & $\frac{a}{\stackrel{2}{0}}$ & 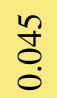 & $\stackrel{8}{0}$ & $\begin{array}{l}\mathscr{8} \\
\ddot{0}\end{array}$ & $\begin{array}{l}\infty \\
\stackrel{8}{0}\end{array}$ & ळे \\
\hline & $I$ & $\begin{array}{l}\text { ô } \\
\text {. }\end{array}$ & $\begin{array}{l}0 \\
\tilde{o}\end{array}$ & 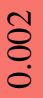 & $\begin{array}{l}\ddot{Q} \\
\ddot{0}\end{array}$ & $\frac{\sigma}{0}$ & $\begin{array}{l}\text { ô } \\
\text { ơ }\end{array}$ & 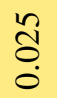 & ले & $\begin{array}{l}\text { } \\
\text { ¿ }\end{array}$ & $\begin{array}{l}\text { \&̊ } \\
\text { ¿ }\end{array}$ & $\begin{array}{l}\overline{8} \\
\stackrel{0}{0}\end{array}$ & $\begin{array}{l}\overline{8} \\
\stackrel{0}{0}\end{array}$ & $\begin{array}{l}\overline{8} \\
\dot{0}\end{array}$ & 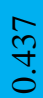 \\
\hline & 0 & $\stackrel{8}{0}$ & $\stackrel{1}{0}$ & \&े & $\begin{array}{l}\bar{J} \\
\stackrel{0}{0}\end{array}$ & $\frac{t}{0}$ & 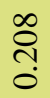 & $\frac{m}{i}$ & $\frac{\infty}{\infty}$ & $\begin{array}{l}\stackrel{0}{0} \\
\text { Oे. }\end{array}$ & $\stackrel{a}{0}$ & $\stackrel{\circ}{\circ}$ & 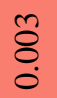 & $\stackrel{8}{8}$ & ले \\
\hline & II & $\begin{array}{l}\text { ठ̊ } \\
\text {. }\end{array}$ & $\stackrel{8}{0}$ & $\underset{\delta}{\tilde{\delta}}$ & $\overrightarrow{0}$ & $\begin{array}{l}\text { ơ } \\
\text { Oे } \\
0\end{array}$ & 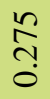 & 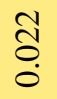 & $\begin{array}{l}\text { ठิ } \\
\stackrel{0}{0}\end{array}$ & $\stackrel{+}{8}$ & $\stackrel{0}{8}$ & $\overline{8}$ & $\overline{8}$ & $\overline{8}$ & \begin{tabular}{l}
$\stackrel{0}{\infty}$ \\
\multirow{2}{*}{} \\
0
\end{tabular} \\
\hline & II & $\begin{array}{l}\text { ঠ̊ } \\
\stackrel{0}{0}\end{array}$ & $\begin{array}{l}+ \\
8\end{array}$ & $\begin{array}{l}\hat{\delta} \\
\stackrel{\delta}{0}\end{array}$ & $\stackrel{n}{0}$ & $\underset{\nabla}{\bar{\nabla}}$ & \begin{tabular}{l} 
它 \\
\hdashline
\end{tabular} & $\frac{n}{0}$ & $\frac{a}{0}$ & $\begin{array}{l}n \\
8\end{array}$ & $\begin{array}{l}\text { ț } \\
\stackrel{0}{0}\end{array}$ & $\overline{8}$ & $\overrightarrow{8}$ & 훙 & $\tilde{n}$ \\
\hline & ค & 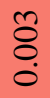 & $\begin{array}{l}n \\
\tilde{o}\end{array}$ & $\begin{array}{l}8 \\
8 \\
0\end{array}$ & $\frac{2}{0}$ & $\stackrel{8}{8}$ & $\stackrel{8}{0}$ & $\begin{array}{l}\text { ț } \\
\stackrel{0}{0}\end{array}$ & $\begin{array}{l}0 \\
8 \\
0\end{array}$ & 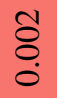 & $\begin{array}{l}\text { ठิ } \\
\text {. }\end{array}$ & $\stackrel{8}{8}$ & $\begin{array}{l}8 \\
8 \\
0\end{array}$ & $\overrightarrow{8}$ & 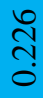 \\
\hline & $U$ & مo & $\frac{\widetilde{\sigma}}{\frac{1}{0}}$ & $\begin{array}{l}\overrightarrow{\widetilde{n}} \\
\infty \\
0 \\
0\end{array}$ & $\frac{n}{7}$ & $\frac{\stackrel{ }{(1}}{0}$ & $\begin{array}{l}\stackrel{a}{\leftrightarrows} \\
\end{array}$ & $\begin{array}{l}\bar{n} \\
\stackrel{0}{0}\end{array}$ & $\begin{array}{l}\infty \\
\stackrel{0}{0} \\
0\end{array}$ & 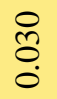 & ঠે & $\begin{array}{l}\infty \\
\stackrel{0}{0}\end{array}$ & $\begin{array}{l}\mathscr{8} \\
\ddot{0}\end{array}$ & $\begin{array}{l}\mathscr{8} \\
\stackrel{0}{0}\end{array}$ & $\begin{array}{l}n \\
\tilde{n} \\
-\end{array}$ \\
\hline & $\varphi$ & $\begin{array}{l}\text { Oै } \\
\stackrel{0}{0} \\
0\end{array}$ & 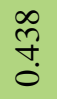 & $\begin{array}{l}\tilde{O} \\
\tilde{0} \\
0\end{array}$ & $\begin{array}{l}\tilde{\delta} \\
0\end{array}$ & $\begin{array}{l}0 \\
\stackrel{\delta}{0} \\
0\end{array}$ & గ్లి & $\stackrel{m}{0}$ & $\begin{array}{l}\text { ปे } \\
\text { Oे }\end{array}$ & $\stackrel{\infty}{8}$ & $\stackrel{8}{0}$ & $\stackrel{0}{0}$ & 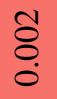 & 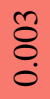 & 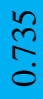 \\
\hline & $\ll$ & $\frac{t}{\overparen{\sigma}}$ & 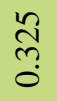 & $\begin{array}{l}\overline{8} \\
\dot{0}\end{array}$ & $\stackrel{\substack{m \\
0}}{!}$ & $\begin{array}{l}n \\
0 \\
0\end{array}$ & $\stackrel{m}{\hat{O}}$ & $\stackrel{m}{0}$ & $\begin{array}{l}n \\
ٌ \\
0\end{array}$ & $\begin{array}{l}\vec{\delta} \\
\stackrel{0}{0}\end{array}$ & 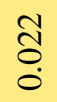 & $\begin{array}{l}8 \\
8 \\
0\end{array}$ & $\begin{array}{l}\stackrel{+}{8} \\
\stackrel{0}{0}\end{array}$ & $\stackrel{0}{8}$ & $\stackrel{+}{\sigma}$ \\
\hline & $\begin{array}{l}\bar{\Xi} \\
\text { ]్తు }\end{array}$ & $\ll$ & 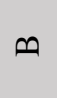 & U & D & 山 & IL & 0 & $I$ & 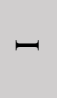 & $\neg$ & $\forall$ & \lrcorner & $\Sigma$ & 氶 \\
\hline & & & & & & & & & & & & & & & \\
\hline
\end{tabular}

Appendix Table A.32 Accessibility indices for origin-destination pairs from raw population figures for fivemile buffer. Green, yellow, and red cells denote relatively high, medium, and low values, respectively. Blue cells denote row or column totals. 


\begin{tabular}{|c|c|c|c|c|c|c|c|c|c|c|c|c|c|c|c|}
\hline \multirow{14}{*}{ 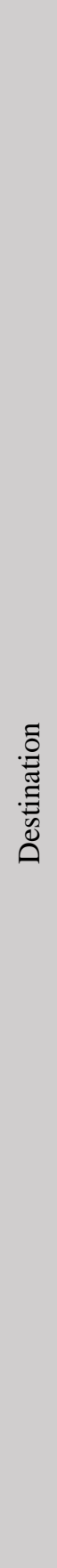 } & 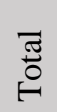 & $\underset{-}{8}$ & $\underset{8}{8}$ & $\underset{-}{8}$ & $\underset{8}{8}$ & $\underset{-}{8}$ & $\underset{8}{8}$ & 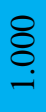 & $\underset{8}{8}$ & 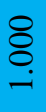 & $\underset{8}{8}$ & $\underset{-}{8}$ & $\underset{8}{8}$ & $\underset{-}{8}$ & $\begin{array}{l}\stackrel{8}{8} \\
\ddot{\imath}\end{array}$ \\
\hline & $\Sigma$ & $\begin{array}{l}8 \\
8 \\
\circ\end{array}$ & $\begin{array}{l}8 \\
\dot{8} \\
\dot{0}\end{array}$ & $\begin{array}{l}8 \\
8 \\
ْ\end{array}$ & ڤ̊ & 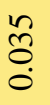 & ஸे & ণิ & $\begin{array}{l}0 \\
\text { Oे } \\
0\end{array}$ & గn & $\begin{array}{l}\hat{\infty} \\
0 \\
0\end{array}$ & $\begin{array}{l}\stackrel{\infty}{\mathbb{U}} \\
\stackrel{0}{0}\end{array}$ & 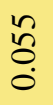 & $\begin{array}{l}\text { જे } \\
\text { ठे }\end{array}$ & $\begin{array}{l}\stackrel{\leftrightarrow}{\circ} \\
\stackrel{\circ}{-}\end{array}$ \\
\hline & \lrcorner & $\stackrel{m}{0}$ & $\begin{array}{l}\text { ปี } \\
\text { ல }\end{array}$ & $\stackrel{+}{\stackrel{+}{0}}$ & $\begin{array}{l}n \\
ٌ \\
0\end{array}$ & $\begin{array}{l}\frac{9}{5} \\
\text {. }\end{array}$ & $\begin{array}{l}+ \\
\stackrel{0}{0} \\
\stackrel{0}{0}\end{array}$ & $\begin{array}{l}0 \\
\stackrel{0}{0} \\
\stackrel{0}{0}\end{array}$ & $\frac{\stackrel{\circ}{\circ}}{\stackrel{0}{0}}$ & $\begin{array}{l}\infty \\
\stackrel{\infty}{0} \\
\dot{0}\end{array}$ & $\begin{array}{l}\tilde{v} \\
\text { vै } \\
0\end{array}$ & $\begin{array}{l}\hat{\delta} \\
\text { ?ִ }\end{array}$ & $\begin{array}{l}\text { ○ } \\
\infty \\
\infty \\
0\end{array}$ & $\frac{\infty}{\stackrel{\infty}{0}}$ & $\frac{\stackrel{m}{I}}{i}$ \\
\hline & 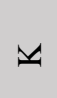 & $\begin{array}{l}8 \\
8 \\
0\end{array}$ & $\begin{array}{l}\circ \\
0 \\
0\end{array}$ & $\hat{8}$ & $\begin{array}{l}0 \\
\stackrel{1}{0} \\
\stackrel{0}{0}\end{array}$ & 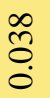 & $\begin{array}{l}\vec{J} \\
\stackrel{0}{0}\end{array}$ & ֶి & $\begin{array}{l}\tilde{b} \\
0 \\
0\end{array}$ & $\stackrel{t}{\stackrel{t}{+}}$ & $\frac{a}{0}$ & $\begin{array}{l}\hat{\sigma} \\
\text { ?ִ }\end{array}$ & $\stackrel{\simeq}{=}$ & $\stackrel{\mathscr{8}}{0}$ & $\stackrel{\nexists}{ \pm}$ \\
\hline & $\neg$ & ¿े. & $\begin{array}{l}\text { ô. } \\
\text { }\end{array}$ & $\begin{array}{l}\text { ô. } \\
\text { ọ }\end{array}$ & 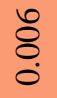 & oे & $\begin{array}{l}0 \\
0 \\
0\end{array}$ & $\begin{array}{l}\text { \& } \\
\vdots \\
0\end{array}$ & $\stackrel{m}{0}$ & $\underset{0}{+}$ & $\begin{array}{l}n \\
\tilde{n} \\
0\end{array}$ & $\begin{array}{l}0 \\
0 \\
0\end{array}$ & 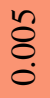 & $\begin{array}{l}8 \\
\vdots \\
0\end{array}$ & $\stackrel{f}{+}$ \\
\hline & - & $\begin{array}{l}+ \\
8 \\
0\end{array}$ & $\hat{8}$ & $\stackrel{n}{8}$ & $\begin{array}{l}\vec{\delta} \\
\stackrel{0}{0}\end{array}$ & চे & \begin{tabular}{l} 
Oे \\
\multirow{0}{0}{}
\end{tabular} & 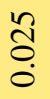 & $\begin{array}{l}\infty \\
\stackrel{\leftrightarrow}{0}\end{array}$ & $\vec{z}$ & $\begin{array}{l}\text { Tे } \\
\stackrel{0}{0}\end{array}$ & $\stackrel{8}{\circ}$ & $\stackrel{n}{8}$ & $\stackrel{\infty}{8}$ & $\hat{\hat{a}}$ \\
\hline & $I$ & ¿े. & 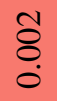 & 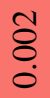 & 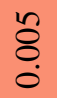 & $\frac{n}{0}$ & 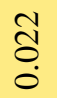 & $\begin{array}{l}\vec{\delta} \\
\stackrel{0}{0}\end{array}$ & $\begin{array}{l}+ \\
\text { ֻे } \\
0\end{array}$ & $\begin{array}{l}\infty \\
\stackrel{0}{0}\end{array}$ & $\begin{array}{l}\qquad \\
\stackrel{8}{0}\end{array}$ & $\begin{array}{l}\overline{8} \\
\stackrel{0}{\circ}\end{array}$ & $\begin{array}{l}\overline{8} \\
\stackrel{0}{0}\end{array}$ & $\begin{array}{l}\overline{8} \\
\stackrel{0}{0}\end{array}$ & 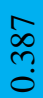 \\
\hline & ט & $\stackrel{8}{8}$ & $\stackrel{2}{\circ}$ & $\stackrel{8}{\circ}$ & $\begin{array}{l}J \\
\stackrel{0}{0}\end{array}$ & $\exists$ & $\begin{array}{l}\text { त̦ } \\
\text { రి }\end{array}$ & 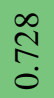 & $\begin{array}{l}\text { ¿े } \\
\text { ஸे }\end{array}$ & $\begin{array}{l}\text { ஸे } \\
\text {. }\end{array}$ & $\begin{array}{l}\stackrel{0}{ } \\
\text { Oִ. }\end{array}$ & $\stackrel{\wp}{\varrho}$ & $\stackrel{8}{8}$ & $\stackrel{\wp}{\varrho}$ & 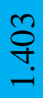 \\
\hline & II & $\begin{array}{l}\overline{8} \\
\dot{0}\end{array}$ & $\begin{array}{l}\text { ठ̊ } \\
\text {. }\end{array}$ & $\begin{array}{l}\text { ㅇ } \\
\delta \\
0\end{array}$ & $\begin{array}{l}0 \\
0 \\
0\end{array}$ & $\begin{array}{l}0 \\
\text { లో } \\
\text { ○े }\end{array}$ & $\underset{\stackrel{\infty}{\sim}}{\stackrel{\infty}{0}}$ & $\stackrel{a}{0}$ & $\frac{\infty}{0}$ & $\begin{array}{l}\stackrel{+}{8} \\
\stackrel{0}{0}\end{array}$ & $\stackrel{8}{8}$ & $\begin{array}{l}\overline{8} \\
0\end{array}$ & $\begin{array}{l}8 \\
8 \\
\circ\end{array}$ & $\begin{array}{l}\overline{8} \\
\dot{0}\end{array}$ & $\begin{array}{l}n \\
\text { m̃ } \\
0\end{array}$ \\
\hline & II & ơ & $\begin{array}{l}\text { t } \\
\stackrel{0}{0}\end{array}$ & 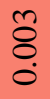 & $\stackrel{+}{0}$ & ?o & 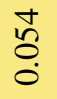 & $\stackrel{+}{\circ}$ & $\stackrel{\circ}{\circ}$ & $\begin{array}{l}n \\
\stackrel{0}{0}\end{array}$ & $\begin{array}{l}\text { ¿̊ } \\
\stackrel{0}{0}\end{array}$ & $\overline{8}$ & $\overrightarrow{8}$ & $\overline{8}$ & \begin{tabular}{l}
$\infty$ \\
\multirow{N}{n}{} \\
0
\end{tabular} \\
\hline & $\theta$ & $\stackrel{8}{8}$ & $\begin{array}{l}n \\
\tilde{o}\end{array}$ & \&̊. & $\stackrel{ }{\stackrel{2}{0}}$ & $\stackrel{8}{\circ}$ & $\begin{array}{l}\stackrel{8}{0} \\
0\end{array}$ & $\stackrel{+}{8}$ & $\begin{array}{l}0 \\
\text { ¿̊ }\end{array}$ & $\begin{array}{l}0 \\
\tilde{O}\end{array}$ & $\begin{array}{l}\text { ठิ } \\
\text { : }\end{array}$ & $\stackrel{8}{8}$ & \&̊ి & $\overline{8}$ & 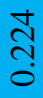 \\
\hline & $u$ & 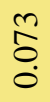 & $\frac{\text { तु }}{\stackrel{0}{0}}$ & $\begin{array}{l}\infty \\
\stackrel{\infty}{+} \\
\stackrel{0}{0}\end{array}$ & 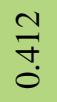 & $\frac{\stackrel{\overbrace{}}{~}}{\dot{0}}$ & $\frac{\vec{c}}{0}$ & 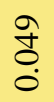 & $\begin{array}{l}\mathscr{0} \\
\mathscr{0} \\
0\end{array}$ & $\begin{array}{l}\text { O্ } \\
\stackrel{0}{0}\end{array}$ & $\begin{array}{l}\stackrel{\infty}{\Omega} \\
\stackrel{0}{0}\end{array}$ & $\begin{array}{l}\infty \\
\stackrel{8}{8} \\
\stackrel{0}{0}\end{array}$ & $\begin{array}{l}n \\
\check{\delta}\end{array}$ & $\stackrel{\infty}{\stackrel{8}{0}}$ & ક̊ષ \\
\hline & 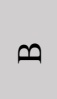 & 㔯 & $\underset{+}{\stackrel{T}{*}}$ & চֶ. & $\begin{array}{l}\stackrel{0}{0} \\
0\end{array}$ & ठิ & ठे. & $\stackrel{\sim}{\sigma}$ & $\begin{array}{l}\vec{\delta} \\
\stackrel{0}{0}\end{array}$ & $\stackrel{\infty}{8}$ & $\stackrel{\infty}{8}$ & 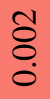 & $\overrightarrow{8}$ & $\begin{array}{l}\text { ठै } \\
\stackrel{0}{0}\end{array}$ & $\begin{array}{l}0 \\
\text { oे } \\
0\end{array}$ \\
\hline & $\ll$ & $\begin{array}{l}0 \\
\$ \\
0 \\
0\end{array}$ & 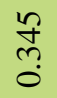 & $\begin{array}{l}\mathscr{8} \\
\stackrel{0}{0}\end{array}$ & $\frac{0}{ \pm}$ & $\begin{array}{l}\hat{\sigma} \\
0 \\
0\end{array}$ & $\begin{array}{l}\hat{\sigma} \\
0 \\
0\end{array}$ & $\begin{array}{l}\text { के } \\
\text { Oे. }\end{array}$ & $\begin{array}{l}8 \\
0\end{array}$ & $\begin{array}{l}\text { Oे } \\
\stackrel{0}{0}\end{array}$ & $\begin{array}{l}\text { ป̂. } \\
\text { Oे }\end{array}$ & $\begin{array}{l}0 \\
8 \\
0\end{array}$ & $\begin{array}{l}\text { ț } \\
\end{array}$ & $\hat{8}$ & $\stackrel{0}{6}$ \\
\hline & $\begin{array}{l}\bar{\Xi} \\
\text { ] } \\
\text { ( }\end{array}$ & $\ll$ & $\infty$ & $U$ & $\theta$ & 山 & IL & ن & $I$ & - & $\neg$ & $\forall$ & \lrcorner & $\Sigma$ & 5 \\
\hline & & & & & & & & & & & & & & & \\
\hline
\end{tabular}

Appendix Table A.33 Accessibility indices for origin-destination pairs from raw housing unit figures for five-mile buffer. Green, yellow, and red cells denote relatively high, medium, and low values, respectively. Blue cells denote row or column totals. 


\begin{tabular}{|c|c|c|c|c|c|c|c|c|c|c|c|c|c|c|c|}
\hline \multirow{14}{*}{ 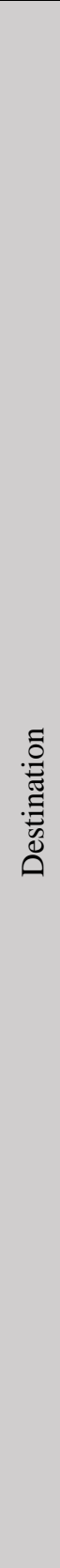 } & $\underset{0}{\tilde{\sigma}}$ & $\stackrel{8}{8}$ & $\underset{-}{8}$ & $\stackrel{8}{8}$ & $\underset{-}{8}$ & $\stackrel{8}{8}$ & $\underset{-}{8}$ & $\underset{-}{8}$ & $\stackrel{8}{8}$ & $\underset{-}{8}$ & $\stackrel{8}{\circ}$ & $\underset{-}{8}$ & $\underset{-}{8}$ & $\underset{-}{8}$ & $\begin{array}{l}\stackrel{8}{0} \\
\stackrel{\sim}{ }\end{array}$ \\
\hline & $\Sigma$ & $\stackrel{8}{8}$ & $\stackrel{+}{0}$ & $\stackrel{\sigma}{0}$ & $\begin{array}{l}\overline{0} \\
\dot{\varphi}\end{array}$ & $\begin{array}{l}\overline{0} \\
\dot{\varphi}\end{array}$ & $\begin{array}{l}\overline{0} \\
\dot{\varphi}\end{array}$ & $\begin{array}{l}\tilde{0} \\
\dot{\varphi}\end{array}$ & $\begin{array}{l}0 \\
\dot{0} \\
\end{array}$ & $\begin{array}{l}\text { do } \\
\stackrel{\leftrightarrow}{i}\end{array}$ & $\begin{array}{l}n \\
0 \\
\dot{\varphi}\end{array}$ & $\stackrel{\overbrace{}}{0}$ & $\stackrel{n}{0}$ & $\stackrel{n}{\stackrel{0}{0}}$ & $\begin{array}{l}\stackrel{+}{\infty} \\
\stackrel{0}{0}\end{array}$ \\
\hline & ـ & $\stackrel{\circ}{\circ}$ & $\stackrel{\leftrightarrow}{\stackrel{\circ}{\circ}}$ & $\stackrel{\Delta}{0}$ & $\begin{array}{l}\text { O̦ } \\
\stackrel{+}{\varphi}\end{array}$ & $\begin{array}{l}0 \\
\stackrel{\rho}{+}\end{array}$ & $\begin{array}{l}\text { ô. } \\
\dot{\varphi}\end{array}$ & $\begin{array}{l}\dot{D} \\
\stackrel{0}{0}\end{array}$ & $\begin{array}{l}\dot{D} \\
\stackrel{0}{\varphi}\end{array}$ & $\stackrel{m}{\dot{p}}$ & $\stackrel{\bar{N}}{\underline{i}}$ & ণֶర & $\stackrel{\Delta}{0}$ & సे & $\stackrel{\mathscr{\infty}}{-}$ \\
\hline & $\forall$ & $\stackrel{8}{\circ}$ & $\stackrel{0}{\stackrel{0}{0}}$ & $\stackrel{\sigma}{0}$ & $\begin{array}{l}\overline{0} \\
\stackrel{0}{\varphi}\end{array}$ & $\begin{array}{l}0 \\
0 \\
\end{array}$ & $\begin{array}{l}\sigma \\
\dot{0}\end{array}$ & $\begin{array}{l}0 \\
0 \\
0\end{array}$ & $\begin{array}{l}0 \\
0\end{array}$ & $\begin{array}{l}\text { ô. } \\
0\end{array}$ & $\begin{array}{l}8 \\
0 \\
\end{array}$ & $\stackrel{\infty}{\stackrel{\infty}{0}}$ & $\stackrel{0}{0}$ & $\stackrel{0}{0}$ & ñ \\
\hline & $\neg$ & $\begin{array}{l}\text { Oे } \\
\stackrel{i}{1}\end{array}$ & $\frac{2}{0}$ & $\begin{array}{l}0 \\
0 \\
0\end{array}$ & $\tilde{\sigma}_{0}^{\circ}$ & $\stackrel{-}{0}$ & $\stackrel{\circ}{\circ}$ & $\stackrel{\text { Oे }}{\circ}$ & $\stackrel{\text { Oै }}{0}$ & $\stackrel{\circ}{\circ}$ & กิ & $\begin{array}{l}\hat{0} \\
0 \\
0\end{array}$ & $\begin{array}{l}0 \\
\stackrel{0}{0}\end{array}$ & $\begin{array}{l}\underset{0}{0} \\
\stackrel{0}{i}\end{array}$ & $\stackrel{\overbrace{}}{\text { ô }}$ \\
\hline & - & $\stackrel{8}{8}$ & $\frac{\sim}{0}$ & ọ. & $\stackrel{\sigma}{0}$ & 뭉. & $\ddot{\circ}$ & $\stackrel{\text { ô }}{0}$ & $\stackrel{\text { O̦ }}{0}$ & $\stackrel{8}{\circ}$ & $\stackrel{\overbrace{}}{0}$ & ō & ö. & ठ․ & $\begin{array}{l}\Re \\
\infty \\
0\end{array}$ \\
\hline & $I$ & $\begin{array}{l}\sigma \\
\stackrel{0}{0}\end{array}$ & $\begin{array}{l}0 \\
\text { ?ִ } \\
\text { in }\end{array}$ & $\begin{array}{l}\dot{D} \\
\stackrel{0}{0}\end{array}$ & 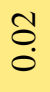 & $\stackrel{\Delta}{0}$ & $\begin{array}{l}\stackrel{8}{0} \\
\stackrel{0}{0}\end{array}$ & $\begin{array}{l}0 \\
0 \\
0\end{array}$ & $\begin{array}{l}0 \\
\infty \\
0\end{array}$ & $\stackrel{8}{\circ}$ & $\stackrel{0}{0}$ & $\begin{array}{l}o \\
\stackrel{0}{0}\end{array}$ & $\begin{array}{l}0 \\
0 \\
\end{array}$ & $\begin{array}{l}\overline{0} \\
\stackrel{0}{0}\end{array}$ & $\begin{array}{l}\infty \\
\stackrel{0}{0}\end{array}$ \\
\hline & 0 & ö. & 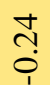 & ڤై & $\stackrel{\leftrightarrow}{O}$ & $\stackrel{\text { ț }}{\circ}$ & $\stackrel{0}{0}$ & 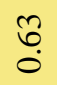 & $\stackrel{0}{0}$ & $\stackrel{t}{0}$ & 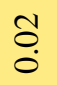 & ō & $\stackrel{8}{\circ}$ & o. & ถి \\
\hline & L & $\begin{array}{l}\ddot{0} \\
\stackrel{\varphi}{\varphi}\end{array}$ & $\begin{array}{l}\vec{n} \\
\stackrel{\varphi}{p}\end{array}$ & $\begin{array}{l}8 \\
\stackrel{0}{0}\end{array}$ & $\stackrel{n}{0}$ & $\stackrel{m}{\circ}$ & $\stackrel{\infty}{\infty}$ & $\frac{\infty}{0}$ & $\stackrel{8}{\circ}$ & $\stackrel{8}{\circ}$ & 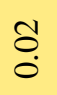 & $\begin{array}{l}0 \\
0\end{array}$ & $\begin{array}{l}0 \\
0\end{array}$ & $\begin{array}{l}\overline{0} \\
0\end{array}$ & $\begin{array}{l}\infty \\
\stackrel{0}{0} \\
0\end{array}$ \\
\hline & 피 & 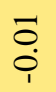 & 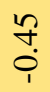 & $\begin{array}{l}n \\
0 \\
\dot{\varphi}\end{array}$ & $\stackrel{\Delta}{\stackrel{d}{0}}$ & $\stackrel{\infty}{\infty}$ & $\begin{array}{l}\stackrel{0}{0} \\
0\end{array}$ & $\stackrel{\infty}{\stackrel{0}{0}}$ & $\stackrel{\Xi}{0}$ & $\stackrel{t}{0}$ & 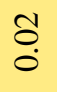 & 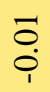 & $\stackrel{8}{0}$ & ¿. & $\begin{array}{l}\overline{0} \\
\stackrel{0}{0}\end{array}$ \\
\hline & D & $\begin{array}{l}0 \\
0 \\
0\end{array}$ & $\stackrel{\infty}{\longrightarrow}$ & 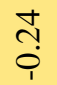 & $\stackrel{8}{\varnothing}$ & $\stackrel{\Xi}{0}$ & $\stackrel{0}{0}$ & $\stackrel{\Delta}{0}$ & $\begin{array}{l}\text { ô } \\
\stackrel{0}{0}\end{array}$ & 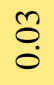 & 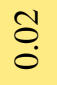 & $\begin{array}{l}\overline{0} \\
\dot{0}\end{array}$ & $\stackrel{8}{8}$ & 官 & $\begin{array}{c}\tilde{N} \\
\stackrel{1}{1}\end{array}$ \\
\hline & $u$ & $\stackrel{\leftrightarrow}{0}$ & $\stackrel{g}{\stackrel{q}{q}}$ & $\stackrel{\infty}{\stackrel{\longrightarrow}{=}}$ & $\begin{array}{l}\text { oे } \\
\stackrel{0}{\varphi}\end{array}$ & $\begin{array}{l}0 \\
0 \\
0\end{array}$ & $\begin{array}{l}\mathcal{O} \\
0 \\
\end{array}$ & $\begin{array}{l}\text { ô } \\
\text { p. }\end{array}$ & $\begin{array}{l}0 \\
0 \\
0\end{array}$ & $\begin{array}{l}\text { O̦ } \\
0 \\
0\end{array}$ & ọ. & ō & $\stackrel{8}{\circ}$ & o. & $\stackrel{n}{n}$ \\
\hline & $\infty$ & $\begin{array}{l}\hat{0} \\
\stackrel{0}{1}\end{array}$ & $\underset{\infty}{\stackrel{+}{\infty}}$ & $\frac{0}{0}$ & $\stackrel{\wp}{0}$ & $\stackrel{\overline{0}}{\circ}$ & ¿. & $\stackrel{\overline{0}}{\circ}$ & $\stackrel{\check{0}}{\circ}$ & $\stackrel{\sigma}{0}$ & $\stackrel{\overline{0}}{\circ}$ & $\stackrel{8}{8}$ & $\stackrel{8}{\circ}$ & $\begin{array}{l}8 \\
\stackrel{0}{0}\end{array}$ & $\begin{array}{l}\mathscr{\infty} \\
\infty \\
\infty \\
1\end{array}$ \\
\hline & $\varangle$ & 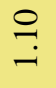 & $\begin{array}{l}\text { ชె } \\
0\end{array}$ & లి & $=$ & $\begin{array}{l}\dot{T} \\
0 \\
\end{array}$ & $\begin{array}{l}\text { do } \\
\stackrel{1}{0}\end{array}$ & $\begin{array}{l}n \\
0 \\
\dot{p}\end{array}$ & $\begin{array}{l}0 \\
0 \\
0\end{array}$ & $\begin{array}{l}n \\
0 \\
0\end{array}$ & $\begin{array}{l}0 \\
0 \\
0\end{array}$ & 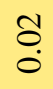 & $\stackrel{\Xi}{\circ}$ & $\begin{array}{l}\stackrel{d}{0} \\
\stackrel{0}{0}\end{array}$ & $\stackrel{\mathbb{Z}}{\Xi}$ \\
\hline & $\begin{array}{l}\bar{D} \\
\text { ज्ञ }\end{array}$ & $\varangle$ & 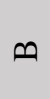 & $U$ & $\theta$ & 디 & L & ن & $I$ & 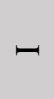 & $\neg$ & $\forall$ & \lrcorner & $\Sigma$ & స్తే \\
\hline & & & & & & & & & & & & & & & \\
\hline
\end{tabular}

Appendix Table A.34 Accessibility indices for origin-destination pairs from normalized job figures for fivemile buffer. Green, yellow, and red cells denote relatively high, medium, and low values, respectively. Blue cells denote row or column totals. 


\begin{tabular}{|c|c|c|c|c|c|c|c|c|c|c|c|c|c|c|c|}
\hline \multirow{14}{*}{ 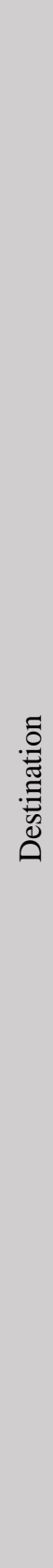 } & 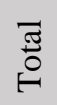 & $\underset{8}{8}$ & $\stackrel{8}{-}$ & $\underset{-}{8}$ & $\underset{.}{8}$ & $\stackrel{8}{8}$ & $\underset{-}{8}$ & $\stackrel{8}{-}$ & $\underset{-}{8}$ & $\stackrel{8}{-}$ & $\underset{-}{8}$ & $\underset{-}{8}$ & $\underset{-}{8}$ & $\stackrel{8}{8}$ & $\begin{array}{l}\stackrel{8}{0} \\
\stackrel{2}{ }\end{array}$ \\
\hline & $\Sigma$ & $\stackrel{0}{0}$ & $\begin{array}{l}n \\
0 \\
\stackrel{i}{0}\end{array}$ & $\stackrel{0}{0}$ & $\begin{array}{l}\overline{0} \\
\stackrel{0}{0}\end{array}$ & $\begin{array}{l}\overline{0} \\
\dot{\varphi}\end{array}$ & $\begin{array}{l}\overline{0} \\
\stackrel{0}{0}\end{array}$ & 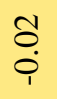 & $\begin{array}{l}\overline{0} \\
\stackrel{0}{0}\end{array}$ & $\begin{array}{l}n \\
0 \\
i\end{array}$ & $\begin{array}{l}n \\
\dot{0} \\
i\end{array}$ & రె. & $\stackrel{\overbrace{}}{0}$ & ک̊. & ñ \\
\hline & \lrcorner & $\stackrel{\overbrace{}}{0}$ & $\begin{array}{l}0 \\
\stackrel{0}{i}\end{array}$ & $\stackrel{\leftrightarrow}{\circ}$ & $\begin{array}{l}\text { no } \\
\text { }\end{array}$ & $\begin{array}{l}0 \\
0 \\
0\end{array}$ & $\begin{array}{l}\text { ô } \\
\text { }\end{array}$ & $\begin{array}{l}\text { ô } \\
\text { ị }\end{array}$ & $\begin{array}{l}\dot{D} \\
\dot{0}\end{array}$ & $\begin{array}{l}\text { त̦ } \\
\stackrel{1}{1}\end{array}$ & $\begin{array}{l}\stackrel{1}{1} \\
\text { pi }\end{array}$ & ڤె. & $\stackrel{n}{0}$ & 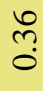 & $\stackrel{\circ}{\rightleftarrows}$ \\
\hline & $\mathscr{V}$ & ठ․ & $\begin{array}{l}0 \\
0\end{array}$ & $\stackrel{0}{0}$ & $\begin{array}{l}\overline{0} \\
\dot{0}\end{array}$ & 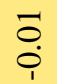 & $\begin{array}{l}0 \\
\dot{0}\end{array}$ & $\begin{array}{l}1 \\
0 \\
\stackrel{\rho}{0}\end{array}$ & $\begin{array}{l}0 \\
\dot{0}\end{array}$ & $\begin{array}{l}n \\
0 \\
\dot{p}\end{array}$ & $\begin{array}{l}\hat{0} \\
\dot{0}\end{array}$ & $\stackrel{n}{\stackrel{f}{0}}$ & $\stackrel{?}{\circ}$ & $\stackrel{\text { ô }}{\circ}$ & 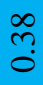 \\
\hline & $\neg$ & $\begin{array}{l}\overline{0} \\
\dot{0}\end{array}$ & 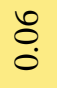 & $\begin{array}{l}0 \\
\stackrel{0}{0}\end{array}$ & $\stackrel{0}{0}$ & $\stackrel{0}{0}$ & $\stackrel{\overline{0}}{\circ}$ & 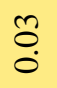 & 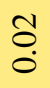 & $\frac{m}{0}$ & $\stackrel{\infty}{\stackrel{\infty}{~}}$ & $\begin{array}{l}8 \\
\dot{0} \\
\end{array}$ & $\begin{array}{l}\text { O̦ } \\
0\end{array}$ & $\begin{array}{l}\text { ¿ } \\
\stackrel{0}{0}\end{array}$ & $\stackrel{?}{\rightarrow}$ \\
\hline & - & 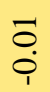 & 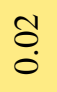 & $\stackrel{8}{8}$ & $\stackrel{0}{0}$ & $\stackrel{\sigma}{0}$ & $\stackrel{\sigma}{0}$ & 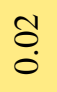 & $\stackrel{\overline{0}}{\circ}$ & $\stackrel{\infty}{\infty}$ & $\stackrel{\text { ô }}{0}$ & $\begin{array}{l}\overline{0} \\
\dot{0}\end{array}$ & $\stackrel{8}{8}$ & $\begin{array}{l}\overline{0} \\
\dot{0}\end{array}$ & ذ̊. \\
\hline & $I$ & $\begin{array}{l}\text { ô } \\
\stackrel{0}{0}\end{array}$ & $\overline{0}$ & $\begin{array}{l}\text { ô } \\
\stackrel{0}{0}\end{array}$ & $\underset{0}{0}$ & $\stackrel{\Xi}{0}$ & $\stackrel{\circ}{\circ}$ & 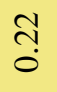 & $\stackrel{\text { oे }}{0}$ & $\frac{n}{0}$ & 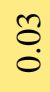 & $\begin{array}{l}\tilde{O} \\
\stackrel{0}{0}\end{array}$ & $\begin{array}{l}0 \\
\stackrel{0}{\varphi}\end{array}$ & $\underset{\text { ô }}{0}$ & $\stackrel{?}{\stackrel{\sim}{\sim}}$ \\
\hline & $\cup$ & $\begin{array}{l}\tilde{0} \\
0 \\
\end{array}$ & $\stackrel{+}{0}$ & $\underset{0}{0}$ & $\stackrel{0}{0}$ & $\stackrel{\text { ô }}{0}$ & $\stackrel{t}{0}$ & ণ্ণ் & $\stackrel{+}{0}$ & 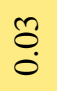 & ö & $\stackrel{8}{\circ}$ & $\stackrel{8}{8}$ & $\stackrel{8}{\circ}$ & $\begin{array}{l}\hat{\sigma} \\
\stackrel{0}{0}\end{array}$ \\
\hline & L & $\begin{array}{l}\text { Oo } \\
\dot{\varphi}\end{array}$ & $\stackrel{0}{\stackrel{0}{0}}$ & $\begin{array}{l}\text { O̦ } \\
\dot{\varphi}\end{array}$ & $\stackrel{n}{0}$ & $\stackrel{m}{0}$ & $\begin{array}{l}\infty \\
0 \\
0\end{array}$ & 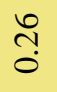 & $\stackrel{5}{0}$ & $\stackrel{8}{\circ}$ & $\underset{0}{0}$ & $\begin{array}{l}\tilde{0} \\
\dot{\varphi}\end{array}$ & $\begin{array}{l}0 \\
\stackrel{0}{\varphi}\end{array}$ & $\begin{array}{l}\overline{0} \\
\dot{\rho}\end{array}$ & ஜํ \\
\hline & 피 & $\begin{array}{l}0 \\
0 \\
\dot{\varphi}\end{array}$ & $\frac{ \pm}{0}$ & 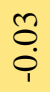 & $\stackrel{+}{0}$ & $\begin{array}{l}+ \\
\infty \\
0\end{array}$ & $\overline{0}$ & $=$ & $\stackrel{+}{0}$ & ¿̊. & $\stackrel{\sigma}{0}$ & $\begin{array}{l}0 \\
0 \\
\end{array}$ & $\stackrel{8}{\circ}$ & $\begin{array}{l}0 \\
0 \\
\end{array}$ & సે \\
\hline & D & $\begin{array}{l}\hat{0} \\
\dot{0}\end{array}$ & 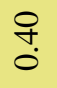 & $\frac{ \pm}{\dot{\varphi}}$ & $\stackrel{g}{g}$ & $\underset{\dot{0}}{\stackrel{t}{0}}$ & $\stackrel{t}{0}$ & $\stackrel{\circ}{\circ}$ & 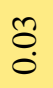 & $\stackrel{\circ}{\circ}$ & $\stackrel{0}{0}$ & $\begin{array}{l}\overline{0} \\
0 \\
0\end{array}$ & $\stackrel{8}{\circ}$ & o. & 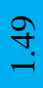 \\
\hline & $u$ & $\stackrel{m}{0}$ & $\begin{array}{l}\overrightarrow{0} \\
\stackrel{0}{\varphi}\end{array}$ & $\stackrel{9}{\Rightarrow}$ & $\begin{array}{l}0 \\
0 \\
1\end{array}$ & $\stackrel{m}{0}$ & $\stackrel{m}{0}$ & $\begin{array}{l}n \\
0 \\
0\end{array}$ & $\begin{array}{l}\text { Oִ } \\
\stackrel{\varphi}{0}\end{array}$ & $\begin{array}{l}0 \\
\stackrel{0}{0}\end{array}$ & $\begin{array}{l}\text { ô } \\
\dot{p}\end{array}$ & ¿̈. & $\stackrel{8}{\circ}$ & ¿̈. & $\stackrel{m}{0}$ \\
\hline & $\infty$ & $\begin{array}{l}0 \\
0 \\
0 \\
1\end{array}$ & $\begin{array}{l}\stackrel{\circ}{n} \\
\stackrel{n}{i}\end{array}$ & $\begin{array}{l}n \\
0 \\
\dot{p}\end{array}$ & $\stackrel{0}{0}$ & $\stackrel{0}{0}$ & ō & 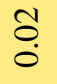 & $\stackrel{\circ}{0}$ & 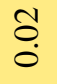 & $\overline{0}$ & $\stackrel{8}{\circ}$ & $\stackrel{8}{8}$ & $\stackrel{8}{\circ}$ & $\stackrel{?}{\stackrel{f}{i}}$ \\
\hline & $\varangle$ & $\Xi$ & $\stackrel{\stackrel{?}{\rightarrow}}{\rightarrow}$ & $\stackrel{0}{0}$ & $\begin{array}{l}n \\
0 \\
\dot{\varphi}\end{array}$ & $\begin{array}{l}0 \\
0 \\
\stackrel{\varphi}{1}\end{array}$ & $\begin{array}{l}0 \\
\stackrel{0}{0} \\
\end{array}$ & $\begin{array}{l}0 \\
\stackrel{\varphi}{\varphi}\end{array}$ & ō & 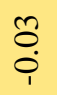 & $\begin{array}{l}0 \\
\dot{\varphi}\end{array}$ & ö. & $\stackrel{8}{\circ}$ & $\overline{0}$ & m़ \\
\hline & $\begin{array}{l}\bar{\Xi} \\
\text { ప్తు }\end{array}$ & $\ll$ & $ص$ & $U$ & $\theta$ & 피 & I & 0 & $I$ & - & $r$ & $\forall$ & $\dashv$ & $\Sigma$ & 䒕 \\
\hline & & & & & & & & & & & & & & & \\
\hline
\end{tabular}

Appendix Table A.35 Accessibility indices for origin-destination pairs from normalized population figures for five-mile buffer. Green, yellow, and red cells denote relatively high, medium, and low values, respectively. Blue cells denote row or column totals. 


\begin{tabular}{|c|c|c|c|c|c|c|c|c|c|c|c|c|c|c|c|}
\hline \multirow{14}{*}{ 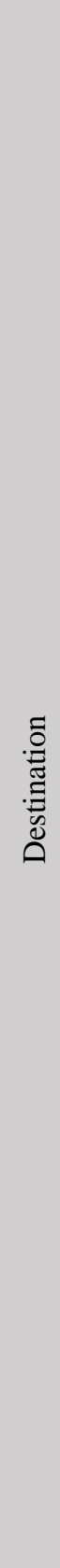 } & 苛 & $\stackrel{8}{8}$ & $\underset{-}{8}$ & $\underset{-}{8}$ & $\underset{-}{8}$ & $\underset{-}{8}$ & $\underset{-}{8}$ & $\underset{-}{8}$ & $\stackrel{8}{-}$ & $\underset{-}{8}$ & $\underset{-}{8}$ & $\underset{-}{8}$ & $\underset{-}{8}$ & $\underset{-}{8}$ & $\begin{array}{l}\stackrel{8}{0} \\
\stackrel{\sim}{ }\end{array}$ \\
\hline & $\Sigma$ & $\stackrel{\sigma}{0}$ & $\begin{array}{l}0 \\
0 \\
\stackrel{i}{i}\end{array}$ & $\stackrel{0}{0}$ & $\begin{array}{l}0 \\
\\
\end{array}$ & $\begin{array}{l}\overline{0} \\
\dot{\varphi}\end{array}$ & $\begin{array}{l}\overrightarrow{0} \\
\stackrel{\varphi}{1}\end{array}$ & $\begin{array}{l}\text { ô } \\
\text { ị }\end{array}$ & $\begin{array}{l}0 \\
0 \\
\end{array}$ & $\begin{array}{l}\text { ț } \\
\dot{0}\end{array}$ & $\begin{array}{l}n \\
\stackrel{\varphi}{+}\end{array}$ & 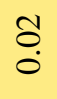 & ڤ̊. & $\stackrel{\tilde{b}}{0}$ & $\begin{array}{l}\infty \\
n \\
0\end{array}$ \\
\hline & $\dashv$ & $\stackrel{0}{\circ}$ & $\frac{m}{0}$ & $\stackrel{\overbrace{}}{0}$ & $\begin{array}{l}\text { ộ } \\
\stackrel{1}{1}\end{array}$ & $\begin{array}{l}0 \\
\stackrel{0}{0}\end{array}$ & $\begin{array}{l}\text { ộ } \\
\text { }\end{array}$ & $\begin{array}{l}\hat{0} \\
0 \\
\end{array}$ & $\begin{array}{l}\dot{0} \\
\stackrel{0}{i}\end{array}$ & $\begin{array}{l}\text { กิ } \\
\text { ị }\end{array}$ & $\begin{array}{l}\stackrel{0}{1} \\
\stackrel{\varphi}{i}\end{array}$ & 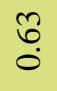 & $\hat{o}$ & $\begin{array}{l}\text { ?} \\
\text { ? }\end{array}$ & $\stackrel{\infty}{=}$ \\
\hline & 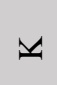 & $\stackrel{\circ}{\circ}$ & $\begin{array}{l}0 \\
0 \\
0\end{array}$ & $\stackrel{0}{0}$ & $\begin{array}{l}\overline{0} \\
\dot{\varphi}\end{array}$ & $\begin{array}{l}0 \\
\dot{0}\end{array}$ & $\begin{array}{l}\overrightarrow{0} \\
\stackrel{0}{0}\end{array}$ & 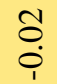 & $\begin{array}{l}\overline{0} \\
\stackrel{p}{\rho}\end{array}$ & $\begin{array}{l}n \\
0 \\
\dot{p}\end{array}$ & $\begin{array}{l}\infty \\
0 \\
0\end{array}$ & $\stackrel{n}{\stackrel{f}{\circ}}$ & $\stackrel{8}{\circ}$ & $\stackrel{n}{0}$ & $\begin{array}{c}\infty \\
\stackrel{0}{0}\end{array}$ \\
\hline & $\neg$ & 官 & $\stackrel{\bullet}{0}$ & $\begin{array}{l}\overline{0} \\
\stackrel{0}{0}\end{array}$ & $\stackrel{0}{0}$ & $\stackrel{\circ}{0}$ & $\stackrel{\overline{0}}{\circ}$ & $\stackrel{\overbrace{}}{0}$ & 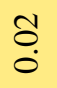 & $=$ & ָิ & $\begin{array}{l}0 \\
\stackrel{0}{0} \\
\dot{0}\end{array}$ & $\begin{array}{l}\text { ô } \\
0 \\
\end{array}$ & $\begin{array}{l}\dot{J} \\
\stackrel{0}{0}\end{array}$ & છे \\
\hline & - & $\begin{array}{l}\overline{0} \\
\dot{\varphi}\end{array}$ & 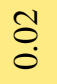 & $\begin{array}{l}\overline{0} \\
\dot{0}\end{array}$ & $\stackrel{0}{0}$ & $\stackrel{\overrightarrow{0}}{\circ}$ & $\stackrel{\overrightarrow{0}}{\circ}$ & $\begin{array}{l}\text { ô } \\
\stackrel{0}{0}\end{array}$ & $\stackrel{\sigma}{\circ}$ & $\begin{array}{l}\infty \\
0 \\
0\end{array}$ & $\begin{array}{l}\text { రి } \\
\text {. }\end{array}$ & $\begin{array}{l}\overline{0} \\
\dot{0}\end{array}$ & $\begin{array}{l}8 \\
\stackrel{0}{0}\end{array}$ & $\begin{array}{l}\overrightarrow{0} \\
\dot{0}\end{array}$ & ڤ̊ \\
\hline & $I$ & $\begin{array}{l}\text { Oे } \\
\stackrel{0}{0}\end{array}$ & $\stackrel{\circ}{\circ}$ & $\begin{array}{l}\text { ô } \\
0 \\
\end{array}$ & 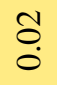 & $\stackrel{\Xi}{0}$ & 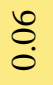 & 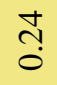 & $\stackrel{\text { के }}{\stackrel{0}{0}}$ & $\stackrel{ \pm}{\circ}$ & $\stackrel{\Delta}{0}$ & $\begin{array}{l}\text { ô } \\
\dot{0}\end{array}$ & $\begin{array}{l}0 \\
0 \\
0\end{array}$ & $\begin{array}{l}\text { ô } \\
\dot{0}\end{array}$ & $\stackrel{f}{f}$ \\
\hline & 0 & $\begin{array}{l}0 \\
0 \\
0\end{array}$ & $\overbrace{0}^{0}$ & o̦. & $\stackrel{\sigma}{0}$ & $\stackrel{\text { Oे }}{0}$ & $\stackrel{\wp}{0}$ & $\stackrel{?}{\stackrel{9}{0}}$ & $\stackrel{0}{0}$ & 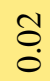 & ō & 8 & 8 & 8 & $n$ \\
\hline & $I$ & $\stackrel{0}{0}$ & $\frac{ \pm}{0}$ & $\begin{array}{l}\text { ț } \\
\stackrel{\leftrightarrow}{1}\end{array}$ & $\stackrel{n}{0}$ & $\frac{m}{0}$ & $\begin{array}{l}\infty \\
\infty \\
0\end{array}$ & 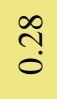 & $\stackrel{0}{0}$ & $\stackrel{\infty}{\circ}$ & $\stackrel{\leftrightarrow}{\circ}$ & $\begin{array}{l}\overline{0} \\
\dot{Q}\end{array}$ & $\begin{array}{l}0 \overline{0} \\
\dot{0}\end{array}$ & $\begin{array}{l}\overline{0} \\
\dot{\varphi}\end{array}$ & $\bar{n}$ \\
\hline & 山ు & $\begin{array}{l}0 \\
0 \\
0\end{array}$ & $\stackrel{7}{\circ}$ & $\begin{array}{l}0 \\
0 \\
0\end{array}$ & $\stackrel{\Xi}{0}$ & $\begin{array}{l}\stackrel{+}{\infty} \\
\dot{0}\end{array}$ & 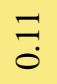 & $\stackrel{ }{\stackrel{0}{0}}$ & $\stackrel{\Xi}{0}$ & $\stackrel{\circ}{\circ}$ & $\underset{0}{0}$ & $\begin{array}{l}0 \\
0 \\
0\end{array}$ & $\stackrel{8}{8}$ & $\begin{array}{l}\ddot{0} \\
\dot{0}\end{array}$ & సِ \\
\hline & D & $\begin{array}{l}\text { Oo } \\
0\end{array}$ & $\stackrel{+}{0}$ & $\frac{n}{\dot{p}}$ & $\stackrel{8}{\circ}$ & $\stackrel{\Xi}{\stackrel{O}{0}}$ & $\stackrel{\Xi}{0}$ & $\stackrel{8}{\circ}$ & 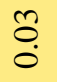 & $\stackrel{n}{0}$ & $\stackrel{\text { ô. }}{0}$ & ơ. & 8 & o̦. & $\stackrel{?}{\rightarrow}$ \\
\hline & $u$ & $\stackrel{ }{\stackrel{0}{0}}$ & $\begin{array}{l}\stackrel{P}{0} \\
\stackrel{0}{1}\end{array}$ & 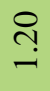 & $\begin{array}{l}0 \\
0 \\
0\end{array}$ & $\begin{array}{l}\text { ô } \\
\text { }\end{array}$ & 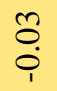 & $\begin{array}{l}n \\
\dot{\varphi} \\
\dot{\varphi}\end{array}$ & $\begin{array}{l}0 \\
0 \\
\stackrel{1}{1}\end{array}$ & $\begin{array}{l}n \\
0 \\
\dot{\varphi}\end{array}$ & 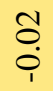 & $\stackrel{\circ}{0}$ & \&: & $\ddot{\circ}$ & $\stackrel{\hat{\jmath}}{\stackrel{0}{0}}$ \\
\hline & $\sim$ & $\begin{array}{l}0 \\
0 \\
\end{array}$ & $\stackrel{\stackrel{n}{c}}{\stackrel{r}{r}}$ & $\begin{array}{l}0 \\
\stackrel{0}{0} \\
\end{array}$ & $\stackrel{\leftrightarrow}{0}$ & $\stackrel{\overline{0}}{\circ}$ & $\stackrel{\overrightarrow{0}}{\circ}$ & 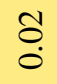 & $\stackrel{\square}{\circ}$ & $\underset{0}{0}$ & రై & $\stackrel{8}{\circ}$ & $\stackrel{8}{\circ}$ & $\stackrel{8}{8}$ & $\stackrel{\overbrace{}}{\tilde{\lambda}}$ \\
\hline & $\ll$ & $\Xi$ & $\stackrel{n}{\sim}$ & $\stackrel{\circ}{\circ}$ & $\begin{array}{l}n \\
0 \\
\dot{p}\end{array}$ & 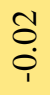 & 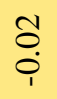 & 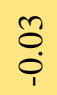 & $\begin{array}{l}0 \\
0 \\
\stackrel{\varphi}{0}\end{array}$ & $\begin{array}{l}\text { Oo } \\
\dot{\varphi}\end{array}$ & $\begin{array}{l}\text { ô } \\
\text { ì }\end{array}$ & $\ddot{\circ}$ & $\underset{0}{8}$ & $\stackrel{\sigma}{\circ}$ & $\begin{array}{l}\hat{N} \\
\text { }\end{array}$ \\
\hline & $\begin{array}{l}\bar{\Xi} \\
\text { త్త }\end{array}$ & $\ll$ & $\varphi$ & $U$ & ค & 山ు & IL & 0 & $I$ & - & $\neg$ & $\forall$ & \lrcorner & $\Sigma$ & $\begin{array}{l}\text { సٓ } \\
\stackrel{0}{\circ}\end{array}$ \\
\hline & & & & & & & & & & & & & & & \\
\hline
\end{tabular}

Appendix Table A.36 Accessibility indices for origin-destination pairs from normalized housing unit figures for five-mile buffer. Green, yellow, and red cells denote relatively high, medium, and low values, respectively. Blue cells denote row or column totals. 